\title{
VERIFICAÇÕES DA PUNÇÃO E DA ESTABILIDADE GLOBAL EM EDIFÍCIOS DE CONCRETO: DESENVOLVIMENTO E APLICAÇÃO DE RECOMENDAÇÕES NORMATIVAS
}

Juliana Soares Lima

Dissertação apresentada à Escola de Engenharia de São Carlos da Universidade de São Paulo, como parte dos requisitos necessários para obtenção do título de Mestre em Engenharia de Estruturas

ORIENTADOR: Libânio Miranda Pinheiro

São Carlos

2001 
A meus pais,

meus primeiros Mestres 


\section{AGRADECIMENTOS}

Ao Prof. Libânio Miranda Pinheiro, pela orientação e pela atenção dispensada a este trabalho.

À amiga Mônica Cristina Cardoso da Guarda, pelas idéias, pelo incentivo, pelo apoio e pela amizade.

Às amigas Tatiana Gesteira Martins de Almeida e Tatiana Bittencourt Dumêt, pelo apoio e pela amizade de sempre.

A Maria Nadir Minatel, por toda sua atenção e ajuda na confecção das referências bibliográficas.

Aos amigos e funcionários do SET, pela receptividade, pelo carinho e pela atenção.

Ao CNPq, pela bolsa de estudos.

A todos que, direta ou indiretamente, contribuíram para a elaboração deste trabalho. 


\section{SUMÁRIO}

LISTA DE FIGURAS ......................................................................i

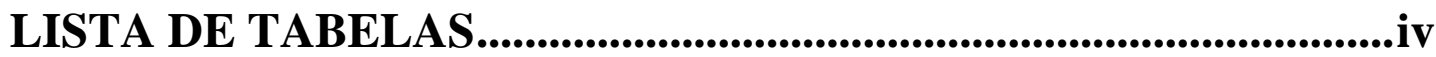

LISTA DE SIGLAS............................................................................

LISTA DE SÍMBOLOS ......................................................................... viii

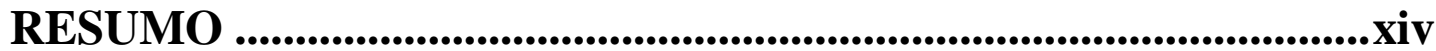

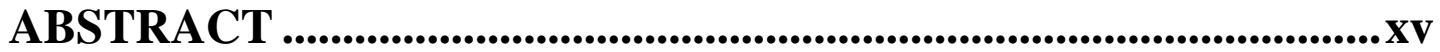

CAPÍTULO 1

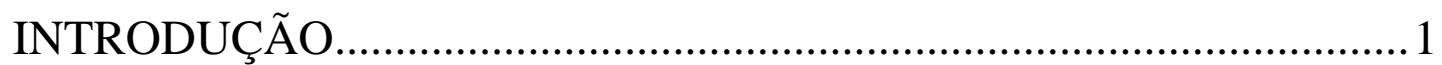

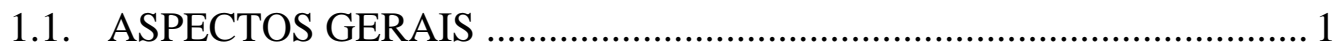

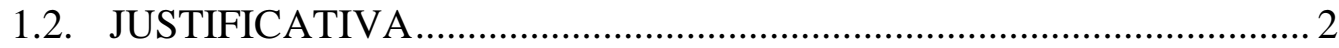

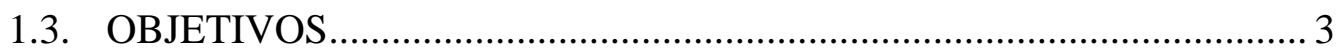

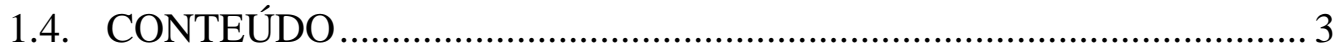




\section{CAPÍTULO 2}

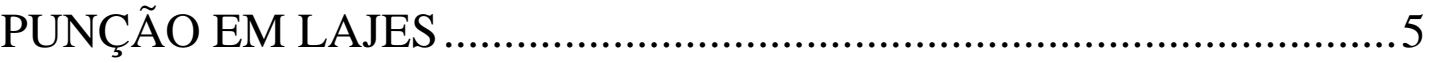

2.1. O FENÔMENO DA PUNÇÃO..............................................................

2.2. INFLUÊNCIA DA ARMADURA PARA PUNÇÃO................................ 7

2.3. COLAPSO PROGRESSIVO ………………………………………... 8

2.4. ANÁLISE TEÓRICA DO PROBLEMA DA PUNÇÃO............................ 9

2.5. MÉTODO DA SUPERFÍCIE DE CONTROLE ...................................... 10

2.6. TRANSFERÊNCIA DE MOMENTOS DESBALANCEADOS..............12

2.7. VERIFICAÇÃO DA PUNÇÃO DE ACORDO COM A

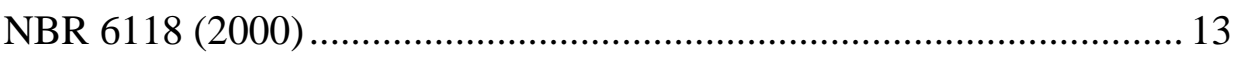

2.7.1. Cálculo das Tensões Resistentes ................................................... 15

a) $\mathrm{Na}$ face do pilar (contorno C).......................................................15

b) A 2d da face do pilar (contorno C'), em lajes sem armadura de punção, ou a 2d da última linha de conectores (contorno C'), em

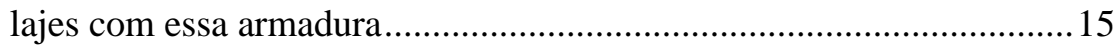

c) A 2d da face do pilar (contorno C'), em lajes com armadura de punção ………………………………………………………......

2.7.2. Cálculo das Tensões Atuantes .................................................... 18

a) Pilar interno, com carregamento simétrico.....................................18

b) Pilar interno, com momento em uma direção..................................19

c) Pilar interno, com momentos nas duas direções...............................21

d) Pilar de borda, sem momento no plano paralelo à borda livre ......21

e) Pilar de borda, com momento no plano paralelo à borda livre......23

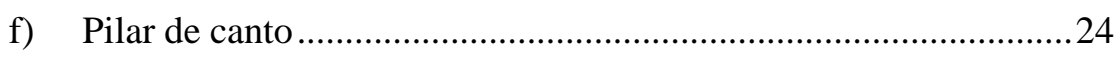

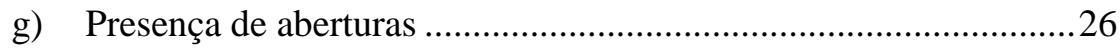

2.7.3. Verificação do Colapso Progressivo …………………………..... 27

2.8. DETALHAMENTO DE ACORDO COM A NBR 6118 (2000)............. 27 
2.9. COMPLEMENTAÇÕES E COMENTÁRIOS SOBRE A

VERIFICAÇÃO DA PUNÇÃO NA NBR 6118 (2000) .......................... 30

2.9.1. Tensão do Concreto no Contorno C ............................................ 30

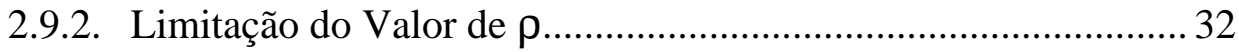

2.9.3. Perímetro Crítico de Pilares Alongados .................................... 32

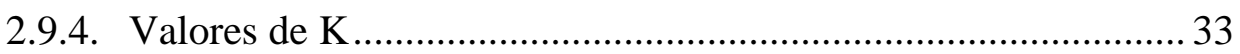

2.9.5. Valores de $\mathrm{W}_{\mathrm{p}}$ para os Contornos $\mathrm{C}$ e $\mathrm{C}$ "................................... 34

2.9.6. Tensão Atuante em Pilares Internos com Momentos nas

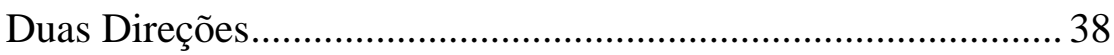

2.9.7. Valores da Excentricidade e* para os Contornos C e C" '........... 38

2.9.8. Método Simplificado para a Punção Excêntrica .......................... 41

2.9.9. Posicionamento dos Conectores Tipo Pino ................................. 43

2.9.10. Espaçamento Mínimo entre a Armadura e a Face do Pilar ......... 44

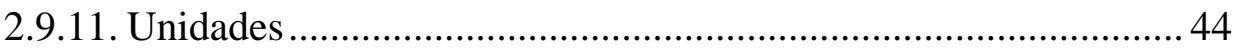

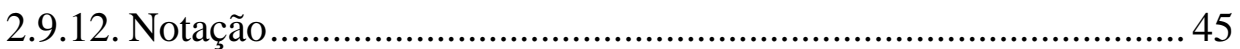

2.10. EXEMPLO DE CÁLCULO ............................................................ 46

2.10.1. Cálculo dos Esforços ................................................................. 46

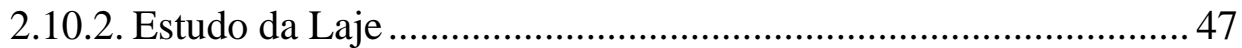

2.10.3. Pilar P6 (pilar interno) ........................................................... 50

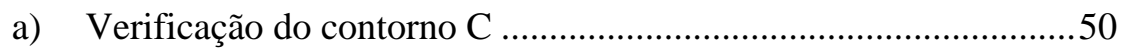

b) Verificação do contorno $C^{\prime}$.......................................................52

c) Verificação do contorno C" ..........................................................54

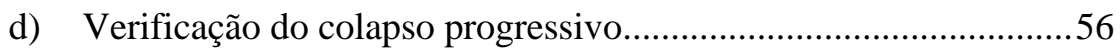

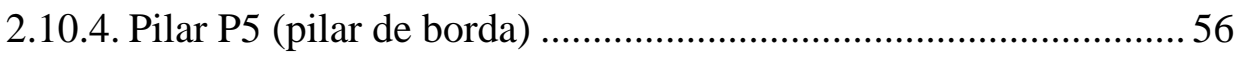

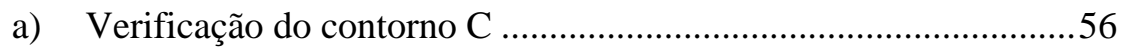

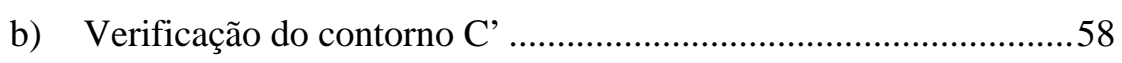

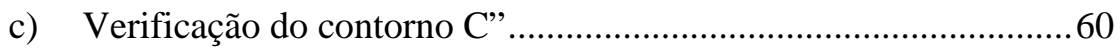

d) Verificação do colapso progressivo..............................................62 
2.10.5. Pilar P1 (pilar de canto) 62

a) Verificação do contorno $\mathrm{C}$.........................................................62

b) Verificação do contorno C' .........................................................65

c) Verificação do contorno C" '.......................................................66

d) Verificação do colapso progressivo.................................................68

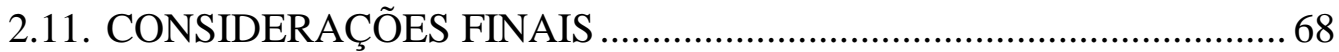

2.12. REFERÊNCIAS BIBLIOGRÁFICAS ….......................................... 70

2.13. BIBLIOGRAFIA COMPLEMENTAR ................................................ 72

\section{CAPÍTULO 3}

ESTABILIDADE GLOBAL DE EDIFÍCIOS .73

3.1. OS EFEITOS DE SEGUNDA ORDEM E A ESTABILIDADE DE

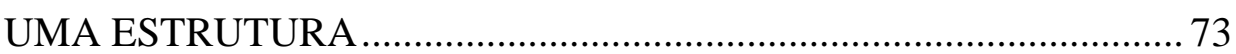

3.2. DESLOCABILIDADE DOS NÓS DE UMA ESTRUTURA ................ 74

3.3. ANÁLISE TEÓRICA DO PROBLEMA DA ESTABILIDADE

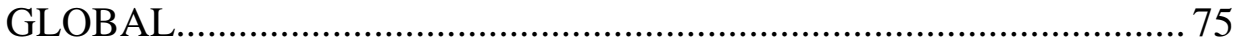

3.3.1. Classificação quanto à Deslocabilidade dos Nós ....................... 75

3.3.2. Determinação dos Efeitos de Segunda Ordem ............................ 76

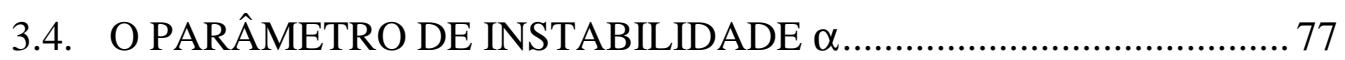

3.4.1. Módulo de Rigidez da Estrutura............................................... 78

3.4.2. Valores Limites de $\alpha$............................................................ 79

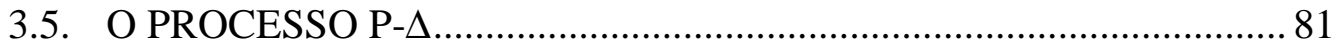

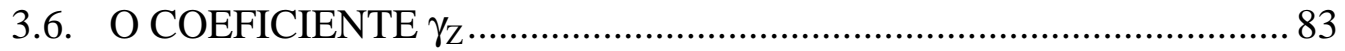

3.7. A INFLUÊNCIA DAS NÃO-LINEARIDADES ................................... 86

3.7.1. Não-Linearidade Física (NLF) .................................................. 86

3.7.2. Não-Linearidade Geométrica (NLG) ….................................... 87 


\subsection{VERIFICAÇÃO DA ESTABILIDADE GLOBAL DE ACORDO}

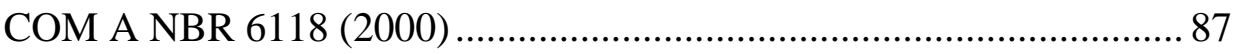

3.8.1. Consideração das Ações Horizontais ........................................ 87

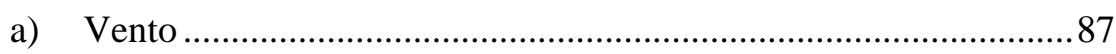

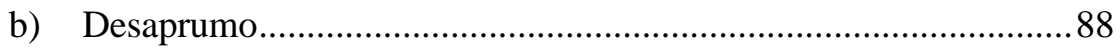

3.8.2. Classificação quanto à Deslocabilidade dos Nós ........................ 89

3.8.3. Determinação do Parâmetro $\alpha$.................................................. 90

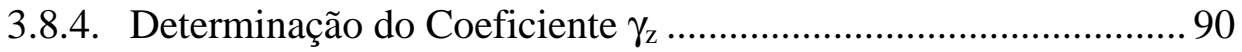

3.8.5. Consideração Simplificada da Não-Linearidade Física .............. 91

3.8.6. Análise de Estruturas de Nós Móveis.......................................... 92

3.9. COMPLEMENTAÇÕES E COMENTÁRIOS SOBRE A

NBR 6118 (2000) - ESTABILIDADE ................................................. 92

3.9.1. Obtenção do Módulo de Rigidez Equivalente $(\mathrm{EI})_{\mathrm{eq}} \ldots \ldots \ldots \ldots \ldots \ldots . . . . . . .93$

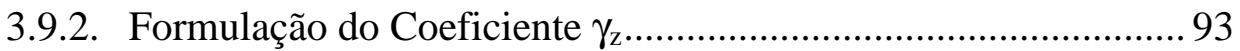

3.9.3. Utilização do Parâmetro $\alpha$ e do Coeficiente $\gamma_{\mathrm{z}}$ na Classificação quanto à Deslocabilidade dos Nós ........................ 95

3.9.4. Utilização do Coeficiente $\gamma_{\mathrm{z}}$ como Majorador............................. 96

3.9.5. Consideração Simplificada da NLF.......................................... 98

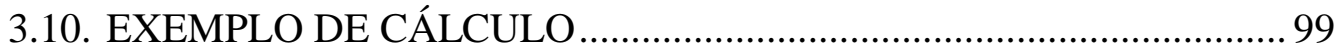

3.10.1. Critérios de Modelagem ........................................................... 101

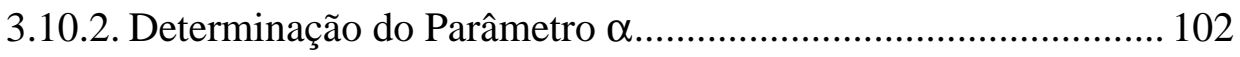

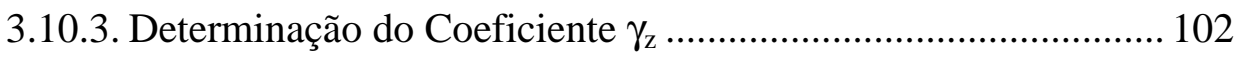

a) Cálculo das forças de arrasto........................................................ 103

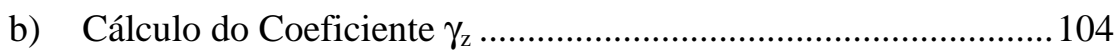

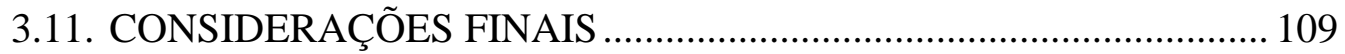

3.12. REFERÊNCIAS BIBLIOGRÁFICAS ............................................... 111

3.13. BIBLIOGRAFIA COMPLEMENTAR ............................................. 113 


\section{CAPÍTULO 4}

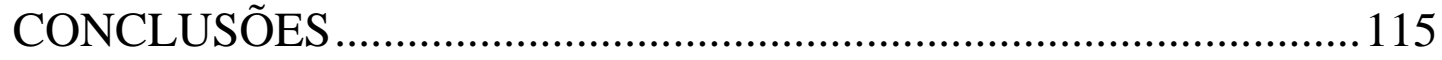

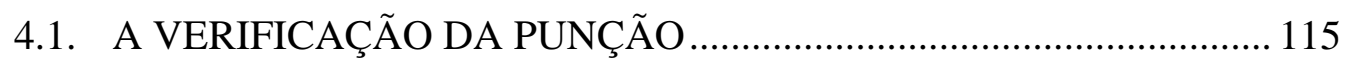

4.1.1. Complementações e Comentários ................................................ 117

4.1.2. Sugestões para Novas Pesquisas ................................................. 119

4.2. A VERIFICAÇÃO DA ESTABILIDADE GLOBAL ............................ 120

4.2.1. Complementações e Comentários ................................................. 121

4.2.2. Sugestões para Novas Pesquisas ................................................ 123

4.3. CONSIDERAÇÕES FINAIS ............................................................... 124

ANEXO A

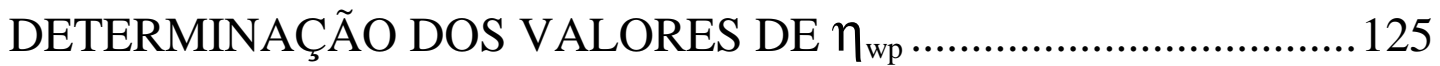

ANEXO B

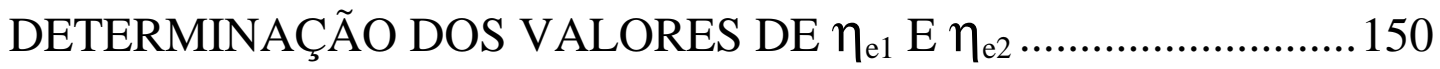

ANEXO C

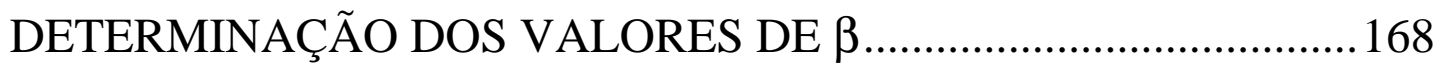

ANEXO D

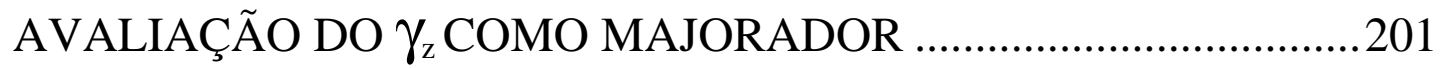

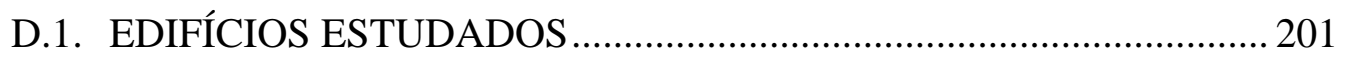

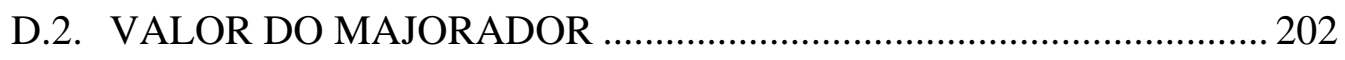

D.3. LIMITE PARA O USO DO $\gamma_{Z}$ COMO MAJORADOR .......................... 204 


\section{LISTA DE FIGURAS}

Figura 2.1 - Estágios de fissuração na face superior de uma laje simétrica. ………..................6

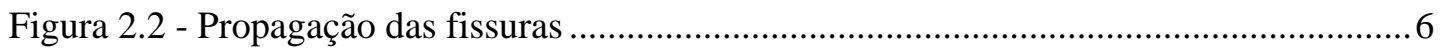

Figura 2.3 - Superfícies de ruína por punção.......................................................................

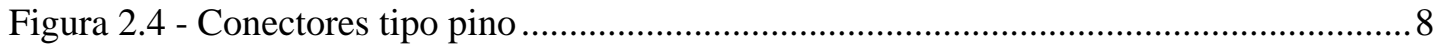

Figura 2.5 - Comportamento da ligação laje-pilar após a ruína por punção.............................. 9

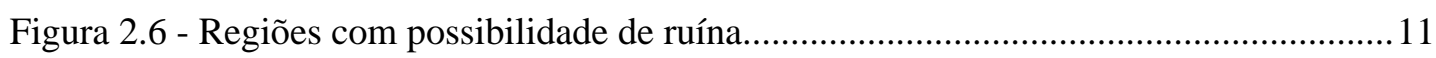

Figura 2.7 - Distribuição de tensões de cisalhamento devidas à transferência de

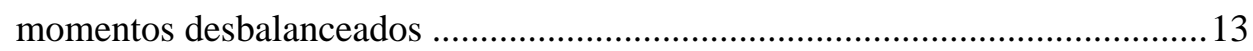

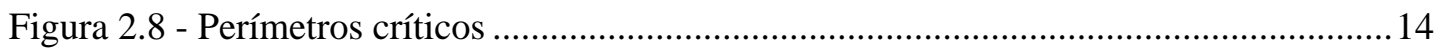

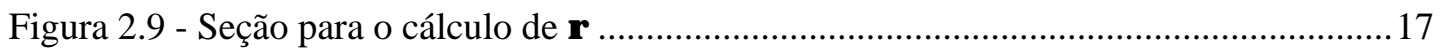

Figura 2.10 - Alturas úteis da laje nas direções $\mathbf{X}$ e $\mathbf{Y}$......................................................... 17

Figura 2.11 - Disposição da armadura $\mathbf{A}_{\text {sw }}$ para pilares internos............................................18

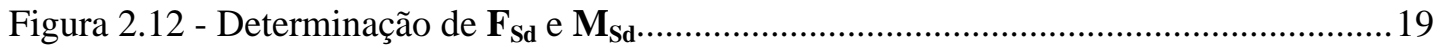

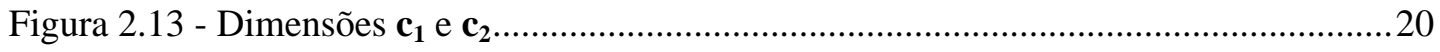

Figura 2.14 - Determinação das dimensões $\mathbf{c}_{1}$ e $\mathbf{c}_{2}$ para pilares internos com momentos

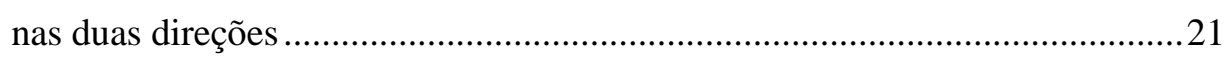

Figura 2.15 - Perímetro crítico reduzido do contorno $\mathbf{C}^{\boldsymbol{\prime}}$ para pilares de borda.....................22

Figura 2.16 - Excentricidade do perímetro crítico reduzido do contorno C' para pilares de borda . .23

Figura 2.17 - Situações de cálculo para verificação de pilares de canto ..................................25

Figura 2.18 - Perímetro crítico reduzido do contorno $\mathbf{C}^{\prime}$ para pilares de canto .......................25

Figura 2.19 - Excentricidade do perímetro crítico reduzido do contorno $\mathbf{C}^{\prime}$ para

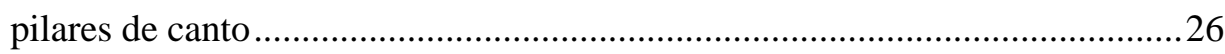

Figura 2.20 - Redução do perímetro crítico na presença de aberturas próximas ao pilar.......27 
Figura 2.21 - Armadura contra colapso progressivo .28

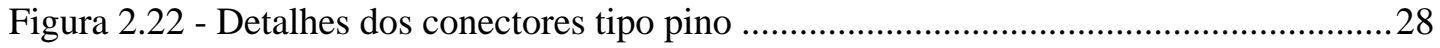

Figura 2.23 - Disposição dos conectores em planta ..............................................................29

Figura 2.24 - Espaçamentos necessários para os conectores ...................................................29

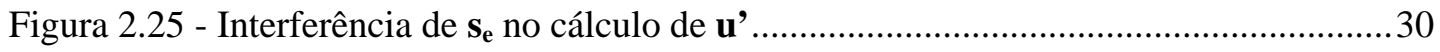

Figura 2.26 - Disposição da armadura de punção em pilares de borda e de canto ...................30

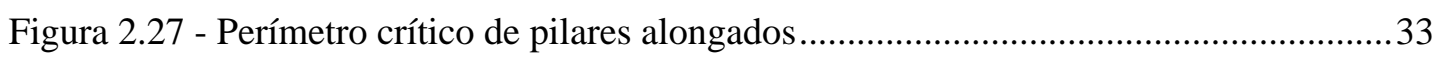

Figura 2.28 - Posicionamento do conector em corte ……….................................................. 43

Figura 2.29 - Disposição da armadura de punção em corte (figura 46 da NBR 6118/2000). .44

Figura 2.30 - Forma do pavimento do exemplo (dimensões em centímetros) ….....................47

Figura 2.31 - Detalhamento da armação positiva ……….......................................................48

Figura 2.32 - Detalhamento da armação negativa ...................................................................49

Figura 2.33 - Arranjo dos conectores tipo pino para o pilar $\mathbf{P 6}$............................................53

Figura 2.34 - Arranjo dos conectores tipo pino para o pilar P5 ............................................60

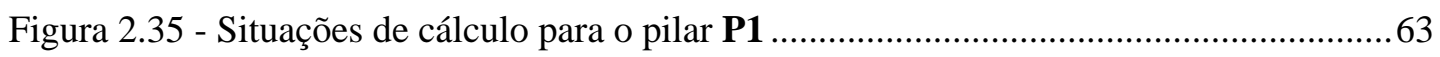

Figura 2.36 - Arranjo dos conectores tipo pino para o pilar P1 ............................................66

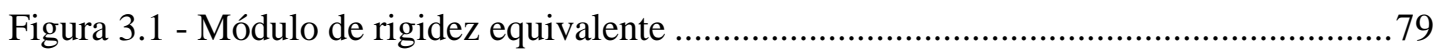

Figura 3.2 - Representação da deformada de estruturas com diferentes sistemas de

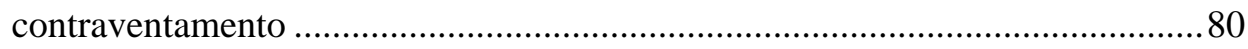

Figura 3.3 - Posições deslocadas em iterações sucessivas ....................................................... 81

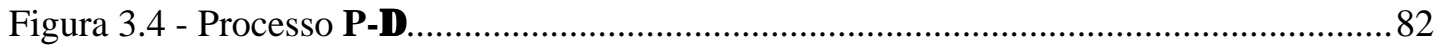

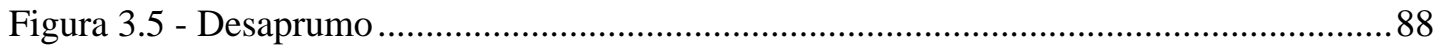

Figura 3.6 - Transformação do desaprumo em forças horizontais fictícias..............................89

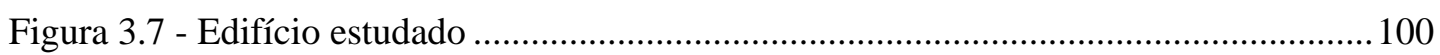

Figura 3.8 - Variação dos acréscimos dos esforços de segunda ordem nas direções $\mathbf{X}$ e $\mathbf{Y}$. .110

Figura A.1 - Teste de Kolmorogov-Smirnov para pilares internos e de canto .......................148

Figura A.2 - Teste de Kolmorogov-Smirnov para pilares de borda ......................................149

Figura B.1 - Teste de Kolmorogov-Smirnov para pilares de borda ......................................166

Figura B.2 - Teste de Kolmorogov-Smirnov para pilares de canto ........................................167

Figura D.1 - Variação dos acréscimos de força normal dos pilares, nas direções $\mathbf{X}$ e $\mathbf{Y}$

(Ed. Orlando Maia II)

Figura D.2 - Variação dos acréscimos de força normal dos pilares, nas direções $\mathbf{X}$ e $\mathbf{Y}$

(Ed. Roma) 
Figura D.3 - Variação dos acréscimos de força normal dos pilares, nas direções $\mathbf{X}$ e $\mathbf{Y}$

(Ed. Vela I)

Figura D.4 - Variação dos acréscimos de força normal dos pilares, nas direções $\mathbf{X}$ e $\mathbf{Y}$

(Ed. Fontana di Trevi)

Figura D.5 - Variação dos acréscimos de força normal dos pilares, nas direções $\mathbf{X}$ e $\mathbf{Y}$

(Ed. Multiplus)

Figura D.6 - Variação dos acréscimos de momentos fletores dos pilares,

nas direções X e Y (Ed. Orlando Maia II)

Figura D.7 - Variação dos acréscimos de momentos fletores dos pilares, nas direções $\mathbf{X}$ e $\mathbf{Y}$ (Ed. Roma)

Figura D.8 - Variação dos acréscimos de momentos fletores dos pilares, nas direções $\mathbf{X}$ e $\mathbf{Y}$ (Ed. Vela I)

Figura D.9 - Variação dos acréscimos de momentos fletores dos pilares,

nas direções $\mathbf{X}$ e $\mathbf{Y}$ (Ed. Fontana di Trevi)

Figura D.10 - Variação dos acréscimos de momentos fletores dos pilares, nas direções $\mathbf{X}$ e $\mathbf{Y}$ (Ed. Multiplus)

Figura D.11 - Variação dos acréscimos de esforços das vigas, nas direções $\mathbf{X}$ e $\mathbf{Y}$

(Ed. Orlando Maia II)

Figura D.12 - Variação dos acréscimos de esforços das vigas, nas direções $\mathbf{X}$ e $\mathbf{Y}$

(Ed. Roma)

Figura D.13 - Variação dos acréscimos de esforços das vigas, nas direções $\mathbf{X}$ e $\mathbf{Y}$

(Ed. Vela I)

Figura D.14 - Variação dos acréscimos de esforços das vigas, nas direções $\mathbf{X}$ e $\mathbf{Y}$

(Ed. Fontana di Trevi)

Figura D.15 - Variação dos acréscimos de esforços das vigas, nas direções $\mathbf{X}$ e $\mathbf{Y}$

(Ed. Multiplus)

Figura D.16 - Diagramas de dispersão

Figura D.17 - Relação entre os acréscimos sugeridos por P- $\Delta$ e $\gamma_{z}$ -

Força normal

Figura D.18 - Relação entre os acréscimos sugeridos por P- $\Delta$ e $\gamma_{\mathbf{z}}$ -

Momentos nos pilares

Figura D.19 - Relação entre os acréscimos sugeridos por P- $\Delta$ e $\gamma_{\mathrm{z}}-$

Esforços nas vigas

Figura D.20 - Relação entre os acréscimos sugeridos por P- $\Delta$ e $\gamma_{z}$ -

Média geral. 


\section{LISTA DE TABELAS}

Tabela 2.1 - Perímetros críticos para pilares internos .........................................................19

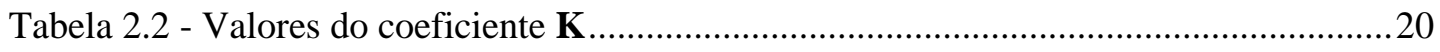

Tabela 2.3 - Perímetros críticos reduzidos para pilares de borda ............................................22

Tabela 2.4 - Perímetros críticos reduzidos para pilares de canto ..............................................25

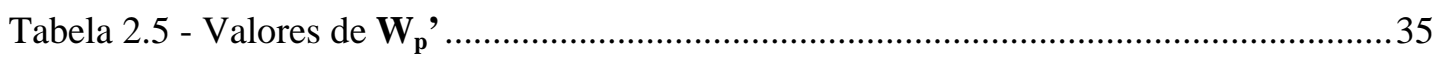

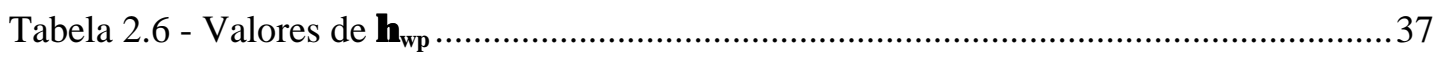

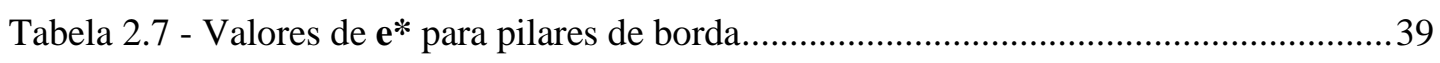

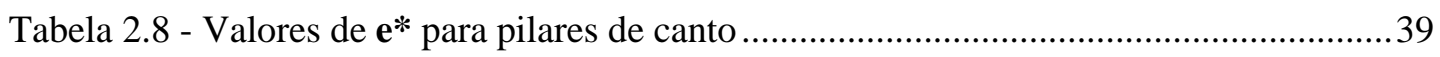

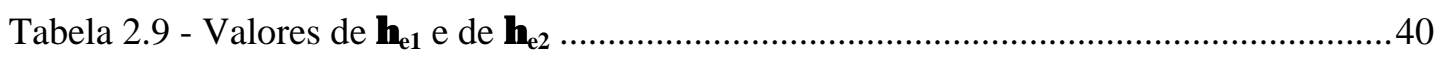

Tabela 2.10 - Valores de $\beta$ agrupados e aproximados.........................................................42

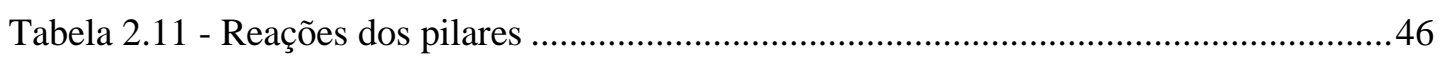

Tabela 2.12 - Capacidade resistente de ligações segundo a NBR 6118 (1978) e a NBR 6118 (2000)

Tabela 2.13 - Tensões limites para dispensa de armadura de cisalhamento segundo a NBR 6118 (1978) e a NBR 6118 (2000) .69

Tabela 3.1 - Valores de $\psi$ e $\alpha_{\lim }$ para diferentes sistemas de contraventamento.....................81

Tabela 3.2 - Pés-direitos, alturas e forças verticais dos pavimentos ..................................... 101

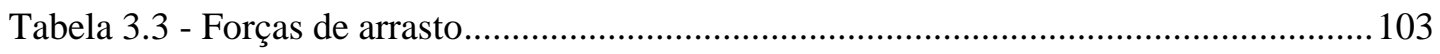

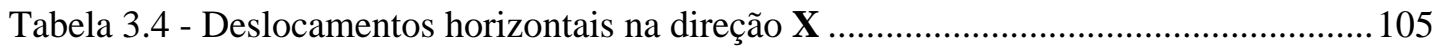

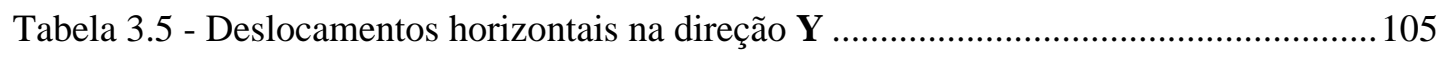

Tabela 3.6 - Deslocamentos horizontais na direção $\mathbf{X}$, devidos às forças verticais ..............106

Tabela 3.7 - Acréscimos percentuais dos esforços pelo processo $\mathbf{P}-\Delta$ - direção $\mathbf{X}$................108

Tabela 3.8 - Acréscimos percentuais dos esforços pelo processo P- $\Delta$ - direção Y ...............108

Tabela 3.9 - Comparação entre majorações............................................................................109 
Tabela A.1 - Valores de $\eta_{\text {wp }}$ para o quantil de $10 \%$ 126

Tabela A.2 - Valores de $\eta_{\text {wp }}$ sugeridos e suas probabilidades de ocorrência .. 127

Tabela A.3 - Valores de $\eta_{\text {wp }}$ para pilares internos com $c_{1} \leq c_{2}$

Tabela A.4 - Valores de $\eta_{\text {wp }}$ para pilares internos com $c_{1}>c_{2}$

Tabela A.5 - Valores de $\eta_{\text {wp }}$ para pilares de borda com $c_{1} \leq c_{2}$

Tabela A.6 - Valores de $\eta_{\mathrm{wp}}$ para pilares de borda com $c_{1}>c_{2}$

Tabela A.7 - Valores de $\eta_{\text {wp }}$ para pilares de canto com $c_{1} \leq c_{2}$

Tabela A.8 - Valores de $\eta_{\text {wp }}$ para pilares de canto com $c_{1}>c_{2}$

Tabela B.1 - Valores de $\eta_{\mathbf{e} 1}$ e de $\eta_{\mathbf{e} 2}$ para o quantil de $10 \%$

Tabela B.2 - Valores de $\eta_{\mathbf{e} 1}$ e de $\eta_{\mathbf{e} 2}$ sugeridos e suas probabilidades de ocorrência. 151

Tabela B.3 - Valores de $\eta_{\mathbf{e} 1}$ e de $\eta_{\mathbf{e} 2}$ para pilares de borda com $c_{1} \leq c_{2}$

Tabela B.4 - Valores de $\eta_{\mathrm{e} 1}$ e de $\eta_{\mathrm{e} 2}$ para pilares de borda com $c_{1}>c_{2}$

Tabela B.5 - Valores de $\eta_{\mathrm{e} 1}$ e de $\eta_{\mathrm{e} 2}$ para pilares de canto com $c_{1} \leq \mathrm{c}_{2}$

Tabela B.6 - Valores de $\eta_{\mathrm{e} 1}$ e de $\eta_{\mathrm{e} 2}$ para pilares de canto com $c_{1}>c_{2}$

Tabela C.1 - Valores de $\beta$ para o nível de significância de $10 \%$

Tabela C.2 - Valores de $\beta$ sugeridos para $c_{1} \leq c_{2}$ e suas probabilidades de ocorrência.......170

Tabela C.3 - Valores de $\beta$ sugeridos para $c_{1}>c_{2}$ e suas probabilidades de ocorrência......170

Tabela C. 4 - Valores de $\beta$ para pilares internos com momento atuante em uma direção e $c_{1} \leq c_{2}$

Tabela C.5 - Valores de $\beta$ para pilares internos com momento atuante em uma direção e $c_{1}>c_{2}$

Tabela C.6 - Valores de $\beta$ para pilares internos com momentos atuantes nas duas direções e $c_{1} \leq c_{2}$

Tabela C.7 - Valores de $\beta$ para pilares internos com momentos atuantes nas duas direções e $c_{1}>c_{2}$

Tabela C.8 - Valores de $\beta$ para pilares de borda sem momento no plano paralelo à borda $\mathrm{e} \mathrm{c}_{1} \leq \mathrm{c}_{2}$

Tabela C.9 - Valores de $\beta$ para pilares de borda sem momento no plano paralelo

à borda e $c_{1}>c_{2}$

Tabela C.10 - Valores de $\beta$ para pilares de borda com momento no plano paralelo à borda e $c_{1} \leq c_{2}$ 
Tabela C.11 - Valores de $\beta$ para pilares de borda com momento no plano paralelo à borda e $c_{1}>c_{2}$ 192

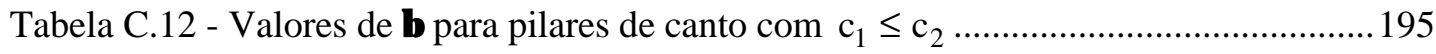

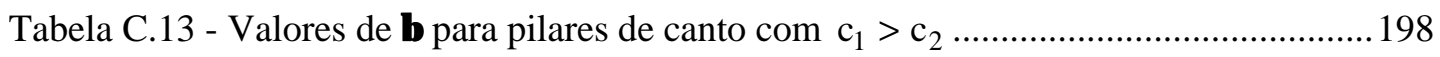

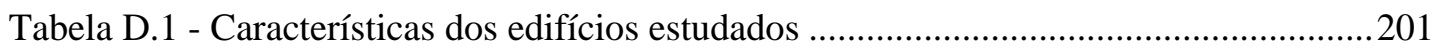

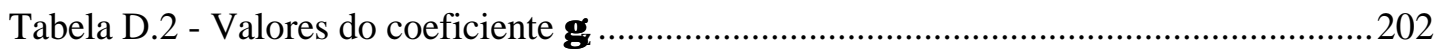

Tabela D.3 - Acréscimos percentuais dos esforços de primeira ordem indicados pelo

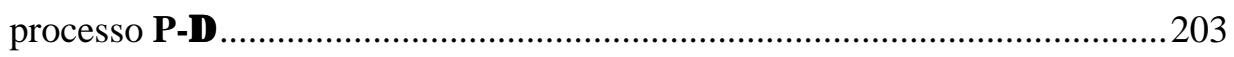

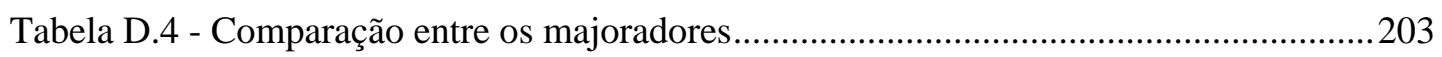

Tabela D.5 - Acréscimos percentuais dos esforços pelo processo P- $\Delta$, na direção X (Ed. Orlando Maia II)

Tabela D.6 - Acréscimos percentuais dos esforços pelo processo $\mathbf{P}-\Delta$, na direção Y (Ed. Orlando Maia II)

Tabela D.7 - Acréscimos percentuais dos esforços pelo processo P- $\Delta$, na direção X (Ed. Roma)

Tabela D.8 - Acréscimos percentuais dos esforços pelo processo P- $\Delta$, na direção Y (Ed. Roma)

Tabela D.9 - Acréscimos percentuais dos esforços pelo processo P- $\Delta$, na direção X (Ed. Vela Branca I)...

Tabela D.10 - Acréscimos percentuais dos esforços pelo processo P- $\Delta$, na direção Y (Ed. Vela Branca I)

Tabela D.11 - Acréscimos percentuais dos esforços pelo processo P- $\Delta$, na direção $\mathbf{X}$ (Ed. Fontana di Trevi)

Tabela D.12 - Acréscimos percentuais dos esforços pelo processo $\mathbf{P}-\Delta$, na direção Y (Ed. Fontana di Trevi)

Tabela D.13 - Acréscimos percentuais dos esforços pelo processo P- $\mathbf{\Delta}$, na direção X (Ed. Multiplus)

Tabela D.14 - Acréscimos percentuais dos esforços pelo processo P- $\Delta$, na direção Y (Ed. Multiplus) 


\section{LISTA DE SIGLAS}

$\begin{array}{ll}\text { ABNT } & \text { - Associação Brasileira de Normas Técnicas } \\ \text { ACI } & \text { - American Concrete Institute } \\ \text { CEB } & \text { - Comité Euro-International du Béton } \\ \text { FIP } & \text { - Féderation Internationale de la Précontrainte } \\ \text { MC } & \text { - Model Code } \\ \text { NBR } & \text { - Norma Brasileira Registrada } \\ \text { NLG } & \text { - Não-Linearidade Geométrica } \\ \text { NLF } & \text { - Não-Linearidade Física }\end{array}$




\section{LISTA DE SÍMBOLOS}

\section{Capítulo 2}

Letras romanas minúsculas
$\mathbf{a}, \mathbf{a}_{1}, \mathbf{a}_{2}$
- trechos dos perímetros críticos reduzidos
c
- dimensão do pilar ou cobrimento da armadura
$\mathbf{c}_{1}, \mathbf{c}_{2}$
- dimensões do pilar
d
- altura útil da laje
$\mathbf{d} \ell$
- comprimento infinitesimal do perímetro crítico
$\mathbf{d}_{\mathbf{x}}, \mathbf{d}_{\mathbf{y}}$
- alturas úteis da laje nas direções ortogonais $\mathbf{X}$ e $\mathbf{Y}$
e
- distância do comprimento infinitesimal do perímetro crítico ao eixo que passa pelo centro do pilar
$\mathbf{e}^{*}$
- excentricidade do perímetro crítico reduzido no contorno C'
$\mathbf{e}_{\mathbf{0}}^{*}$
- excentricidade do perímetro crítico reduzido no contorno $\mathbf{C}$
$\mathbf{e}^{* *}$
- excentricidade do perímetro crítico reduzido no contorno $\mathbf{C}$ "
$\mathbf{f}_{\text {cd }}$
- resistência de cálculo do concreto à compressão
$\mathbf{f}_{\mathrm{ck}}$
- resistência característica do concreto à compressão
$\mathbf{f}_{\mathrm{ywd}}$
- resistência de cálculo da armadura de punção
$\mathbf{f}_{\mathbf{y d}}$
- tensão de escoamento da armadura de colapso progressivo 
h

$\ell_{\mathbf{b}}$

p

$\mathbf{S}_{\mathbf{e}}$

$\mathbf{S}_{\mathbf{o}}$

$\mathbf{S}_{\mathbf{r}}$

$\mathbf{u}$

$\mathbf{u}_{\mathbf{o}}$

$\mathbf{u}^{\prime}$

u*

$\mathbf{u}_{\mathbf{0}} *$

u'*

Letras romanas maiúsculas
- altura da laje

- comprimento de ancoragem

- distância da face do pilar até a última linha de conectores

- espaçamento entre os conectores mais afastados do pilar

- espaçamento entre a face do pilar e a primeira linha de conectores

- espaçamento radial entre linhas de conectores

- perímetro crítico do contorno $\mathbf{C}^{\prime}$

- perímetro crítico do contorno $\mathbf{C}$

- perímetro crítico do contorno C'

- perímetro crítico reduzido do contorno $\mathbf{C}^{\prime}$

- perímetro crítico reduzido do contorno $\mathbf{C}$

- perímetro crítico reduzido do contorno C"
$\mathbf{A}_{\mathbf{s}}$

$\mathbf{A}_{\text {sw }}$

C

C'

C'

D

$\mathbf{F}_{\text {Sd }}$

$\mathbf{K}, \mathbf{K}_{1}, \mathbf{K}_{2}$

$\mathbf{M}_{\mathrm{sd}}, \mathbf{M}_{\mathrm{sd1}}, \mathbf{M}_{\mathrm{sd} 2}$

$\mathbf{M}_{\mathrm{sd}}$ *

$\mathbf{N}_{1 d}$
- soma das áreas das armaduras positivas, devidamente ancoradas, que cruzam cada uma das faces do pilar

- área da armadura de punção

- contorno crítico na face do pilar

- contorno crítico a $2 \mathbf{d}$ da face do pilar

- contorno crítico a $2 \mathbf{d}$ da região armada

- diâmetro do pino

- força normal de cálculo

- coeficientes que fornecem a parcela de momento transferida por cisalhamento

- momentos desbalanceados de cálculo

- momento resultante da excentricidade do perímetro crítico reduzido u* em relação ao centro do pilar

- força vertical acumulada 
$\mathbf{N}_{2 \mathrm{~d}}$

$\mathbf{W}_{\mathbf{p}}, \mathbf{W}_{\mathbf{p} 1}, \mathbf{W}_{\mathbf{p} 2} \quad$ - módulos de resistência plástica do perímetro crítico $\mathbf{u}$

$\mathbf{W}_{\mathbf{p o}}, \mathbf{W}_{\mathbf{p} 1, \mathbf{o}}, \mathbf{W}_{\mathbf{p 2 , 0}} \quad$ - módulos de resistência plástica do perímetro crítico $\mathbf{u}_{\mathbf{o}}$

$\mathbf{W}_{\mathbf{p}}, \mathbf{W}_{\mathbf{p 1}}, \mathbf{W}_{\mathbf{p} 2}$ ' - módulos de resistência plástica do perímetro crítico $\mathbf{u}$ '

$\mathbf{X}, \mathbf{Y}$

- direções da armadura de flexão na laje

Letras gregas

$\alpha$

$\alpha_{\mathbf{v}}$

$\beta$

$\eta_{\mathrm{e} 1}, \eta_{\mathrm{e} 2}$

$\eta_{w p}$

$\rho$

$\rho_{x}, \rho_{y}$

$\tau_{\text {Rd1 }}$

$\tau_{\mathbf{R d} 2}$

$\tau_{\mathbf{R d} 3}$

$\tau_{\mathbf{S d}}$
- inclinação entre o eixo da armadura de punção e o plano da laje

- coeficiente de efetividade do concreto

- coeficiente para consideração do efeito da excentricidade

- coeficiente para correção de $\mathbf{e}^{*}$ em função do contorno estudado

- coeficiente para correção do $\mathbf{W}_{\mathbf{p}}$ ' em função da situação de cálculo

- taxa geométrica de armadura longitudinal

- taxas geométricas de armadura longitudinal nas direções ortogonais $\mathbf{X}$ e $\mathbf{Y}$

- tensão resistente de cálculo do concreto a $2 \mathbf{d}$ ou da face do pilar (lajes sem armadura de punção) ou da região armada

- tensão resistente de cálculo do concreto na face do pilar

- tensão resistente de cálculo do concreto a $2 \mathbf{d}$ da face do pilar (lajes com armadura de punção)

- tensão solicitante de cálculo do concreto ao cisalhamento 


\section{Capítulo 3}

Letras romanas minúsculas

$\mathbf{a}$

$\mathbf{a}_{\mathbf{h}}$

$\mathbf{a}_{\mathbf{v}}$

$\mathbf{a}_{\mathbf{v i}}$

$\mathbf{d}_{\mathbf{i}}$

$\mathbf{d}_{\mathbf{i}+\mathbf{1}}$

$\mathbf{f}_{\mathbf{c k}}$

$\mathbf{h}_{\mathbf{i}}$

$\mathbf{h}_{\mathbf{i}+\mathbf{1}}$

$\ell$

n

$\mathbf{q}$

$\mathbf{r}$

$\mathbf{X}_{\mathbf{i}}$

$\mathbf{y}_{\mathbf{i}}$

$\mathbf{y}_{\text {id }}$
- deslocamento horizontal no topo da estrutura

- deslocamento horizontal no nível do centro de gravidade das cargas verticais da estrutura, decorrente da incidência apenas de ações horizontais

- deslocamento horizontal no nível do centro de gravidade das cargas verticais da estrutura, decorrente da incidência apenas de ações verticais

- deslocamento horizontal do pavimento i, decorrente da incidência apenas de ações verticais

- deslocamento horizontal relativo do pavimento i em relação ao pavimento i-1

- deslocamento horizontal relativo do pavimento $\mathbf{i}+\mathbf{1}$ em relação ao pavimento $\mathbf{i}$

- resistência característica do concreto à compressão

- pé-direito do pavimento i

- pé-direito do pavimento $\mathbf{i + 1}$

- altura total da estrutura, em metros

- número de pavimentos, número de pilares contínuos de um pórtico ou número de iterações

- força horizontal uniformemente distribuída

- razão de progressão geométrica

- distância vertical do pavimento i à base do edifício

- deslocamento horizontal do pavimento i

- deslocamento horizontal do pavimento i, provocado por forças horizontais com valores de cálculo 
Letras romanas maiúsculas

$\mathbf{A}_{\mathrm{s}}$

$\mathbf{A}_{\mathrm{s}}$

$\mathbf{C}_{\mathbf{a}}$

$\mathbf{E}$

$\mathbf{E}_{\mathbf{c}}$

EI

$(\mathbf{E I})_{\mathrm{eq}}$

$(\mathbf{E I})_{\text {sec }}$

$\mathbf{F}_{\text {ai }}$

$\mathbf{F H}_{\text {id }}$

H

$\mathbf{H}_{\mathbf{i}}$

$\Delta \mathbf{H}_{\mathbf{i}}$

\section{I}

$\mathbf{I}_{\mathbf{c}}$

$\mathbf{M}_{1}$

$M_{1 \mathrm{~d}}$

$\mathbf{M}_{1, \text { tot,d }}$

$\mathbf{M}_{2}$

$\mathbf{M}_{2 \mathrm{~d}}$

$\Delta \mathbf{M}_{1}$

$\Delta \mathbf{M}_{\mathbf{d}}$

$\Delta \mathbf{M}_{\text {tot,d }}$
- área da armadura de tração

- área da armadura de compressão

- coeficiente de arrasto

- módulo de deformação longitudinal

- módulo de deformação longitudinal inicial do concreto

- módulo de rigidez

- módulo de rigidez equivalente

- módulo de rigidez secante

- força de arrasto aplicada no pavimento $\mathbf{i}$

- força horizontal total aplicada no pavimento i, com valor de cálculo

- altura total da estrutura

- força horizontal fictícia aplicada no pavimento i (processo P- $\Delta$ )

- força horizontal fictícia devida ao desaprumo, aplicada no pavimento i

- momento de inércia da seção transversal bruta

- momento de inércia da seção transversal bruta de um elemento de concreto

- momento externo de primeira ordem na base da estrutura indeformada

- momento externo de primeira ordem na base da estrutura indeformada, com valores de cálculo

- momento de primeira ordem, com valores de cálculo

- momento final na posição de equilíbrio (primeira ordem + segunda ordem)

- momento total, com valores de cálculo

- acréscimo de momentos na primeira iteração

- acréscimo de momentos na primeira iteração, com valor de cálculo

- acréscimo de momentos após a análise de primeira ordem, com valor de cálculo 


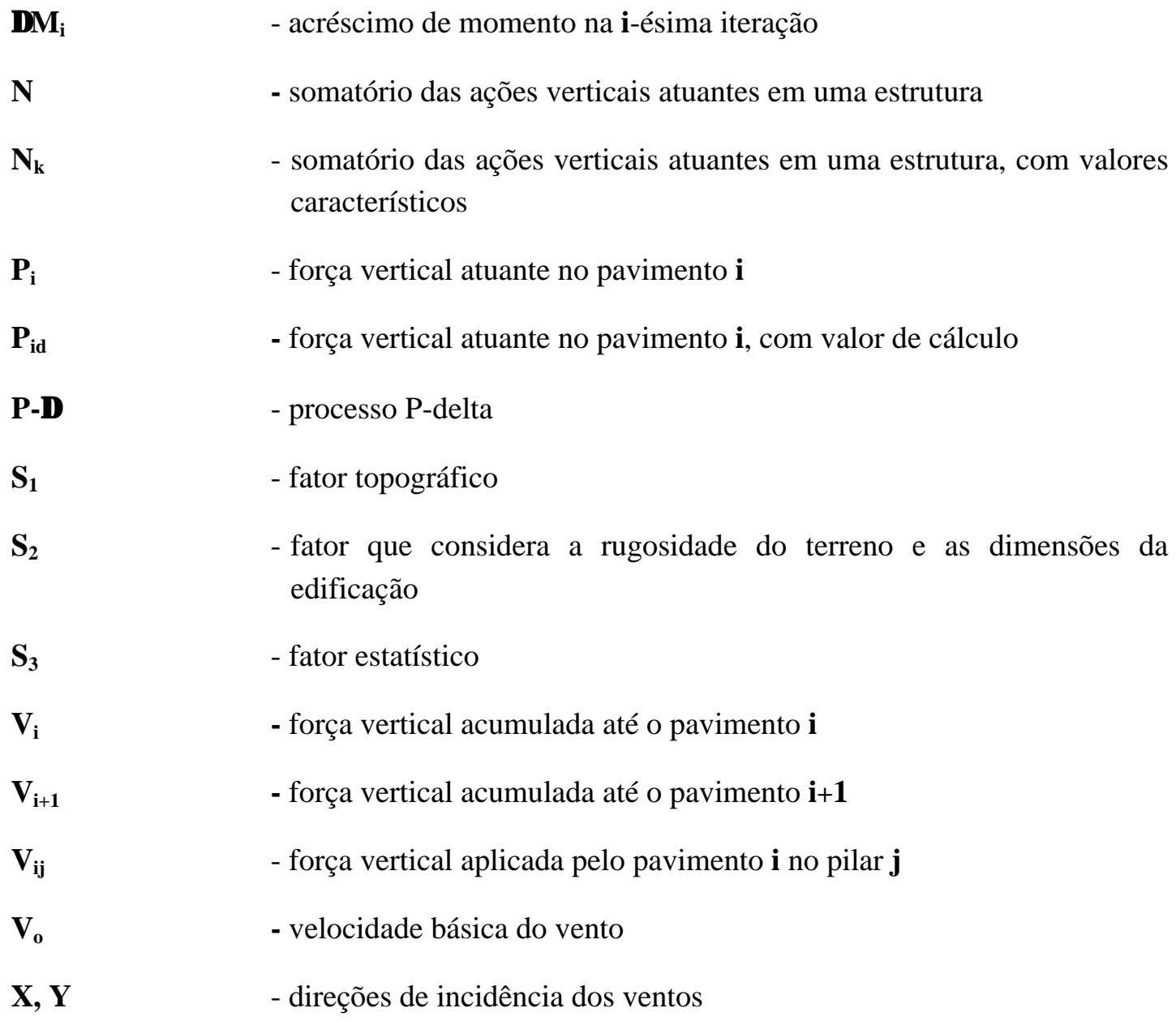

Letras gregas

$\alpha$

$\alpha_{\lim }$

$\psi$

$\gamma_{\mathrm{f}}$

$\gamma_{\mathrm{z}}$

$\theta_{\mathrm{a}}$
- parâmetro alfa ou parâmetro de instabilidade

- valor limite para o parâmetro de instabilidade alfa

- parâmetro de forma da linha elástica

- coeficiente de ponderação

- coeficiente gama-Z

- ângulo de desaprumo 


\section{RESUMO}

LIMA, J.S. (2001). Verificações da punção e da estabilidade global de edifícios de concreto: desenvolvimento e aplicação de recomendações normativas. São Carlos. 225p. Dissertação (Mestrado) - Escola de Engenharia de São Carlos, Universidade de São Paulo.

Neste trabalho, são estudadas as verificações da punção e da estabilidade global segundo a revisão da NBR 6118. A partir da análise dos fenômenos físicos e com base nos estudos teóricos realizados, são feitas sugestões para serem contornadas algumas omissões da Norma. Também são propostas complementações que facilitem o entendimento das novas recomendações e, ainda, modificações que melhorem seus resultados. Sugerem-se métodos simplificados relacionados à punção excêntrica, e propõem-se algumas alterações quanto ao uso do $\gamma_{\mathrm{z}}$ como coeficiente majorador na avaliação da estabilidade global. Observa-se que as verificações, apesar de mais trabalhosas, apresentam melhorias significativas em relação à NBR 6118 (1978), mostrando-se mais detalhadas e eficientes. Ainda assim, considera-se importante a introdução de algumas complementações, como aquelas sugeridas neste trabalho.

Palavras-chave: concreto armado; punção; estabilidade global; efeitos de segunda ordem; edifício; normalização. 


\section{ABSTRACT}

LIMA, J.S. (2001). Punching shear and global stability of concrete buildings: development and application of code provisions. São Carlos. 225p. Dissertação (Mestrado) - Escola de Engenharia de São Carlos, Universidade de São Paulo.

This work presents an overview of the requirements for punching shear and global stability of buildings in the draft Brazilian Code for concrete structures. Suggestions are made for fulfilling some omissions of the Code, based on theoretical studies and physical phenomena analysis. Some complements and changes are also proposed to facilitate the understanding of the new recommendations and to improve their results. Simplified methods related to the eccentric punching and modifications in the use of $\gamma_{\mathrm{z}}$ as a first order effects magnifier are suggested. It is concluded that the new provisions are more detailed and efficient, presenting significant improvements on both topics, especially when compared to NBR 6118 (1978). Nevertheless, it is considered important the introduction of some complements, as those suggested in this work.

Keywords: reinforced concrete; punching; stability; second order effects; building; code provisions. 


\section{Capítulo 1}

\section{INTRODUÇÃO}

\subsection{ASPECTOS GERAIS}

A simples observação dos centros urbanos em qualquer lugar do mundo é suficiente para se constatar as mudanças sofridas pelos padrões arquitetônicos e urbanísticos nas últimas décadas. Essa formação de novas paisagens é produto direto dos avanços das tecnologias e dos materiais.

No que diz respeito à Engenharia de Estruturas, em especial, o surgimento de novos equipamentos e técnicas de ensaio e instrumentação, e o advento do computador e sua popularização, foram os grandes responsáveis pela possibilidade de sofisticação e refinamento das análises. As modelagens numéricas vêm se mostrando cada vez mais capazes de representar o comportamento dos elementos estruturais e de estruturas como um todo, e as pesquisas experimentais já vêm utilizando modelos mais completos e complexos. Com isso, os fenômenos físicos puderam ser melhor conhecidos, as estimativas de esforços e deslocamentos puderam ser melhor aproximadas, e vêm se conseguindo projetar estruturas mais arrojadas.

Dentro desse novo contexto, e considerando-se as necessidades inerentes à modernidade, surge a necessidade de se rever o projeto de concreto estrutural. Algumas prescrições das normas em vigor já estão ultrapassadas, não sendo mais condizentes com as estruturas que vêm sendo construídas, e certas omissões já não são mais admissíveis.

Por isso, a Associação Brasileira de Normas Técnicas (ABNT) está finalizando a nova NBR 6118 - Projeto de estruturas de concreto, que substituirá três normas: a NBR 6118 - Projeto e execução de obras de concreto armado, a NBR 7197 - Projeto de estruturas de concreto protendido, e a NBR 5627 - Projeto de concreto simples. Nesse texto, estarão novas diretrizes para a elaboração de projetos estruturais, com várias complementações e modificações em relação às versões que ainda estão em vigor. 
Entretanto, é importante salientar que essas novas recomendações, apesar de certamente serem baseadas em estudos mais recentes, ainda não estão consolidadas. Apenas com trabalhos específicos sobre cada um dos tópicos abordados é que se pode conhecer melhor os fundamentos dos procedimentos propostos, e identificar e preencher as principais lacunas existentes.

\subsection{JUSTIFICATIVA}

O texto provisório da nova NBR 6118, aqui chamado de NBR 6118 (2000), já foi lançado e está em fase de consulta pública. Alguns de seus temas chamam atenção, seja pelo fato de não terem sido abordados na versão anterior, seja pelas modificações que sofreram. Dentre eles, pode-se citar o dimensionamento de vigas ao esforço cortante e à torção, que trazem nova formulação; a verificação de lajes à punção, que traz novos procedimentos; o cálculo dos esforços de segunda ordem globais e a verificação da estabilidade global de edifícios, que antes não eram sequer mencionados; e os aspectos de qualidade e estados limites de serviço, aos quais vêm se dando bastante ênfase e que também eram negligenciados ou tratados apenas superficialmente no texto anterior. Pode-se falar ainda das questões de análise estrutural, instabilidade local e regiões de descontinuidade.

Frente a todas essas novidades e considerando-se que várias das novas recomendações não têm suas origens indicadas, que algumas modificações não são justificadas, e que os pontos mencionados na seção de comentários não respondem a dúvidas comuns que o projetista de estruturas pode vir a ter, o estudo desse texto torna-se fundamental. Compreendendo-se os fenômenos físicos relacionados a cada um dos assuntos, pode-se identificar seus aspectos fundamentais, ou seja, aqueles que não podem ser negligenciados no projeto, e então verificar se eles estão sendo considerados, e de forma coerente, pela Norma. Pode-se estudar as formulações adotadas e indicar coeficientes ou expressões que venham apresentando melhores desempenhos, apontando-se maneiras práticas de utilizá-los. Resolvendo-se exemplos de situações práticas, pode-se aplicar e também esclarecer as recomendações da Norma, além de se identificar suas principais limitações. E propostas para complementações ou modificações devem surgir naturalmente.

Em especial para este trabalho, foram escolhidos dois tópicos: as verificações da punção e da estabilidade global, sendo que ambos os procedimentos são novidades em relação à NBR 6118 (1978).

No caso da punção, o método adotado anteriormente deu lugar a um novo enfoque, que ainda não é largamente conhecido. E com o aumento da utilização de lajes lisas, tanto a 
compreensão do fenômeno da punção quanto de sua verificação vêm se tornando elementos essenciais para a elaboração do projeto.

Já no caso da estabilidade global, nem havia prescrições na versão anterior. E com o aumento do número de pavimentos dos edifícios e de sua esbeltez, a avaliação correta dos efeitos do vento e, principalmente, dos efeitos de segunda ordem por ele causados, vêm se tornando ainda mais importantes.

É claro que os outros tópicos mencionados anteriormente também merecem atenção, mas ficam como propostas para pesquisas futuras.

\subsection{OBJETIVOS}

Pode-se dizer que são dois os objetivos principais deste trabalho.

O primeiro é esclarecer os procedimentos da NBR 6118 (2000) relativos às verificações da punção e da estabilidade global, elaborando-se um texto didático que auxilie a sua compreensão. A partir da análise dos fenômenos físicos e com base nos estudos teóricos realizados, pretende-se, inclusive, fazer sugestões para serem contornadas as omissões da Norma que, em algumas situações, prejudicam seu entendimento.

O segundo é avaliar a abordagem da NBR 6118 (2000) no que diz respeito aos tópicos estudados, propondo-se tanto complementações que facilitem o entendimento das novas recomendações quanto modificações que melhorem seus resultados. Novamente com base nos estudos teóricos, pretende-se destacar alguns aspectos que deveriam ser considerados nas verificações e não o são, e outros que precisariam ser alterados.

E para ilustrar tanto os procedimentos da Norma como as complementações e alterações sugeridas, serão apresentados exemplos de cálculo de situações práticas.

\subsection{CONTEÚDO}

No capítulo 2, são estudadas as características da ruptura por punção e os procedimentos para o projeto de grande parte das situações práticas de pilares retangulares, incluindo pilares internos, de borda e de canto, e lajes armadas e não armadas para punção. As recomendações da NBR 6118 (2000) são apresentadas, justificadas e criticadas, sendo sugeridas algumas complementações e modificações. Realiza-se, ainda, um exemplo de cálculo para ilustrar os procedimentos discutidos.

No capítulo 3, são estudados a determinação dos efeitos de segunda ordem, a importância da verificação da estabilidade global e os procedimentos de projeto usualmente adotados para este fim. As recomendações da NBR 6118 (2000), que permitem o uso do 
parâmetro de instabilidade $\alpha$ e do coeficiente $\gamma_{\mathbf{z}}$, são apresentadas e analisadas com base em um processo mais rigoroso, o $\mathbf{P}-\Delta$, sugerindo-se, novamente, algumas complementações e modificações. Realiza-se, também, um exemplo de cálculo para ilustrar os procedimentos discutidos.

Por fim, no capítulo 4, são apresentadas as conclusões e algumas considerações finais sobre os estudos realizados. Destacam-se as principais propostas para a versão definitiva da NBR 6118, além de sugestões para novas pesquisas. 


\section{CAPÍtulo 2}

\section{PUNÇÃO EM LAJES}

Com o aumento da utilização de lajes lisas, tanto a compreensão do fenômeno da punção quanto a sua verificação tornam-se elementos essenciais para a elaboração do projeto. Neste capítulo, são estudadas as características da ruptura por punção e os procedimentos para o projeto de grande parte das situações práticas de pilares retangulares, incluindo pilares internos, de borda e de canto, e lajes armadas e não armadas para punção. As recomendações da NBR 6118 (2000) são apresentadas, justificadas e criticadas, sendo sugeridas algumas complementações e modificações. Por fim, realiza-se um exemplo de cálculo para ilustrar os procedimentos discutidos.

\subsection{O FENÔMENO DA PUNÇÃO}

A punção é um problema freqüente em lajes lisas e está relacionado à concentração de tensões cisalhantes nas proximidades dos pilares. A região da laje próxima ao pilar sofre uma pequena rotação e move-se verticalmente, fraturando a zona comprimida e separando os dois elementos. Como praticamente não ocorre escoamento da armadura de flexão da laje, fica caracterizada uma ruína do tipo frágil.

À medida que a estrutura vai sendo carregada, várias fissuras radiais de flexão vão sendo formadas (Figura 2.1a). A cerca de $2 / 3$ da força última de punção, aparecem fissuras circunferenciais (Figura 2.1b), formadas da face carregada para a face oposta da laje, sob uma inclinação que varia entre $25^{\circ}$ e $30^{\circ}$ com o plano da laje (Figura 2.2).

No caso simétrico de pilares internos, a superfície de ruína é praticamente um tronco de cone (Figura 2.3a). No caso de pilares de borda e de canto (Figura 2.3b e Figura 2.3c, respectivamente), as superfícies são mais irregulares e a análise da ruína é consideravelmente mais difícil, principalmente devido à influência dos efeitos de flexão e de torção. 
(a)

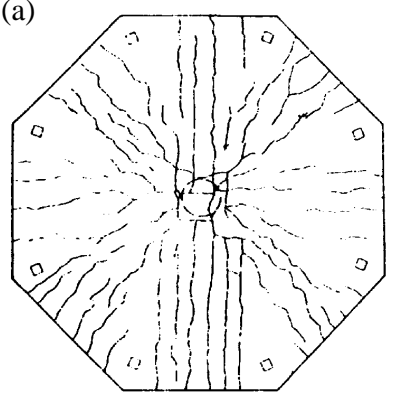

(b)

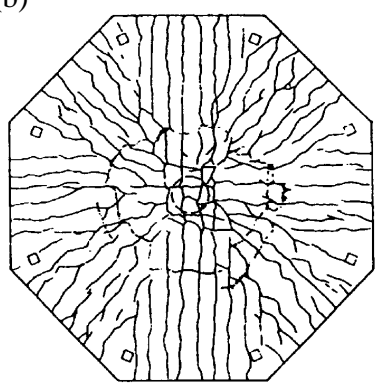

Figura 2.1 - Estágios de fissuração na face superior de uma laje simétrica.

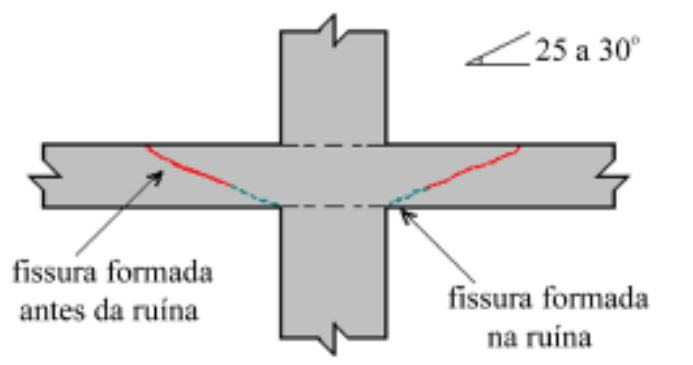

Figura 2.2 - Propagação das fissuras

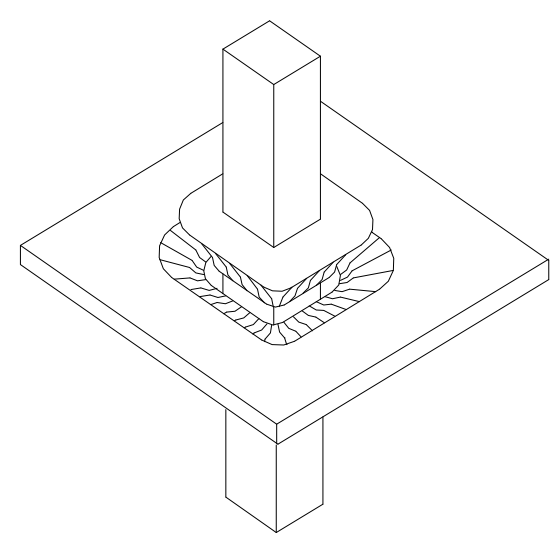

(a) Pilar interno

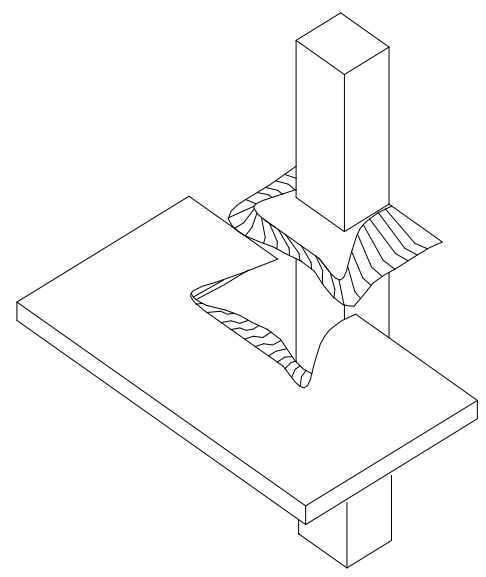

(b) Pilar de borda

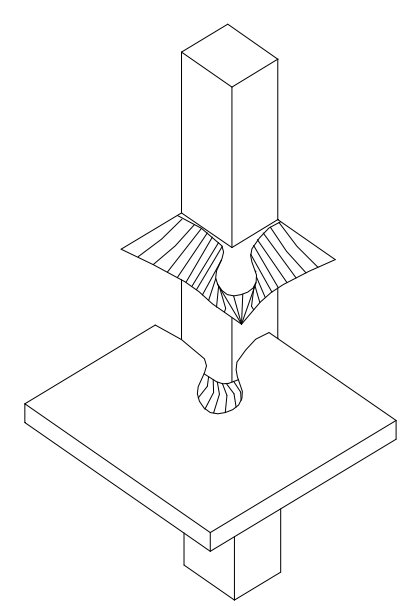

(c) Pilar de canto

Figura 2.3 - Superfícies de ruína por punção 


\subsection{INFLUÊNCIA DA ARMADURA PARA PUNÇÃO}

Para se evitar a ruína por punção, muitas vezes é necessário se aumentar a resistência da ligação laje-pilar. Soluções comuns como capitéis e "drop panels" podem ser indesejáveis do ponto de vista arquitetônico ou construtivo, e, por isso, o uso de armaduras de cisalhamento para o combate à punção, ou, simplesmente, armaduras de punção, vem crescendo bastante. Essa alternativa, extremamente favorável do ponto de vista da ductilidade, contribui para a mudança do tipo de ruína previsto, de frágil (punção) para dúctil (flexão).

Quando são utilizadas armaduras de punção, o plano preferencial para a formação da superfície de ruína é modificado e vai se afastando da face do pilar. A capacidade resistente da ligação aumenta numa boa proporção, tanto que, de acordo com GOMES (1991), a resistência das lajes com armaduras de punção pode chegar ao dobro da resistência das lajes sem essas armaduras. Esse aumento proporcionado pelas armadura, entretanto, é limitado pela tensão de esmagamento da biela comprimida na face do pilar.

De qualquer forma, a nova tensão resistente da ligação tem uma parcela referente à armadura de punção e outra referente ao concreto.

A parcela do concreto corresponde a cerca de $75 \%$ da resistência da laje sem armadura de punção, segundo os estudos de REGAN \& BRAESTRUP (1985), com base nos trabalhos de DILGER \& GHALI (1981), LANGOHR et al. (1976) e SEIBLE et al. (1980), dentre outros. Essa redução seria conseqüência, principalmente, das maiores deformações e aberturas de fissuras relacionadas ao trabalho da armadura de cisalhamento. De acordo com GOMES (1991), entretanto, com base em seus resultados experimentais, existem casos em que a parcela do concreto pode atingir quase $100 \%$ da resistência da laje não armada para punção, a depender da ancoragem desenvolvida.

Já a parcela da armadura depende de vários parâmetros, como a disposição e os espaçamentos dos elementos, a eficiência das ancoragens, além da própria área de aço. Podem ser utilizados estribos ou conectores tipo pino (studs), modelos mais usuais dentre outras possibilidades.

Apesar dos estribos serem escolhidos com maior freqüência, a garantia de sua ancoragem requer cuidados essenciais. $\mathrm{O}$ estribo deve envolver tanto a armadura de flexão superior quanto a inferior, o que dificulta e pode atrasar o processo executivo. Pequenas falhas nessas ligações provocam escorregamento e já comprometem a eficiência da armação, como mencionado por DILGER \& GHALI (1981).

Mais efetivos em termos de ancoragem e mais facilmente colocados nas lajes, os conectores tipo pino vêm apresentado bom desempenho no aumento da resistência da ligação laje-pilar, como comprovado experimentalmente por DILGER \& GHALI (1981), 
MOKHTAR et al. (1985), ELGABRY \& GHALI (1987) e LIM \& RAGAN (1995). Esse tipo de armação consiste em conjuntos de pinos com pequenas chapas soldadas na parte superior (cabeças de ancoragem), soldados em uma chapa de aço na parte inferior (Figura 2.4). Segundo GHALI (1989), numa mesma situação, esse tipo de armadura requer uma menor área de aço que os estribos, o que também significa economia. Por tudo isso, os conectores tipo pino vêm sendo cada vez mais empregados em diversos países.

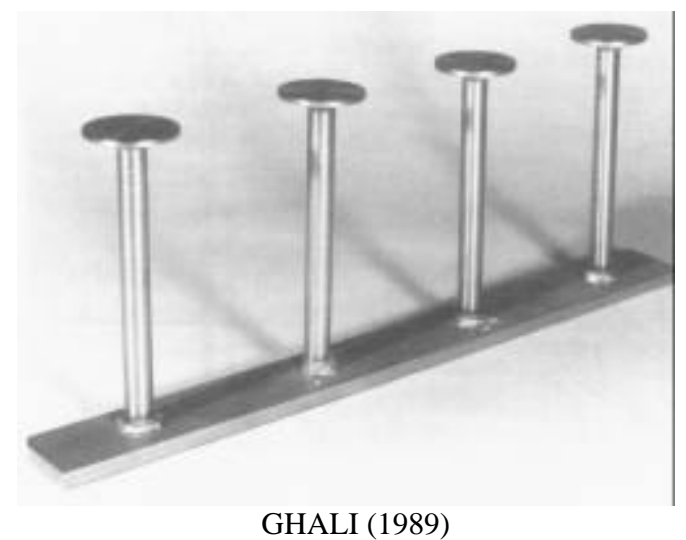

GHALI (1989)

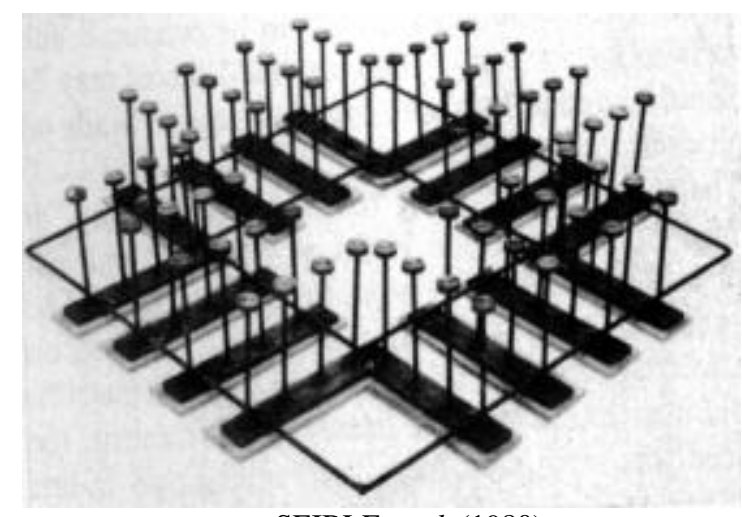

SEIBLE et al. (1980)

Figura 2.4 - Conectores tipo pino

\subsection{COLAPSO PROGRESSIVO}

Num edifício, a ruína localizada de uma ligação aumenta a força e a excentricidade nos pilares próximos, podendo desencadear a ruína generalizada de um pavimento e até de uma estrutura, se os painéis de laje caírem uns por cima dos outros. Essa sucessão de ruínas dos painéis é chamada de colapso progressivo, e ocorre devido à capacidade inadequada de uma ligação de absorver as tensões residuais de cisalhamento, relacionadas ao comportamento pós-punção.

A principal medida para se evitar o colapso progressivo é se garantir a ductilidade da ligação laje-pilar. As armaduras negativas, posicionadas na parte superior da laje, podem até aumentar a resistência da ligação, mas não sua ductilidade. Quando tem início o fenômeno da punção, elas tendem a romper o cobrimento superior no ponto em que a fissuração começou, deformando consideravelmente a laje (Figura 2.5a). Muitas vezes, a ruína generalizada não é impedida.

As armaduras de punção até proporcionam um certo aumento de ductilidade, porém muitas vezes insuficiente para evitar o colapso progressivo. A solução que vem demonstrando melhores resultados é a utilização de barras na face inferior da laje (armadura positiva), passando pelos pilares ou ancoradas neles. Essa disposição é bastante efetiva na absorção das tensões residuais de cisalhamento, contribuindo para a melhoria do 
comportamento pós-punção, principalmente pelo chamado efeito pino (dowel action) (Figura 2.5b). Paraisso, é essencial que a ancoragem das barras esteja além do "cone" de punção.

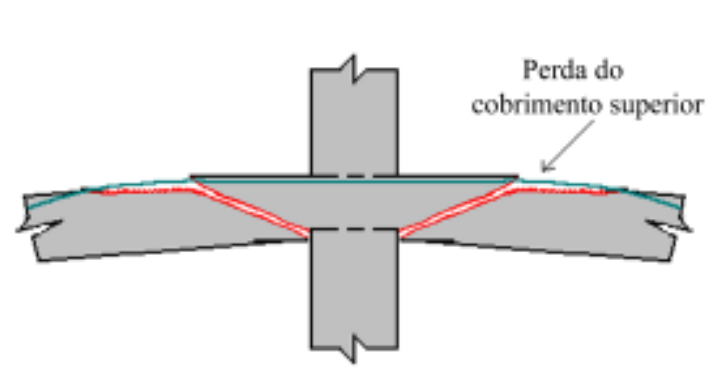

(a) Sem armadura inferior

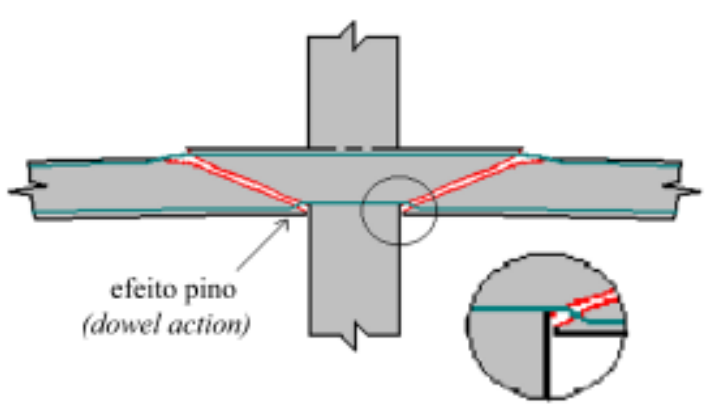

(b) Com armadura inferior

Figura 2.5 - Comportamento da ligação laje-pilar após a ruína por punção

Essa solução foi bastante estudada por HAWKINS \& MITCHELL (1979), que comprovaram experimentalmente sua eficiência, desde que a armadura seja corretamente detalhada.

\subsection{ANÁLISE TEÓRICA DO PROBLEMA DA PUNÇÃO}

Desde os primeiros estudos relacionados à punção, muitas abordagens e métodos de cálculo já foram propostos. Mas até hoje não foi criado um modelo para representação do fenômeno que obtivesse uma aceitação geral.

Para se calcular a resistência de uma ligação à punção, pode-se ter como base a própria resistência da laje à flexão, como propõem LONG \& BOND (1967). Isso é possível porque, de uma certa forma, os dois fenômenos estão relacionados, e até, em alguns casos, a carga de ruína por flexão não difere muito da carga de ruína por punção. No entanto, como esta pode ser inferior àquela, e sendo a ruína por punção brusca e frágil, é necessário se garantir a segurança, com verificações adicionais às de flexão.

Enfoques mais racionais podem ser obtidos com a utilização de modelos mecânicos, elásticos ou plásticos. KINNUNEM \& NYLANDER ${ }^{1}$ apud REGAN (1999) criaram o primeiro modelo teórico para lajes sem armadura de punção, e $\operatorname{ANDERSSON}^{2}$ apud GOMES \& REGAN (1999), para lajes com essa armadura. Também podem ser citados

${ }^{1}$ KINNUNEM, S.;NYLANDER, H. (1960). Punching of concrete slabs without shear reinforcement. Transaction, n.158, KTH, Stockholm apud REGAN (1999).

${ }^{2}$ ANDERSSON, J. (1963). Punching of concrete slabs with shear reinforcement. Meddelande n.47, Institutionen för Byggnadsstatik, Kungliga Tekniska Högskolan, Stockholm apud GOMES \& REGAN (1999). 
trabalhos mais recentes como o de SHEHATA ${ }^{3}$ apud REGAN \& BRAESTRUP (1985) e o de GOMES \& REGAN (1999). Outros modelos, com base na Mecânica da Fratura, já foram desenvolvidos e podem ser implementados em programas computacionais.

A forma mais utilizada para se verificar a punção, entretanto, consiste em calcular uma tensão de cisalhamento em uma superfície denominada superfície de controle, e compará-la a uma tensão resistente do concreto. Cabe o comentário de que este método não representa fisicamente o fenômeno da punção, mas, como colocam REGAN \& BRAESTRUP (1985), quando é bem calibrado, fornece previsões bastante próximas da realidade.

\subsection{MÉTODO DA SUPERFÍCIE DE CONTROLE}

O método da superfície de controle é adotado pelas principais normas internacionais para a verificação da punção. Como já foi comentado, consiste em comparar tensões de cisalhamento atuantes em superfícies consideradas críticas, com tensões resistentes do concreto.

As superfícies críticas a serem estudadas estão relacionadas às regiões com possibilidade de ruína por punção, localizadas entre a face do pilar e o início da armadura, dentro da região armada e além dela (Figura 2.6). Em função dessas regiões, pode-se definir as posições das superfícies em relação às faces do pilar, ou, no caso da superfície além da região armada, em relação ao limite das armaduras. É que, neste caso, tudo se passa como se as condições fossem as mesmas da região ao redor de um pilar, em lajes sem armadura de punção, sendo que as faces do pilar seriam o limite da região armada.

Os contornos das superfícies são aproximadamente circulares ou arredondados, e as alturas, iguais às alturas úteis da laje. Mas isso não significa que se considere a ruptura por punção associada a uma superfície quase cilíndrica. Trata-se apenas de uma aproximação, pois, como se sabe, a superfície de ruína mais se parece com um tronco de cone. Além disso, a tensão de cisalhamento atuante no contorno crítico não tem nenhum significado físico. Portanto, esse método da superfície de controle deve ser entendido somente como um método empírico, que pode conduzir a resultados que se aproximam bastante daqueles dos modelos mecânicos.

De qualquer modo, a ruína por punção pode ser evitada em qualquer uma das superfícies críticas. No primeiro caso (Figura 2.6a), mais difícil de ocorrer, a ruína pode ser evitada com o detalhamento correto da armadura, limitando-se o espaçamento entre a face do

\footnotetext{
3 SHEHATA, I.A.E.M. (1985). Theory of punching in concrete slabs. London. PhD Thesis, The Polytechnic of Central London apud REGAN \& BRAESTRUP (1985).
} 
pilar e o início da região armada. No segundo caso (Figura 2.6b), a ruína é evitada com o dimensionamento correto da armadura, além de seu detalhamento coerente, e, no terceiro caso (Figura 2.6c), com a disposição da armadura até um contorno a partir do qual a tensão já possa ser absorvida apenas pelo concreto. Essas recomendações são respeitadas quando a tensão atuante no contorno crítico, correspondente a cada situação, for menor que a tensão resistente.
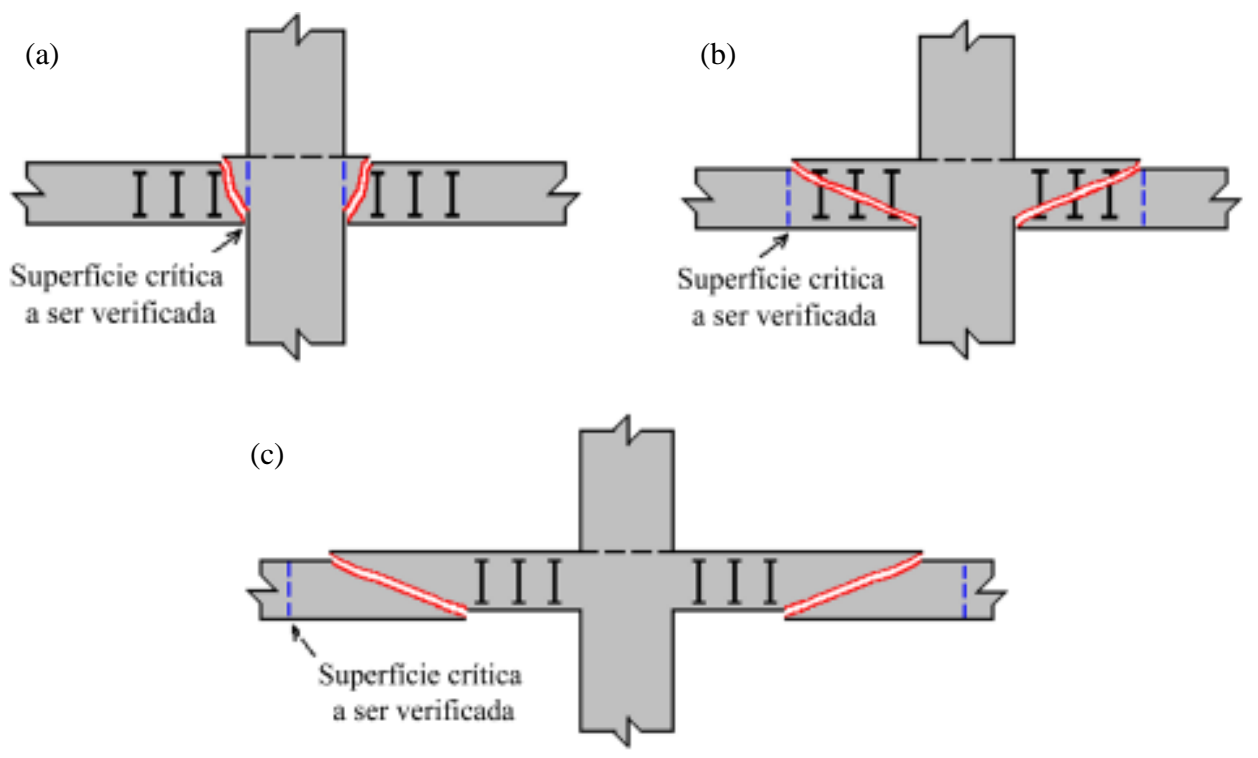

Figura 2.6 - Regiões com possibilidade de ruína

Essa tensão resistente do concreto ao cisalhamento a ser considerada nas verificações, depende de vários fatores, dentre os quais podem ser citados:

- resistência do concreto à compressão;

- altura útil da laje ${ }^{4}$ (em geral, tomada como a média entre as alturas úteis das duas direções ortogonais da armadura de flexão);

\footnotetext{
${ }^{4}$ Uma questão que poderia ser levantada diz respeito à preferência do uso da altura útil $\mathbf{d}$ em vez da própria altura da laje $\mathbf{h}$. Isso funciona como se a resistência à punção de uma ligação pudesse ser consideravelmente alterada pelo posicionamento vertical da armadura de flexão da laje, aumentando com a redução do cobrimento superior (maior d). Entretanto, isso vai de encontro a diversos resultados experimentais, como os de ALEXANDER \& SIMMONDS (1992), que obtiveram um aumento de apenas 3\%. BRAESTRUP (1995) sugere, inclusive, que o uso de $\mathbf{h}$ é mais apropriado. Mas deve-se lembrar, mais uma vez, que o método da superfície de controle não se baseia em nenhum modelo mecânico, estando distante do mecanismo de punção em si. Como na grande maioria dos casos os resultados com uso de d são conservadores, como indicam ALEXANDER \& SIMMONDS (1992), pode-se utilizá-lo nas verificações. Tanto é que, as principais normas internacionais trabalham em termos de $\mathbf{d}$.
} 
- dimensões do pilar (que determinam os perímetros críticos);

- taxa de armadura longitudinal da laje.

Quando a laje está armada para punção, também interferem na resistência da ligação:

- tipo do aço da armadura de punção;

- área de aço;

- espaçamento radial dessa armadura.

Nos casos em que há aberturas na laje, a verificação da punção depende ainda de outros fatores, como suas dimensões e seu posicionamento. Além de serem extremamente indesejáveis do ponto de vista estrutural, as aberturas reduzem a ancoragem e o confinamento, e quanto mais próximas estiverem dos pilares, maior será a redução da tensão resistente na região. Os resultados de EL-SALAKAWY et al. (1999) mostram o comportamento das ligações nessas situações.

O procedimento usualmente adotado, dentro da idéia do método da superfície de controle, consiste em reduzir o perímetro crítico de acordo com projeções das aberturas que estiverem próximas aos pilares. As projeções radiais são as mais utilizadas, mas, de segundo REGAN (1974), fornecem resultados muito conservadores no caso de aberturas próximas às faces dos pilares. Já as projeções retas têm demonstrado melhores resultados, apesar de também apresentarem limitações. Nenhum destes procedimentos, entretanto, considera possíveis efeitos de excentricidades devidas às aberturas, que podem ser bastante significativos, como alerta REGAN (1974).

Ainda sobre o método da superfície de controle, vale o comentário de que a tensão de compressão diagonal não poderá ser ultrapassada em nenhum dos contornos críticos estudados, sob pena de esmagamento do concreto. Essa avaliação é feita indiretamente, na região mais adjacente ao pilar (em que há maior concentração de tensões), através da comparação da tensão aí atuante com a tensão resistente do concreto.

\subsection{TRANSFERÊNCIA DE MOMENTOS DESBALANCEADOS}

Quando um momento desbalanceado é transferido em uma ligação laje-pilar, parte se dá por flexão, parte por torção e parte por cisalhamento. Essa distribuição pode ser considerada por uma variedade de métodos, como a Teoria das Placas ou a Analogia de Vigas, e depende essencialmente das dimensões do pilar e da espessura da laje. 
Para a punção, em especial, interessa a parcela transferida por cisalhamento. E como mostra REGAN (1999), com base no trabalho de MAST (1970), as tensões cisalhantes podem ser representadas com uma distribuição aproximadamente uniforme (Figura 2.7).

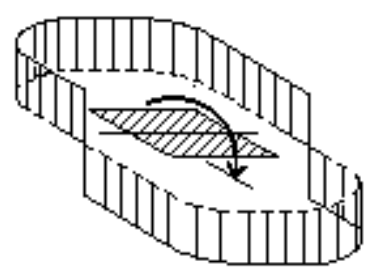

Figura 2.7 - Distribuição de tensões de cisalhamento devidas à transferência de momentos desbalanceados

À medida que vão se afastando das faces do pilar, as tensões cisalhantes provocadas pelos momentos fletores vão decrescendo, até se anularem. Inclusive, na verificação além da região armada, alguns autores consideram que não há mais influência do momento, pois este já não seria transferido por cisalhamento nesse contorno. Daí, concluem que, nessas situações, o cálculo da tensão atuante pode ser feito apenas com a parcela da reação vertical.

Este critério, entretanto, não é adotado pela NBR 6118 (2000). Em todos os contornos, a parcela de tensão devida aos momentos desbalanceados deve ser adicionada à parcela da reação vertical, e a tensão atuante final é comparada à resistência do concreto.

\subsection{VERIFICAÇÃO DA PUNÇÃO DE ACORDO COM A NBR 6118 (2000)}

O modelo empírico de cálculo adotado pela NBR 6118 (2000) é baseado no método da superfície de controle, sendo considerada a inclinação das fissuras de punção como $26,6^{\circ}$ $(\operatorname{arctg} 1 / 2)$. Compara-se a tensão de cisalhamento atuante em cada uma das superfícies críticas perpendiculares ao plano médio da laje, com a tensão resistente correspondente. Compara-se também a tensão solicitante máxima com a capacidade resistente da ligação, dada pela resistência do concreto à compressão diagonal.

Quando não for prevista armadura de punção, duas verificações devem ser feitas:

- verificação da compressão do concreto, no contorno $\mathbf{C}\left(\tau_{\mathrm{Rd} 2} \geq \tau_{\mathrm{Sd}}\right)$;

- verificação da punção, no contorno $\mathbf{C}^{\prime}\left(\tau_{\mathrm{Rd} 1} \geq \tau_{\mathrm{Sd}}\right)$. 
Quando for prevista armadura de punção, três verificações devem ser feitas:

- verificação da compressão do concreto, no contorno $\mathbf{C}\left(\tau_{\mathrm{Rd} 2} \geq \tau_{\mathrm{Sd}}\right)$;

- verificação da punção, no contorno $\mathbf{C}^{\prime}\left(\tau_{\mathrm{Rd} 3} \geq \tau_{\mathrm{Sd}}\right)$;

- verificação da punção, no contorno $\mathbf{C}^{\prime}\left(\tau_{\mathrm{Rd} 1} \geq \tau_{\mathrm{Sd}}\right)$.

Os contornos críticos $\mathbf{C}, \mathbf{C}$ ' e $\mathbf{C}$ ' encontram-se, respectivamente, na face do pilar, à distância $2 \mathbf{d}$ da face do pilar e à distância $2 \mathbf{d}$ da última linha de armaduras. As tensões resistentes $\tau_{\mathbf{R d} 1}, \tau_{\mathbf{R d} 2}$ e $\tau_{\mathbf{R d} 3}$ são calculadas conforme o item 2.7.1, e as tensões solicitantes $\tau_{\mathbf{S d}}$, conforme o item 2.7.2.

A distância a ser adotada da face do pilar até a superfície crítica já foi alvo de muitas discussões. À medida que ela aumenta, o perímetro crítico também aumenta, e a tensão de cisalhamento diminui, para uma mesma carga atuante. Hoje em dia, sabe-se que o importante é utilizar uma resistência do concreto ao cisalhamento coerente com a distância adotada, desde que esta se mantenha dentro de certos limites. Distâncias reduzidas ou muito grandes tendem a fornecer resultados contra a segurança no caso de lajes bastante armadas à flexão, como comentam REGAN \& BRAESTRUP (1985). As comparações feitas por BRAESTRUP (1995) indicam que a definição do perímetro crítico a 2d mostra-se bastante apropriada.

Sendo assim, a determinação de cada um dos contornos críticos C, C' e C'” pode ser feita como apresentado na Figura 2.8, de acordo com a posição do pilar na estrutura.
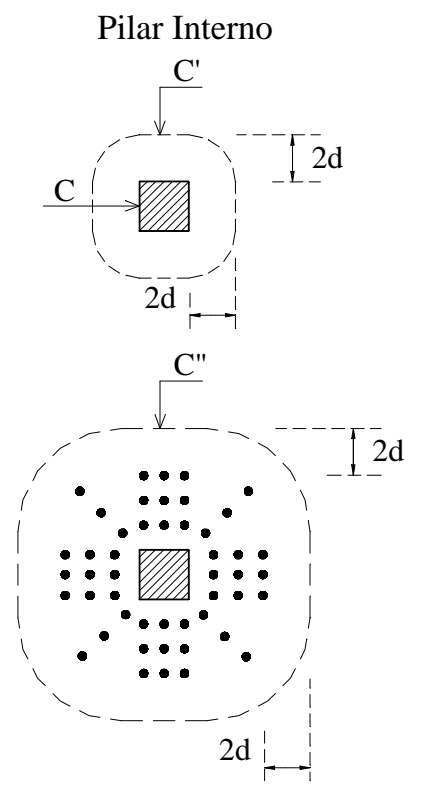
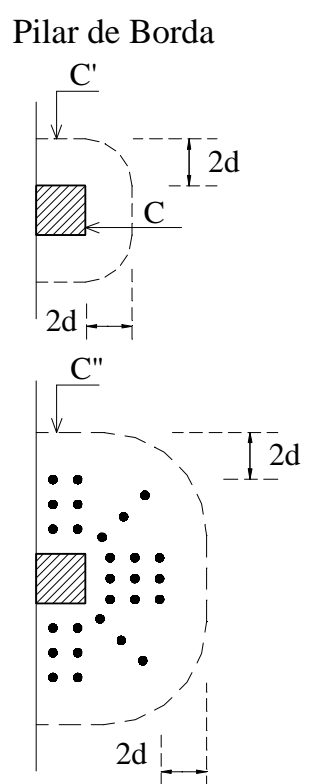

Pilar de Canto
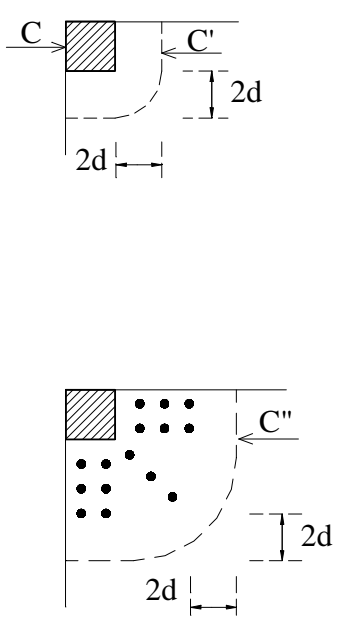

Figura 2.8 - Perímetros críticos 


\subsubsection{CÁLCULO DAS TENSÕES RESISTENTES}

Para o cálculo das tensões resistentes, são utilizadas as expressões indicadas a seguir.

\section{a) Na face do pilar (contorno C)}

A capacidade resistente de uma ligação é verificada neste contorno, onde a tensão solicitante é máxima, e é dada pela resistência do concreto à compressão diagonal, como mencionado anteriormente.

Segundo a NBR 6118 (2000), o valor dessa resistência à compressão diagonal para a verificação da punção é considerado igual ao da verificação de cisalhamento de vigas ${ }^{5}$, tomando-se $45^{\circ}$ para a inclinação da biela comprimida. Assim,

$$
\tau_{\mathrm{Rd} 2}=0,27 \cdot \alpha_{\mathrm{v}} \cdot \mathrm{f}_{\mathrm{cd}}
$$

sendo:

$\mathbf{f}_{\mathrm{cd}}$ - resistência de cálculo do concreto à compressão;

$\alpha_{\mathrm{v}}$ - coeficiente de efetividade do concreto, dado por $\alpha_{\mathrm{v}}=\left(1-\frac{\mathrm{f}_{\mathrm{ck}}}{250}\right)$;

$\mathbf{f}_{\text {ck }}$ - resistência característica do concreto à compressão, em MPa.

Os valores obtidos com a eq.(2.1) são a favor da segurança, uma vez que é desprezado o ganho de resistência do concreto devido ao estado multiaxial em que ele se encontra na laje.

b) A 2d da face do pilar (contorno C'), em lajes sem armadura de punção, ou a 2d da última linha de conectores (contorno C"), em lajes com essa armadura

$\mathrm{Na}$ expressão da resistência da ligação nesses contornos, alguns fatores devem ser considerados.

5 A resistência do concreto à compressão diagonal para a verificação de cisalhamento de vigas é definida como:

$\tau_{\mathrm{Rd} 2}=0,54 \cdot \alpha_{\mathrm{v}} \cdot \mathrm{f}_{\mathrm{cd}} \cdot \operatorname{sen}^{2} \theta \cdot(\operatorname{cotg} \alpha+\cot \mathrm{g} \theta)$

sendo:

$\theta$ - inclinação da biela comprimida;

$\alpha$ - inclinação entre o eixo da armadura de cisalhamento e o plano da laje. 
A influência da espessura da laje se dá através do chamado efeito de escala ( considerado na formulação através do coeficiente obtido experimentalmente $\left(1+\sqrt{\frac{20}{d}}\right)$, com d em centímetros. Este coeficiente incorpora a observação de que, fixando-se os demais parâmetros, quanto maior a espessura da laje, menor sua tensão resistente, pois a armadura de tração é menos efetiva no controle das fissuras. Quando a laje está armada para punção, o efeito de escala é bem menos pronunciado, como indicam REGAN \& BRAESTRUP (1985) e SHERIF \& DILGER (1996), e, por isso, alguns autores até dispensam sua consideração nesses casos. Aparentemente, a redução da tensão de cisalhamento com o aumento da altura da laje é compensada pelo acréscimo obtido com a melhoria das ancoragens.

A influência da armadura longitudinal é considerada através de sua taxa, com o coeficiente $(\rho)^{1 / 3}$, como demonstram SHERIF \& DILGER (1996) a partir de diversas séries de resultados experimentais. Essa taxa deve ser calculada para uma largura considerável da laje, que pode ser adotada como a largura do pilar mais 3d para cada lado. Essa proposta fornece resultados razoáveis, como indicado em REGAN \& BRAESTRUP (1985). A tensão de escoamento não é considerada por não afetar significativamente a resistência da ligação, como também comentam SHERIF \& DILGER (1996).

$\mathrm{O}$ crescimento da resistência à punção com a resistência do concreto pode ser representado por uma função de $\left(\mathrm{f}_{\mathrm{ck}}\right)^{1 / 3}$ com uma ótima aproximação, como demonstrado por REGAN \& BRAESTRUP (1985) e SHERIF \& DILGER (1996), e também concluído por BRAESTRUP (1995). Para concretos com agregados leves, essa resistência deve ser reduzida a 80\%, como apontam REGAN \& BRAESTRUP (1985).

Assim sendo, a resistência do concreto ao cisalhamento para a situação em estudo pode ser escrita como:

$$
\tau_{\mathrm{Rd} 1}=0,13 \cdot\left(1+\sqrt{\frac{20}{\mathrm{~d}}}\right) \cdot\left(100 \cdot \rho \cdot \mathrm{f}_{\mathrm{ck}}\right)^{1 / 3}
$$

sendo:

$\mathbf{f}_{\text {ck }}$ em MPa;

$\rho$ - taxa geométrica de armadura longitudinal, dada por $\rho=\sqrt{\rho_{\mathrm{x}} \cdot \rho_{\mathrm{y}}}$. Para o cálculo de $\rho_{\mathrm{x}}$ e $\rho_{\mathrm{y}}$, deverá ser considerada uma faixa de largura igual à dimensão do pilar, mais $3 \mathbf{d}$ para cada lado, ou até a borda, se for mais próxima (Figura 2.9); 
d - altura útil da laje no contorno crítico estudado, em centímetros, dada por $\mathrm{d}=\frac{\mathrm{d}_{\mathrm{x}}+\mathrm{d}_{\mathrm{y}}}{2}$, sendo $\mathbf{d}_{\mathbf{x}}$ e $\mathbf{d}_{\mathbf{y}}$ indicados na Figura 2.10 .

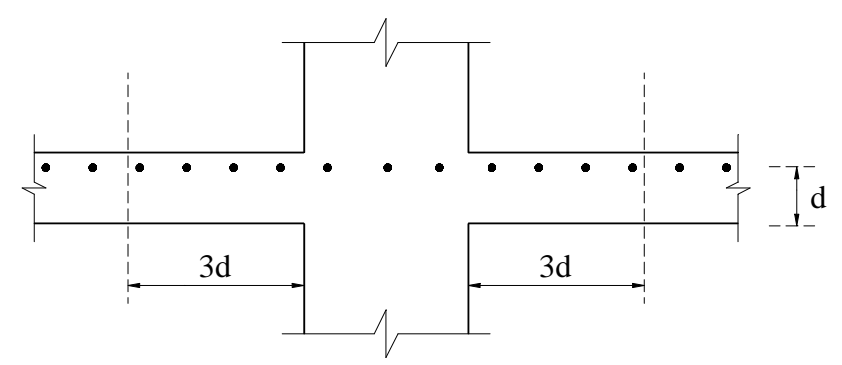

Figura 2.9 - Seção para o cálculo de $\rho$

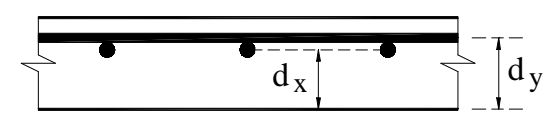

Figura 2.10 - Alturas úteis da laje nas direções $\mathbf{X}$ e $\mathbf{Y}$

\section{c) A 2d da face do pilar (contorno C'), em lajes com armadura de punção}

Nesta verificação, a tensão resistente tem duas parcelas, como explicado no item 2.2. A primeira é relativa ao concreto, com seu valor reduzido em relação ao das lajes sem armadura de punção. E a segunda é relativa à armadura, e sofre influência direta de sua disposição. Assim, a resistência do concreto ao cisalhamento a $2 \mathbf{d}$ da face do pilar, em lajes com armadura de punção, pode ser escrita como:

$$
\tau_{\mathrm{Rd} 3}=0,10 \cdot\left(1+\sqrt{\frac{20}{\mathrm{~d}}}\right) \cdot\left(100 \cdot \rho \cdot \mathrm{f}_{\mathrm{ck}}\right)^{1 / 3}+1,5 \cdot \frac{\mathrm{d}}{\mathrm{s}_{\mathrm{r}}} \cdot \frac{\mathrm{A}_{\mathrm{sw}} \cdot \mathrm{f}_{\mathrm{ywd}} \cdot \operatorname{sen} \alpha}{\mathrm{u} \cdot \mathrm{d}}
$$

sendo:

$\mathbf{A}_{\text {sw }}$ - área da armadura de punção num contorno paralelo a $\mathbf{C}^{\prime}$ (Figura 2.11);

$\mathbf{f}_{\mathbf{y w d}}$ - resistência de cálculo da armadura de punção, em MPa. Para conectores, o valor de $\mathbf{f}_{\mathbf{y w d}}$ não poderá ser superior a $300 \mathrm{MPa}$ em lajes de altura até $15 \mathrm{~cm}$. Se essa altura for superior a $35 \mathrm{~cm}, \mathbf{f}_{\mathbf{y w d}}$ poderá chegar a $435 \mathrm{MPa}$. Para valores intermediários da altura da laje, permitese fazer interpolação linear;

$\alpha$ - inclinação entre o eixo da armadura de punção e o plano da laje; 
$\mathbf{s}_{\mathbf{r}}$ - espaçamento radial entre linhas de conectores;

u - perímetro crítico do contorno $\mathbf{C}^{\prime}$ correspondente à posição do pilar (u para pilares internos ou $\mathbf{u}^{*}$ para pilares de borda e de canto, como definido nos itens 2.7.2a, 2.7.2d e 2.7.2f).

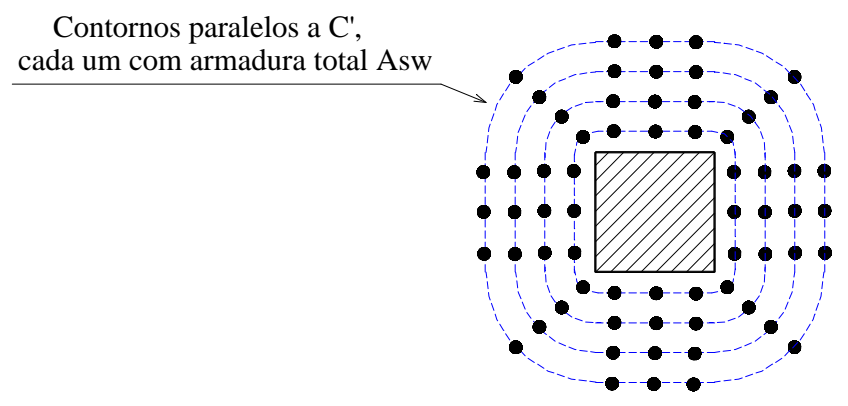

Figura 2.11 - Disposição da armadura $\mathbf{A}_{\mathbf{s w}}$ para pilares internos

Vale o comentário de que o coeficiente 1,5 da eq.(2.3) pressupõe que o arranjo de armaduras de punção seja feito radialmente, com cada linha de armadura descrevendo circunferências, pelo menos, aproximadas, como ressalta REGAN (1999).

\subsubsection{CÁlCULO DAS TENSÕES ATUANTES}

Para o cálculo das tensões atuantes, devem ser considerados a posição dos pilares na estrutura e o tipo de carregamento. As expressões a serem utilizadas são apresentadas a seguir.

\section{a) Pilar interno, com carregamento simétrico}

Neste caso, a tensão atuante depende apenas da reação do pilar, e pode ser escrita como:

$$
\tau_{\mathrm{Sd}}=\frac{\mathrm{F}_{\mathrm{Sd}}}{\mathrm{u} \cdot \mathrm{d}}
$$

sendo:

$\mathbf{F}_{\mathbf{S d}}$ - força normal de cálculo, dada por $\mathrm{F}_{\mathrm{Sd}}=\mathrm{N}_{2 \mathrm{~d}}-\mathrm{N}_{1 \mathrm{~d}}$ (Figura 2.12). A NBR 6118 (2000) permite também uma redução da reação do pilar para a verificação da punção, de valor igual ao da força distribuída aplicada na face oposta da laje, dentro do perímetro crítico estudado;

u - perímetro crítico do contorno considerado (Tabela 2.1); 
d - altura útil da laje no contorno crítico;

$\mathbf{c}_{1}$ e $\mathbf{c}_{2}$ - dimensões do pilar;

p - distância da face do pilar até a última linha de conectores.

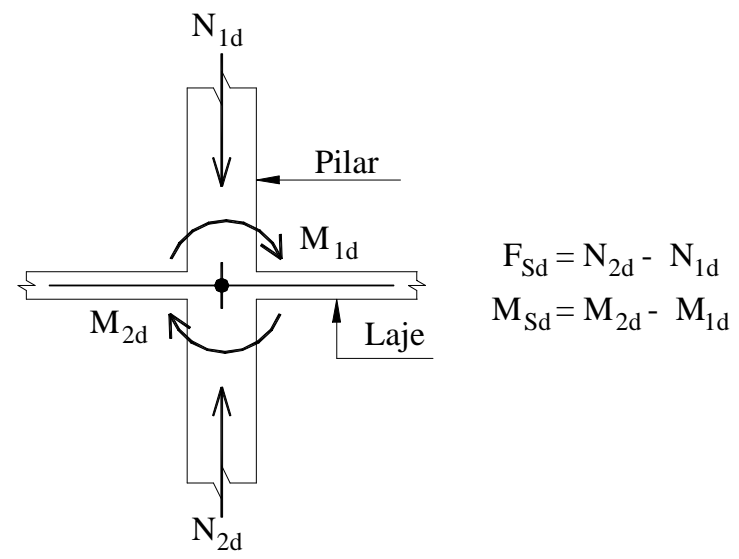

Figura 2.12 - Determinação de $\mathbf{F}_{\mathbf{S d}}$ e $\mathbf{M}_{\mathbf{S d}}$.

Tabela 2.1 - Perímetros críticos para pilares internos

\begin{tabular}{|c|l|}
\hline Contorno Crítico & Perímetro Crítico $u$ \\
\hline $\boldsymbol{C}$ & $\mathrm{u}_{\mathrm{o}}=2 \cdot\left(\mathrm{c}_{1}+\mathrm{c}_{2}\right)$ \\
\hline$C^{\prime}$ & $\mathrm{u}_{\mathrm{o}}=2 \cdot\left(\mathrm{c}_{1}+\mathrm{c}_{2}\right)+4 \cdot \pi \cdot \mathrm{d}$ \\
\hline$C^{\prime}{ }^{\prime}$ & $\mathrm{u}^{\prime}=2 \cdot\left(\mathrm{c}_{1}+\mathrm{c}_{2}\right)+4 \cdot \pi \cdot \mathrm{d}+2 \cdot \pi \cdot \mathrm{p}$ \\
\hline \multicolumn{2}{|c|}{ Observação: $u^{\prime}$ calculado supondo $\mathrm{s}_{\mathrm{e}} \leq 2 \mathrm{~d}(\mathrm{ver}$ item 2.8$)$} \\
\hline
\end{tabular}

\section{b) Pilar interno, com momento em uma direção}

Neste caso, a tensão atuante depende, além da reação do pilar, da parcela do momento desbalanceado transferida por cisalhamento. Assim,

$$
\tau_{\mathrm{Sd}}=\frac{\mathrm{F}_{\mathrm{Sd}}}{\mathrm{u} \cdot \mathrm{d}}+\frac{\mathrm{K} \cdot \mathrm{M}_{\mathrm{Sd}}}{\mathrm{W}_{\mathrm{p}} \cdot \mathrm{d}}
$$

sendo:

$\mathbf{M}_{S d}$ - momento desbalanceado de cálculo, dado por $M_{S d}=M_{2 d}+M_{1 d}$ (Figura 2.12);

$\mathbf{K}$ - coeficiente que fornece a parcela de momento $\mathrm{K} \cdot \mathrm{M}_{\mathrm{Sd}}$ transferida por cisalhamento

(Tabela 2.2), e que só depende da relação $\frac{\mathrm{c}_{1}}{\mathrm{c}_{2}}$ entre as dimensões do pilar (Figura 2.13); 
$\mathbf{c}_{1}$ - dimensão do pilar na direção da excentricidade;

$\mathbf{c}_{2}$ - dimensão do pilar na direção perpendicular à excentricidade;

Tabela 2.2 - Valores do coeficiente $\mathbf{K}$

\begin{tabular}{|c|c|c|c|c|}
\hline $\boldsymbol{c}_{\boldsymbol{1}} / \boldsymbol{c}_{2}$ & $\mathbf{0 , 5}$ & $\mathbf{1}$ & $\mathbf{2}$ & $\mathbf{3}$ \\
\hline $\boldsymbol{K}$ & 0,45 & 0,60 & 0,70 & 0,80 \\
\hline
\end{tabular}

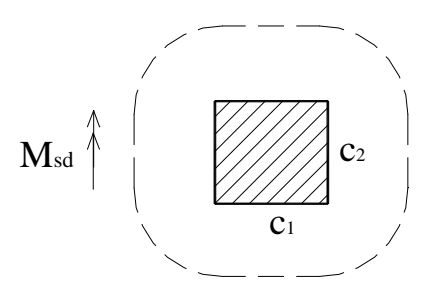

Figura 2.13 - Dimensões $\mathbf{c}_{1}$ e $\mathbf{c}_{2}$

$\mathbf{W}_{\mathbf{p}}$ - módulo de resistência plástica do perímetro crítico, dado por $\mathrm{W}_{\mathrm{p}}=\int_{0}^{\mathrm{u}}|\mathrm{e}| \cdot \mathrm{d} \ell$, onde $\mathbf{d} \ell$ é o comprimento infinitesimal de $\mathbf{u}$ e e é a distância de $\mathbf{d} \ell$ ao eixo que passa pelo centro do pilar e em torno do qual atua $\mathbf{M}_{\mathbf{S d}}$. De acordo com essa definição, a NBR 6118 (2000) apresenta apenas a seguinte expressão, correspondente ao contorno crítico $\mathbf{C}^{\prime}$ :

$$
\mathrm{W}_{\mathrm{p}}=\frac{\mathrm{c}_{1}^{2}}{2}+\mathrm{c}_{1} \cdot \mathrm{c}_{2}+4 \cdot \mathrm{c}_{2} \cdot \mathrm{d}+16 \cdot \mathrm{d}^{2}+2 \cdot \pi \cdot \mathrm{d} \cdot \mathrm{c}_{1}
$$

Quanto aos contornos C e C', não é feita nenhuma indicação sobre a obtenção dos respectivos valores de $\mathbf{W}_{\mathbf{p}}$.

Observa-se que a eq.(2.5) descreve uma relação linear entre a parcela da reação vertical e a do momento desbalanceado, o que é somente uma aproximação. Além disso, os valores de $\mathbf{K}$ apresentados não dependem da altura útil da laje, o que seria desejável. Apesar disso, as comparações de REGAN (1999) entre resultados fornecidos por essa expressão e vários resultados experimentais demonstraram que a previsão de transferência de momento com o coeficiente $\mathbf{K}$ está apropriada. 


\section{c) Pilar interno, com momentos nas duas direções}

Neste caso, é feita uma superposição dos efeitos dos momentos nas duas direções, da seguinte forma:

$$
\tau_{\mathrm{Sd}}=\frac{\mathrm{F}_{\mathrm{Sd}}}{\mathrm{u} \cdot \mathrm{d}}+\frac{\mathrm{K}_{1} \cdot \mathrm{M}_{\mathrm{Sd} 1}}{\mathrm{~W}_{\mathrm{p} 1} \cdot \mathrm{d}}+\frac{\mathrm{K}_{2} \cdot \mathrm{M}_{\mathrm{Sd} 2}}{\mathrm{~W}_{\mathrm{p} 2} \cdot \mathrm{d}}
$$

sendo:

$\mathbf{M}_{\mathbf{S d} 1}$ e $\mathbf{M}_{\mathbf{S d} 2}$ - momentos desbalanceados de cálculo;

$\mathbf{K}_{\mathbf{1}}$ e $\mathbf{K}_{\mathbf{2}}$ - coeficientes dados pela Tabela 2.2;

$\mathbf{W}_{\mathbf{p} 1}$ e $\mathbf{W}_{\mathbf{p} 2}$ - módulos de resistência plástica nas direções paralelas aos momentos correspondentes, obtidos pela eq.(2.6) para o contorno $\mathbf{C}^{\prime}$. Nenhuma indicação é feita para os contornos C e C'.

Observe-se que, para o cálculo das grandezas $\mathbf{K}$ e $\mathbf{W}_{\mathbf{p}}$ de cada uma das parcelas dos momentos, as dimensões $\mathbf{c}_{1}$ e $\mathbf{c}_{2}$ são permutadas (Figura 2.14).

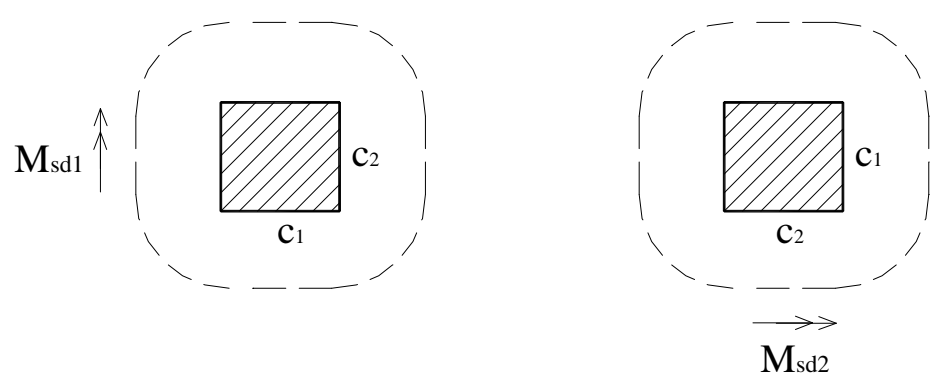

Figura 2.14 - Determinação das dimensões $\mathbf{c}_{1}$ e $\mathbf{c}_{2}$ para pilares internos com momentos nas duas direções

\section{d) Pilar de borda, sem momento no plano paralelo à borda livre}

Este caso é semelhante àquele do pilar interno com momento em apenas uma direção, sendo que é necessário considerar a excentricidade dos perímetros críticos. Assim:

$$
\tau_{\mathrm{Sd}}=\frac{\mathrm{F}_{\mathrm{Sd}}}{\mathrm{u} * \mathrm{~d}}+\frac{\mathrm{K}_{1} \cdot \mathrm{M}_{\mathrm{Sd}}}{\mathrm{W}_{\mathrm{p} 1} \cdot \mathrm{d}}
$$


sendo:

$\mathbf{u}^{*}$ - perímetro crítico reduzido do contorno estudado (Figura 2.15 e Tabela 2.3). Essa redução é necessária, pois a parte mais próxima à borda não é efetiva na absorção das tensões cisalhantes;
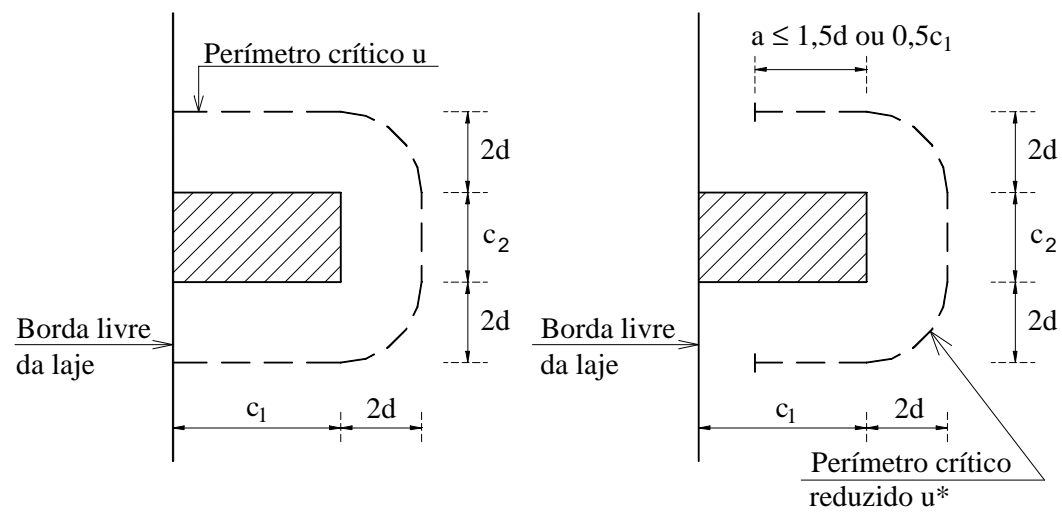

Figura 2.15 - Perímetro crítico reduzido do contorno $\mathbf{C}^{\mathbf{9}}$ para pilares de borda

Tabela 2.3 - Perímetros críticos reduzidos para pilares de borda

\begin{tabular}{|c|l|}
\hline Contorno Crítico & Perímetro Crítico Reduzido $\boldsymbol{u}^{*}$ \\
\hline $\boldsymbol{C}$ & $\mathrm{u}_{\mathrm{o}}{ }^{*}=2 \cdot \mathrm{a}+\mathrm{c}_{2}$ \\
\hline $\boldsymbol{C}$ & $\mathrm{u}^{*}=2 \cdot \mathrm{a}+\mathrm{c}_{2}+2 \cdot \pi \cdot \mathrm{d}$ \\
\hline $\boldsymbol{C}^{\prime}$, & $\mathrm{u}^{\prime *}=2 \cdot \mathrm{a}+\mathrm{c}_{2}+2 \cdot \pi \cdot \mathrm{d}+\pi \cdot \mathrm{p}$ \\
\hline \multicolumn{2}{|c|}{ Observação: $\boldsymbol{u}^{* *}$ calculado supondo $\mathrm{s}_{\mathrm{e}} \leq 2 \mathrm{~d}(\mathrm{ver}$ item 2.8$)$} \\
\hline
\end{tabular}

a - menor valor entre $1,5 \cdot \mathrm{d}$ e $0,5 \cdot \mathrm{c}_{1}$;

$\mathbf{c}_{1}$ - dimensão do pilar na direção perpendicular à borda;

$\mathbf{c}_{2}$ - dimensão do pilar na direção da borda;

$\mathbf{M}_{\mathrm{Sd}}$ - momento resultante de cálculo, dado pela expressão $\mathrm{M}_{\mathrm{Sd}}=\left(\mathrm{M}_{\mathrm{Sd} 1}-\mathrm{M}_{\mathrm{Sd}} *\right) \geq 0$;

$\mathbf{M}_{\mathbf{S d 1}}$ - momento desbalanceado de cálculo, no plano perpendicular à borda livre;

$\mathbf{M}_{\mathbf{S d}}{ }^{*}$ - momento resultante da excentricidade do perímetro crítico reduzido $\mathrm{u}^{*}$ em relação ao centro do pilar, no plano perpendicular à borda livre, ou seja, $\mathrm{M}_{\mathrm{Sd}} *=\mathrm{F}_{\mathrm{Sd}} \cdot \mathrm{e}^{*}$;

$\mathbf{e}^{*}$ - excentricidade do perímetro crítico reduzido (Figura 2.16), dada por $\mathrm{e}^{*}=\int_{0}^{\mathrm{u}^{*}}|\mathrm{e}| \cdot \mathrm{d} \ell / \int_{0}^{\mathrm{u}^{*}} \mathrm{~d} \ell$.

De acordo com essa definição, a NBR 6118 (2000) apresenta apenas a seguinte expressão, correspondente ao contorno crítico $\mathbf{C}$ ': 


$$
e^{*}=\frac{c_{1} \cdot a-a^{2}+\frac{c_{1} \cdot c_{2}}{2}+2 \cdot c_{2} \cdot d+8 \cdot d^{2}+\pi \cdot d \cdot c_{1}}{2 \cdot a+c_{2}+2 \cdot \pi \cdot d}
$$

Nenhuma indicação é feita para os contornos C e C’"

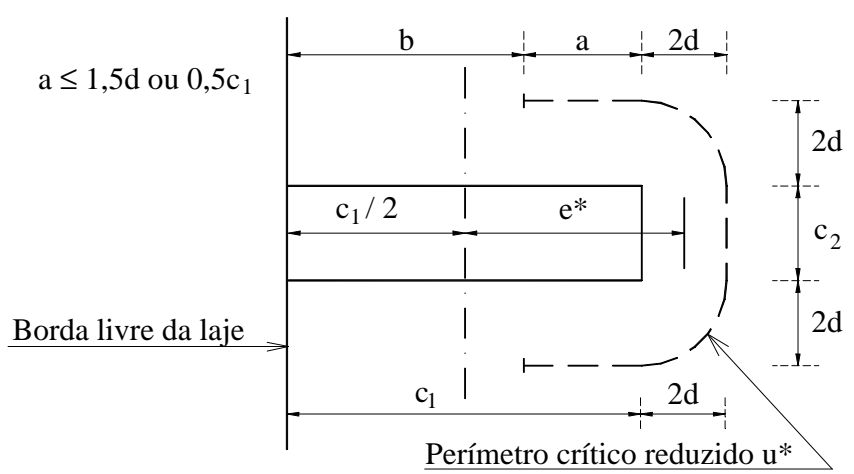

Figura 2.16 - Excentricidade do perímetro crítico reduzido do contorno C' para pilares de borda

$\mathbf{W}_{\text {p1 }}$ - módulo de resistência plástica na direção perpendicular à borda livre. Novamente, a NBR 6118 (2000) só fornece a expressão para o contorno C':

$$
\mathrm{W}_{\mathrm{p} 1}=\frac{\mathrm{c}_{1}^{2}}{2}+\frac{\mathrm{c}_{1} \cdot \mathrm{c}_{2}}{2}+2 \cdot \mathrm{c}_{2} \cdot \mathrm{d}+8 \cdot \mathrm{d}^{2}+\pi \cdot \mathrm{d} \cdot \mathrm{c}_{1}
$$

Nenhuma indicação é feita para os contornos C e C’"

Observe-se que, neste caso de pilares de borda sem momento no plano paralelo à borda livre, não é necessário utilizar o momento no plano perpendicular à borda livre com seu valor integral. A excentricidade do perímetro crítico provoca um momento $\mathbf{M}_{\mathbf{S d}}$ * de sentido oposto ao de $\mathbf{M}_{\mathbf{S d} 1}$, podendo até anular o efeito deste. A favor da segurança, mesmo que $\mathbf{M}_{\mathbf{S d}}$ * seja maior que $\mathbf{M}_{\mathbf{S d} \mathbf{1}}$, o que significaria "alívio" da tensão de cisalhamento atuante, esta situação não é considerada $\left(\mathrm{M}_{\mathrm{Sd} 1}-\mathrm{M}_{\mathrm{Sd}} * \geq 0\right)$.

\section{e) Pilar de borda, com momento no plano paralelo à borda livre}

Este caso é semelhante àquele do pilar interno com momentos nas duas direções. Entretanto, além da consideração da excentricidade dos perímetros críticos, é necessário se reduzir o coeficiente que determina a parcela do momento no plano paralelo à borda livre 
transferida por cisalhamento $\left(\mathbf{K}_{\mathbf{2}}\right)$, uma vez que somente uma das faces do pilar na direção deste momento pode ser utilizada. A expressão fica, então:

$$
\tau_{\mathrm{Sd}}=\frac{\mathrm{F}_{\mathrm{Sd}}}{\mathrm{u} \cdot \mathrm{d}}+\frac{\mathrm{K}_{1} \cdot \mathrm{M}_{\mathrm{Sd}}}{\mathrm{W}_{\mathrm{p} 1} \cdot \mathrm{d}}+\frac{\mathrm{K}_{2} \cdot \mathrm{M}_{\mathrm{Sd} 2}}{\mathrm{~W}_{\mathrm{p} 2} \cdot \mathrm{d}}
$$

sendo:

$\mathbf{M}_{\mathbf{S d} 2}$ - momento no plano paralelo à borda livre;

$\mathbf{c}_{1}$ - dimensão do pilar na direção perpendicular à borda;

$\mathbf{c}_{2}$ - dimensão do pilar na direção da borda;

$\mathbf{K}_{\mathbf{2}}$ - coeficiente dado pela Tabela 2.2, mas que depende da relação $\frac{c_{2}}{2 \cdot c_{1}}$. A inversão da relação é apenas uma questão de notação, uma vez que $\mathbf{c}_{1}$ neste caso é perpendicular à excentricidade, e $\mathbf{c}_{2}$, paralelo. $\mathrm{O}$ fator $1 / 2$, como foi comentado, considera $\mathrm{o}$ fato de que somente uma das laterais $\mathbf{c}_{2}$ participa da transferência do momento por cisalhamento;

$\mathbf{W}_{\mathbf{p 2}}$ - módulo de resistência plástica na direção paralela à borda livre, para o qual a NBR 6118 (2000) só fornece a expressão correspondente ao contorno C':

$$
\mathrm{W}_{\mathrm{p} 2}=\frac{\mathrm{c}_{2}^{2}}{4}+\mathrm{c}_{1} \cdot \mathrm{c}_{2}+4 \cdot \mathrm{c}_{1} \cdot \mathrm{d}+8 \cdot \mathrm{d}^{2}+\pi \cdot \mathrm{d} \cdot \mathrm{c}_{2}
$$

A obtenção dos valores de $\mathbf{W}_{\mathbf{p 2}}$ para os contornos $\mathbf{C}$ e $\mathbf{C}$ ” não é mencionada.

\section{f) Pilar de canto}

No caso de pilares de canto, fazem-se as verificações separadas para cada uma das direções (Figura 2.17). Isso ocorre porque as tensões máximas provocadas pelos momentos das duas direções ocorrem em pontos diferentes, tornando a simples superposição de efeitos bastante conservadora. São adotadas, portanto, duas situações de cálculo.

Para cada borda adotada, deverá ser considerado o momento no plano perpendicular a ela. Assim, valem as disposições para pilares de borda sem momento no plano paralelo à borda livre.

O coeficiente $\mathbf{K}_{1}$ é obtido normalmente de acordo com a Tabela 2.2, lembrando que $\mathbf{c}_{1}$ é sempre o lado perpendicular à borda adotada, como na Figura 2.17. 


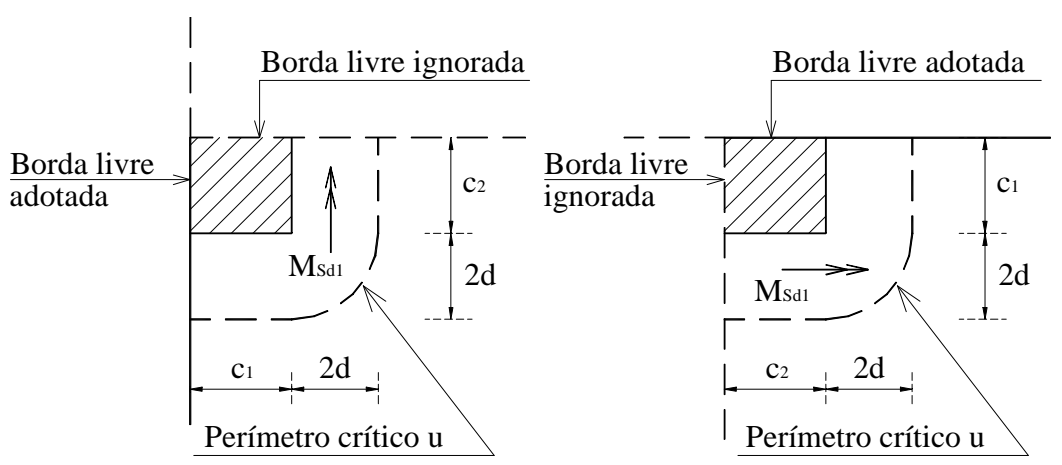

Figura 2.17 - Situações de cálculo para verificação de pilares de canto

Os perímetros críticos reduzidos dos contornos estudados (Figura 2.18) têm os valores indicados na Tabela 2.4 .
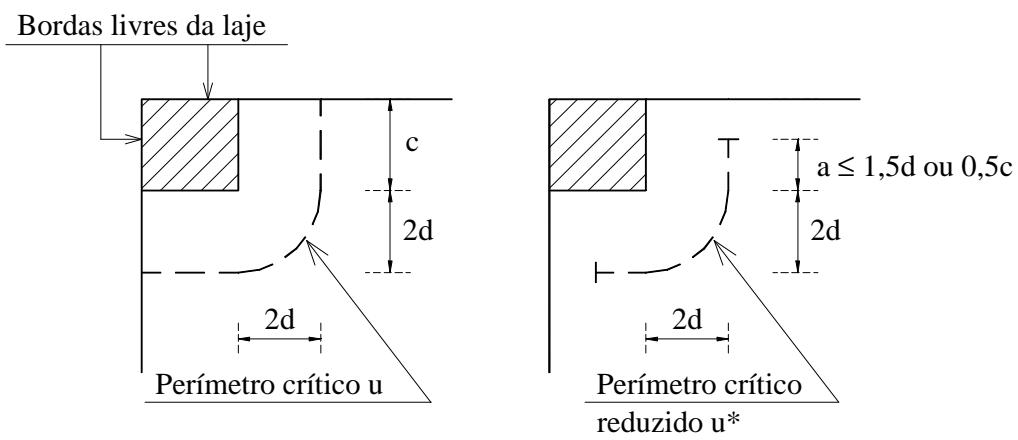

Figura 2.18 - Perímetro crítico reduzido do contorno C' para pilares de canto

Tabela 2.4 - Perímetros críticos reduzidos para pilares de canto

\begin{tabular}{|c|l|}
\hline Contorno Crítico & \multicolumn{1}{|c|}{ Perímetro Crítico Reduzido * $^{*}$} \\
\hline $\boldsymbol{C}$ & $\mathrm{u}_{\mathrm{o}}{ }^{*}=\mathrm{a}_{1}+\mathrm{a}_{2}$ \\
\hline $\boldsymbol{C}^{\prime}$ & $\mathrm{u}^{*}=\mathrm{a}_{1}+\mathrm{a}_{2}+\pi \cdot \mathrm{d}$ \\
\hline$C^{\prime}$ & $\mathrm{u}^{\prime *}=\mathrm{a}_{1}+\mathrm{a}_{2}+\pi \cdot \mathrm{d}+\frac{\pi \cdot \mathrm{p}}{2}$ \\
\hline \multicolumn{2}{|c|}{ Observação: $u^{* *}$ calculado supondo $\mathrm{s}_{\mathrm{e}} \leq 2 \mathrm{~d}(\mathrm{ver}$ item 2.8$)$} \\
\hline
\end{tabular}


A excentricidade $\mathbf{e}^{*}$ do perímetro crítico reduzido do contorno $\mathbf{C}^{\prime}$ (Figura 2.19) pode ser obtida pela expressão:

$$
\mathrm{e}^{*}=\frac{\mathrm{c}_{1} \cdot \mathrm{a}_{1}-\mathrm{a}_{1}{ }^{2}+\mathrm{a}_{2} \cdot \mathrm{c}_{1}+4 \cdot \mathrm{a}_{2} \cdot \mathrm{d}+8 \cdot \mathrm{d}^{2}+\pi \cdot \mathrm{d} \cdot \mathrm{c}_{1}}{2 \cdot\left(\mathrm{a}_{1}+\mathrm{a}_{2}+\pi \cdot d\right)}
$$

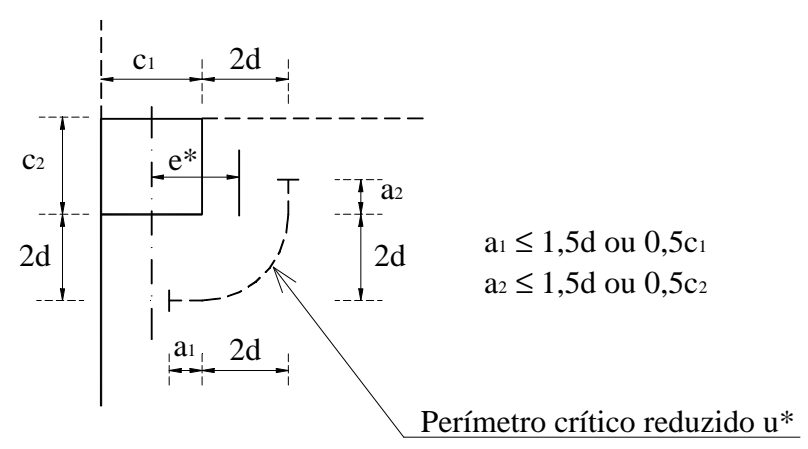

Figura 2.19 - Excentricidade do perímetro crítico reduzido do contorno C' para pilares de canto

O módulo de resistência plástica $\mathbf{W}_{\mathbf{p} 1}$ do contorno $\mathbf{C}^{\prime}$ pode ser calculado pela expressão:

$$
\mathrm{W}_{\mathrm{p} 1}=\frac{\mathrm{c}_{1}^{2}}{4}+\frac{\mathrm{c}_{1} \cdot \mathrm{c}_{2}}{2}+2 \cdot \mathrm{c}_{2} \cdot \mathrm{d}+4 \cdot \mathrm{d}^{2}+\frac{\pi \cdot \mathrm{d} \cdot \mathrm{c}_{1}}{2}
$$

A obtenção de $\mathbf{e}^{*}$ e $\mathbf{W}_{\text {p1 }}$ para os contornos $\mathbf{C}$ e $\mathbf{C}$ " não é mencionada pela NBR 6118 (2000).

\section{g) Presença de aberturas}

Existindo aberturas na laje a uma distância inferior a 8d da face do pilar (contorno C), os perímetros críticos não poderão ser adotados com seus valores integrais apresentados nos itens anteriores. A parte localizada entre as duas linhas que saem do centro do pilar e tangenciam os limites da abertura (projeção radial) não deve ser considerada (Figura 2.20). 


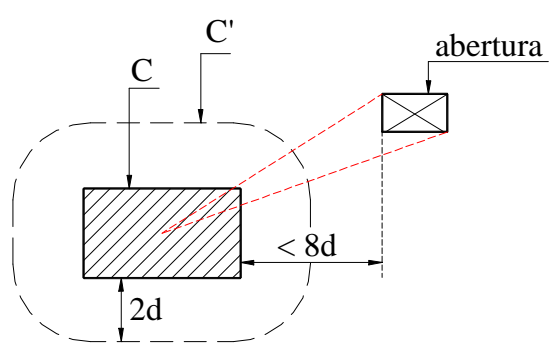

Figura 2.20 - Redução do perímetro crítico na presença de aberturas próximas ao pilar

\subsubsection{VERIFICAÇÃO DO COLAPSO PROGRESSIVO}

Para garantir a ductilidade da ligação e prevenir o colapso progressivo, deverá ser prevista uma armadura na parte inferior da laje, que atravesse o pilar e esteja ancorada além do contorno C'. Deve ser verificado se:

$$
A_{s} \cdot f_{y d} \geq F_{S d}
$$

sendo:

$\mathbf{A}_{\text {s }}$ - soma das áreas das barras inferiores, devidamente ancoradas, que cruzam cada uma das faces do pilar (Figura 2.21);

$\mathbf{f}_{\mathbf{y d}}$ - valor de cálculo da tensão de escoamento do aço.

\subsection{DETALHAMENTO DE ACORDO COM A NBR 6118 (2000)}

O detalhamento das armaduras de punção deve assegurar que elas possam atingir a tensão de escoamento, sem provocar ruptura do concreto ou escorregamento das ancoragens. Apenas dessa forma, pode-se considerar o aumento da resistência da ligação.

De acordo com a NBR 6118 (2000), tanto estribos quanto conectores tipo pino podem ser utilizados. Em vista das vantagens dos conectores comentadas anteriormente (item 2.2), tanto do ponto de vista estrutural quanto executivo, este tipo de armadura é o mais recomendado, inclusive pela própria Norma.

Para se garantir uma ancoragem efetiva dos conectores, e também que eles atinjam sua tensão de escoamento, algumas limitações geométricas são adotadas. Cada uma das placas de ancoragem superiores deve apresentar uma espessura maior que $2 / 3$ do diâmetro $\mathbf{D}$ do pino, e uma área de pelo menos 10 vezes a dele, como propõem DILGER \& GHALI (1981) e GHALI (1989). A placa inferior deve ter uma espessura maior que 0,5D e largura superior a 2,5D. Além disso, as extremidades dos conectores devem estar ancoradas fora do plano da armadura de flexão da laje (Figura 2.22). 


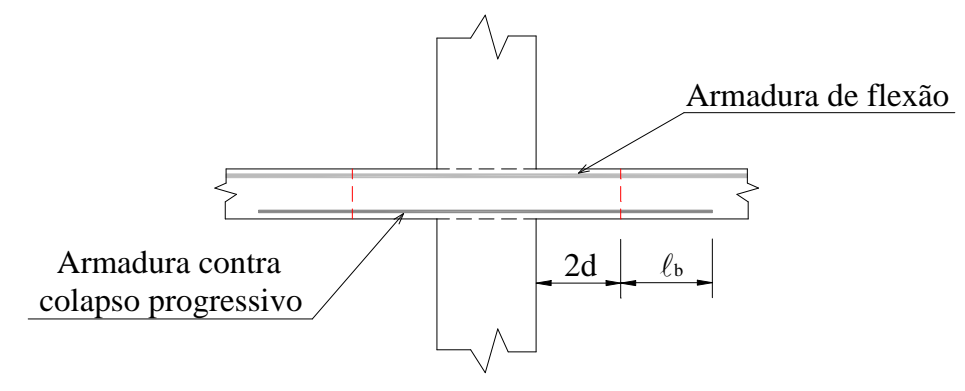

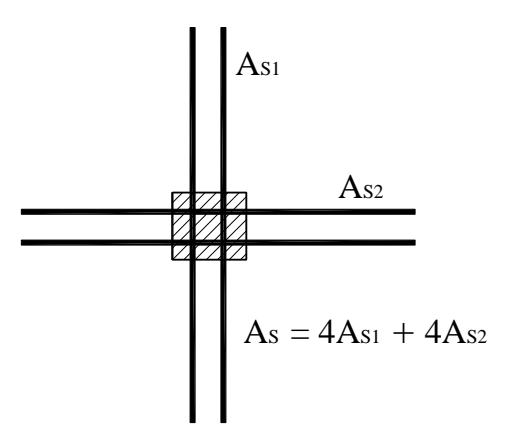

Pilar interno

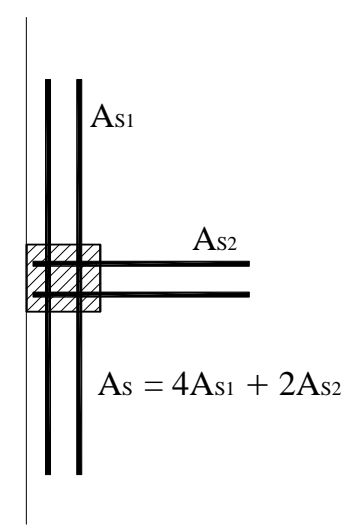

Pilar de borda

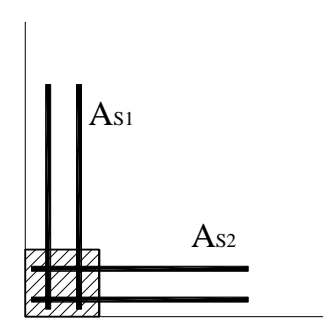

$\mathrm{A} s=2 \mathrm{~A} s 1+2 \mathrm{As} 2$

Pilar de canto

Figura 2.21 - Armadura contra colapso progressivo
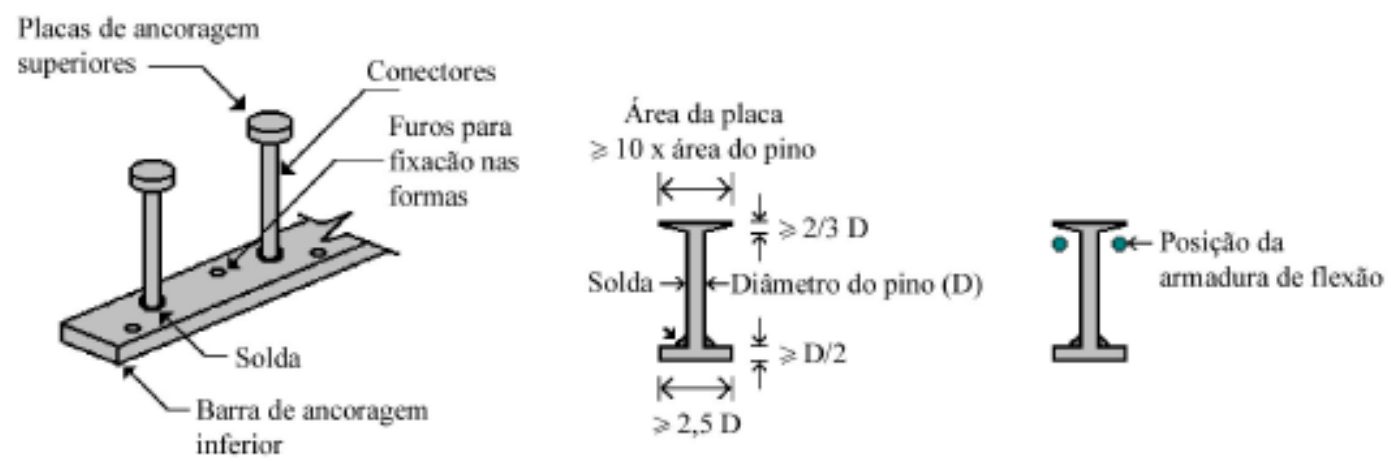

Figura 2.22 - Detalhes dos conectores tipo pino

A disposição dos conectores tanto pode ser radial, como em LANGOHR et al. (1976), quanto em linhas paralelas ou perpendiculares às faces do pilar, como em SEIBLE $e t$ al. (1980) (Figura 2.23). Inclusive GHALI \& MEGALLY (2000), utilizando análises numéricas, concluíram que as diferenças dos arranjos dos conectores não afetam significativamente o comportamento estrutural, nem em termos de resistência nem em termos de ductilidade. Por razões construtivas, entretanto, recomendam o uso da disposição ortogonal. Já o trabalho de GOMES (1991) sugere que a disposição radial tende a fornecer melhores resultados, devido à melhor distribuição de tensões. 


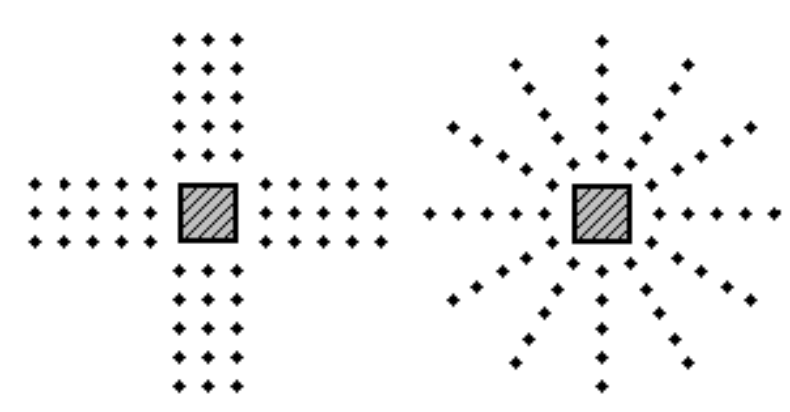

Figura 2.23 - Disposição dos conectores em planta

Em qualquer dos casos, é necessário se utilizar pelo menos três linhas de conectores e se obedecer a espaçamentos máximos, garantindo, dessa forma, a absorção das tensões cisalhantes. $\mathrm{O}$ espaçamento entre a face do pilar e a primeira linha de conectores $\left(\mathbf{s}_{\mathbf{0}}\right)$ deve ser inferior a $0,5 \mathbf{d}$, e entre duas linhas consecutivas de conectores $\left(\mathbf{s}_{\mathbf{r}}\right)$, inferior a $0,75 \mathbf{d}$ (Figura 2.24).

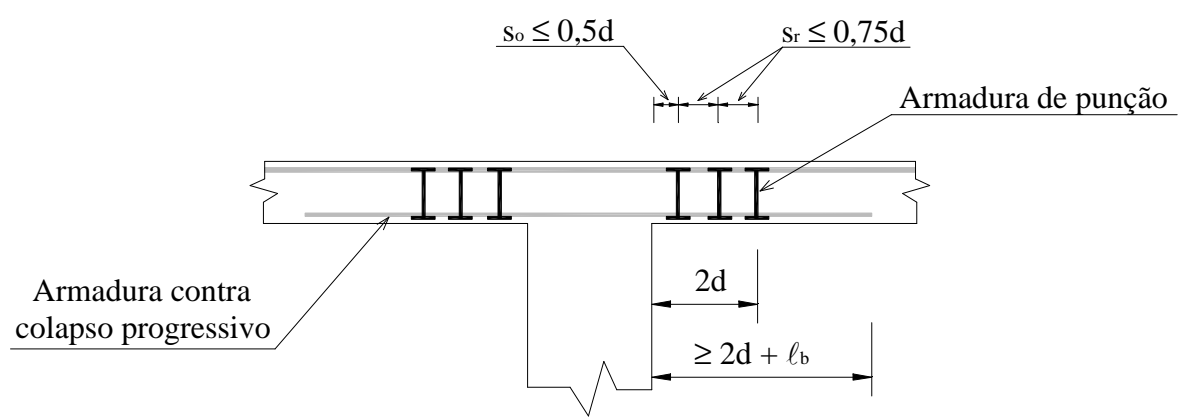

Figura 2.24 - Espaçamentos necessários para os conectores

Entre os conectores mais afastados do pilar, se o espaçamento $\left(\mathbf{s}_{\mathbf{e}}\right)$ for maior que $2 \mathbf{d}$, deve ser desprezada uma parte do perímetro crítico que seria usado na verificação do contorno C", conforme a Figura 2.25. Sugere-se, entretanto, que o limite de 2d seja respeitado, permitindo uma melhor distribuição das tensões.

Para os pilares de borda e de canto, recomenda-se dispor os conectores além do perímetro crítico reduzido, apesar dessa área de aço adicional não ser computada na verificação (Figura 2.26). 

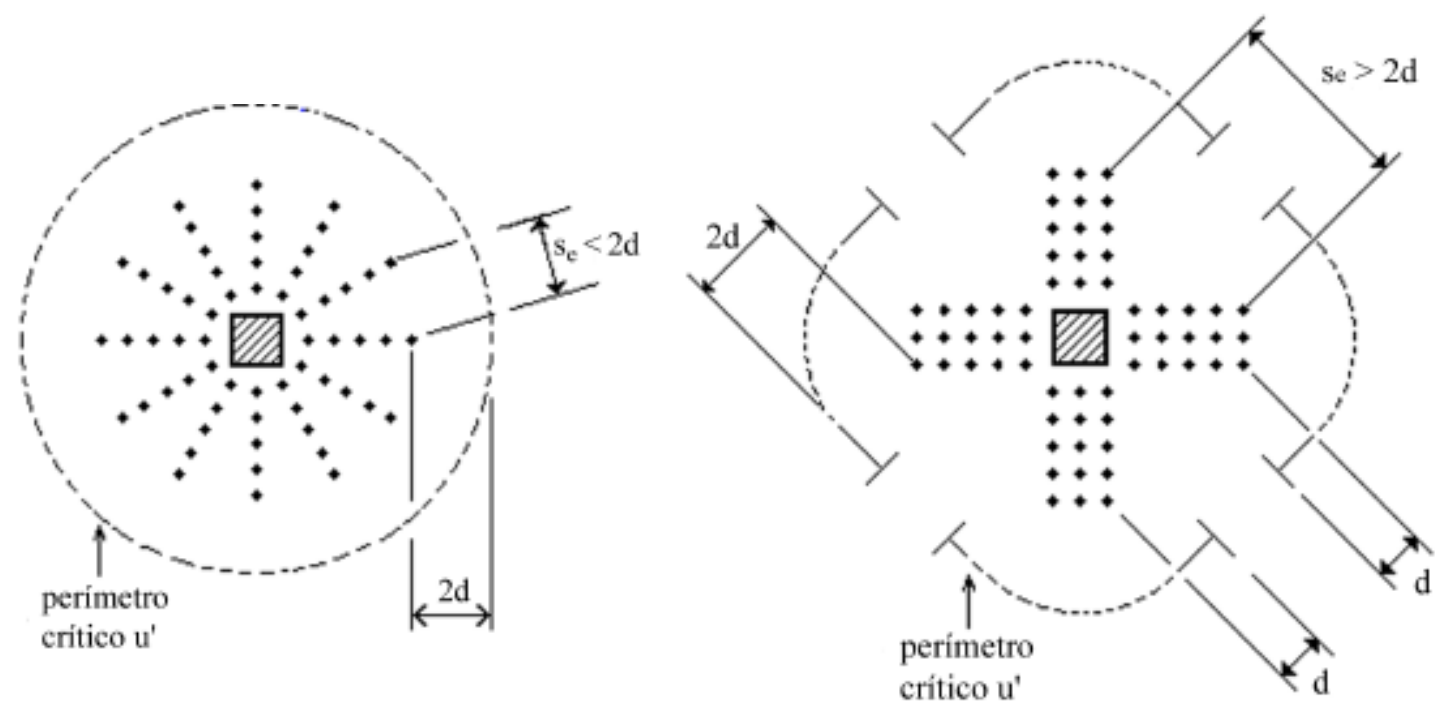

Figura 2.25 - Interferência de $\mathbf{s}_{\mathrm{e}}$ no cálculo de $\mathbf{u}$ '

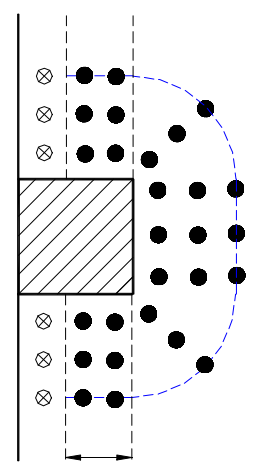

- = Armadura de punção calculada

$\otimes=$ Armadura de punção adicional

$\mathrm{a} \leq 1,5 \mathrm{~d}$ ou $0,5 \mathrm{c}_{1}$

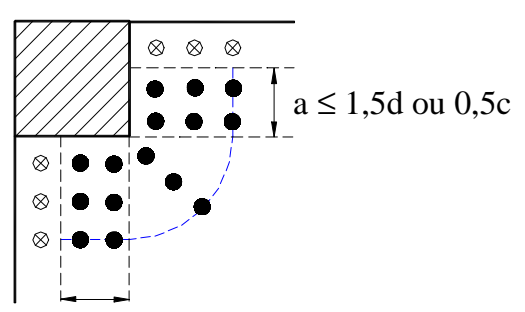

$\mathrm{a} \leq 1,5 \mathrm{~d}$ ou $0,5 \mathrm{c}$

Figura 2.26 - Disposição da armadura de punção em pilares de borda e de canto

\subsection{COMPLEMENTAÇÕES E COMENTÁRIOS SOBRE A VERIFICAÇÃO DA PUNÇÃO NA NBR 6118 (2000)}

Para facilitar e melhorar a verificação da punção, além de balizar um pouco mais o projeto de suas armaduras, algumas diretrizes adicionais devem ser atendidas. São recomendadas sua análise e incorporação na versão definitiva da nova NBR 6118.

\subsubsection{TENSÃO DO CONCRETO NO CONTORNO C}

As tensões nas proximidades da ligação de uma laje com um pilar têm uma distribuição bastante complexa. Tanto é que as bielas comprimidas estão, na realidade, submetidas a um estado multiaxial de tensões, o que lhes confere resistências muitas vezes 
superiores em relação aos casos observados, por exemplo, em vigas. Portanto, a abordagem da NBR 6118 (2000), que recomenda o uso da eq.(2.1), tende a ser conservadora.

Como já foi comentado, a resistência das bielas pode ser escrita em função da resistência do concreto à compressão diagonal, que, por sua vez, é considerada como apenas uma parcela da resistência do concreto à compressão. No CEB MC-90 (1993), uma das principais referências da NBR 6118 (2000), duas são as razões empregadas para não se adotar esta resistência com seu valor integral.

A primeira é que, com a formação de fissuras de flexão, a absorção das tensões torna-se mais difícil e a resistência na região diminui. Esse efeito é considerado através da introdução de um coeficiente de valor $0,6 \cdot\left(1-\frac{\mathrm{f}_{\mathrm{ck}}}{250}\right)$.

A segunda é que, como as expressões apresentadas nos itens 2.7.1.b) e 2.7.1.c) não têm validade em regiões com grande concentração de tensões, optou-se por restringir de forma indireta o seu uso, através de uma redução de $50 \%$ da tensão resistente do concreto. Este aspecto, comentado por REGAN (1999), é considerado através de um coeficiente de valor 0,5 .

Assim sendo, a expressão da resistência do concreto à compressão diagonal apresentada no CEB MC-90 (1993) pode ser escrita como:

$$
\begin{aligned}
\tau_{\mathrm{Rd} 2} & =0,5 \cdot 0,6 \cdot\left(1-\frac{\mathrm{f}_{\mathrm{ck}}}{250}\right) \cdot \mathrm{f}_{\mathrm{cd}} \\
\tau_{\mathrm{Rd} 2} & =0,3 \cdot\left(1-\frac{\mathrm{f}_{\mathrm{ck}}}{250}\right) \cdot \mathrm{f}_{\mathrm{cd}}
\end{aligned}
$$

Alterando-se o coeficiente de segurança de $\mathbf{1 , 5}$ para $\mathbf{1 , 4}$, valor adotado pela NBR 6118 (2000), obtém-se:

$$
\tau_{\mathrm{Rd} 2}=0,32 \cdot\left(1-\frac{\mathrm{f}_{\mathrm{ck}}}{250}\right) \cdot \mathrm{f}_{\mathrm{cd}}
$$

Observa-se que esta expressão fornece resultados menos conservadores que a eq.(2.1), com diferenças superiores a 15\%. Como sua base é experimental, o estado multiaxial é considerado, de uma certa forma. E tanto para os pilares intermediários, que em geral apresentam uma reação vertical maior, quanto para os pilares de borda e de canto, nos 
quais o perímetro crítico considerado é o reduzido, essa possibilidade de aumento da tensão resistente proporcionado pela eq.(2.16) é bastante significativa.

Propõe-se, então, a substituição da eq.(2.1) pela (2.16), no item 19.4.4.1 na versão definitiva da NBR 6118.

\subsubsection{LIMITAÇÃO DO VALOR DE $\rho$}

Como já foi comentado no item 2.7.1.b), o aumento da taxa de armadura $\rho$ também aumenta a resistência da ligação à punção. Entretanto, alguns resultados experimentais, inclusive os de FUSCO (1984), mostram que essa contribuição da taxa $\rho$ só é efetiva até um limite de aproximadamente $\mathbf{0 , 0 2}$.

Como pode ocorrer que o $\rho$ calculado para a faixa já mencionada em 2.7.1.b) seja superior a $\mathbf{0 , 0 2}$, considera-se importante a introdução deste limite na versão definitiva da NBR 6118. Propõe-se, então, uma complementação da definição de $\rho$ no item 19.4.4.2.

- Sugestão de redação:

" $\rho$ é a taxa geométrica de armadura de flexão aderente (armadura não aderente deve ser desprezada), considerada efetiva desde que $\rho \leq 0,02$ ".

\subsubsection{PERÍMETRO CRÍTICO DE PILARES ALONGADOS}

O estudo de pilares alongados é um pouco mais complexo que o daqueles em que não há grandes diferenças de tamanho entre os lados. Comparando-se ligações com pilares de mesma área e diferentes dimensões, observa-se que aquelas com os mais alongados apresentam cones de punção menores e resistências mais baixas, além de uma ruína mais abrupta.

A NBR 6118 (2000) não faz nenhum comentário quanto à verificação da punção no caso desses pilares, mesmo eles sendo usualmente empregados. Considera-se importante a introdução de alguma recomendação específica para essas situações na versão definitiva da NBR 6118, apesar de muitas vezes ser necessária a utilização de análises mais rigorosas e modelos mais racionais.

Uma alternativa bastante simplificada, dentro do método já apresentado, é se calcular o perímetro crítico desprezando-se a parte central dos lados maiores, onde as tensões são mais baixas. Esse procedimento já era adotado pela NBR 6118 (1978), e pode continuar a ser utilizado na falta de um método mais rigoroso. A redução do perímetro crítico pode ser feita como indicado na Figura 2.27. 


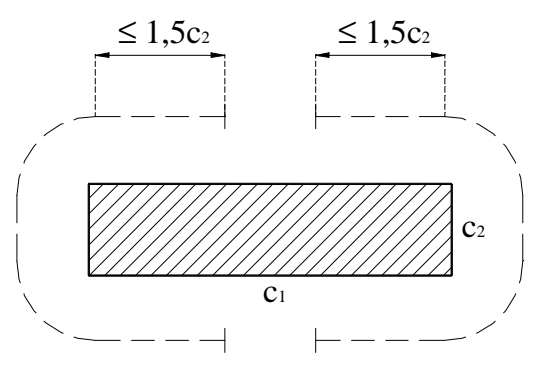

Figura 2.27 - Perímetro crítico de pilares alongados

Sugere-se, então, a introdução da Figura 2.27, como figura 44, e uma complementação ao item 19.4.3.6.

- Sugestão de redação:

"No caso de pilares alongados, o trecho do perímetro crítico contido entre duas retas paralelas aos lados menores, distantes deles $1,5 c_{2}$, deve ser desprezado (ver figura 44).” (Figura 2.27).

\subsubsection{VALORES DE K}

Como já foi mencionado no item 2.6, apenas uma parcela do momento fletor é transmitida por cisalhamento em uma ligação. Quanto mais alongado for o pilar na direção perpendicular à excentricidade ou na direção da borda livre, maior será a parcela do momento transmitida por flexão. Por outro lado, quanto mais alongado for o pilar na direção da excentricidade ou na direção perpendicular à borda livre, maior será a parcela do momento transmitida por cisalhamento.

Na NBR 6118 (2000), essa parcela transmitida por cisalhamento é determinada pelo coeficiente K, cujos valores são apresentados na Tabela 2.2. Entretanto, não há comentário sobre os procedimentos que devem ser seguidos nos casos em que a relação $\frac{\mathrm{c}_{1}}{\mathrm{c}_{2}}$ entre as dimensões do pilar é menor que $\mathbf{0 , 5}$ ou maior que $\mathbf{3}$, situações possíveis na prática. Também não são mencionados os casos de valores intermediários aos apresentados na Tabela 2.2. De qualquer forma, considera-se importante que seja feita alguma alusão a essas situações.

Para a obtenção dos valores intermediários de $\mathbf{K}$, pode ser feita uma interpolação linear entre os valores da Tabela 2.2, ou se utilizar diretamente as seguintes expressões: 


$$
\begin{aligned}
& \mathrm{K}=0,3 \cdot\left(\frac{\mathrm{c}_{1}}{\mathrm{c}_{2}}\right)+0,3 \quad \text { para } 0,5 \leq \frac{\mathrm{c}_{1}}{\mathrm{c}_{2}}<1 ; \\
& \mathrm{K}=0,1 \cdot\left(\frac{\mathrm{c}_{1}}{\mathrm{c}_{2}}\right)+0,5 \quad \text { para } 1 \leq \frac{\mathrm{c}_{1}}{\mathrm{c}_{2}} \leq 3 .
\end{aligned}
$$

Sugere-se, então, uma complementação ao item 19.4.3.2.

- Sugestão de redação:

" $O$ coeficiente $K$ assume os valores indicados na tabela 27, sendo que os valores intermediários podem ser interpolados linearmente".

Quanto aos valores que extrapolam os limites da Tabela 2.2, deve-se enfatizar que uma determinação mais precisa só pode ser feita com base em modelos numéricos específicos ou resultados experimentais. Pelo menos para os casos em que $\frac{\mathrm{c}_{1}}{\mathrm{c}_{2}}<0,5$, na falta de uma análise mais rigorosa, pode ser feita uma indicação para o uso de um valor conservador, $\mathrm{K}=0,45$.

\subsubsection{VALORES DE WP PARA OS CONTORNOS C E C"}

Já foi mencionado que, na NBR 6118 (2000), não há comentários sobre a obtenção das expressões de $\mathbf{W}_{\mathbf{p}}$ para os contornos $\mathbf{C}$ e C'. Essa omissão pode acarretar o uso de valores indevidos desse parâmetro para as verificações na face do pilar e além da região armada, não devendo persistir na versão definitiva da NBR 6118.

No CEB MC-90 (1993), no qual a verificação de punção da NBR 6118 (2000) é baseada, não ocorre esse problema. Para o contorno C", fica claro que deve ser calculado um $\mathbf{W}_{\mathbf{p}}$ ' correspondente ao perímetro crítico $\mathbf{u}$ ', de forma análoga ao $\mathbf{W}_{\mathbf{p}}$ para o contorno $\mathbf{u}$. Resolvendo-se a integral de definição, podem ser obtidas as expressões de $\mathbf{W}_{\mathbf{p}}$ ' da Tabela 2.5, para cada situação de cálculo.

Para o contorno C, o CEB MC-90 (1993) escreve a tensão solicitante em termos de uma força de compressão efetiva, $\mathbf{F}_{\mathbf{S d}, \mathbf{e}}$, que considera o efeitos dos momentos fletores. Sua expressão é dada por:

$$
\tau_{\mathrm{Sd}}=\frac{\mathrm{F}_{\mathrm{Sd}, \mathrm{ef}}}{\mathrm{u}_{\mathrm{o}} \cdot \mathrm{d}}
$$


Tabela 2.5 - Valores de $\mathbf{W}_{\mathbf{p}}$,

\begin{tabular}{|c|c|}
\hline $\begin{array}{l}\text { Situação de } \\
\text { Cálculo }\end{array}$ & $W_{p}$ \\
\hline $\begin{array}{c}\text { Pilar interno } \\
\left(W_{p}\right)\end{array}$ & $\begin{array}{r}\mathrm{W}_{\mathrm{p}}^{\prime}=\frac{\mathrm{c}_{1}^{2}}{2}+\mathrm{c}_{1} \cdot \mathrm{c}_{2}+4 \cdot \mathrm{c}_{2} \cdot \mathrm{d}+16 \cdot \mathrm{d}^{2}+2 \cdot \pi \cdot d \cdot \mathrm{c}_{1}+2 \cdot \mathrm{c}_{2} \cdot \mathrm{p}+ \\
+16 \cdot \mathrm{d} \cdot \mathrm{p}+4 \cdot \mathrm{p}^{2}+\pi \cdot \mathrm{c}_{1} \cdot \mathrm{p}\end{array}$ \\
\hline $\begin{array}{l}\text { Pilar de borda } \\
\quad\left(W_{p 1}\right)\end{array}$ & $\begin{array}{r}\mathrm{W}_{\mathrm{p} 1}{ }^{\prime}=\frac{\mathrm{c}_{1}^{2}}{2}+\frac{\mathrm{c}_{1} \cdot \mathrm{c}_{2}}{2}+2 \cdot \mathrm{c}_{2} \cdot \mathrm{d}+8 \cdot \mathrm{d}^{2}+\pi \cdot \mathrm{d} \cdot \mathrm{c}_{1}+\mathrm{c}_{2} \cdot \mathrm{p}+8 \cdot \mathrm{d} \cdot \mathrm{p}+ \\
+\frac{\pi \cdot \mathrm{p} \cdot \mathrm{c}_{1}}{2}+2 \cdot \mathrm{p}^{2}\end{array}$ \\
\hline $\begin{array}{l}\text { Pilar de borda } \\
\qquad\left(W_{p 2}\right)\end{array}$ & $\begin{array}{r}\mathrm{W}_{\mathrm{p} 2}{ }^{\prime}=\frac{\mathrm{c}_{2}^{2}}{4}+\mathrm{c}_{1} \cdot \mathrm{c}_{2}+4 \cdot \mathrm{c}_{1} \cdot \mathrm{d}+8 \cdot \mathrm{d}^{2}+\pi \cdot \mathrm{d} \cdot \mathrm{c}_{2} \\
+2 \cdot \mathrm{c}_{1} \cdot \mathrm{p}+8 \cdot \mathrm{d} \cdot \mathrm{p}+ \\
+\frac{\pi \cdot \mathrm{p} \cdot \mathrm{c}_{2}}{2}+2 \cdot \mathrm{p}^{2}\end{array}$ \\
\hline $\begin{array}{l}\text { Pilar de canto } \\
\left(W_{p 1}\right)\end{array}$ & $\begin{aligned} & \mathrm{W}_{\mathrm{p} 1}{ }^{\prime}=\frac{\mathrm{c}_{1}^{2}}{4}+\frac{\mathrm{c}_{1} \cdot \mathrm{c}_{2}}{2}+2 \cdot \mathrm{c}_{2} \cdot \mathrm{d}+4 \cdot \mathrm{d}^{2}+\frac{\pi \cdot \mathrm{d} \cdot \mathrm{c}_{1}}{2}+\mathrm{c}_{2} \cdot \mathrm{p}+4 \cdot \mathrm{d} \cdot \mathrm{p}+ \\
&+\frac{\pi \cdot \mathrm{p} \cdot \mathrm{c}_{1}}{4}+\mathrm{p}^{2}\end{aligned}$ \\
\hline
\end{tabular}

sendo:

$$
\mathrm{F}_{\mathrm{Sd}, \text { ef }}=\mathrm{F}_{\mathrm{Sd}} \cdot\left(1+\mathrm{K} \cdot \frac{\mathrm{M}_{\mathrm{Sd}}}{\mathrm{F}_{\mathrm{Sd}}} \cdot \frac{\mathrm{u}}{\mathrm{W}_{\mathrm{p}}}\right)
$$

Substituindo a eq.(2.18) na eq.(2.17), e rearrumando para se obter uma expressão similar à da NBR 6118 (2000), tem-se:

$$
\tau_{\mathrm{Sd}}=\frac{\mathrm{F}_{\mathrm{Sd}}}{\mathrm{u}_{\mathrm{o}} \cdot \mathrm{d}}+\frac{\mathrm{K} \cdot \mathrm{M}_{\mathrm{Sd}}}{\frac{\mathrm{u}_{\mathrm{o}}}{\mathrm{u}} \cdot \mathrm{W}_{\mathrm{p}} \cdot \mathrm{d}}
$$

Observa-se que o CEB MC-90 (1993), apesar de não fornecer uma expressão direta para o cálculo do $\mathbf{W}_{\mathbf{p}}$ no contorno $\mathbf{C}$, utiliza uma redução do próprio $\mathbf{W}_{\mathbf{p}}$ do contorno $\mathbf{C}$ ' para o cálculo da tensão solicitante na face do pilar ${ }^{6}$. Pode-se escrever então:

\footnotetext{
${ }^{6}$ Deve-se ressaltar que essa redução do $\mathbf{W}_{\mathbf{p}}$ do contorno $\mathbf{C}$ ' não corresponde à aplicação da integral de definição ao perímetro crítico $\mathbf{u}_{\mathbf{0}}$.
} 


$$
\mathrm{W}_{\mathrm{po}}=\frac{\mathrm{u}_{\mathrm{o}}}{\mathrm{u}} \cdot \mathrm{W}_{\mathrm{p}}
$$

Para pilares de borda e de canto, devem ser utilizados os perímetros críticos reduzidos:

$$
\mathrm{W}_{\mathrm{po}}=\frac{\mathrm{u}_{\mathrm{o}}^{*}}{\mathrm{u}^{*}} \cdot \mathrm{W}_{\mathrm{p}}
$$

Assim como foi feita uma redução do $\mathbf{W}_{\mathbf{p}}$ para se calcular o $\mathbf{W}_{\mathbf{p o}}$, pode-se pensar numa majoração do $\mathbf{W}_{\mathbf{p}}$ para se obter o $\mathbf{W}_{\mathbf{p}}$ '. Essa interpretação é bastante prática, pois permite que os valores de $\mathbf{W}_{\mathbf{p}}$ ' sejam calculados de uma forma mais simples que aquela apresentada na Tabela 2.5. Assim sendo, pode-se escrever:

$$
\mathrm{W}_{\mathrm{p}}{ }^{\prime}=\eta_{\mathrm{wp}} \frac{\mathrm{u}^{\prime}}{\mathrm{u}} \cdot \mathrm{w}_{\mathrm{p}}
$$

Para pilares de borda e de canto:

$$
\mathrm{W}_{\mathrm{p}}{ }^{\prime}=\eta_{\mathrm{wp}} \frac{\mathrm{u}^{\prime *}}{\mathrm{u} *} \cdot \mathrm{W}_{\mathrm{p}}
$$

sendo:

$\eta_{\mathbf{w p}}$ - coeficiente para correção do $\mathbf{W}_{\mathbf{p}}$ ' em função da situação de cálculo.

Para determinar os valores de $\eta_{\mathrm{wp}}$, as seguintes expressões foram utilizadas:

$$
\begin{aligned}
& \eta_{\mathrm{wp}}=\frac{\frac{\mathrm{W}_{\mathrm{p}}^{\prime}}{\mathrm{W}_{\mathrm{p}}}}{\frac{\mathrm{u}^{\prime}}{\mathrm{u}}} \quad \text { para pilares internos; } \\
& \eta_{\mathrm{wp}}=\frac{\frac{\mathrm{W}_{\mathrm{p}}^{\prime}}{\mathrm{W}_{\mathrm{p}}}}{\frac{\mathrm{u}^{\prime *}}{\mathrm{u}^{*}}} \quad \text { para pilares de borda e de canto. }
\end{aligned}
$$

Foram resolvidos diversos exemplos para cada situação de cálculo, supondo-se $\mathbf{W}_{\mathbf{p}}$, calculado pela Tabela 2.5 e $\mathrm{s}_{\mathrm{e}} \leq 2 \cdot \mathrm{d}$. Os dados utilizados e a análise estatística 
desenvolvida encontram-se no Anexo A. Observou-se que podem ser adotados os valores de $\eta_{\mathrm{wp}}$ apresentados na Tabela 2.6, mantendo-se o nível de significância em torno de 10\%. Mas vale ressaltar que esses valores ainda podem ser melhorados, a partir de outras análises mais refinadas e que considerem uma amostragem maior e mais diversificada.

Tabela 2.6 - Valores de $\eta_{\text {wp }}$

\begin{tabular}{|c|c|c|}
\hline $\begin{array}{c}\text { Situação de } \\
\text { Cálculo }\end{array}$ & $\boldsymbol{c}_{1} \leq \boldsymbol{c}_{2}$ & $\boldsymbol{c}_{1}>\boldsymbol{c}_{2}$ \\
\hline $\begin{array}{c}\text { Pilar interno } \\
\left(\boldsymbol{W}_{p}{ }^{\prime}\right)\end{array}$ & 1,6 & 1,3 \\
\hline $\begin{array}{c}\text { Pilar de borda } \\
\left(\boldsymbol{W}_{p 1}{ }^{\prime}\right)\end{array}$ & 1,5 & 1,1 \\
\hline $\begin{array}{c}\text { Pilar de borda } \\
\left(\boldsymbol{W}_{p 2}{ }^{\prime}\right)\end{array}$ & 1,3 & 1,3 \\
\hline $\begin{array}{c}\text { Pilar de canto } \\
\left(\boldsymbol{W}_{p 1}{ }^{\prime}\right)\end{array}$ & 1,3 & 1,1 \\
\hline \multicolumn{2}{|c|}{}
\end{tabular}

Pelo que foi exposto, percebe-se que tanto a redução quanto a majoração do $\mathbf{W}_{\mathbf{p}}$, para a determinação de $\mathbf{W}_{\mathbf{p}}$ e $\mathbf{W}_{\mathbf{p}}$ ', respectivamente, podem ser introduzidas na versão definitiva da NBR 6118. Para cálculos mais rigorosos, entretanto, recomenda-se a adoção das expressões completas de $\mathbf{W}_{\mathbf{p}}$, apresentadas na Tabela 2.5.

- Sugestões de redação:

- item 19.4.4.1

" $\tau_{S d}$ é calculado conforme 19.4.3, com $u_{o}$, perímetro do contorno $C$, em lugar de $u$, $\underline{e}$ $\underline{W}_{p o}$, módulo de resistência plástica do contorno $C$, em lugar de $W_{p}$. $W_{p o}$ pode ser obtido fazendo-se $\mathrm{W}_{\mathrm{po}}=\frac{\mathrm{u}_{\mathrm{o}}}{\mathrm{u}} \cdot \mathrm{W}_{\mathrm{p}}$ para pilares internos, e $\mathrm{W}_{\mathrm{po}}=\frac{\mathrm{u}_{\mathrm{o}} *}{\mathrm{u} *} \cdot \mathrm{W}_{\mathrm{p}}$ para pilares de borda e de canto."

- item 19.4.4.4

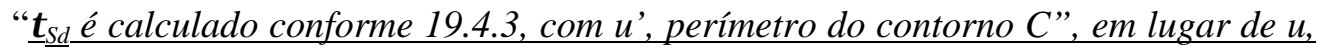
$\underline{e} W_{p}{ }^{\prime}$, módulo de resistência plástica do contorno $C$ ", em lugar de $W_{p}$. $W_{p}$ 'pode ser obtido fazendo-se $\mathrm{W}_{\mathrm{p}}{ }^{\prime}=\eta_{\mathrm{wp}} \frac{\mathrm{u}^{\prime}}{\mathrm{u}} \cdot \mathrm{W}_{\mathrm{p}}$ para pilares internos, e $\mathrm{W}_{\mathrm{p}}{ }^{\prime}=\eta_{\mathrm{wp}} \frac{\mathrm{u}^{\prime *}}{\mathrm{u}^{*}} \cdot \mathrm{W}_{\mathrm{p}}$ para pilares de borda e de canto. O coeficiente $\eta_{\underline{w p}}$ assume os valores indicados na tabela 28". (Tabela 2.6) 


\subsubsection{TENSÃO ATUANTE EM PILARES INTERNOS COM MOMENTOS NAS DUAS DIREÇÕES}

A distribuição uniforme das tensões cisalhantes apresentada na Figura 2.7 consiste em uma simplificação que conduz a bons resultados em boa parte dos casos. Entretanto, como mostra MAST (1970), as tensões atingem seus valores máximos nas regiões do contorno crítico perpendiculares à excentricidade, diminuindo até zero no eixo de aplicação do momento. Assim, quando houver momentos aplicados nas duas direções, a tensão máxima resultante terá um valor inferior à simples soma entre as parcelas dos momentos em cada direção, visto que as tensões máximas não ocorrem nos mesmos pontos. Em outras palavras, o cálculo da tensão atuante conforme a expressão (2.7) conduz a resultados conservadores.

CORES \& ARROYO (1995) apresentam uma proposta do Task Group 2.3 do CEB, comprovada por resultados experimentais, em que a tensão solicitante que considera os efeitos dos momentos das duas direções é dada por:

$$
\tau_{\mathrm{Sd}}=\frac{\mathrm{F}_{\mathrm{Sd}}}{\mathrm{u} \cdot \mathrm{d}}+\sqrt{\left(\frac{\mathrm{K}_{1} \cdot \mathrm{M}_{\mathrm{Sd} 1}}{\mathrm{~W}_{\mathrm{p} 1} \cdot \mathrm{d}}\right)^{2}+\left(\frac{\mathrm{K}_{2} \cdot \mathrm{M}_{\mathrm{Sd} 2}}{\mathrm{~W}_{\mathrm{p} 2} \cdot \mathrm{d}}\right)^{2}}
$$

Para a versão definitiva da NBR 6118, sugere-se analisar a adoção desta expressão no lugar da eq.(2.7), o que alteraria o comentário do item 19.4.3.2 no anexo A19.

\subsubsection{VALORES DA EXCENTRICIDADE $\mathrm{e}^{*}$ PARA OS CONTORNOS C E C'}

Como já foi comentado, a NBR 6118 (2000) não apresenta as expressões para o cálculo de $\mathbf{e}^{*}$ correspondente aos contornos $\mathbf{C}$ e $\mathbf{C}$ ”. Assim como no caso do $\mathbf{W}_{\mathbf{p}}$, essa omissão pode acarretar a escolha de valores indevidos de $\mathbf{e}^{*}$ para as verificações na face do pilar e além da região armada, e deve ser solucionada na versão definitiva da NBR 6118.

Uma primeira idéia seria aplicar a integral de definição de $\mathbf{e}^{*}$, mencionada no item 2.7.2.d), aos contornos críticos $\mathbf{C}$ e $\mathbf{C}$ '. Com isso, são obtidas as expressões da Tabela 2.7, para pilares de borda, e da Tabela 2.8, para pilares de canto.

Observa-se, entretanto, que o cálculo de $\mathbf{e}^{*}$ segundo essas expressões pode se tornar um pouco trabalhoso. Fazendo-se uma analogia à solução apresentada para o $\mathbf{W}_{\mathbf{p}}$, pode-se propor que as excentricidades dos perímetros críticos reduzidos dos contornos $\mathbf{C}$ e $\mathbf{C}$ " sejam escritas da seguinte forma: 
Tabela 2.7 - Valores de $\mathbf{e}^{*}$ para pilares de borda

\begin{tabular}{|c|c|}
\hline Contorno Crítico & Excentricidade do perímetro crítico $e^{*}$ \\
\hline$C$ & $\mathrm{e}_{\mathrm{o}} *=\frac{\mathrm{c}_{1} \cdot \mathrm{a}-\mathrm{a}^{2}+\frac{\mathrm{c}_{1} \cdot \mathrm{c}_{2}}{2}}{2 \cdot \mathrm{a}+\mathrm{c}_{2}}$ \\
\hline$C ”$ & $\mathrm{e}^{\prime *}=\frac{\left(\begin{array}{c}\mathrm{c}_{1} \cdot \mathrm{a}-\mathrm{a}^{2}+\frac{\mathrm{c}_{1} \cdot \mathrm{c}_{2}}{2}+2 \cdot \mathrm{c}_{2} \cdot d+8 \cdot \mathrm{d}^{2}+\pi \cdot d \cdot \mathrm{c}_{1}+ \\
+\mathrm{c}_{2} \cdot \mathrm{p}+8 \cdot \mathrm{d} \cdot \mathrm{p}+\frac{\pi \cdot \mathrm{p} \cdot \mathrm{c}_{1}}{2}+2 \cdot \mathrm{p}^{2}\end{array}\right.}{2 \cdot \mathrm{a}+\mathrm{c}_{2}+2 \cdot \pi \cdot \mathrm{d}+\pi \cdot \mathrm{p}}$ \\
\hline
\end{tabular}

Tabela 2.8 - Valores de $\mathbf{e}^{*}$ para pilares de canto

\begin{tabular}{|c|c|}
\hline Contorno Crítico & Excentricidade do perímetro crítico $e^{*}$ \\
\hline$C$ & $\mathrm{e}_{\mathrm{o}}{ }^{*}=\frac{\mathrm{c}_{1} \cdot \mathrm{a}_{1}-\mathrm{a}_{1}{ }^{2}+\mathrm{a}_{2} \cdot \mathrm{c}_{1}}{2 \cdot\left(\mathrm{a}_{1}+\mathrm{a}_{2}\right)}$ \\
\hline$C^{\prime \prime}$ & $\mathrm{e}^{* *}=\frac{\left(\begin{array}{r}\mathrm{c}_{1} \cdot \mathrm{a}_{1}-\mathrm{a}_{1}{ }^{2}+\mathrm{a}_{2} \cdot \mathrm{c}_{1}+4 \cdot \mathrm{a}_{2} \cdot \mathrm{d}+8 \cdot \mathrm{d}^{2}+\pi \cdot \mathrm{d} \cdot \mathrm{c}_{1} \\
+2 \cdot \mathrm{a}_{2} \cdot \mathrm{p}+8 \cdot \mathrm{d} \cdot \mathrm{p}+\frac{\pi \cdot \mathrm{p} \cdot \mathrm{c}_{1}}{2}+2 \cdot \mathrm{p}^{2}\end{array}\right)}{2 \cdot\left(\mathrm{a}_{1}+\mathrm{a}_{2}+\pi \cdot \mathrm{d}+\frac{\pi \cdot \mathrm{p}}{2}\right)}$ \\
\hline
\end{tabular}

$$
\begin{aligned}
& \mathrm{e}_{\mathrm{o}}^{*}=\eta_{\mathrm{e} 1} \frac{\mathrm{u}_{\mathrm{o}} *}{\mathrm{u}^{*}} \cdot \mathrm{e}^{*} \\
& \mathrm{e}^{\prime *}=\eta_{\mathrm{e} 2} \frac{\mathrm{u}^{\prime *}}{\mathrm{u}^{*}} \cdot \mathrm{e}^{*}
\end{aligned}
$$

sendo:

$\eta_{\mathrm{e} 1}, \eta_{\mathrm{e} 2}$ - coeficientes para correção de $\mathbf{e}^{*}$ em função do contorno estudado.

Para a determinação dos valores de $\eta_{\mathbf{e} 1}$ e $\eta_{\mathbf{e} 2}$, as seguintes expressões foram utilizadas:

$$
\eta_{\mathrm{e} 1}=\frac{\frac{\mathrm{e}_{\mathrm{o}}^{*}}{\mathrm{e}^{*}}}{\frac{\mathrm{u}_{\mathrm{o}}^{*}}{\mathrm{u}^{*}}}
$$




$$
\eta_{\mathrm{e} 2}=\frac{\frac{\mathrm{e}^{\prime *}}{\mathrm{e}^{*}}}{\frac{\mathrm{u}^{\prime *}}{\mathrm{u}^{*}}}
$$

Diversos exemplos foram resolvidos, supondo-se $\mathbf{e}_{\mathbf{o}}^{*}$ e $\mathbf{e}^{\boldsymbol{}^{*}}$ calculados pela Tabela 2.7 e pela Tabela 2.8 , e, novamente, $\mathrm{s}_{\mathrm{e}} \leq 2 \cdot \mathrm{d}$. Os dados utilizados e a análise estatística desenvolvida encontram-se no Anexo B. Observou-se que podem ser adotados os valores de $\eta_{\mathrm{e} 1}$ e de $\eta_{\mathrm{e} 2}$ apresentados na Tabela 2.9, tanto para pilares de borda quanto de canto, mantendo-se o nível de significância em torno de $10 \%$. Mas vale ressaltar que esses valores ainda podem ser melhorados, a partir de outras análises mais refinadas e que considerem uma amostragem maior e mais diversificada.

Tabela 2.9 - Valores de $\eta_{\mathrm{e} 1}$ e de $\eta_{\mathrm{e} 2}$

\begin{tabular}{|c|c|c|}
\hline Coeficientes & $\boldsymbol{c}_{1} \leq \boldsymbol{c}_{2}$ & $\boldsymbol{c}_{\boldsymbol{1}}>\boldsymbol{c}_{2}$ \\
\hline$\eta_{e 1}$ & 0,5 & 1,0 \\
\hline$\eta_{e 2}$ & 1,0 & 0,8 \\
\hline
\end{tabular}

Assim sendo, propõe-se a introdução das expressões de redução e majoração do $\mathbf{e}^{*}$, utilizadas na determinação, respectivamente, de $\mathbf{e}_{\mathbf{0}}{ }^{*}$ e e ${ }^{* *}$, no item 19.4.3.4 do Anexo A.19. Para cálculos mais rigorosos, entretanto, recomenda-se a adoção das expressões completas, indicadas na Tabela 2.7 e na Tabela 2.8 .

- Sugestão de redação:

"Tanto para pilares de borda como de canto, permite-se calcular as excentricidades do perímetro crítico reduzido nos contornos $C$ e $C$ " a partir das expressões:

$$
\begin{aligned}
& \mathrm{e}_{\mathrm{o}}^{*}=\eta_{\mathrm{e} 1} \cdot \frac{\mathrm{u}_{\mathrm{o}} *}{\mathrm{u}^{*}} \cdot \mathrm{e}^{*} \\
& \mathrm{e}^{\prime *}=\eta_{\mathrm{e} 2} \cdot \frac{\mathrm{u}^{\prime *}}{\mathrm{u}^{*}} \cdot \mathrm{e}^{*}
\end{aligned}
$$

Os coeficientes $\eta_{\underline{e l}}$ e $\eta_{\underline{e 2}}$ assumem os valores indicados na tabela A.5" (Tabela 2.9). 


\subsubsection{MÉTODO SIMPLIFICADO PARA A PUNÇÃO EXCÊNTRICA}

Nos itens 2.7.2.b) ao 2.7.2.f), foram apresentadas expressões para o cálculo das tensões solicitantes nos casos em que atuam momentos fletores desbalanceados, além da força normal. Essas expressões, entretanto, podem se tornar ou pouco práticas, em situações nas quais não se necessite de uma avaliação mais rigorosa da punção, ou até mesmo inconvenientes, quando se desejar uma análise mais imediata do problema.

Em qualquer um desses casos, pode ser interessante a utilização de um método mais simplificado para a verificação da punção excêntrica. Uma alternativa é a adoção de um coeficiente majorador da tensão atuante causada pela força normal, que leve em consideração o efeito da excentricidade. Assim,

$$
\tau_{\mathrm{Sd}}=\beta \cdot \frac{\mathrm{F}_{\mathrm{Sd}}}{\mathrm{u} \cdot \mathrm{d}}
$$

sendo:

$\boldsymbol{\beta}$ - coeficiente para a consideração do efeito da excentricidade.

Pode-se imaginar que o valor de $\beta$ sofrerá variações de acordo com a situação de cálculo e o contorno crítico estudados. De uma maneira geral, com base no cálculo de $\tau_{\mathbf{S d}}$ pelo método mais rigoroso já apresentado, pode-se escrever:

- no contorno $\mathbf{C}$ :

$$
\beta=\frac{\frac{\mathrm{F}_{\mathrm{Sd}}}{\mathrm{u}_{\mathrm{o}} \cdot \mathrm{d}}+\frac{\mathrm{K}_{1} \cdot\left(\mathrm{M}_{\mathrm{Sd} 1}-\mathrm{F}_{\mathrm{Sd}} \cdot \mathrm{e}_{\mathrm{o}} *\right)}{\mathrm{W}_{\mathrm{p} 1, \mathrm{o}} \cdot \mathrm{d}}+\frac{\mathrm{K}_{2} \cdot \mathrm{M}_{\mathrm{Sd} 2}}{\mathrm{~W}_{\mathrm{p} 2, \mathrm{o}} \cdot \mathrm{d}}}{\frac{\mathrm{F}_{\mathrm{Sd}}}{\mathrm{u}_{\mathrm{o}} \cdot \mathrm{d}}}
$$

- no contorno $\mathbf{C}^{\prime}$ :

$$
\beta=\frac{\frac{F_{S d}}{u \cdot d}+\frac{K_{1} \cdot\left(M_{S d 1}-F_{S d} \cdot e^{*}\right)}{W_{p 1} \cdot d}+\frac{K_{2} \cdot M_{S d 2}}{W_{p 2} \cdot d}}{\frac{F_{S d}}{u \cdot d}}
$$

- no contorno C":

$$
\beta=\frac{\frac{F_{S d}}{u^{\prime} \cdot d}+\frac{K_{1} \cdot\left(M_{S d 1}-F_{S d} \cdot e^{\prime *}\right)}{W_{p 1} \cdot d}+\frac{K_{2} \cdot M_{S d 2}}{W_{p 2} \cdot d}}{\frac{F_{S d}}{u^{\prime} \cdot d}}
$$


Para que os valores de $\beta$ em cada contorno fossem obtidos a partir dessas expressões, foram resolvidos diversos exemplos para cada situação de cálculo, supondo-se $s_{e} \leq 2 \cdot d$. Os dados utilizados e a análise estatística desenvolvida encontram-se no Anexo C. Mantendo-se o nível de significância em, no máximo, 10\%, observou-se que poderiam ser adotados os valores de $\beta$ da Tabela 2.10. Mas vale ressaltar que esses valores ainda podem ser melhorados a partir de outras análises mais refinadas, e que considerem, principalmente, uma variação maior do carregamento.

Tabela 2.10 - Valores de $\beta$ agrupados e aproximados

\begin{tabular}{|l|c|c|c|c|c|c|}
\hline \multirow{2}{*}{\multicolumn{1}{c|}{ Situação de Cálculo }} & \multicolumn{3}{|c|}{$\boldsymbol{c}_{1} \leq \boldsymbol{c}_{2}$} & \multicolumn{3}{c|}{$\boldsymbol{c}_{1}>\boldsymbol{c}_{2}$} \\
\cline { 2 - 7 } & $\boldsymbol{C}$ & $\boldsymbol{C}^{\prime}$ & $\boldsymbol{C}^{\prime}$ & $\boldsymbol{C}$ & $\boldsymbol{C}^{\prime}$ & $\boldsymbol{C}^{\prime}$ \\
\hline Pilar interno, com carregamento simétrico & 1,0 & 1,0 & 1,0 & 1,0 & 1,0 & 1,0 \\
\hline Pilar interno, com momento aplicado & 1,2 & 1,2 & 1,1 & 1,2 & 1,2 & 1,1 \\
\hline Pilar de borda & 1,5 & 1,3 & 1,2 & 1,7 & 1,4 & 1,1 \\
\hline Pilar de canto & 1,7 & 1,4 & 1,1 & 1,5 & 1,2 & 1,1 \\
\hline
\end{tabular}

Propõe-se então a introdução desse método simplificado para o cálculo de $\tau_{\mathbf{S d}}$, na parte de comentários da versão definitiva da NBR 6118, item 19.4.3 no anexo A.19.

- Sugestão de redação:

"Permite-se verificar a punção excêntrica através da majoração da tensão solicitante devida à força normal, utilizando-se a seguinte expressão:

$$
\tau_{\mathrm{Sd}}=\beta \cdot \frac{\mathrm{F}_{\mathrm{Sd}}}{\mathrm{u} \cdot \mathrm{d}}
$$

onde:

$\beta$ é o coeficiente para a consideração do efeito da excentricidade, cujos valores estão indicados na tabela A.4". (Tabela 2.10) 


\subsubsection{POSICIONAMENTO DOS CONECTORES TIPO PINO}

A resistência das ligações laje-pilar com armadura de punção está diretamente relacionada ao posicionamento correto dos conectores tipo pino. As análises experimentais e as formulações desenvolvidas pressupõem que as chapas metálicas das extremidades dos conectores devem estar o mais próximo possível das faces superior e inferior da laje, praticamente envolvendo as armaduras de flexão (Figura 2.28). Isso é necessário para se evitar a possibilidade de que as fissuras passem ou por cima ou por baixo dessas armaduras, o que faria com que a resistência prevista não fosse atingida.

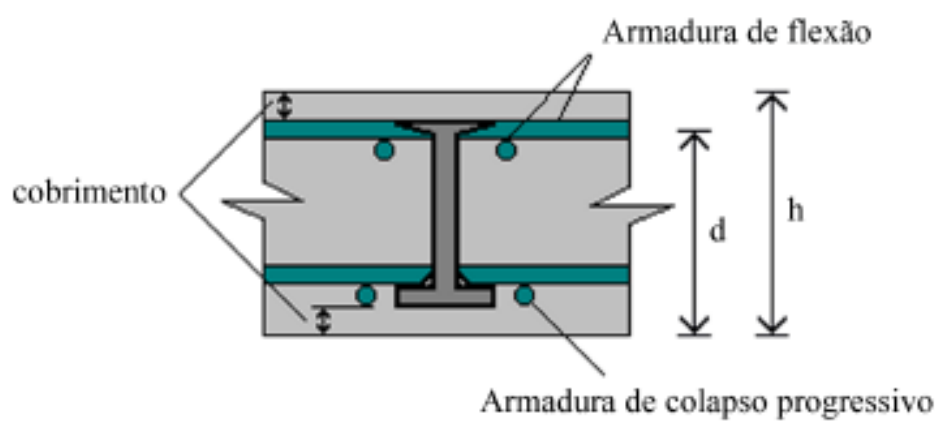

Figura 2.28 - Posicionamento do conector em corte

Alguns trabalhos, como o de GOMES \& ANDRADE (2000), vêm estudando a possibilidade de posicionar os conectores sobre a armadura de flexão inferior e abaixo da superior, o que facilitaria significativamente a execução. Apesar dos resultados ainda não serem conclusivos, certamente a contribuição da armadura será inferior à do caso da Figura 2.28, sendo necessárias algumas adaptações no cálculo das tensões resistentes.

Assim sendo, considera-se importante explicitar o posicionamento dos conectores ao qual a formulação da NBR 6118 (2000) está relacionada. Propõe-se acrescentar um comentário na descrição de $\mathbf{A}_{\mathbf{s w}}$ no item 19.4.4.3.

- Sugestão de redação:

“... Cada uma dessas extremidades deve estar ancorada fora do plano da armadura de flexão correspondente e o mais próximo possível das faces externas da laje, respeitandose o cobrimento".

Pode-se também adicionar a Figura 2.28 ao comentário do item 19.4.4.3 no anexo A19, como figura A.18. 


\subsubsection{ESPAÇAMENTO MÍNIMO ENTRE A ARMADURA E A FACE DO PILAR}

Distâncias muito pequenas entre a primeira linha de armaduras e a face do pilar não permitem uma boa ancoragem dos conectores na zona comprimida, uma vez que eles podem ser atravessados por fissuras de pequena inclinação. DILGER \& GHALI (1981) já propunham a introdução de um limite mínimo para esse espaçamento, sugerindo 0,25d. Mas REGAN (1999), com base em resultados experimentais, sugere um valor um pouco maior, $0,3 \mathbf{d}$.

Recomenda-se que seja analisada a adoção deste último limite na versão definitiva da NBR 6118, evitando a possibilidade da primeira linha de conectores tornar-se menos efetiva na absorção das tensões cisalhantes. Uma pequena alteração na figura 46 poderia ser feita, com o objetivo de indicar esse espaçamento mínimo de $0,3 \mathbf{d}$ entre a face do pilar e a primeira linha de armaduras (Figura 2.29).

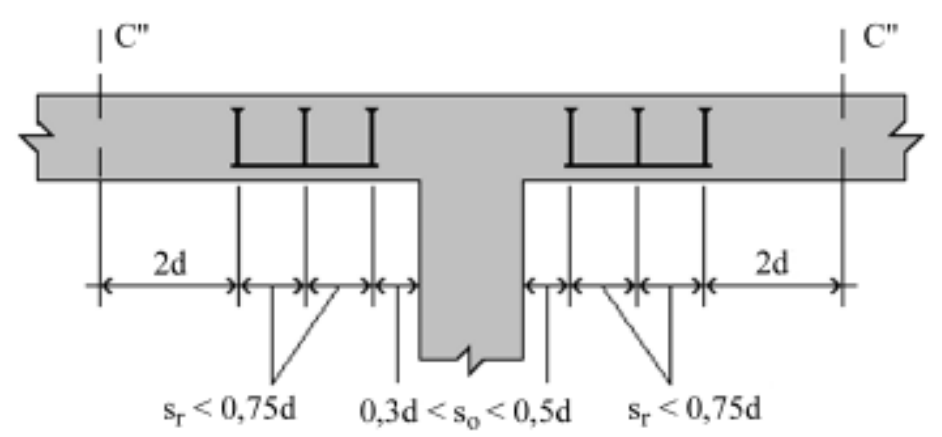

Figura 2.29 - Disposição da armadura de punção em corte (figura 46 da NBR 6118/2000)

\subsubsection{UNIDADES}

Nas expressões para o cálculo das tensões solicitantes, podem ser utilizadas unidades de força e de comprimento quaisquer, desde que coerentes. No caso das tensões resistentes, entretanto, as expressões requerem resistências característica e de cálculo do concreto à compressão em MPa.

Para se evitarem equívocos nos cálculos destas tensões, propõe-se que seja explicitada a unidade da resistência do concreto a ser utilizada, a partir das seguintes complementações. 
- Sugestões de redação:

- $\quad$ item 19.4.4.1

" $f_{\underline{c k}} \underline{e}$ a resistência característica do concreto à compressão, em MPa

$f_{c d}$ é a resistência de cálculo do concreto à compressão, em $\mathrm{MPa}$ "

- $\quad$ item 19.4.4.2

"onde:

$f_{\text {ck_em }}$ emPa"

- item 19.4.4.3

"onde:

$f_{\text {ck }}$ em MPa"

\subsubsection{NOTAÇÃO}

Para facilitar o entendimento da verificação da punção, evitar possíveis confusões de notação e contemplar algumas sugestões deste trabalho, propõe-se introduzir alguns novos símbolos no item 19.4 - Dimensionamento de lajes à punção. São eles:

$$
\begin{array}{ll}
\mathbf{e}_{\mathbf{0}}^{*} & \text { - excentricidade do perímetro crítico reduzido no contorno } \mathbf{C} \\
\mathbf{e}^{\prime *} & \text { - excentricidade do perímetro crítico reduzido no contorno } \mathbf{C} " \\
\mathbf{u}_{\mathbf{0}}^{*} & \text { - perímetro crítico reduzido do contorno } \mathbf{C} \\
\mathbf{u} * & \text { - perímetro crítico reduzido do contorno } \mathbf{C} " \\
\mathbf{W}_{\mathbf{p o}}, \mathbf{W}_{\mathbf{p} 1, \mathbf{o}}, \mathbf{W}_{\mathbf{p} 2, \mathbf{o}} & \text { - módulos de resistência plástica do perímetro crítico } \mathbf{u}_{\mathbf{o}} \\
\mathbf{W}_{\mathbf{p}}, \mathbf{W}_{\mathbf{p} 1}, \mathbf{W}_{\mathbf{p} 2}, & \text { - módulos de resistência plástica do perímetro crítico } \mathbf{u}, \\
\beta & \text { - coeficiente para consideração do efeito da excentricidade } \\
\eta_{\mathbf{w p}} & \text { - coeficiente para correção do } \mathbf{W}_{\mathbf{p}}, \text { em função da situação de cálculo } \\
\eta_{\mathbf{e} 1}, \eta_{\mathbf{e} 2} & \text { - coeficientes para correção de } \mathbf{e}^{*} \text { em função do contorno estudado }
\end{array}
$$

Além disso, alguns símbolos já utilizados na verificação da punção não são mencionados no Capítulo 4 - Simbologia, e devem ser inseridos. São eles: 
- $\quad$ item 4.1

$\begin{array}{ll}\mathbf{c}_{1}, \mathbf{c}_{2} & \text { - dimensões do pilar } \\ \mathbf{e}^{*} & \text { - excentricidade do perímetro crítico reduzido no contorno } \mathbf{C}, \\ \mathbf{u}^{\prime} & \text { - perímetro crítico do contorno } \mathbf{C},\end{array}$

- $\quad$ item 4.2

C" - contorno crítico a $2 \boldsymbol{d}$ da região armada

$\mathbf{W}_{\mathbf{p} 1}, \mathbf{W}_{\mathbf{p} 2} \quad$ - módulos de resistência plástica do perímetro crítico $\mathbf{u}$

- $\quad$ item 4.3

$\alpha_{\mathrm{v}} \quad$ - coeficiente de efetividade do concreto

$\tau_{\mathbf{R d} 3} \quad-$ tensão resistente de cálculo do concreto a $2 \mathbf{d}$ da face do pilar (lajes com armadura de punção)

\subsection{EXEMPLO DE CÁLCULO}

Para exemplificar a utilização dos critérios para a verificação da punção, foram estudadas as regiões dos pilares P1, P5 e P6, indicados na Figura 2.30. Este pavimento foi adaptado de GUARDA (1995).

\subsubsection{CÁLCULO DOS ESFORÇOS}

Os esforços foram obtidos a partir da resolução da placa por elementos finitos, utilizando o programa SAP 90.

As reações dos pilares são apresentadas na Tabela 2.11.

Tabela 2.11 - Reações dos pilares

\begin{tabular}{|c|c|c|c|c|}
\hline \multirow{2}{*}{ Pilar } & \multirow{2}{*}{$\begin{array}{c}\text { Dimensões } \\
(\mathrm{cm} x \mathrm{~cm})\end{array}$} & \multicolumn{3}{|c|}{ Esforço } \\
\hline & & $N(k N)$ & $M_{x}(k N . c m)$ & $M_{y}(k N . c m)$ \\
\hline$P 1$ & $30 \times 30$ & 77 & 4344 & 1850 \\
\hline$P 5$ & $40 \times 30$ & 178 & 8536 & 2049 \\
\hline P6 & $30 \times 40$ & 329 & 1313 & 3002 \\
\hline
\end{tabular}




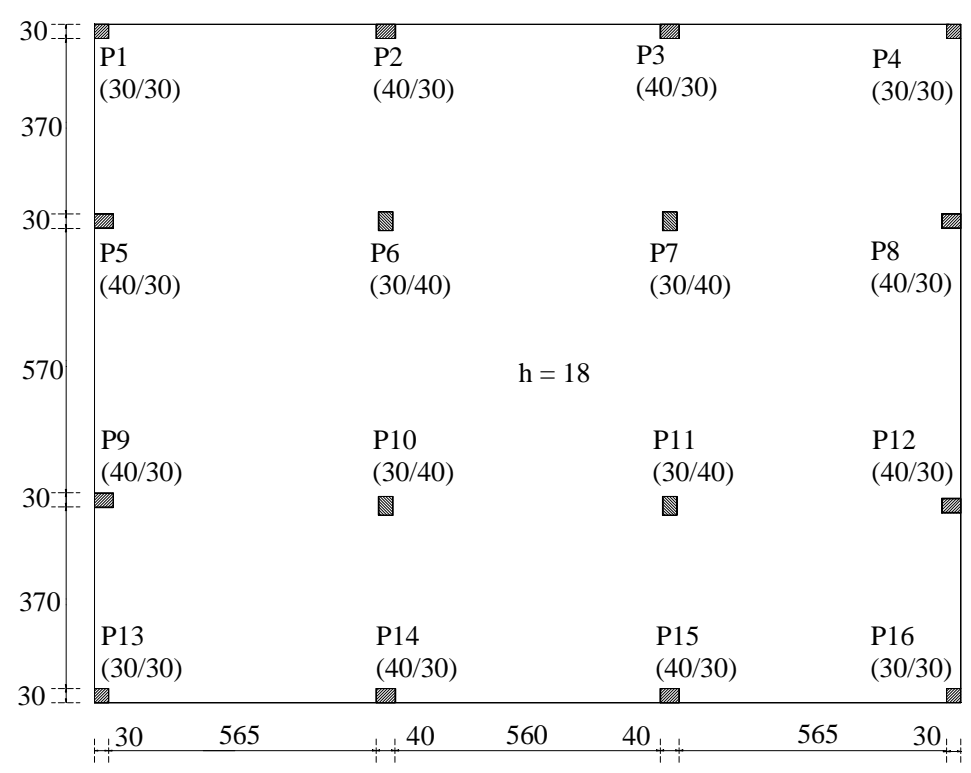

Figura 2.30 - Forma do pavimento do exemplo (dimensões em centímetros)

\subsubsection{ESTUDO DA LAJE}

O dimensionamento e o detalhamento da laje foram realizados de acordo com as recomendações da NBR 6118 (2000). Adotaram-se os seguintes valores:

$$
\begin{aligned}
& \mathrm{f}_{\mathrm{cd}}=\frac{30}{1,4}=21,43 \mathrm{MPa} \\
& \mathrm{c}=2,0 \mathrm{~cm} \\
& \mathrm{~d}_{\mathrm{x}}=18-2-0,5 \cdot 1,25=15,375 \mathrm{~cm} \\
& \mathrm{~d}_{\mathrm{y}}=18-2-1,5 \cdot 1,25=14,125 \mathrm{~cm} \\
& \mathrm{~d}=\frac{\mathrm{d}_{\mathrm{x}}+\mathrm{d}_{\mathrm{y}}}{2}=14,75 \mathrm{~cm}
\end{aligned}
$$

Os detalhamentos das armaduras positivas e negativas estão indicados na Figura 2.31 e na Figura 2.32, respectivamente. Nos dois casos, foi utilizada a simetria do pavimento.

Com esses detalhamentos e com os esforços nos pilares, pode-se iniciar a verificação da punção. 


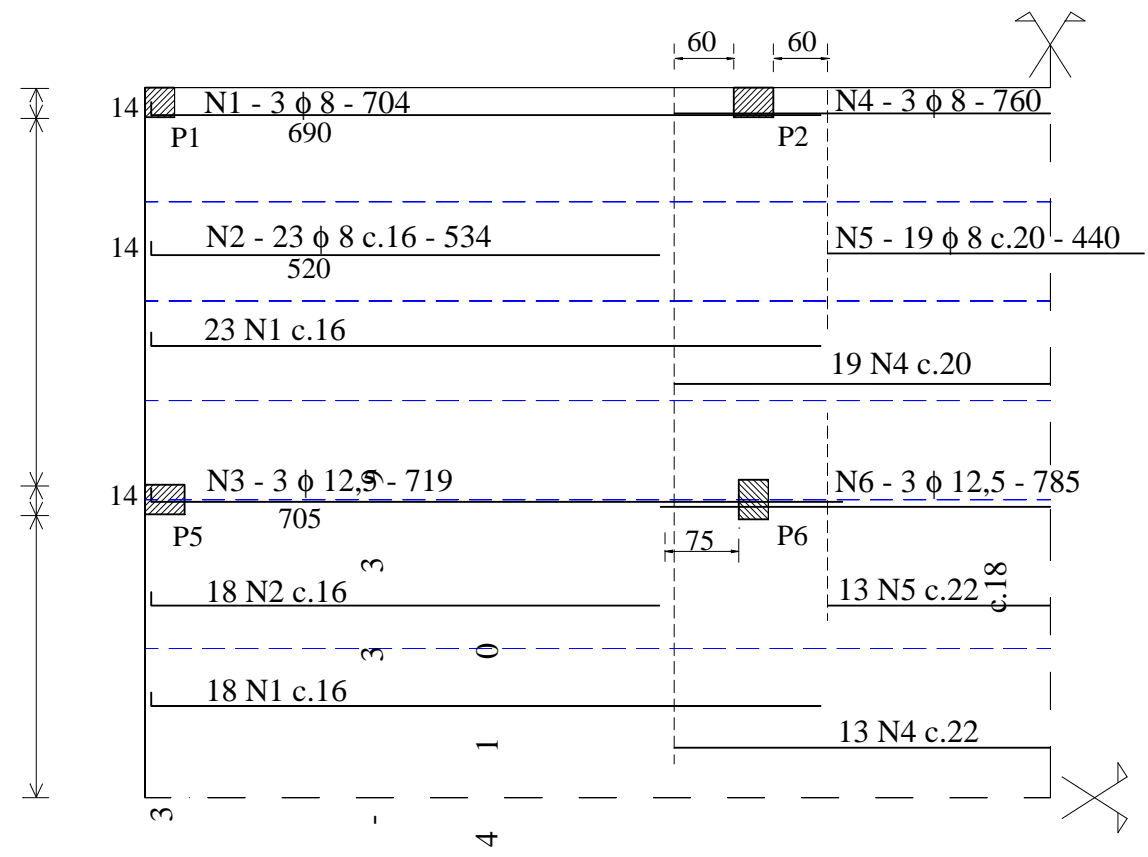

(a) direção $X$

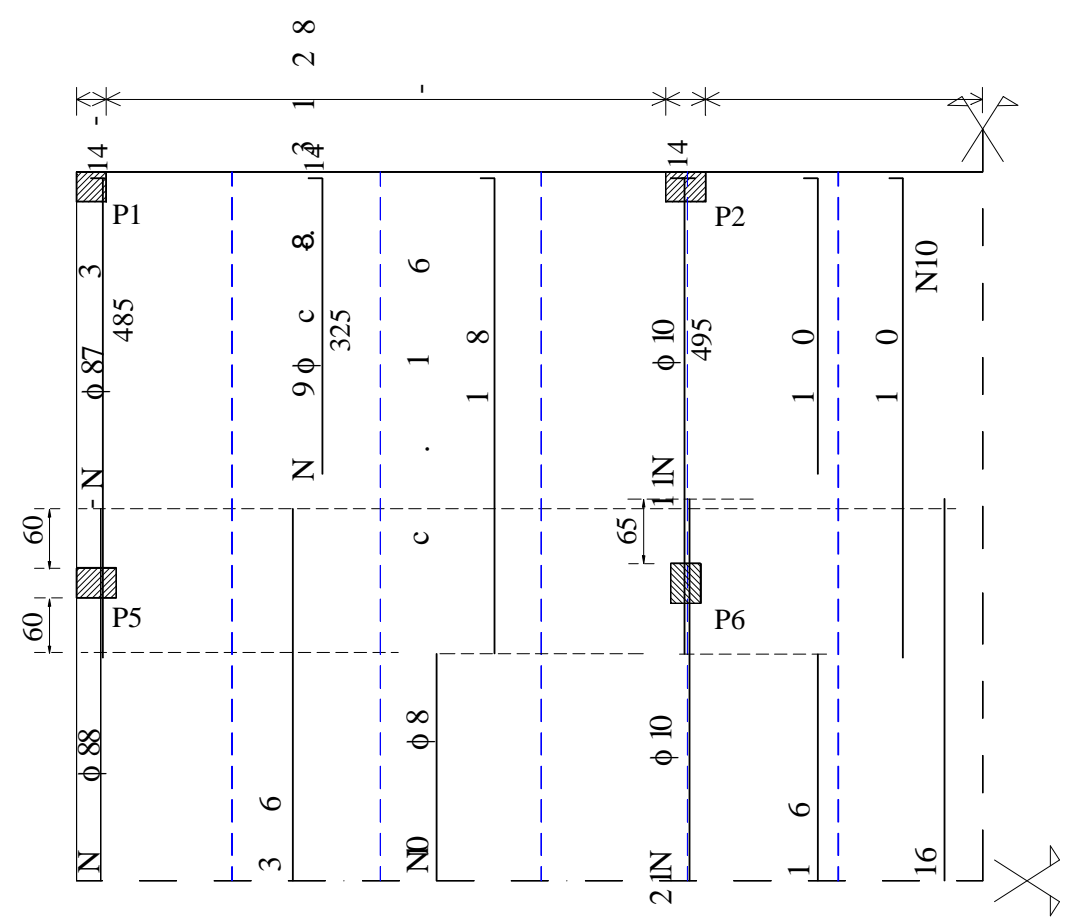

(b) direção Y

Figura 2.31 - Detalhamento da armação positiva 


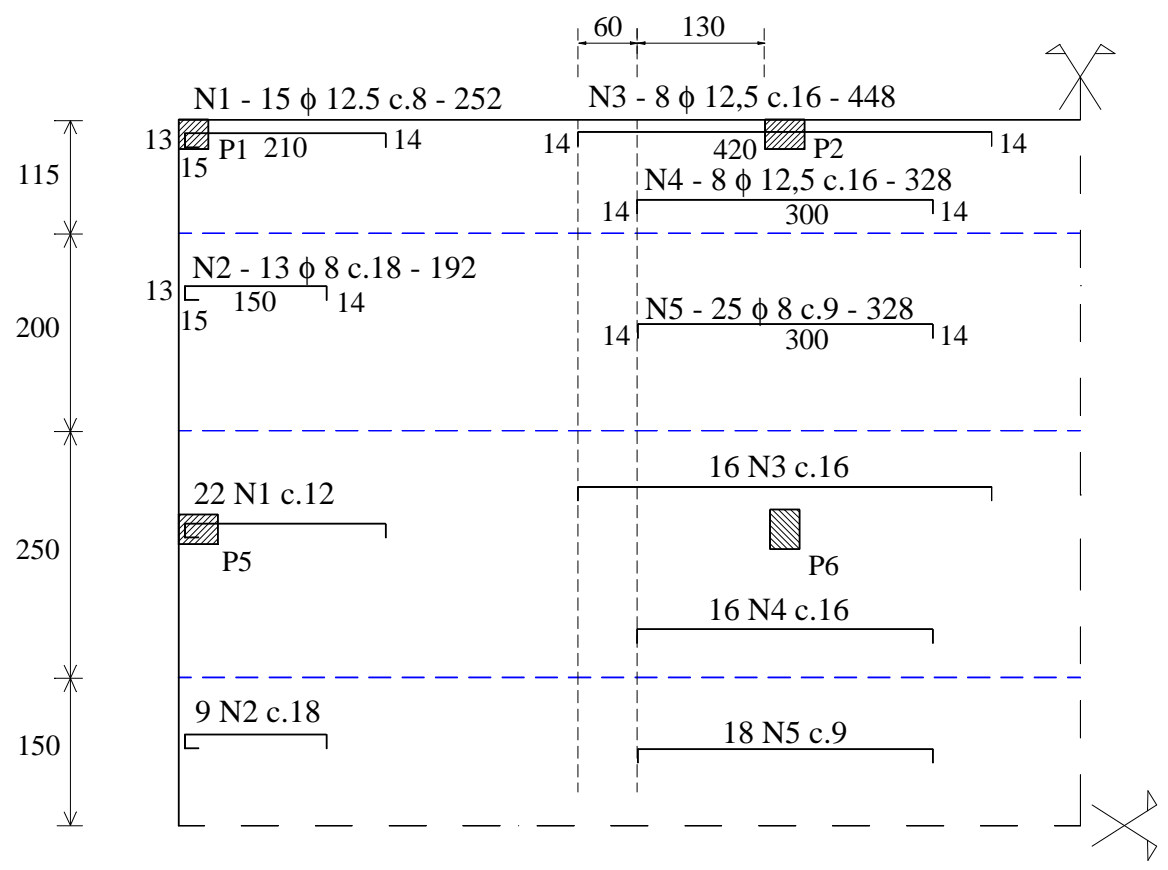

(a) direção $X$

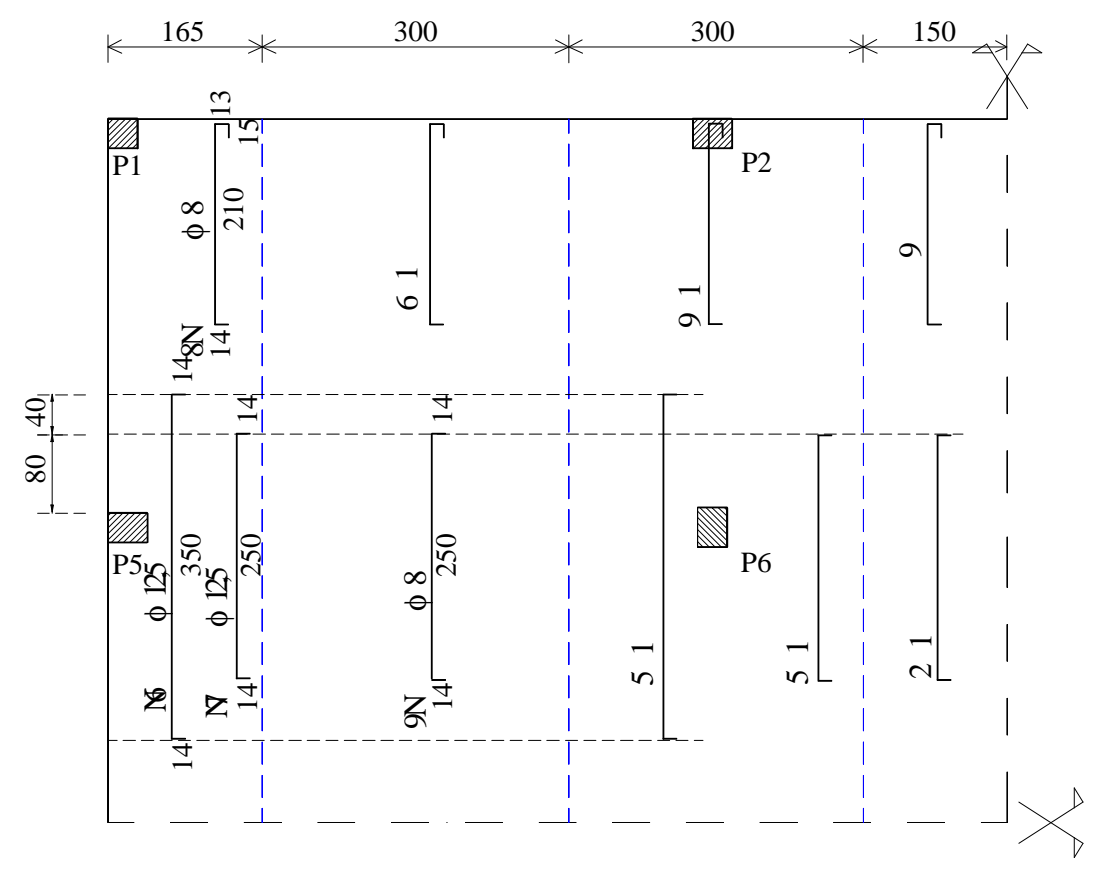

(b) direção Y

Figura 2.32 - Detalhamento da armação negativa 


\subsubsection{PILAR P6 (PILAR INTERNO)}

$$
\begin{aligned}
& \mathrm{F}_{\mathrm{Sd}}=1,4 \cdot 329=461 \mathrm{kN} \\
& \mathrm{M}_{\mathrm{Sd} 1}=1,4 \cdot 1313=1838 \mathrm{kN} \cdot \mathrm{cm} \\
& \mathrm{M}_{\mathrm{Sd} 2}=1,4 \cdot 3002=4203 \mathrm{kN} \cdot \mathrm{cm}
\end{aligned}
$$

\section{a) Verificação do contorno $C$}

Tensão resistente (eq.2.1):

$$
\tau_{\mathrm{Rd} 2}=0,27 \cdot\left(1-\frac{30}{250}\right) \cdot 21,43=5,09 \mathrm{MPa}
$$

$\underline{\text { Tensão resistente (eq.2.16 - sugestão): }}$

$$
\tau_{\mathrm{Rd} 2}=0,32 \cdot\left(1-\frac{30}{250}\right) \cdot 21,43=6,03 \mathrm{MPa}
$$

$\underline{\text { Tensão solicitante (eq.2.7): }}$

Pela Tabela 2.1:

$$
\begin{aligned}
& \mathrm{u}_{\mathrm{o}}=2 \cdot(30+40)=140 \mathrm{~cm} \\
& \mathrm{u}=2 \cdot(30+40)+4 \cdot \pi \cdot 14,75=325 \mathrm{~cm}
\end{aligned}
$$

Pela Tabela 2.2:

$$
\begin{array}{lll}
\frac{\mathrm{c}_{1}}{\mathrm{c}_{2}}=\frac{30}{40}=0,75 & \frac{1-0,5}{0,6-0,45}=\frac{1-0,75}{0,6-\mathrm{K}_{1}} \Rightarrow \mathrm{K}_{1}=0,525 \\
\frac{\mathrm{c}_{1}}{\mathrm{c}_{2}}=\frac{40}{30}=1,33 & \frac{2-1}{0,7-0,6}=\frac{2-1,33}{0,7-\mathrm{K}_{2}} \Rightarrow \mathrm{K}_{2}=0,633
\end{array}
$$

Pela eq.(2.6):

$$
\begin{aligned}
& \mathrm{W}_{\mathrm{p} 1}=\frac{30^{2}}{2}+30 \cdot 40+4 \cdot 40 \cdot 14,75+16 \cdot 14,75^{2}+2 \cdot \pi \cdot 14,75 \cdot 30 \\
& \mathrm{~W}_{\mathrm{p} 1}=10271 \mathrm{~cm}^{2} \\
& \mathrm{~W}_{\mathrm{p} 2}=\frac{40^{2}}{2}+40 \cdot 30+4 \cdot 30 \cdot 14,75+16 \cdot 14,75^{2}+2 \cdot \pi \cdot 14,75 \cdot 40 \\
& \mathrm{~W}_{\mathrm{p} 2}=10958 \mathrm{~cm}^{2}
\end{aligned}
$$


Pela eq.(2.20) - sugestão:

$$
\begin{aligned}
& \mathrm{W}_{\mathrm{p} 1, \mathrm{o}}=\frac{140}{325} \cdot 10271=4424 \mathrm{~cm}^{2} \\
& \mathrm{~W}_{\mathrm{p} 2, \mathrm{o}}=\frac{140}{325} \cdot 10958=4720 \mathrm{~cm}^{2}
\end{aligned}
$$

Assim,

$$
\begin{aligned}
\tau_{\mathrm{Sd}} & =\frac{461}{140 \cdot 14,75}+\frac{0,525 \cdot 1838}{4424 \cdot 14,75}+\frac{0,633 \cdot 4203}{4720 \cdot 14,75}=0,223+0,015+0,038 \\
\tau_{\mathrm{Sd}} & =0,276 \frac{\mathrm{kN}}{\mathrm{cm}^{2}}=2,76 \mathrm{MPa}
\end{aligned}
$$

Tensão solicitante (eq.2.24 - sugestão):

$$
\begin{aligned}
& \tau_{\mathrm{Sd}}=\frac{461}{140 \cdot 14,75}+\sqrt{\left(\frac{0,525 \cdot 1838}{4424 \cdot 14,75}\right)^{2}+\left(\frac{0,633 \cdot 4203}{4720 \cdot 14,75}\right)^{2}} \\
& \tau_{\mathrm{Sd}}=0,223+\sqrt{0,015^{2}+0,038^{2}}=0,264 \frac{\mathrm{kN}}{\mathrm{cm}^{2}}=2,64 \mathrm{MPa}
\end{aligned}
$$

\section{$\underline{\text { Tensão solicitante (eq.2.27 - sugestão): }}$}

Pela Tabela 2.10, $\beta=1,2$.

Assim:

$$
\tau_{\mathrm{Sd}}=1,2 \cdot \frac{461}{140 \cdot 14,75}=0,268 \frac{\mathrm{kN}}{\mathrm{cm}^{2}}=2,68 \mathrm{MPa}
$$

De qualquer forma,

$$
\tau_{\mathrm{Rd} 2} \geq \tau_{\mathrm{Sd}} \quad \Rightarrow \quad \mathrm{OK}
$$

Observa-se que quando são utilizadas as expressões sugeridas, eq.(2.16) e eq.(2.24), ao invés das expressões da NBR 6118 (2000), eq.(2.1) e eq.(2.7), a verificação é satisfeita com mais "folga". Nota-se também que o método simplificado para o cálculo de $\tau_{\mathbf{S d}}$ conduziu a um bom resultado, apesar de sua grande simplificação em relação à eq.(2.7) e à eq.(2.24). 


\section{b) Verificação do contorno C'}

Tensão resistente (eq.2.2):

De acordo com a Figura 2.9 e com a Figura 2.32, tem-se:

$$
\begin{array}{r}
\rho_{x}=\frac{16 \cdot 1,23}{15,375 \cdot(2 \cdot 3 \cdot 14,75+40)}=0,00996 \\
\rho_{y}=\frac{10 \cdot 1,23}{14,125 \cdot(2 \cdot 3 \cdot 14,75+30)}=0,00735 \\
\rho=\sqrt{\rho_{x} \cdot \rho_{y}}=\sqrt{0,00996 \cdot 0,00735}=0,00856
\end{array}
$$

Assim,

$$
\tau_{\mathrm{Rd} 1}=0,13 \cdot\left(1+\sqrt{\frac{20}{14,75}}\right) \cdot(100 \cdot 0,00856 \cdot 30)^{1 / 3}=0,83 \mathrm{MPa}
$$

\section{Tensão solicitante (eq.2.7):}

$$
\begin{aligned}
& \tau_{\mathrm{Sd}}=\frac{461}{325 \cdot 14,75}+\frac{0,525 \cdot 1838}{10271 \cdot 14,75}+\frac{0,633 \cdot 4203}{10958 \cdot 14,75}=0,096+0,006+0,016 \\
& \tau_{\mathrm{Sd}}=0,118 \frac{\mathrm{kN}}{\mathrm{cm}^{2}}=1,18 \mathrm{MPa} \\
& \tau_{\mathrm{Rd} 1} \leq \tau_{\mathrm{Sd}} \quad \Rightarrow \quad \text { é necessária armadura de punção }
\end{aligned}
$$

Serão utilizados conectores tipo pino, aço CA-50. Sendo $18 \mathrm{~cm}$ a espessura da laje, tem-se:

$$
\frac{435-300}{35-15}=\frac{435-\mathrm{f}_{\mathrm{ywd}}}{35-18} \Rightarrow \mathrm{f}_{\mathrm{ywd}}=320,25 \mathrm{MPa}
$$

A área de aço necessária é obtida igualando-se a tensão solicitante à eq.(2.3).

$$
\begin{aligned}
1,18 & =0,10 \cdot\left(1+\sqrt{\frac{20}{14,75}}\right) \cdot(100 \cdot 0,00856 \cdot 30)^{1 / 3}+1,5 \cdot \frac{14,75}{\mathrm{~s}_{\mathrm{r}}} \cdot \frac{\mathrm{A}_{\mathrm{sw}} \cdot 320,25 \cdot 1}{325 \cdot 14,75} \\
\frac{\mathrm{A}_{\mathrm{sw}}}{\mathrm{s}_{\mathrm{r}}} & =0,366 \frac{\mathrm{cm}^{2}}{\mathrm{~cm}}
\end{aligned}
$$

Adotando-se 16 conectores $\phi 6,3$ em cada linha e $s_{r}=10 \mathrm{~cm}$, tem-se:

$$
\begin{aligned}
& \mathrm{A}_{\mathrm{sw}}=16 \cdot 0,32=5,12 \mathrm{~cm}^{2} \\
& \frac{\mathrm{A}_{\mathrm{sW}}}{\mathrm{s}_{\mathrm{r}}}=\frac{5,12}{10}=0,512 \frac{\mathrm{cm}^{2}}{\mathrm{~cm}} \geq 0,366 \frac{\mathrm{cm}^{2}}{\mathrm{~cm}} \Rightarrow \mathrm{OK}
\end{aligned}
$$


Assim, utilizando-se quatro linhas de conectores e respeitando-se os espaçamentos mínimos, o arranjo será como o da Figura 2.33.

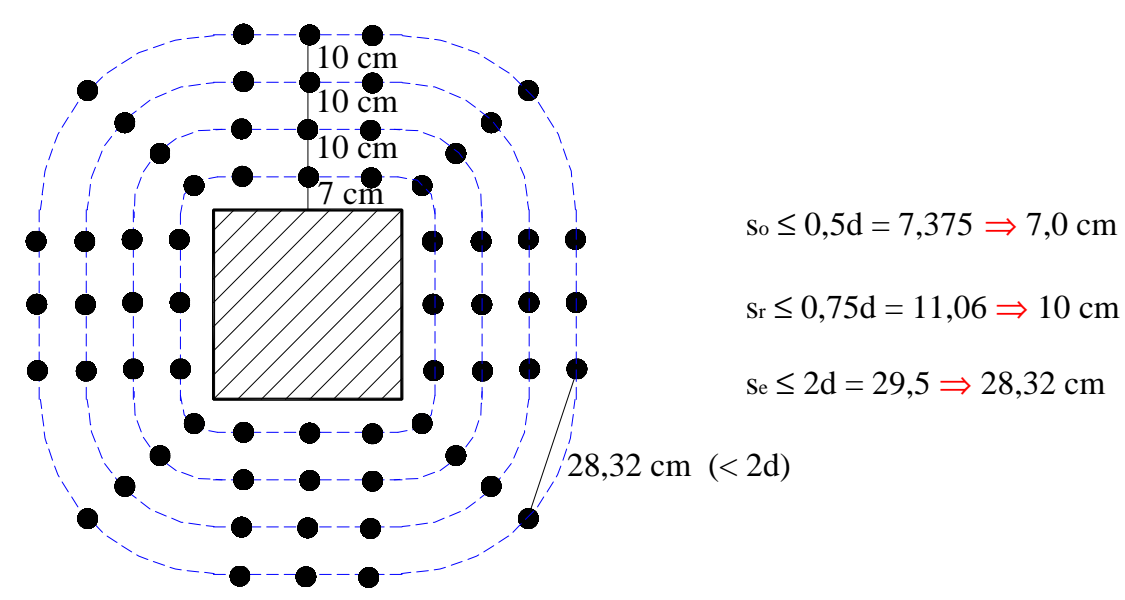

Figura 2.33 - Arranjo dos conectores tipo pino para o pilar P6

$\underline{\text { Tensão solicitante (eq.2.24 - sugestão): }}$

$$
\begin{aligned}
& \tau_{\mathrm{Sd}}=\frac{461}{325 \cdot 14,75}+\sqrt{\left(\frac{0,525 \cdot 1838}{10271 \cdot 14,75}\right)^{2}+\left(\frac{0,633 \cdot 4203}{10958 \cdot 14,75}\right)^{2}} \\
& \tau_{\mathrm{Sd}}=0,096+\sqrt{0,006^{2}+0,016^{2}}=0,113 \frac{\mathrm{kN}}{\mathrm{cm}^{2}}=1,13 \mathrm{MPa}
\end{aligned}
$$

Mesmo se utilizando esta expressão, a armadura de punção não pode ser dispensada. Entretanto, a área de aço necessária, obtida a partir da eq.(2.3), é menor que a calculada no item anterior $\left(\frac{\mathrm{A}_{\mathrm{sw}}}{\mathrm{s}_{\mathrm{r}}}=0,332 \frac{\mathrm{cm}^{2}}{\mathrm{~cm}}\right)$.

Tensão solicitante (eq.2.27 - sugestão):

Pela Tabela 2.10, $\beta=1,2$.

Assim:

$$
\tau_{\mathrm{Sd}}=1,2 \cdot \frac{461}{325 \cdot 14,75}=0,115 \frac{\mathrm{kN}}{\mathrm{cm}^{2}}=1,15 \mathrm{MPa}
$$

Observa-se que o método simplificado para o cálculo de $\tau_{\mathbf{S d}}$ forneceu novamente um resultado próximo daqueles obtidos com a eq.(2.7) e com a eq.(2.24). Nota-se também que foram respeitados os limites $\rho \leq 0,02$ e $s_{o} \geq 0,3 \mathrm{~d}=4,43 \mathrm{~cm}$, propostos neste trabalho. 


\section{c) Verificação do contorno C"}

Tensão resistente (eq.2.2):

$$
\tau_{\mathrm{Rd} 1}=0,83 \mathrm{MPa} \quad \text { (como calculado no item 2.10.3.b) }
$$

\section{Tensão solicitante (eq.2.7):}

Como $\mathrm{s}_{\mathrm{e}} \leq 2 \mathrm{~d}$, pela Tabela 2.1:

$$
\mathrm{u}^{\prime}=2 \cdot(30+40)+4 \cdot \pi \cdot 14,75+2 \cdot \pi \cdot 37=558 \mathrm{~cm}
$$

Pela eq.(2.22) - sugestão, tomando-se $\eta_{\mathrm{wp}}=1,6$ para $\mathbf{W}_{\mathbf{p} 1}$, e $\eta_{\mathrm{wp}}=1,3$ para $\mathbf{W}_{\mathbf{p} 2}$, de acordo com a Tabela 2.6:

$$
\begin{aligned}
& \mathrm{W}_{\mathrm{p} 1}{ }^{\prime}=1,6 \cdot \frac{558}{325} \cdot 10271=28215 \mathrm{~cm}^{2} \\
& \mathrm{~W}_{\mathrm{p} 2}{ }^{\prime}=1,3 \cdot \frac{558}{325} \cdot 10958=24458 \mathrm{~cm}^{2}
\end{aligned}
$$

Assim,

$$
\begin{aligned}
& \tau_{\mathrm{Sd}}=\frac{461}{558 \cdot 14,75}+\frac{0,525 \cdot 1838}{28215 \cdot 14,75}+\frac{0,633 \cdot 4203}{24458 \cdot 14,75}=0,056+0,002+0,007 \\
& \tau_{\mathrm{Sd}}=0,065 \frac{\mathrm{kN}}{\mathrm{cm}^{2}}=0,65 \mathrm{MPa}
\end{aligned}
$$

Calculando-se os valores de $\mathbf{W}_{\mathbf{p 1}}$ ' e de $\mathbf{W}_{\mathbf{p} \mathbf{2}}$ ' a partir da expressão indicada na Tabela 2.5, têm-se:

$$
\begin{aligned}
& \begin{array}{l}
\mathrm{W}_{\mathrm{p} 1}{ }^{\prime}=\frac{30^{2}}{2}+30 \cdot 40+4 \cdot 40 \cdot 14,75+16 \cdot 14,75^{2}+2 \cdot \pi \cdot 14,75 \cdot 30+ \\
\quad+2 \cdot 40 \cdot 37+16 \cdot 14,75 \cdot 37+4 \cdot 37^{2}+\pi \cdot 30 \cdot 37
\end{array} \\
& \begin{aligned}
& \mathrm{W}_{\mathrm{p} 1}{ }^{\prime}=30926 \mathrm{~cm}^{2} \\
& \mathrm{~W}_{\mathrm{p} 2}{ }^{\prime}=\frac{40^{2}}{2}+40 \cdot 30+4 \cdot 30 \cdot 14,75+16 \cdot 14,75^{2}+2 \cdot \pi \cdot 14,75 \cdot 40+ \\
& \quad+2 \cdot 30 \cdot 37+16 \cdot 14,75 \cdot 37+4 \cdot 37^{2}+\pi \cdot 40 \cdot 37
\end{aligned} \\
& \mathrm{~W}_{\mathrm{p} 2}{ }^{\prime}=32036 \mathrm{~cm}^{2}
\end{aligned}
$$


E assim:

$$
\begin{aligned}
\tau_{\mathrm{Sd}} & =\frac{461}{558 \cdot 14,75}+\frac{0,525 \cdot 1838}{30926 \cdot 14,75}+\frac{0,633 \cdot 4203}{32036 \cdot 14,75}=0,056+0,002+0,006 \\
\tau_{\mathrm{Sd}} & =0,064 \frac{\mathrm{kN}}{\mathrm{cm}^{2}}=0,64 \mathrm{MPa}
\end{aligned}
$$

\section{Tensão solicitante (eq.2.24 - sugestão):}

Considerando-se os valores de $\mathbf{W}_{\mathbf{p 1}}$ ' e $\mathbf{W}_{\mathbf{p 2}}$ ' calculados pela eq.(2.22) - sugestão:

$$
\begin{aligned}
& \tau_{\mathrm{Sd}}=\frac{461}{558 \cdot 14,75}+\sqrt{\left(\frac{0,525 \cdot 1838}{28215 \cdot 14,75}\right)^{2}+\left(\frac{0,633 \cdot 4203}{24458 \cdot 14,75}\right)^{2}} \\
& \tau_{\mathrm{Sd}}=0,056+\sqrt{0,002^{2}+0,007^{2}}=0,063 \frac{\mathrm{kN}}{\mathrm{cm}^{2}}=0,63 \mathrm{MPa}
\end{aligned}
$$

Com o uso da expressão da Tabela 2.5:

$$
\begin{aligned}
& \tau_{\mathrm{Sd}}=\frac{461}{558 \cdot 14,75}+\sqrt{\left(\frac{0,525 \cdot 1838}{30926 \cdot 14,75}\right)^{2}+\left(\frac{0,633 \cdot 4203}{32036 \cdot 14,75}\right)^{2}} \\
& \tau_{\mathrm{Sd}}=0,056+\sqrt{0,002^{2}+0,006^{2}}=0,062 \frac{\mathrm{kN}}{\mathrm{cm}^{2}}=0,62 \mathrm{MPa}
\end{aligned}
$$

\section{Tensão solicitante (eq.2.27 - sugestão):}

Pela Tabela 2.10, $\beta=1,1$.

Assim:

$$
\tau_{\mathrm{Sd}}=1,1 \cdot \frac{461}{558 \cdot 14,75}=0,062 \frac{\mathrm{kN}}{\mathrm{cm}^{2}}=0,62 \mathrm{MPa}
$$

De qualquer forma,

$$
\tau_{\mathrm{Rd} 1} \geq \tau_{\mathrm{Sd}} \quad \Rightarrow \quad \mathrm{OK}
$$

Observa-se que os valores de $\mathbf{W}_{\mathbf{p} 1}$ ' e de $\mathbf{W}_{\mathbf{p} 2}$ ' obtidos pela eq.(2.22), apesar de conservadores, não são distantes daqueles calculados a partir da Tabela 2.5 e são muito mais facilmente calculados. O importante, entretanto, é que as tensões solicitantes obtidas nos dois casos são bastante parecidas. Acredita-se que a boa aproximação dos resultados justifica o uso do método simplificado, o mesmo ocorrendo para o cálculo de $\tau_{\text {sd }}$ pela eq.(2.27), que forneceu um bom resultado em relação àqueles obtidos tanto com a eq.(2.7) quanto com a eq.(2.24). 
d) Verificação do colapso progressivo

$$
\begin{gathered}
A_{\mathrm{s}}=6 \cdot 0,8+6 \cdot 1,23=12,18 \mathrm{~cm}^{2} \\
\mathrm{~A}_{\mathrm{s}} \cdot \mathrm{f}_{\mathrm{yd}}=12,18 \cdot \frac{50}{1,15}=530 \mathrm{kN} \\
\mathrm{A}_{\mathrm{s}} \cdot \mathrm{f}_{\mathrm{yd}} \geq \mathrm{F}_{\mathrm{Sd}} \Rightarrow 530 \geq 461 \quad \Rightarrow \quad \mathrm{OK}
\end{gathered}
$$

\subsubsection{PILAR P5 (PILAR DE BORDA)}

$$
\begin{array}{ll}
\mathrm{F}_{\mathrm{Sd}}=1,4 \cdot 178=249 \mathrm{kN} \\
\mathrm{M}_{\mathrm{Sd} 1}=1,4 \cdot 8536=11950 \mathrm{kN} \cdot \mathrm{cm} \\
\mathrm{M}_{\mathrm{Sd} 2}=1,4 \cdot 2049=2869 \mathrm{kN} \cdot \mathrm{cm} \\
\mathrm{M}_{\mathrm{Sd} 1}=\mathrm{M}_{\mathrm{Sdx}} & \text { (perpendicular à borda livre) } \\
\mathrm{M}_{\mathrm{Sd} 2}=\mathrm{M}_{\mathrm{Sdy}} & \text { (paralelo à borda livre) } \\
\mathrm{c}_{1}=40 \mathrm{~cm} & \text { (perpendicular à borda livre) } \\
\mathrm{c}_{2}=30 \mathrm{~cm} & \text { (paralelo à borda livre) }
\end{array}
$$

\section{a) Verificação do contorno $\mathrm{C}$}

Tensão resistente (eq.2.1):

$$
\tau_{\mathrm{Rd} 2}=5,09 \mathrm{MPa}
$$

Tensão resistente (eq.2.16 - sugestão):

$$
\tau_{\mathrm{Rd} 2}=6,03 \mathrm{MPa}
$$

Tensão solicitante (eq.2.11):

$$
\mathrm{a} \leq\left\{\begin{array}{l}
1,5 \cdot \mathrm{d}=1,5 \cdot 14,75=22,125 \mathrm{~cm} \\
0,5 \cdot \mathrm{c}_{1}=0,5 \cdot 40=20 \mathrm{~cm}
\end{array} \quad \Rightarrow \mathrm{a}=20 \mathrm{~cm}\right.
$$

Pela Tabela 2.3:

$$
\begin{aligned}
& \mathrm{u}_{\mathrm{o}}^{*}=2 \cdot 20+30=70 \mathrm{~cm} \\
& \mathrm{u}^{*}=2 \cdot 20+30+2 \cdot \pi \cdot 14,75=163 \mathrm{~cm}
\end{aligned}
$$


Pela eq.(2.9):

$$
\begin{aligned}
& \mathrm{e}^{*}=\frac{40 \cdot 20-20^{2}+\frac{40 \cdot 30}{2}+2 \cdot 30 \cdot 14,75+8 \cdot 14,75^{2}+\pi \cdot 14,75 \cdot 40}{2 \cdot 20+30+2 \cdot \pi \cdot 14,75} \\
& \mathrm{e}^{*}=33,68 \mathrm{~cm}
\end{aligned}
$$

Pela eq.(2.25) - sugestão, tomando-se $\eta_{\mathrm{el}}=1,0$, de acordo com a Tabela 2.9:

$$
\mathrm{e}_{\mathrm{o}} * \frac{70}{163} \cdot 33,68=14,46 \mathrm{~cm}
$$

Logo,

$$
\begin{gathered}
\mathrm{M}_{\mathrm{Sd}} *=\mathrm{F}_{\mathrm{Sd}} \cdot \mathrm{e}_{\mathrm{o}}^{*}=249 \cdot 14,46=3600 \mathrm{kN} \cdot \mathrm{cm} \\
\mathrm{M}_{\mathrm{Sd}}=\left(\mathrm{M}_{\mathrm{Sd} 1}-\mathrm{M}_{\mathrm{Sd}} *\right)=(11950-3600)=8350 \mathrm{kN} \cdot \mathrm{cm}
\end{gathered}
$$

Pela Tabela 2.2:

$$
\begin{array}{lll}
\frac{\mathrm{c}_{1}}{\mathrm{c}_{2}}=\frac{40}{30}=1,33 \quad \frac{2-1}{0,7-0,6}=\frac{2-1,33}{0,7-\mathrm{K}_{1}} & \Rightarrow & \mathrm{K}_{1}=0,633 \\
\frac{\mathrm{c}_{2}}{2 \cdot \mathrm{c}_{1}}=\frac{30}{2 \cdot 40}=0,375 \leq 0,5 & \Rightarrow & \mathrm{K}_{2}=0,45
\end{array}
$$

(como sugestão deste trabalho)

Pela eq.(2.10):

$$
\mathrm{W}_{\mathrm{p} 1}=\frac{40^{2}}{2}+\frac{40 \cdot 30}{2}+2 \cdot 30 \cdot 14,75+8 \cdot 14,75^{2}+\pi \cdot 14,75 \cdot 40=5879 \mathrm{~cm}^{2}
$$

Pela eq.(2.12):

$$
\mathrm{W}_{\mathrm{p} 2}=\frac{30^{2}}{4}+40 \cdot 30+4 \cdot 40 \cdot 14,75+8 \cdot 14,75^{2}+\pi \cdot 14,75 \cdot 30=6916 \mathrm{~cm}^{2}
$$

Pela eq.(2.21) - sugestão:

$$
\begin{aligned}
& \mathrm{W}_{\mathrm{p} 1, \mathrm{o}}=\frac{70}{163} \cdot 5879=2525 \mathrm{~cm}^{2} \\
& \mathrm{~W}_{\mathrm{p} 2, \mathrm{o}}=\frac{70}{163} \cdot 6916=2970 \mathrm{~cm}^{2}
\end{aligned}
$$

Assim,

$$
\begin{aligned}
& \tau_{\mathrm{Sd}}=\frac{249}{70 \cdot 14,75}+\frac{0,633 \cdot 8350}{2525 \cdot 14,75}+\frac{0,45 \cdot 2869}{2970 \cdot 14,75}=0,241+0,142+0,029 \\
& \tau_{\mathrm{Sd}}=0,412 \frac{\mathrm{kN}}{\mathrm{cm}^{2}}=4,12 \mathrm{MPa}
\end{aligned}
$$


$\underline{\text { Tensão solicitante (eq.2.27 - sugestão): }}$

Pela Tabela 2.10, $\beta=1,7$.

Assim,

$$
\tau_{\mathrm{Sd}}=1,7 \cdot \frac{249}{70 \cdot 14,75}=0,410 \frac{\mathrm{kN}}{\mathrm{cm}^{2}}=4,10 \mathrm{MPa}
$$

De qualquer forma,

$$
\tau_{\mathrm{Rd} 2} \geq \tau_{\mathrm{Sd}} \quad \Rightarrow \quad \mathrm{OK}
$$

Com o aumento da tensão resistente proporcionado pela eq.(2.16) em relação à eq.(2.1), a verificação é novamente satisfeita com mais folga. Observa-se também que o valor de $\mathbf{e}_{\mathbf{o}}$ * obtido com o uso da eq.(2.25) está bastante próximo daquele obtido a partir da expressão da Tabela 2.7 ,

$$
\mathrm{e}_{\mathrm{o}}^{*}=\frac{40 \cdot 20-20^{2}+\frac{40 \cdot 30}{2}}{2 \cdot 20+30}=14,29 \mathrm{~cm}
$$

sendo, entretanto, muito mais facilmente calculado. $\mathrm{O}$ mesmo ocorre para o cálculo de $\tau_{\mathbf{S d}}$ pela eq.(2.27), cujo resultado se aproxima bastante daquele obtido com a eq.(2.11).

\section{b) Verificação do contorno C'}

Tensão resistente (eq.2.2):

Com base na Figura 2.9 e na Figura 2.32, tem-se:

$$
\begin{array}{r}
\rho_{\mathrm{x}}=\frac{9 \cdot 1,23}{15,375 \cdot(2 \cdot 3 \cdot 14,75+30)}=0,00608 \\
\rho_{\mathrm{y}}=\frac{7 \cdot 1,23}{14,125 \cdot(3 \cdot 14,75+40)}=0,00724 \\
\rho=\sqrt{\rho_{\mathrm{x}} \cdot \rho_{\mathrm{y}}}=\sqrt{0,00608 \cdot 0,00724}=0,00663 \\
\tau_{\mathrm{Rd} 1}=0,13 \cdot\left(1+\sqrt{\frac{20}{14,75}}\right) \cdot(100 \cdot 0,00663 \cdot 30)^{1 / 3}=0,76 \mathrm{MPa}
\end{array}
$$

$\underline{\text { Tensão solicitante (eq.2.11): }}$

$$
\begin{gathered}
\mathrm{M}_{\mathrm{Sd}} *=\mathrm{F}_{\mathrm{Sd}} \cdot \mathrm{e}^{*}=249 \cdot 33,68=8386 \mathrm{kN} \cdot \mathrm{cm} \\
\mathrm{M}_{\mathrm{Sd}}=\left(\mathrm{M}_{\mathrm{Sd} 1}-\mathrm{M}_{\mathrm{Sd}} *\right)=(11950-8386)=3564 \mathrm{kN} \cdot \mathrm{cm}
\end{gathered}
$$


Assim:

$$
\begin{aligned}
& \tau_{\mathrm{Sd}}=\frac{249}{163 \cdot 14,75}+\frac{0,633 \cdot 3564}{5879 \cdot 14,75}+\frac{0,45 \cdot 2869}{6916 \cdot 14,75}=0,104+0,026+0,013 \\
& \tau_{\mathrm{Sd}}=0,143 \frac{\mathrm{kN}}{\mathrm{cm}^{2}}=1,43 \mathrm{MPa} \\
& \tau_{\mathrm{Rd} 1} \leq \tau_{\mathrm{Sd}} \Rightarrow \text { é necessária armadura de punção }
\end{aligned}
$$

Serão utilizados novamente conectores tipo pino, aço CA-50.

A área de aço necessária é obtida igualando-se a tensão solicitante à eq.(2.3).

$$
\begin{aligned}
1,43 & =0,10 \cdot\left(1+\sqrt{\frac{20}{14,75}}\right) \cdot(100 \cdot 0,00663 \cdot 30)^{1 / 3}+1,5 \cdot \frac{14,75}{\mathrm{~s}_{\mathrm{r}}} \cdot \frac{\mathrm{A}_{\mathrm{sw}} \cdot 320,25 \cdot 1}{163 \cdot 14,75} \\
\frac{\mathrm{A}_{\mathrm{sw}}}{\mathrm{s}_{\mathrm{r}}} & =0,286 \frac{\mathrm{cm}^{2}}{\mathrm{~cm}}
\end{aligned}
$$

Adotando-se 9 conectores $\phi 6,3$ efetivos em cada linha e $s_{r}=10 \mathrm{~cm}$, tem-se:

$$
\begin{aligned}
\mathrm{A}_{\mathrm{sw}} & =9 \cdot 0,32=2,88 \mathrm{~cm}^{2} \\
\frac{\mathrm{A}_{\mathrm{sw}}}{\mathrm{s}_{\mathrm{r}}} & =\frac{2,88}{10}=0,288 \frac{\mathrm{cm}^{2}}{\mathrm{~cm}} \geq 0,286 \frac{\mathrm{cm}^{2}}{\mathrm{~cm}} \Rightarrow \mathrm{OK}
\end{aligned}
$$

Assim, utilizando-se quatro linhas de conectores e respeitando-se os espaçamentos mínimos, o arranjo será como o da Figura 2.34.

\section{Tensão solicitante (eq.2.27 - sugestão):}

Pela Tabela 2.10, $\beta=1,4$.

Assim,

$$
\tau_{\mathrm{Sd}}=1,4 \cdot \frac{249}{163 \cdot 14,75}=0,145 \frac{\mathrm{kN}}{\mathrm{cm}^{2}}=1,45 \mathrm{MPa}
$$

Observa-se que o cálculo de $\tau_{\mathbf{S d}}$ pelo método simplificado conduziu novamente a um bom resultado em relação àquele obtido com a eq.(2.11). Nota-se também que, mais uma vez, foram respeitados os limites $\rho \leq 0,02$ e $s_{o} \geq 0,3 \mathrm{~d}=4,43 \mathrm{~cm}$, propostos neste trabalho. 


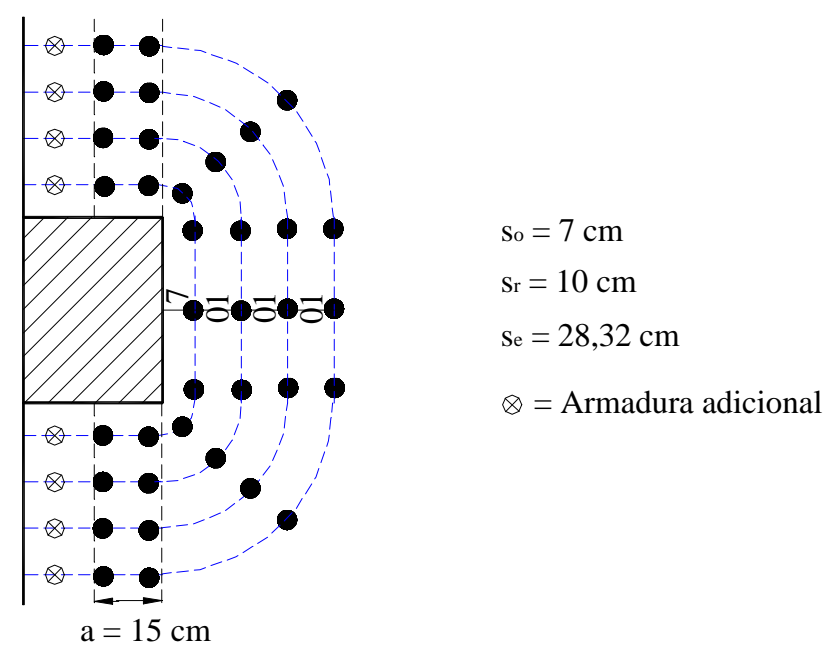

Figura 2.34 - Arranjo dos conectores tipo pino para o pilar P5

\section{c) Verificação do contorno C",}

Tensão resistente (eq.2.2):

$$
\tau_{\mathrm{Rd} 1}=0,76 \mathrm{MPa}
$$

(como calculado no item 2.10.4.b)

Tensão solicitante (eq.2.11):

Como $\mathrm{s}_{\mathrm{e}} \leq 2 \mathrm{~d}$, pela Tabela 2.3:

$$
\mathrm{u}^{\prime *}=2 \cdot 20+30+2 \cdot \pi \cdot 14,75+\pi \cdot 37=279 \mathrm{~cm}
$$

Pela eq.(2.26) - sugestão, tomando-se $\eta_{\mathrm{e} 2}=0,8$, de acordo com a Tabela 2.9:

$$
\mathrm{e}^{\prime *}=0,8 \cdot \frac{279}{163} \cdot 33,68=46,12 \mathrm{~cm}
$$

Logo,

$$
\begin{gathered}
\mathrm{M}_{\mathrm{Sd}} *=\mathrm{F}_{\mathrm{Sd}} \cdot \mathrm{e}^{\prime *}=249 \cdot 46,12=11484 \mathrm{kN} \cdot \mathrm{cm} \\
\mathrm{M}_{\mathrm{Sd}}=\left(\mathrm{M}_{\mathrm{Sd} 1}-\mathrm{M}_{\mathrm{Sd}} *\right)=(11950-11484)=466 \mathrm{kN} \cdot \mathrm{cm}
\end{gathered}
$$

Pela eq.(2.23) - sugestão, tomando-se $\eta_{\mathrm{wp}}=1,1$ para o $\mathbf{W}_{\mathbf{p} 1}$, e $\eta_{\mathrm{wp}}=1,3$ para o $\mathbf{W}_{\mathbf{p} 2}$, de acordo com a Tabela 2.6:

$$
\begin{aligned}
& \mathrm{W}_{\mathrm{p} 1}{ }^{\prime}=1,1 \cdot \frac{279}{163} \cdot 5879=11069 \mathrm{~cm}^{2} \\
& \mathrm{~W}_{\mathrm{p} 2}{ }^{\prime}=1,3 \cdot \frac{279}{163} \cdot 6916=15389 \mathrm{~cm}^{2}
\end{aligned}
$$


Assim,

$$
\begin{aligned}
& \tau_{\mathrm{Sd}}=\frac{249}{279 \cdot 14,75}+\frac{0,633 \cdot 466}{11069 \cdot 14,75}+\frac{0,45 \cdot 2869}{15389 \cdot 14,75}=0,060+0,002+0,005 \\
& \tau_{\mathrm{Sd}}=0,067 \frac{\mathrm{kN}}{\mathrm{cm}^{2}}=0,67 \mathrm{MPa}
\end{aligned}
$$

Calculando-se a excentricidade pela expressão da Tabela 2.7, têm-se:

$$
\begin{aligned}
& \mathrm{e}^{\prime *}=\frac{\left(\begin{array}{l}
40 \cdot 20-20^{2}+\frac{40 \cdot 30}{2}+2 \cdot 30 \cdot 14,75+8 \cdot 14,75^{2}+ \\
+\pi \cdot 14,75 \cdot 40+30 \cdot 37+8 \cdot 14,75 \cdot 37+\frac{\pi \cdot 37 \cdot 40}{2}+2 \cdot 37^{2}
\end{array}\right)}{2 \cdot 20+30+2 \cdot \pi \cdot 14,75+\pi \cdot 37} \\
& \mathrm{e}^{\prime *}=57,43 \mathrm{~cm}
\end{aligned}
$$

Logo:

$$
\begin{aligned}
\mathrm{M}_{\mathrm{Sd}} *=\mathrm{F}_{\mathrm{Sd}} \cdot \mathrm{e}^{\prime *}=249 \cdot 57,43=14300 \mathrm{kN} \cdot \mathrm{cm} \\
\mathrm{M}_{\mathrm{sd}}=\left(\mathrm{M}_{\mathrm{sd} 1}-\mathrm{M}_{\mathrm{sd}} *\right)=(11950-14300)=-2350 \mathrm{kN} \cdot \mathrm{cm} \leq 0 \\
\mathrm{M}_{\mathrm{sd}}=0
\end{aligned}
$$

Calculando-se $\mathbf{W}_{\mathbf{p} 1}$ ' e $\mathbf{W}_{\mathbf{p} 2}$ ' pelas expressões da Tabela 2.5, têm-se:

$$
\begin{aligned}
& \mathrm{W}_{\mathrm{p} 1}{ }^{\prime}=\frac{40^{2}}{2}+\frac{40 \cdot 30}{2}+2 \cdot 30 \cdot 14,75+8 \cdot 14,75^{2}+\pi \cdot 14,75 \cdot 40+ \\
& +30 \cdot 37+8 \cdot 14,75 \cdot 37+\frac{\pi \cdot 37 \cdot 40}{2}+2 \cdot 37^{2} \\
& \mathrm{~W}_{\mathrm{p} 1}{ }^{\prime}=16418 \mathrm{~cm}^{2} \\
& \mathrm{~W}_{\mathrm{p} 2}{ }^{\prime}=\frac{30^{2}}{4}+40 \cdot 30+4 \cdot 40 \cdot 14,75+8 \cdot 14,75^{2}+\pi \cdot 14,75 \cdot 30+ \\
& +2 \cdot 40 \cdot 37+8 \cdot 14,75 \cdot 37+\frac{\pi \cdot 37 \cdot 30}{2}+2 \cdot 37^{2} \\
& \mathrm{~W}_{\mathrm{p} 2}{ }^{\prime}=18723 \mathrm{~cm}^{2}
\end{aligned}
$$

E assim,

$$
\begin{aligned}
\tau_{\mathrm{Sd}} & =\frac{249}{279 \cdot 14,75}+\frac{0,633 \cdot 0}{16418 \cdot 14,75}+\frac{0,45 \cdot 2869}{18723 \cdot 14,75}=0,060+0+0,005 \\
\tau_{\mathrm{Sd}} & =0,065 \frac{\mathrm{kN}}{\mathrm{cm}^{2}}=0,65 \mathrm{MPa}
\end{aligned}
$$


$\underline{\text { Tensão solicitante (eq.2.27 - sugestão): }}$

Pela Tabela 2.10, $\beta=1,1$.

Assim,

$$
\tau_{\mathrm{Sd}}=1,1 \cdot \frac{249}{279 \cdot 14,75}=0,066 \frac{\mathrm{kN}}{\mathrm{cm}^{2}}=0,66 \mathrm{MPa}
$$

De qualquer forma,

$$
\tau_{\mathrm{Rd} 1} \geq \tau_{\mathrm{Sd}} \quad \Rightarrow \quad \mathrm{OK}
$$

Observa-se que os valores de $\mathbf{W}_{\mathbf{p 1}} \mathbf{1}$ e de $\mathbf{W}_{\mathbf{p} 2}$ ' obtidos pela eq.(2.23), apesar de conservadores, não são distantes daqueles calculados a partir da Tabela 2.8, o mesmo ocorrendo para o $\mathbf{e}^{\boldsymbol{T}^{*}}$ obtido pela eq.(2.26), em relação ao da Tabela 2.7. O importante, entretanto, é que as tensões solicitantes calculadas para os dois casos são bastante parecidas, justificando, mais uma vez, o uso do método simplificado. E quanto ao cálculo de $\tau_{\mathbf{S d}}$ pela eq.(2.27), observa-se que o resultado obtido ficou novamente próximo daqueles correspondentes à eq.(2.11).

\section{d) Verificação do colapso progressivo}

$$
\begin{gathered}
A_{\mathrm{s}}=6 \cdot 0,5+3 \cdot 1,23=6,69 \mathrm{~cm}^{2} \\
A_{\mathrm{s}} \cdot \mathrm{f}_{\mathrm{yd}}=6,69 \cdot \frac{50}{1,15}=291 \mathrm{kN} \\
\mathrm{A}_{\mathrm{s}} \cdot \mathrm{f}_{\mathrm{yd}} \geq \mathrm{F}_{\mathrm{Sd}} \Rightarrow \quad 291 \geq 249 \quad \Rightarrow \quad \mathrm{OK}
\end{gathered}
$$

\subsubsection{PILAR P1 (PILAR DE CANTO)}

$$
\begin{aligned}
& \mathrm{F}_{\mathrm{Sd}}=1,4 \cdot 77=108 \mathrm{kN} \\
& \mathrm{M}_{\mathrm{Sdx}}=1,4 \cdot 4344=6082 \mathrm{kN} \cdot \mathrm{cm} \\
& \mathrm{M}_{\text {Sdy }}=1,4 \cdot 1850=2590 \mathrm{kN} \cdot \mathrm{cm}
\end{aligned}
$$

As duas situações de cálculo para as verificações estão representadas na Figura 2.35.

\section{a) Verificação do contorno $\mathrm{C}$}

Tensão resistente (eq.2.1):

$\tau_{\mathrm{Rd} 2}=5,09 \mathrm{MPa}$ (como calculado no item 2.10.3.a)

$\underline{\text { Tensão resistente (eq.2.16 - sugestão): }}$

$$
\tau_{\mathrm{Rd} 2}=6,03 \mathrm{MPa}
$$




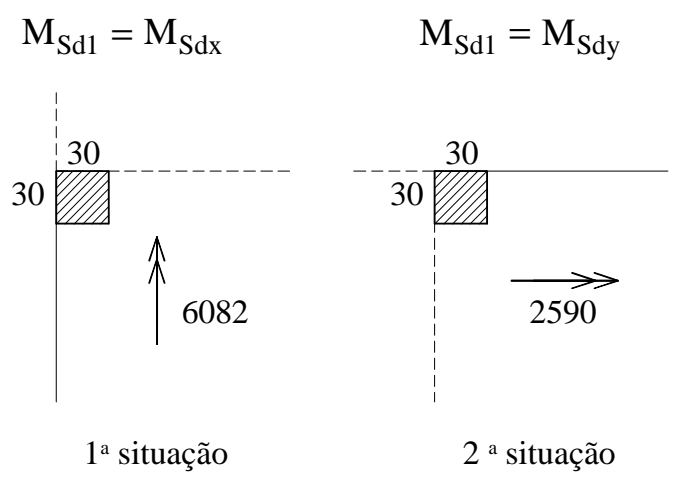

Figura 2.35 - Situações de cálculo para o pilar P1

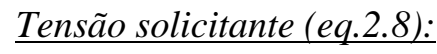

$$
a_{1}=a_{2} \leq\left\{\begin{array}{l}
1,5 \cdot d=1,5 \cdot 14,75=22,125 \mathrm{~cm} \\
0,5 \cdot c_{1}=0,5 \cdot 30=15 \mathrm{~cm}
\end{array} \quad \Rightarrow \quad a_{1}=a_{2}=15 \mathrm{~cm}\right.
$$

Pela Tabela 2.4:

$$
\begin{aligned}
& \mathrm{u}_{\mathrm{o}}^{*}=2 \cdot 15=30 \mathrm{~cm} \\
& \mathrm{u}^{*}=15+15+\pi \cdot 14,75=76 \mathrm{~cm}
\end{aligned}
$$

Como o pilar é quadrado, $c_{1}=c_{2}$, e as excentricidades e os valores de $\mathbf{K}$ e de $\mathbf{W}_{\mathbf{p}}$ são iguais para as duas situações de cálculo. O determinante da situação mais crítica é, portanto, apenas o valor do momento $\mathbf{M}_{\mathbf{s d}}$. Se o pilar fosse retangular, seria necessário se calcular a tensão solicitante segundo as duas situações de cálculo, para então se descobrir a mais crítica.

Pela eq.(2.13):

$$
\begin{aligned}
& \mathrm{e}^{*}=\frac{30 \cdot 15-15^{2}+15 \cdot 30+4 \cdot 15 \cdot 14,75+8 \cdot 14,75^{2}+\pi \cdot 14,75 \cdot 30}{2 \cdot(15+15+\pi \cdot 14,75)} \\
& \mathrm{e}^{*}=30,72 \mathrm{~cm}
\end{aligned}
$$

Pela eq.(2.25) - sugestão, tomando-se $\eta_{\mathrm{e} 1}=0,5$, de acordo com a Tabela 2.9:

$$
\mathrm{e}_{\mathrm{o}} *=0,5 \cdot \frac{30}{76} \cdot 30,72=6,06 \mathrm{~cm}
$$

Logo:

$$
\mathrm{M}_{\mathrm{Sd}} *=\mathrm{F}_{\mathrm{Sd}} \cdot \mathrm{e}_{\mathrm{o}} *=108 \cdot 6,06=655 \mathrm{kN} \cdot \mathrm{cm}
$$

Sendo a $1^{\text {a }}$ situação a mais crítica,

$$
\mathrm{M}_{\mathrm{sd}}=\left(\mathrm{M}_{\mathrm{sd} 1}-\mathrm{M}_{\mathrm{sd}} *\right)=(6082-655)=5427 \mathrm{kN} \cdot \mathrm{cm}
$$

Pela Tabela 2.2, $\mathrm{K}_{1}=0,6$. 
Pela eq.(2.14):

$$
\mathrm{W}_{\mathrm{p} 1}=\frac{30^{2}}{4}+\frac{30 \cdot 30}{2}+2 \cdot 30 \cdot 14,75+4 \cdot 14,75^{2}+\frac{\pi \cdot 14,75 \cdot 30}{2}=3125 \mathrm{~cm}^{2}
$$

Pela eq.(2.21) - sugestão:

$$
\mathrm{W}_{\mathrm{p} 1, \mathrm{o}}=\frac{30}{76} \cdot 3125=1234 \mathrm{~cm}^{2}
$$

Assim:

$$
\tau_{\mathrm{Sd}}=\frac{108}{30 \cdot 14,75}+\frac{0,6 \cdot 5427}{1234 \cdot 14,75}=0,244+0,179=0,423 \frac{\mathrm{kN}}{\mathrm{cm}^{2}}=4,23 \mathrm{MPa}
$$

Calculando-se a excentricidade pela expressão da Tabela 2.8, têm-se:

$$
\mathrm{e}_{\mathrm{o}} *=\frac{30 \cdot 15-15^{2}+15 \cdot 30}{2 \cdot(15+15)}=11,25 \mathrm{~cm}
$$

Logo:

$$
\begin{array}{r}
\mathrm{M}_{\mathrm{Sd}} *=\mathrm{F}_{\mathrm{Sd}} \cdot \mathrm{e}_{\mathrm{o}}^{*}=108 \cdot 11,25=1215 \mathrm{kN} \cdot \mathrm{cm} \\
\mathrm{M}_{\mathrm{sd}}=\left(\mathrm{M}_{\mathrm{sd} 1}-\mathrm{M}_{\mathrm{sd}} *\right)=(6082-1215)=4867 \mathrm{kN} \cdot \mathrm{cm}
\end{array}
$$

E assim:

$$
\tau_{\mathrm{Sd}}=\frac{108}{30 \cdot 14,75}+\frac{0,6 \cdot 4867}{1234 \cdot 14,75}=0,244+0,160=0,404 \frac{\mathrm{kN}}{\mathrm{cm}^{2}}=4,04 \mathrm{MPa}
$$

\section{Tensão solicitante (eq.2.27 - sugestão):}

Pela Tabela 2.10, $\beta=1,7$.

Assim,

$$
\tau_{\mathrm{Sd}}=1,7 \cdot \frac{108}{30 \cdot 14,75}=0,415 \frac{\mathrm{kN}}{\mathrm{cm}^{2}}=4,15 \mathrm{MPa}
$$

De qualquer forma,

$$
\tau_{\mathrm{Rd} 2} \geq \tau_{\mathrm{Sd}} \quad \Rightarrow \quad \mathrm{OK}
$$

Mais uma vez, com o aumento da tensão resistente proporcionado pela eq.(2.16) em relação à eq.(2.1), a verificação é satisfeita com mais folga. Também se observa que, apesar do valor conservador de $\mathbf{e}_{\mathbf{0}}{ }^{*}$ obtido com o uso da eq.(2.25) não estar próximo daquele obtido a partir da Tabela 2.8, a diferença entre as tensões solicitantes calculadas nos dois casos é pequena. E quanto ao método simplificado para o cálculo de $\tau_{\mathbf{S d}}$, ele forneceu, novamente, um resultado próximo daqueles obtidos com a eq.(2.8). 


\section{b) Verificação do contorno C'}

Tensão resistente (eq.2.2):

Com base na Figura 2.9 e na Figura 2.32, tem-se:

$$
\begin{gathered}
\rho_{\mathrm{x}}=\frac{9 \cdot 1,23}{15,375 \cdot(3 \cdot 14,75+30)}=0,00970 \\
\rho_{\mathrm{y}}=\frac{5 \cdot 0,5}{14,125 \cdot(3 \cdot 14,75+30)}=0,00238 \\
\rho=\sqrt{\rho_{\mathrm{x}} \cdot \rho_{\mathrm{y}}}=\sqrt{0,00970 \cdot 0,00238}=0,00481 \\
\tau_{\mathrm{Rd} 1}=0,13 \cdot\left(1+\sqrt{\frac{20}{14,75}}\right) \cdot(100 \cdot 0,00481 \cdot 30)^{1 / 3}=0,68 \mathrm{MPa}
\end{gathered}
$$

\section{Tensão solicitante (eq.2.8):}

$$
\mathrm{M}_{\mathrm{Sd}} *=\mathrm{F}_{\mathrm{Sd}} \cdot \mathrm{e}^{*}=108 \cdot 30,72=3318 \mathrm{kN} \cdot \mathrm{cm}
$$

Sendo a primeira situação a mais crítica,

$$
\mathrm{M}_{\mathrm{sd}}=\left(\mathrm{M}_{\mathrm{sd} 1}-\mathrm{M}_{\mathrm{sd}} *\right)=(6082-3318)=2764 \mathrm{kN} \cdot \mathrm{cm}
$$

E assim,

$$
\begin{aligned}
& \tau_{\mathrm{Sd}}=\frac{108}{76 \cdot 14,75}+\frac{0,6 \cdot 2764}{3125 \cdot 14,75}=0,096+0,036=0,132 \frac{\mathrm{kN}}{\mathrm{cm}^{2}}=1,32 \mathrm{MPa} \\
& \tau_{\mathrm{Rd} 1} \leq \tau_{\mathrm{Sd}} \Rightarrow \text { é necessária armadura de punção }
\end{aligned}
$$

Mais uma vez, serão utilizados conectores tipo pino, aço CA-50.

A área de aço necessária é obtida igualando-se a tensão solicitante à eq.(2.3).

$$
\begin{aligned}
& 1,32=0,10 \cdot\left(1+\sqrt{\frac{20}{14,75}}\right) \cdot(100 \cdot 0,00481 \cdot 30)^{1 / 3}+1,5 \cdot \frac{14,75}{\mathrm{~s}_{\mathrm{r}}} \cdot \frac{\mathrm{A}_{\mathrm{sw}} \cdot 320,25 \cdot 1}{76 \cdot 14,75} \\
& \frac{\mathrm{A}_{\mathrm{sw}}}{\mathrm{s}_{\mathrm{r}}}=0,125 \frac{\mathrm{cm}^{2}}{\mathrm{~cm}}
\end{aligned}
$$

Adotando-se 5 conectores $\phi 6,3$ efetivos em cada linha e $\mathrm{s}_{\mathrm{r}}=10 \mathrm{~cm}$, tem-se:

$$
\begin{aligned}
& \mathrm{A}_{\mathrm{sw}}=5 \cdot 0,32=1,60 \mathrm{~cm}^{2} \\
& \frac{\mathrm{A}_{\mathrm{sw}}}{\mathrm{s}_{\mathrm{r}}}=\frac{1,60}{10}=0,160 \frac{\mathrm{cm}^{2}}{\mathrm{~cm}} \geq 0,125 \frac{\mathrm{cm}^{2}}{\mathrm{~cm}} \Rightarrow \mathrm{OK}
\end{aligned}
$$

Assim, utilizando-se quatro linhas de conectores e respeitando-se os espaçamentos mínimos, o arranjo será como o da Figura 2.36. 


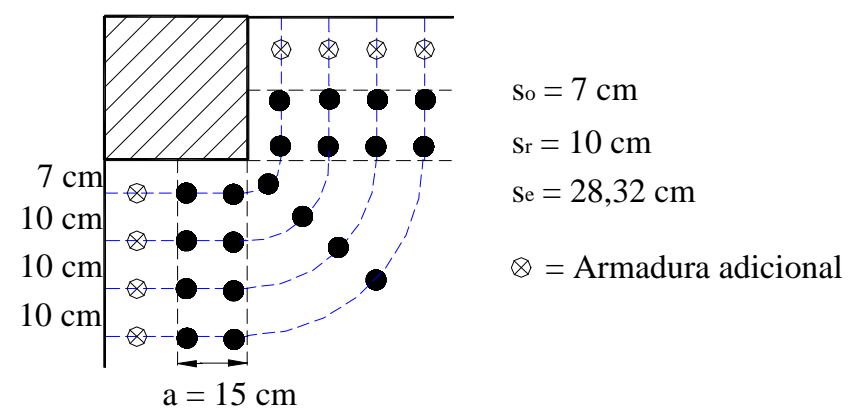

Figura 2.36 - Arranjo dos conectores tipo pino para o pilar P1

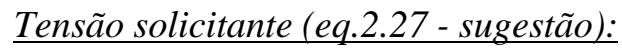

Pela Tabela 2.10, $\beta=1,4$.

Assim,

$$
\tau_{\mathrm{Sd}}=1,4 \cdot \frac{108}{76 \cdot 14,75}=0,135 \frac{\mathrm{kN}}{\mathrm{cm}^{2}}=1,35 \mathrm{MPa}
$$

Nota-se que o resultado da eq.(2.27) para $\tau_{\mathbf{S d}}$ se aproxima bastante daquele obtido pela eq.(2.8), sendo, entretanto, muito mais facilmente calculado. Observa-se também que foram respeitados, mais uma vez, os limites $\rho \leq 0,02$ e $s_{o} \geq 0,3 d=4,43 \mathrm{~cm}$, propostos neste trabalho.

\section{c) Verificação do contorno C"}

Tensão resistente (eq.2.2):

$$
\tau_{\mathrm{Rd} 1}=0,68 \mathrm{MPa}
$$

\section{Tensão solicitante (eq.2.8):}

Como $\mathrm{s}_{\mathrm{e}} \leq 2 \mathrm{~d}$, pela Tabela 2.4:

$$
\mathrm{u}^{\prime *}=15+15+\pi \cdot 14,75+\frac{\pi \cdot 37}{2}=134 \mathrm{~cm}
$$

Pela eq.(2.26) - sugestão, tomando-se $\eta_{\mathrm{e} 2}=1,0$, de acordo com a Tabela 2.9:

$$
\mathrm{e}^{\prime *}=\frac{134}{76} \cdot 30,72=54,16 \mathrm{~cm}
$$

Logo:

$$
\mathrm{M}_{\mathrm{Sd}} *=\mathrm{F}_{\mathrm{Sd}} \cdot \mathrm{e}^{\prime *}=108 \cdot 54,16=5849 \mathrm{kN} \cdot \mathrm{cm}
$$

Como a primeira situação é a mais crítica,

$$
\mathrm{M}_{\mathrm{sd}}=\left(\mathrm{M}_{\mathrm{sd} 1}-\mathrm{M}_{\mathrm{sd}} *\right)=(6082-5849)=233 \mathrm{kN} \cdot \mathrm{cm}
$$


Pela eq.(2.23) - sugestão, tomando-se $\eta_{\mathrm{wp}}=1,3$, de acordo com a Tabela 2.6:

$$
\mathrm{W}_{\mathrm{p1}}{ }^{\prime}=1,3 \cdot \frac{134}{76} \cdot 3125=7163 \mathrm{~cm}^{2}
$$

Assim,

$$
\tau_{\mathrm{Sd}}=\frac{108}{134 \cdot 14,75}+\frac{0,6 \cdot 233}{7163 \cdot 14,75}=0,055+0,001=0,056 \frac{\mathrm{kN}}{\mathrm{cm}^{2}}=0,56 \mathrm{MPa}
$$

Calculando-se a excentricidade pela expressão da Tabela 2.8, têm-se:

$$
\begin{aligned}
& \mathrm{e}^{\prime *}=\frac{\left(\begin{array}{l}
30 \cdot 15-15^{2}+15 \cdot 30+4 \cdot 15 \cdot 14,75+8 \cdot 14,75^{2}+ \\
+\pi \cdot 14,75 \cdot 30+2 \cdot 15 \cdot 37+8 \cdot 14,75 \cdot 37+\frac{\pi \cdot 37 \cdot 30}{2}+2 \cdot 37^{2}
\end{array}\right)}{2 \cdot\left(15+15+\pi \cdot 14,75+\frac{\pi \cdot 37}{2}\right)} \\
& \mathrm{e}^{\prime *}=54,47 \mathrm{~cm}
\end{aligned}
$$

Logo:

$$
\begin{array}{r}
\mathrm{M}_{\mathrm{Sd}} *=\mathrm{F}_{\mathrm{Sd}} \cdot \mathrm{e}^{*}=108 \cdot 54,47=5883 \mathrm{kN} \cdot \mathrm{cm} \\
\mathrm{M}_{\mathrm{sd}}=\left(\mathrm{M}_{\mathrm{sd} 1}-\mathrm{M}_{\mathrm{sd}} *\right)=(6082-5883)=199 \mathrm{kN} \cdot \mathrm{cm}
\end{array}
$$

Calculando-se $\mathbf{W}_{\mathbf{p} 1}$ ' pela expressão da Tabela 2.5, têm-se:

$$
\begin{aligned}
\mathrm{W}_{\mathrm{p} 1}{ }^{\prime}=\frac{30^{2}}{4}+\frac{30 \cdot 30}{2}+ & 2 \cdot 30 \cdot 14,75+4 \cdot 14,75^{2}+\frac{\pi \cdot 14,75 \cdot 30}{2}+ \\
& +30 \cdot 37+4 \cdot 14,75 \cdot 37+\frac{\pi \cdot 37 \cdot 30}{4}+37^{2} \\
\mathrm{~W}_{\mathrm{p} 1}{ }^{\prime}=8659 \mathrm{~cm}^{2} &
\end{aligned}
$$

E assim,

$$
\tau_{\mathrm{Sd}}=\frac{108}{134 \cdot 14,75}+\frac{0,6 \cdot 199}{8659 \cdot 14,75}=0,055+0,001=0,056 \frac{\mathrm{kN}}{\mathrm{cm}^{2}}=0,56 \mathrm{MPa}
$$

Tensão solicitante (eq.2.27 - sugestão):

Pela Tabela 2.10, $\beta=1,1$.

Assim,

$$
\tau_{\mathrm{Sd}}=1,1 \cdot \frac{108}{134 \cdot 14,75}=0,060 \frac{\mathrm{kN}}{\mathrm{cm}^{2}}=0,60 \mathrm{MPa}
$$

De qualquer forma,

$$
\tau_{\mathrm{Rd} 1} \geq \tau_{\mathrm{Sd}} \quad \Rightarrow \quad \mathrm{OK}
$$


Observa-se que valor do $\mathbf{W}_{\mathbf{p 1}}$ ' obtido com o uso da eq.(2.23), apesar de conservador, está novamente próximo daquele obtido a partir da expressão da Tabela 2.5, sendo muito mais facilmente calculado. O mesmo acontece com o valor de $\mathbf{e}^{\boldsymbol{}^{*} *}$ obtido pela eq.(2.26), em relação àquele indicado na Tabela 2.8. Desta vez, inclusive, nem se pode considerar diferenças entre os valores das tensões solicitantes calculadas nos dois casos. E quanto ao cálculo de $\tau_{\text {Sd }}$ pela eq.(2.27), observa-se que, mais uma vez, o resultado obtido ficou próximo daqueles correspondentes à eq.(2.8).

\section{d) Verificação do colapso progressivo}

$$
\begin{gathered}
A_{s}=6 \cdot 0,5=3,0 \mathrm{~cm}^{2} \\
A_{\mathrm{s}} \cdot \mathrm{f}_{\mathrm{yd}}=3,0 \cdot \frac{50}{1,15}=130 \mathrm{kN} \\
\mathrm{A}_{\mathrm{s}} \cdot \mathrm{f}_{\mathrm{yd}} \geq \mathrm{F}_{\mathrm{Sd}} \quad \Rightarrow \quad 130 \geq 108 \quad \Rightarrow \quad \mathrm{OK}
\end{gathered}
$$

\subsection{CONSIDERAÇÕES FINAIS}

Uma vez conhecido o processo de cálculo sugerido pela NBR 6118 (2000) para a verificação da punção, é interessante se destacar algumas diferenças em relação à versão anterior da norma, NBR 6118 (1978).

A Tabela 2.12 apresenta uma comparação entre a capacidade resistente de ligações de diferentes $\mathbf{f}_{\text {ck }}$, segundo a NBR 6118 (1978) e segundo a NBR 6118 (2000). Já na Tabela 2.13, a comparação é feita entre as tensões limites para a dispensa da armadura de cisalhamento, segundo as duas versões da norma.

Observa-se que a NBR 6118 (2000) é bem mais rigorosa quanto à necessidade de colocação de armaduras de cisalhamento, reduzindo a tensão limite a valores em torno de 65\% em relação aos da NBR 6118 (1978). Em contrapartida, a capacidade resistente da ligação foi praticamente dobrada, possibilitando o uso de maior taxa de armadura. Uma explicação para isso é a tentativa de se afastar cada vez mais a possibilidade de ruína brusca, através do aumento da ductilidade da ligação pela introdução de armadura. Do ponto de vista estrutural, como já foi comentado no item 2.2, essa prática é realmente bastante desejável.

O que se percebe, de uma maneira geral, é que a verificação da punção em lajes lisas, de acordo com o Projeto de Revisão da NBR 6118 (2000), mostra-se bem mais detalhada e eficiente que a da versão anterior da norma. Além de contemplar os casos de punção excêntrica, o novo texto permite uma melhor observação do acréscimo de resistência 
obtido com o uso de armaduras de punção, como os conectores tipo pino, e salienta a importância de se atenderem às disposições construtivas, para que as tensões cisalhantes possam ser absorvidas como previsto.

Mas mesmo com toda essa evolução em relação à versão anterior, acredita-se que algumas alterações e complementações podem ser incorporadas à versão definitiva da nova NBR 6118, melhorando tanto as verificações quanto o detalhamento. Algumas sugestões foram apresentadas neste capítulo.

Tabela 2.12 - Capacidade resistente de ligações segundo a NBR 6118 (1978)

e a NBR 6118 (2000)

\begin{tabular}{|c|c|c|}
\hline \multirow{2}{*}{$\begin{array}{c}\boldsymbol{f}_{\boldsymbol{c k}} \\
\mathbf{M P a})\end{array}$} & NBR 6118 (1978) & NBR 6118 (2000) \\
\cline { 2 - 3 } & $\tau_{\mathrm{Rd} 2}=0,45 \cdot \sqrt{\mathrm{f}_{\mathrm{ck}}}(\mathrm{MPa})$ & $\tau_{\mathrm{Rd} 2}=0,27 \cdot \alpha_{\mathrm{v}} \cdot \mathrm{f}_{\mathrm{cd}}(\mathrm{MPa})$ \\
\hline $\mathbf{2 0}$ & 2,01 & 3,55 \\
\hline $\mathbf{2 5}$ & 2,25 & 4,34 \\
\hline $\mathbf{3 0}$ & 2,46 & 5,09 \\
\hline $\mathbf{3 5}$ & 2,66 & 5,81 \\
\hline $\mathbf{4 0}$ & 2,85 & 6,48 \\
\hline $\mathbf{4 5}$ & 3,02 & 7,12 \\
\hline $\mathbf{5 0}$ & 3,18 & 7,71 \\
\hline * A notação original foi alterada para facilitar a comparação com a NBR 6118 \\
$(2000)$
\end{tabular}

Tabela 2.13 - Tensões limites para dispensa de armadura de cisalhamento segundo a NBR 6118 (1978) e a NBR 6118 (2000)

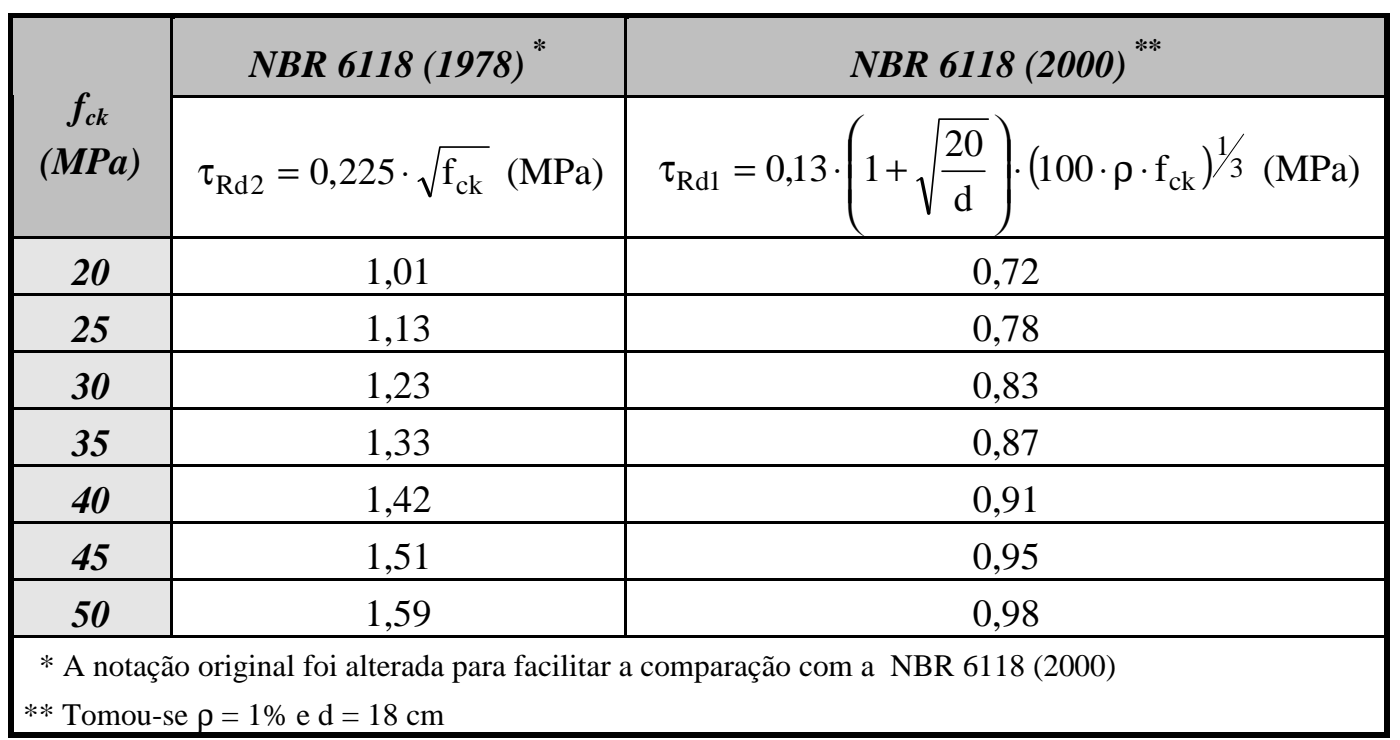




\subsection{REFERÊNCIAS BIBLIOGRÁFICAS}

ALEXANDER, S.D.; SIMMONDS, S.H. (1992). Test of column-flat plate connections. ACI Structural Journal, v.89, n.5, p.495-502, Sept-Oct.

AMERICAN CONCRETE INSTITUTE (1999). ACI 318/99 - Building code requirements for reinforced concrete. Farmington Hills, ACI.

ASSOCIAÇÃO BRASILEIRA DE NORMAS TÉCNICAS (1978). NBR 6118 - Projeto e execução de obras de concreto armado. Rio de Janeiro.

ASSOCIAÇÃO BRASILEIRA DE NORMAS TÉCNICAS (2000). Revisão da NBR 6118 Projeto de estruturas de concreto.

BRAESTRUP, M.W. (1995). Central punching of reinforced concrete slabs. CEB Bulletin d'Information, n.223, p.233-243, June.

COMITÉ EURO-INTERNACIONAL DU BÉTON (1993). CEB-FIP model code 1990. London, Thomas Telford.

CORES, H.; ARROYO, J.C. (1995). Ultimate limit state design of R.C. and P.C. slabs. $C E B$ Bulletin d'Information, n.223, p.209-231, June.

DILGER, W.H; GHALI, A. (1981). Shear reinforcement of concrete slabs. Journal of the Structural Division, ASCE, v.107, n.ST12, p. 2403-2420, Dec.

EL-SALAKAWY, E.F.; POLAK, M.A.; SOLIMAN, M.H. (1999). Reinforced concrete slabcolumn edge connections with openings. ACI Structural Journal, v.96, n.1, p.79-87, JanFeb.

ELGABRY, A.A.; GHALI, A. (1987). Tests on concrete slab-column connections with studshear reinforcement subjected to shear-moment transfer. ACI Structural Journal, v.84, n.5, p.433-442, Sept-Oct.

FUSCO, P.B. (1984). Estruturas de concreto - solicitações tangenciais: problemas básicos de cisalhamento no concreto estrutural, problemas gerais de dimensionamento. São Paulo, Escola Politécnica, Universidade de São Paulo.

GHALI, A. (1989). An efficient solution to punching of slabs. Concrete International, v.11, n.6, p.50-54, Nov.

GHALI, A.; MEGALLY, S. (2000). Stud shear reinforcement for punching: north american and european practices. In: INTERNATIONAL WORKSHOP ON PUNCHING SHEAR CAPACITY OF RC SLABS, Stockholm. Proceedings. p.201-209. 
GOMES, R.B. (1991). Punching resistance of reinforced concrete flat slabs with shear reinforcement. London. PhD Thesis, The Polytechnic of Central London.

GOMES, R.B.; REGAN, P.E. (1999). Punching resistance of RC flat slabs with shear reinforcement. Journal of Structural Engineering, ASCE, v.125, n.6, p.684-692, June.

GOMES, R.B.; ANDRADE, M.A. (2000). Does a punching shear reinforcement need to embrace a flexural reinforcement of a reinforced concrete flat slab? In: INTERNATIONAL WORKSHOP ON PUNCHING SHEAR CAPACITY OF RC SLABS, Stockholm. Proceedings. p.109-116.

GUARDA, M.C.C. (1995). Cálculo de lajes-cogumelo pela teoria das charneiras plásticas. São Carlos. Dissertação (Mestrado) - Escola de Engenharia de São Carlos, Universidade de São Paulo.

HAWKINS, N.M.; MITCHELL, D. (1979). Progressive collapse of flat plate structures. Journal of the American Concrete Institute, v.76, n.7, p.775-808, July.

LANGOHR, P.H.; GHALI, A.; DILGER, W.H. (1976). Special shear reinforcement for concrete flat plates. Journal of the American Concrete Institute, v.73, n.3, p.141-146, Mar.

LIM, F.K.; RAGAN, B.V. (1995). Studies on concrete slabs with stud shear reinforcement in vicinity of edge and corner columns. ACI Structural Journal, v.92, n.5, p.515-525, SeptOct.

LONG, A.E.; BOND, D. (1967). Punching failure of reinforced concrete slabs. Proceedings of The Institution of Civil Engineers, v.37, p.109-135, May.

MAST, P.E. (1970). Stresses in flat plates near columns. Journal of the American Concrete Institute, v.67, n.10, p.761-768, Oct.

MOKHTAR, A.; GHALI, A.; DILGER, W. (1985). Stud shear reinforcement for flat concrete plates. Journal of the American Concrete Institute, v.82, n.5, p.676-683, SeptOct.

REGAN, P.E. (1974). Design for punching shear. The Structural Engineer, v.52, n.6, p.197207, June.

REGAN, P.E.; BRAESTRUP, M.W. (1985). Punching shear in reinforced concrete - a state of art report. CEB Bulletin d'Information, n.168, Jan.

REGAN, P.E. (1999). Basic design for moment, shear and torsion. FIB Bulletin, v.2, p.141223, Apr.

SEIBLE, F.; GHALI, A.; DILGER, W.H. (1980). Preassembled shear reinforcing units for flat plates. Journal of the American Concrete Institute, v.77, n.1, p.28-35, Jan-Feb. 
SHERIF, A.G.; DILGER, W.H. (1996). Critical review of the CSA A23.3-94 punching shear strength provisions for interior columns. Canadian Journal of Civil Engineering, v.23, n.5, p.998-1011, Oct.

\subsection{BIBLIOGRAFIA COMPLEMENTAR}

ACI COMMITEE 421 (1992). Shear reinforcement of slabs. ACI Structural Journal, v.89, n.5, p.587-601. Sept-Oct.

ANG, A.H-S.; TANG, W.H. (1975). Probability concepts in engineering planning and design. New York, John Wiley \& Sons. v.1: Basic principles.

FEDERATION INTERNATIONALE DE LA PRÉCONTRAINTE (1999). Practical design of structural concrete. London, SETO. (FIP Recomendations).

FUSCO, P.B. (1977). Estruturas de concreto: fundamentos estatísticos da segurança das estruturas. São Paulo, McGraw-Hill do Brasil.

GHALI, A.; MEGALLY, S. (1999). Design for punching shear strength with ACI 318-95. ACI Structural Journal, v.96, n.4, p.539-548. July-Aug.

GUARDA, M.C.C.; LIMA, J.S.; PINHEIRO, L.M. (2000). Novas diretrizes para a análise da punção no projeto de lajes lisas [CD-ROM]. In: SIMPÓSIO EPUSP SOBRE ESTRUTURAS DE CONCRETO, 4., São Paulo. Anais.

MELGES, J.L.P. (1995). Punção em lajes: exemplos de cálculo e análise teóricoexperimental. São Carlos. Dissertação (Mestrado) - Escola de Engenharia de São Carlos, Universidade de São Paulo.

MELO, G.S.S.A.; REGAN, P.E. (1998). Post-punching resistance of connections between flat slabs and interior columns. Magazine of Concrete Research, v.50, n.4, p.319-327, Dec.

REGAN, P.E. (1986). Design of reinforced concrete flat slabs. In: NARAYANAN, R. Concrete framed structures: stability and strength. London, Elsevier. Cap. 8, p.217-248.

WALRAVEN, J. (2000). Design of structures for punching: present status of revision of EC-2. In: INTERNATIONAL WORKSHOP ON PUNCHING SHEAR CAPACITY OF RC SLABS, Stockholm. Proceedings. p.211-224. 


\section{CApítulo 3}

\section{ESTABILIDADE GLOBAL DE EDIFÍCIOS}

Com o aumento do número de pavimentos dos edifícios e de sua esbeltez, a avaliação dos efeitos do vento e, principalmente, dos efeitos de segunda ordem por ele causados, torna-se ainda mais importante. Neste capítulo, são estudados a determinação desses efeitos, a importância da verificação da estabilidade global e os procedimentos de projeto usualmente adotados para este fim. As recomendações da NBR 6118 (2000), que permitem o uso do parâmetro de instabilidade $\alpha$ e do coeficiente $\gamma_{z}$, são apresentadas e analisadas com base em um processo mais rigoroso, o $\boldsymbol{P}-\Delta$, sugerindo-se algumas modificações. Por fim, realizase um exemplo de cálculo para ilustrar os procedimentos discutidos.

\subsection{OS EFEITOS DE SEGUNDA ORDEM E A ESTABILIDADE DE UMA ESTRUTURA}

Os edifícios altos são construções cada vez mais comuns nos principais centros urbanos. Com o crescimento das cidades e a crescente valorização de seu espaço, tornou-se quase que uma obrigação urbanística o emprego de estruturas que compensassem a redução da área da projeção horizontal com o aumento do número de pavimentos.

Até algumas décadas atrás, não eram muitas as edificações mais altas e, em geral, a própria arquitetura conduzia a estruturas robustas. Mas o desenvolvimento de novas tecnologias e de novos materiais possibilitou uma modificação desses padrões arquitetônicos, tornando as estruturas mais esbeltas. Como consequiência direta, a rigidez no plano horizontal diminuiu e os efeitos das ações horizontais tornaram-se ainda mais significativos para o estudo da estabilidade.

A estabilidade de uma estrutura pode ser entendida como a sua capacidade de manter o equilíbrio sob a incidência de ações. Num primeiro momento, até se poderia pensar que 
este é um problema para resolução da estrutura em sua posição indeformada, ou seja, para uma análise de primeira ordem. Entretanto, esse tipo de avaliação não considera os esforços adicionais que aparecem devido à associação entre os deslocamentos horizontais dos nós da estrutura e o carregamento vertical pré-existente. Para tanto, é preciso considerar a estrutura em sua posição deformada, ou seja, deve-se realizar uma análise de segunda ordem.

Dessa forma, pode-se dizer que os efeitos de primeira ordem são aqueles obtidos a partir de uma análise de equilíbrio que considera a posição geométrica inicial, isto é, indeformada, e os de segunda ordem, aqueles resultantes da análise da estrutura deformada. Enquanto nos estudos de primeira ordem os esforços e os deslocamentos variam linearmente com as ações, nos de segunda ordem, essas relações tornam-se não-lineares.

Vale ressaltar que as novas equações de equilíbrio e de compatibilidade decorrentes do deslocamento lateral dos nós acarretam dois tipos de esforços de segunda ordem: os globais e os locais. Os esforços globais são aqueles introduzidos pelo deslocamento dos nós da estrutura, e os locais, aqueles decorrentes da modificação nos eixos das barras, principalmente dos pilares, que deixam de ser retilíneos devido aos deslocamentos diferenciados de seus pontos extremos.

Para a avaliação dos efeitos globais de segunda ordem, são necessários apenas os esforços nas extremidades de cada barra, ou seja, nos nós. Para os efeitos locais, entretanto, é preciso se conhecer a distribuição dos esforços em cada barra, o que só é possível quando forem conhecidos os momentos fletores e as forças normais finais. Portanto, a análise da estabilidade global de uma estrutura deve preceder a análise da estabilidade local dos pilares, devendo-se lembrar que a dispensa da consideração dos efeitos globais não implica a garantia da estabilidade local, e vice-versa.

Como este capítulo trata apenas da análise dos efeitos de segunda ordem globais, eles serão aqui denominados simplesmente de efeitos de segunda ordem.

\subsection{DESLOCABILIDADE DOS NÓS DE UMA ESTRUTURA}

As ações horizontais propiciam o surgimento de deslocamentos horizontais, que, associados ao carregamento vertical, produzem efeitos de segunda ordem. Esses efeitos podem ser mais ou menos significativos, com maiores ou menores deslocamentos, a depender da disposição dos elementos estruturais.

A deslocabilidade da estrutura é uma característica muito importante, não só em relação à ruína, como também em relação à utilização. Além da instabilidade que pode acarretar, os deslocamentos excessivos totais ou entre pavimentos podem gerar desconforto 
aos usuários e, ainda, mau funcionamento dos elementos não estruturais ligados à estrutura, como esquadrias e paredes de vedação.

As estruturas mais rígidas, quase indeslocáveis, e com pequena interferência dos efeitos de segunda ordem em seus esforços totais, são chamadas de estruturas de nós fixos. As mais flexíveis, bastante deslocáveis, e cujos efeitos de segunda ordem contribuem significativamente para o aumento dos esforços finais, são chamadas de estruturas de nós móveis.

Numa edificação considerada de nós fixos, pode-se utilizar apenas os efeitos de primeira ordem para o dimensionamento de suas peças. Caso ela seja de nós móveis, os esforços adicionais introduzidos por seu afastamento da posição original devem ser obrigatoriamente considerados, sob pena de perda do equilíbrio da estrutura ou de colapso de algum de seus elementos. É indutivo, portanto, que a análise de uma estrutura de nós fixos é bem mais simplificada que a de uma de nós móveis.

Vale reforçar que pode haver perda de estabilidade de algum pilar isolado, mesmo em uma estrutura considerada de nós fixos, devido aos efeitos de segunda ordem locais. Por isso, não pode ser dispensada a verificação local da peça, tanto nas estruturas consideradas deslocáveis quanto nas consideradas indeslocáveis.

\subsection{ANÁlISE TEÓRICA DO PROBLEMA DA ESTABILIDADE GLOBAL}

São dois os principais pontos a serem discutidos na análise de estabilidade global de edifícios: como se classificar uma estrutura quanto à deslocabilidade dos nós e como devem ser determinados os efeitos de segunda ordem daquelas classificadas como de nós móveis.

\subsubsection{CLASSIFICAÇÃO QUANTO À DESLOCABILIDADE DOS NÓS}

De uma maneira geral, uma edificação poderá ser considerada de nós fixos se os efeitos de segunda ordem forem inferiores a $10 \%{ }^{7}$ dos de primeira ordem. Colocando-se de outra forma, os esforços totais não devem exceder os esforços de primeira ordem acrescidos em mais de $10 \%$. Para os momentos fletores, por exemplo, tem-se então:

$$
\mathrm{M}_{2 \mathrm{~d}} \leq 1,1 \cdot \mathrm{M}_{1 \mathrm{~d}}
$$

\footnotetext{
${ }^{7}$ O ACI 318 (1999) e alguns pesquisadores são mais rigorosos na classificação de uma estrutura de nós fixos, sugerindo que, para esta situação, os efeitos de segunda ordem devem ser inferiores a 5\% dos de primeira ordem.
} 
sendo:

$\mathbf{M}_{2 \mathbf{d}}$ - valor de cálculo do momento total (primeira ordem + segunda ordem);

$\mathbf{M}_{1 \mathbf{d}}$ - valor de cálculo do momento de primeira ordem.

Em termos práticos, o estudo da deslocabilidade dos nós de uma estrutura não é feito segundo esta verificação. Geralmente, apenas os efeitos de primeira ordem são conhecidos, pois a análise de segunda ordem consome mais tempo e só é desejável para os casos em que já se imagina que a estrutura seja de nós móveis.

Assim, é importante se utilizar um critério que analise a deslocabilidade dos nós somente com esses resultados de primeira ordem, até para que o projetista decida, quando uma estrutura for considerada de nós móveis, se é o caso de enrijecê-la para torná-la de nós fixos, ou então partir realmente para a análise de segunda ordem.

Em função disso, diferentes tipos de parâmetros já foram sugeridos, alguns sendo calculados em função de cargas críticas, outros a partir da rigidez de cada pavimento. Os valores obtidos são comparados a valores limites, determinando se a estrutura é de nós fixos ou móveis. Podem ser destacados os estudos de BECK \& KÖNIG (1966), que introduziram o denominado parâmetro de instabilidade $\alpha$, base de diversos procedimentos de normas internacionais e comentado no item 3.4, e os estudos de FRANCO \& VASCONCELOS (1991), que introduziram o denominado coeficiente $\gamma_{\mathbf{z}}$, comentado no item 3.6.

\subsubsection{DETERMINAÇÃO DOS EFEITOS DE SEGUNDA ORDEM}

Quando uma estrutura é classificada como de nós móveis, surge a necessidade de se considerar também a parcela dos efeitos de segunda ordem no dimensionamento dos elementos estruturais. Esta análise, portanto, exige a adoção de métodos mais sofisticados que os da análise de primeira ordem.

Diferentes tipos de abordagem já foram propostos. Algumas são realizadas em função de cargas críticas, outras modificando as forças laterais incidentes, outras adicionando termos de segunda ordem às matrizes de rigidez das estruturas. Alguns comentários podem ser encontrados em MacGREGOR \& HAGE (1977) e LAI \& MacGREGOR (1983).

Observa-se, entretanto, que é o chamado processo $\mathbf{P}-\Delta$ o mais utilizado para a análise da estrutura deformada e conseqüente obtenção dos acréscimos sofridos pelos efeitos de primeira ordem, fornecendo resultados com aproximações muito boas para os casos de edifícios convencionais, como demonstram MacGREGOR \& HAGE (1977). Algumas 
considerações sobre esse processo são apresentadas no item 3.5. Mas, apesar do $\mathbf{P}-\boldsymbol{\Delta}$ ser um processo relativamente simples, o tempo despendido é, muitas vezes, maior que o desejado.

Assim, passou-se a trabalhar a idéia de se utilizar um coeficiente majorador dos esforços de primeira ordem, de forma a se tentar prever, a partir dos resultados de primeira ordem, o acréscimo percentual que eles sofreriam com a adição dos efeitos de segunda ordem. Esse tipo de abordagem é bastante simplificado, evidentemente, mas pode apresentar resultados satisfatórios na análise de estruturas convencionais. Algumas indicações são feitas no item 3.6, e comentários adicionais podem ser encontrados em MacGREGOR \& HAGE (1977) e em FRANCO \& VASCONCELOS (1991).

\subsection{O PARÂMETRO DE INSTABILIDADE $\alpha$}

Os primeiros estudos voltados para a avaliação dos efeitos de segunda ordem enfocavam apenas o comportamento de barras isoladas. BECK \& KÖNIG (1966), com base na teoria de Eüler, desenvolveram os primeiros trabalhos de maior repercussão que envolveram estruturas como um todo, trabalhando em regime elástico-linear.

Sem contar com a facilidade dos computadores, consideraram o edifício equivalente a um pilar único, engastado na base e livre no topo, de seção constante, e sujeito a uma força vertical uniformemente distribuída ao longo do seu comprimento. Esse pilar tinha rigidez igual à soma das rigidezes dos pilares isolados que participavam do contraventamento da estrutura.

Resolvendo a equação diferencial que permitia a determinação da carga crítica, Beck e König observaram que a perda de estabilidade da estrutura se relacionava a um coeficiente denominado $\alpha$, que dependia do carregamento e das características geométricas do pilar (comprimento e rigidez), da seguinte forma:

$$
\alpha=H \cdot \sqrt{\frac{N}{E I}}
$$

sendo:

H - altura total da estrutura;

$\mathbf{N}$ - somatório das ações verticais atuantes;

EI - módulo de rigidez da estrutura. 
Concluíram ainda que, para manter os efeitos de segunda ordem inferiores a $10 \%$ dos de primeira, ou seja, para que uma estrutura pudesse ser considerada de nós fixos, o valor de $\alpha$ deveria ser menor ou igual a $\mathbf{0 , 6}$.

Posteriormente, diversos aspectos desses estudos de Beck e König foram discutidos e melhorados, como apresentado por LIMA (1998). Dentre essas melhorias, destacam-se as questões do módulo de rigidez da estrutura e dos valores limite de $\alpha$.

\subsubsection{MÓDULO DE RIGIDEZ DA ESTRUTURA}

VASCONCELOS (1985) chama a atenção para o fato de que o módulo de rigidez EI calculado como a soma das rigidezes individuais dos pilares só pode ser representativo no caso de estruturas pré-moldadas. Para estruturas moldadas no local, há um acréscimo de rigidez considerável devido à solidarização entre vigas e pilares, que, se não for considerado, acarreta valores de $\alpha$ bastante conservadores.

Sobre esse problema, FRANCO (1985a) comenta que a rigidez do pilar único que representa a estrutura deveria ser equivalente à dos pilares individuais, sendo que a equivalência residiria na igualdade de flechas horizontais no topo, decorrentes da incidência das ações horizontais.

Por exemplo, para um edifício de altura $\mathbf{H}$, módulo de rigidez EI, submetido a uma força $\mathbf{q}$ horizontal, e que apresenta um deslocamento a no topo, o módulo de rigidez equivalente $(\mathbf{E I})_{\text {eq }}$ seria o módulo de rigidez de um pilar como o de Beck, de comprimento $\mathbf{H}$, submetido à força q, e com deslocamento no topo também igual a a (Figura 3.1).

Por simplificação, é comum a consideração de q como uma força horizontal unitária e concentrada no topo ou como uma força unitária e uniformemente distribuída ao longo da altura da edificação. Para este último caso, que inclusive se aproxima mais do tipo de ação do vento, a expressão do módulo de rigidez equivalente fica:

$$
(\mathrm{EI})_{\mathrm{eq}}=\frac{\mathrm{q} \cdot \mathrm{H}^{4}}{8 \cdot \mathrm{a}}
$$

sendo:

q - ação horizontal unitária uniformemente distribuída;

a - deslocamento horizontal no topo da estrutura, provocado pela ação q. 


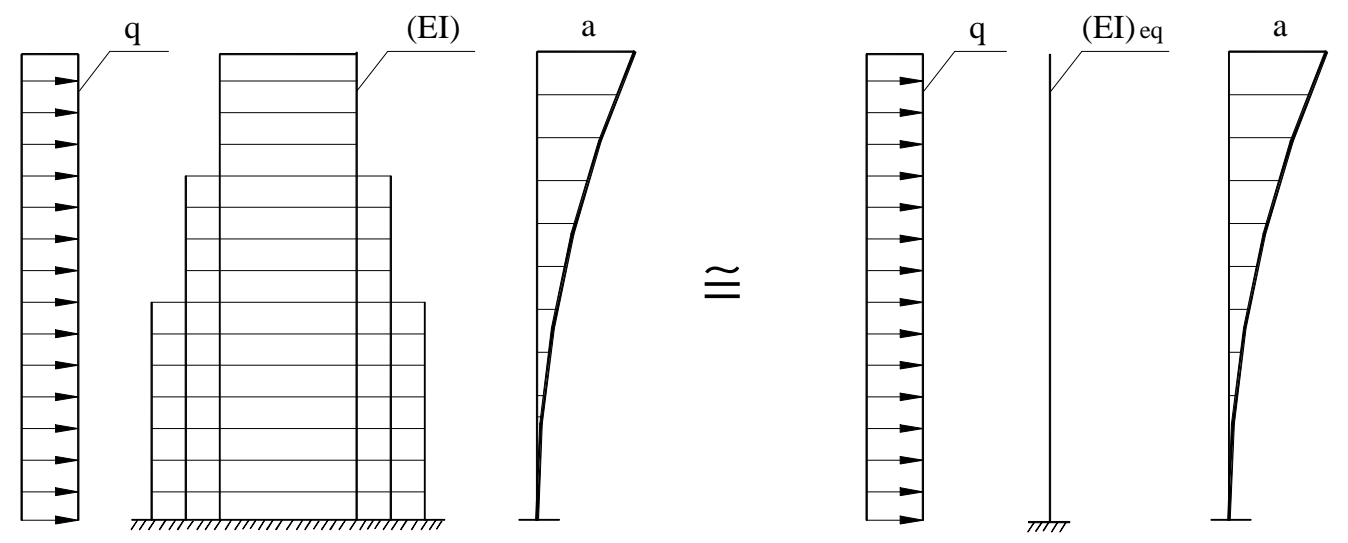

Figura 3.1 - Módulo de rigidez equivalente

Sendo assim, a expressão do parâmetro $\alpha$ pode ser escrita como:

$$
\alpha=H \cdot \sqrt{\frac{\mathrm{N}}{(\mathrm{EI})_{\mathrm{eq}}}}
$$

\subsubsection{VALORES LIMITES DE $\alpha$}

FRANCO (1985b) demonstrou que o valor limite para $\alpha$ não é único e depende do sistema de contraventamento da estrutura, responsável pela caracterização de sua linha elástica.

Pela Figura 3.2, observa-se que os deslocamentos ao longo da altura são bastante diferentes para cada caso. No caso de pilares-parede, a tendência de crescimento dos deslocamentos aumenta à medida que se aproxima do topo; no caso de pórticos, à medida que se aproxima da base; e no caso de associações entre eles, há uma compensação de tal forma que surge um ponto de inflexão na deformada. Assim, pode-se dizer que, enquanto as estruturas contraventadas por pilares-parede demonstram maior capacidade de absorver esforços nas proximidades da fundação, as estruturas contraventadas por pórticos aumentam sua participação quanto mais se aproxima do topo.

As diferenças entre as deformadas realmente sugerem diferentes respostas aos efeitos de segunda ordem e, conseqüentemente, diferentes valores de $\alpha_{\lim }$. FRANCO (1985b) obteve esses limites estudando o chamado parâmetro de forma da linha elástica $(\psi)$, um coeficiente que considera os deslocamentos laterais de cada pavimento (e, indiretamente, a deformada), dado por: 


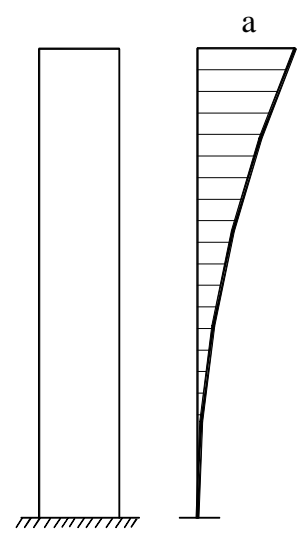

Pilar-Parede

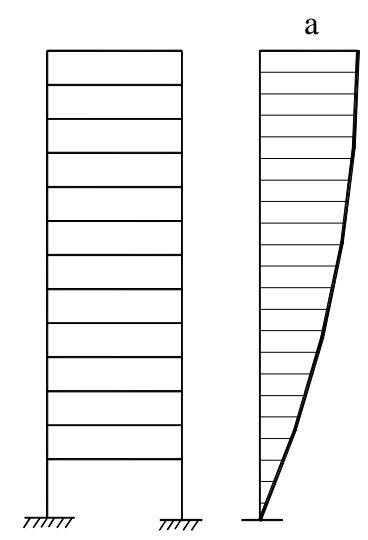

Pórtico

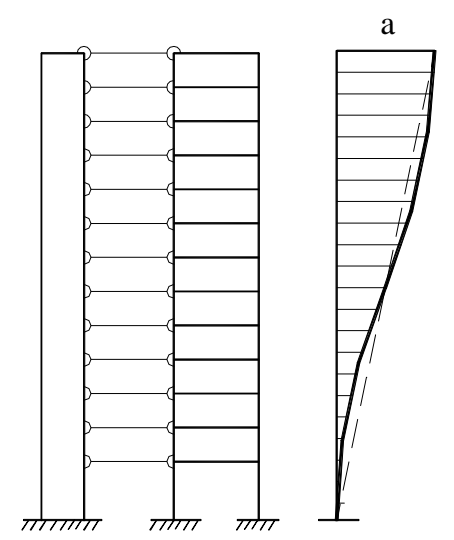

Associação

Figura 3.2 - Representação da deformada de estruturas com diferentes sistemas de contraventamento

$$
\psi=\frac{\sum_{i=1}^{n} P_{i} \cdot y_{i}}{a \cdot N}
$$

sendo:

$\mathbf{P}_{\mathbf{i}}$ - força vertical atuante no pavimento $\mathbf{i}$;

$\mathbf{y}_{\mathbf{i}}$ - deslocamento horizontal do pavimento $\mathbf{i}$;

a - deslocamento no topo da estrutura;

$\mathbf{N}$ - somatório das ações verticais atuantes;

n - número de pavimentos.

Nesta expressão, ele escreveu o somatório em forma de integral e substituiu o $\mathbf{y}_{\mathbf{i}}$ por equações da linha elástica para cada um dos sistemas de contraventamento, determinando, então, valores aproximados para os parâmetros de forma. Esses valores, substituídos na expressão de $\boldsymbol{\alpha}_{\lim }$ deduzida por ele:

$$
\alpha_{\lim }=\sqrt{\frac{2}{11 \cdot \psi}}
$$

forneceram os resultados apresentados na Tabela 3.1. 
Tabela 3.1 - Valores de $\psi$ e $\alpha_{\lim }$ para diferentes sistemas de contraventamento

\begin{tabular}{|c|c|c|}
\hline Tipo de Contraventamento & $\psi$ & $\alpha_{\lim }$ \\
\hline Pilares-parede & 0,40 & 0,7 \\
\hline Associações & 0,50 & 0,6 \\
\hline Pórticos & 0,67 & 0,5 \\
\hline
\end{tabular}

\subsection{O PROCESSO P- $\Delta$}

Com a incidência das ações laterais, os nós da estrutura sofrem deslocamentos denominados de primeira ordem. As forças verticais aplicadas nesses nós, agora deslocados, provocam o aparecimento de novos esforços, que causam novos deslocamentos, e assim sucessivamente. Os esforços e deslocamentos adicionais podem ser obtidos pelo chamado processo $\mathbf{P}-\Delta$, que realiza uma análise através de sucessivas iterações, nas quais buscam-se novas condições de equilíbrio para a estrutura (Figura 3.3). A idéia geral do processo clássico é descrita a seguir.

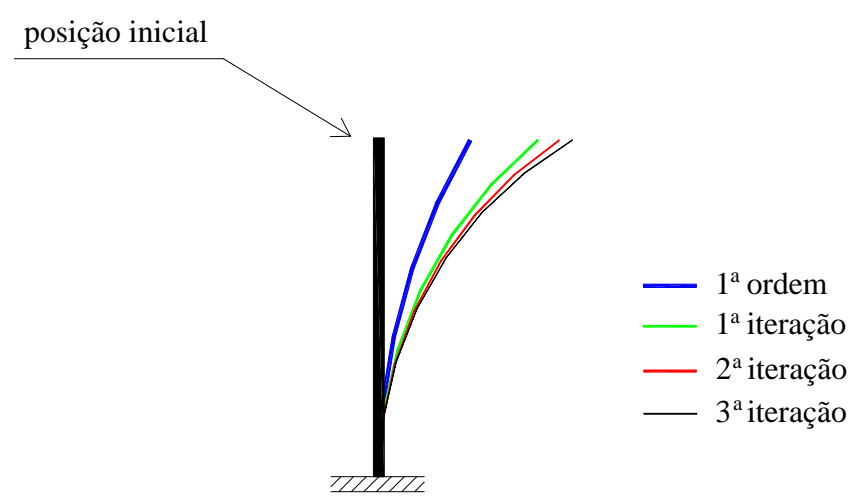

Figura 3.3 - Posições deslocadas em iterações sucessivas

Inicialmente, faz-se a análise da estrutura indeformada (primeira ordem), submetida às ações horizontais (Figura 3.4a). Com os deslocamentos resultantes desta primeira análise, determinam-se os deslocamentos relativos entre pavimentos.

As forças verticais em cada pavimento geram momentos proporcionais aos deslocamentos relativos. Esses momentos podem ser substituídos por binários equivalentes constituídos de forças horizontais (Figura 3.4b), cujas resultantes, em cada pavimento, são as chamadas forças horizontais fictícias (Figura 3.4c), dadas por: 


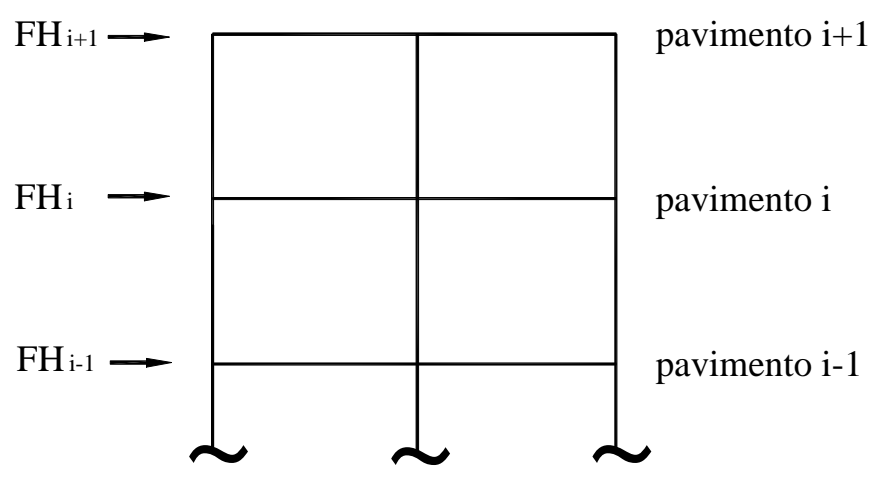

(a) Estrutura indeformada

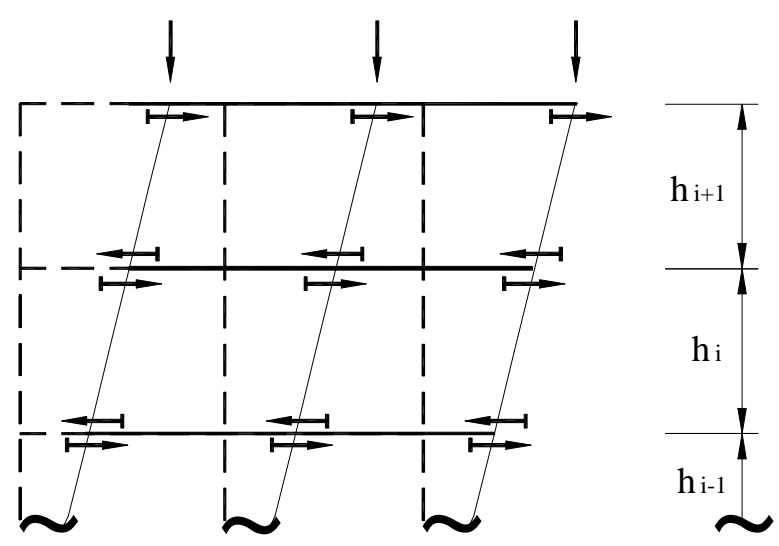

$\longrightarrow$ Forças iniciais

$\longmapsto$ Forças fictícias

(b) Estrutura deformada

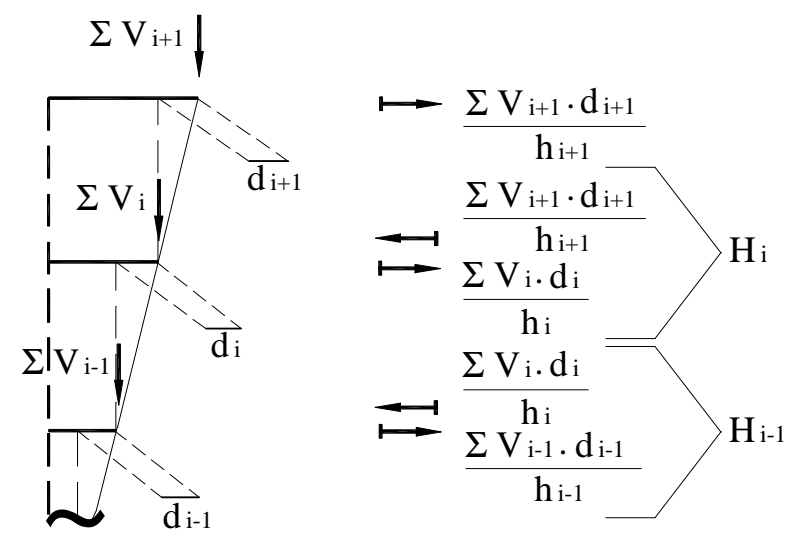

(c) Forças horizontais fictícias

Figura 3.4 - Processo P- $\Delta$ 


$$
\mathrm{H}_{\mathrm{i}}=\frac{\sum \mathrm{V}_{\mathrm{i}} \cdot \mathrm{d}_{\mathrm{i}}}{\mathrm{h}_{\mathrm{i}}}-\frac{\sum \mathrm{V}_{\mathrm{i}+1} \cdot \mathrm{d}_{\mathrm{i}+1}}{\mathrm{~h}_{\mathrm{i}+1}}
$$

sendo:

$\mathbf{V}_{\mathbf{i}}$ e $\mathbf{V}_{\mathbf{i}+\mathbf{1}}$ - forças verticais acumuladas até os pavimentos $\mathbf{i}$ e $\mathbf{i}+\mathbf{1}$, respectivamente;

$\mathbf{h}_{\mathbf{i}}$ e $\mathbf{h}_{\mathbf{i}+\mathbf{1}}$ - pés-direitos dos pavimentos $\mathbf{i}$ e $\mathbf{i}+\mathbf{1}$, respectivamente;

$\mathbf{d}_{\mathbf{i}}$ e $\mathbf{d}_{\mathbf{i + 1}}$ - deslocamentos horizontais relativos do pavimento $\mathbf{i}$ em relação ao pavimento i-1 e do pavimento $\mathbf{i}+\mathbf{1}$ em relação ao pavimento $\mathbf{i}$, respectivamente.

Essas forças horizontais fictícias devem ser somadas às forças horizontais iniciais, resultando nas forças horizontais modificadas, com as quais é feita a análise seguinte. Novos deslocamentos são obtidos e novas forças horizontais fictícias e modificadas são calculadas, dando-se continuidade ao processo. Observe-se que as forças horizontais modificadas ao final de cada iteração devem ser determinadas pelo somatório das forças horizontais fictícias com as forças horizontais iniciais, e não com as forças horizontais modificadas da iteração anterior.

Repetem-se as sucessivas análises até a convergência dos deslocamentos, ponto correspondente à posição de equilíbrio. Os esforços referentes a esta posição são os esforços finais procurados, que incluem os de segunda ordem. Segundo MacGREGOR (1988), o processo pode ser interrompido quando os deslocamentos de uma dada iteração não excederem em mais de $5 \%$ os da iteração anterior.

Vale ressaltar que, para computar os deslocamentos laterais com mais precisão, a rigidez EI das barras deveria ser modificada após cada iteração, em função dos novos valores de momentos e considerando os diagramas momento-curvatura. Entretanto, como essa correção tende a ser bastante trabalhosa e exige o conhecimento prévio das armaduras, podem ser adotados processos simplificados, como aquele indicado no item 3.7.1.

Mas algumas outras melhorias podem ser introduzidas em relação ao procedimento apresentado, como aquelas estudadas por LAI \& MacGREGOR (1983) e MacGREGOR (1993).

\subsection{O COEFICIENTE $\gamma_{\mathrm{Z}}$}

Aplicando-se o processo $\mathbf{P}-\Delta$ em estruturas regulares submetidas a forças horizontais e verticais uniformemente distribuídas, respectivamente, ao longo da altura e ao longo do eixo vertical, pode-se observar que as razões entre os acréscimos de deslocamentos referentes a uma certa iteração e os acréscimos referentes à iteração anterior, têm 
praticamente o mesmo valor, quaisquer que sejam essas iterações. Assumindo-se a hipótese de que essa razão seja realmente igual para todas as iterações, pode-se aproximar o desenvolvimento progressivo dos deslocamentos horizontais por uma progressão geométrica decrescente. O mesmo ocorre para os momentos fletores, como comentam VASCONCELOS \& FRANÇA (1997).

Com base nessas observações, FRANCO \& VASCONCELOS (1991) introduziram o chamado coeficiente $\gamma_{\mathbf{z}}$.

Seja $\mathbf{M}_{\mathbf{1}}$ o momento externo de primeira ordem na base da estrutura indeformada, $\Delta \mathbf{M}_{\mathbf{i}}$ o acréscimo no valor do momento na $\mathbf{i}$-ésima iteração e $\mathbf{M}_{2}$ o momento final após $\mathbf{n}$ iterações necessárias para o equilíbrio. Pode-se escrever:

$\mathrm{M}_{2}=\mathrm{M}_{1}+\Delta \mathrm{M}_{1}+\Delta \mathrm{M}_{2}+\ldots+\Delta \mathrm{M}_{\mathrm{n}}$

A razão desta progressão geométrica é dada por:

$$
\mathrm{r}=\frac{\Delta \mathrm{M}_{1}}{\mathrm{M}_{1}}=\frac{\Delta \mathrm{M}_{2}}{\Delta \mathrm{M}_{1}}=\frac{\Delta \mathrm{M}_{\mathrm{n}}}{\Delta \mathrm{M}_{\mathrm{n}-1}}
$$

e pode-se escrever:

$$
\mathrm{M}_{2}=\left(1+\mathrm{r}+\mathrm{r}^{2}+\mathrm{r}^{3}+\ldots+\mathrm{r}^{\mathrm{n}}\right) \cdot \mathrm{M}_{1}
$$

Quando $\mathbf{n}$ tende ao infinito,

$$
\begin{aligned}
& \mathrm{M}_{2}=\frac{1}{1-\mathrm{r}} \cdot \mathrm{M}_{1} \\
& \mathrm{M}_{2}=\frac{1}{1-\frac{\Delta \mathrm{M}_{1}}{\mathrm{M}_{1}}} \cdot \mathrm{M}_{1}
\end{aligned}
$$

Denominando-se $\gamma_{\mathrm{z}}$ o coeficiente que majora o momento de primeira ordem, pode-se escrever, considerando-se valores de cálculo:

$$
\gamma_{\mathrm{z}}=\frac{1}{1-\frac{\Delta \mathrm{M}_{\mathrm{d}}}{\mathrm{M}_{1 \mathrm{~d}}}}
$$


Este coeficiente pode ser entendido, portanto, como a soma da progressão geométrica cuja razão é a relação entre o acréscimo de momentos após a análise de primeira ordem $\Delta \mathbf{M}_{\mathbf{d}}$ e o momento de primeira ordem $\mathbf{M}_{\mathbf{1 d}}$.

Realizando-se o cálculo dos deslocamentos em regime elástico e considerando o comportamento não-linear dos materiais da forma simplificada apresentada em 3.7.1, o $\gamma_{\mathbf{z}}$ pode ser calculado com as ações verticais e horizontais de serviço, nos casos usuais de edifícios. Isso ocorre uma vez que o coeficiente de ponderação das ações verticais pode ser tomado igual a 1,0, e os coeficientes das ações horizontais e dos deslocamentos correspondentes serão cancelados no cálculo da razão da progressão. Mas em casos especiais, como garagens e bibliotecas, as ações verticais devem ser ponderadas com um coeficiente maior, considerado igual a 1,1. A demonstração de como pode ser introduzida a segurança no cálculo do coeficiente $\gamma_{\mathrm{z}}$ em diversas situações, inclusive em análises nãolineares, está indicada em FRANCO \& VASCONCELOS (1991) e VASCONCELOS \& FRANÇA (1997).

Quanto à sua aplicação, o $\gamma_{\mathrm{z}}$ pode ser usado para a classificação das estruturas quanto à deslocabilidade dos nós, de maneira análoga ao parâmetro $\alpha$. Seu valor é calculado e comparado com o valor limite, acima do qual a estrutura deve ser considerada de nós móveis. Lembrando-se do critério que dispensa a adição dos efeitos de segunda ordem se eles não ultrapassarem $10 \%$ dos de primeira ordem, a estrutura pode ser considerada de nós fixos quando $\gamma_{\mathrm{z}} \leq 1,1$.

A principal vantagem do $\gamma_{\mathrm{z}}$, entretanto, é que ele também pode ser utilizado como coeficiente majorador dos efeitos de primeira ordem. De acordo com as indicações de LIMA (1998) e com os comentários de FRANCO (1997), o coeficiente de majoração dos efeitos de primeira ordem de uma estrutura convencional, simétrica e com ações verticais e horizontais uniformemente distribuídas é exatamente o $\gamma_{\mathbf{z}}$. Mesmo nos casos em que não há uma simetria perfeita da estrutura e considerando-se a ação do vento como não uniforme, a aproximação dos resultados é muito boa.

Mas vale ressaltar que esta aproximação cai gradativamente com o aumento do valor do $\gamma_{\mathrm{z}}$. Segundo FRANCO \& VASCONCELOS (1991), a majoração é bem aplicada até $\gamma_{\mathbf{z}}=1,2$; segundo CARMO (1995), até $\boldsymbol{\gamma}_{\mathbf{z}}=1,3$.

Para estruturas cujo valor de $\gamma_{\mathbf{z}}$ seja superior ao limite adotado, deve-se utilizar um método mais rigoroso, como o $\mathbf{P}-\Delta$, por exemplo. 


\subsection{A INFLUÊNCIA DAS NÃO-LINEARIDADES}

Para que os efeitos de primeira e de segunda ordens de uma estrutura sejam determinados e sua estabilidade seja analisada, é necessária a criação de modelos que apresentem comportamentos próximos da realidade. Um importante fator a ser considerado é a influência das Não-Linearidades Física e Geométrica.

\subsubsection{NÃO-LINEARIDADE FÍSICA (NLF)}

A Não-Linearidade Física é o fenômeno correspondente à perda de proporcionalidade entre tensão aplicada e deformação sofrida pelo material. No caso do concreto, isso começa a acontecer antes mesmo de se atingir o limite de proporcionalidade, principalmente devido a fatores como a formação e a abertura de fissuras nas seções transversais das peças.

Para uma análise ideal de segunda ordem, o módulo de rigidez EI deveria refletir a distribuição das fissuras ao longo dos elementos, a fluência, a retração e o próprio comportamento inelástico do concreto e do aço das armaduras. Mas essa análise, para estruturas de edifícios, acaba tomando muito tempo e não compensando, frente aos bons resultados que os métodos simplificados podem fornecer.

A idéia atualmente mais aceita é a de se considerar uma porcentagem de perda da rigidez que simule os diversos aspectos anteriormente citados. KORDINA ${ }^{8}$ e $\mathrm{HAGE}^{9}$ apud MacGREGOR \& HAGE (1977) estudaram a variação de rigidez de diversos tipos de vigas (seções retangulares e T) e pilares de pórticos, submetidos a momentos devidos a carregamentos verticais, horizontais, e ambos combinados. Com base nos resultados desses estudos, MacGREGOR \& HAGE (1977) concluíram que, à medida que o carregamento é aumentado, os valores convergem para 0,4 EI para vigas e 0,8 EI para pilares, sendo E o módulo de deformação longitudinal secante do concreto e $\mathbf{I}$ o momento de inércia da seção bruta do elemento. Para lajes, segundo FRANCO (1997), pode ser utilizado 0,3 EI, valor próximo do proposto por MacGREGOR (1993).

Essa consideração da NLF através da redução do módulo de rigidez vem apresentando bons resultados, sendo inclusive adotada por diversos pesquisadores e normas internacionais.

\footnotetext{
${ }^{8}$ KORDINA, K. (1972). Cracking and crack control. In: INTERNATIONAL CONFERENCE ON PLANNING AND DESIGN OF TALL BUILDINGS, Bethlehem, USA. Proceedings. v.3, p.721-722. apud MacGREGOR \& HAGE (1977).

${ }^{9}$ HAGE, S.E. (1974). The second-order analysis of reinforced concrete frames. Edmonton, Canada. Thesis (Master of Science) - University of Alberta apud MacGREGOR \& HAGE (1977).
} 


\subsubsection{NÃO-LINEARIDADE GEOMÉTRICA (NLG)}

A Não-Linearidade Geométrica está relacionada com a saída da estrutura de sua posição indeformada, por exemplo, quando sobre ela incidem ações horizontais. A interação dos deslocamentos horizontais resultantes com as forças verticais torna esse afastamento crescente, até que a nova posição de equilíbrio, se ela existir, seja alcançada.

Os modelos usualmente adotados mantêm os nós em suas posições iniciais e modificam ou as forças incidentes (processo P- $\Delta$ ) ou a matriz de rigidez da estrutura, de acordo com os deslocamentos horizontais. Essas análises são mais refinadas e demandam ferramentas de análise mais sofisticadas, tornando-se, algumas vezes, inconvenientes.

Justamente por isso, em geral, considera-se obrigatória a consideração da NLG apenas para os casos de estruturas de nós móveis, nas quais não seja possível a utilização de um coeficiente majorador dos efeitos de primeira ordem.

\subsection{VERIFICAÇÃO DA ESTABILIDADE GLOBAL DE ACORDO COM A NBR 6118 (2000)}

A seguir, são indicados os procedimentos prescritos na NBR 6118 (2000) para as diversas etapas da verificação da estabilidade global.

\subsubsection{CONSIDERAÇÃO DAS AÇÕES HORIZONTAIS}

De acordo com a NBR 6118 (2000), são duas as ações horizontais a serem consideradas no projeto de edifícios: as forças devidas ao vento e as forças fictícias devidas ao desaprumo (imperfeições geométricas). Entretanto, esses carregamentos não precisam ser superpostos, sendo analisada apenas a situação mais desfavorável, ou seja, aquela que provoca o maior momento total na base da estrutura.

\section{a) Vento}

Para a maioria dos casos de edifícios usuais, o vento pode ser considerado como uma ação estática, distribuída segundo uma parábola do segundo grau ao longo da edificação ${ }^{10}$.

A NBR 6118 (2000) remete o cálculo das forças devidas ao ventos (forças de arrasto) para a NBR 6123 (1988), não sendo realizada nenhuma consideração adicional.

\footnotetext{
${ }^{10} \mathrm{Na}$ verdade, é comum se transformar essa ação distribuída em forças concentradas e aplicadas na altura dos pavimentos, tomando-se os quinhões relativos a cada um deles.
} 


\section{b) Desaprumo}

O desaprumo consiste em uma inclinação acidental, um deslocamento angular em relação à posição inicial, variável de edificação para edificação e decorrente de imperfeições construtivas (Figura 3.5). Seus efeitos podem ser significativos para a análise da estabilidade global.

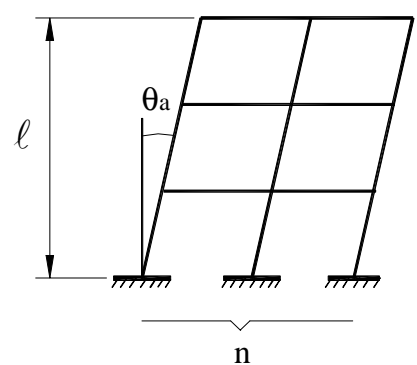

Figura 3.5 - Desaprumo

A NBR 6118 (2000) recomenda que o desaprumo seja estimado através da seguinte expressão:

$$
\theta_{\mathrm{a}}=\theta_{1} \cdot \sqrt{\frac{1+\frac{1}{\mathrm{n}}}{2}}
$$

sendo:

$\theta_{1}=\frac{1}{100 \cdot \sqrt{\ell}}$, tal que: $\left\{\begin{array}{l}\text { para estruturas de nós fixos : } \frac{1}{400} \leq \theta_{1} \leq \frac{1}{200} \\ \text { para estruturas de nós móveis : } \frac{1}{300} \leq \theta_{1} \leq \frac{1}{200}\end{array}\right.$

$\ell$ - altura total da estrutura, em metros;

n - número de pilares contínuos do pórtico.

Este deslocamento angular deve ser transformado em um conjunto de forças horizontais fictícias auto-equilibradas equivalentes (Figura 3.6), isto é, que provoque o mesmo momento em relação à base da estrutura. Essas forças $\Delta \mathbf{H}_{\mathbf{i}}$ é que deverão ser utilizadas na verificação da estabilidade global. Equacionando: 


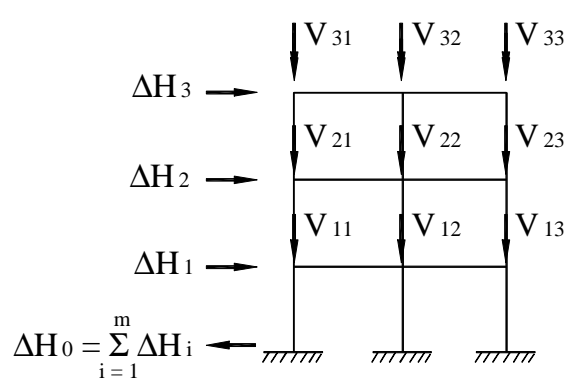

Figura 3.6 - Transformação do desaprumo em forças horizontais fictícias

$$
\Delta \mathrm{H}_{\mathrm{i}}=\sum_{\mathrm{j}=1}^{\mathrm{n}} \mathrm{V}_{\mathrm{ij}} \cdot \operatorname{tg} \theta_{\mathrm{a}}
$$

sendo:

n o número de pilares contínuos do pórtico;

$\boldsymbol{\theta}_{\mathrm{a}} \mathrm{o}$ ângulo de desaprumo do pórtico, em radianos (sendo $\theta_{\mathrm{a}} \approx \operatorname{tg} \theta_{\mathrm{a}}$ );

$\mathbf{V}_{\mathbf{i j}}$ a ação vertical aplicada pelo pavimento $\mathbf{i}$ no pilar $\mathbf{j}$.

\subsubsection{CLASSIFICAÇÃO QUANTO À DESLOCABILIDADE DOS NÓS}

A NBR 6118 (2000) enfatiza que todas as estruturas são deslocáveis. No entanto, por conveniência de análise, permite a seguinte classificação:

- pode-se considerar uma estrutura como de nós fixos se seus efeitos de segunda ordem forem inferiores a $10 \%$ dos de primeira ordem. Nesses casos, pode-se dispensar a adição da parcela dos esforços de segunda ordem no dimensionamento dos elementos;

- deve-se considerar uma estrutura como de nós móveis se seus efeitos de segunda ordem forem superiores a $10 \%$ dos de primeira ordem. Nesses casos, a parcela dos esforços de segunda ordem deve ser somada à de primeira ordem no dimensionamento dos elementos.

São indicados dois processos simplificados para esta classificação, sem a necessidade de um cálculo mais rigoroso: o parâmetro de instabilidade $\alpha$ e o coeficiente $\gamma_{\mathrm{z}}$. 


\subsubsection{DETERMINAÇÃO DO PARÂMETRO $\alpha$}

A NBR 6118 (2000) permite o uso do parâmetro de instabilidade $\alpha$ apenas para estruturas que possam ser consideradas simétricas. A condição para que elas possam ser classificadas como de nós fixos é a seguinte:

$$
\alpha \leq \alpha_{1}
$$

sendo:

$$
\alpha=H \cdot \sqrt{\frac{N_{k}}{(E I)_{e q}}}
$$

H - altura total do edifício;

$\mathbf{N}_{\mathbf{k}}$ - somatório das ações verticais atuantes, com valores característicos;

$(\mathbf{E I})_{\text {eq }}$ - módulo de rigidez equivalente da estrutura, obtido através da igualdade de flechas no topo entre a estrutura real e um pilar equivalente, engastado na base e livre no topo, de seção constante, e submetido ao mesmo carregamento horizontal característico;

$$
\begin{aligned}
& \alpha_{1}=0,2+0,1 \cdot \mathrm{n} \quad \text { se } \mathrm{n} \leq 3 ; \\
& \alpha_{1}=\left\{\begin{array}{l}
0,5 \text { (pórticos) } \\
0,6 \text { (associações) } \\
0,7 \text { (pilares - parede) }
\end{array} \quad \text { se } \mathrm{n} \geq 4 ;\right.
\end{aligned}
$$

n - número de pavimentos do edifício.

\subsubsection{DETERMINAÇÃO DO COEFICIENTE $\gamma_{\mathrm{Z}}$}

Pode-se determinar o coeficiente $\gamma_{\mathrm{z}}$ a partir de uma análise linear de primeira ordem que considere a NLF através das expressões do item 3.8.5. Esse coeficiente pode funcionar de modo análogo ao parâmetro $\alpha$, na classificação da estrutura quanto à deslocabilidade dos nós, e também como majorador dos efeitos de primeira ordem.

De acordo com a NBR 6118 (2000), a condição para que uma estrutura seja considerada como de nós fixos é a seguinte:

$$
\gamma_{\mathrm{z}} \leq 1,1
$$


sendo:

$$
\gamma_{\mathrm{z}}=\frac{1}{1-\frac{\Delta \mathrm{M}_{\text {tot, } \mathrm{d}}}{\mathrm{M}_{1, \mathrm{tot}, \mathrm{d}}} \cdot \frac{\mathrm{a}_{\mathrm{h}}+\mathrm{a}_{\mathrm{v}}}{\mathrm{a}_{\mathrm{h}}}}
$$

$\Delta \mathbf{M}_{\text {tot,d }}$ - acréscimo de momentos após a análise de primeira ordem, dado pela soma dos produtos das forças verticais atuantes em cada pavimento (com valores de cálculo) pelos respectivos deslocamentos horizontais:

$$
\ddot{\mathrm{A}} \mathrm{M}_{\mathrm{tot}, \mathrm{d}}=\sum\left(\mathrm{P}_{\mathrm{id}} \cdot \mathrm{y}_{\mathrm{id}}\right)
$$

$\mathbf{M}_{1, \text { tot,d }}$ - momento de primeira ordem, dado pela soma dos produtos de todas as forças horizontais da estrutura (com valores de cálculo) pelas distâncias em relação à base:

$$
\mathrm{M}_{1, \mathrm{tot}, \mathrm{d}}=\sum\left(\mathrm{FH}_{\mathrm{id}} \cdot \mathrm{x}_{\mathrm{i}}\right)
$$

$\mathbf{P}_{\text {id }}$ - força vertical atuante no pavimento $\mathbf{i}$, com valor de cálculo;

$\mathbf{y}_{\mathbf{i d}}$ - deslocamento horizontal do pavimento $\mathbf{i}$, com valor de cálculo;

$\mathbf{F H}_{\text {id }}$ - força horizontal aplicada no pavimento i, com valor de cálculo;

$\mathbf{x}_{\mathbf{i}}$ - distância vertical do pavimento $\mathbf{i}$ à base;

$\mathbf{a}_{\mathbf{h}}$ - deslocamento horizontal no nível do centro de gravidade das forças verticais da estrutura, decorrente da incidência apenas de ações horizontais;

$\mathbf{a}_{\mathbf{v}}$ - deslocamento horizontal no nível do centro de gravidade das forças verticais da estrutura, decorrente da incidência apenas de ações verticais.

\subsubsection{CONSIDERAÇÃO SIMPLIFICADA DA NÃO-LINEARIDADE FÍSICA}

Para a análise da estabilidade global, permite-se considerar a não-linearidade física de maneira aproximada, através das seguintes reduções do módulo de rigidez:

- lajes: $(\mathrm{EI})_{\mathrm{sec}}=0,3 \mathrm{E}_{\mathrm{c}} \mathrm{I}_{\mathrm{c}}$;

- vigas: $(\mathrm{EI})_{\mathrm{sec}}=0,4 \mathrm{E}_{\mathrm{c}} \mathrm{I}_{\mathrm{c}}$, para $\mathrm{A}_{\mathrm{s}}^{\prime} \neq \mathrm{A}_{\mathrm{s}}$;

$$
(\mathrm{EI})_{\mathrm{sec}}=0,5 \mathrm{E}_{\mathrm{c}} \mathrm{I}_{\mathrm{c}} \text {, para } \mathrm{A}_{\mathrm{s}}^{\prime}=\mathrm{A}_{\mathrm{s}} \text {; }
$$

- pilares: $(\mathrm{EI})_{\mathrm{sec}}=0,8 \mathrm{E}_{\mathrm{c}} \mathrm{I}_{\mathrm{c}}$; 
sendo:

$\mathbf{I}_{\mathbf{c}}$ - momento de inércia da seção bruta de concreto, incluindo mesas colaborantes;

$\mathbf{E}_{\mathbf{c}}$ - módulo de deformação longitudinal inicial do concreto, dado por:

$$
\mathrm{E}_{\mathrm{c}}=5600 \cdot \sqrt{\mathrm{f}_{\mathrm{ck}}} \quad(\mathrm{MPa})
$$

$\mathbf{f}_{\text {ck }}$ - resistência característica do concreto à compressão, em MPa;

$\mathbf{A}_{\text {s - área da armadura de tração; }}$

$\mathbf{A}^{\prime}{ }_{\mathrm{s}}$ - área da armadura de compressão.

Quando a estrutura de contraventamento for composta apenas por vigas e pilares, permite-se considerar, para esses dois elementos, $(\mathrm{EI})_{\mathrm{sec}}=0,7 \mathrm{E}_{\mathrm{c}} \mathrm{I}_{\mathrm{c}}$.

\subsubsection{ANÁLISE DE ESTRUTURAS DE NÓS MÓVEIS}

Como já foi mencionado, os efeitos de segunda devem ser obrigatoriamente considerados para o dimensionamento dos elementos em estruturas de nós móveis. Sua análise pode ser feita de três maneiras:

- utilizando o coeficiente $\gamma_{\mathrm{z}}$ como majorador, que é uma solução aproximada e válida apenas para estruturas regulares em que $\gamma_{\mathrm{z}} \leq 1,3$. A avaliação dos esforços finais (primeira ordem + segunda ordem) é feita com a multiplicação dos momentos de primeira ordem por $0,95 \cdot \gamma_{\mathrm{Z}}$;

- utilizando o processo P- $\Delta$, para considerar a NLG, e os valores dos módulos de rigidez reduzidos do item 3.8.5, para considerar a NLF;

- realizando uma análise não-linear de segunda ordem, considerando a NLG através de modificações na matriz de rigidez da estrutura, e a NLF através dos diagramas momento-curvatura de cada seção.

\subsection{COMPLEMENTAÇÕES E COMENTÁRIOS SOBRE A NBR 6118 (2000) - ESTABILIDADE}

Para melhorar a verificação da estabilidade global e simplificá-la, além de dar mais destaque a certos aspectos importantes, algumas diretrizes adicionais devem ser atendidas. São recomendadas sua análise e incorporação na versão definitiva da nova NBR 6118. 


\subsubsection{OBTENÇÃO DO MÓDULO DE RIGIDEZ EQUIVALENTE (EI) eq}

A NBR 6118 (2000) determina o módulo de rigidez equivalente de uma estrutura a partir do "carregamento horizontal característico". Incide-se este carregamento sobre a estrutura, determina-se o deslocamento no topo e calcula-se, então, o módulo de rigidez de um pilar equivalente, que apresente este mesmo deslocamento sob a ação das mesmas forças.

O problema é que, considerando como "carregamento horizontal característico" as forças devidas ao vento ou ao desaprumo, aplicadas no nível de cada pavimento, seu arranjo varia de caso para caso e depende do número de pavimentos e das proporções dos pésdireitos. Sendo assim, não é possível se encontrar uma expressão geral para relacionar o módulo de rigidez equivalente e o deslocamento no topo. A obtenção de (EI) eq estaria relacionada, portanto, ou à determinação de uma equação da linha elástica para cada edifício estudado, ou à resolução da estrutura por tentativas.

Dadas as simplificações embutidas no próprio conceito de rigidez equivalente, considera-se esses processos trabalhosos demais e pouco apropriados, em termos práticos. $\mathrm{O}$ “carregamento horizontal característico" poderia ser substituído por um arranjo único, cuja expressão para o cálculo de a fosse conhecida e facilmente empregada. A utilização de uma força uniformemente distribuída ao longo da altura da edificação, como já foi comentado no item 3.4.1, parece apropriada e permite o cálculo do módulo de rigidez equivalente através de uma expressão bastante simples (eq.3.1).

Recomenda-se, então, a introdução de uma referência quanto à consideração desse tipo de carregamento na versão definitiva da NBR 6118, com o objetivo de fornecer ao projetista uma forma simples para a obtenção de $(\mathbf{E I})_{\text {eq }}$. Propõe-se um comentário no anexo A.15, relativo ao item 15.4.1.

- Sugestão de redação:

"No caso de edifícios, o carregamento horizontal característico pode ser considerado uniformemente distribuído ao longo da altura, sendo o valor da rigidez equivalente obtido através da expressão $(E I)_{e q}=\frac{q \cdot H^{4}}{8 \cdot a} "$.

\subsubsection{FORMULAÇÃO DO COEFICIENTE $\gamma_{\mathrm{Z}}$}

A introdução dos deslocamentos $\mathbf{a}_{\mathbf{v}}$ e $\mathbf{a}_{\mathbf{h}}$ no denominador da eq.(3.4), em relação à eq.(3.2), visa à consideração da influência da excentricidade existente entre o ponto de aplicação das forças verticais e o centro de gravidade do pavimento, na análise da estabilidade global. É que essa excentricidade propicia um deslocamento horizontal da 
estrutura em relação à sua posição inicial, mesmo ela estando submetida apenas a ações verticais.

Nos edifícios assimétricos, há um certo afastamento em relação às hipóteses iniciais adotadas para o $\gamma_{z}$, comentadas no item 3.6, pois os efeitos da excentricidade passam a ser mais significativos para a determinação dos esforços e deslocamentos. Nestes casos, acredita-se que, mesmo com a modificação introduzida na eq.(3.4) para considerar esses efeitos, a utilização deste método simplificado pode não conduzir a bons resultados, principalmente em estruturas com grandes excentricidades. Seria mais indicada, então, uma análise mais rigorosa, que permitisse a consideração da NLG.

Nos edifícios convencionais onde há uma certa simetria de forma, por outro lado, também pode ser considerada a simetria na aplicação do carregamento. O ponto de aplicação da resultante das forças verticais tende a coincidir com o centro de gravidade do pavimento, e $\mathbf{a}_{\mathbf{v}}$ será muito pequeno em relação a $\mathbf{a}_{\mathbf{h}}$. CARMO (1995) também observa, inclusive com um exemplo, que a influência da excentricidade em estruturas regulares é pequena e pode ser desprezada. Para esses casos, então, a expressão do $\gamma_{\mathbf{z}}$ proposta pela NBR 6118 (2000) recai na própria eq.(3.2), que pode ser reescrita como:

$$
\gamma_{\mathrm{z}}=\frac{1}{1-\frac{\Delta \mathrm{M}_{\mathrm{tot}, \mathrm{d}}}{\mathrm{M}_{1, \mathrm{tot}, \mathrm{d}}}}
$$

Assim sendo, considera-se mais prudente a substituição da eq.(3.4) pela eq.(3.8) na versão definitiva da NBR 6118, enfatizando-se sua limitação ao caso de estruturas sem grandes assimetrias. Para estes casos, propõe-se a introdução de um comentário no anexo A.15, relativo ao item 15.4.2, que indique a utilização de um método mais rigoroso.

- Sugestão de redação:

"Nos casos de estruturas com grandes assimetrias, a análise de segunda ordem deve considerar os efeitos da não-linearidade geométrica. Podem ser utilizados os processos descritos em 15.6.1" (item 3.8.6) 


\subsubsection{UTILIZAÇÃO DO PARÂMETRO $\alpha$ E DO COEFICIENTE $\gamma_{\mathrm{Z}}$ NA CLASSIFICAÇÃO QUANTO À DESLOCABILIDADE DOS NÓS}

Com base nos estudos de LIMA (1998), LIMA \& GUARDA (1999a) analisaram a eficiência do parâmetro $\alpha$ e do coeficiente $\gamma_{z}$ na classificação das estruturas quanto à deslocabilidade dos nós. Essa eficiência foi determinada através de uma comparação com as indicações fornecidas pelo processo $\mathbf{P}-\Delta$.

Foram estudados edifícios reais, com estruturas de concreto armado convencionais e bem comportadas, com diferentes números de pavimentos (variou-se entre 14 e 25), e diferentes sistemas de contraventamento (estruturas contraventadas por pórticos, pilaresparede e associações entre os dois). Todos os edifícios foram modelados como pórticos tridimensionais no programa SAP90, utilizando as particularidades das formas de todos os níveis (maior rigidez dos pavimentos inferiores) e considerando as lajes como diafragmas rígidos. As ações horizontais atuantes foram as do vento, calculadas de acordo com as recomendações da NBR 6123 (1988).

Para cada edifício, foram calculados os valores do parâmetro $\alpha$, do parâmetro de forma $\psi$, do $\boldsymbol{\alpha}_{\text {lim }}$ e do coeficiente $\gamma_{\mathrm{z}}$, e então feita a classificação. A seguir, aplicou-se o processo $\mathbf{P}-\Delta$, para o qual, com os resultados da última iteração (posição de equilíbrio) e da análise de primeira ordem, foram determinados os acréscimos percentuais sofridos pelo deslocamento no topo da estrutura, pelos momentos fletores e forças cortantes nas vigas, e pelas forças normais e momentos fletores na base e no topo dos pilares, no nível de cada pavimento. Analisando-se os valores desses acréscimos, foi feita a classificação quanto à deslocabilidade dos nós pelo $\mathbf{P}-\Delta$.

Os resultados obtidos indicaram que, em $40 \%$ dos casos, o parâmetro $\alpha$ classificou como de nós móveis estruturas que poderiam ser de nós fixos. Já que os valores limites propostos pela Norma pareceram bastante adequados se comparados com os valores teóricos obtidos a partir do coeficiente de forma, a falta de precisão do parâmetro $\alpha$ possivelmente está mais relacionada com o excesso de simplificações do método que propriamente com um problema de valor limite. O coeficiente $\gamma_{\mathbf{z}}$, por outro lado, forneceu a classificação correta para todos os casos estudados.

Observe-se que, em relação às ações, por exemplo, o $\gamma_{z}$ possibilita a consideração de uma força variável com a altura (como as forças de arrasto), enquanto o $\alpha$ é calculado com uma força uniformemente distribuída. Para que essa melhoria de hipótese pudesse ser estendida ao cálculo do parâmetro $\alpha$, seriam necessários estudos adicionais sobre a obtenção da linha elástica, como foi comentado no item 3.9.1. Mas como o coeficiente $\gamma_{z}$ não 
considera a forma da elástica da edificação, e sim, os momentos provocados pelo seu carregamento, pode-se submeter o modelo estudado a condições mais próximas das reais.

Assim, o parâmetro $\alpha$ pode até ser utilizado como um "termômetro" na fase inicial do projeto, um indicativo da rigidez da estrutura, mas, para a análise da deslocabilidade dos nós, pode fornecer resultados muito conservadores. Com os recursos e ferramentas disponíveis para a análise estrutural, e com a necessidade de se atentar para o aspecto econômico, julga-se que não é mais necessário se trabalhar com um parâmetro tão simplificado, tendo-se à disposição um outro que, além de fornecer resultados muito melhores, pode funcionar como majorador dos efeitos de primeira ordem - o $\boldsymbol{\gamma}_{\mathbf{z}}$. Considera-se importante alguma indicação da norma a esse respeito.

Propõe-se, então, a introdução de um outro comentário ao item 15.4.2 no anexo A.15.

- Sugestão de redação:

"Deve-se dar preferência à utilização do coeficiente $\gamma_{z}$ para se verificar a possibilidade de dispensa da consideração dos esforços globais de $2^{a}$ ordem. Seus resultados são menos conservadores que os do parâmetro de instabilidade."

\subsubsection{UTILIZAÇÃO DO COEFICIENTE $\gamma_{\mathrm{Z}}$ COMO MAJORADOR}

Com as facilidades dos computadores e com o desenvolvimento de novas ferramentas para a análise estrutural, não seria necessária a distinção entre estruturas de nós móveis e de nós fixos. Como se sabe, toda estrutura é deslocável, sendo seus deslocamentos mais ou menos relevantes. Assim, pode-se dizer que, em termos práticos, não interessa se os efeitos de segunda ordem são maiores ou menores que $10 \%$ dos de primeira ordem. Se o valor do coeficiente de majoração é conhecido, deveria ser considerado na determinação dos esforços finais, mesmo sendo pequeno.

LIMA \& GUARDA (1999b), com base nos estudos de LIMA (1998), avaliaram a eficiência do $\gamma_{\mathrm{z}}$ como coeficiente majorador dos efeitos de primeira ordem e os limites para sua aplicação. Essa eficiência foi mais uma vez determinada através de uma comparação com as indicações fornecidas pelo processo $\mathbf{P}-\Delta$, como já foi mencionado no item 3.9.3.

Para cada um dos edifícios estudados, calcularam-se os valores do coeficiente $\gamma_{\mathrm{z}}$, e aplicou-se o processo P- $\Delta$. Foram realizados dois tipo de análise: a primeira, em termos dos acréscimos médios indicados pelo processo $\mathbf{P}-\Delta$ para cada um dos efeitos de segunda ordem 
(deslocamentos no topo da estrutura, momentos fletores e forças cortantes nas vigas, e forças normais e momentos fletores na base e no topo dos pilares); e a segunda, observando a variação desses efeitos em função da altura da edificação.

Estendendo-se esses estudos, como indicado no Anexo D, percebeu-se que a majoração com $0,95 \gamma_{\mathrm{z}}$ se distancia mais das médias do $\mathbf{P}-\Delta$ para todos os efeitos de segunda ordem, enquanto que o uso do $\gamma_{\mathrm{z}}$, com seu valor integral, mostra-se bastante eficiente e praticamente coincide com as médias do processo mais rigoroso. Para os dados de CARMO (1995) e de PINTO (1997), a conclusão é a mesma.

Considerando-se a variação que cada um dos efeitos de segunda ordem sofreu com a altura do edifício, atentou-se para as seguintes particularidades:

- os incrementos das forças normais dos pilares tendem a sofrer pequenos decréscimos à medida que se aproximam do topo, mantendo-se próximos aos valores de $\gamma_{\mathrm{z}}$ ao longo de toda a altura;

- os momentos fletores na base e no topo dos pilares e os momentos fletores e forças cortantes nas vigas, que têm variações semelhantes, sofrem um aumento até cerca de $25 \%$ da altura, um decréscimo até aproximadamente $75 \%$ da altura, seguido de um leve aumento até o topo. Nos pavimentos inferiores, $0,95 \gamma_{\mathrm{z}}$ tende a subestimar mais os acréscimos, enquanto $\gamma_{\mathrm{z}}$ tende a superestimá-los mais na parte superior.

Deve-se notar que, no caso de edifícios mais altos que os estudados, os efeitos de segunda ordem tendem a ser ainda mais significativos nos pavimentos inferiores, e a subestimativa decorrente da utilização de $0,95 \gamma_{\mathrm{z}}$ poderá ser, proporcionalmente, ainda maior.

Com isso, até se poderia utilizar a sugestão de LIMA (1998), de adotar $1,2 \gamma_{\mathbf{z}}$ nos primeiros $25 \%$ da altura, e $0,8 \gamma_{\mathrm{z}}$ nos últimos $25 \%$ da altura, aproximando mais os resultados do processo P- $\Delta$. Mas, de uma forma geral, tomando-se um valor único, o que se pode constatar é que a majoração utilizando o $\gamma_{\mathrm{z}}$ já é satisfatória, e mostra-se mais eficiente que aquela feita com $0,95 \gamma_{\mathrm{z}}$.

Quanto à questão do valor limite para a utilização do $\gamma_{\mathrm{z}}$ como majorador, foram traçadas retas representativas das variações dos valores de $\gamma_{\mathbf{z}}$ em relação aos acréscimos médios sugeridos pelo processo $\mathbf{P}-\Delta$, para cada um dos efeitos de segunda ordem e para a média entre eles. A análise efetuada também se encontra no Anexo D.

Observou-se que, à medida que os valores dos acréscimos aumentam, todas as retas vão se afastando daquela correspondente a valores de acréscimos iguais para $\gamma_{\mathbf{z}}$ e $\mathbf{P}-\Delta$. Como 
a partir de $20 \%$ as diferenças já se mostraram mais significativas, concluiu-se que o limite recomendado deve ficar realmente em torno de 1,2. PINTO (1997) chega a conclusão semelhante a partir da análise de cada um dos esforços médios e distribuídos em faixas de altura, em 25 edifícios de concreto armado.

No estudo de CARMO (1995), em que o limite de $\mathbf{1 , 3}$ é proposto para o $\gamma_{\mathbf{z}}$, todos os edifícios estudados tinham estruturas de contraventamento semelhantes $(\psi \approx 0,6)$ e foram modelados apenas com o pavimento-tipo. Além disso, foi adotada a redução da rigidez igual para todos os elementos $(0,7 \mathbf{E I})$, que, como será comentado no item 3.9.5, pode conduzir a subestimativas dos deslocamentos, a alterações dos valores de $\gamma_{z}$ e, por fim, a modificações dos resultados das análises.

Considerando-se o fato de o limite de $\mathbf{1 , 2}$ ter sido obtido tanto a partir de análises que apresentam melhorias em relação às anteriormente citadas (com estruturas com diversos tipos de contraventamento, consideração das particularidades das formas de cada pavimento e utilização de reduções diferenciadas para as vigas e pilares), quanto a partir dos estudos de PINTO (1997) (com outras estruturas e uma análise estatística mais refinada) é razoável que a questão do valor limite seja revista, se possível, com mais dados de outros exemplos.

Portanto, recomendam-se duas alterações no item 15.6.1, com o objetivo de se fazer a majoração dos esforços de primeira ordem com o valor integral de $\gamma_{\mathbf{z}}$, e até o limite de $\mathbf{1 , 2}$.

- Sugestão de redação:

"Solução aproximada para a determinação dos esforços globais de $2^{a}$ ordem, válida para estruturas regulares, consiste na avaliação dos esforços finais ( $1^{a}$ ordem $+2^{a}$ ordem) pela multiplicação por $\tilde{a}_{z}$ dos momentos de $1^{a}$ ordem, desde que $\tilde{a}_{z} \leq 1,2$ ”.

\subsubsection{CONSIDERAÇÃO SIMPLIFICADA DA NLF}

As análises de PINTO (1997) para as vigas mostraram que a redução da rigidez varia de acordo com as condições de apoio. Foram obtidos valores de 0,4 EI a 0,6 EI para vigas biapoiadas, e de 0,6 EI a 0,64 EI para vigas biengastadas, sendo os inferiores correspondentes ao domínio 2 e os superiores, ao limite entre os domínios 3 e 4 . Como as vinculações estudadas foram as extremas, as vigas usuais devem apresentar reduções intermediárias entre as duas situações.

PINTO (1997) observou também que a redução da rigidez para os casos com armaduras duplas é menor que para armaduras simples. Esse resultado é bastante razoável, uma vez que a armadura contribui para o controle da fissuração. 
Frente a essas considerações, acredita-se que esteja um pouco baixo o valor de 0,4 EI proposto pela NBR 6118 (2000) para todos os casos em que $\mathrm{A}_{\mathrm{s}}^{\prime} \neq \mathrm{A}_{\mathrm{s}}$, que é a situação mais usual. Talvez fosse melhor se prever reduções diferentes para armaduras simples e duplas, mas esse processo poderia se tornar um pouco trabalhoso. Sugere-se, então, a análise de um valor único de 0,5 EI para todas as vigas, o que está coerente com os resultados de PINTO (1997).

Já nas análises para pilares, PINTO (1997) obteve uma redução de rigidez diferenciada a depender da solicitação predominante (força normal ou momento fletor). Mas o valor de 0,8 EI, adotado pela NBR 6118 (2000), está a favor da segurança.

De qualquer forma, parece acertada a diferenciação entre as reduções de vigas e de pilares, uma vez que os tipos de solicitação, de fissuração e de ruptura de um e de outro elementos são completamente diferentes. Inclusive, vários estudos já comprovaram esse comportamento experimentalmente, como foi mencionado no item 3.7.1.

A NBR 6118 (2000), entretanto, ainda permite a adoção do módulo de rigidez único, de 0,7 EI tanto para vigas quanto para pilares, possivelmente no intuito de facilitar a análise da estrutura. Esse procedimento deve ser visto com algumas ressalvas pois, como comenta CARMO (1995), as diferenças obtidas para os deslocamentos não devem ser ignoradas, principalmente nos casos em que as vigas contribuam significativamente para a rigidez global. Permitir que o valor do módulo de rigidez das vigas seja aumentado de 0,4 EI para $0,7 \mathbf{E I}$, o que representa cerca de $75 \%$, pode inclusive levar à consideração de uma estrutura de nós móveis como fixos, num caso extremo.

Por isso, se a versão definitiva da NBR 6118 realmente permitir uma redução única do módulo de rigidez, acredita-se que o valor de 0,7 EI deva ser revisto.

\subsection{EXEMPLO DE CÁLCULO}

Para exemplificar a utilização dos critérios para a verificação da estabilidade global, foi analisado um edifício residencial de 14 pavimentos, cobertura com piscina, play-ground e garagem, formando 16 níveis, além da fundação. Adotou-se $25 \mathrm{MPa}$ como resistência característica do concreto.

A forma básica do pavimento-tipo, bem como o corte esquemático, encontram-se na Figura 3.7. O nível da garagem encontra-se no subsolo (nível $0,0 \mathrm{~m}$ ) e, dentre os 14 pavimentos, 13 são tipo. Os pés-direitos, as alturas e as forças verticais por pavimento (valores característicos) encontram-se na Tabela 3.2. 


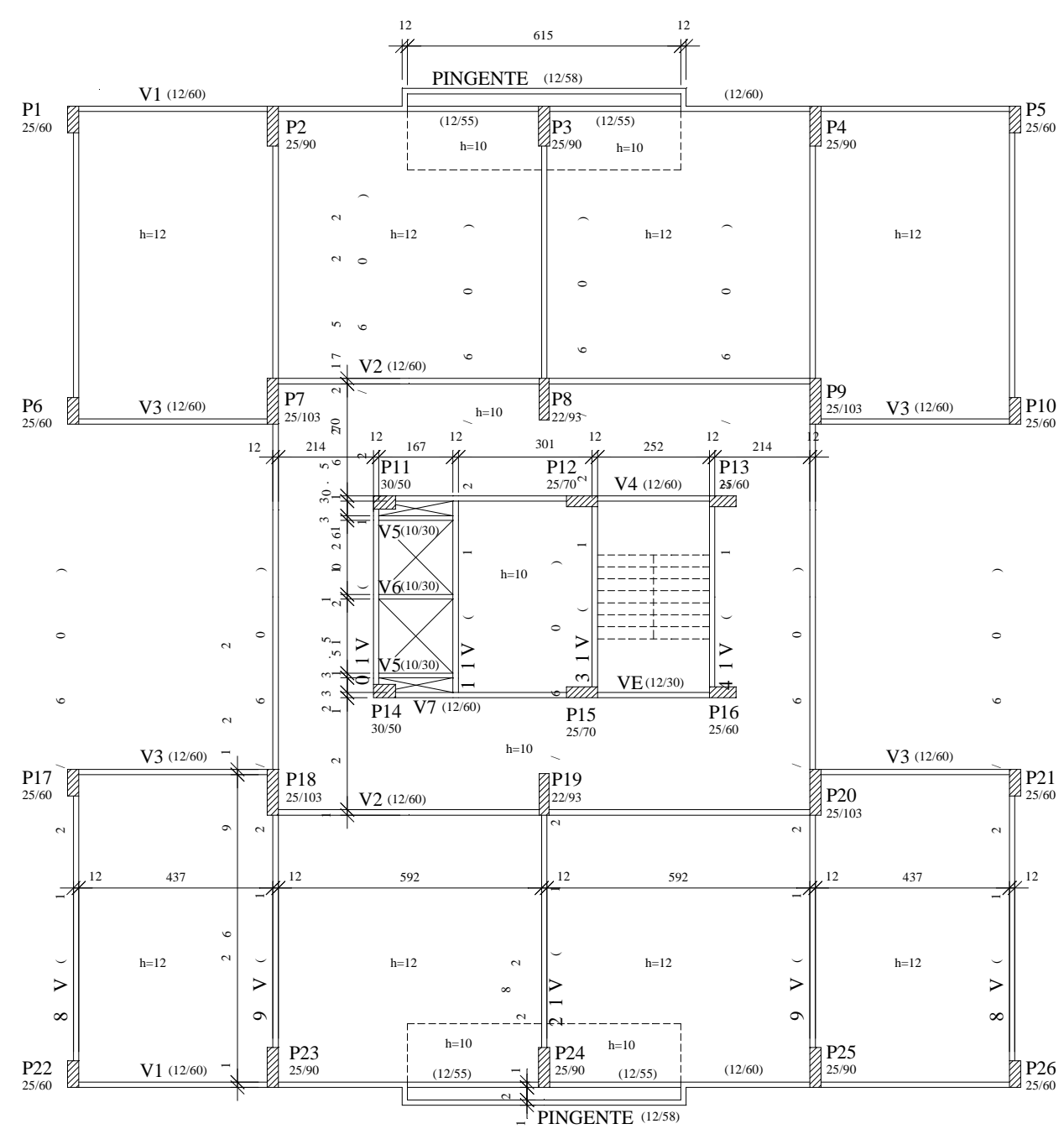

PLANTA BAIXA

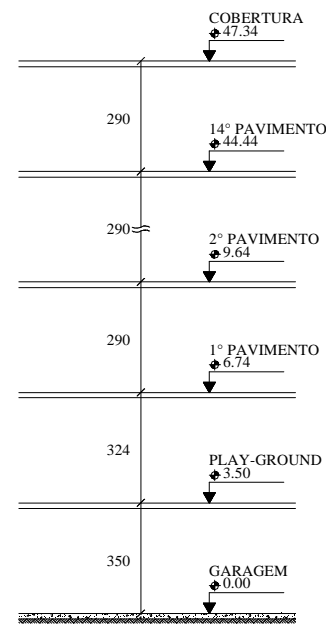

CORTE ESQUEMÁTICO

Figura 3.7 - Edifício estudado 
Tabela 3.2 - Pés-direitos, alturas e forças verticais dos pavimentos

\begin{tabular}{|c|c|c|c|}
\hline Pavimento & Pé-direito (m) & $\begin{array}{c}(1) \\
x_{i}(m) \\
\end{array}$ & $\begin{array}{c}(2) \\
P_{i}(k N)\end{array}$ \\
\hline Cob. & 2,90 & 47,34 & 7505 \\
\hline $14^{\circ}$ & 2,90 & 44,44 & 4389 \\
\hline $13^{o}$ & 2,90 & 41,54 & 4389 \\
\hline $12^{\circ}$ & 2,90 & 38,64 & 4389 \\
\hline $11^{o}$ & 2,90 & 35,74 & 4389 \\
\hline $10^{\circ}$ & 2,90 & 32,84 & 4389 \\
\hline $9^{o}$ & 2,90 & 29,94 & 4389 \\
\hline $8^{o}$ & 2,90 & 27,04 & 4389 \\
\hline $7^{o}$ & 2,90 & 24,14 & 4389 \\
\hline $6^{0}$ & 2,90 & 21,24 & 4389 \\
\hline $5^{\circ}$ & 2,90 & 18,34 & 4389 \\
\hline $4^{o}$ & 2,90 & 15,44 & 4389 \\
\hline $3^{o}$ & 2,90 & 12,54 & 4389 \\
\hline $2^{o}$ & 2,90 & 9,64 & 4389 \\
\hline $1^{o}$ & 3,24 & 6,74 & 4433 \\
\hline$P . G$. & 3,50 & 3,50 & 9023 \\
\hline & \multicolumn{3}{|c|}{$N=\sum P_{i}=78018 k N$} \\
\hline
\end{tabular}

\subsubsection{CRITÉRIOS DE MODELAGEM}

A estrutura foi modelada como um pórtico espacial no programa SAP 90, considerando-se as lajes trabalhando como diafragmas rígidos. A solidarização entre as vigas e os pilares foi representada com a utilização de trechos rígidos. Vale ressaltar que as formas de todos os níveis foram consideradas com suas peculiaridades.

Para o cálculo do módulo de deformação do concreto, foi utilizada a eq.(3.7). A Não-Linearidade Física foi considerada de forma simplificada, através da redução dos módulos de rigidez, sendo 0,5 EI para as vigas e 0,8 EI para os pilares. 


\subsubsection{DETERMINAÇÃO DO PARÂMETRO $\alpha$}

\section{Parâmetro $\alpha(e q .3 .3)$}

Para o cálculo do parâmetro $\alpha$, aplicou-se uma força horizontal unitária uniformemente distribuída, como comentado no item 3.4.1. Os deslocamentos obtidos no topo, para as direções $\mathbf{X}$ e $\mathbf{Y}$, foram:

$$
\begin{aligned}
& a_{x}=0,002086 \mathrm{~cm} \\
& a_{y}=0,001715 \mathrm{~cm}
\end{aligned}
$$

Pela eq.(3.1):

$$
\begin{aligned}
& (\mathrm{EI})_{\text {eqx }}=\frac{1 \cdot 47,34^{4}}{8 \cdot 0,002086}=3,01 \cdot 10^{8} \mathrm{kN} \cdot \mathrm{m}^{2} \\
& (\mathrm{EI})_{\text {eqy }}=\frac{1 \cdot 47,34^{4}}{8 \cdot 0,001715}=3,66.10^{8} \mathrm{kN} \cdot \mathrm{m}^{2}
\end{aligned}
$$

Assim,

$$
\begin{aligned}
& \alpha_{x}=47,34 \cdot \sqrt{\frac{78018}{3,01 \cdot 10^{8}}}=0,76 \\
& \alpha_{y}=47,34 \cdot \sqrt{\frac{78018}{3,66 \cdot 10^{8}}}=0,69
\end{aligned}
$$

De acordo com o item 3.4.2, como a estrutura tem comportamento de pórtico, $\alpha_{\lim x}=\alpha_{\lim y}=0,5$. Daí:

$$
\begin{aligned}
& \alpha_{x} \geq \alpha_{\lim , x} \\
& \alpha_{y} \geq \alpha_{\text {lim }, y}
\end{aligned}
$$

Portanto, a estrutura é classificada como de nós móveis nas duas direções.

\subsubsection{DETERMINAÇÃO DO COEFICIENTE $\gamma_{\mathrm{Z}}$}

Para a determinação do coeficiente $\gamma_{z}$, utilizou-se a ação do vento, uma vez que esta situação mostrou-se mais crítica que o desaprumo tanto para a direção $\mathbf{X}$ quanto para a direção $\mathbf{Y}$. 


\section{a) Cálculo das forças de arrasto}

O cálculo das forças de arrasto foi feito de acordo com as recomendações da NBR 6123 (1988). Foram adotados:

- Velocidade básica do vento:

$\mathrm{V}_{\mathrm{o}}=30 \mathrm{~m} / \mathrm{s}$

- Fatores $\mathbf{S}_{1}, \mathbf{S}_{2}$ e $\mathbf{S}_{3}$ :

$\mathrm{S}_{1}=1,0 \quad$ (terreno fracamente acidentado)

$\mathrm{S}_{2}=($ categoria IV e classe $\mathrm{B})$

$\mathrm{S}_{3}=1,0 \quad$ (edificações para residência)

- Coeficientes de arrasto para as direções $\mathbf{X}$ e $\mathbf{Y}$ :

$\mathrm{C}_{\mathrm{ax}}=1,29$

$\mathrm{C}_{\mathrm{ay}}=1,24$

Os valores característicos das forças de arrasto são apresentados na Tabela 3.3.

Tabela 3.3 - Forças de arrasto

\begin{tabular}{|c|c|c|}
\hline Pavimento & $\begin{array}{c}(3) \\
F_{a i, x}(k N)\end{array}$ & $\begin{array}{c}(4) \\
F_{a i, y}(k N)\end{array}$ \\
\hline Cob. & 23,33 & 21,77 \\
\hline $14^{o}$ & 45,93 & 42,85 \\
\hline $13^{o}$ & 45,16 & 42,14 \\
\hline $12^{\circ}$ & 44,35 & 41,38 \\
\hline $11^{o}$ & 43,50 & 40,58 \\
\hline $10^{\circ}$ & 42,59 & 39,73 \\
\hline $9^{o}$ & 41,61 & 38,82 \\
\hline $8^{o}$ & 40,57 & 37,85 \\
\hline $7^{o}$ & 39,43 & 36,79 \\
\hline $6^{0}$ & 38,19 & 35,63 \\
\hline $5^{\circ}$ & 36,82 & 34,35 \\
\hline $4^{o}$ & 35,26 & 32,90 \\
\hline $3^{o}$ & 33,48 & 31,23 \\
\hline $2^{o}$ & 31,35 & 29,25 \\
\hline $1^{o}$ & 30,34 & 28,31 \\
\hline P.G. & 13,59 & 12,68 \\
\hline
\end{tabular}




\section{b) Cálculo do Coeficiente $\gamma_{\mathrm{z}}$}

\section{Coeficiente $\gamma_{\underline{z}}($ eq.3.4)}

Aplicando-se as forças de arrasto no nível de cada pavimento, foram obtidos os deslocamentos horizontais apresentados na Tabela 3.4 e na Tabela 3.5, para as direções $\mathbf{X}$ e $\mathbf{Y}$, respectivamente.

Pela eq.(3.5), considerando-se $\boldsymbol{\gamma}_{\mathrm{f}}=\mathbf{1 , 0}$ para as ações verticais e $\boldsymbol{\gamma}_{\mathrm{f}}=\mathbf{1 , 4}$ para as ações horizontais:

$$
\begin{aligned}
& \ddot{\mathrm{AM}} \mathrm{tot}, \mathrm{d}, \mathrm{x}=1,4 \cdot 1543,85=2161,39 \mathrm{kN} \cdot \mathrm{m} \\
& \ddot{\mathrm{AM}}_{\mathrm{tot}, \mathrm{d}, \mathrm{y}}=1,4 \cdot 1138,97=1594,56 \mathrm{kN} \cdot \mathrm{m}
\end{aligned}
$$

Pela eq.(3.6), considerando-se $\boldsymbol{\gamma}_{\mathbf{f}}=\mathbf{1 , 4}$ para as ações horizontais:

$$
\begin{aligned}
& \mathrm{M}_{1, \text { tot, }, \mathrm{x}}=1,4 \cdot 15988,16=22383,42 \mathrm{kN} \cdot \mathrm{m} \\
& \mathrm{M}_{1, \mathrm{tot}, \mathrm{d}, \mathrm{y}}=1,4 \cdot 14916,69=20883,37 \mathrm{kN} \cdot \mathrm{m}
\end{aligned}
$$

Para o cálculo dos deslocamentos $\mathbf{a}_{\mathbf{h}}$, foram utilizados os dados da Tabela 3.4 e da Tabela 3.5. Logo:

$$
\begin{array}{r}
a_{h, x}=\frac{\sum_{i=1}^{m}\left(P_{i} \cdot y_{i, x}\right)}{N}=\frac{1543,85}{78018}=0,019788 m \\
a_{h, y}=\frac{\sum_{i=1}^{m}\left(P_{i} \cdot y_{i, y}\right)}{N}=\frac{1138,97}{78018}=0,014599 m
\end{array}
$$

Para o cálculo dos deslocamentos $\mathbf{a}_{\mathbf{v}}$, o pórtico foi submetido apenas às forças verticais. Os valores dos $\mathbf{a}_{\mathbf{v i}, \mathbf{y}}$ foram nulos, devido à simetria do pavimento em relação ao eixo $\mathbf{X}$, e os valores dos $\mathbf{a}_{\mathbf{v i}, \mathbf{x}}$ encontram-se na Tabela 3.6.

Logo:

$$
\begin{aligned}
& a_{v, x}=\frac{\sum_{i=1}^{m}\left(P_{i} \cdot a_{v i, x}\right)}{N}=\frac{69,95}{78018}=0,000896 m \\
& a_{v, y}=0
\end{aligned}
$$


Tabela 3.4 - Deslocamentos horizontais na direção $\mathbf{X}$

\begin{tabular}{|c|c|c|c|}
\hline Pavimento & $\begin{array}{c}(5) \\
y_{i, x}(m)\end{array}$ & $\begin{array}{c}(2 x 5) \\
P_{i} \cdot y_{i, x}\end{array}$ & $\begin{array}{c}(1 x 3) \\
x_{i} \cdot F_{a i, x}\end{array}$ \\
\hline Cob. & 0,031849 & 239,03 & 1104,44 \\
\hline $14^{\circ}$ & 0,031149 & 136,71 & 2041,13 \\
\hline $13^{o}$ & 0,030279 & 132,89 & 1875,95 \\
\hline $12^{\circ}$ & 0,029211 & 128,21 & 1713,68 \\
\hline $11^{o}$ & 0,027946 & 122,65 & 1554,69 \\
\hline $10^{\circ}$ & 0,026490 & 116,26 & 1398,66 \\
\hline $9^{o}$ & 0,024848 & 109,06 & 1245,80 \\
\hline $8^{o}$ & 0,023030 & 101,08 & 1097,01 \\
\hline $7^{o}$ & 0,021046 & 92,37 & 951,84 \\
\hline $6^{0}$ & 0,018908 & 82,99 & 811,16 \\
\hline $5^{\circ}$ & 0,016630 & 72,99 & 675,28 \\
\hline $4^{o}$ & 0,014230 & 62,46 & 544,41 \\
\hline $3^{o}$ & 0,011724 & 51,46 & 419,84 \\
\hline $2^{o}$ & 0,009132 & 40,08 & 302,21 \\
\hline $1^{o}$ & 0,006439 & 28,54 & 204,49 \\
\hline P.G. & 0,003000 & 27,07 & 47,57 \\
\hline & & $\sum\left(P_{i} \cdot y_{i, x}\right)=1543,85$ & $\sum\left(x_{i} \cdot F_{a i, x}\right)=15988,16$ \\
\hline
\end{tabular}

Tabela 3.5 - Deslocamentos horizontais na direção Y

\begin{tabular}{|c|c|c|c|}
\hline Pavimento & $\begin{array}{c}(6) \\
y_{i, y}(m)\end{array}$ & $\begin{array}{c}(2 x 6) \\
P_{i} \cdot y_{i, y}\end{array}$ & $\begin{array}{c}(1 x 4) \\
x_{i} \cdot F_{a i, y}\end{array}$ \\
\hline Cob. & 0,024225 & 181,81 & 1030,59 \\
\hline $14^{o}$ & 0,023693 & 103,99 & 1904,25 \\
\hline $13^{\circ}$ & 0,023031 & 101,08 & 1750,50 \\
\hline $12^{o}$ & 0,022221 & 97,53 & 1598,92 \\
\hline $11^{\circ}$ & 0,021222 & 93,14 & 1450,33 \\
\hline $10^{\circ}$ & 0,020069 & 88,08 & 1304,73 \\
\hline $9^{o}$ & 0,018756 & 82,32 & 1162,27 \\
\hline $8^{o}$ & 0,017289 & 75,88 & 1023,46 \\
\hline $7^{o}$ & 0,015675 & 68,80 & 888,11 \\
\hline $6^{0}$ & 0,013923 & 61,11 & 756,78 \\
\hline $5^{\circ}$ & 0,012044 & 52,86 & 629,98 \\
\hline $4^{o}$ & 0,010049 & 44,11 & 507,98 \\
\hline $3^{o}$ & 0,007955 & 34,91 & 391,62 \\
\hline $2^{o}$ & 0,005790 & 25,41 & 281,97 \\
\hline $1^{o}$ & 0,003606 & 15,99 & 190,81 \\
\hline P.G. & 0,001324 & 11,95 & 44,38 \\
\hline & & $\sum\left(P_{i} \cdot y_{i, y}\right)=1138,97$ & $\sum\left(x_{i} \cdot F_{a i, y}\right)=14916,69$ \\
\hline
\end{tabular}


Tabela 3.6 - Deslocamentos horizontais na direção $\mathbf{X}$, devidos às forças verticais

\begin{tabular}{|c|c|c|}
\hline Pavimento & $\begin{array}{c}(7) \\
a_{v i, x}(m)\end{array}$ & $\begin{array}{c}(2 x 7) \\
\boldsymbol{P}_{i} \cdot a_{v i, x}\end{array}$ \\
\hline Cob. & 0,002103 & 15,78 \\
\hline $14^{o}$ & 0,001915 & 8,40 \\
\hline $13^{o}$ & 0,001734 & 7,61 \\
\hline $12^{\circ}$ & 0,001556 & 6,83 \\
\hline $11^{\circ}$ & 0,001381 & 6,06 \\
\hline $10^{\circ}$ & 0,001210 & 5,31 \\
\hline $9^{o}$ & 0,001045 & 4,59 \\
\hline $8^{o}$ & 0,000885 & 3,88 \\
\hline $7^{\circ}$ & 0,000734 & 3,22 \\
\hline $6^{o}$ & 0,000591 & 2,59 \\
\hline $5^{\circ}$ & 0,000459 & 2,01 \\
\hline $4^{o}$ & 0,000339 & 1,49 \\
\hline $3^{o}$ & 0,000233 & 1,02 \\
\hline $2^{o}$ & 0,000144 & 0,63 \\
\hline $1^{o}$ & 0,000073 & 0,32 \\
\hline P.G. & 0,000020 & 0,18 \\
\hline & & $\sum\left(P_{i} \cdot a_{v i, x}\right)=69,95$ \\
\hline
\end{tabular}

E, portanto:

$$
\begin{aligned}
& \gamma_{\mathrm{z}, \mathrm{x}}=\frac{1}{1-\frac{2161,39}{22383,42} \cdot \frac{0,019788+0,000896}{0,019788}}=1,112 \\
& \gamma_{\mathrm{z}, \mathrm{y}}=\frac{1}{1-\frac{1594,56}{20883,37} \cdot \frac{0,01150+0}{0,01150}}=1,083
\end{aligned}
$$

Assim, a estrutura é classificada como de nós móveis na direção $\mathbf{X}$ e de nós fixos na direção Y. Os valores de $\gamma_{\mathrm{z}}$ podem ser utilizados como coeficientes majoradores, uma vez que são inferiores ao limite de $\mathbf{1 , 3}$ proposto pela NBR 6118 (2000), ou, considerando-se a proposta deste trabalho, ao limite de $\mathbf{1 , 2}$.

Majorando-se de acordo com a NBR 6118 (2000), com 0,95 $\gamma_{z}$, têm-se:

$$
\begin{aligned}
& \text { direção } \mathbf{X} \quad \Rightarrow \quad 0,95 \cdot 1,112=1,056 \\
& \text { direção } \mathbf{Y} \Rightarrow 0,95 \cdot 1,083=1,029
\end{aligned}
$$


Majorando-se de acordo com as sugestões deste trabalho, com o valor integral de $\gamma_{\mathrm{z}}$, têm-se:

$$
\begin{aligned}
& \text { direção } \mathbf{X} \Rightarrow 1,112 \\
& \text { direção } \mathbf{Y} \Rightarrow 1,083
\end{aligned}
$$

Para o dimensionamento dos elementos estruturais, os esforços de primeira ordem devem, então, ser multiplicados por esses valores.

\section{Coeficiente $\boldsymbol{\gamma}_{\underline{z}}$ (eq.3.8 - sugestão)}

Observa-se que a estrutura em estudo apresenta um eixo de simetria em $\mathbf{X}$, não havendo, portanto, excentricidade na aplicação das forças verticais nesta direção. Em Y, apesar da simetria não ser perfeita, ela pode ser admitida, uma vez que as diferenças existentes na parte central da forma não devem causar uma excentricidade relevante entre o ponto de aplicação da resultante das forças verticais e o centro de gravidade dos pavimentos. Assim sendo, os valores de $\gamma_{\mathrm{z}}$ podem ser obtidos da seguinte forma:

$$
\begin{aligned}
& \gamma_{\mathrm{zx}}=\frac{1}{1-\frac{2161,39}{22383,42}}=1,107 \\
& \gamma_{\mathrm{zy}}=\frac{1}{1-\frac{1594,56}{20883,37}}=1,083
\end{aligned}
$$

Também neste caso, a estrutura foi classificada como de nós móveis na direção $\mathbf{X}$ e de nós fixos na direção $\mathbf{Y}$. Nota-se que é muito pequena a diferença entre os valores do $\gamma_{\mathbf{z}, \mathbf{x}}$ calculados pela eq.(3.4) e pela eq.(3.8), e que, entre os valores do $\gamma_{\mathbf{z}, \mathbf{y}}$, é nula. Assim sendo, acredita-se que a trabalhosa determinação de $\mathbf{a}_{\mathbf{v}}$ realmente não compensa frente aos ótimos resultados obtidos a partir da expressão mais simplificada, decorrente das considerações de simetria.

Apenas para ilustrar, realizou-se a análise da estrutura através do processo $\mathbf{P}-\Delta$, de acordo com as indicações do item 3.5. Foram calculadas as médias entre os acréscimos percentuais dos resultados de primeira ordem em relação aos da última iteração, para cada um dos esforços, nas duas direções (Tabela 3.7 e Tabela 3.8). Escrevendo-se esses acréscimos médios na forma de majoradores, pode-se constatar que o $\gamma_{\mathrm{z}}$ se aproxima mais do $\mathbf{P}-\Delta$ que o $0,95 \gamma_{\mathrm{z}}$ (Tabela 3.9). 
Tabela 3.7 - Acréscimos percentuais dos esforços pelo processo $\mathbf{P}-\Delta$ - direção $\mathbf{X}$

\begin{tabular}{|c|c|c|c|c|c|}
\hline \multirow{2}{*}{ Pavimento } & \multicolumn{3}{|c|}{ Pilares } & \multicolumn{2}{|c|}{ Vigas } \\
\hline & Normal & Mom. Base & Mom. Topo & Cortante & Momento \\
\hline Cob. & 7,3 & 8,5 & 8,7 & 8,0 & 8,2 \\
\hline $14^{o}$ & 7,4 & 6,8 & 6,3 & 7,6 & 7,7 \\
\hline $13^{\circ}$ & 7,6 & 6,0 & 6,1 & 7,1 & 6,8 \\
\hline $12^{\circ}$ & 8,1 & 6,1 & 5,5 & 6,0 & 6,1 \\
\hline $11^{o}$ & 8,2 & 6,2 & 6,6 & 6,5 & 6,5 \\
\hline $10^{\circ}$ & 8,2 & 7,0 & 7,3 & 7,3 & 7,3 \\
\hline $9^{o}$ & 8,2 & 7,9 & 8,4 & 7,7 & 7,7 \\
\hline $8^{o}$ & 8,3 & 8,3 & 8,7 & 8,3 & 8,3 \\
\hline $7^{o}$ & 8,2 & 9,0 & 9,3 & 8,9 & 8,9 \\
\hline $6^{\circ}$ & 8,5 & 9,5 & 9,5 & 9,1 & 9,3 \\
\hline $5^{\circ}$ & 8,8 & 10,2 & 10,5 & 10,0 & 10,0 \\
\hline $4^{o}$ & 9,0 & 10,8 & 11,1 & 10,6 & 10,6 \\
\hline $3^{o}$ & 9,1 & 11,0 & 11,2 & 11,0 & 11,1 \\
\hline $2^{o}$ & 9,8 & 11,7 & 12,4 & 11,6 & 11,6 \\
\hline $1^{o}$ & 10,0 & 12,8 & 12,9 & 11,0 & 11,2 \\
\hline P.G. & 10,2 & 11,2 & 11,4 & 9,3 & 9,4 \\
\hline Média & 8,6 & 8,9 & 9,1 & 8,8 & 8,8 \\
\hline \multicolumn{6}{|c|}{ Média final $=8,8$} \\
\hline
\end{tabular}

Tabela 3.8 - Acréscimos percentuais dos esforços pelo processo $\mathbf{P}-\Delta$ - direção $\mathbf{Y}$

\begin{tabular}{|c|c|c|c|c|c|}
\hline \multirow{2}{*}{ Pavimento } & \multicolumn{3}{|c|}{ Pilares } & \multicolumn{2}{|c|}{ Vigas } \\
\hline & \begin{tabular}{|l|} 
Normal \\
\end{tabular} & Mom. Base & Mom. Topo & Cortante & Momento \\
\hline Cob. & 5,2 & 5,1 & 4,8 & 5,5 & 5,5 \\
\hline $14^{o}$ & 5,0 & 4,2 & 3,9 & 5,1 & 5,1 \\
\hline $13^{o}$ & 5,0 & 3,7 & 4,1 & 4,3 & 4,3 \\
\hline $12^{o}$ & 5,3 & 3,5 & 4,7 & 4,7 & 4,7 \\
\hline $11^{o}$ & 5,5 & 3,9 & 5,4 & 5,3 & 5,2 \\
\hline $10^{\circ}$ & 6,2 & 4,6 & 6,3 & 6,1 & 6,1 \\
\hline $9^{o}$ & 6,4 & 5,8 & 6,8 & 6,8 & 6,8 \\
\hline $8^{o}$ & 6,5 & 6,3 & 7,5 & 7,0 & 6,9 \\
\hline $7^{o}$ & 6,8 & 6,8 & 8,2 & 8,0 & 8,0 \\
\hline $6^{0}$ & 7,0 & 7,2 & 8,7 & 8,2 & 8,2 \\
\hline $5^{\circ}$ & 7,4 & 8,3 & 9,5 & 9,0 & 9,0 \\
\hline $4^{o}$ & 7,6 & 9,1 & 10,4 & 9,8 & 9,8 \\
\hline $3^{o}$ & 7,9 & 10,0 & 10,3 & 10,0 & 10,0 \\
\hline $2^{o}$ & 8,3 & 10,4 & 10,0 & 10,0 & 10,0 \\
\hline $1^{o}$ & 8,4 & 8,8 & 8,3 & 9,2 & 9,3 \\
\hline P.G. & 8,4 & 7,0 & 7,7 & 7,2 & 7,2 \\
\hline Média & 6,7 & 6,5 & 7,3 & 7,3 & 7,3 \\
\hline \multicolumn{6}{|c|}{ Média final = 7,0 } \\
\hline
\end{tabular}


Tabela 3.9 - Comparação entre majorações

\begin{tabular}{|c|c|c|c|}
\hline Direção & $\mathbf{0 , 9 5 \gamma _ { z }}$ & $\boldsymbol{\gamma}_{z}$ & $\boldsymbol{P}$ - $\boldsymbol{\Delta}$ \\
\hline $\mathrm{X}$ & 1,052 & 1,107 & 1,088 \\
\hline $\mathrm{Y}$ & 1,029 & 1,083 & 1,070 \\
\hline
\end{tabular}

Considerando-se a variação dos acréscimos obtidos por P- $\Delta$ ao longo da altura da edificação, como foi feito no Anexo $\mathrm{D}$, observa-se que o $0,95 \gamma_{\mathrm{z}}$ forneceu uma subestimativa razoável dos esforços de segunda ordem, principalmente nas faixas inferiores da estrutura, que são as mais críticas (Figura 3.8). Já o $\boldsymbol{\gamma}_{\mathbf{z}}$, de uma maneira geral, apresentou bons resultados para todos os casos.

\subsection{CONSIDERAÇÕES FINAIS}

Uma vez apresentada a verificação da estabilidade global segundo a NBR 6118 (2000), pode-se comentar sua grande evolução em relação à NBR 6118 (1978).

Nesta versão anterior, obrigava-se a consideração do vento nos casos em que esta ação pudesse produzir efeitos "importantes" e nos casos de estruturas "deslocáveis" em que ou a altura fosse maior que 4 vezes a largura menor, ou o número de filas de pilares em uma dada direção fosse inferior a 4. Além de serem bastante vagas, as recomendações não mencionavam um ponto extremamente importante da análise de edifícios, que é o estudo dos efeitos de segunda ordem globais.

Tal postura não mais poderia ser admitida, pois, com o crescimento do número de pavimentos dos edifícios e de sua esbeltez, os deslocamentos laterais aumentaram e os efeitos de segunda ordem tornaram-se mais relevantes. Por isso, o Projeto de Revisão da NBR 6118 (2000) menciona não apenas a análise das ações horizontais, mas também toda a avaliação da estabilidade global.

De uma maneira geral, o que se observa é que esse novo texto está bem detalhado, comentando desde a importância da análise da ação do vento e do desaprumo, da classificação das estruturas quanto à deslocabilidade dos nós e dos processos a serem adotados, até a necessidade de se considerarem os efeitos de segunda ordem em estruturas de nós móveis.

Ainda assim, acredita-se que pequenas alterações podem ser incorporadas à versão definitiva da nova NBR 6118, melhorando tanto a compreensão quanto a aproximação das verificações. Algumas sugestões foram apresentadas neste capítulo. 
Direção X
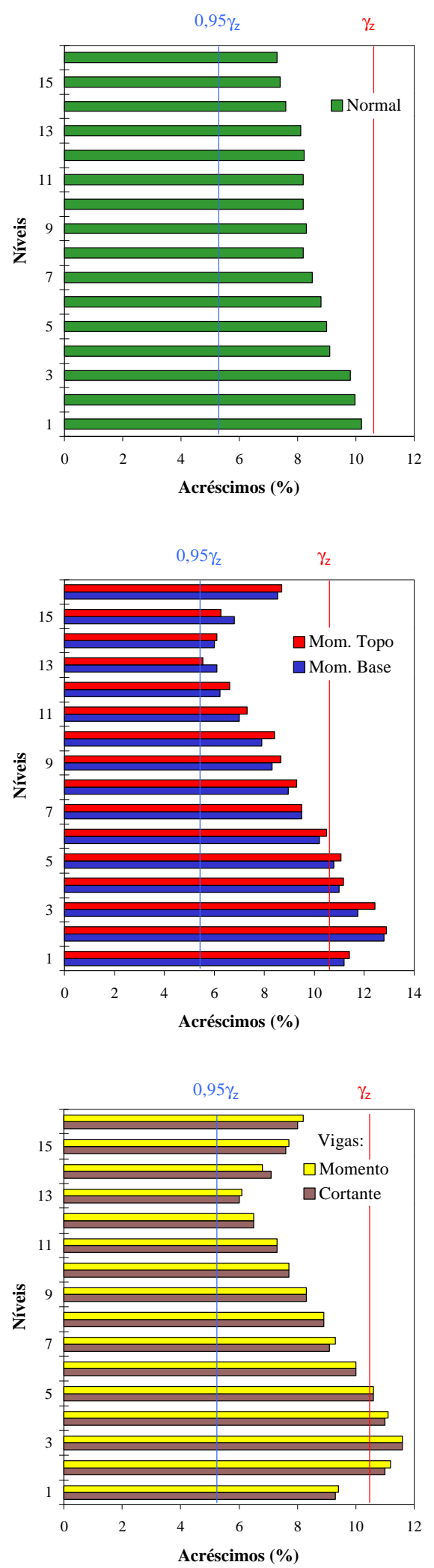

Direção Y
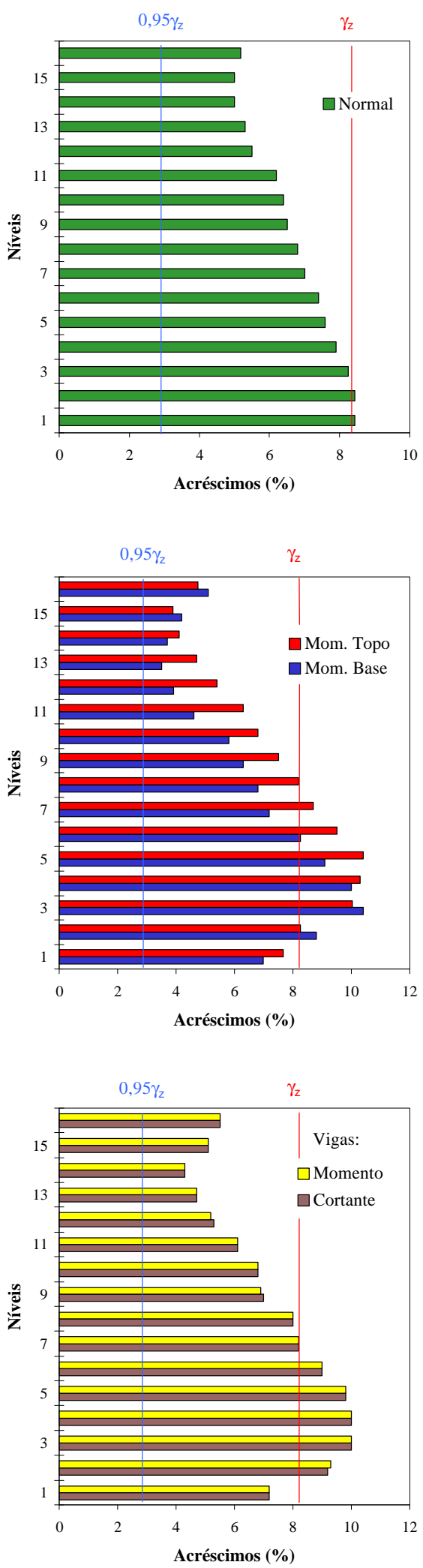

Figura 3.8 - Variação dos acréscimos dos esforços de segunda ordem nas direções $\mathbf{X}$ e $\mathbf{Y}$ 


\subsection{REFERÊNCIAS BIBLIOGRÁFICAS}

ASSOCIAÇÃO BRASILEIRA DE NORMAS TÉCNICAS (1978). NBR 6118 - Projeto e execução de obras de concreto armado. Rio de Janeiro

ASSOCIAÇÃO BRASILEIRA DE NORMAS TÉCNICAS (2000). Revisão da NBR 6118 Projeto de estruturas de concreto.

ASSOCIAÇÃO BRASILEIRA DE NORMAS TÉCNICAS (1988). NBR 6123 - Forças devidas ao vento em edificações. Rio de Janeiro.

ASSOCIAÇÃO BRASILEIRA DE NORMAS TÉCNICAS (1984). NBR 8681 - Ações e segurança nas estruturas. Rio de Janeiro.

BECK, H.; KÖNIG, G. (1966). Restraining forces (Festhaltekräfte) in the analysis of tall buildings. In: SYMPOSIUM ON TALL BUILDINGS, Oxford. Proceedings. p.513-536.

CARMO, R.M.S. (1995). Efeitos de segunda ordem em edifícios usuais de concreto armado. São Carlos. Dissertação (Mestrado) - Escola de Engenharia de São Carlos, Universidade de São Paulo.

COMITÉ EURO-INTERNACIONAL DU BÉTON (1993). CEB-FIP model code 1990. London, Thomas Telford.

FRANCO, M. (1985a). Problema de instabilidade dos edifícios altos. In: REUNIÃO ANUAL DO IBRACON: Colóquio sobre Estabilidade Global das Estruturas de Concreto Armado, São Paulo. Anais.

FRANCO, M. (1985b). O parâmetro de instabilidade dos edifícios altos. Revista Portuguesa de Engenharia de Estruturas, Lisboa, n.23, p.69-72.

FRANCO, M.; VASCONCELOS, A.C. (1991). Practical assessment of second order effects in tall buildings. In: COLOQUIUM ON THE CEB-FIP MC90, Rio de Janeiro. Proceedings. p.307-324.

FRANCO, M. (1997). Instabilidade local e global dos edifícios altos de concreto armado. In: INSTITUTO DE ENGENHARIA. Divisão de Estruturas. Coletânea de trabalhos sobre estabilidade global e local das estruturas de edifícios. São Paulo, Instituto de Engenharia/TQS. p.55-76. (Trabalho apresentado no International Symposium da IASS, Milão, 1995) 
LAI, S.A.; MacGREGOR, J.G. (1983). Geometric nonlinearities in unbraced multistory frames. Journal of the Structural Engineering, ASCE, v.109, n.ST11, p.2528-2545, Nov.

LIMA, J.S. (1998). Avaliação dos efeitos de segunda ordem em edifícios altos. Salvador. Trabalho de Iniciação Científica - Escola Politécnica, Universidade Federal da Bahia.

LIMA, J.S.; GUARDA, M.C.C. (1999a). Comparação entre o parâmetro alfa e o coeficiente Yz na análise da estabilidade global de edifícios altos [CD-ROM]. In: CONGRESSO BRASILEIRO DO CONCRETO, 41., Salvador. Anais.

LIMA, J.S.; GUARDA, M.C.C. (1999b). Utilização do coeficiente Yz como majorador de efeitos de primeira ordem em edifícios altos [CD-ROM]. In: CONGRESSO BRASILEIRO DO CONCRETO, 41., Salvador. Anais.

MacGREGOR, J.G.; HAGE, S.E. (1977). Stability analysis and design of concrete frames. Journal of the Structural Division, ASCE, v.103, n.ST10, p. 1953-1970, Oct.

MacGREGOR, J.G. (1992). Reinforced concrete: mechanics and design. 2. ed. Englewood Cliffs, Prentice-Hall.

MacGREGOR, J.G. (1993). Design of slender concrete columns: revisited. ACI Structural Journal. v.90, n.3, p. 302-309, May-Jun.

PINTO, R.S. (1997). Não-linearidade física e geométrica no projeto de edifícios usuais de concreto armado. São Carlos. Dissertação (Mestrado) - Escola de Engenharia de São Carlos, Universidade de São Paulo.

VASCONCELOS, A.C. (1985). Critérios para dispensa de consideração do efeito de $2^{\mathrm{a}}$ ordem. In: REUNIÃO ANUAL DO IBRACON: Colóquio sobre Estabilidade Global das Estruturas de Concreto Armado, São Paulo. Anais.

VASCONCELOS, A.C.; FRANÇA, R.L.S. (1997). Um método simplificado e muito preciso para avaliação dos momentos de segunda ordem em edifícios altos usuais. In: INSTITUTO DE ENGENHARIA. Divisão de Estruturas. Coletânea de trabalhos sobre estabilidade global e local das estruturas de edifícios. São Paulo, Instituto de Engenharia/TQS. p.77-97. (Trabalho apresentado no FIP Symposium, Johannesburg, 1997). 


\subsection{BIBLIOGRAFIA COMPLEMENTAR}

AMERICAN CONCRETE INSTITUTE (1999). ACI 318/99 - Building code requirements for reinforced concrete. Farmington Hills, ACI.

ANTUNES, H.M.C.C. (1978). Carregamento crítico de instabilidade geral para estruturas tridimensionais de edifícios altos. São Carlos. Tese (Doutorado) - Escola de Engenharia de São Carlos, Universidade de São Paulo.

ASSOCIAÇÃO BRASILEIRA DE NORMAS TÉCNICAS (1980). NBR 6120 - Cargas para o cálculo de estruturas de edificações. Rio de Janeiro.

COMITÉ EURO-INTERNACIONAL DU BÉTON (1977). CEB-FIP manual of buckling and instability. CEB Bulletin d'Information, n.123.

CORRÊA, M.R.S. (1991). Aperfeiçoamento de modelos usualmente empregados no projeto de sistemas estruturais de edifícios. São Carlos. Tese (Doutorado) - Escola de Engenharia de São Carlos, Universidade de São Paulo.

FINTEL, M. (1975). Deflections of high-rise concrete buildings. Journal of the American Concrete Institute, v.72, n.7, p.324-328.

FRANÇA, R.L.S. (1985). Exemplo de cálculo do esforço de 2a. ordem em um edifício de concreto armado. In: REUNIÃO ANUAL DO IBRACON: Colóquio sobre Estabilidade Global das Estruturas de Concreto Armado, São Paulo. Anais.

FUSCO, P.B. (1981). Estruturas de concreto: solicitações normais. Rio de Janeiro, Guanabara Dois.

GRAZIANO, F.P. (2000). O coeficiente de majoração dos esforços globais $\gamma_{z}$ e algumas relações úteis. Edição Eletrônica da ABECE, julho. (e-artigos ABECE n.1).

LIMA, J.S.; GUARDA, M.C.C. (2000). Resultados da aplicação da nova NBR 6118 na avaliação da estabilidade global de edifícios [CD-ROM]. In: SIMPÓSIO EPUSP SOBRE ESTRUTURAS DE CONCRETO ARMADO, 4., São Paulo. Anais.

MENEGOTTO, M. (1999). ULS of buckling. FIB Bulletin, v.2, p.225-240, Apr.

SANTOS, L.M.; FRANCO, M. (1993). Instabilidade e efeitos de segunda ordem nas estruturas de concreto. In: SIMPÓSIO EPUSP SOBRE ESTRUTURAS DE CONCRETO ARMADO, 3., São Paulo. Anais.

SPIEGEL, M.R. (1985). Estatística. 2.ed. São Paulo, MacGraw-Hill do Brasil. (Coleção Schaum). 
VASCONCELOS, A.C. (1986). Como enrijecer edifícios muito flexíveis? In: LA INGENIARIA ESTRUCTURAL SUDAMERICANA EM LA DÉCADA DEL 80: Homenaje al Ingeriero Julio Ricaldoni, Montevidéo, Uruguai. Tomo I. p.237-268.

VASCONCELOS, A.C. (1997). Origem dos parâmetros de estabilidade $\alpha$ e $\gamma_{\mathrm{z}}$. In: INSTITUTO DE ENGENHARIA. Divisão de Estruturas. Coletânea de trabalhos sobre estabilidade global e local das estruturas de edifícios. São Paulo, Instituto de Engenharia/TQS. p.3-13.

WOOD, B.R.; BEAULIEU, D.; ADAMS, P.F. (1976). Column design by P- $\Delta$ method. Journal of the Structural Division, ASCE, v.102, n.ST2, p. 411-427, Feb. 


\section{CAPÍtulo 4}

\section{CONCLUSÕES}

Neste capítulo, são apresentadas as conclusões e algumas considerações finais sobre os estudos realizados neste trabalho. Destacam-se as principais complementações e modificações propostas para a versão definitiva da NBR 6118, relativas às verificações de punção e de estabilidade global, além de sugestões para novas pesquisas.

\subsection{A VERIFICAÇÃO DA PUNÇÃO}

A NBR 6118 (2000) adota o método da superfície de controle para a verificação da punção. Este método, que é apenas empírico, não se propõe a representar fisicamente a forma de ruína, mas seus resultados podem se aproximar bastante daqueles obtidos a partir de modelos mecânicos. Estudou-se, então, as principais características e limitações relacionadas a esta análise da punção, sob a ótica da NBR 6118 (2000).

Para facilitar a compreensão das verificações, foram apresentadas expressões para o cálculo das tensões atuantes em cada contorno crítico, e para cada situação de cálculo: pilares internos com carregamento simétrico, pilares internos com momentos aplicados em uma e nas duas direções, pilares de borda com e sem momentos no plano paralelo à borda livre, e pilares de canto. Neste último caso, ressaltou-se que as verificações são feitas separadamente para cada direção, pois os momentos correspondentes provocam tensões cujos valores máximos ocorrem em pontos diferentes.

Para todos os casos com momentos fletores atuantes, observou-se que a parcela transferida por cisalhamento gera uma tensão que é suposta uniforme (Figura 2.7). Notou-se, também, que as expressões utilizadas pressupõem uma relação linear entre esta parcela e a da reação vertical, o que é apenas uma aproximação. Foram explicadas as determinações do 
coeficiente $\mathbf{K}$, do parâmetro $\mathbf{W}_{\mathbf{p}}$ e da excentricidade do perímetro crítico $\mathbf{e}^{*}$, apontando-se as omissões da NBR 6118 (2000) para os cálculos nos contornos C e C’”

Destacaram-se algumas situações em que o perímetro crítico não deve ser tomado com seu valor integral. É o caso de pilares de borda, de pilares de canto, de pilares próximos a aberturas, e do contorno C" quando os conectores da última linha estiverem tangencialmente afastados mais de $2 \mathbf{d}$ (Figura 2.25).

Quanto às tensões resistentes, chamou-se atenção para o fato de que elas dependem de diversos fatores, como da resistência do concreto à compressão, das dimensões do pilar, da altura útil e da taxa de armadura longitudinal da laje e, ainda, quando houver armadura de punção, de sua área, de seu espaçamento radial e do tipo do aço.

O que se pode observar das verificações estudadas é que a NBR 6118 (2000) é bem mais rigorosa que a NBR 6118 (1978) quanto à colocação de armaduras de cisalhamento. Por outro lado, a capacidade resistente das ligações foi praticamente dobrada, possibilitando o uso de maior taxa de armadura. Ao que parece, o objetivo foi exatamente esse: obrigar à colocação de mais armaduras para a ruína se tornar menos frágil.

O uso de armaduras, aliás, vem ganhando destaque justamente por proporcionar um aumento de resistência da ligação aliado ao aumento de ductilidade. Os já mencionados conectores tipo pino são apenas um dos tipos possíveis de armaduras de punção, e são sugeridos pela própria NBR 6118 (2000). Foram comentados, inclusive, alguns dos aspectos relacionados ao detalhamento desses conectores, tais como suas dimensões mínimas, seus espaçamentos máximos, seu posicionamento vertical e a necessidade de se dispor conectores adicionais nas proximidades das bordas.

Com base em todo o estudo desenvolvido, sugerem-se algumas alternativas para a solução de problemas de punção em lajes, seja reduzindo as tensões atuantes, seja aumentando as tensões resistentes.

- Se a verificação no contorno $\mathbf{C}$ não for atendida, pode-se aumentar a espessura da laje na região (com capitéis ou drop-panels) ou aumentar as dimensões do pilar;

- No caso da verificação no contorno $\mathbf{C}^{\prime}$ em lajes sem armadura de punção, pode-se aumentar a taxa de armadura longitudinal da laje na região ou adicionar armadura de punção;

- No contorno C' em lajes armadas, pode-se aumentar a taxa de armadura longitudinal da laje na região, aumentar o diâmetro dos conectores, aumentar o número de conectores por linha ou diminuir o espaçamento entre as linhas;

- E no caso do contorno C", também pode-se aumentar a taxa de armadura longitudinal da laje na região ou, ainda, aumentar o número de linhas de conectores. 
$\mathrm{O}$ aumento do $\mathbf{f}_{\mathbf{c k}}$ da laje e o uso de fibras na região da ligação são apenas mais algumas dentre outras soluções possíveis. Evidentemente, o problema da punção é bem mais complexo que simples verificações dos contornos críticos, mas a boa aproximação dos resultados obtidos vem sendo comprovada por diversos trabalhos experimentais.

\subsubsection{COMPLEMENTAÇÕES E COMENTÁRIOS}

Estudando-se as recomendações da NBR 6118 (2000) para a verificação da punção, puderam ser feitas algumas sugestões.

Como já foi mencionado, identificou-se que há uma omissão quanto às expressões de $\mathbf{W}_{\mathbf{p}}$ a serem utilizadas nas verificações da face do pilar (contorno $\mathbf{C}$ ) e a $2 \mathbf{d}$ da região armada (contorno C"). Frente a esse problema, tentou-se encontrar uma forma simples para a obtenção dos valores de $\mathbf{W}_{\text {po }}$ e de $\mathbf{W}_{\mathbf{p}}$, e propôs-se, respectivamente, a redução e a majoração do $\mathbf{W}_{\mathbf{p}}$ relativo ao contorno C'. Com base no CEB MC-90 (1993) e resolvendo-se diversos exemplos de cálculo, chegou-se às seguintes expressões:

$$
\begin{array}{ll}
\mathrm{W}_{\mathrm{po}}=\frac{\mathrm{u}_{\mathrm{o}}}{\mathrm{u}} \cdot \mathrm{W}_{\mathrm{p}} & \text { para pilares internos; } \\
\mathrm{W}_{\mathrm{po}}=\frac{\mathrm{u}_{\mathrm{o}} *}{\mathrm{u} *} \cdot \mathrm{W}_{\mathrm{p}} & \text { para pilares de borda e de canto; } \\
\mathrm{W}_{\mathrm{p}}{ }^{\prime}=\eta_{\mathrm{wp}} \cdot \frac{\mathrm{u}^{\prime}}{\mathrm{u}} \cdot \mathrm{W}_{\mathrm{p}} & \text { para pilares internos; } \\
\mathrm{W}_{\mathrm{p}}{ }^{\prime}=\eta_{\mathrm{wp}} \cdot \frac{\mathrm{u}^{\prime *}}{\mathrm{u} *} \cdot \mathrm{W}_{\mathrm{p}} & \text { para pilares de borda e de canto. }
\end{array}
$$

Os valores do coeficiente $\eta_{\mathbf{w p}}$, para a correção do $\mathbf{W}_{\mathbf{p}}$ ' em função da situação de cálculo, foram apresentados na Tabela 2.6.

Outra omissão semelhante diz respeito à determinação das expressões de $\mathbf{e}^{*}$ para as verificações na face do pilar e a $2 \mathbf{d}$ da região armada. Numa solução análoga à do $\mathbf{W}_{\mathbf{p}}$, propôs-se a obtenção dos valores de $\mathbf{e}_{\mathbf{0}}{ }^{*}$ e $\mathbf{e}^{\boldsymbol{T}^{*}}$, respectivamente, pela redução e pela majoração do $\mathbf{e}^{*}$ no contorno $\mathbf{C}^{\prime}$. Resolvendo-se diversos exemplos de cálculo, chegou-se às seguintes expressões, válidas tanto para pilares de borda quanto de canto:

$$
\begin{aligned}
& \mathrm{e}_{\mathrm{o}}^{*}=\eta_{\mathrm{e} 1} \cdot \frac{\mathrm{u}_{\mathrm{o}} *}{\mathrm{u}^{*}} \cdot \mathrm{e}^{*} \\
& \mathrm{e}^{*}=\eta_{\mathrm{e} 2} \cdot \frac{\mathrm{u}^{\prime *}}{\mathrm{u}^{*}} \cdot \mathrm{e}^{*}
\end{aligned}
$$


Os valores dos coeficientes $\eta_{\mathrm{e} 1}$ e $\eta_{\mathrm{e} 2}$, para a correção do $\mathbf{e}^{*}$ em função do contorno estudado, foram apresentados na Tabela 2.9.

Pelos resultados do exemplo do item 2.10, observou-se que tanto os valores das excentricidades $\mathbf{e}_{\mathbf{o}} *$ e $\mathbf{e}^{\boldsymbol{*} *}$ quanto os de $\mathbf{W}_{\mathbf{p}}$, obtidos pelo método simplificado sugerido, ficaram próximos daqueles calculados segundo os métodos mais rigorosos.

Também propôs-se um método simplificado para a consideração da punção excêntrica, o que evita o cálculo do coeficiente $\mathbf{K}$, do parâmetro $\mathbf{W}_{\mathbf{p}}$, da excentricidade $\mathbf{e}^{*} \mathrm{e}$ do momento $\mathbf{M}_{\mathbf{S d}}{ }^{*}$. Consiste em majorar a tensão cisalhante provocada pela reação vertical, através da expressão:

$$
\tau_{\mathrm{Sd}}=\beta \cdot \frac{\mathrm{F}_{\mathrm{Sd}}}{\mathrm{u} \cdot \mathrm{d}}
$$

Os valores de $\beta$ para os três contornos críticos $\mathbf{C}$, C' e C', e para as seis situações de cálculo, foram obtidos a partir da resolução de diversos exemplos e apresentados na Tabela 2.10. E pelo exemplo resolvido no item 2.10, observou-se que este método simplificado também pode fornecer bons resultados.

Para o cálculo da tensão resistente na face do pilar, comentou-se que a formulação da NBR 6118 (2000) tende a ser conservadora, pois considera a resistência do concreto à compressão diagonal como no caso de vigas. O acréscimo devido ao estado multiaxial é desprezado. Com base no CEB MC-90 (1993), propôs-se a seguinte expressão:

$$
\tau_{\mathrm{Rd} 2}=0,32 \cdot \alpha_{\mathrm{v}} \cdot \mathrm{f}_{\mathrm{cd}}
$$

Resultados conservadores também foram observados com o emprego da expressão da NBR 6118 (2000) para o cálculo da tensão atuante em pilares internos com momentos nas duas direções, já que as tensões provocadas por cada um dos momentos não atingem o valor máximo no mesmo ponto. Com base no trabalho do Task Group 2.3 do CEB, sugeriu-se a análise da seguinte expressão:

$$
\tau_{\mathrm{Sd}}=\frac{\mathrm{F}_{\mathrm{Sd}}}{\mathrm{u} \cdot \mathrm{d}}+\sqrt{\left(\frac{\mathrm{K}_{1} \cdot \mathrm{M}_{\mathrm{Sd} 1}}{\mathrm{~W}_{\mathrm{p} 1} \cdot \mathrm{d}}\right)^{2}+\left(\frac{\mathrm{K}_{2} \cdot \mathrm{M}_{\mathrm{Sd} 2}}{\mathrm{~W}_{\mathrm{p} 2} \cdot \mathrm{d}}\right)^{2}}
$$


Pelo exemplo resolvido no item 2.10, observou-se que os valores obtidos com o uso desta expressão são razoavelmente inferiores aos da proposta da NBR 6118 (2000). Esse enfoque representa, então, uma possível melhoria do cálculo da tensão atuante, e que não necessita de maiores elaborações.

Outro aspecto para o qual chamou-se atenção foi a necessidade de se apresentar uma figura mais detalhada mostrando o posicionamento vertical dos conectores, que devem praticamente envolver as armaduras de flexão (Figura 2.28). Dessa forma, eles permanecem bem ancorados, conseguem costurar as fissuras, escoar e então aumentar a resistência da ligação, como previsto pelas expressões estudadas.

Mencionou-se ainda que devem ser introduzidos um limite máximo de $\mathbf{0 , 0 2}$ para a contribuição da armadura de flexão na resistência à punção, a partir do qual ela não parece ser efetiva, e um limite mínimo de aproximadamente $0,3 \mathbf{d}$ para a distância entre a primeira linha de armaduras e a face do pilar, evitando que os primeiros conectores comecem a ter sua ancoragem prejudicada por fissuras de pequena inclinação.

Finalmente, sugeriu-se a introdução de algum comentário sobre o caso de pilares alongados. Na falta de um método mais preciso, pelo menos a redução do perímetro crítico proposta na NBR 6118 (1978) poderia ser adotada.

\subsubsection{SUGESTÕES PARA NOVAS PESQUISAS}

Uma das sugestões para novas pesquisas é o estudo da expressão para o cálculo das tensões atuantes em pilares internos submetidos a momentos em duas direções. Não parece haver mais dúvidas de que a recomendação da NBR 6118 (2000) é conservadora, mas somente com base em resultados experimentais é que se pode confirmar a proposta do Task Group 2.3 do CEB.

Outras duas sugestões dizem respeito aos pilares alongados, que necessitam de estudos mais específicos devido às peculiaridades do fenômeno da punção nesses casos. Pelo menos dois aspectos precisam ser melhor avaliados: o coeficiente $\mathbf{K}$ e a redução do perímetro crítico $\mathbf{u}$.

O estudo do coeficiente $\mathbf{K}$ para situações em que as relações entre os lados do pilar extrapolam os limites da Tabela 2.2, justamente o caso de pilares alongados, seria de grande utilidade. Sugere-se que seja feita uma análise experimental de ligações com pilares de diversas relações entre os lados, principalmente com $c_{1} / c_{2}>3$, e, com alguns resultados e com uma análise numérica adequada, poderia ser determinada a parcela do momento transferida por cisalhamento em vários casos. E se a relação entre as parcelas das tensões 
devidas à reação vertical e ao momento atuante não puder ser considerada linear, outras propostas seriam elaboradas.

Já o estudo da redução do perímetro crítico para o caso de pilares alongados, seria uma forma de subsidiar um pouco mais a adoção deste procedimento. Analisando-se a influência de vários aspectos como a relação entre os lados do pilar e a altura útil da laje, poderia ser obtida uma definição mais precisa do trecho de $\mathbf{u}$ a ser considerado no cálculo das tensões. Sugere-se, então, um trabalho experimental com ligações que apresentem essas variáveis, possibilitando uma melhor calibração das recomendações a serem indicadas em norma.

Por fim, recomenda-se um estudo estatístico mais refinado para a obtenção de valores mais precisos de $\eta_{\mathrm{wp}}, \eta_{\mathrm{e} 1}, \eta_{\mathrm{e} 2}$ e $\beta$. Poderia ser investigada também a possibilidade de utilização desses coeficientes para situações não abrangidas neste trabalho, com base em uma amostragem maior e mais diversificada. E inclusive, no caso específico do $\beta$, considerase importante uma maior variação do carregamento, o que daria maior respaldo ao método proposto.

\subsection{A VERIFICAÇÃO DA ESTABILIDADE GLOBAL}

Com a associação entre os deslocamentos horizontais de uma estrutura e seu carregamento vertical, surgem os chamados efeitos de segunda ordem. A proporção desses efeitos, em relação aos de primeira ordem, é o ponto de partida para a verificação da estabilidade global. Foram estudadas, então, as principais características e limitações relacionadas a esta análise, sob a ótica da NBR 6118 (2000).

Para facilitar a compreensão do processo, dividiu-se o problema da estabilidade em duas questões: uma relacionada à avaliação da importância dos efeitos de segunda ordem no dimensionamento dos elementos estruturais, e outra, relacionada à determinação desses efeitos.

Quanto à primeira questão, mostrou-se que a análise de primeira ordem é suficiente apenas para algumas estruturas, sendo necessária, para outras, o estudo de sua posição geométrica deslocada. Nas chamadas estruturas de nós fixos, a interferência dos efeitos de segunda ordem nos esforços totais é pequena e pode-se dispensar sua consideração no dimensionamento de elementos. Já nas chamadas estruturas de nós móveis, esses efeitos contribuem significativamente para o aumento dos esforços finais e devem ser obrigatoriamente determinados e adicionados aos de primeira ordem. Para essa classificação quanto à deslocabilidade dos nós, foram apresentados dois métodos simplificados: o parâmetro de instabilidade $\alpha$ e o coeficiente $\gamma_{\mathbf{z}}$. 
Em relação ao parâmetro $\alpha$, comentou-se que ele foi desenvolvido a partir da analogia entre um edifício e um pilar engastado na base e livre no topo, de seção constante. Explicou-se a vantagem da utilização do módulo de rigidez equivalente para este pilar ao invés da soma das rigidezes dos pilares isolados. Ressaltou-se, ainda, que o valor limite de $\boldsymbol{\alpha}$, a partir do qual a estrutura é considerada de nós móveis, não é único e depende do sistema de contraventamento da estrutura.

Em relação ao coeficiente $\gamma_{\mathrm{z}}$, demonstrou-se sua caracterização como a soma de uma progressão geométrica cuja razão é a relação entre os acréscimos de momentos em duas iterações sucessivas. Mencionou-se a possibilidade de se considerar a Não-Linearidade Física de maneira simplificada, através da redução do módulo de rigidez, e de serem utilizados os valores característicos das ações para a obtenção dos deslocamentos, nos casos de análises elásticas de estruturas usuais. Destacou-se, ainda, o uso do $\gamma_{\mathrm{z}}$ como coeficiente majorador dos efeitos de primeira ordem, o que representa uma grande vantagem em relação ao $\alpha$.

Quanto à segunda questão, relacionada à determinação dos efeitos de segunda ordem, comentou-se tanto sua importância para estruturas de nós móveis quanto a necessidade do emprego de métodos mais rigorosos, considerando a Não-Linearidade Geométrica, nos casos em que a majoração por $\gamma_{\mathrm{z}}$ não se aplica. Para estas situações, estudou-se um processo que realiza sucessivas iterações até a posição final de equilíbrio, o $\mathbf{P}-\Delta$, com a consideração da NLF de maneira simplificada, salientando-se que os resultados obtidos têm aproximações muito boas para os casos de edifícios convencionais.

Chamou-se atenção, ainda, para a necessidade da verificação da estabilidade local independentemente da análise global, uma vez que pode haver perda de estabilidade de algum pilar isolado mesmo em uma estrutura classificada como de nós fixos.

De uma maneira geral, o que se percebe é que a NBR 6118 (2000) introduz a avaliação da estabilidade global de maneira bem detalhada, principalmente considerando-se que este assunto não era abordado pela NBR 6118 (1978). E com base em todo o estudo desenvolvido, observou-se que realmente existem várias alternativas para se realizar essa verificação, mas a maior conveniência de um ou outro método, inclusive a opção, no casos de estruturas de nós móveis, por uma análise de segunda ordem ou pelo enrijecimento da estrutura, varia de acordo com a situação.

\subsubsection{COMPLEMENTAÇÕES E COMENTÁRIOS}

Estudando-se as recomendações da NBR 6118 (2000) para a verificação da estabilidade global, puderam ser feitas algumas sugestões. 
Na determinação do módulo de rigidez equivalente, comentou-se que a utilização do "carregamento horizontal característico" pode ser bastante trabalhosa, uma vez que não é possível se obter uma forma geral para a equação da linha elástica. Frente às simplificações inerentes ao próprio conceito de rigidez equivalente, sugeriu-se a introdução de um comentário na versão definitiva da NBR 6118 permitindo a consideração do "carregamento horizontal característico" como uma força unitária uniformemente distribuída ao longo da altura da edificação, o que resultaria na seguinte equação de $(\mathbf{E I})_{\mathbf{e q}}$ :

$$
(\mathrm{EI})_{\mathrm{eq}}=\frac{\mathrm{q} \cdot \mathrm{H}^{4}}{8 \cdot \mathrm{a}}
$$

Quanto à expressão do $\gamma_{\mathrm{z}}$ apresentada na NBR 6118 (2000), observou-se que ela pode conduzir a resultados contra a segurança no caso de estruturas assimétricas com grandes excentricidades. Já para estruturas mais simétricas, cujas excentricidades sejam pequenas ou nulas, percebeu-se que os resultados estão bastante próximos daqueles fornecidos pela expressão original, como indicado no exemplo do item 3.10. Podendo a determinação do termo $\mathbf{a}_{\mathbf{v}}$ tornar-se trabalhosa e sendo a utilização do $\gamma_{\mathbf{z}}$ um processo simplificado, considerou-se mais conveniente a adoção deste coeficiente com sua expressão original já bastante estudada,

$$
\gamma_{\mathrm{z}}=\frac{1}{1-\frac{\Delta \mathrm{M}_{\mathrm{tot}, \mathrm{d}}}{\mathrm{M}_{1, \mathrm{tot}, \mathrm{d}}}}
$$

limitando-se seu uso a estruturas regulares e sem grandes assimetrias. Para os casos em que a excentricidade acarreta deslocamentos horizontais relevantes em relação à posição inicial da estrutura, mesmo ela estando submetida apenas a ações verticais, propôs-se o uso de um processo mais rigoroso, que considere a NLG.

Quanto ao $\gamma_{\mathrm{z}}$ como majorador, notou-se que a recomendação da NBR 6118 (2000) para se aplicar $0,95 \gamma_{\mathrm{z}}$ não conduz a bons resultados. É claro que a variação dos efeitos de segunda ordem com a altura é bastante significativa, e difícil de ser considerada por uma constante, mas tanto em termos de acréscimos médios quanto em termos de acréscimos ao longo da altura da edificação, $0,95 \gamma_{\mathrm{z}}$ forneceu uma subestimativa razoável dos esforços finais, principalmente nos pavimentos inferiores. A majoração com $\gamma_{\mathrm{z}}$, por outro lado, mostrou-se bastante satisfatória e mais eficiente que aquela feita com $0,95 \gamma_{z}$, como foi 
observado pela figura 3.8, referente ao exemplo do item 3.10. Sugeriu-se, então a adoção do $\gamma_{\mathrm{z}}$ com seu valor integral.

Quanto ao limite para o uso do $\gamma_{\mathrm{z}}$ como majorador, ressaltou-se que o valor de $\mathbf{1 , 2}$ está mais compatível que o $\mathbf{1 , 3}$ indicado pela NBR 6118 (2000).

Mencionou-se ainda a importância de ser introduzido um comentário sobre a preferência à utilização do $\gamma_{\mathbf{z}}$ em relação ao $\alpha$, já que este parâmetro pode conduzir a resultados bastante conservadores.

Finalmente, chamou-se atenção para dois aspectos relacionados à redução da rigidez para a consideração da NLF. O primeiro foi a possibilidade de estar um pouco baixo o valor 0,4 EI apontado pela NBR 6118 (2000) para a redução da rigidez de vigas em que $\mathrm{A}_{\mathrm{s}}^{\prime} \neq \mathrm{A}_{\mathrm{s}}$. Com base no estudo de PINTO (1997), sugeriu-se a análise do valor de 0,5 EI. E o segundo foi a observação de que o uso de um valor único de 0,7 EI, tanto para vigas quanto para pilares, como permite a NBR 6118 (2000), pode levar à obtenção de deslocamentos menores que os reais. Como essa recomendação, num caso extremo, pode até levar à classificação de uma estrutura de nós móveis como fixos, propôs-se uma reavaliação desse valor de 0,7 EI.

\subsubsection{SUGESTÕES PARA NOVAS PESQUISAS}

Uma das sugestões para novas pesquisas diz respeito à consideração simplificada da NLF em vigas, já que o valor da redução da rigidez não parece estar completamente definido. Sabe-se que há variações entre os casos com armaduras simples e duplas, e a depender das condições de apoio. Propõe-se um estudo experimental para analisar a influência de cada um desses fatores, indicando se o valor de 0,4 EI é realmente conservador e quais os casos em que realmente se pode adotar 0,5 EI.

Outra sugestão está relacionada à questão do limite para o uso do $\gamma_{\mathrm{z}}$ como majorador, que ainda precisa ser melhor definida. Apesar dos estudos de LIMA \& GUARDA (2000) e de PINTO (1997) apontarem o valor de 1,2, recomenda-se que seja feita uma análise específica desse problema, tomando-se uma maior quantidade de edifícios, mais flexíveis e mais altos.

Por fim, sugere-se o estudo de uma expressão para a variação do coeficiente $\gamma_{\mathrm{z}}$ com a altura da edificação, ou, pelo menos, uma variação por faixas de altura. Isso permitiria um certo refinamento da majoração dos esforços de primeira ordem, sem implicar maiores dificuldades de análise. 


\subsection{CONSIDERAÇÕES FINAIS}

Com a utilização de lajes lisas e estruturas mais esbeltas, as análises dos problemas da punção e da estabilidade global vêm se tornando ainda mais importantes. Para esses dois aspectos, a NBR 6118 (2000) apresenta melhorias significativas em relação à NBR 6118 (1978).

Quanto à punção, o que se observa é que a verificação está um pouco mais complicada e conduz a uma maior área de armadura de cisalhamento. Inclusive, considera-se importante a introdução de algumas simplificações, mas também de algumas complementações, como aquelas que foram propostas neste trabalho. De uma forma geral, entretanto, deve-se ter em mente que a análise está bem mais detalhada e eficiente, possibilitando o desenvolvimento de um projeto melhor.

Quanto à estabilidade global, como sua verificação tornou-se obrigatória, percebe-se que a análise estrutural ficará um pouco mais trabalhosa, principalmente nos casos de estruturas de nós móveis. Apesar de todo o procedimento estar bem detalhado, também se julga importante a introdução de algumas modificações como aquelas propostas neste trabalho. E como a desconsideração dos efeitos de segunda ordem pode implicar uma subestimativa dos esforços solicitantes, e sua consideração desnecessária, uma superestimativa, deve-se atentar para a forma de utilização das novas recomendações, garantindo-se resultados compatíveis com a segurança desejada.

Enfim, acredita-se que as verificações da punção e da estabilidade global estejam realmente melhor elaboradas, mas apenas conhecendo-se as limitações dos métodos empregados e a confiabilidade dos resultados obtidos é que se pode adequá-las às complexidades de cada situação em estudo. 


\section{AneXo A}

\section{DETERMINAÇÃO DOS VALORES DE $\eta_{\text {wp }}$}

Para a determinação dos valores de $\eta_{\mathrm{wp}}$, foram resolvidos diversos exemplos com as seguintes características:

- altura útil da laje entre 12 e $22 \mathrm{~cm}$;

- menor dimensão da seção do pilar entre 20 e 30 cm;

- maior dimensão da seção do pilar até 5 vezes a outra;

- distância da última linha de armaduras à face do pilar de pelo menos $2 \mathrm{~d}$.

Os 360 exemplos por situação de cálculo foram divididos em função da direção da excentricidade em relação aos lados do pilar, sendo 186 para $c_{1} \leq c_{2}$ e 174 para $\mathrm{c}_{1}>\mathrm{c}_{2}$. Assim, foram estudados os seguintes casos:

- pilares internos, com $\mathrm{c}_{1} \leq \mathrm{c}_{2}$ (Tabela A.3);

- pilares internos, com $c_{1}>c_{2}$ (Tabela A.4);

- pilares de borda, com $c_{1} \leq c_{2}$ (Tabela A.5);

- pilares de borda, com $c_{1}>c_{2}$ (Tabela A.6);

- pilares de canto, com $c_{1} \leq c_{2}$ (Tabela A.7);

- pilares de canto, com $c_{1}>c_{2}$ (Tabela A.8). 
Em cada um deles, foram calculados a média e o desvio padrão de $\eta_{\text {wp. }}$ Entretanto, para que valores mais representativos fossem obtidos e suas probabilidades de ocorrência fossem conhecidas, estudou-se a possibilidade de se admitir $\eta_{\text {wр }}$ como uma variável de distribuição normal. Essa verificação foi feita utilizando-se o chamado Kolmogorov-Smirnov goodness-of-fit test, no qual são comparadas as freqüências relativas acumuladas de cada valor de $\eta_{w p}$ em ordem crescente, com o da função de distribuição esperada. Se as diferenças forem maiores que o limite do nível de significância desejado, a hipótese é rejeitada. As curvas obtidas para cada caso encontram-se na Figura A.1 e na Figura A.2, nas quais:

$\mathbf{s}(\mathbf{x})$ - função da frequiência acumulada obtida;

$\mathbf{f}(\mathbf{x})$ - função da distribuição teórica proposta;

n - posição do valor da variável, considerando-se sua ordem crescente.

Observa-se que, em todas as situações, a distribuição pode ser realmente considerada como normal, com o nível de significância de $1 \%$. E, portanto, tomando-se o quantil de $10 \%$, pode-se escrever:

$$
\eta_{\mathrm{wp}}=\bar{\eta}_{\mathrm{wp}}-1,28 \cdot \delta
$$

sendo:

$\bar{\eta}_{\mathrm{wp}}$ - valor médio dos $\eta_{\mathrm{wp}}$;

$\boldsymbol{\delta}$ - desvio padrão.

Os valores obtidos dessa forma encontram-se na Tabela A.1. Aproximando-se esses resultados, podem ser sugeridos os valores da Tabela A.2.

Tabela A.1 - Valores de $\eta_{\text {wp }}$ para o quantil de $10 \%$

\begin{tabular}{|l|c|c|}
\hline Situação de Cálculo & $\boldsymbol{c}_{1} \leq \boldsymbol{c}_{2}$ & $\boldsymbol{c}_{1}>\boldsymbol{c}_{2}$ \\
\hline Pilar interno $\left(\boldsymbol{W}_{\boldsymbol{p}}{ }^{\prime}\right)$ & 1,59 & 1,36 \\
\hline Pilar de borda $\left(\boldsymbol{W}_{p 1}{ }^{\prime}\right)$ & 1,55 & 1,08 \\
\hline Pilar de borda $\left(\boldsymbol{W}_{p 2}{ }^{\prime}\right)$ & 1,29 & 1,29 \\
\hline Pilar de canto $\left(\boldsymbol{W}_{p 1}{ }^{\prime}\right)$ & 1,28 & 1,06 \\
\hline
\end{tabular}


Tabela A.2 - Valores de $\eta_{\text {wp }}$ sugeridos e suas probabilidades de ocorrência

\begin{tabular}{|c|c|c|}
\hline Situação de Cálculo & $\boldsymbol{c}_{1} \leq \boldsymbol{c}_{2}$ & $\boldsymbol{c}_{\boldsymbol{1}}>\boldsymbol{c}_{2}$ \\
\hline Pilar interno $\left(\boldsymbol{W}_{\boldsymbol{p}}{ }^{\prime}\right)$ & $1,6(87 \%)$ & $1,3(97 \%)$ \\
\hline Pilar de borda $\left(\boldsymbol{W}_{p 1}{ }^{\prime}\right)$ & $1,5(99 \%)$ & $1,1(88 \%)$ \\
\hline Pilar de borda $\left(\boldsymbol{W}_{p 2}{ }^{\prime}\right)$ & $1,3(89 \%)$ & $1,3(89 \%)$ \\
\hline Pilar de canto $\left(\boldsymbol{W}_{p 1}{ }^{\prime}\right)$ & $1,3(87 \%)$ & $1,1(87 \%)$ \\
\hline
\end{tabular}

Tabela A.3 - Valores de $\eta_{\text {wp }}$ para pilares internos com $c_{1} \leq c_{2}$

\begin{tabular}{|c|c|c|c|c|c|c|c|c|c|c|}
\hline & c2 & d & $p$ & u & $u^{\prime}$ & wp & wp' & $\mathrm{u}^{\prime} / \mathrm{u}$ & $\mathrm{wp} / \mathrm{wp}$ & $\eta_{w}$ \\
\hline 20 & 20 & 12 & $25 \mid$ & 231 & 388 & 5372 & 15243 & 1,68 & 2,84 & 1,69 \\
\hline & 30 & 12 & 25 & 251 & 408 & 52 & 16423 & 1,6 & 2,71 & 1,67 \\
\hline & 40 & 12 & $25 \mid$ & 271 & 428 & 32 & & 1,2 & 61 & 1,65 \\
\hline & 50 & 12 & 25 & 291 & 448 & 412 & 1878 & 1,5 & 5 & 1,6 \\
\hline 20 & 60 & 12 & $25 \mid$ & 311 & 468 & 8092 & 1996 & 1,5 & 2,47 & 1,6 \\
\hline 20 & 70 & 12 & $25 \mid$ & 331 & 488 & 8772 & 2114 & 1,4 & 2,4 & 1,63 \\
\hline 20 & \begin{tabular}{|l|}
80 \\
\end{tabular} & 12 & $25 \mid$ & 351 & 508 & 9452 & 22323 & 1,4 & 2,36 & 1,63 \\
\hline 20 & \begin{tabular}{|l|} 
\\
\end{tabular} & 12 & $25 \mid$ & 371 & 528 & 10132 & 23503 & 1,4 & 2,32 & 1,63 \\
\hline 20 & 100 & 12 & 25 & 391 & 548 & 0812 & 246 & 1,4 & & 1,6 \\
\hline 20 & \begin{tabular}{|l|}
20 \\
\end{tabular} & 14 & 29 & \begin{tabular}{|l|}
256 \\
\end{tabular} & 438 & 6615 & 194 & 1,7 & 2.9 & 1,7 \\
\hline 20 & 30 & 14 & $29 \mid$ & 276 & 458 & 7375 & 20797 & 1,6 & 2,82 & 1,70 \\
\hline 20 & 40 & 14 & \begin{tabular}{|l|}
29 \\
\end{tabular} & 296 & 478 & 8135 & 22137 & 1,6 & 2,72 & 1,68 \\
\hline 20 & \begin{tabular}{|l|}
50 \\
\end{tabular} & 14 & 29 & 316 & 498 & 8895 & 23477 & 1,58 & 2,64 & 1,67 \\
\hline 20 & 60 & 14 & $29 \mid$ & 336 & 518 & 9655 & 248 & 1,5 & 2,57 & 1,6 \\
\hline 20 & \begin{tabular}{|l|}
70 \\
\end{tabular} & 14 & 29 & \begin{tabular}{|l|}
356 \\
\end{tabular} & 538 & 415 & 26157 & 1,5 & , II & 1,6 \\
\hline 20 & 80 & 14 & $29 \mid$ & 376 & 558 & 11175 & 27497 & 1,4 & & 1,66 \\
\hline 20 & \begin{tabular}{|l|}
90 \\
\end{tabular} & 14 & \begin{tabular}{|l|}
29 \\
\end{tabular} & 396 & 578 & 11935 & 28837 & 1,4 & 2,42 & 1,65 \\
\hline 20 & 100 & 14 & 29 & 416 & 598 & 12695 & 30177 & 1,4 & 2,38 & 1,65 \\
\hline 20 & 20 & 16 & 33 & 281 & 488 & 9887 & 24184 & 1,7 & 3,03 & 1,74 \\
\hline 20 & 30 & 16 & 33 & 301 & 508 & 827 & 25684 & 1,6 & 2,91 & 1,72 \\
\hline 20 & 40 & 16 & 33 & 321 & 528 & 9667 & 27184 & 1,6 &, 81 & 1,71 \\
\hline 20 & 50 & 16 & 33 & 341 & 548 & 10507 & 28684 & 1,6 &, 73 & 1,70 \\
\hline 20 & 60 & 16 & 33 & 361 & 568 & 11347 & 30184 & 1,5 & 2,66 & 1,6 \\
\hline 20 & 70 & 16 & 33 & 381 & 588 & 12187 & 31684 & 1,5 & 2,60 & 1,68 \\
\hline 20 & 80 & 16 & 33 & 401 & 608 & 13027 & 33184 & 1,5 & 2,55 & 1,68 \\
\hline 20 & 90 & 16 & 33 & 421 & 628 & 13867 & 34684 & 1,4 &, 00 & 1,68 \\
\hline 20 & 100 & 16 & 33 & \begin{tabular}{|l|}
441 \\
\end{tabular} & 648 & 14707 & 36184 & 1,4 & 2,46 & 1,67 \\
\hline 20 & 20 & 18 & 38 & 306 & 54 & 9486 & 30114 & 1,7 & 7 & 1,7 \\
\hline 20 & \begin{tabular}{|l|}
30 \\
\end{tabular} & 18 & \begin{tabular}{|l|}
38 \\
\end{tabular} & \begin{tabular}{|l|}
326 \\
\end{tabular} & 565 & 10406 & 31794 & 1,73 & 3,06 & 1,76 \\
\hline 20 & 40 & 18 & 38 & 346 & 585 & 11326 & 33474 & 1,6 & 2,96 & 1,75 \\
\hline 20 & 50 & 18 & 38 & 366 & 605 & 246 & 5154 & 1,6 & 2,87 & 1,74 \\
\hline 20 & \begin{tabular}{|l|}
60 \\
\end{tabular} & 18 & 38 & 386 & 62. & 13166 & 36834 & 1,6 & 2,80 & 1,73 \\
\hline 20 & 70 & 18 & 38 & 406 & 64 & 14086 & 385 & 1,5 & 2,73 & 1,72 \\
\hline 20 & \begin{tabular}{|l|}
80 \\
\end{tabular} & 18 & \begin{tabular}{|l|}
38 \\
\end{tabular} & \begin{tabular}{|l|}
426 \\
\end{tabular} & 66 & 15006 & 40194 & 1,5 & 2,68 & 1,72 \\
\hline 20 & 90 & 18 & $38 \mid$ & 446 & 685 & 15926 & 41874 & 1,54 & 2,63 & 1,71 \\
\hline 20 & 100 & 18 & 38 & 466 & 705 & 16846 & 43554 & 1,5 & 2,59 & 1,71 \\
\hline 20 & 20 & 20 & 40 & 331 & 583 & 11113 & 34427 & 1,7 & 3,1 & 1,76 \\
\hline 20 & 30 & 20 & 40 & 351 & 60 & 2113 & 36227 & 1,7 & 2,99 & 1,74 \\
\hline 20 & 40 & 20 & 40 & 371 & 623 & 5115 & 38027 & 1,6 & 2,9 & 1,73 \\
\hline 20 & 50 & 20 & 40 & 391 & 64 & & 39827 & & & \\
\hline & & & & & 663 & . & 162 & & 2,7 & \\
\hline
\end{tabular}




\begin{tabular}{|c|c|c|c|c|c|c|c|c|c|c|}
\hline $\mathrm{c} 1$ & $\mathrm{c} 2$ & $\mathrm{~d}$ & $\mathrm{p}$ & u & $\mathrm{u}^{\prime}$ & $\mathrm{wp}$ & wp' & $\mathrm{u}^{\prime} / \mathrm{u}$ & wp'/wp & $\eta_{\mathrm{w}}$ \\
\hline 20 & 70 & 20 & 40 & 431 & 683 & 16113 & 43427 & 1,58 & 2,70 & 1,70 \\
\hline 20 & 80 & 20 & 40 & 451 & 703 & 17113 & 45227 & 1,56 & 2,64 & 1,70 \\
\hline 20 & 90 & 20 & 40 & 471 & 723 & 18113 & 47027 & 1,53 & 2,60 & 1,69 \\
\hline 20 & 100 & 20 & 40 & 491 & 743 & 19113 & 48827 & 1,51 & 2,55 & 1,69 \\
\hline 20 & 20 & 22 & 45 & 356 & 639 & 12869 & 41436 & 1,79 & 3,22 & 1,80 \\
\hline 20 & 30 & 22 & 45 & 376 & 659 & 13949 & 43416 & 1,75 & 3,11 & 1,78 \\
\hline 20 & 40 & 22 & 45 & 396 & 679 & 15029 & 45396 & 1,71 & 3,02 & 1,76 \\
\hline 20 & 50 & 22 & 45 & 416 & 699 & 16109 & 47376 & 1,68 & 2,94 & 1,75 \\
\hline 20 & 60 & 22 & 45 & 436 & 719 & 17189 & 49356 & 1,65 & 2,87 & 1,74 \\
\hline 20 & 70 & 22 & 45 & 456 & 739 & 18269 & 51336 & 1,62 & 2,81 & 1,74 \\
\hline 20 & 80 & 22 & 45 & 476 & 759 & 19349 & 53316 & 1,59 & 2,76 & 1,73 \\
\hline 20 & 90 & 22 & 45 & 496 & 779 & 20429 & 55296 & 1,57 & 2,71 & 1,72 \\
\hline 20 & 100 & 22 & 45 & 516 & 799 & 21509 & 57276 & 1,55 & 2,66 & 1,72 \\
\hline 25 & 40 & 12 & 25 & 281 & 438 & 7421 & 18685 & 1,56 & 2,52 & 1,61 \\
\hline 25 & 50 & 12 & 25 & 301 & 458 & 8151 & 19915 & 1,52 & 2,44 & 1,60 \\
\hline 25 & 60 & 12 & 25 & 321 & 478 & 8881 & 21145 & 1,49 & 2,38 & 1,60 \\
\hline 25 & 75 & 12 & 25 & 351 & 508 & 9976 & 22990 & 1,45 & 2,30 & 1,59 \\
\hline 25 & 80 & 12 & 25 & 361 & 518 & 10341 & 23605 & 1,44 & 2,28 & 1,59 \\
\hline 25 & 90 & 12 & 25 & 381 & 538 & 11071 & 24835 & 1,41 & 2,24 & 1,59 \\
\hline 25 & 100 & 12 & 25 & 401 & 558 & 11801 & 26065 & 1,39 & 2,21 & 1,59 \\
\hline 25 & 110 & 12 & 25 & 421 & 578 & 12531 & 27295 & 1,37 & 2,18 & 1,59 \\
\hline 25 & 125 & 12 & 25 & 451 & 608 & 13626 & 29140 & 1,35 & 2,14 & 1,59 \\
\hline 25 & 40 & 14 & 29 & 306 & 488 & 8888 & 23345 & 1,60 & 2,63 & 1,65 \\
\hline 25 & 50 & 14 & 29 & 326 & 508 & 9698 & 24735 & 1,56 & 2,55 & 1,64 \\
\hline 25 & 60 & 14 & 29 & 346 & 528 & 10508 & 26125 & 1,53 & 2,49 & 1,63 \\
\hline 25 & 75 & 14 & 29 & 376 & 558 & 11723 & 28210 & 1,48 & 2,41 & 1,62 \\
\hline 25 & 80 & 14 & 29 & 386 & 568 & 12128 & 28905 & 1,47 & 2,38 & 1,62 \\
\hline 25 & 90 & 14 & 29 & 406 & 588 & 12938 & 30295 & 1,45 & 2,34 & 1,62 \\
\hline 25 & 100 & 14 & 29 & 426 & 608 & 13748 & 31685 & 1,43 & 2,30 & 1,61 \\
\hline 25 & 110 & 14 & 29 & 446 & 628 & 14558 & 33075 & 1,41 & 2,27 & 1,61 \\
\hline 25 & 125 & 14 & 29 & 476 & 658 & 15773 & 35160 & 1,38 & 2,23 & 1,61 \\
\hline 25 & 40 & 16 & 33 & 331 & 538 & 10482 & 28518 & 1,63 & 2,72 & 1,67 \\
\hline 25 & 50 & 16 & 33 & 351 & 558 & 11372 & 30068 & 1,59 & 2,64 & 1,66 \\
\hline 25 & 60 & 16 & 33 & 371 & 578 & 12262 & 31618 & 1,56 & 2,58 & 1,65 \\
\hline 25 & 75 & 16 & 33 & 401 & 608 & 13597 & 33943 & 1,52 & 2,50 & 1,65 \\
\hline 25 & 80 & 16 & 33 & 411 & 618 & 14042 & 34718 & 1,50 & 2,47 & 1,64 \\
\hline 25 & 90 & 16 & 33 & 431 & 638 & 14932 & 36268 & 1,48 & 2,43 & 1,64 \\
\hline 25 & 100 & 16 & 33 & 451 & 658 & 15822 & 37818 & 1,46 & 2,39 & 1,64 \\
\hline 25 & 110 & 16 & 33 & 471 & 678 & 16712 & 39368 & 1,44 & 2,36 & 1,64 \\
\hline 25 & 125 & 16 & 33 & 501 & 708 & 18047 & 41693 & 1,41 & 2,31 & 1,63 \\
\hline 25 & 40 & 18 & 38 & 356 & 595 & 12204 & 34948 & 1,67 & 2,86 & 1,71 \\
\hline 25 & 50 & 18 & 38 & 376 & 615 & 13174 & 36678 & 1,63 & 2,78 & 1,70 \\
\hline 25 & 60 & 18 & 38 & 396 & 635 & 14144 & 38408 & 1,60 & 2,72 & 1,69 \\
\hline 25 & 75 & 18 & 38 & 426 & 665 & 15599 & 41003 & 1,56 & 2,63 & 1,68 \\
\hline 25 & 80 & 18 & 38 & 436 & 675 & 16084 & 41868 & 1,55 & 2,60 & 1,68 \\
\hline 25 & 90 & 18 & 38 & 456 & 695 & 17054 & 43598 & 1,52 & 2,56 & 1,68 \\
\hline 25 & 100 & 18 & 38 & 476 & 715 & 18024 & 45328 & 1,50 & 2,51 & 1,68 \\
\hline 25 & 110 & 18 & 38 & 496 & 735 & 18994 & 47058 & 1,48 & 2,48 & 1,67 \\
\hline 25 & 125 & 18 & 38 & 526 & 765 & 20449 & 49653 & 1,45 & 2,43 & 1,67 \\
\hline 25 & 40 & 20 & 40 & 381 & 633 & 14054 & 39596 & 1,66 & 2,82 & 1,70 \\
\hline 25 & 50 & 20 & 40 & 401 & 653 & 15104 & 41446 & 1,63 & 2,74 & 1,69 \\
\hline 25 & 60 & 20 & 40 & 421 & 673 & 16154 & 43296 & 1,60 & 2,68 & 1,68 \\
\hline 25 & 75 & 20 & 40 & 451 & 703 & 17729 & 46071 & 1,56 & 2,60 & 1,67 \\
\hline 25 & 80 & 20 & 40 & 461 & 713 & 18254 & 46996 & 1,54 & 2,57 & 1,67 \\
\hline J & 90 & 20 & 40 & 481 & 733 & 19304 & 48846 & 1,52 & 2,53 & 1,66 \\
\hline
\end{tabular}




\begin{tabular}{|c|c|c|c|c|c|c|c|c|c|c|}
\hline $\mathrm{c} 1$ & $\mathrm{c} 2$ & $\mathrm{~d}$ & $\mathrm{p}$ & u & $\mathrm{u}^{\prime}$ & $\mathrm{wp}$ & wp' & $\mathrm{u}^{\prime} / \mathrm{u}$ & wp'/wp & $\pi$ \\
\hline 25 & 100 & 20 & 40 & 501 & 753 & 20354 & 50696 & 1,50 & 2,49 & 1,66 \\
\hline 25 & 110 & 20 & 40 & 521 & 773 & 21404 & 52546 & 1,48 & 2,45 & 1,66 \\
\hline 25 & 125 & 20 & 40 & 551 & 803 & 22979 & 55321 & 1,46 & 2,41 & 1,65 \\
\hline 25 & 40 & 22 & 45 & 406 & 689 & 16032 & 47107 & 1,70 & 2,94 & 1,73 \\
\hline 25 & 50 & 22 & 45 & 426 & 709 & 17162 & 49137 & 1,66 & 2,86 & 1,72 \\
\hline 25 & 60 & 22 & 45 & 446 & 729 & 18292 & 51167 & 1,63 & 2,80 & 1,71 \\
\hline 25 & 75 & 22 & 45 & 476 & 759 & 19987 & 54212 & 1,59 & 2,71 & 1,70 \\
\hline 25 & 80 & 22 & 45 & 486 & 769 & 20552 & 55227 & 1,58 & 2,69 & 1,70 \\
\hline 25 & 90 & 22 & 45 & 506 & 789 & 21682 & 57257 & 1,56 & 2,64 & 1,69 \\
\hline 25 & 100 & 22 & 45 & 526 & 809 & 22812 & 59287 & 1,54 & 2,60 & 1,69 \\
\hline 25 & 110 & 22 & 45 & 546 & 829 & 23942 & 61317 & 1,52 & 2,56 & 1,69 \\
\hline 25 & 125 & 22 & 45 & 576 & 859 & 25637 & 64362 & 1,49 & 2,51 & 1,68 \\
\hline 30 & 30 & 12 & 25 & 271 & 428 & 7356 & 18512 & 1,58 & 2,52 & 1,59 \\
\hline 30 & 40 & 12 & 25 & 291 & 448 & 8136 & 19792 & 1,54 & 2,43 & 1,58 \\
\hline 30 & 50 & 12 & 25 & 311 & 468 & 8916 & 21072 & 1,51 & 2,36 & 1,57 \\
\hline 30 & 60 & 12 & 25 & 331 & 488 & 9696 & 22352 & 1,47 & 2,31 & 1,56 \\
\hline 30 & 70 & 12 & 25 & 351 & 508 & 10476 & 23632 & 1,45 & 2,26 & 1,56 \\
\hline 30 & 80 & 12 & 25 & 371 & 528 & 11256 & 24912 & 1,42 & 2,21 & 1,55 \\
\hline 30 & 90 & 12 & 25 & 391 & 548 & 12036 & 26192 & 1,40 & 2,18 & 1,55 \\
\hline 30 & 100 & 12 & 25 & 411 & 568 & 12816 & 27472 & 1,38 & 2,14 & 1,55 \\
\hline 30 & 110 & 12 & 25 & 431 & 588 & 13596 & 28752 & 1,36 & 2,11 & 1,55 \\
\hline 30 & 120 & 12 & 25 & \begin{tabular}{|l|l} 
\\
\end{tabular} & 608 & 14376 & 30032 & 1,35 & 2,09 & 1,55 \\
\hline 30 & 130 & 12 & 25 & 471 & 628 & 15156 & 31312 & 1,33 & 2,07 & 1,55 \\
\hline 30 & 140 & 12 & 25 & 491 & 648 & 15936 & 32592 & 1,32 & 2,05 & 1,55 \\
\hline 30 & 150 & 12 & 25 & 511 & 668 & 16716 & 33872 & 1,31 & 2,03 & 1,55 \\
\hline 30 & 30 & 14 & 29 & 296 & 478 & 8805 & 23138 & 1,62 & 2,63 & 1,63 \\
\hline 30 & 40 & 14 & 29 & 316 & 498 & 9665 & 24578 & 1,58 & 2,54 & 1,61 \\
\hline 30 & 50 & 14 & 29 & 336 & 518 & 10525 & 26018 & 1,54 & 2,47 & 1,60 \\
\hline 30 & 60 & 14 & 29 & 356 & 538 & 11385 & 27458 & 1,51 & 2,41 & 1,60 \\
\hline 30 & 70 & 14 & 29 & 376 & 558 & 12245 & 28898 & 1,48 & 2,36 & 1,59 \\
\hline 30 & 80 & 14 & 29 & 396 & 578 & 13105 & 30338 & 1,46 & 2,32 & 1,59 \\
\hline 30 & 90 & 14 & 29 & 416 & 598 & 13965 & 31778 & 1,44 & 2,28 & 1,58 \\
\hline 30 & 100 & 14 & 29 & 436 & 618 & 14825 & 33218 & 1,42 & 2,24 & 1,58 \\
\hline 30 & 110 & 14 & 29 & 456 & 638 & 15685 & 34658 & 1,40 & 2,21 & 1,58 \\
\hline 30 & 120 & 14 & 29 & 476 & 658 & 16545 & 36098 & 1,38 & 2,18 & 1,58 \\
\hline 30 & 130 & 14 & 29 & \begin{tabular}{|l|}
496 \\
\end{tabular} & 678 & 17405 & 37538 & 1,37 & 2,16 & 1,58 \\
\hline 30 & 140 & 14 & 29 & 516 & 698 & 18265 & 38978 & 1,35 & 2,13 & 1,58 \\
\hline 30 & 150 & 14 & 29 & 536 & 718 & 19125 & 40418 & 1,34 & 2,11 & 1,58 \\
\hline 30 & 30 & 16 & 33 & \begin{tabular}{|l|}
321 \\
\end{tabular} & 528 & 10382 & 28276 & 1,65 & 2,72 & 1,65 \\
\hline 30 & 40 & 16 & 33 & 341 & 548 & 11322 & 29876 & 1,61 & 2,64 & 1,64 \\
\hline 30 & 50 & 16 & 33 & 361 & 568 & 12262 & 31476 & 1,57 & 2,57 & 1,63 \\
\hline 30 & 60 & 16 & 33 & 381 & 588 & 13202 & 33076 & 1,54 & 2,51 & 1,62 \\
\hline 30 & 70 & 16 & 33 & 401 & 608 & 14142 & 34676 & 1,52 & 2,45 & 1,62 \\
\hline 30 & 80 & 16 & 33 & 421 & 628 & 15082 & 36276 & 1,49 & 2,41 & 1,61 \\
\hline 30 & 90 & 16 & 33 & 441 & 648 & 16022 & 37876 & 1,47 & 2,36 & 1,61 \\
\hline 30 & 100 & 16 & 33 & 461 & 668 & 16962 & 39476 & 1,45 & 2,33 & 1,61 \\
\hline 30 & 110 & 16 & 33 & 481 & 688 & 17902 & 41076 & 1,43 & 2,29 & 1,60 \\
\hline 30 & 120 & 16 & 33 & 501 & 708 & 18842 & 42676 & 1,41 & 2,26 & 1,60 \\
\hline 30 & 130 & 16 & 33 & 521 & 728 & 19782 & 44276 & 1,40 & 2,24 & 1,60 \\
\hline 30 & 140 & 16 & 33 & 541 & 748 & 20722 & 45876 & 1,38 & 2,21 & 1,60 \\
\hline 30 & 150 & 16 & 33 & 561 & 768 & 21662 & 47476 & 1,37 & 2,19 & 1,60 \\
\hline 30 & 30 & 18 & 38 & 346 & 585 & 12087 & 34668 & 1,69 & 2,87 & 1,70 \\
\hline 30 & 40 & 18 & 38 & 366 & 605 & 13107 & 36448 & 1,65 & 2,78 & 1,68 \\
\hline 30 & 50 & 18 & 38 & 386 & 625 & 14127 & 38228 & 1,62 & 2,71 & 1,67 \\
\hline 30 & 60 & 18 & 38 & 406 & 645 & 15147 & 40008 & 1,59 & 2,64 & 1,66 \\
\hline
\end{tabular}




\begin{tabular}{|c|c|c|c|c|c|c|c|c|c|c|}
\hline $\mathrm{c} 1$ & $\mathrm{c} 2$ & $\mathrm{~d}$ & $\mathrm{p}$ & $\mathrm{u}$ & $\mathrm{u}^{\prime}$ & wp & wp' & $\mathrm{u}^{\prime} / \mathrm{u}$ & $\mathrm{wp} / \mathrm{wp}$ & $\eta_{\text {wp }}$ \\
\hline 30 & 70 & 18 & 38 & 426 & 665 & 16167 & 41788 & 1,56 & 2,58 & 1,66 \\
\hline 30 & 80 & 18 & 38 & 446 & 685 & 17187 & 43568 & 1,54 & 2,53 & 1,65 \\
\hline 30 & 90 & 18 & 38 & 466 & 705 & 18207 & 45348 & 1,51 & 2,49 & 1,65 \\
\hline 30 & 100 & 18 & 38 & 486 & 725 & 19227 & 47128 & 1,49 & 2,45 & 1,64 \\
\hline 30 & 110 & 18 & 38 & 506 & 745 & 20247 & 48908 & 1,47 & 2,42 & 1,64 \\
\hline 30 & 120 & 18 & 38 & 526 & 765 & 21267 & 50688 & 1,45 & 2,38 & 1,64 \\
\hline 30 & 130 & 18 & 38 & 546 & 785 & 22287 & 52468 & 1,44 & 2,35 & 1,64 \\
\hline 30 & 140 & 18 & 38 & 566 & 805 & 23307 & 54248 & 1,42 & 2,33 & 1,64 \\
\hline 30 & 150 & 18 & 38 & 586 & 825 & 24327 & 56028 & 1,41 & 2,30 & 1,64 \\
\hline 30 & 30 & 20 & 40 & 371 & 623 & 13920 & 39290 & 1,68 & 2,82 & 1,68 \\
\hline 30 & 40 & 20 & 40 & 391 & 643 & 15020 & 41190 & 1,64 & 2,74 & 1,67 \\
\hline 30 & 50 & 20 & 40 & 411 & 663 & 16120 & 43090 & 1,61 & 2,67 & 1,66 \\
\hline 30 & 60 & 20 & 40 & 431 & 683 & 17220 & 44990 & 1,58 & 2,61 & 1,65 \\
\hline 30 & 70 & 20 & 40 & 451 & 703 & 18320 & 46890 & 1,56 & 2,56 & 1,64 \\
\hline 30 & 80 & 20 & 40 & 471 & 723 & 19420 & 48790 & 1,53 & 2,51 & 1,64 \\
\hline 30 & 90 & 20 & 40 & 491 & 743 & 20520 & 50690 & 1,51 & 2,47 & 1,63 \\
\hline 30 & 100 & 20 & 40 & 511 & 763 & 21620 & 52590 & 1,49 & 2,43 & 1,63 \\
\hline 30 & 110 & 20 & 40 & 531 & 783 & 22720 & 54490 & 1,47 & 2,40 & 1,63 \\
\hline 30 & 120 & 20 & 40 & 551 & 803 & 23820 & 56390 & 1,46 & 2,37 & 1,63 \\
\hline 30 & 130 & 20 & 40 & 571 & 823 & 24920 & 58290 & 1,44 & 2,34 & 1,62 \\
\hline 30 & 140 & 20 & 40 & 591 & 843 & 26020 & 60190 & 1,43 & 2,31 & 1,62 \\
\hline 30 & 150 & 20 & 40 & 611 & 863 & 27120 & 62090 & 1,41 & 2,29 & 1,62 \\
\hline 30 & 30 & 22 & 45 & 396 & 679 & 15881 & 46762 & 1,71 & 2,94 & 1,72 \\
\hline 30 & 40 & 22 & 45 & 416 & 699 & 17061 & 48842 & 1,68 & 2,86 & 1,71 \\
\hline 30 & 50 & 22 & 45 & \begin{tabular}{|l|l|} 
\\
\end{tabular} & 719 & 18241 & 50922 & 1,65 & 2,79 & 1,69 \\
\hline 30 & 60 & 22 & 45 & 456 & 739 & 19421 & 53002 & 1,62 & 2,73 & 1,69 \\
\hline 30 & 70 & 22 & 45 & 476 & 759 & 20601 & 55082 & 1,59 & 2,67 & 1,68 \\
\hline 30 & 80 & 22 & 45 & 496 & 779 & 21781 & 57162 & 1,57 & 2,62 & 1,67 \\
\hline 30 & 90 & 22 & 45 & 516 & 799 & 22961 & 59242 & 1,55 & 2,58 & 1,67 \\
\hline 30 & 100 & 22 & 45 & 536 & 819 & 24141 & 61322 & 1,53 & 2,54 & 1,66 \\
\hline 30 & 110 & 22 & 45 & 556 & 839 & 25321 & 63402 & 1,51 & 2,50 & 1,66 \\
\hline 30 & 120 & 22 & 45 & 576 & 859 & 26501 & 65482 & 1,49 & 2,47 & 1,66 \\
\hline 30 & 130 & 22 & 45 & 596 & 879 & 27681 & 67562 & 1,47 & 2,44 & 1,66 \\
\hline 30 & 140 & 22 & 45 & 616 & 899 & 28861 & 69642 & 1,46 & 2,41 & 1,65 \\
\hline 30 & 150 & 22 & 45 & 636 & 919 & 30041 & 71722 & 1,44 & 2,39 & 1,65 \\
\hline & & & & & & & & & média & 1,65 \\
\hline & & & & & & & & & desvio & 0,0535 \\
\hline
\end{tabular}

Tabela A.4 - Valores de $\eta_{\text {wp }}$ para pilares internos com $c_{1}>c_{2}$

\begin{tabular}{|c|c|c|c||c|c|c|c||c|c||c|}
\hline $\mathrm{c} 1$ & $\mathrm{c} 2$ & $\mathrm{~d}$ & $\mathrm{p}$ & $\mathrm{u}$ & $\mathrm{u}^{\prime}$ & $\mathrm{wp}$ & $\mathrm{wp}$ & $\mathrm{u}^{\prime} / \mathrm{u}$ & $\mathrm{wp} / \mathrm{wp}$ & $\eta_{\text {wp }}$ \\
\hline 30 & 20 & 12 & 25 & 251 & 408 & 6576 & 17232 & 1,63 & 2,62 & 1,61 \\
\hline 30 & 20 & 14 & 29 & 276 & 458 & 7945 & 21698 & 1,66 & 2,73 & 1,64 \\
\hline 30 & 20 & 16 & 33 & 301 & 508 & 9442 & 26676 & 1,69 & 2,83 & 1,67 \\
\hline 30 & 20 & 18 & 38 & 326 & 565 & 11067 & 32888 & 1,73 & 2,97 & 1,72 \\
\hline 30 & 20 & 20 & 40 & 351 & 603 & 12820 & 37390 & 1,72 & 2,92 & 1,70 \\
\hline 30 & 20 & 22 & 45 & 376 & 659 & 14701 & 44682 & 1,75 & 3,04 & 1,74 \\
\hline 40 & 20 & 12 & 25 & 271 & 428 & 7880 & 19322 & 1,58 & 2,45 & 1,55 \\
\hline 40 & 25 & 12 & 25 & 281 & 438 & 8320 & 20012 & 1,56 & 2,41 & 1,54 \\
\hline 40 & 30 & 12 & 25 & 291 & 448 & 8760 & 20702 & 1,54 & 2,36 & 1,53 \\
\hline 40 & 20 & 14 & 29 & 296 & 478 & 9375 & 24039 & 1,62 & 2,56 & 1,59 \\
\hline 40 & 25 & 14 & 29 & 306 & 488 & 9855 & 24809 & 1,60 & 2,52 & 1,58 \\
\hline 40 & 30 & 14 & 29 & 316 & 498 & 10335 & 25579 & 1,58 & 2,48 & 1,57
\end{tabular}




\begin{tabular}{|c|c|c|c|c|c|c|c|c|c|c|}
\hline $\mathrm{c} 1$ & $\mathrm{c} 2$ & $\mathrm{~d}$ & $\mathrm{p}$ & u & $\mathrm{u}^{\prime}$ & $\mathrm{wp}$ & wp' & $\mathrm{u}^{\prime} / \mathrm{u}$ & wp'/wp & $\eta_{w}$ \\
\hline 40 & 20 & 16 & 33 & 321 & 528 & 10997 & 29268 & 1,65 & 2,66 & 1,62 \\
\hline 40 & 25 & 16 & 33 & 331 & 538 & 11517 & 30118 & 1,63 & 2,62 & 1,61 \\
\hline 40 & 30 & 16 & 33 & 341 & 548 & 12037 & 30968 & 1,61 & 2,57 & 1,60 \\
\hline 40 & 20 & 18 & 38 & 346 & 585 & 12748 & 35763 & 1,69 & 2,81 & 1,66 \\
\hline 40 & 25 & 18 & 38 & 356 & 595 & 13308 & 36703 & 1,67 & 2,76 & 1,65 \\
\hline 40 & 30 & 18 & 38 & 366 & 605 & 13868 & 37643 & 1,65 & 2,71 & 1,64 \\
\hline 40 & 20 & 20 & 40 & 371 & 623 & 14627 & 40453 & 1,68 & 2,77 & 1,65 \\
\hline 40 & 25 & 20 & 40 & 381 & 633 & 15227 & 41453 & 1,66 & 2,72 & 1,64 \\
\hline 40 & 30 & 20 & 40 & 391 & 643 & 15827 & 42453 & 1,64 & 2,68 & 1,63 \\
\hline 40 & 20 & 22 & 45 & 396 & 679 & 16633 & 48028 & 1,71 & 2,89 & 1,69 \\
\hline 40 & 25 & 22 & 45 & 406 & 689 & 17273 & 49118 & 1,70 & 2,84 & 1,68 \\
\hline 40 & 30 & 22 & 45 & 416 & 699 & 17913 & 50208 & 1,68 & 2,80 & 1,67 \\
\hline 50 & 20 & 12 & 25 & 291 & 448 & 9284 & 21511 & 1,54 & 2,32 & 1,50 \\
\hline 50 & 25 & 12 & 25 & 301 & 458 & 9774 & 22251 & 1,52 & 2,28 & 1,50 \\
\hline 50 & 30 & 12 & 25 & 311 & 468 & 10264 & 22991 & 1,51 & 2,24 & 1,49 \\
\hline 50 & 20 & 14 & 29 & 316 & 498 & 10904 & 26480 & 1,58 & 2,43 & 1,54 \\
\hline 50 & 25 & 14 & 29 & 326 & 508 & 11434 & 27300 & 1,56 & 2,39 & 1,53 \\
\hline 50 & 30 & 14 & 29 & 336 & 518 & 11964 & 28120 & 1,54 & 2,35 & 1,52 \\
\hline 50 & 20 & 16 & 33 & 341 & 548 & 12653 & 31960 & 1,61 & 2,53 & 1,57 \\
\hline 50 & 25 & 16 & 33 & 351 & 558 & 13223 & 32860 & 1,59 & 2,49 & 1,56 \\
\hline 50 & 30 & 16 & 33 & 361 & 568 & 13793 & 33760 & 1,57 & 2,45 & 1,55 \\
\hline 50 & 20 & 18 & 38 & 366 & 605 & 14529 & 38738 & 1,65 & 2,67 & 1,61 \\
\hline 50 & 25 & 18 & 38 & 376 & 615 & 15139 & 39728 & 1,63 & 2,62 & 1,61 \\
\hline 50 & 30 & 18 & 38 & 386 & 625 & 15749 & 40718 & 1,62 & 2,59 & 1,60 \\
\hline 50 & 20 & 20 & 40 & 391 & 643 & 16533 & 43616 & 1,64 & 2,64 & 1,61 \\
\hline 50 & 25 & 20 & 40 & 401 & 653 & 17183 & 44666 & 1,63 & 2,60 & 1,60 \\
\hline 50 & 30 & 20 & 40 & 411 & 663 & 17833 & 45716 & 1,61 & 2,56 & 1,59 \\
\hline 50 & 20 & 22 & 45 & 416 & 699 & 18666 & 51474 & 1,68 & 2,76 & 1,64 \\
\hline 50 & 25 & 22 & 45 & 426 & 709 & 19356 & 52614 & 1,66 & 2,72 & 1,63 \\
\hline 50 & 30 & 22 & 45 & 436 & 719 & 20046 & 53754 & 1,65 & 2,68 & 1,63 \\
\hline 60 & 20 & 12 & 25 & 311 & 468 & 10788 & 23800 & 1,51 & 2,21 & 1,47 \\
\hline 60 & 25 & 12 & 25 & 321 & 478 & 11328 & 24590 & 1,49 & 2,17 & 1,46 \\
\hline 60 & 30 & 12 & 25 & 331 & 488 & 11868 & 25380 & 1,47 & 2,14 & 1,45 \\
\hline 60 & 20 & 14 & 29 & 336 & 518 & 12534 & 29020 & 1,54 & 2,32 & 1,50 \\
\hline 60 & 25 & 14 & 29 & 346 & 528 & 13114 & 29890 & 1,53 & 2,28 & 1,49 \\
\hline 60 & 30 & 14 & 29 & 356 & 538 & 13694 & 30760 & 1,51 & 2,25 & 1,49 \\
\hline 60 & 20 & 16 & 33 & 361 & 568 & 14408 & 34752 & 1,57 & 2,41 & 1,53 \\
\hline 60 & 25 & 16 & 33 & 371 & 578 & 15028 & 35702 & 1,56 & 2,38 & 1,52 \\
\hline 60 & 30 & 16 & 33 & \begin{tabular}{|l|}
381 \\
\end{tabular} & 588 & 15648 & 36652 & 1,54 & 2,34 & 1,52 \\
\hline 60 & 20 & 18 & 38 & 386 & 625 & 16410 & 41813 & 1,62 & 2,55 & 1,57 \\
\hline 60 & 25 & 18 & 38 & 396 & 635 & 17070 & 42853 & 1,60 & 2,51 & 1,57 \\
\hline 60 & 30 & 18 & 38 & 406 & 645 & 17730 & 43893 & 1,59 & 2,48 & 1,56 \\
\hline 60 & 20 & 20 & 40 & 411 & 663 & 18540 & 46880 & 1,61 & 2,53 & 1,57 \\
\hline 60 & 25 & 20 & 40 & 421 & 673 & 19240 & 47980 & 1,60 & 2,49 & 1,56 \\
\hline 60 & 30 & 20 & 40 & 431 & 683 & 19940 & 49080 & 1,58 & 2,46 & 1,56 \\
\hline 60 & 20 & 22 & 45 & 436 & 719 & 20798 & 55020 & 1,65 & 2,65 & 1,61 \\
\hline 60 & 25 & 22 & 45 & 446 & 729 & 21538 & 56210 & 1,63 & 2,61 & 1,60 \\
\hline 60 & 30 & 22 & 45 & 456 & 739 & 22278 & 57400 & 1,62 & 2,58 & 1,59 \\
\hline 70 & 20 & 12 & 25 & 331 & 488 & 12392 & 26190 & 1,47 & 2,11 & 1,43 \\
\hline 70 & 30 & 12 & 25 & 351 & 508 & 13572 & 27870 & 1,45 & 2,05 & 1,42 \\
\hline 70 & 20 & 14 & 29 & 356 & 538 & 14264 & 31661 & 1,51 & 2,22 & 1,47 \\
\hline 70 & 30 & 14 & 29 & 376 & 558 & 15524 & 33501 & 1,48 & 2,16 & 1,45 \\
\hline 70 & 20 & 16 & 33 & \begin{tabular}{|l|}
381 \\
\end{tabular} & 588 & 16263 & 37644 & 1,54 & 2,31 & 1,50 \\
\hline 70 & 30 & 16 & 33 & 401 & 608 & 17603 & 39644 & 1,52 & 2,25 & 1,48 \\
\hline 70 & 20 & 18 & 38 & 406 & 645 & 18391 & 44987 & 1,59 & 2,45 & 1,54 \\
\hline
\end{tabular}




\begin{tabular}{|c|c|c|c|c|c|c|c|c|c|c|}
\hline $\mathrm{c} 1$ & $\mathrm{c} 2$ & $\mathrm{~d}$ & $\mathrm{p}$ & $\mathrm{u}$ & $\mathrm{u}^{\prime}$ & wp & wp' & $\mathrm{u}^{\prime} / \mathrm{u}$ & $\mathrm{wp} / \mathrm{wp}$ & $\eta_{\mathrm{wp}}$ \\
\hline 70 & 30 & 18 & 38 & 426 & 665 & 19811 & 47167 & 1,56 & 2,38 & 1,53 \\
\hline 70 & 20 & 20 & 40 & 431 & 683 & 20646 & 50243 & 1,58 & 2,43 & 1,54 \\
\hline 70 & 30 & 20 & 40 & 451 & 703 & 22146 & 52543 & 1,56 & 2,37 & 1,52 \\
\hline 70 & 20 & 22 & 45 & 456 & 739 & 23030 & 58666 & 1,62 & 2,55 & 1,57 \\
\hline 70 & 30 & 22 & 45 & 476 & 759 & 24610 & 61146 & 1,59 & 2,48 & 1,56 \\
\hline 75 & 25 & 12 & 25 & 351 & 508 & 13846 & 28287 & 1,45 & 2,04 & 1,41 \\
\hline 75 & 25 & 14 & 29 & 376 & 558 & 15821 & 33964 & 1,48 & 2,15 & 1,45 \\
\hline 75 & 25 & 16 & 33 & 401 & 608 & 17923 & 40153 & 1,52 & 2,24 & 1,48 \\
\hline 75 & 25 & 18 & 38 & 426 & 665 & 20154 & 47727 & 1,56 & 2,37 & 1,52 \\
\hline 75 & 25 & 20 & 40 & 451 & 703 & 22512 & 53137 & 1,56 & 2,36 & 1,52 \\
\hline 75 & 25 & 22 & 45 & 476 & 759 & 24999 & 61792 & 1,59 & 2,47 & 1,55 \\
\hline 80 & 20 & 12 & 25 & 351 & 508 & 14096 & 28679 & 1,45 & 2,03 & 1,41 \\
\hline 80 & 25 & 12 & 25 & 361 & 518 & 14736 & 29569 & 1,44 & 2,01 & 1,40 \\
\hline 80 & 30 & 12 & 25 & 371 & 528 & 15376 & 30459 & 1,42 & 1,98 & 1,39 \\
\hline 80 & 20 & 14 & 29 & 376 & 558 & 16093 & 34402 & 1,48 & 2,14 & 1,44 \\
\hline 80 & 25 & 14 & 29 & 386 & 568 & 16773 & 35372 & 1,47 & 2,11 & 1,43 \\
\hline 80 & 30 & 14 & 29 & 396 & 578 & 17453 & 36342 & 1,46 & 2,08 & 1,43 \\
\hline 80 & 20 & 16 & 33 & 401 & 608 & 18218 & 40636 & 1,52 & 2,23 & 1,47 \\
\hline 80 & 25 & 16 & 33 & 411 & 618 & 18938 & 41686 & 1,50 & 2,20 & 1,46 \\
\hline 80 & 30 & 16 & 33 & 421 & 628 & 19658 & 42736 & 1,49 & 2,17 & 1,46 \\
\hline 80 & 20 & 18 & 38 & 426 & 665 & 20472 & 48262 & 1,56 & 2,36 & 1,51 \\
\hline 80 & 25 & 18 & 38 & 436 & 675 & 21232 & 49402 & 1,55 & 2,33 & 1,50 \\
\hline 80 & 30 & 18 & 38 & 446 & 685 & 21992 & 50542 & 1,54 & 2,30 & 1,50 \\
\hline 80 & 20 & 20 & 40 & 451 & 703 & 22853 & 53706 & 1,56 & 2,35 & 1,51 \\
\hline 80 & 25 & 20 & 40 & 461 & 713 & 23653 & 54906 & 1,54 & 2,32 & 1,50 \\
\hline 80 & 30 & 20 & 40 & 471 & 723 & 24453 & 56106 & 1,53 & 2,29 & 1,50 \\
\hline 80 & 20 & 22 & 45 & 476 & 759 & 25362 & 62412 & 1,59 & 2,46 & 1,54 \\
\hline 80 & 25 & 22 & 45 & 486 & 769 & 26202 & 63702 & 1,58 & 2,43 & 1,54 \\
\hline 80 & 30 & 22 & 45 & 496 & 779 & 27042 & 64992 & 1,57 & 2,40 & 1,53 \\
\hline 90 & 20 & 12 & 25 & 371 & 528 & 15900 & 31268 & 1,42 & 1,97 & 1,38 \\
\hline 90 & 25 & 12 & 25 & 381 & 538 & 16590 & 32208 & 1,41 & 1,94 & 1,37 \\
\hline 90 & 30 & 12 & 25 & 391 & 548 & 17280 & 33148 & 1,40 & 1,92 & 1,37 \\
\hline 90 & 20 & 14 & 29 & 396 & 578 & 18023 & 37242 & 1,46 & 2,07 & 1,42 \\
\hline 90 & 25 & 14 & 29 & 406 & 588 & 18753 & 38262 & 1,45 & 2,04 & 1,41 \\
\hline 90 & 30 & 14 & 29 & 416 & 598 & 19483 & 39282 & 1,44 & 2,02 & 1,40 \\
\hline 90 & 20 & 16 & 33 & 421 & 628 & 20274 & 43728 & 1,49 & 2,16 & 1,45 \\
\hline 90 & 25 & 16 & 33 & 431 & 638 & 21044 & 44828 & 1,48 & 2,13 & 1,44 \\
\hline 90 & 30 & 16 & 33 & 441 & 648 & 21814 & 45928 & 1,47 & 2,11 & 1,43 \\
\hline 90 & 20 & 18 & 38 & 446 & 685 & 22653 & 51637 & 1,54 & 2,28 & 1,48 \\
\hline 90 & 25 & 18 & 38 & 456 & 695 & 23463 & 52827 & 1,52 & 2,25 & 1,48 \\
\hline 90 & 30 & 18 & 38 & 466 & 705 & 24273 & 54017 & 1,51 & 2,23 & 1,47 \\
\hline 90 & 20 & 20 & 40 & 471 & 723 & 25160 & 57270 & 1,53 & 2,28 & 1,48 \\
\hline 90 & 25 & 20 & 40 & 481 & 733 & 26010 & 58520 & 1,52 & 2,25 & 1,48 \\
\hline 90 & 30 & 20 & 40 & 491 & 743 & 26860 & 59770 & 1,51 & 2,23 & 1,47 \\
\hline 90 & 20 & 22 & 45 & 496 & 779 & 27795 & 66258 & 1,57 & 2,38 & 1,52 \\
\hline 90 & 25 & 22 & 45 & 506 & 789 & 28685 & 67598 & 1,56 & 2,36 & 1,51 \\
\hline 90 & 30 & 22 & 45 & 516 & 799 & 29575 & 68938 & 1,55 & 2,33 & 1,51 \\
\hline 100 & 20 & 12 & 25 & 391 & 548 & 17804 & 33958 & 1,40 & 1,91 & 1,36 \\
\hline 100 & 25 & 12 & 25 & 401 & 558 & 18544 & 34948 & 1,39 & 1,88 & 1,35 \\
\hline 100 & 30 & 12 & 25 & 411 & 568 & 19284 & 35938 & 1,38 & 1,86 & 1,35 \\
\hline 100 & 20 & 14 & 29 & 416 & 598 & 20052 & 40183 & 1,44 & 2,00 & 1,39 \\
\hline 100 & 25 & 14 & 29 & 426 & 608 & 20832 & 41253 & 1,43 & 1,98 & 1,39 \\
\hline 100 & 30 & 14 & 29 & 436 & 618 & 21612 & 42323 & 1,42 & 1,96 & 1,38 \\
\hline 100 & 20 & 16 & 33 & 441 & 648 & 22429 & 46920 & 1,47 & 2,09 & 1,42 \\
\hline 100 & 25 & 16 & 33 & 451 & 658 & 23249 & 48070 & 1,46 & 2,07 & 1,42 \\
\hline
\end{tabular}




\begin{tabular}{|c|c|c|c|c|c|c|c|c|c|c|}
\hline $\mathrm{c} 1$ & $\mathrm{c} 2$ & $\mathrm{~d}$ & $\mathrm{p}$ & $\mathrm{u}$ & $\mathrm{u}^{\prime}$ & wp & $\mathrm{wp}^{\prime}$ & $\mathrm{u}^{\prime} / \mathrm{u}$ & $\mathrm{wp}^{\prime} / \mathrm{wp}$ & $\eta_{w_{\mathrm{p}}}$ \\
\hline 100 & 30 & 16 & 33 & 461 & 668 & 24069 & 49220 & 1,45 & 2,04 & 1,41 \\
\hline 100 & 20 & 18 & 38 & 466 & 705 & 24934 & 55112 & 1,51 & 2,21 & 1,46 \\
\hline 100 & 25 & 18 & 38 & 476 & 715 & 25794 & 56352 & 1,50 & 2,18 & 1,46 \\
\hline 100 & 30 & 18 & 38 & 486 & 725 & 26654 & 57592 & 1,49 & 2,16 & 1,45 \\
\hline 100 & 20 & 20 & 40 & 491 & 743 & 27566 & 60933 & 1,51 & 2,21 & 1,46 \\
\hline 100 & 25 & 20 & 40 & 501 & 753 & 28466 & 62233 & 1,50 & 2,19 & 1,46 \\
\hline 100 & 30 & 20 & 40 & 511 & 763 & 29366 & 63533 & 1,49 & 2,16 & 1,45 \\
\hline 100 & 20 & 22 & 45 & 516 & 799 & 30327 & 70204 & 1,55 & 2,31 & 1,50 \\
\hline 100 & 25 & 22 & 45 & 526 & 809 & 31267 & 71594 & 1,54 & 2,29 & 1,49 \\
\hline 100 & 30 & 22 & 45 & 536 & 819 & 32207 & 72984 & 1,53 & 2,27 & 1,48 \\
\hline 110 & 25 & 12 & 25 & 421 & 578 & 20598 & 37787 & 1,37 & 1,83 & 1,34 \\
\hline 110 & 30 & 12 & 25 & 431 & 588 & 21388 & 38827 & 1,36 & 1,82 & 1,33 \\
\hline 110 & 25 & 14 & 29 & 446 & 628 & 23012 & 44344 & 1,41 & 1,93 & 1,37 \\
\hline 110 & 30 & 14 & 29 & 456 & 638 & 23842 & 45464 & 1,40 & 1,91 & 1,36 \\
\hline 110 & 25 & 16 & 33 & 471 & 678 & 25554 & 51412 & 1,44 & 2,01 & 1,40 \\
\hline 110 & 30 & 16 & 33 & 481 & 688 & 26424 & 52612 & 1,43 & 1,99 & 1,39 \\
\hline 110 & 25 & 18 & 38 & 496 & 735 & 28225 & 59977 & 1,48 & 2,12 & 1,43 \\
\hline 110 & 30 & 18 & 38 & 506 & 745 & 29135 & 61267 & 1,47 & 2,10 & 1,43 \\
\hline 110 & 25 & 20 & 40 & 521 & 773 & 31023 & 66046 & 1,48 & 2,13 & 1,44 \\
\hline 110 & 30 & 20 & 40 & 531 & 783 & 31973 & 67396 & 1,47 & 2,11 & 1,43 \\
\hline 110 & 25 & 22 & 45 & 546 & 829 & 33949 & 75690 & 1,52 & 2,23 & 1,47 \\
\hline 110 & 30 & 22 & 45 & 556 & 839 & 34939 & 77130 & 1,51 & 2,21 & 1,46 \\
\hline 120 & 30 & 12 & 25 & 451 & 608 & 23592 & 41817 & 1,35 & 1,77 & 1,31 \\
\hline 120 & 30 & 14 & 29 & 476 & 658 & 26172 & 48705 & 1,38 & 1,86 & 1,35 \\
\hline 120 & 30 & 16 & 33 & 501 & 708 & 28880 & 56104 & 1,41 & 1,94 & 1,37 \\
\hline 120 & 30 & 18 & 38 & 526 & 765 & 31716 & 65041 & 1,45 & 2,05 & 1,41 \\
\hline 120 & 30 & 20 & 40 & 551 & 803 & 34680 & 71359 & 1,46 & 2,06 & 1,41 \\
\hline 120 & 30 & 22 & 45 & 576 & 859 & 37772 & 81376 & 1,49 & 2,15 & 1,45 \\
\hline 125 & 25 & 12 & 25 & 451 & 608 & 23866 & 42234 & 1,35 & 1,77 & 1,31 \\
\hline 125 & 25 & 14 & 29 & 476 & 658 & 26469 & 49167 & 1,38 & 1,86 & 1,34 \\
\hline 125 & 25 & 16 & 33 & 501 & 708 & 29200 & 56613 & 1,41 & 1,94 & 1,37 \\
\hline 125 & 25 & 18 & 38 & 526 & 765 & 32059 & 65601 & 1,45 & 2,05 & 1,41 \\
\hline 125 & 25 & 20 & 40 & 551 & 803 & 35046 & 71954 & 1,46 & 2,05 & 1,41 \\
\hline 125 & 25 & 22 & 45 & 576 & 859 & 38160 & 82022 & 1,49 & 2,15 & 1,44 \\
\hline 130 & 30 & 12 & 25 & 471 & 628 & 25896 & 44906 & 1,33 & 1,73 & 1,30 \\
\hline 130 & 30 & 14 & 29 & 496 & 678 & 28601 & 52045 & 1,37 & 1,82 & 1,33 \\
\hline 130 & 30 & 16 & 33 & 521 & 728 & 31435 & 59697 & 1,40 & 1,90 & 1,36 \\
\hline 130 & 30 & 18 & 38 & 546 & 785 & 34397 & 68916 & 1,44 & 2,00 & 1,39 \\
\hline 130 & 30 & 20 & 40 & 571 & 823 & 37486 & 75423 & 1,44 & 2,01 & 1,40 \\
\hline 130 & 30 & 22 & 45 & 596 & 879 & 40704 & 85722 & 1,47 & 2,11 & 1,43 \\
\hline 140 & 30 & 12 & 25 & 491 & 648 & 28300 & 48095 & 1,32 & 1,70 & 1,29 \\
\hline 140 & 30 & 14 & 29 & 516 & 698 & 31131 & 55486 & 1,35 & 1,78 & 1,32 \\
\hline 140 & 30 & 16 & 33 & 541 & 748 & 34090 & 63389 & 1,38 & 1,86 & 1,34 \\
\hline 140 & 30 & 18 & 38 & 566 & 805 & 37178 & 72891 & 1,42 & 1,96 & 1,38 \\
\hline 140 & 30 & 20 & 40 & 591 & 843 & 40393 & 79586 & 1,43 & 1,97 & 1,38 \\
\hline 140 & 30 & 22 & 45 & 616 & 899 & 43736 & 90168 & 1,46 & 2,06 & 1,41 \\
\hline 150 & 30 & 12 & 25 & 511 & 668 & 30804 & 51385 & 1,31 & 1,67 & 1,28 \\
\hline 150 & 30 & 14 & 29 & 536 & 718 & 33761 & 59027 & 1,34 & 1,75 & 1,30 \\
\hline 150 & 30 & 16 & 33 & 561 & 768 & 36846 & 67181 & 1,37 & 1,82 & 1,33 \\
\hline 150 & 30 & 18 & 38 & 586 & 825 & 40059 & 76966 & 1,41 & 1,92 & 1,37 \\
\hline 150 & 30 & 20 & 40 & 611 & 863 & 43400 & 83849 & 1,41 & 1,93 & 1,37 \\
\hline 150 & 30 & 22 & 45 & 636 & 919 & 46869 & 94714 & 1,44 & 2,02 & 1,40 \\
\hline & & & & & & & & & média & 1,48 \\
\hline & & & & & & & & & desvio & 0,0989 \\
\hline
\end{tabular}


Tabela A.5 - Valores de $\eta_{\mathrm{wp}}$ para pilares de borda com $\mathrm{c}_{1} \leq \mathrm{c}_{2}$

\begin{tabular}{|c|c|c|c|c|c|c|c|c|c|c|c|c|c|c|c|}
\hline $\mathrm{c} 1$ & c2 & $\mathrm{d}$ & $\mathrm{p}$ & $\mathrm{a}$ & $\mathrm{u}^{*}$ & $\mathrm{u}^{\prime *}$ & wp1 & wp1' & wp2 & wp2' & $\mathrm{u}^{\prime *} / \mathrm{u}^{*}$ & wp1'/wp1 & wp2'/wp2 & $\eta_{\mathrm{wp}}(\mathrm{wp} 1)$ & $\eta_{\mathrm{wp}}(\mathrm{wp} 2)$ \\
\hline 20 & 20 & 12 & 25 & 10 & 115 & 194 & 2786 & 7721 & 3366 & 8801 & 1,68 & 2,77 & 2,61 & 1,65 & 1,56 \\
\hline 20 & 30 & 12 & 25 & 10 & 125 & 204 & 3126 & 8311 & 4068 & 9896 & 1,63 & 2,66 & 2,43 & 1,63 & 1,50 \\
\hline 20 & 40 & 12 & 25 & 10 & 135 & 214 & 3466 & 8901 & 4820 & 11041 & 1,58 & 2,57 & 2,29 & 1,63 & 1,45 \\
\hline 20 & 50 & 12 & 25 & 10 & 145 & 224 & 3806 & 9491 & 5622 & 12235 & 1,54 & 2,49 & 2,18 & 1,62 & 1,41 \\
\hline 20 & 60 & 12 & 25 & 10 & 155 & 234 & 4146 & 10081 & 6474 & 13480 & 1,51 & 2,43 & 2,08 & 1,62 & 1,38 \\
\hline 20 & 70 & 12 & 25 & 10 & 165 & 244 & 4486 & 10671 & 7376 & 14775 & 1,47 & 2,38 & 2,00 & 1,61 & 1,36 \\
\hline 20 & 80 & 12 & 25 & 10 & 175 & 254 & 4826 & 11261 & 8328 & 16120 & 1,45 & 2,33 & 1,94 & 1,61 & 1,34 \\
\hline 20 & 90 & 12 & 25 & 10 & 185 & 264 & 5166 & 11851 & 9330 & 17514 & 1,42 & 2,29 & 1,88 & 1,61 & 1,32 \\
\hline 20 & 100 & 12 & 25 & 10 & 195 & 274 & 5506 & 12441 & 10382 & 18959 & 1,40 & 2,26 & 1,83 & 1,61 & 1,30 \\
\hline 20 & 20 & 14 & 29 & 10 & 128 & 219 & 3408 & 9829 & 4068 & 11069 & 1,71 & 2,88 & 2,72 & 1,68 & 1,59 \\
\hline 20 & 30 & 14 & 29 & 10 & 138 & 229 & 3788 & 10499 & 4832 & 12289 & 1,66 & 2,77 & 2,54 & 1,67 & 1,53 \\
\hline 20 & 40 & 14 & 29 & 10 & 148 & 239 & 4168 & 11169 & 5647 & 13559 & 1,62 & 2,68 & 2,40 & 1,66 & 1,49 \\
\hline 20 & 50 & 14 & 29 & 10 & 158 & 249 & 4548 & 11839 & 6512 & 14880 & 1,58 & 2,60 & 2,28 & 1,65 & 1,45 \\
\hline 20 & 60 & 14 & 29 & 10 & 168 & 259 & 4928 & 12509 & 7427 & 16250 & 1,54 & 2,54 & 2,19 & 1,65 & 1,42 \\
\hline 20 & 70 & 14 & 29 & 10 & 178 & 269 & 5308 & 13179 & 8392 & 17670 & 1,51 & 2,48 & 2,11 & 1,64 & 1,39 \\
\hline 20 & 80 & 14 & 29 & 10 & 188 & 279 & 5688 & 13849 & 9407 & 19141 & 1,48 & 2,43 & 2,03 & 1,64 & 1,37 \\
\hline 20 & 90 & 14 & 29 & 10 & 198 & 289 & 6068 & 14519 & 10471 & 20661 & 1,46 & 2,39 & 1,97 & 1,64 & 1,35 \\
\hline 20 & 100 & 14 & 29 & 10 & 208 & 299 & 6448 & 15189 & 11586 & 22232 & 1,44 & 2,36 & 1,92 & 1,64 & 1,33 \\
\hline 20 & 20 & 16 & 33 & 10 & 141 & 244 & 4093 & 12192 & 4833 & 13592 & 1,74 & 2,98 & 2,81 & 1,71 & 1,62 \\
\hline 20 & 30 & 16 & 33 & 10 & 151 & 254 & 4513 & 12942 & 5661 & 14938 & 1,69 & 2,87 & 2,64 & 1,70 & 1,56 \\
\hline 20 & 40 & 16 & 33 & 10 & 161 & 264 & 4933 & 13692 & 6539 & 16334 & 1,65 & 2,78 & 2,50 & 1,69 & 1,52 \\
\hline 20 & 50 & 16 & 33 & 10 & 171 & 274 & 5353 & 14442 & 7466 & 17780 & 1,61 & 2,70 & 2,38 & 1,68 & 1,48 \\
\hline 20 & 60 & 16 & 33 & 10 & 181 & 284 & 5773 & 15192 & 8444 & 19276 & 1,57 & 2,63 & 2,28 & 1,67 & 1,45 \\
\hline 20 & 70 & 16 & 33 & 10 & 191 & 294 & 6193 & 15942 & 9472 & 20822 & 1,54 & 2,57 & 2,20 & 1,67 & 1,42 \\
\hline 20 & 80 & 16 & 33 & 10 & 201 & 304 & 6613 & 16692 & 10549 & 22418 & 1,52 & 2,52 & 2,13 & 1,66 & 1,40 \\
\hline 20 & 90 & 16 & 33 & 10 & 211 & 314 & 7033 & 17442 & 11677 & 24064 & 1,49 & 2,48 & 2,06 & 1,66 & 1,38 \\
\hline 20 & 100 & 16 & 33 & 10 & 221 & 324 & 7453 & 18192 & 12855 & 25760 & 1,47 & 2,44 & 2,00 & 1,66 & 1,36 \\
\hline 20 & 20 & 18 & 38 & 10 & 153 & 272 & 4843 & 15157 & 5663 & 16737 & 1,78 & 3,13 & 2,96 & 1,76 & 1,66 \\
\hline 20 & 30 & 18 & 38 & 10 & 163 & 282 & 5303 & 15997 & 6553 & 18224 & 1,73 & 3,02 & 2,78 & 1,74 & 1,61 \\
\hline 20 & 40 & 18 & 38 & 10 & 173 & 292 & 5763 & 16837 & 7494 & 19762 & 1,69 & 2,92 & 2,64 & 1,73 & 1,56 \\
\hline 20 & 50 & 18 & 38 & 10 & 183 & 302 & 6223 & 17677 & 8484 & 21349 & 1,65 & 2,84 & 2,52 & 1,72 & 1,52 \\
\hline 20 & 60 & 18 & 38 & 10 & 193 & 312 & 6683 & 18517 & 9525 & 22986 & 1,62 & 2,77 & 2,41 & 1,71 & 1,49 \\
\hline 20 & 70 & 18 & 38 & 10 & 203 & 322 & 7143 & 19357 & 10615 & 24674 & 1,59 & 2,71 & 2,32 & 1,71 & 1,46 \\
\hline 20 & 80 & 18 & 38 & 10 & 213 & 332 & 7603 & 20197 & 11756 & 26411 & 1,56 & 2,66 & 2,25 & 1,70 & 1,44 \\
\hline 20 & 90 & 18 & 38 & 10 & 223 & 342 & 8063 & 21037 & 12946 & 28199 & 1,54 & 2,61 & 2,18 & 1,70 & 1,42 \\
\hline 20 & 100 & 18 & 38 & 10 & 233 & 352 & 8523 & 21877 & 14187 & 30036 & 1,51 & 2,57 & 2,12 & 1,70 & 1,40 \\
\hline 20 & 20 & 20 & 40 & 10 & 166 & 291 & 5657 & 17313 & 6557 & 19013 & 1,76 & 3,06 & 2,90 & 1,74 & 1,65 \\
\hline 20 & 30 & 20 & 40 & 10 & 176 & 301 & 6157 & 18213 & 7510 & 20595 & 1,72 & 2,96 & 2,74 & 1,72 & 1,60 \\
\hline 20 & 40 & 20 & 40 & 10 & 186 & 311 & 6657 & 19113 & 8513 & 22227 & 1,68 & 2,87 & 2,61 & 1,71 & 1,56 \\
\hline 20 & 50 & 20 & 40 & 10 & 196 & 321 & 7157 & 20013 & 9567 & 23908 & 1,64 & 2,80 & 2,50 & 1,70 & 1,52 \\
\hline 20 & 60 & 20 & 40 & 10 & 206 & 331 & 7657 & 20913 & 10670 & 25640 & 1,61 & 2,73 & 2,40 & 1,70 & 1,49 \\
\hline 20 & 70 & 20 & 40 & 10 & 216 & 341 & 8157 & 21813 & 11823 & 27421 & 1,58 & 2,67 & 2,32 & 1,69 & 1,47 \\
\hline 20 & 80 & 20 & 40 & 10 & 226 & 351 & 8657 & 22713 & 13027 & 29253 & 1,56 & 2,62 & 2,25 & 1,69 & 1,44 \\
\hline 20 & 90 & 20 & 40 & 10 & 236 & 361 & 9157 & 23613 & 14280 & 31135 & 1,53 & 2,58 & 2,18 & 1,68 & 1,42 \\
\hline 20 & 100 & 20 & 40 & 10 & 246 & 371 & 9657 & 24513 & 15583 & 33066 & 1,51 & 2,54 & 2,12 & 1,68 & 1,40 \\
\hline 20 & 20 & 22 & 45 & 18 & 194 & 336 & 6534 & 20818 & 7514 & 22698 & 1,73 & 3,19 & 3,02 & 1,84 & 1,75 \\
\hline 20 & 30 & 22 & 45 & 18 & 204 & 346 & 7074 & 21808 & 8530 & 24421 & 1,69 & 3,08 & 2,86 & 1,82 & 1,69 \\
\hline 20 & 40 & 22 & 45 & 18 & 214 & 356 & 7614 & 22798 & \begin{tabular}{|l}
9597 \\
\end{tabular} & 26194 & 1,66 & 2,99 & 2,73 & 1,80 & 1,64 \\
\hline 20 & 50 & 22 & 45 & 18 & 224 & 366 & 8154 & 23788 & 10713 & 28017 & 1,63 & 2,92 & 2,62 & 1,79 & 1,60 \\
\hline 20 & 60 & 22 & 45 & 18 & 234 & 376 & 8694 & 24778 & 11879 & 29890 & 1,60 & 2,85 & 2,52 & 1,78 & 1,57 \\
\hline 20 & 70 & 22 & 45 & 18 & 244 & 386 & 9234 & 25768 & 13095 & 31813 & 1,58 & 2,79 & 2,43 & 1,77 & 1,54 \\
\hline 20 & 80 & 22 & 45 & 18 & 254 & 396 & 9774 & 26758 & 14361 & 33786 & 1,56 & 2,74 & 2,35 & 1,76 & 1,51 \\
\hline 20 & 90 & 22 & 45 & 18 & 264 & 406 & 10314 & 27748 & \begin{tabular}{|l|l}
15677 \\
\end{tabular} & 3580 & 1,54 & 2,69 & 2,28 & 1,75 & 1,49 \\
\hline
\end{tabular}




\begin{tabular}{|c|c|c|c|c|c|c|c|c|c|c|c|c|c|c|c|}
\hline $\mathrm{c1}$ & $\mathrm{c} 2$ & $\mathrm{~d}$ & $\mathrm{p}$ & $\mathrm{a}$ & $\mathrm{u}^{*}$ & $\mathrm{u}^{\prime *}$ & wp1 & wp1' & wp2 & wp2' & $\mathrm{u}^{\prime *} / \mathrm{u}^{*}$ & wp1'/wp1 & wp2'/wp2 & $\eta_{\mathrm{wp}}$ (wp1) & $\eta_{\text {wp }}(\mathrm{wp} 2)$ \\
\hline 20 & 100 & 22 & 45 & 18 & 274 & 416 & 10854 & 28738 & 17044 & 37882 & 1,52 & 2,65 & 2,22 & 1,75 & 1,47 \\
\hline 25 & 40 & 12 & 25 & 13 & 140 & 219 & 3867 & 9499 & 5260 & 11731 & 1,56 & 2,46 & 2,23 & 1,58 & 1,43 \\
\hline 25 & 50 & 12 & 25 & 13 & 150 & 229 & 4232 & 10114 & 6112 & 12975 & 1,52 & 2,39 & 2,12 & 1,57 & 1,39 \\
\hline 25 & 60 & 12 & 25 & 13 & 160 & 239 & 4597 & 10729 & 7014 & 14270 & 1,49 & 2,33 & 2,03 & 1,57 & 1,37 \\
\hline 25 & 75 & 12 & 25 & 13 & 175 & 254 & 5144 & 11651 & 8461 & 16306 & 1,45 & 2,26 & 1,93 & 1,56 & 1,33 \\
\hline 25 & 80 & 12 & 25 & 13 & 180 & 259 & 5327 & 11959 & 8968 & 17010 & 1,44 & 2,24 & 1,90 & 1,56 & 1,32 \\
\hline 25 & 90 & 12 & 25 & 13 & 190 & 269 & 5692 & 12574 & 10020 & 18454 & 1,41 & 2,21 & 1,84 & 1,56 & 1,30 \\
\hline 25 & 100 & 12 & 25 & 13 & 200 & 279 & 6057 & 13189 & 11122 & 19949 & 1,39 & 2,18 & 1,79 & 1,56 & 1,29 \\
\hline 25 & 110 & 12 & 25 & 13 & 210 & 289 & 6422 & 13804 & 12274 & 21494 & 1,37 & 2,15 & 1,75 & 1,57 & 1,28 \\
\hline 25 & 125 & 12 & 25 & 13 & 225 & 304 & 6969 & 14726 & 14096 & 23904 & 1,35 & 2,11 & 1,70 & 1,57 & 1,26 \\
\hline 25 & 40 & 14 & 29 & 13 & 153 & 244 & 4600 & 11829 & 6127 & 14329 & 1,60 & 2,57 & 2,34 & 1,61 & 1,47 \\
\hline 25 & 50 & 14 & 29 & 13 & 163 & 254 & 5005 & 12524 & 7042 & 15700 & 1,56 & 2,50 & 2,23 & 1,60 & 1,43 \\
\hline 25 & 60 & 14 & 29 & 13 & 173 & 264 & 5410 & 13219 & 8007 & 17120 & 1,53 & 2,44 & 2,14 & 1,60 & 1,40 \\
\hline 25 & 75 & 14 & 29 & 13 & 188 & 279 & 6018 & 14261 & 9548 & 19344 & 1,48 & 2,37 & 2,03 & 1,60 & 1,36 \\
\hline 25 & 80 & 14 & 29 & 13 & 193 & 284 & 6220 & 14609 & 10087 & 20111 & 1,47 & 2,35 & 1,99 & 1,60 & 1,35 \\
\hline 25 & 90 & 14 & 29 & 13 & 203 & 294 & 6625 & 15304 & 11201 & 21681 & 1,45 & 2,31 & 1,94 & 1,59 & 1,34 \\
\hline 25 & 100 & 14 & 29 & 13 & 213 & 304 & 7030 & 15999 & 12366 & 23302 & 1,43 & 2,28 & 1,88 & 1,59 & 1,32 \\
\hline 25 & 110 & 14 & 29 & 13 & 223 & 314 & 7435 & 16694 & 13581 & 24972 & 1,41 & 2,25 & 1,84 & 1,59 & 1,31 \\
\hline 25 & 125 & 14 & 29 & 13 & 238 & 329 & 8043 & 17736 & 15497 & 27571 & 1,38 & 2,21 & 1,78 & 1,59 & 1,29 \\
\hline 25 & 40 & 16 & 33 & 13 & 166 & 269 & 5397 & 14415 & 7059 & 17184 & 1,63 & 2,67 & 2,43 & 1,64 & 1,50 \\
\hline 25 & 50 & 16 & 33 & 13 & 176 & 279 & 5842 & 15190 & 8036 & 18680 & 1,59 & 2,60 & 2,32 & 1,63 & 1,46 \\
\hline 25 & 60 & 16 & 33 & 13 & 186 & 289 & 6287 & 15965 & 9064 & 20226 & 1,56 & 2,54 & 2,23 & 1,63 & 1,43 \\
\hline 25 & 75 & 16 & 33 & 13 & 201 & 304 & 6955 & 17128 & 10699 & 22639 & 1,52 & 2,46 & 2,12 & 1,62 & 1,39 \\
\hline 25 & 80 & 16 & 33 & 13 & 206 & 309 & 7177 & 17515 & 11269 & 23468 & 1,50 & 2,44 & 2,08 & 1,62 & 1,38 \\
\hline 25 & 90 & 16 & 33 & 13 & 216 & 319 & 7622 & 18290 & 12447 & 25164 & 1,48 & 2,40 & 2,02 & 1,62 & 1,37 \\
\hline 25 & 100 & 16 & 33 & 13 & 226 & 329 & 8067 & 19065 & 13675 & 26910 & 1,46 & 2,36 & 1,97 & 1,62 & 1,35 \\
\hline 25 & 110 & 16 & 33 & 13 & 236 & 339 & 8512 & 19840 & 14952 & 28706 & 1,44 & 2,33 & 1,92 & 1,62 & 1,33 \\
\hline 25 & 125 & 16 & 33 & 13 & 251 & 354 & 9180 & 21003 & 16962 & 31494 & 1,41 & 2,29 & 1,86 & 1,62 & 1,31 \\
\hline 25 & 40 & 18 & 38 & 13 & 178 & 297 & 6258 & 17630 & 8054 & 20702 & 1,67 & 2,82 & 2,57 & 1,69 & 1,54 \\
\hline 25 & 50 & 18 & 38 & 13 & 188 & 307 & 6743 & 18495 & 9094 & 22339 & 1,63 & 2,74 & 2,46 & 1,68 & 1,50 \\
\hline 25 & 60 & 18 & 38 & 13 & 198 & 317 & 7228 & 19360 & 10185 & 24026 & 1,60 & 2,68 & 2,36 & 1,67 & 1,47 \\
\hline 25 & 75 & 18 & 38 & 13 & 213 & 332 & 7956 & 20658 & 11914 & 26651 & 1,56 & 2,60 & 2,24 & 1,66 & 1,43 \\
\hline 25 & 80 & 18 & 38 & 13 & 218 & 337 & 8198 & 21090 & 12516 & 27551 & 1,55 & 2,57 & 2,20 & 1,66 & 1,42 \\
\hline 25 & 90 & 18 & 38 & 13 & 228 & 347 & 8683 & 21955 & 13756 & 29389 & 1,52 & 2,53 & 2,14 & 1,66 & 1,40 \\
\hline 25 & 100 & 18 & 38 & 13 & 238 & 357 & 9168 & 22820 & 15047 & 31276 & 1,50 & 2,49 & 2,08 & 1,66 & 1,38 \\
\hline 25 & 110 & 18 & 38 & 13 & 248 & 367 & 9653 & 23685 & 16387 & 33213 & 1,48 & 2,45 & 2,03 & 1,66 & 1,37 \\
\hline 25 & 125 & 18 & 38 & 13 & 263 & 382 & 10381 & 24983 & 18492 & 36213 & 1,45 & 2,41 & 1,96 & 1,66 & 1,35 \\
\hline 25 & 40 & 20 & 40 & 13 & 191 & 316 & 7183 & 19954 & 9113 & 23227 & 1,66 & 2,78 & 2,55 & 1,67 & 1,54 \\
\hline 25 & 50 & 20 & 40 & 13 & \begin{tabular}{|l}
201 \\
\end{tabular} & 326 & 7708 & 20879 & 10217 & 24958 & 1,63 & 2,71 & 2,44 & 1,67 & 1,50 \\
\hline 25 & 60 & 20 & 40 & 13 & 211 & 336 & 8233 & 21804 & 11370 & 26740 & 1,60 & 2,65 & 2,35 & 1,66 & 1,47 \\
\hline 25 & 75 & 20 & 40 & 13 & 226 & 351 & 9021 & 23192 & 13194 & 29506 & 1,56 & 2,57 & 2,24 & 1,65 & 1,44 \\
\hline 25 & 80 & 20 & 40 & 13 & 231 & 356 & 9283 & 23654 & 13827 & 30453 & 1,54 & 2,55 & 2,20 & 1,65 & 1,43 \\
\hline 25 & 90 & 20 & 40 & 13 & 241 & 366 & 9808 & 24579 & 15130 & 32385 & 1,52 & 2,51 & 2,14 & 1,65 & 1,41 \\
\hline 25 & 100 & 20 & 40 & 13 & 251 & 376 & 10333 & 25504 & 16483 & 34366 & 1,50 & 2,47 & 2,08 & 1,64 & 1,39 \\
\hline 25 & 110 & 20 & 40 & 13 & 261 & 386 & 10858 & 26429 & 17887 & 36398 & 1,48 & 2,43 & 2,03 & 1,64 & 1,37 \\
\hline 25 & 125 & 20 & 40 & 13 & 276 & 401 & 11646 & 27817 & 20085 & 39539 & 1,46 & 2,39 & 1,97 & 1,64 & 1,35 \\
\hline 25 & 40 & 22 & 45 & 13 & 203 & 345 & 8172 & 23710 & 10237 & 27284 & 1,70 & 2,90 & 2,67 & 1,71 & 1,57 \\
\hline 25 & 50 & 22 & 45 & 13 & 213 & 355 & 8737 & 24725 & 11403 & 29157 & 1,66 & 2,83 & 2,56 & 1,70 & 1,54 \\
\hline 25 & 60 & 22 & 45 & 13 & 223 & 365 & 9302 & 25740 & 12619 & 31080 & 1,63 & 2,77 & 2,46 & 1,69 & 1,51 \\
\hline 25 & 75 & 22 & 45 & 13 & 238 & 380 & 10150 & 27262 & 14537 & 34058 & 1,59 & 2,69 & 2,34 & 1,69 & 1,47 \\
\hline 25 & 80 & 22 & 45 & 13 & 243 & 385 & 10432 & 27770 & 15201 & 35076 & 1,58 & 2,66 & 2,31 & 1,68 & 1,46 \\
\hline 25 & 90 & 22 & 45 & 13 & 253 & 395 & 10997 & 28785 & 16567 & 37149 & 1,56 & 2,62 & 2,24 & 1,68 & 1,44 \\
\hline 25 & 100 & 22 & 45 & 13 & 263 & 405 & 11562 & 29800 & 17984 & 39272 & 1,54 & 2,58 & 2,18 & 1,68 & 1,42 \\
\hline 25 & 110 & 22 & 45 & 13 & 273 & 415 & 12127 & 30815 & 19450 & 41445 & 1,52 & 2,54 & 2,13 & 1,67 & 1,40 \\
\hline 25 & 125 & 22 & $|45|$ & 13 & 288 & 430 & 12975 & 32337 & 21743 & 44798 & 1,49 & 2,49 & 2,06 & 1,67 & 1,38 \\
\hline
\end{tabular}




\begin{tabular}{|c|c|c|c|c|c|c|c|c|c|c|c|c|c|c|c|}
\hline $\mathrm{c1}$ & $\mathrm{c} 2$ & $\mathrm{~d}$ & $\mathrm{p}$ & $\mathrm{a}$ & $\mathrm{u}^{*}$ & $\mathrm{u}^{\prime *}$ & wp1 & wp1' & wp2 & wp2' & $\mathrm{u}^{\prime *} / \mathrm{u}^{*}$ & wp1'/wp1 & wp2'/wp2 & $\eta_{\mathrm{wp}}$ (wp1) & $\eta_{\text {wp }}(\mathrm{wp} 2)$ \\
\hline 30 & 30 & 12 & 25 & 15 & 135 & 214 & 3903 & 9481 & 4848 & 11176 & 1,58 & 2,43 & 2,31 & 1,54 & 1,46 \\
\hline 30 & 40 & 12 & 25 & 15 & 145 & 224 & 4293 & 10121 & 5700 & 12421 & 1,54 & 2,36 & 2,18 & 1,53 & 1,41 \\
\hline 30 & 50 & 12 & 25 & 15 & 155 & 234 & 4683 & 10761 & 6602 & 13715 & 1,51 & 2,30 & 2,08 & 1,53 & 1,38 \\
\hline 30 & 60 & 12 & 25 & 15 & 165 & 244 & 5073 & 11401 & 7554 & 15060 & 1,47 & 2,25 & 1,99 & 1,52 & 1,35 \\
\hline 30 & 70 & 12 & 25 & 15 & 175 & 254 & 5463 & 12041 & 8556 & 16455 & 1,45 & 2,20 & 1,92 & 1,52 & 1,33 \\
\hline 30 & 80 & 12 & 25 & 15 & 185 & 264 & 5853 & 12681 & 9608 & 17900 & 1,42 & 2,17 & 1,86 & 1,52 & 1,31 \\
\hline 30 & 90 & 12 & 25 & 15 & 195 & 274 & 6243 & 13321 & 10710 & 19394 & 1,40 & 2,13 & 1,81 & 1,52 & 1,29 \\
\hline 30 & 100 & 12 & 25 & 15 & 205 & 284 & 6633 & 13961 & 11862 & 20939 & 1,38 & 2,10 & 1,77 & 1,52 & 1,28 \\
\hline 30 & 110 & 12 & 25 & 15 & 215 & 294 & 7023 & 14601 & 13064 & 22534 & 1,36 & 2,08 & 1,72 & 1,52 & 1,26 \\
\hline 30 & 120 & 12 & 25 & 15 & 225 & 304 & 7413 & 15241 & 14316 & 24178 & 1,35 & 2,06 & 1,69 & 1,52 & 1,25 \\
\hline 30 & 130 & 12 & 25 & 15 & 235 & 314 & 7803 & 15881 & 15618 & 25873 & 1,33 & 2,04 & 1,66 & 1,53 & 1,24 \\
\hline 30 & 140 & 12 & 25 & 15 & 245 & 324 & 8193 & 16521 & 16970 & 27618 & 1,32 & 2,02 & 1,63 & 1,53 & 1,23 \\
\hline 30 & 150 & 12 & 25 & 15 & 255 & 334 & 8583 & 17161 & 18372 & 29412 & 1,31 & 2,00 & 1,60 & 1,53 & 1,22 \\
\hline 30 & 30 & 14 & 29 & 15 & 148 & 239 & 4627 & 11794 & 5692 & 13729 & 1,62 & 2,55 & 2,41 & 1,58 & 1,49 \\
\hline 30 & 40 & 14 & 29 & 15 & 158 & 249 & 5057 & 12514 & 6607 & 15099 & 1,58 & 2,47 & 2,29 & 1,57 & 1,45 \\
\hline 30 & 50 & 14 & 29 & 15 & 168 & 259 & 5487 & 13234 & 7572 & 16520 & 1,54 & 2,41 & 2,18 & 1,56 & 1,41 \\
\hline 30 & 60 & 14 & 29 & 15 & 178 & 269 & 5917 & 13954 & 8587 & 17990 & 1,51 & 2,36 & 2,10 & 1,56 & 1,39 \\
\hline 30 & 70 & 14 & 29 & 15 & 188 & 279 & 6347 & 14674 & 9652 & 19510 & 1,48 & 2,31 & 2,02 & 1,56 & 1,36 \\
\hline 30 & 80 & 14 & 29 & 15 & 198 & 289 & 6777 & 15394 & 10767 & 21081 & 1,46 & 2,27 & 1,96 & 1,56 & 1,34 \\
\hline 30 & 90 & 14 & 29 & 15 & 208 & 299 & 7207 & 16114 & 11931 & 22701 & 1,44 & 2,24 & 1,90 & 1,55 & 1,32 \\
\hline 30 & 100 & 14 & 29 & 15 & 218 & 309 & 7637 & 16834 & 13146 & 24372 & 1,42 & 2,20 & 1,85 & 1,55 & 1,31 \\
\hline 30 & 110 & 14 & 29 & 15 & 228 & 319 & 8067 & 17554 & 14411 & 26092 & 1,40 & 2,18 & 1,81 & 1,55 & 1,29 \\
\hline 30 & 120 & 14 & 29 & 15 & 238 & 329 & 8497 & 18274 & 15726 & 27862 & 1,38 & 2,15 & 1,77 & 1,56 & 1,28 \\
\hline 30 & 130 & 14 & 29 & 15 & 248 & 339 & 8927 & 18994 & 17091 & 29683 & 1,37 & 2,13 & 1,74 & 1,56 & 1,27 \\
\hline 30 & 140 & 14 & 29 & 15 & 258 & 349 & 9357 & 19714 & 18506 & 31553 & 1,35 & 2,11 & 1,71 & 1,56 & 1,26 \\
\hline 30 & 150 & 14 & 29 & 15 & 268 & 359 & 9787 & 20434 & 19970 & 33473 & 1,34 & 2,09 & 1,68 & 1,56 & 1,25 \\
\hline 30 & 30 & 16 & 33 & 15 & 161 & 264 & 5416 & 14363 & 6601 & 16538 & 1,65 & 2,65 & 2,51 & 1,61 & 1,52 \\
\hline 30 & 40 & 16 & 33 & 15 & 171 & 274 & 5886 & 15163 & 7579 & 18034 & 1,61 & 2,58 & 2,38 & 1,60 & 1,48 \\
\hline 30 & 50 & 16 & 33 & 15 & 181 & 284 & 6356 & 15963 & 8606 & 19580 & 1,57 & 2,51 & 2,28 & 1,60 & 1,45 \\
\hline 30 & 60 & 16 & 33 & 15 & 191 & 294 & 6826 & 16763 & 9684 & 21176 & 1,54 & 2,46 & 2,19 & 1,59 & 1,42 \\
\hline 30 & 70 & 16 & 33 & 15 & 201 & 304 & 7296 & 17563 & 10812 & 22822 & 1,52 & 2,41 & 2,11 & 1,59 & 1,39 \\
\hline 30 & 80 & 16 & 33 & 15 & 211 & 314 & 7766 & 18363 & 11989 & 24518 & 1,49 & 2,36 & 2,05 & 1,58 & 1,37 \\
\hline 30 & 90 & 16 & 33 & 15 & 221 & 324 & 8236 & 19163 & 13217 & 26264 & 1,47 & 2,33 & 1,99 & 1,58 & 1,35 \\
\hline 30 & 100 & 16 & 33 & 15 & 231 & 334 & 8706 & 19963 & 14495 & 28060 & 1,45 & 2,29 & 1,94 & 1,58 & 1,34 \\
\hline 30 & 110 & 16 & 33 & 15 & 241 & 344 & 9176 & 20763 & 15822 & 29906 & 1,43 & 2,26 & 1,89 & 1,58 & 1,32 \\
\hline 30 & 120 & 16 & 33 & 15 & 251 & 354 & 9646 & 21563 & 17200 & 31802 & 1,41 & 2,24 & 1,85 & 1,58 & 1,31 \\
\hline 30 & 130 & 16 & 33 & 15 & 261 & 364 & 10116 & 22363 & 18628 & 33748 & 1,40 & 2,21 & 1,81 & 1,58 & 1,30 \\
\hline 30 & 140 & 16 & 33 & 15 & 271 & 374 & 10586 & 23163 & 20105 & 35744 & 1,38 & 2,19 & 1,78 & 1,58 & 1,29 \\
\hline 30 & 150 & 16 & 33 & 15 & \begin{tabular}{|l|}
281 \\
\end{tabular} & 384 & 11056 & 23963 & 21633 & 37790 & 1,37 & 2,17 & 1,75 & 1,58 & 1,28 \\
\hline 30 & 30 & 18 & 38 & 15 & 173 & 292 & 6268 & 17559 & 7573 & 20004 & 1,69 & 2,80 & 2,64 & 1,66 & 1,56 \\
\hline 30 & 40 & 18 & 38 & 15 & 183 & 302 & 6778 & 18449 & 8614 & 21642 & 1,65 & 2,72 & 2,51 & 1,65 & 1,52 \\
\hline 30 & 50 & 18 & 38 & 15 & 193 & 312 & 7288 & 19339 & 9704 & 23329 & 1,62 & 2,65 & 2,40 & 1,64 & 1,49 \\
\hline 30 & 60 & 18 & 38 & 15 & 203 & 322 & 7798 & 20229 & 10845 & 25066 & 1,59 & 2,59 & 2,31 & 1,63 & 1,46 \\
\hline 30 & 70 & 18 & 38 & 15 & 213 & 332 & 8308 & 21119 & 12035 & 26854 & 1,56 & 2,54 & 2,23 & 1,63 & 1,43 \\
\hline 30 & 80 & 18 & 38 & 15 & 223 & 342 & 8818 & 22009 & 13276 & 28691 & 1,54 & 2,50 & 2,16 & 1,63 & 1,41 \\
\hline 30 & 90 & 18 & 38 & 15 & 233 & 352 & 9328 & 22899 & 14566 & 30579 & 1,51 & 2,45 & 2,10 & 1,62 & 1,39 \\
\hline 30 & 100 & 18 & 38 & 15 & 243 & 362 & 9838 & 23789 & 15907 & 32516 & 1,49 & 2,42 & 2,04 & 1,62 & 1,37 \\
\hline 30 & 110 & 18 & 38 & 15 & 253 & 372 & 10348 & 24679 & 17297 & 34503 & 1,47 & 2,38 & 1,99 & 1,62 & 1,36 \\
\hline 30 & 120 & 18 & 38 & 15 & 263 & 382 & 10858 & 25569 & 18738 & 36541 & 1,45 & 2,35 & 1,95 & 1,62 & 1,34 \\
\hline 30 & 130 & 18 & 38 & 15 & 273 & 392 & 11368 & 26459 & 20228 & 38628 & 1,44 & 2,33 & 1,91 & 1,62 & 1,33 \\
\hline 30 & 140 & 18 & 38 & 15 & 283 & 402 & 11878 & 27349 & 21769 & 40765 & 1,42 & 2,30 & 1,87 & 1,62 & 1,32 \\
\hline 30 & 150 & 18 & 38 & 15 & 293 & 412 & 12388 & 28239 & 23359 & 42953 & 1,41 & 2,28 & 1,84 & 1,62 & 1,31 \\
\hline 30 & 30 & 20 & 40 & 15 & 186 & 311 & 7185 & 19870 & 8610 & 22495 & 1,68 & 2,77 & 2,61 & 1,65 & 1,56 \\
\hline 30 & 40 & 20 & 40 & 15 & 196 & 321 & 7735 & 20820 & 9713 & 24227 & 1,64 & 2,69 & 2,49 & 1,64 & 1,52 \\
\hline 30 & 50 & 20 & $|40|$ & 15 & 206 & 331 & 8285 & 21770 & 10867 & 26008 & 1,61 & 2,63 & 2,39 & 1,63 & 1,49 \\
\hline
\end{tabular}




\begin{tabular}{|c|c|c|c|c|c|c|c|c|c|c|c|c|c|c|c|}
\hline $\mathrm{c} 1$ & $\mathrm{c} 2$ & $\mathrm{~d}$ & $\mathrm{p}$ & $\mathrm{a}$ & $\mathrm{u}^{*}$ & $\mathrm{u}^{\prime *}$ & wp1 & wp1' & wp2 & wp2' & $\mathrm{u}^{\prime *} / \mathrm{u}^{*}$ & wp1'/wp1 & wp2'/wp2 & $\eta_{\mathrm{wp}}(\mathrm{wp} 1)$ & $\eta_{\text {wp }}(\mathrm{wp} 2)$ \\
\hline 30 & 60 & 20 & 40 & 15 & 216 & 341 & 8835 & 22720 & 12070 & 27840 & 1,58 & 2,57 & 2,31 & 1,62 & 1,46 \\
\hline 30 & 70 & 20 & 40 & 15 & 226 & 351 & 9385 & 23670 & 13323 & 29721 & 1,56 & 2,52 & 2,23 & 1,62 & 1,43 \\
\hline 30 & 80 & 20 & 40 & 15 & 236 & 361 & 9935 & 24620 & 14627 & 31653 & 1,53 & 2,48 & 2,16 & 1,62 & 1,41 \\
\hline 30 & 90 & 20 & 40 & 15 & 246 & 371 & 10485 & 25570 & 15980 & 33635 & 1,51 & 2,44 & 2,10 & 1,61 & 1,39 \\
\hline 30 & 100 & 20 & 40 & 15 & 256 & 381 & 11035 & 26520 & 17383 & 35666 & 1,49 & 2,40 & 2,05 & 1,61 & 1,38 \\
\hline 30 & 110 & 20 & 40 & 15 & 266 & 391 & 11585 & 27470 & 18837 & 37748 & 1,47 & 2,37 & 2,00 & 1,61 & 1,36 \\
\hline 30 & 120 & 20 & 40 & 15 & 276 & 401 & 12135 & 28420 & 20340 & 39880 & 1,46 & 2,34 & 1,96 & 1,61 & 1,35 \\
\hline 30 & 130 & 20 & 40 & 15 & 286 & 411 & 12685 & 29370 & 21893 & 42061 & 1,44 & 2,32 & 1,92 & 1,61 & 1,33 \\
\hline 30 & 140 & 20 & 40 & 15 & 296 & 421 & 13235 & 30320 & 23496 & 44293 & 1,43 & 2,29 & 1,89 & 1,61 & 1,32 \\
\hline 30 & 150 & 20 & 40 & 15 & 306 & 431 & 13785 & 31270 & 25150 & 46575 & 1,41 & 2,27 & 1,85 & 1,61 & 1,31 \\
\hline 30 & 30 & 22 & 45 & 15 & 198 & 340 & 8165 & 23606 & 9710 & 26501 & 1,71 & 2,89 & 2,73 & 1,69 & 1,59 \\
\hline 30 & 40 & 22 & 45 & 15 & 208 & 350 & 8755 & 24646 & 10877 & 28374 & 1,68 & 2,81 & 2,61 & 1,68 & 1,55 \\
\hline 30 & 50 & 22 & 45 & 15 & 218 & 360 & 9345 & 25686 & 12093 & 30297 & 1,65 & 2,75 & 2,51 & 1,67 & 1,52 \\
\hline 30 & 60 & 22 & 45 & 15 & 228 & 370 & 9935 & 26726 & 13359 & 32270 & 1,62 & 2,69 & 2,42 & 1,66 & 1,49 \\
\hline 30 & 70 & 22 & 45 & 15 & 238 & 380 & 10525 & 27766 & 14675 & 34293 & 1,59 & 2,64 & 2,34 & 1,66 & 1,47 \\
\hline 30 & 80 & 22 & 45 & 15 & 248 & 390 & 11115 & 28806 & 16041 & 36366 & 1,57 & 2,59 & 2,27 & 1,65 & 1,44 \\
\hline 30 & 90 & 22 & 45 & 15 & 258 & 400 & 11705 & 29846 & 17457 & 38489 & 1,55 & 2,55 & 2,20 & 1,65 & 1,42 \\
\hline 30 & 100 & 22 & 45 & 15 & 268 & 410 & 12295 & 30886 & 18924 & 40662 & 1,53 & 2,51 & 2,15 & 1,64 & 1,41 \\
\hline 30 & 110 & 22 & 45 & 15 & 278 & 420 & 12885 & 31926 & 20440 & 42885 & 1,51 & 2,48 & 2,10 & 1,64 & 1,39 \\
\hline 30 & 120 & 22 & 45 & 15 & 288 & 430 & 13475 & 32966 & 22006 & 45158 & 1,49 & 2,45 & 2,05 & 1,64 & 1,38 \\
\hline 30 & 130 & 22 & 45 & 15 & 298 & 440 & 14065 & 34006 & 23622 & 47481 & 1,47 & 2,42 & 2,01 & 1,64 & 1,36 \\
\hline 30 & 140 & 22 & 45 & 15 & 308 & 450 & 14655 & 35046 & 25288 & 49854 & 1,46 & 2,39 & 1,97 & 1,64 & 1,35 \\
\hline 30 & 150 & 22 & 45 & 15 & 318 & 460 & 15245 & 36086 & 27004 & 52277 & 1,44 & 2,37 & 1,94 & 1,64 & 1,34 \\
\hline & & & & & & & & & & & & & média & 1,63 & 1,42 \\
\hline & & & & & & & & & & & & & desvio & 0,0622 & 0,0986 \\
\hline
\end{tabular}

Tabela A.6 - Valores de $\eta_{\mathrm{wp}}$ para pilares de borda com $c_{1}>c_{2}$

\begin{tabular}{|c|c|c|c|c|c|c|c|c|c|c|c|c|c|c|c|}
\hline $\mathrm{c} 1$ & $\mathrm{c} 2$ & $\mathrm{~d}$ & $\mathrm{p}$ & $\mathrm{a}$ & $\mathrm{u}^{*}$ & $\mathrm{u}^{\prime *}$ & wp1 & wp1' & wp2 & wp2' & $\mathrm{u}^{\prime *} / \mathrm{u}^{*}$ & wp1 1/wp1 & wp2'/wp2 & $\eta_{\mathrm{wp}}(\mathrm{wp} 1)$ & $\eta_{\text {wp }}(\mathrm{wp} 2)$ \\
\hline 30 & 20 & 12 & 25 & 15 & 125 & 204 & 3513 & 8841 & 4046 & 9981 & 1,63 & 2,52 & 2,47 & 1,55 & 1,52 \\
\hline 30 & 20 & 14 & 29 & 15 & 138 & 229 & 4197 & 11074 & 4828 & 12409 & 1,66 & 2,64 & 2,57 & 1,59 & 1,55 \\
\hline 30 & 20 & 16 & 33 & 15 & 151 & 254 & 4946 & 13563 & 5673 & 15092 & 1,69 & 2,74 & 2,66 & 1,62 & 1,58 \\
\hline 30 & 20 & 18 & 38 & 15 & 163 & 282 & 5758 & 16669 & 6583 & 18417 & 1,73 & 2,89 & 2,80 & 1,67 & 1,62 \\
\hline 30 & 20 & 20 & 40 & 15 & 176 & 301 & 6635 & 18920 & 7557 & 20813 & 1,72 & 2,85 & 2,75 & 1,66 & 1,61 \\
\hline 30 & 20 & 22 & 45 & 15 & 188 & 330 & 7575 & 22566 & 8594 & 24678 & 1,75 & 2,98 & 2,87 & 1,70 & 1,64 \\
\hline 40 & 20 & 12 & 25 & 18 & 131 & 210 & 4340 & 10061 & 4726 & 11161 & 1,60 & 2,32 & 2,36 & 1,45 & 1,48 \\
\hline 40 & 25 & 12 & 25 & 18 & 136 & 215 & 4560 & 10406 & 5171 & 11802 & 1,58 & 2,28 & 2,28 & 1,45 & 1,45 \\
\hline 40 & 30 & 12 & 25 & 18 & 141 & 220 & 4780 & 10751 & 5628 & 12456 & 1,56 & 2,25 & 2,21 & 1,45 & 1,42 \\
\hline 40 & 20 & 14 & 29 & 20 & 148 & 239 & 5087 & 12419 & 5588 & 13749 & 1,62 & 2,44 & 2,46 & 1,51 & 1,52 \\
\hline 40 & 25 & 14 & 29 & 20 & 153 & 244 & 5327 & 12804 & 6064 & 14453 & 1,60 & 2,40 & 2,38 & 1,51 & 1,49 \\
\hline 40 & 30 & 14 & 29 & 20 & 158 & 249 & 5567 & 13189 & 6552 & 15169 & 1,58 & 2,37 & 2,32 & 1,50 & 1,47 \\
\hline 40 & 20 & 16 & 33 & 20 & 161 & 264 & 5899 & 15034 & 6513 & 16592 & 1,65 & 2,55 & 2,55 & 1,55 & 1,55 \\
\hline 40 & 25 & 16 & 33 & 20 & 166 & 269 & 6159 & 15459 & 7021 & 17359 & 1,63 & 2,51 & 2,47 & 1,54 & 1,52 \\
\hline 40 & 30 & 16 & 33 & 20 & 171 & 274 & 6419 & 15884 & 7541 & 18138 & 1,61 & 2,47 & 2,41 & 1,54 & 1,50 \\
\hline 40 & 20 & 18 & 38 & 20 & 173 & 292 & 6774 & 18282 & 7503 & 20097 & 1,69 & 2,70 & 2,68 & 1,60 & 1,59 \\
\hline 40 & 25 & 18 & 38 & 20 & 178 & 297 & 7054 & 18752 & 8042 & 20934 & 1,67 & 2,66 & 2,60 & 1,59 & 1,56 \\
\hline 40 & 30 & 18 & 38 & 20 & 183 & 302 & 7334 & 19222 & 8593 & 21784 & 1,65 & 2,62 & 2,53 & 1,59 & 1,53 \\
\hline 40 & 20 & 20 & 40 & 20 & 186 & 311 & 7713 & 20627 & 8557 & 22613 & 1,68 & 2,67 & 2,64 & 1,59 & 1,58 \\
\hline 40 & 25 & 20 & 40 & 20 & 191 & 316 & 8013 & 21127 & 9127 & 23498 & 1,66 & 2,64 & 2,57 & 1,59 & 1,55 \\
\hline 40 & 30 & 20 & 40 & 20 & 196 & 321 & 8313 & 21627 & 9710 & 24395 & 1,64 & 2,60 & 2,51 & 1,58 & 1,53 \\
\hline 40 & 20 & 22 & 45 & 20 & 198 & 340 & 8717 & 24414 & 9674 & 26658 & \begin{tabular}{|l}
1,71 \\
\end{tabular} & 2,80 & 2,76 & 1,63 & 1,61 \\
\hline 40 & 25 & 22 & 45 & 20 & 203 & 345 & 9037 & 24959 & 10276 & 27613 & 1,70 & 2,76 & 2,69 & 1,63 & 1,58 \\
\hline 40 & 30 & 22 & 45 & 20 & 208 & 350 & 9357 & 25504 & 10890 & 28581 & 1,68 & 2,73 & 2,62 & 1,62 & 1,56 \\
\hline
\end{tabular}




\begin{tabular}{|c|c|c|c|c|c|c|c|c|c|c|c|c|c|c|c|}
\hline $\mathrm{c} 1$ & $\mathrm{c} 2$ & $\mathrm{~d}$ & $\mathrm{p}$ & $\mathrm{a}$ & $\mathrm{u}^{*}$ & $\mathrm{u}^{\prime *}$ & wp1 & wp1' & wp2 & wp2' & $\mathrm{u}^{\prime} * \mathrm{u}^{*}$ & wp1'/wp1 & wp2'/wp2 & $\eta_{\mathrm{wp}}(\mathrm{wp} 1)$ & $\eta_{w p}(w p 2)$ \\
\hline 50 & 20 & 12 & 25 & 18 & 131 & 210 & 5267 & 11380 & 5406 & 12341 & 1,60 & 2,16 & 2,28 & 1,35 & 1,43 \\
\hline 50 & 25 & 12 & 25 & 18 & 136 & 215 & 5512 & 11750 & 5901 & 13032 & 1,58 & 2,13 & 2,21 & 1,35 & 1,40 \\
\hline 50 & 30 & 12 & 25 & 18 & 141 & 220 & 5757 & 12120 & 6408 & 13736 & 1,56 & 2,11 & 2,14 & 1,35 & 1,38 \\
\hline 50 & 20 & 14 & 29 & 21 & 150 & 241 & 6077 & 13865 & 6348 & 15089 & 1,61 & 2,28 & 2,38 & 1,42 & 1,48 \\
\hline 50 & 25 & 14 & 29 & 21 & 155 & 246 & 6342 & 14275 & 6874 & 15843 & 1,59 & 2,25 & 2,30 & 1,42 & 1,45 \\
\hline 50 & 30 & 14 & 29 & 21 & 160 & 251 & 6607 & 14685 & 7412 & 16609 & 1,57 & 2,22 & 2,24 & 1,42 & 1,43 \\
\hline 50 & 20 & 16 & 33 & 24 & 169 & 272 & 6951 & 16605 & 7353 & 18092 & 1,62 & 2,39 & 2,46 & 1,48 & 1,52 \\
\hline 50 & 25 & 16 & 33 & 24 & 174 & 277 & 7236 & 17055 & 7911 & 18909 & 1,60 & 2,36 & 2,39 & 1,48 & 1,50 \\
\hline 50 & 30 & 16 & 33 & 24 & 179 & 282 & 7521 & 17505 & 8481 & 19738 & 1,58 & 2,33 & 2,33 & 1,47 & 1,47 \\
\hline 50 & 20 & 18 & 38 & 25 & 183 & 302 & 7889 & 19994 & 8423 & 21777 & 1,65 & 2,53 & 2,59 & 1,53 & 1,57 \\
\hline 50 & 25 & 18 & 38 & 25 & 188 & 307 & 8194 & 20489 & 9012 & 22664 & 1,63 & 2,50 & 2,51 & 1,53 & 1,54 \\
\hline 50 & 30 & 18 & 38 & 25 & 193 & 312 & 8499 & 20984 & 9613 & 23564 & 1,62 & 2,47 & 2,45 & 1,53 & 1,51 \\
\hline 50 & 20 & 20 & 40 & 25 & 196 & 321 & 8892 & 22433 & 9557 & 24413 & 1,64 & 2,52 & 2,55 & 1,54 & 1,56 \\
\hline 50 & 25 & 20 & 40 & 25 & 201 & 326 & 9217 & 22958 & 10177 & 25348 & 1,63 & 2,49 & 2,49 & 1,53 & 1,53 \\
\hline 50 & 30 & 20 & 40 & 25 & 206 & 331 & 9542 & 23483 & 10810 & 26295 & 1,61 & 2,46 & 2,43 & 1,53 & 1,51 \\
\hline 50 & 20 & 22 & 45 & 25 & 208 & 350 & 9958 & 26362 & 10754 & 28638 & 1,68 & 2,65 & 2,66 & 1,58 & 1,59 \\
\hline 50 & 25 & 22 & 45 & 25 & 213 & 355 & 10303 & 26932 & 11406 & 29643 & 1,66 & 2,61 & 2,60 & 1,57 & 1,56 \\
\hline 50 & 30 & 22 & 45 & 25 & 218 & 360 & 10648 & 27502 & 12070 & 30661 & 1,65 & 2,58 & 2,54 & 1,57 & 1,54 \\
\hline 60 & 20 & 12 & 25 & 18 & 131 & 210 & 6294 & 12800 & 6086 & 13521 & 1,60 & 2,03 & 2,22 & 1,27 & 1,39 \\
\hline 60 & 25 & 12 & 25 & 18 & 136 & 215 & 6564 & 13195 & 6631 & 14262 & 1,58 & 2,01 & 2,15 & 1,28 & 1,36 \\
\hline 60 & 30 & 12 & 25 & 18 & 141 & 220 & 6834 & 13590 & 7188 & 15016 & 1,56 & 1,99 & 2,09 & 1,28 & 1,34 \\
\hline 60 & 20 & 14 & 29 & 21 & 150 & 241 & 7167 & 15410 & 7108 & 16429 & 1,61 & 2,15 & 2,31 & 1,34 & 1,44 \\
\hline 60 & 25 & 14 & 29 & 21 & 155 & 246 & 7457 & 15845 & 7684 & 17233 & 1,59 & 2,12 & 2,24 & 1,34 & 1,41 \\
\hline 60 & 30 & 14 & 29 & 21 & 160 & 251 & 7747 & 16280 & 8272 & 18049 & 1,57 & 2,10 & 2,18 & 1,34 & 1,39 \\
\hline 60 & 20 & 16 & 33 & 24 & 169 & 272 & 8104 & 18276 & 8193 & 19592 & 1,62 & 2,26 & 2,39 & 1,40 & 1,48 \\
\hline 60 & 25 & 16 & 33 & 24 & 174 & 277 & 8414 & 18751 & 8801 & 20459 & 1,60 & 2,23 & 2,32 & 1,40 & 1,46 \\
\hline 60 & 30 & 16 & 33 & 24 & 179 & 282 & 8724 & 19226 & 9421 & 21338 & 1,58 & 2,20 & 2,26 & 1,39 & 1,43 \\
\hline 60 & 20 & 18 & 38 & 27 & 187 & 306 & 9105 & 21806 & 9343 & 23457 & 1,64 & 2,40 & 2,51 & 1,46 & 1,53 \\
\hline 60 & 25 & 18 & 38 & 27 & 192 & 311 & 9435 & 22326 & 9982 & 24394 & 1,62 & 2,37 & 2,44 & 1,46 & 1,51 \\
\hline 60 & 30 & 18 & 38 & 27 & 197 & 316 & 9765 & 22846 & 10633 & 25344 & 1,61 & 2,34 & 2,38 & 1,46 & 1,48 \\
\hline 60 & 20 & 20 & 40 & 30 & 206 & 331 & 10170 & 24340 & 10557 & 26213 & 1,61 & 2,39 & 2,48 & 1,49 & 1,54 \\
\hline 60 & 25 & 20 & 40 & 30 & 211 & 336 & 10520 & 24890 & 11227 & 27198 & 1,60 & 2,37 & 2,42 & 1,48 & 1,52 \\
\hline 60 & 30 & 20 & 40 & 30 & 216 & 341 & 10870 & 25440 & 11910 & 28195 & 1,58 & 2,34 & 2,37 & 1,48 & 1,50 \\
\hline 60 & 20 & 22 & 45 & 30 & 218 & 360 & 11299 & 28410 & 11834 & 30618 & 1,65 & 2,51 & 2,59 & 1,53 & 1,57 \\
\hline 60 & 25 & 22 & 45 & 30 & 223 & 365 & 11669 & 29005 & 12536 & 31673 & 1,63 & 2,49 & 2,53 & 1,52 & 1,55 \\
\hline 60 & 30 & 22 & 45 & 30 & 228 & 370 & 12039 & 29600 & 13250 & 32741 & 1,62 & 2,46 & 2,47 & 1,52 & 1,53 \\
\hline 70 & 20 & 12 & 25 & 18 & 131 & 210 & 7421 & 14320 & 6766 & 14701 & 1,60 & 1,93 & 2,17 & 1,21 & 1,36 \\
\hline 70 & 30 & 12 & 25 & 18 & 141 & 220 & 8011 & 15160 & 7968 & 16296 & 1,56 & 1,89 & 2,05 & 1,22 & 1,31 \\
\hline 70 & 20 & 14 & 29 & 21 & 150 & 241 & 8357 & 17055 & 7868 & 17769 & 1,61 & 2,04 & 2,26 & 1,27 & 1,40 \\
\hline 70 & 30 & 14 & 29 & 21 & 160 & 251 & 8987 & 17975 & 9132 & 19489 & 1,57 & 2,00 & 2,13 & 1,27 & 1,36 \\
\hline 70 & 20 & 16 & 33 & 24 & 169 & 272 & 9357 & 20047 & 9033 & 21092 & 1,62 & 2,14 & 2,33 & 1,33 & 1,45 \\
\hline 70 & 30 & 16 & 33 & 24 & 179 & 282 & 10027 & 21047 & 10361 & 22938 & 1,58 & 2,10 & 2,21 & 1,33 & 1,40 \\
\hline 70 & 20 & 18 & 38 & 27 & 187 & 306 & 10420 & 23719 & 10263 & 25137 & 1,64 & 2,28 & 2,45 & 1,39 & 1,50 \\
\hline 70 & 30 & 18 & 38 & 27 & 197 & 316 & 11130 & 24809 & 11653 & 27124 & 1,61 & 2,23 & 2,33 & 1,39 & 1,45 \\
\hline 70 & 20 & 20 & 40 & 30 & 206 & 331 & 11548 & 26346 & 11557 & 28013 & 1,61 & 2,28 & 2,42 & 1,42 & 1,50 \\
\hline 70 & 30 & 20 & 40 & 30 & 216 & 341 & 12298 & 27496 & 13010 & 30095 & 1,58 & 2,24 & 2,31 & 1,41 & 1,46 \\
\hline 70 & 20 & 22 & 45 & 33 & 224 & 366 & 12740 & 30558 & 12914 & 32598 & 1,63 & 2,40 & 2,52 & 1,47 & 1,55 \\
\hline 70 & 30 & 22 & 45 & 33 & 234 & 376 & 13530 & 31798 & 14430 & 34821 & 1,60 & 2,35 & 2,41 & 1,47 & 1,50 \\
\hline 75 & 25 & 12 & 25 & 18 & 136 & 215 & 8329 & 15550 & 7726 & 16107 & 1,58 & 1,87 & 2,08 & 1,18 & 1,32 \\
\hline 75 & 25 & 14 & 29 & 21 & 155 & 246 & 9317 & 18388 & 8899 & 19318 & 1,59 & 1,97 & 2,17 & 1,24 & 1,37 \\
\hline 75 & 25 & 16 & 33 & 24 & 174 & 277 & 10368 & 21483 & 10136 & 22784 & 1,60 & 2,07 & 2,25 & 1,30 & 1,41 \\
\hline 75 & 25 & 18 & 38 & 27 & 192 & 311 & 11483 & 25270 & 11437 & 26989 & 1,62 & 2,20 & 2,36 & 1,36 & 1,46 \\
\hline 75 & 25 & 20 & 40 & 30 & 211 & 336 & 12662 & 27975 & 12802 & 29973 & 1,60 & 2,21 & 2,34 & 1,38 & 1,47 \\
\hline 75 & 25 & 22 & 45 & 33 & 229 & 371 & 13906 & 32302 & 14231 & 34718 & 1,62 & 2,32 & 2,44 & 1,44 & 1,51 \\
\hline 80 & 20 & 12 & 25 & 18 & 131 & 210 & 8648 & 15940 & 7446 & 15881 & 1,60 & 1,84 & 2,13 & 1,15 & 1,33 \\
\hline
\end{tabular}




\begin{tabular}{|c|c|c|c|c|c|c|c|c|c|c|c|c|c|c|c|}
\hline $\mathrm{c} 1$ & $\mathrm{c} 2$ & $\mathrm{~d}$ & $\mathrm{p}$ & $\mathrm{a}$ & $\mathrm{u}^{*}$ & $\mathrm{u}^{\prime *}$ & wp1 & wp1' & wp2 & wp2' & $\mathrm{u}^{\prime} * \mathrm{u}^{*}$ & wp1'/wp1 & wp2'/wp2 & $\eta_{\mathrm{wp}}(\mathrm{wp} 1)$ & $\eta_{\text {wp }}(\mathrm{wp} 2)$ \\
\hline 80 & 25 & 12 & 25 & 18 & 136 & 215 & 8968 & 16385 & 8091 & 16722 & 1,58 & 1,83 & 2,07 & 1,16 & 1,31 \\
\hline 80 & 30 & 12 & 25 & 18 & 141 & 220 & 9288 & 16830 & 8748 & 17576 & 1,56 & 1,81 & 2,01 & 1,16 & 1,29 \\
\hline 80 & 20 & 14 & 29 & 21 & 150 & 241 & 9647 & 18801 & 8628 & 19109 & 1,61 & 1,95 & 2,21 & 1,21 & 1,38 \\
\hline 80 & 25 & 14 & 29 & 21 & 155 & 246 & 9987 & 19286 & 9304 & 20013 & 1,59 & 1,93 & 2,15 & 1,22 & 1,35 \\
\hline 80 & 30 & 14 & 29 & 21 & 160 & 251 & 10327 & 19771 & 9992 & 20929 & 1,57 & 1,91 & 2,09 & 1,22 & 1,33 \\
\hline 80 & 20 & 16 & 33 & 24 & 169 & 272 & 10709 & 21918 & 9873 & 22592 & 1,62 & 2,05 & 2,29 & 1,27 & 1,42 \\
\hline 80 & 25 & 16 & 33 & 24 & 174 & 277 & 11069 & 22443 & 10581 & 23559 & 1,60 & 2,03 & 2,23 & 1,27 & 1,39 \\
\hline 80 & 30 & 16 & 33 & 24 & 179 & 282 & 11429 & 22968 & 11301 & 24538 & 1,58 & 2,01 & 2,17 & 1,27 & 1,37 \\
\hline 80 & 20 & 18 & 38 & 27 & 187 & 306 & 11836 & 25731 & 11183 & 26817 & 1,64 & 2,17 & 2,40 & 1,33 & 1,46 \\
\hline 80 & 25 & 18 & 38 & 27 & 192 & 311 & 12216 & 26301 & 11922 & 27854 & 1,62 & 2,15 & 2,34 & 1,33 & 1,44 \\
\hline 80 & 30 & 18 & 38 & 27 & \begin{tabular}{|l|} 
\\
\end{tabular} & 316 & 12596 & 26871 & 12673 & 28904 & 1,61 & 2,13 & 2,28 & 1,33 & 1,42 \\
\hline 80 & 20 & 20 & 40 & 30 & 206 & 331 & 13027 & 28453 & 12557 & 29813 & 1,61 & 2,18 & 2,37 & 1,36 & 1,47 \\
\hline 80 & 25 & 20 & 40 & 30 & 211 & 336 & 13427 & 29053 & 13327 & 30898 & 1,60 & 2,16 & 2,32 & 1,36 & 1,45 \\
\hline 80 & 30 & 20 & 40 & 30 & 216 & 341 & 13827 & 29653 & 14110 & 31995 & 1,58 & 2,14 & 2,27 & 1,36 & 1,43 \\
\hline 80 & 20 & 22 & 45 & 33 & 224 & 366 & 14281 & 32806 & 13994 & 34578 & 1,63 & 2,30 & 2,47 & 1,41 & 1,52 \\
\hline 80 & 25 & 22 & 45 & 33 & 229 & 371 & 14701 & 33451 & 14796 & 35733 & 1,62 & 2,28 & 2,42 & 1,41 & 1,49 \\
\hline 80 & 30 & 22 & 45 & 33 & 234 & 376 & 15121 & 34096 & 15610 & 36901 & 1,60 & 2,25 & 2,36 & 1,41 & 1,47 \\
\hline 90 & 20 & 12 & 25 & 18 & 131 & 210 & 9975 & 17659 & 8126 & 17061 & 1,60 & 1,77 & 2,10 & 1,11 & 1,31 \\
\hline 90 & 25 & 12 & 25 & 18 & 136 & 215 & 10320 & 18129 & 8821 & 17952 & 1,58 & 1,76 & 2,04 & 1,11 & 1,29 \\
\hline 90 & 30 & 12 & 25 & 18 & 141 & 220 & 10665 & 18599 & 9528 & 18856 & 1,56 & 1,74 & 1,98 & 1,12 & 1,27 \\
\hline 90 & 20 & 14 & 29 & 21 & 150 & 241 & 11036 & 20646 & 9388 & 20449 & 1,61 & 1,87 & 2,18 & 1,16 & 1,36 \\
\hline 90 & 25 & 14 & 29 & 21 & 155 & 246 & 11401 & 21156 & 10114 & 21403 & 1,59 & 1,86 & 2,12 & 1,17 & 1,33 \\
\hline 90 & 30 & 14 & 29 & 21 & 160 & 251 & 11766 & 21666 & 10852 & 22369 & 1,57 & 1,84 & 2,06 & 1,17 & 1,31 \\
\hline 90 & 20 & 16 & $33 \mid$ & 24 & 169 & 272 & 12162 & 23889 & 10713 & 24092 & 1,62 & 1,96 & 2,25 & 1,22 & 1,39 \\
\hline 90 & 25 & 16 & $33 \mid$ & 24 & 174 & 277 & 12547 & 24439 & 11471 & 25109 & 1,60 & 1,95 & 2,19 & 1,22 & 1,37 \\
\hline 90 & 30 & 16 & $33 \mid$ & 24 & 179 & 282 & 12932 & 24989 & 12241 & 26138 & 1,58 & 1,93 & 2,14 & 1,22 & 1,35 \\
\hline 90 & 20 & 18 & 38 . & 27 & 187 & 306 & 13351 & 27844 & 12103 & 28497 & 1,64 & 2,09 & 2,35 & 1,27 & 1,44 \\
\hline 90 & 25 & 18 & 38 & 27 & 192 & 311 & 13756 & 28439 & 12892 & 29584 & 1,62 & 2,07 & 2,29 & 1,27 & 1,42 \\
\hline 90 & 30 & 18 & 38 & 27 & 197 & 316 & 14161 & 29034 & 13693 & 30684 & 1,61 & 2,05 & 2,24 & 1,28 & 1,40 \\
\hline 90 & 20 & 20 & 40 & 30 & 206 & 331 & 14605 & 30660 & 13557 & 31613 & 1,61 & 2,10 & 2,33 & 1,30 & 1,45 \\
\hline 90 & 25 & 20 & 40 & 30 & 211 & 336 & 15030 & 31285 & 14377 & 32748 & 1,60 & 2,08 & 2,28 & 1,30 & 1,43 \\
\hline 90 & 30 & 20 & 40 & 30 & 216 & 341 & 15455 & 31910 & 15210 & 33895 & 1,58 & 2,06 & 2,23 & 1,30 & 1,41 \\
\hline 90 & 20 & 22 & 45 & 33 & 224 & 366 & 15922 & 35154 & 15074 & 36558 & 1,63 & 2,21 & 2,43 & 1,35 & 1,49 \\
\hline 90 & 25 & 22 & 45 & 33 & 229 & 371 & 16367 & 35824 & 15926 & 37763 & 1,62 & 2,19 & 2,37 & 1,35 & 1,47 \\
\hline 90 & 30 & 22 & 45 & 33 & 234 & 376 & 16812 & 36494 & 16790 & 38981 & 1,60 & 2,17 & 2,32 & 1,35 & 1,45 \\
\hline 100 & 20 & 12 & 25 & 18 & 131 & 210 & 11402 & 19479 & 8806 & 18241 & 1,60 & 1,71 & 2,07 & 1,07 & 1,30 \\
\hline 100 & 25 & 12 & $25 \mid$ & 18 & 136 & 215 & 11772 & 19974 & 9551 & 19182 & 1,58 & 1,70 & 2,01 & 1,08 & 1,27 \\
\hline 100 & 30 & 12 & 25 & 18 & 141 & 220 & 12142 & 20469 & 10308 & 20136 & 1,56 & 1,69 & 1,95 & 1,08 & 1,26 \\
\hline 100 & 20 & 14 & 29 & 21 & 150 & 241 & 12526 & 22592 & 10148 & 21789 & 1,61 & 1,80 & 2,15 & 1,12 & 1,34 \\
\hline 100 & 25 & 14 & $29 \mid$ & 21 & 155 & 246 & 12916 & 23127 & 10924 & 22793 & 1,59 & 1,79 & 2,09 & 1,13 & 1,31 \\
\hline 100 & 30 & 14 & 29 & 21 & 160 & 251 & 13306 & 23662 & 11712 & 23809 & 1,57 & 1,78 & 2,03 & 1,13 & 1,30 \\
\hline 100 & 20 & 16 & 33 & 24 & 169 & 272 & 13715 & 25960 & 11553 & 25592 & 1,62 & 1,89 & 2,22 & 1,17 & 1,37 \\
\hline 100 & 25 & 16 & 33 & 24 & 174 & 277 & 14125 & 26535 & 12361 & 26659 & 1,60 & 1,88 & 2,16 & 1,18 & 1,35 \\
\hline 100 & 30 & 16 & 33 & 24 & 179 & 282 & 14535 & 27110 & 13181 & 27738 & 1,58 & 1,87 & 2,10 & 1,18 & 1,33 \\
\hline 100 & 20 & 18 & 38 & 27 & 187 & 306 & 14967 & 30056 & 13023 & 30177 & 1,64 & 2,01 & 2,32 & 1,23 & 1,41 \\
\hline 100 & 25 & 18 & 38 & 27 & 192 & 311 & 15397 & 30676 & 13862 & 31314 & 1,62 & 1,99 & 2,26 & 1,23 & 1,39 \\
\hline 100 & 30 & 18 & 38 & 27 & 197 & 316 & 15827 & 31296 & 14713 & 32464 & 1,61 & 1,98 & 2,21 & 1,23 & 1,37 \\
\hline 100 & 20 & 20 & 40 & 30 & 206 & 331 & 16283 & 32966 & 14557 & 33413 & 1,61 & 2,02 & 2,30 & 1,26 & 1,42 \\
\hline 100 & 25 & 20 & 40 & 30 & 211 & 336 & 16733 & 33616 & 15427 & 34598 & 1,60 & 2,01 & 2,24 & 1,26 & 1,40 \\
\hline 100 & 30 & 20 & 40 & 30 & 216 & 341 & 17183 & 34266 & 16310 & 35795 & 1,58 & 1,99 & 2,19 & 1,26 & 1,39 \\
\hline 100 & 20 & 22 & 45 & 33 & 224 & 366 & 17664 & 37602 & 16154 & 38538 & 1,63 & 2,13 & 2,39 & 1,31 & 1,46 \\
\hline 100 & 25 & 22 & 45 & 33 & 229 & 371 & 18134 & 38297 & 17056 & 39793 & 1,62 & 2,11 & 2,33 & 1,31 & 1,44 \\
\hline 100 & 30 & 22 & 45 & 33 & 234 & 376 & 18604 & 38992 & 17970 & 41061 & 1,60 & 2,10 & 2,28 & 1,31 & 1,42 \\
\hline 110 & 25 & 12 & 25 & 18 & 136 & 215 & 13324 & 21919 & 10281 & 20412 & 1,58 & 1,65 & 1,99 & 1,04 & 1,26 \\
\hline 110 & 30 & 12 & $25 \mid$ & 18 & 141 & 220 & 13719 & 22439 & 11088 & 21416 & 1,56 & 1,64 & 1,93 & 1,05 & 1,24 \\
\hline
\end{tabular}




\begin{tabular}{|c|c|c|c|c|c|c|c|c|c|c|c|c|c|c|c|}
\hline $\mathrm{c} 1$ & $\mathrm{c} 2$ & $\mathrm{~d}$ & $\mathrm{p}$ & $\mathrm{a}$ & $\mathrm{u}^{*}$ & $\mathrm{u}^{\prime *}$ & wp1 & wp1' & wp2 & wp2' & $\mathrm{u}^{\prime} * / \mathrm{u}^{*}$ & wp1'/wp1 & wp2'/wp2 & $\eta_{\text {wp }}(\mathrm{wp} 1)$ & $\eta_{\mathrm{wp}}(\mathrm{wp} 2)$ \\
\hline 110 & 25 & 14 & 29 & 21 & 155 & 246 & 14531 & 25197 & 11734 & 24183 & 1,59 & 1,73 & 2,06 & 1,09 & 1,30 \\
\hline 110 & 30 & 14 & 29 & 21 & 160 & 251 & 14946 & 25757 & 12572 & 25249 & 1,57 & 1,72 & 2,01 & 1,10 & 1,28 \\
\hline 110 & 25 & 16 & 33 & 24 & 174 & 277 & 15802 & 28731 & 13251 & 28209 & 1,60 & 1,82 & 2,13 & 1,14 & 1,33 \\
\hline 110 & 30 & 16 & 33 & 24 & 179 & 282 & 16237 & 29331 & 14121 & 29338 & 1,58 & 1,81 & 2,08 & 1,14 & 1,31 \\
\hline 110 & 25 & 18 & 38 & 27 & 192 & 311 & 17137 & 33013 & 14832 & 33044 & 1,62 & 1,93 & 2,23 & 1,19 & 1,37 \\
\hline 110 & 30 & 18 & 38 & 27 & 197 & 316 & 17592 & 33658 & 15733 & 34244 & 1,61 & 1,91 & 2,18 & 1,19 & 1,36 \\
\hline 110 & 25 & 20 & 40 & 30 & 211 & 336 & 18537 & 36048 & 16477 & 36448 & 1,60 & 1,94 & 2,21 & 1,22 & 1,39 \\
\hline 110 & 30 & 20 & 40 & 30 & 216 & 341 & 19012 & 36723 & 17410 & 37695 & 1,58 & 1,93 & 2,17 & 1,22 & 1,37 \\
\hline 110 & 25 & 22 & 45 & 33 & 229 & 371 & 20000 & 40870 & 18186 & 41823 & 1,62 & 2,04 & 2,30 & 1,26 & 1,42 \\
\hline 110 & 30 & 22 & 45 & 33 & 234 & 376 & 20495 & 41590 & 19150 & 43141 & 1,60 & 2,03 & 2,25 & 1,27 & 1,40 \\
\hline 120 & 30 & 12 & 25 & 18 & 141 & 220 & 15396 & 24508 & 11868 & 22696 & 1,56 & 1,59 & 1,91 & 1,02 & 1,23 \\
\hline 120 & 30 & 14 & 29 & 21 & 160 & 251 & 16686 & 27952 & 13432 & 26689 & 1,57 & 1,68 & 1,99 & 1,07 & 1,27 \\
\hline 120 & 30 & 16 & 33 & 24 & 179 & 282 & 18040 & 31652 & 15061 & 30938 & 1,58 & 1,75 & 2,05 & 1,11 & 1,30 \\
\hline 120 & 30 & 18 & 38 & 27 & 197 & 316 & 19458 & 36121 & 16753 & 36024 & 1,61 & 1,86 & 2,15 & 1,16 & 1,34 \\
\hline 120 & 30 & 20 & 40 & 30 & 216 & 341 & 20940 & 39280 & 18510 & 39595 & 1,58 & 1,88 & 2,14 & 1,19 & 1,35 \\
\hline 120 & 30 & 22 & 45 & 33 & 234 & 376 & 22486 & 44288 & 20330 & 45221 & 1,60 & 1,97 & 2,22 & 1,23 & 1,39 \\
\hline 125 & 25 & 12 & 25 & 28 & 156 & 235 & 15839 & 25023 & 11376 & 22257 & 1,50 & 1,58 & 1,96 & 1,05 & 1,30 \\
\hline 125 & 25 & 14 & 29 & 21 & 155 & 246 & 17141 & 28490 & 12949 & 26268 & 1,59 & 1,66 & 2,03 & 1,05 & 1,28 \\
\hline 125 & 25 & 16 & 33 & 24 & 174 & 277 & 18506 & 32213 & 14586 & 30534 & 1,60 & 1,74 & 2,09 & 1,09 & 1,31 \\
\hline 125 & 25 & 18 & 38 & 27 & 192 & 311 & 19936 & 36707 & 16287 & 35639 & 1,62 & 1,84 & 2,19 & 1,14 & 1,35 \\
\hline 125 & 25 & 20 & 40 & 30 & 211 & 336 & 21429 & 39883 & 18052 & 39223 & 1,60 & 1,86 & 2,17 & 1,17 & 1,36 \\
\hline 125 & 25 & 22 & 45 & 33 & 229 & 371 & 22986 & 44917 & 19881 & 44868 & 1,62 & 1,95 & 2,26 & 1,21 & 1,40 \\
\hline 130 & 30 & 12 & 25 & 18 & 141 & 220 & 17173 & 26678 & 12648 & 23976 & 1,56 & 1,55 & 1,90 & 1,00 & 1,22 \\
\hline 130 & 30 & 14 & 29 & 21 & 160 & 251 & 18526 & 30248 & 14292 & 28129 & 1,57 & 1,63 & 1,97 & 1,04 & 1,25 \\
\hline 130 & 30 & 16 & 33 & 24 & 179 & 282 & 19943 & 34073 & 16001 & 32538 & 1,58 & 1,71 & 2,03 & 1,08 & 1,29 \\
\hline 130 & 30 & 18 & 38 & 27 & 197 & 316 & 21423 & 38683 & 17773 & 37804 & 1,61 & 1,81 & 2,13 & 1,12 & 1,32 \\
\hline 130 & 30 & 20 & 40 & 30 & 216 & 341 & 22968 & 41936 & 19610 & 41495 & 1,58 & 1,83 & 2,12 & 1,15 & 1,34 \\
\hline 130 & 30 & 22 & 45 & 33 & 234 & 376 & 24577 & 47086 & 21510 & 47301 & 1,60 & 1,92 & 2,20 & 1,19 & 1,37 \\
\hline 140 & 30 & 12 & 25 & 18 & 141 & 220 & 19050 & 28948 & 13428 & 25256 & 1,56 & 1,52 & 1,88 & 0,98 & 1,21 \\
\hline 140 & 30 & 14 & 29 & 21 & 160 & 251 & 20466 & 32643 & 15152 & 29569 & 1,57 & 1,60 & 1,95 & 1,02 & 1,24 \\
\hline 140 & 30 & 16 & 33 & 24 & 179 & 282 & 21945 & 36594 & 16941 & 34138 & 1,58 & 1,67 & 2,02 & 1,05 & 1,27 \\
\hline 140 & 30 & 18 & 38 & 27 & 197 & 316 & 23489 & 41345 & 18793 & 39584 & 1,61 & 1,76 & 2,11 & 1,10 & 1,31 \\
\hline 140 & 30 & 20 & 40 & 30 & 216 & 341 & 25096 & 44693 & 20710 & 43395 & 1,58 & 1,78 & 2,10 & 1,13 & 1,32 \\
\hline 140 & 30 & 22 & 45 & 33 & 234 & 376 & 26768 & 49984 & 22690 & 49381 & 1,60 & 1,87 & 2,18 & 1,16 & 1,36 \\
\hline 150 & 30 & 12 & 25 & 18 & 141 & 220 & 21027 & 31317 & 14208 & 26536 & 1,56 & 1,49 & 1,87 & 0,96 & 1,20 \\
\hline 150 & 30 & 14 & 29 & 21 & 160 & 251 & 22505 & 35138 & 16012 & 31009 & 1,57 & 1,56 & 1,94 & 0,99 & 1,23 \\
\hline 150 & 30 & 16 & 33 & 24 & 179 & 282 & 24048 & 39215 & 17881 & 35738 & 1,58 & 1,63 & 2,00 & 1,03 & 1,26 \\
\hline 150 & 30 & 18 & 38 & 27 & 197 & 316 & 25654 & 44108 & 19813 & 41364 & 1,61 & 1,72 & 2,09 & 1,07 & 1,30 \\
\hline 150 & 30 & 20 & 40 & 30 & 216 & 341 & 27325 & 47550 & 21810 & 45295 & 1,58 & 1,74 & 2,08 & 1,10 & 1,31 \\
\hline 150 & 30 & 22 & 45 & 33 & 234 & 376 & 29059 & 52982 & 23870 & 51461 & 1,60 & 1,82 & 2,16 & 1,14 & 1,34 \\
\hline & & & & & & & & & & & & & média & 1,31 & 1,41 \\
\hline & & & & & & & & & & & & & desvio & 0,1772 & 0,0992 \\
\hline
\end{tabular}

Tabela A.7 - Valores de $\eta_{\mathrm{wp}}$ para pilares de canto com $\mathrm{c}_{1} \leq \mathrm{c}_{2}$

\begin{tabular}{|c|c|c|c|c|c||c|c|c|c||c|c||c|}
\hline $\mathrm{c} 1$ & $\mathrm{c} 2$ & $\mathrm{~d}$ & $\mathrm{p}$ & $\mathrm{a} 1$ & $\mathrm{a} 2$ & $\mathrm{u}^{*}$ & $\mathrm{u}^{\prime *}$ & $\mathrm{wp}$ & $\mathrm{wp}$ & $\mathrm{u}^{\prime *} / \mathrm{u}^{*}$ & $\mathrm{wp} / \mathrm{wp}$ & $\eta_{\mathrm{wp}}$ \\
\hline 20 & 20 & 12 & 25 & 10 & 10 & 58 & 97 & 1733 & 4451 & 1,68 & 2,57 & 1,53 \\
\hline 20 & 30 & 12 & 25 & 10 & 15 & 63 & 102 & 2073 & 5041 & 1,63 & 2,43 & 1,50 \\
\hline 20 & 40 & 12 & 25 & 10 & 18 & 66 & 105 & 2413 & 5631 & 1,60 & 2,33 & 1,46 \\
\hline 20 & 50 & 12 & 25 & 10 & 18 & 66 & 105 & 2753 & 6221 & 1,60 & 2,26 & 1,41 \\
\hline 20 & 60 & 12 & 25 & 10 & 18 & 66 & 105 & 3093 & 6811 & 1,60 & 2,20 & 1,38 \\
\hline 20 & 70 & 12 & 25 & 10 & 18 & 66 & 105 & 3433 & 7401 & 1,60 & 2,16 & 1,35 \\
\hline 20 & 80 & 12 & 25 & 10 & 18 & 66 & 105 & 3773 & 7991 & 1,60 & 2,12 & 1,33
\end{tabular}




\begin{tabular}{|c|c|c|c|c|c|c|c|c|c|c|c|c|}
\hline & $\mathrm{c} 2$ & $\mathrm{~d}$ & $\mathrm{p}$ & $\mathrm{a} 1$ & $\mathrm{a} 2$ & $u^{*}$ & $\mathrm{u}^{\prime *}$ & wp & $\mathrm{wp}^{\prime}$ & $\mathrm{u}^{\prime *} / \mathrm{u}^{*}$ & $\mathrm{wp} / \mathrm{wp}$ & $\eta_{\mathrm{wp}}$ \\
\hline 20 & 90 & 12 & 25 & \begin{tabular}{|l|}
10 \\
\end{tabular} & 18 & 66 & 105 & 4113 & 8581 & 1,60 & 2,09 & 1,31 \\
\hline 20 & \begin{tabular}{|l}
100 \\
\end{tabular} & 12 & 25 & 10 & 18 & 66 & 105 & 4453 & 9171 & 1,60 & 2,06 & 1,29 \\
\hline 20 & 20 & 14 & 29 & \begin{tabular}{|l|}
10 \\
\end{tabular} & 10 & 64 & 110 & 2084 & 5584 & 1,71 & 2,68 & 1,57 \\
\hline 20 & 30 & 14 & 29 & 10 & 15 & 69 & 115 & 2464 & 6254 & 1,66 & 2,54 & 1,53 \\
\hline 20 & 40 & 14 & 29 & 10 & 20 & 74 & 120 & 2844 & 6924 & 1,62 & 2,43 & 1,51 \\
\hline 20 & 50 & 14 & 29 & 10 & 21 & 75 & 121 & 3224 & 7594 & 1,61 & 2,36 & 1,47 \\
\hline 20 & 60 & 14 & 29 & 10 & 21 & 75 & 121 & 3604 & 8264 & 1,61 & 2,29 & 1,43 \\
\hline 20 & 70 & 14 & 29 & 10 & 21 & 75 & 121 & 3984 & 8934 & 1,61 & 2,24 & 1,40 \\
\hline 20 & 80 & 14 & 29 & 10 & 21 & 75 & 121 & 4364 & 9604 & 1,61 & 2,20 & 1,37 \\
\hline 20 & 90 & 14 & 29 & 10 & 21 & 75 & 121 & 4744 & 10274 & 1,61 & 2,17 & 1,35 \\
\hline 20 & 100 & 14 & 29 & 10 & 21 & 75 & 121 & 5124 & 10944 & 1,61 & 2,14 & 1,33 \\
\hline 20 & 20 & 16 & 33 & 10 & 10 & 70 & 122 & 2467 & 6846 & 1,74 & 2,78 & 1,60 \\
\hline 20 & 30 & 16 & 33 & 10 & 15 & 75 & 127 & 2887 & 7596 & 1,69 & 2,63 & 1,56 \\
\hline 20 & 40 & 16 & 33 & 10 & 20 & 80 & 132 & 3307 & 8346 & 1,65 & 2,52 & 1,53 \\
\hline 20 & 50 & 16 & 33 & 10 & 24 & 84 & 136 & 3727 & 9096 & 1,62 & 2,44 & 1,51 \\
\hline 20 & 60 & 16 & 33 & 10 & 24 & 84 & 136 & 4147 & 9846 & 1,62 & 2,37 & 1,47 \\
\hline 20 & 70 & 16 & 33 & 10 & 24 & 84 & 136 & 4567 & 10596 & 1,62 & 2,32 & 1,44 \\
\hline 20 & 80 & 16 & 33 & 10 & 24 & 84 & 136 & 4987 & 11346 & 1,62 & 2,28 & 1,41 \\
\hline 20 & 90 & 16 & 33 & 10 & 24 & 84 & 136 & 5407 & 12096 & 1,62 & 2,24 & 1,39 \\
\hline 20 & \begin{tabular}{|l}
100 \\
\end{tabular} & 16 & 33 & 10 & 24 & 84 & 136 & 5827 & 12846 & 1,62 & 2,20 & 1,37 \\
\hline 20 & 20 & 18 & 38 & 10 & 10 & 77 & 136 & 2881 & 8418 & 1,7 & 22 & 1,64 \\
\hline 20 & 30 & 18 & 38 & 10 & 15 & 82 & 141 & 3341 & 9258 & 1,73 & 2,77 & 1,60 \\
\hline 20 & 40 & 18 & 38 & 10 & 20 & 87 & 146 & 3801 & 10098 & .6 & 66 & 1,57 \\
\hline 20 & 50 & 18 & 38 & 10 & 25 & 92 & 151 & 4261 & 10938 & 1,65 & 2,57 & 1,55 \\
\hline 20 & 60 & 18 & 38 & 10 & 27 & 94 & 153 & 4721 & 11778 & 1,64 & 2,49 & 1,52 \\
\hline 20 & 70 & 18 & 38 & 10 & 27 & 94 & 153 & 5181 & 12618 & 1,64 & 2,44 & 1,49 \\
\hline 20 & 80 & 18 & 38 & \begin{tabular}{|l|}
10 \\
\end{tabular} & 27 & 94 & 153 & 5641 & 13458 & 1,6 & 39 & 1,46 \\
\hline 20 & 90 & 18 & 38 & 10 & 27 & 94 & 153 & 6101 & 14298 & 1,64 & 2,34 & 1,43 \\
\hline 20 & 100 & 18 & 38 & 10 & 27 & 94 & 15 & 6561 & 15138 & 1,6 & 31 & 1,41 \\
\hline 20 & 20 & 20 & 40 & 10 & 10 & 83 & 146 & 3328 & 9557 & 1,76 & 2,87 & 1,63 \\
\hline 20 & 30 & 20 & 40 & $|10|$ & 15 & 88 & 151 & 3828 & 10457 & 1,72 & 73 & 1,59 \\
\hline 20 & 40 & 20 & 40 & 10 & 20 & 93 & 156 & 4328 & 11357 & 1,68 & 62 & 1,56 \\
\hline 20 & 50 & 20 & 40 & 10 & 25 & 98 & 161 & 4828 & 12257 & 1,64 & 54 & 1,55 \\
\hline 20 & 60 & 20 & 40 & $|10|$ & 30 & 103 & 166 & 5328 & 13157 & 1,61 & ,47 & 1,53 \\
\hline 20 & 70 & 20 & 40 & \begin{tabular}{|l|}
10 \\
\end{tabular} & 30 & 103 & 166 & 5828 & 14057 & 1,61 & 41 & 1,50 \\
\hline 20 & 80 & 20 & 40 & 10 & 30 & 103 & 166 & 6328 & 14957 & 1,61 & 2,36 & 1,47 \\
\hline 20 & 90 & 20 & 40 & 10 & 30 & 103 & 166 & 6828 & 15857 & 1,6 & 32 & 1,44 \\
\hline 20 & 100 & 20 & 40 & 10 & 30 & 103 & 166 & 7328 & 16757 & 1,61 & 2,29 & 1,42 \\
\hline 20 & 20 & 2 & 45 & 18 & 10 & 97 & 168 & 3807 & 11399 & 1,7 & .99 & 1,73 \\
\hline 20 & 30 & 22 & 45 & 18 & 15 & 102 & 173 & 4347 & 12389 & 1,69 & 2,85 & 1,68 \\
\hline 20 & 40 & 22 & 45 & 18 & 20 & 107 & 178 & 4887 & 13379 & 1,66 & 74 & 1,65 \\
\hline 20 & 50 & 22 & 45 & 18 & 25 & 112 & 183 & 5427 & 14369 & 1,63 & 2,65 & 1,62 \\
\hline 20 & 60 & 22 & 45 & 18 & 30 & 117 & 188 & 5967 & 15359 & 1,60 & 57 & 1,61 \\
\hline 20 & 70 & 22 & 45 & 18 & 33 & 120 & 191 & 6507 & 16349 & 1,59 & 2,51 & 1,58 \\
\hline 20 & 80 & 22 & 45 & 18 & 33 & 120 & 191 & 847 & 17339 & 1,59 & 46 & 1,55 \\
\hline 20 & 90 & 22 & 45 & 18 & 33 & 120 & 191 & 7587 & 18329 & 1,59 & 2,42 & 1,52 \\
\hline 20 & 100 & 22 & 45 & 18 & 33 & 120 & 191 & 8127 & 19319 & 1,59 & ,38 & 1,50 \\
\hline 25 & 40 & 12 & 25 & 13 & 18 & 68 & 107 & 2663 & 5979 & 1,58 & 2,24 & 1,42 \\
\hline 25 & 50 & 12 & 25 & 13 & 18 & 68 & 107 & 3028 & 6594 & 1,58 & ,18 & 1,38 \\
\hline 25 & 60 & 12 & 25 & 13 & 18 & 68 & 107 & 3393 & 7209 & 1,58 & 2,12 & 1,35 \\
\hline 25 & 75 & 12 & 25 & 13 & 18 & 68 & 107 & 3941 & 8132 & 1, & ,06 & 1,31 \\
\hline 25 & 80 & 12 & 25 & 13 & 18 & 68 & 107 & 4123 & 8439 & 1,58 & 2,05 & 1,30 \\
\hline 25 & 90 & 12 & 25 & 13 & 18 & 68 & 107 & 4488 & 9054 & 1,58 & 2,02 & 1,28 \\
\hline 25 & 100 & 12 & 25 & 13 & 18 & 68 & 107 & 4853 & 9669 & 1,58 & 1,99 & 1,26 \\
\hline & 110 & 12 & | 25 & $|13|$ & 18 & 168 & 107 & 5218 & 10284 & 1,58 & 1,97 & 1,20 \\
\hline
\end{tabular}




\begin{tabular}{|c|c|c|c|c|c|c|c|c|c|c|c|c|}
\hline & c2 & $\mathrm{d}$ & $\mathrm{p}$ & a1 & $\mathrm{a} 2$ & $u^{*}$ & $\mathrm{u}^{\prime *}$ & wp & $\mathrm{wp}^{\prime}$ & $\mathrm{u}^{\prime *} / \mathrm{u}^{*}$ & $\mathrm{wp} / \mathrm{wp}$ & $\eta_{\mathrm{wp}}$ \\
\hline 25 & 125 & 12 & 25 & \begin{tabular}{|l|}
13 \\
\end{tabular} & 18 & 68 & 107 & 5766 & 11207 & 1,58 & 1,94 & 1,23 \\
\hline 25 & 40 & 14 & 29 & 13 & 20 & 76 & 122 & 3110 & 7304 & 1,60 & 2,35 & 1,47 \\
\hline 25 & 50 & 14 & 29 & \begin{tabular}{|l|}
13 \\
\end{tabular} & 21 & 77 & 123 & 515 & 7999 & 1,59 & 2,28 & 1,43 \\
\hline 25 & 60 & 14 & 29 & 13 & 21 & 77 & 123 & 3920 & 8694 & 1,59 & 2,22 & 1,40 \\
\hline 25 & 75 & 14 & 29 & 13 & 21 & 77 & 123 & 4528 & 9737 & 1,59 & 2,15 & 1,35 \\
\hline 25 & 80 & 14 & 29 & 13 & 21 & 77 & 123 & 4730 & 10084 & 1,59 & 2,13 & 1,34 \\
\hline 25 & 90 & 14 & 29 & 13 & 21 & 77 & 123 & 5135 & 10779 & 1,59 & 2,10 & 1,32 \\
\hline 25 & 100 & 14 & 29 & 13 & 21 & 77 & 123 & 5540 & 11474 & 1,59 & 2,07 & 1,30 \\
\hline 25 & 110 & 14 & 29 & 13 & 21 & 77 & 123 & 5945 & 12169 & 1,59 & 2,05 & 1,29 \\
\hline 25 & 125 & 14 & 29 & 13 & 21 & 77 & 123 & 6553 & 13212 & 1,59 & 2,02 & 1,27 \\
\hline 25 & 40 & 16 & 33 & 13 & 20 & 83 & 135 & 3589 & 8758 & 1,63 & 2,44 & 1,50 \\
\hline 25 & 50 & 16 & 33 & 13 & 24 & 87 & 139 & 4034 & 9533 & 1,60 & 2,36 & 1,48 \\
\hline 25 & 60 & 16 & 33 & 13 & 24 & 87 & 139 & 4479 & 10308 & 1,60 & 2,30 & 1,44 \\
\hline 25 & 75 & 16 & 33 & 13 & 24 & 87 & 139 & 5146 & 11470 & 1,60 & 2,23 & 1,40 \\
\hline 25 & 80 & 16 & 33 & 13 & 24 & 87 & 139 & 5369 & 11858 & 1,60 & 2,21 & 1,38 \\
\hline 25 & 90 & 16 & 33 & 13 & 24 & 87 & 139 & 5814 & 12633 & 1,60 & 2,17 & 1,36 \\
\hline 25 & 100 & 16 & 33 & 13 & 24 & 87 & 139 & 6259 & 13408 & 1,60 & 2,14 & 1,34 \\
\hline 25 & 110 & 16 & 33 & 13 & 24 & 87 & 139 & 6704 & 14183 & 1,60 & 2,12 & 1,32 \\
\hline 25 & 125 & 16 & 33 & 13 & 24 & 87 & 135 & 7371 & 15345 & 1,60 & 08 & 1,30 \\
\hline 25 & 40 & 18 & 38 & 13 & 20 & 89 & 149 & 4099 & 10545 & 1,67 & 2,57 & 1,54 \\
\hline 25 & 50 & 18 & 38 & 13 & 25 & 94 & 154 & 4584 & 11410 & 1,63 & 49 & 1,52 \\
\hline 25 & 60 & 18 & 38 & 13 & 27 & 96 & 156 & 5069 & 12275 & 1,62 & 2,42 & 1,49 \\
\hline 25 & 75 & 18 & 38 & 13 & 27 & 96 & 15 & 5797 & 13573 & 1,6 & 34 & 1,44 \\
\hline 25 & 80 & 18 & 38 & 13 & 27 & 96 & 156 & 6039 & 14005 & 1,62 & 2,32 & 1,43 \\
\hline 25 & 90 & 18 & 38 & 13 & 27 & 96 & 156 & 6524 & 14870 & 1,62 & 28 & 1,41 \\
\hline 25 & 100 & 18 & 38 & 13 & 27 & 96 & 156 & 7009 & 15735 & 1,62 & 2,24 & 1,38 \\
\hline 25 & 110 & 18 & 38 & 13 & 27 & 96 & 156 & 7494 & 16600 & 1,62 & 22 & 1,37 \\
\hline 25 & 125 & 18 & 38 & 13 & 27 & 96 & 156 & 8222 & 17898 & 1,62 & 2,18 & 1,34 \\
\hline 25 & 40 & 20 & 40 & 13 & 20 & 95 & 158 & 4642 & 11827 & 1,66 & 55 & 1,54 \\
\hline 25 & 50 & 20 & 40 & 13 & 25 & 100 & 163 & 5167 & 12752 & 1,63 & 47 & 1,52 \\
\hline 25 & 60 & 20 & 40 & 13 & 30 & 105 & 168 & 5692 & 13677 & 1,60 & 40 & 1,51 \\
\hline 25 & 75 & 20 & 40 & 13 & 30 & 105 & 168 & 6479 & 15065 & 1,60 & 33 & 1,46 \\
\hline 25 & 80 & 20 & 40 & 13 & 30 & 105 & 168 & 6742 & 15527 & 1,60 & 30 & 1,44 \\
\hline 25 & 90 & 20 & 40 & 13 & 30 & 105 & 168 & 7267 & 16452 & 1,60 & 26 & 1,42 \\
\hline 25 & 100 & 20 & 40 & 13 & 30 & 105 & 168 & 7792 & 17377 & 1,60 & 23 & 1,40 \\
\hline 25 & 110 & 20 & 40 & 13 & 30 & 105 & 168 & 8317 & 18302 & 1,60 & 2,20 & 1,38 \\
\hline 25 & 125 & 20 & 40 & 13 & 30 & 105 & 168 & 9104 & 19690 & 1,60 & 16 & 1,35 \\
\hline 25 & 40 & 22 & 45 & 13 & 20 & 102 & 172 & 5216 & 13885 & 1,70 & 2,66 & 1,57 \\
\hline 25 & 50 & 2 & 45 & 13 & 25 & 107 & 177 & 5781 & 14900 & 1,66 & 58 & 1,55 \\
\hline 25 & 60 & 22 & 45 & 13 & 30 & 112 & 182 & 6346 & 15915 & 1,63 & 2,51 & 1,54 \\
\hline 25 & 75 & 22 & 45 & 13 & 33 & 115 & 185 & 7194 & 17437 & 1,62 & 42 & 1,50 \\
\hline 25 & 80 & 22 & 45 & 13 & 33 & 115 & 185 & 7476 & 17945 & 1,62 & 2,40 & 1,48 \\
\hline 25 & 90 & 22 & 45 & 13 & 33 & 115 & 185 & 41 & 18960 & 1,62 & 36 & 1,46 \\
\hline 25 & 100 & 22 & 45 & 13 & 33 & 115 & 185 & 8606 & 19975 & 1,62 & 2,32 & 1,44 \\
\hline 25 & 110 & 22 & 45 & 13 & 33 & 115 & 185 & 9171 & 20990 & 62 & 29 & 1,42 \\
\hline 25 & 125 & 22 & 45 & 13 & 33 & 115 & 185 & 10019 & 22512 & 1,62 & 2,25 & 1,39 \\
\hline 30 & 30 & 12 & 25 & 15 & 15 & 68 & 107 & 536 & 5701 & 1,58 & 25 & 1,42 \\
\hline 30 & 40 & 12 & 25 & 15 & 18 & 71 & 110 & 2926 & 6341 & 1,56 & 2,17 & 1,39 \\
\hline 30 & 50 & 12 & 25 & 15 & 18 & 71 & 110 & 5310 & 6981 & 1,56 & 2,10 & 1,35 \\
\hline 30 & 60 & 12 & 25 & 15 & 18 & 71 & 110 & 3706 & 7621 & 1,56 & 2,06 & 1,32 \\
\hline 30 & 70 & 12 & 25 & 15 & 18 & 71 & 110 & 4096 & 8261 & 1, &, 02 & 1,30 \\
\hline 30 & 80 & 12 & 25 & 15 & 18 & 71 & 110 & 4486 & 8901 & 1,56 & 1,98 & 1,28 \\
\hline 30 & 90 & 12 & 25 & 15 & 18 & 71 & 110 & 4876 & 9541 & 1,56 & 1,96 & 1,26 \\
\hline 30 & 100 & 12 & 25 & 15 & 18 & 71 & 110 & 5266 & 10181 & 1,56 & 1,93 & 1,24 \\
\hline & 110 & 12 & 25 & $|15|$ & 18 & 71 & 110 & 5656 & 10821 & 1,56 & 1,91 & 1,23 \\
\hline
\end{tabular}




\begin{tabular}{|c|c|c|c|c|c|c|c|c|c|c|c|c|}
\hline & c2 & $\mathrm{d}$ & $\mathrm{p}$ & a1 & $\mathrm{a} 2$ & $\mathrm{u}^{*}$ & $\mathrm{u}^{\prime *}$ & wp & $\mathrm{wp}^{\prime}$ & $\mathrm{u}^{\prime *} / \mathrm{u}^{*}$ & $\mathrm{wp} / \mathrm{wp}$ & $\eta_{\mathrm{wp}_{\mathrm{p}}}$ \\
\hline 30 & 120 & 12 & 25 & \begin{tabular}{|l|}
15 \\
\end{tabular} & 18 & 71 & 110 & 6046 & 1461 & 1,56 & 1,90 & 1,22 \\
\hline 30 & \begin{tabular}{|l}
130 \\
\end{tabular} & 12 & 25 & \begin{tabular}{|l|}
15 \\
\end{tabular} & 18 & 71 & 110 & 6436 & 2101 & 1,56 & 1,88 & 1,21 \\
\hline 30 & \begin{tabular}{|l}
140 \\
\end{tabular} & 12 & 25 & \begin{tabular}{|l|}
15 \\
\end{tabular} & 18 & 1 & 110 & 826 & 2741 & 1,56 & 1,87 & 1,20 \\
\hline 30 & 150 & 12 & 25 & 15 & 18 & 71 & 110 & 7216 & 13381 & 1,56 & 1,85 & 1,19 \\
\hline 30 & 30 & 14 & 29 & 15 & 15 & 74 & 120 & 2959 & 6977 & 1,62 & 2,36 & 1,46 \\
\hline 30 & 40 & 14 & 29 & 15 & 20 & 79 & 125 & 3389 & 7697 & 1,58 & 2,27 & 1,44 \\
\hline 30 & 50 & 14 & 29 & 15 & 21 & 80 & 126 & 3819 & 8417 & 1,57 & 2,20 & 1,40 \\
\hline 30 & 60 & 14 & 29 & 15 & 21 & 80 & 126 & 4249 & 9137 & 1,57 & 2,15 & 1,37 \\
\hline 30 & 70 & 14 & 29 & 15 & 21 & 80 & 126 & 4679 & 9857 & 1,57 & 2,11 & 1,34 \\
\hline 30 & 80 & 14 & 29 & 15 & 21 & 80 & 126 & 5109 & 10577 & 1,57 & 2,07 & 1,32 \\
\hline 30 & 90 & 14 & 29 & 15 & 21 & 80 & 126 & 5539 & 11297 & 1,57 & 2,04 & 1,30 \\
\hline 30 & 100 & 14 & 29 & 15 & 21 & 80 & 126 & 5969 & 12017 & 1,57 & 2,01 & 1,28 \\
\hline 30 & 110 & 14 & 29 & 15 & 21 & 80 & 126 & 6399 & 12737 & 1,57 & 1,99 & 1,27 \\
\hline 30 & 120 & 14 & 29 & 15 & 21 & 80 & 126 & 6829 & 13457 & 1,57 & 1,97 & 1,26 \\
\hline 30 & 130 & 14 & 29 & 15 & 21 & 80 & 126 & 7259 & 14177 & 1,57 & 1,95 & 1,24 \\
\hline 30 & 140 & 14 & 29 & 15 & 21 & 80 & 126 & 7689 & 14897 & 1,57 & 1,94 & 1,23 \\
\hline 30 & 150 & 14 & 29 & 15 & 21 & 80 & 126 & 8119 & 15617 & 1,57 & 1,92 & 1,23 \\
\hline 30 & 30 & 16 & 33 & 15 & 15 & 80 & 132 & 3413 & 8382 & 1,65 & 2,46 & 1,49 \\
\hline 30 & 40 & 16 & 33 & 15 & 20 & 85 & 13 & 3883 & 9182 & 1,61 & 2,36 & 1,47 \\
\hline 30 & 50 & 16 & 33 & 15 & 24 & 89 & 141 & 4353 & 9982 & 1,58 & 2,29 & 1,45 \\
\hline 30 & 60 & 16 & 33 & 15 & 24 & 89 & 141 & 4823 & 10782 & 1,5 & 24 & 1,41 \\
\hline 30 & 70 & 16 & 33 & 15 & 24 & 89 & 141 & 5293 & 11582 & 1,58 & 2,19 & 1,38 \\
\hline 30 & 80 & 16 & 33 & 15 & 24 & 89 & 141 & 5763 & 12382 & $1,5 \gamma$ & 2,15 & 1,36 \\
\hline 30 & 90 & 16 & 33 & 15 & 24 & 89 & 141 & 6233 & 13182 & 1,58 & 2,11 & 1,34 \\
\hline 30 & 100 & 16 & 33 & 15 & 24 & 89 & 141 & 6703 & 13982 & 1,5 & 99 & 1,32 \\
\hline 30 & 110 & 16 & 33 & 15 & 24 & 89 & 141 & 7173 & 14782 & 1,58 & 2,06 & 1,30 \\
\hline 30 & 120 & 16 & 33 & 15 & 24 & 89 & 141 & 7643 & 15582 & 1, & 04 & 1,29 \\
\hline 30 & 130 & 16 & 33 & 15 & 24 & 89 & 141 & 8113 & 16382 & 1,58 & 2,02 & 1,28 \\
\hline 30 & 140 & 16 & 33 & 15 & 24 & 89 & 141 & 8583 & 17182 & 1, & 00 & 1,27 \\
\hline 30 & 150 & 16 & 33 & 15 & 24 & 89 & 141 & 9053 & 17982 & 1,58 & ,99 & 1,26 \\
\hline 30 & 30 & 18 & 38 & $\mid 15$ & 15 & 87 & 146 & 3899 & 10115 & 1,6 & 59 & 1,54 \\
\hline 30 & 40 & 18 & 38 & 15 & 20 & 92 & 151 & 4409 & 11005 & 1,65 &, 50 & 1,51 \\
\hline 30 & 50 & 18 & 38 & 15 & 25 & 97 & 156 & 4919 & 11895 & 1,6 & 42 & 1,49 \\
\hline 30 & 60 & 18 & 38 & $\mid 15$ & 27 & 99 & 158 & 5429 & 12785 & 1,6 & 2,35 & 1,47 \\
\hline 30 & 70 & 18 & 38 & 15 & 27 & 99 & 158 & 5939 & 13675 & 1,61 & 30 & 1,43 \\
\hline 30 & 80 & 18 & 38 & 15 & 27 & 99 & 158 & 6449 & 14565 & 1,61 & 2,26 & 1,41 \\
\hline 30 & 90 & 18 & 38 & 15 & 27 & 99 & 158 & 6959 & 15455 & 1,61 & 22 & 1,38 \\
\hline 30 & 100 & 18 & 38 & 15 & 27 & 99 & 158 & 7469 & 16345 & 1,61 & 2,19 & 1,36 \\
\hline 30 & 110 & 18 & 38 & 15 & 27 & 99 & 158 & 7979 & 17235 & 1,61 & 16 & 1,35 \\
\hline 30 & 120 & 18 & 38 & 15 & 27 & 99 & 158 & 8489 & 18125 & 1,61 & 14 & 1,33 \\
\hline 30 & 130 & 18 & 38 & 15 & 27 & 99 & 158 & 999 & 19015 & 1,61 & 11 & 1,32 \\
\hline 30 & 140 & 18 & 38 & 15 & 27 & 99 & 158 & 9509 & 19905 & 1,61 & 2,09 & 1,30 \\
\hline 30 & 150 & 18 & 38 & $\mid 15$ & 27 & 99 & 158 & 10019 & 20795 & 61 & 88 & 1,29 \\
\hline 30 & 30 & 20 & 40 & 15 & 15 & 93 & 156 & 4417 & 11360 & 1,68 & 2,57 & 1,53 \\
\hline 30 & 40 & 20 & 40 & 15 & 20 & 98 & 161 & 4967 & 12310 & 1,64 & 48 & 1,51 \\
\hline 30 & 50 & 20 & 40 & 15 & 25 & 103 & 166 & 5517 & 13260 & 1,61 & 2,40 & 1,49 \\
\hline 30 & 60 & 20 & 40 & 15 & 30 & 108 & 171 & 6067 & 14210 & 1,58 &, 34 & 1,48 \\
\hline 30 & 70 & 20 & 40 & 15 & 30 & 108 & 171 & 6617 & 15160 & 1,58 & 2,29 & 1,45 \\
\hline 30 & 80 & 2 & 40 & 15 & 30 & 108 & 171 & 7167 & 16110 & 1,58 & 25 & 1,42 \\
\hline 30 & 90 & 20 & 40 & 15 & 30 & 108 & 171 & 7717 & 17060 & 1,58 & 2,21 & 1,40 \\
\hline 30 & 100 & 20 & 40 & 15 & 30 & 108 & 171 & 8267 & 18010 & 1,2 & ,18 & 1,38 \\
\hline 30 & 110 & 20 & 40 & 15 & 30 & 108 & 171 & 8817 & 18960 & 1,58 & 2,15 & 1,36 \\
\hline 30 & 120 & 20 & 40 & 15 & 30 & 108 & 171 & 9367 & 19910 & 1,58 & 2,13 & 1,34 \\
\hline 30 & 130 & 20 & 40 & 15 & 30 & 108 & 171 & 9917 & 20860 & 1,58 & 2,10 & 1,33 \\
\hline & 140 & 20 & 140 & 15 & 30 & 108 & 171 & 10467 & 2181 & 1,58 & 2,08 & 1,32 \\
\hline
\end{tabular}




\begin{tabular}{|c|c|c|c|c|c||c|c|c|c||c|c||c|}
$\mathrm{c} 1$ & $\mathrm{c} 2$ & $\mathrm{~d}$ & $\mathrm{p}$ & $\mathrm{a} 1$ & $\mathrm{a} 2$ & $\mathrm{u}^{*}$ & $\mathrm{u}^{\prime *}$ & $\mathrm{wp}$ & $\mathrm{wp}$ & $\mathrm{u}^{\prime *} / \mathrm{u}^{*}$ & $\mathrm{wp} / \mathrm{wp}$ & $\eta_{\text {wp }}$ \\
\hline 30 & 150 & 20 & 40 & 15 & 30 & 108 & 171 & 11017 & 22760 & 1,58 & 2,07 & 1,31 \\
\hline 30 & 30 & 22 & 45 & 15 & 15 & 99 & 170 & 4968 & 13363 & 1,71 & 2,69 & 1,57 \\
\hline 30 & 40 & 22 & 45 & 15 & 20 & 104 & 175 & 5558 & 14403 & 1,68 & 2,59 & 1,54 \\
\hline 30 & 50 & 22 & 45 & 15 & 25 & 109 & 180 & 6148 & 15443 & 1,65 & 2,51 & 1,52 \\
\hline 30 & 60 & 22 & 45 & 15 & 30 & 114 & 185 & 6738 & 16483 & 1,62 & 2,45 & 1,51 \\
\hline 30 & 70 & 22 & 45 & 15 & 33 & 117 & 188 & 7328 & 17523 & 1,60 & 2,39 & 1,49 \\
\hline 30 & 80 & 22 & 45 & 15 & 33 & 117 & 188 & 7918 & 18563 & 1,60 & 2,34 & 1,46 \\
\hline 30 & 90 & 22 & 45 & 15 & 33 & 117 & 188 & 8508 & 19603 & 1,60 & 2,30 & 1,44 \\
\hline 30 & 100 & 22 & 45 & 15 & 33 & 117 & 188 & 9098 & 20643 & 1,60 & 2,27 & 1,41 \\
\hline 30 & 110 & 22 & 45 & 15 & 33 & 117 & 188 & 9688 & 21683 & 1,60 & 2,24 & 1,40 \\
\hline 30 & 120 & 22 & 45 & 15 & 33 & 117 & 188 & 10278 & 22723 & 1,60 & 2,21 & 1,38 \\
\hline 30 & 130 & 22 & 45 & 15 & 33 & 117 & 188 & 10868 & 23763 & 1,60 & 2,19 & 1,36 \\
\hline 30 & 140 & 22 & 45 & 15 & 33 & 117 & 188 & 11458 & 24803 & 1,60 & 2,16 & 1,35 \\
\hline 30 & 150 & 22 & 45 & 15 & 33 & 117 & 188 & 12048 & 25843 & 1,60 & 2,15 & 1,34 \\
\hline
\end{tabular}

Tabela A.8 - Valores de $\eta_{\text {wp }}$ para pilares de canto com $c_{1}>c_{2}$

\begin{tabular}{|c|c|c|c|c|c|c|c|c|c|c|c|c|}
\hline $\mathrm{c} 1$ & c2 & $\mathrm{d}$ & $\mathrm{p}$ & a1 & $\mathrm{a} 2$ & $\mathrm{u}^{*}$ & $\mathrm{u}^{\prime *}$ & wp & wp' & $\mathrm{u}^{\prime *} / \mathrm{u}^{*}$ & $\mathrm{wp}^{\prime} / \mathrm{wp}$ & $\eta_{\mathrm{wp}}$ \\
\hline 30 & 20 & 12 & 25 & 15 & 10 & 63 & 102 & 2146 & 5061 & 1,63 & 2,36 & 1,45 \\
\hline 30 & 20 & 14 & 29 & 15 & 10 & 69 & 115 & 2529 & 6257 & 1,66 & 2,47 & 1,49 \\
\hline 30 & 20 & 16 & 33 & 15 & 10 & 75 & 127 & 2943 & 7582 & 1,69 & 2,58 & 1,53 \\
\hline 30 & 20 & 18 & 38 & 15 & 10 & 82 & 141 & 3389 & 9225 & 1,73 & 2,72 & 1,57 \\
\hline 30 & 20 & 20 & 40 & 15 & 10 & 88 & 151 & 3867 & 10410 & 1,72 & 2,69 & 1,57 \\
\hline 30 & 20 & 22 & 45 & 15 & 10 & 94 & 165 & 4378 & 12323 & 1,75 & 2,81 & 1,61 \\
\hline 40 & 20 & 12 & 25 & 18 & 10 & 66 & 105 & 2610 & 5720 & 1,60 & 2,19 & 1,37 \\
\hline 40 & 25 & 12 & 25 & 18 & 13 & 68 & 107 & 2830 & 6065 & 1,58 & 2,14 & 1,36 \\
\hline 40 & 30 & 12 & 25 & 18 & 15 & 71 & 110 & 3050 & 6410 & 1,56 & 2,10 & 1,35 \\
\hline 40 & 20 & 14 & 29 & 20 & 10 & 74 & 120 & 3024 & 6980 & 1,62 & 2,31 & 1,43 \\
\hline 40 & 25 & 14 & 29 & 20 & 13 & 76 & 122 & 3264 & 7365 & 1,60 & 2,26 & 1,41 \\
\hline 40 & 30 & 14 & 29 & 20 & 15 & 79 & 125 & 3504 & 7750 & 1,58 & 2,21 & 1,40 \\
\hline 40 & 20 & 16 & 33 & 20 & 10 & 80 & 132 & 3469 & 8367 & 1,65 & 2,41 & 1,47 \\
\hline 40 & 25 & 16 & 33 & 20 & 13 & 83 & 135 & 3729 & 8792 & 1,63 & 2,36 & 1,45 \\
\hline 40 & 30 & 16 & 33 & 20 & 15 & 85 & 137 & 3989 & 9217 & 1,61 & 2,31 & 1,44 \\
\hline 40 & 20 & 18 & 38 & 20 & 10 & 87 & 146 & 3947 & 10081 & 1,69 & 2,55 & 1,51 \\
\hline 40 & 25 & 18 & 38 & 20 & 13 & 89 & 149 & 4227 & 10551 & 1,67 & 2,50 & 1,49 \\
\hline 40 & 30 & 18 & 38 & 20 & 15 & 92 & 151 & 4507 & 11021 & 1,65 & 2,45 & 1,48 \\
\hline 40 & 20 & 20 & 40 & 20 & 10 & 93 & 156 & 4457 & 11313 & 1,68 & 2,54 & 1,51 \\
\hline 40 & 25 & 20 & 40 & 20 & 13 & 95 & 158 & 4757 & 11813 & 1,66 & 2,48 & 1,50 \\
\hline 40 & 30 & 20 & 40 & 20 & 15 & 98 & 161 & 5057 & 12313 & 1,64 & 2,44 & 1,48 \\
\hline 40 & 20 & 22 & 45 & 20 & 10 & 99 & 170 & 4998 & 13297 & 1,71 & 2,66 & 1,55 \\
\hline 40 & 25 & 22 & 45 & 20 & 13 & 102 & 172 & 5318 & 13842 & 1,70 & 2,60 & 1,53 \\
\hline 40 & 30 & 22 & 45 & 20 & 15 & 104 & 175 & 5638 & 14387 & 1,68 & 2,55 & 1,52 \\
\hline 50 & 20 & 12 & 25 & 18 & 10 & 66 & 105 & 3123 & 6430 & 1,60 & 2,06 & 1,29 \\
\hline 50 & 25 & 12 & 25 & 18 & 13 & 68 & 107 & 3368 & 6800 & 1,58 & 2,02 & 1,28 \\
\hline 50 & 30 & 12 & 25 & 18 & 15 & 71 & 110 & 3613 & 7170 & 1,56 & 1,98 & 1,28 \\
\hline 50 & 20 & 14 & 29 & 21 & 10 & 75 & 121 & 3569 & 7752 & 1,61 & 2,17 & 1,35 \\
\hline 50 & 25 & 14 & 29 & 21 & 13 & 77 & 123 & 3834 & 8162 & 1,59 & 2,13 & 1,34 \\
\hline 50 & 30 & 14 & 29 & 21 & 15 & 80 & 126 & 4099 & 8572 & 1,57 & 2,09 & 1,33 \\
\hline 50 & 20 & 16 & 33 & 24 & 10 & 84 & 136 & 4046 & 9203 & 1,62 & 2,27 & 1,41 \\
\hline 50 & 25 & 16 & 33 & 24 & 13 & 87 & 139 & 4331 & 9653 & 1,60 & 2,23 & 1,40 \\
\hline 50 & 30 & 16 & 33 & 24 & 15 & 89 & 141 & 4616 & 10103 & 1,58 & 2,19 & 1,38 \\
\hline
\end{tabular}




\begin{tabular}{|c|c|c|c|c|c|c|c|c|c|c|c|c|}
\hline & c2 & $\mathrm{d}$ & $p$ & a1 & $\mathrm{a} 2$ & $\mathrm{u}^{*}$ & $\mathrm{u}^{\prime *}$ & wp & wp' & $\mathrm{u}^{\prime} * / \mathrm{u}^{*}$ & wp'/wp & $\eta_{\mathrm{w}}$ \\
\hline 50 & 20 & 18 & 38 & 25 & 10 & 92 & 151 & 4555 & 0987 & 1,65 & 2,41 & 1,46 \\
\hline 50 & 25 & 18 & 38 & 25 & 13 & 94 & 154 & 360 & 1482 & 1,63 & 2,36 & 1,45 \\
\hline 50 & 30 & 18 & 38 & 25 & 15 & 97 & 156 & 5165 & 1977 & 1,62 & 2,32 & 1,43 \\
\hline 50 & 20 & 20 & 40 & 25 & 10 & 98 & 161 & 5096 & 12267 & 1,64 & 2,41 & 1,47 \\
\hline 50 & 25 & 20 & 40 & 25 & 13 & 100 & 163 & 5421 & 12792 & 1,63 & 2,36 & 1,45 \\
\hline 50 & 30 & 20 & 40 & $25 \mid$ & 15 & 103 & 166 & 5746 & 13317 & 1,61 & 2,32 & 1,44 \\
\hline 50 & 20 & 22 & 45 & 25 & 10 & 104 & 175 & 5669 & 14321 & 1,68 & 2,53 & 1,50 \\
\hline 50 & 25 & 22 & 45 & 25 & 13 & 107 & 177 & 6014 & 14891 & 1,66 & 2,48 & 1,49 \\
\hline 50 & 30 & 22 & 45 & 25 & 15 & 109 & 180 & 6359 & 15461 & 1,65 & 2,43 & 1,48 \\
\hline 60 & 20 & 12 & 25 & 18 & 10 & 66 & 105 & 3687 & 7190 & 1,60 & 1,95 & 1,22 \\
\hline 60 & 25 & 12 & 25 & 18 & 13 & 68 & 107 & 3957 & 7585 & 1,58 & 1,92 & 1,22 \\
\hline 60 & 30 & 12 & 25 & 18 & 15 & 71 & 110 & 4227 & 7980 & 1,56 & 1,89 & 1,21 \\
\hline 60 & 20 & 14 & 29 & 21 & 10 & 75 & 121 & 4163 & 8575 & 1,61 & 2,06 & 1,28 \\
\hline 60 & 25 & 14 & 29 & 21 & 13 & 77 & 123 & 4453 & 9010 & 1,5 & 02 & 1,27 \\
\hline 60 & 30 & 14 & 29 & 21 & 15 & 80 & 126 & 4743 & 9445 & 1,57 & 1,99 & 1,27 \\
\hline 60 & 20 & 16 & 33 & 24 & 10 & 84 & 136 & 4672 & 10088 & 1,62 &, 16 & 1,34 \\
\hline 60 & 25 & 16 & 33 & 24 & 13 & 87 & 139 & 4982 & 10563 & 1,60 & 2,12 & 1,33 \\
\hline 60 & 30 & 16 & 33 & 24 & 15 & 89 & 141 & 5292 & 11038 & $1,5 \gamma$ & 09 & 1,32 \\
\hline 60 & 20 & 18 & 38 & $27 \mid$ & 10 & 94 & 153 & 5212 & 11943 & 1,64 & 2,29 & 1,40 \\
\hline 60 & 25 & 18 & 38 & $27 \mid$ & 13 & 96 & 156 & 5542 & 12463 & 1,62 & 25 & 1,39 \\
\hline 60 & 30 & 18 & 38 & 27 & 15 & 99 & 158 & 5872 & 12983 & 1,61 & 2,21 & 1,38 \\
\hline 60 & 20 & 20 & 40 & 30 & 10 & 103 & 166 & 5785 & 13270 & 1,61 & 29 & 1,42 \\
\hline 60 & 25 & 20 & 40 & 30 & 13 & 105 & 168 & 6135 & 13820 & 1,60 & 2,25 & 1,41 \\
\hline 60 & 30 & 20 & 40 & 30 & 15 & 108 & 171 & 6485 & 14370 & 1, & 22 & 1,40 \\
\hline 60 & 20 & 22 & 45 & 30 & 10 & 109 & 180 & 6389 & 15395 & 1,65 & 41 & 1,46 \\
\hline 60 & 25 & 22 & 45 & 30 & 13 & 112 & 182 & 6759 & 15990 & 1,6 & 37 & 1,45 \\
\hline 60 & 30 & 2 & 45 & 30 & 15 & 114 & 185 & 7129 & 16585 & 1,6 & 33 & 1,44 \\
\hline 70 & 20 & 12 & 25 & 18 & 10 & 66 & 105 & 4300 & 8000 & 1,60 & 86 & 1,16 \\
\hline 70 & 30 & 1 & 25 & 18 & 15 & 71 & 110 & 4890 & 8840 & 1, & 31 & 1,16 \\
\hline 70 & 20 & 14 & 29 & 21 & 10 & 75 & 121 & 4808 & 9448 & 1,6 &, 96 & 1,22 \\
\hline 70 & 30 & 14 & 29 & 21 & 15 & 80 & 126 & 5438 & 10368 & 1,5 &, 91 & 1,21 \\
\hline 70 & 20 & 1 & 33 & 24 & 10 & 84 & 136 & 5348 & 11024 & 1,62 & 06 & 1,28 \\
\hline 70 & 30 & 16 & 33 & 24 & 15 & 89 & 141 & 6018 & 12024 & 1,58 & 00 & 1,26 \\
\hline 70 & 20 & 18 & 38 & $27 \mid$ & 10 & 94 & 153 & 5920 & 12949 & 1,64 & 19 & 1,34 \\
\hline 70 & 30 & 18 & 38 & $27 \mid$ & 15 & 99 & 158 & 6630 & 14039 & 1,61 & 2,12 & 1,32 \\
\hline 70 & 20 & 20 & 40 & 30 & 10 & 103 & 166 & 6524 & 14323 & 1,61 & 20 & 1,36 \\
\hline 70 & 30 & 20 & 40 & 30 & 15 & 108 & 171 & 7274 & 15473 & 1,58 &, 13 & 1,34 \\
\hline 70 & 20 & 22 & 45 & 33 & 10 & 112 & 183 & 160 & 16519 & 63 &, 31 & 1,41 \\
\hline 70 & 30 & 22 & 45 & 33 & 15 & 117 & 188 & 7950 & 17759 & 1,60 & 2,23 & 1,39 \\
\hline 75 & 25 & 1 & 25 & 18 & 13 & 68 & 107 & 4933 & 856 & 58 & 80 & 1,14 \\
\hline 75 & 25 & 14 & 29 & 21 & 13 & 77 & 123 & 5477 & 10375 & 1,59 & 1,89 & 1,19 \\
\hline 75 & 25 & 16 & 33 & 24 & 13 & 87 & 139 & 6053 & 12023 & 60 &, 99 & 1,24 \\
\hline 75 & 25 & 18 & 38 & $27 \mid$ & 13 & 96 & 156 & 6660 & 14029 & 1,62 & 2,11 & 1,30 \\
\hline 75 & 25 & 20 & 40 & 30 & 13 & 105 & 168 & 7300 & 15456 & 1,6 &, 12 & 1,33 \\
\hline 75 & 25 & 22 & 45 & 33 & 13 & 115 & 185 & 7972 & 17732 & 1,62 & 2,22 & 1,38 \\
\hline 80 & 20 & 12 & 25 & 18 & 10 & 66 & 105 & 4964 & 8860 & 1,60 &, 78 & 1,12 \\
\hline 80 & 25 & 12 & 25 & 18 & 13 & 68 & 107 & 5284 & 9305 & 1,58 & 1,76 & 1,12 \\
\hline 80 & 30 & 12 & 25 & 18 & 15 & 71 & 110 & 5604 & 9750 & 1,56 & 1,74 & 1,12 \\
\hline 80 & 20 & 14 & 29 & 21 & 10 & 75 & 121 & 5503 & 10370 & 1,61 & 1,88 & 1,17 \\
\hline 80 & 25 & 14 & 29 & 21 & 13 & 77 & 123 & 5843 & 10855 & 1,59 & 1,86 & 1,17 \\
\hline 80 & 30 & 14 & 29 & 21 & 15 & 80 & 126 & 6183 & 11340 & 1,57 & 1,83 & 1,17 \\
\hline 80 & 20 & 16 & 33 & 24 & 10 & 84 & 136 & 6075 & 12009 & 1,62 & 1,98 & 1,22 \\
\hline 80 & 25 & 16 & 33 & 24 & 13 & 87 & 139 & 6435 & 12534 & 1,60 & 1,95 & 1,22 \\
\hline 80 & 30 & 16 & 33 & 24 & 15 & 89 & 141 & 6795 & 13059 & 1,58 & 1,92 & 1,22 \\
\hline 30 & $\angle 0$ & 18 & 38 & $|27|$ & 10 & 94 & 153 & 6678 & 14006 & 1,64 & 2,10 & 1,28 \\
\hline
\end{tabular}




\begin{tabular}{|c|c|c|c|c|c|c|c|c|c|c|c|c|}
\hline $\mathrm{c} 1$ & c2 & $\mathrm{d}$ & $\mathrm{p}$ & $\mathrm{a} 1$ & $\mathrm{a} 2$ & $\mathrm{u}^{*}$ & $\mathrm{u}^{\prime *}$ & wp & $\mathrm{wp}^{\prime}$ & $\mathrm{u}^{\prime *} / \mathrm{u}^{*}$ & wp'/wp & $\eta_{\mathrm{wp}}$ \\
\hline 80 & 25 & 18 & 38 & 27 & 13 & 96 & 156 & 7058 & 14576 & 1,62 & 2,07 & 1,27 \\
\hline 80 & 30 & 18 & 38 & 27 & 15 & \begin{tabular}{|l|}
99 \\
\end{tabular} & 158 & 7438 & 15146 & 1,61 & 2,04 & 1,27 \\
\hline 80 & 20 & 20 & 40 & 30 & 10 & 103 & 166 & 7313 & 15427 & 1,61 & 2,11 & 1,31 \\
\hline 80 & 25 & 20 & 40 & 30 & 13 & 105 & 168 & 7713 & 16027 & 1,60 & 2,08 & 1,30 \\
\hline 80 & 30 & 20 & 40 & 30 & 15 & 108 & 171 & 8113 & 16627 & 1,58 & 2,05 & 1,29 \\
\hline 80 & 20 & 22 & 45 & 33 & 10 & 112 & 183 & 7981 & 17693 & 1,63 & 2,22 & 1,36 \\
\hline 80 & 25 & 22 & 45 & 33 & 13 & 115 & 185 & 8401 & 18338 & 1,62 & 2,18 & 1,35 \\
\hline 80 & 30 & 22 & 45 & 33 & 15 & 117 & 188 & 8821 & 18983 & 1,60 & 2,15 & 1,34 \\
\hline 90 & 20 & 12 & 25 & 18 & 10 & 66 & 105 & 5677 & 9770 & 1,60 & 1,72 & 1,08 \\
\hline 90 & 25 & 12 & 25 & 18 & 13 & 68 & 107 & 6022 & 10240 & 1,58 & 1,70 & 1,08 \\
\hline 90 & 30 & 12 & 25 & 18 & 15 & 71 & 110 & 6367 & 10710 & 1,56 & 1,68 & 1,08 \\
\hline 90 & 20 & 14 & 29 & 21 & 10 & 75 & 121 & 6248 & 11343 & 1,61 & 1,82 & 1,13 \\
\hline 90 & 25 & 14 & 29 & 21 & 13 & 77 & 123 & 6613 & 11853 & 1,59 & 1,79 & 1,13 \\
\hline 90 & 30 & 14 & 29 & 21 & 15 & 80 & 126 & 6978 & 12363 & 1,57 & 1,77 & 1,13 \\
\hline 90 & 20 & 16 & 33 & 24 & 10 & 84 & 136 & 6851 & 13045 & 1,62 & 1,90 & 1,18 \\
\hline 90 & 25 & 16 & 33 & 24 & 13 & 87 & 139 & 7236 & 13595 & 1,60 & 1,88 & 1,18 \\
\hline 90 & 30 & 16 & 33 & 24 & 15 & 89 & 141 & 7621 & 14145 & 1,58 & 1,86 & 1,17 \\
\hline 90 & 20 & 18 & 38 & 27 & 10 & 94 & 153 & 7486 & 15112 & 1,64 & 2,02 & 1,23 \\
\hline 90 & 25 & 18 & 38 & 27 & 13 & 96 & 156 & 7891 & 15707 & 1,62 & 1,99 & 1,23 \\
\hline 90 & 30 & 18 & 38 & 27 & 15 & 99 & 158 & 8296 & 16302 & 1,61 & 1,97 & 1,22 \\
\hline 90 & 20 & 20 & 40 & 30 & 10 & 103 & 166 & 8152 & 16580 & 1,61 & 2,03 & 1,26 \\
\hline 90 & 25 & 20 & 40 & 30 & 13 & 105 & 168 & 8577 & 17205 & 1,60 & 2,01 & 1,26 \\
\hline 90 & 30 & 20 & 40 & 30 & 15 & 108 & 171 & 9002 & 17830 & 1,58 & 1,98 & 1,25 \\
\hline 90 & 20 & 22 & 45 & 33 & 10 & 112 & 183 & 8851 & 18917 & 1,63 & 2,14 & 1,31 \\
\hline 90 & 25 & 22 & 45 & 33 & 13 & 115 & 185 & 9296 & 19587 & 1,62 & 2,11 & 1,30 \\
\hline 90 & 30 & 22 & 45 & 33 & 15 & 117 & 188 & 9741 & 20257 & 1,60 & 2,08 & 1,30 \\
\hline 100 & 20 & 12 & 25 & 18 & 10 & 66 & 105 & 6441 & 10729 & 1,60 & 1,67 & 1,04 \\
\hline 100 & 25 & 12 & 25 & 18 & 13 & 68 & 107 & 6811 & 11224 & 1,58 & 1,65 & 1,05 \\
\hline 100 & 30 & 12 & 25 & 18 & 15 & 71 & 110 & 7181 & 11719 & 1,56 & 1,63 & 1,05 \\
\hline 100 & 20 & 14 & 29 & 21 & 10 & 75 & 121 & 7043 & 12366 & 1,61 & 1,76 & 1,09 \\
\hline 100 & 25 & 14 & 29 & 21 & 13 & 77 & 123 & 7433 & 12901 & 1,59 & 1,74 & 1,09 \\
\hline 100 & 30 & 14 & 29 & 21 & 15 & 80 & 126 & 7823 & 13436 & 1,57 & 1,72 & 1,09 \\
\hline 100 & 20 & 16 & 33 & 24 & 10 & 84 & 136 & 7677 & 14130 & 1,62 & 1,84 & 1,14 \\
\hline 100 & 25 & 16 & 33 & 24 & 13 & 87 & 139 & 8087 & 14705 & 1,60 & 1,82 & 1,14 \\
\hline 100 & 30 & 16 & 33 & \begin{tabular}{|l|}
24 \\
\end{tabular} & 15 & 89 & 141 & 8497 & 15280 & 1,58 & 1,80 & 1,14 \\
\hline 100 & 20 & 18 & 38 & 27 & 10 & 94 & 153 & 8343 & 16268 & 1,64 & 1,95 & 1,19 \\
\hline 100 & 25 & 18 & 38 & 27 & 13 & 96 & 156 & 8773 & 16888 & 1,62 & 1,92 & 1,19 \\
\hline 100 & 30 & 18 & 38 & 27 & 15 & 99 & 158 & 9203 & 17508 & 1,61 & 1,90 & 1,18 \\
\hline 100 & 20 & 20 & 40 & 30 & 10 & 103 & 166 & 9042 & 17783 & 1,61 & 1,97 & 1,22 \\
\hline 100 & 25 & 20 & 40 & $30 \mid$ & 13 & 105 & 168 & 9492 & 18433 & 1,60 & 1,94 & 1,22 \\
\hline 100 & 30 & 20 & 40 & 30 & 15 & 108 & 171 & 9942 & 19083 & 1,58 & 1,92 & 1,21 \\
\hline 100 & 20 & 22 & 45 & 33 & 10 & 112 & 183 & 9772 & 20191 & 1,63 & 2,07 & 1,27 \\
\hline 100 & 25 & 22 & 45 & $33 \mid$ & 13 & 115 & 185 & 10242 & 20886 & 1,62 & 2,04 & 1,26 \\
\hline 100 & 30 & 22 & 45 & 33 & 15 & 117 & 188 & 10712 & 21581 & 1,60 & 2,01 & 1,26 \\
\hline 110 & 25 & 12 & 25 & 18 & 13 & 68 & 107 & 7649 & 12259 & 1,58 & 1,60 & 1,02 \\
\hline 110 & 30 & 12 & 25 & 18 & 15 & 71 & 110 & 8044 & 12779 & 1,56 & 1,59 & 1,02 \\
\hline 110 & 25 & 14 & 29 & 21 & 13 & 77 & 123 & 8303 & 13998 & 1,59 & 1,69 & 1,06 \\
\hline 110 & 30 & 14 & 29 & 21 & 15 & 80 & 126 & 8718 & 14558 & 1,57 & 1,67 & 1,06 \\
\hline 110 & 25 & 16 & 33 & 24 & 13 & 87 & 139 & 8989 & 15866 & 1,60 & 1,77 & 1,10 \\
\hline 110 & 30 & 16 & 33 & \begin{tabular}{|l|}
24 \\
\end{tabular} & 15 & 89 & 141 & 9424 & 16466 & 1,58 & 1,75 & 1,11 \\
\hline 110 & 25 & 18 & 38 & 27 & 13 & 96 & 156 & 9706 & 18119 & 1,62 & 1,87 & 1,15 \\
\hline 110 & 30 & 18 & 38 & 27 & 15 & \begin{tabular}{|l|}
99 \\
\end{tabular} & 158 & 10161 & 18764 & 1,61 & 1,85 & 1,15 \\
\hline 110 & 25 & 20 & 40 & 30 & 13 & 105 & 168 & 10456 & 19712 & 1,60 & 1,89 & 1,18 \\
\hline 110 & 30 & 20 & 40 & 30 & 15 & 108 & 171 & 10931 & 20387 & 1,58 & 1,87 & 1,18 \\
\hline 110 & 25 & 22 & $|45|$ & 33 & 13 & 115 & 185 & 11237 & 22235 & 1,62 & 1,98 & 1,22 \\
\hline
\end{tabular}




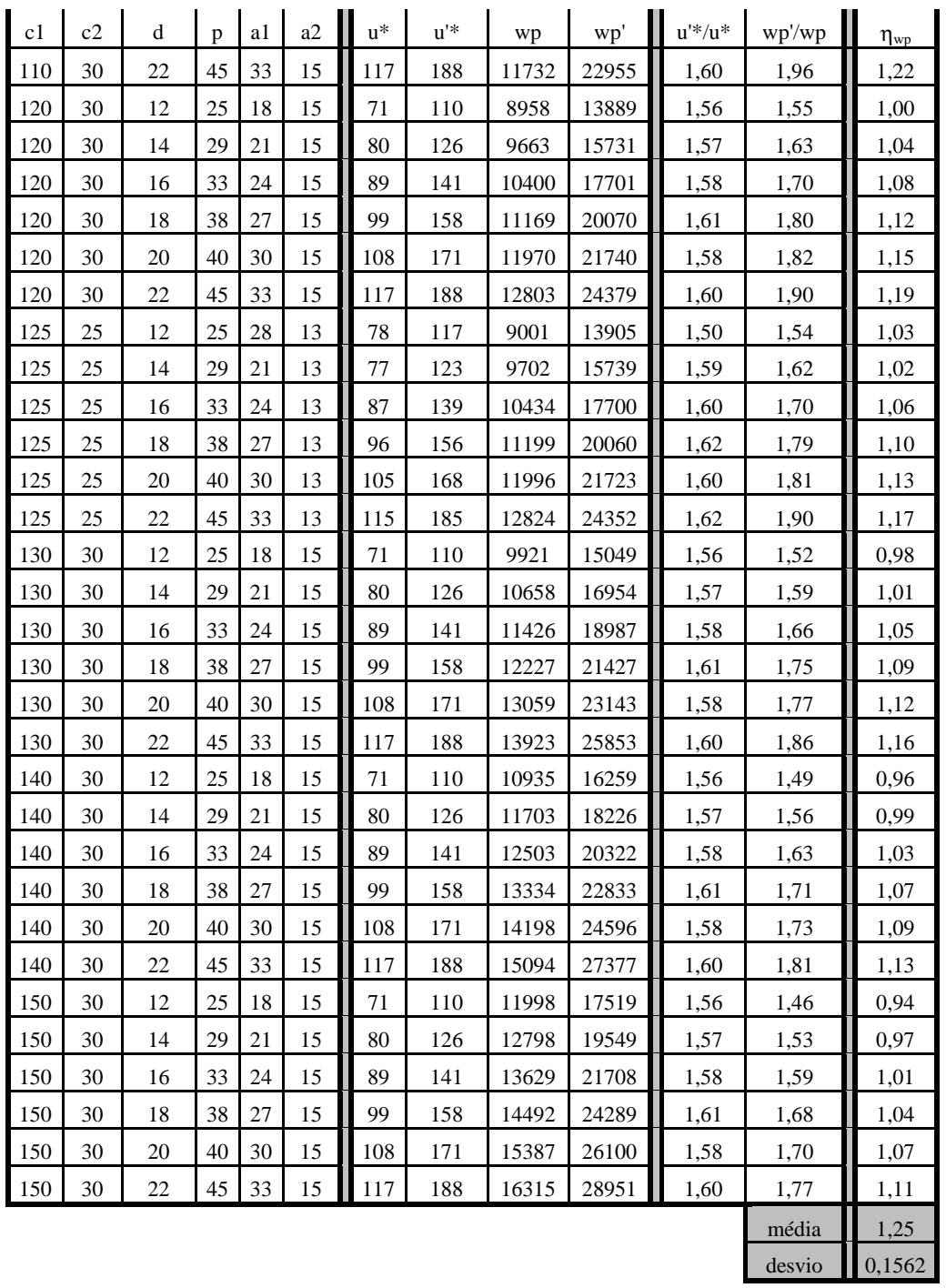



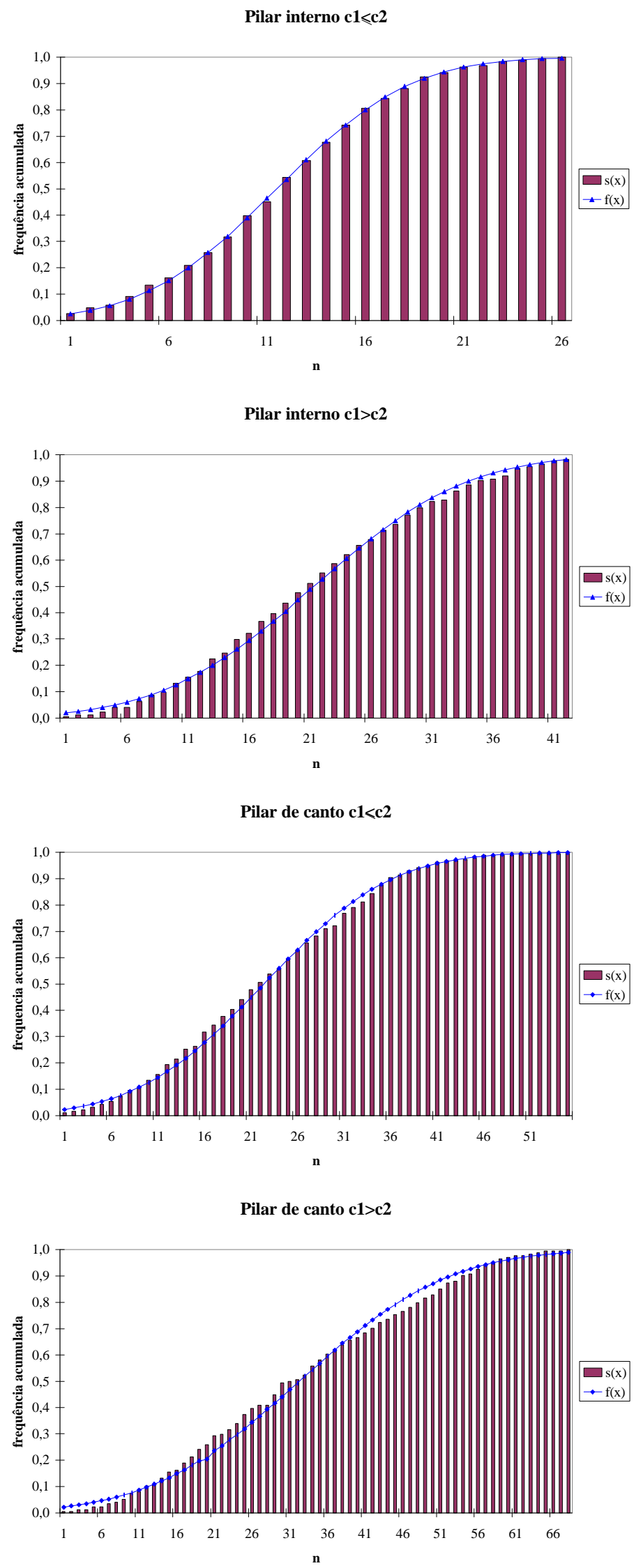

Figura A.1 - Teste de Kolmorogov-Smirnov para pilares internos e de canto 

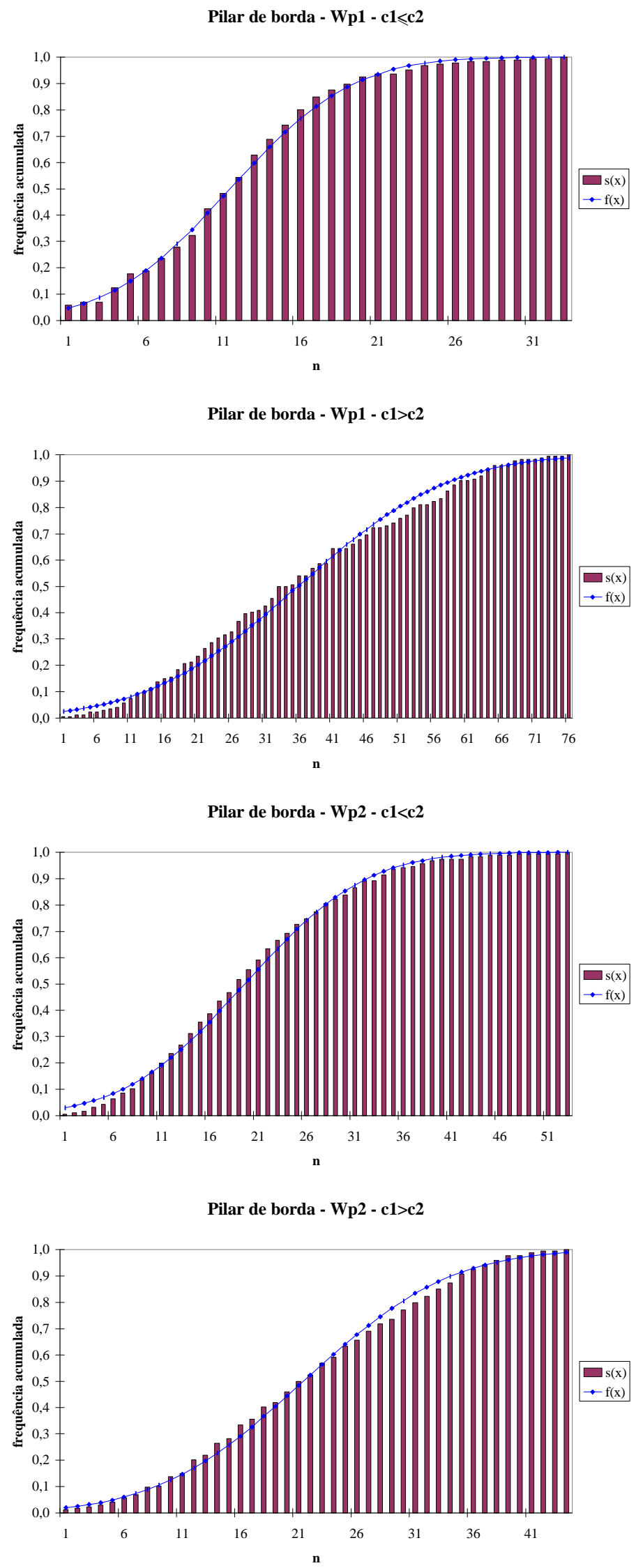

Figura A.2 - Teste de Kolmorogov-Smirnov para pilares de borda 
ANEXO B

\section{DETERMINAÇÃO DOS VALORES DE $\eta_{\mathrm{e} 1}$ E $\eta_{\mathrm{e} 2}$}

Para a determinação dos valores de $\eta_{\mathrm{e} 1}$ e de $\eta_{\mathrm{e} 2}$, foram resolvidos diversos exemplos com mesmas características mencionadas no Anexo A. Novamente, os exemplos foram agrupados de acordo com a situação de cálculo, e considerando-se a direção da excentricidade em relação aos lados do pilar. Foram estudados os seguintes casos:

- pilares de borda com $\mathrm{c}_{1} \leq \mathrm{c}_{2}$ (Tabela B.3);

- pilares de borda com $c_{1}>c_{2}$ (Tabela B.4);

- pilares de canto com $\mathrm{c}_{1} \leq \mathrm{c}_{2}$ (Tabela B.5);

- pilares de canto com $c_{1}>c_{2}$ (Tabela B.6).

Foram calculados as médias e os desvios padrões de $\eta_{\mathbf{e} 1}$ e de $\eta_{\mathbf{e} 2}$, e estudou-se a possibilidade de se admiti-los como variáveis de distribuição normal. Mais uma vez foi utilizado o Kolmogorov-Smirnov goodness-of-fit test, cujas curvas, relativas a cada caso, encontram-se na Figura B.1 e na Figura B.2. Observa-se que a aproximação mostrou-se válida para todas as situações estudadas, com nível de significância de 1\%. Portanto, tomando-se o quantil de $10 \%$, pode-se escrever:

$$
\begin{aligned}
& \eta_{\mathrm{e} 1}=\bar{\eta}_{\mathrm{e} 1}-1,28 \cdot \delta_{1} \\
& \eta_{\mathrm{e} 2}=\bar{\eta}_{\mathrm{e} 2}-1,28 \cdot \delta_{2}
\end{aligned}
$$


sendo:

$\bar{\eta}_{\mathrm{e} 1}-$ valor médio dos $\eta_{\mathrm{e} 1}$;

$\bar{\eta}_{\mathrm{e} 2}$ - valor médio dos $\eta_{\mathrm{e} 2}$;

$\delta_{1}$ - desvio padrão correspondente a $\eta_{\mathrm{e} 1}$;

$\boldsymbol{\delta}_{2}$ - desvio padrão correspondente a $\eta_{\mathrm{e} 2 \text {. }}$

Os valores obtidos dessa forma encontram-se na Tabela B.1. Aproximando-se esses resultados, podem ser sugeridos os valores da Tabela B.2.

Tabela B.1 - Valores de $\eta_{\mathrm{e} 1}$ e de $\eta_{\mathrm{e} 2}$ para o quantil de $10 \%$

\begin{tabular}{|l|c|c|}
\hline Situação de Cálculo & $\boldsymbol{c}_{1} \leq \boldsymbol{c}_{2}$ & $\boldsymbol{c}_{1}>\boldsymbol{c}_{2}$ \\
\hline Pilar de borda $\left(\eta_{e 1}\right)$ & 0,50 & 1,06 \\
\hline Pilar de canto $\left(\eta_{e 1}\right)$ & 0,63 & 1,06 \\
\hline Pilar de borda $\left(\eta_{e 2}\right)$ & 1,03 & 0,80 \\
\hline Pilar de canto $\left(\eta_{e 2}\right)$ & 1,01 & 0,80 \\
\hline
\end{tabular}

Tabela B.2 - Valores de $\eta_{\mathrm{e} 1}$ e de $\eta_{\mathrm{e} 2}$ sugeridos e suas probabilidades de ocorrência

\begin{tabular}{|c|c|c|}
\hline Situação de Cálculo & $\boldsymbol{c}_{1} \leq \boldsymbol{c}_{2}$ & $\boldsymbol{c}_{1}>\boldsymbol{c}_{2}$ \\
\hline \multirow{2}{*}{$\eta_{e 1}$} & 0,5 & 1,0 \\
& $\begin{array}{c}\text { (90\% para pilares de borda) } \\
\text { (99\% para pilares de canto) }\end{array}$ & $\begin{array}{c}\text { (94\% para pilares de borda) } \\
(97 \% \text { para pilares de canto) }\end{array}$ \\
\hline \multirow{2}{*}{$\eta_{e 2}$} & 1,0 & 0,8 \\
& $\begin{array}{c}\text { (97\% para pilares de borda) } \\
\text { (98\% para pilares de canto) }\end{array}$ & $\begin{array}{c}\text { (90\% para pilares de borda) } \\
\text { (90\% para pilares de canto) }\end{array}$ \\
\hline
\end{tabular}

Tabela B.3 - Valores de $\eta_{\mathbf{e} 1}$ e de $\eta_{\mathbf{e} 2}$ para pilares de borda com $c_{1} \leq c_{2}$

\begin{tabular}{|c|c|c|c|c||c|c|c||c|c|c||c|c|c|c||c|c|}
\hline $\mathrm{c} 1$ & $\mathrm{c} 2$ & $\mathrm{~d}$ & $\mathrm{p}$ & $\mathrm{a}$ & $\mathrm{uo}$ & $\mathrm{u}^{*}$ & $\mathrm{u}^{\prime *}$ & $\mathrm{eo}^{*}$ & $\mathrm{e}^{*}$ & $\mathrm{e}^{\prime *}$ & $\mathrm{uo}^{*} / \mathrm{u}^{*}$ & $\mathrm{u}^{\prime *} / \mathrm{u}^{*}$ & $\mathrm{e}^{*} / \mathrm{e}^{*}$ & $\mathrm{e}^{\prime *} / \mathrm{e}^{*}$ & $\eta_{\mathrm{e} 1}$ & $\eta_{\mathrm{e} 2}$ \\
\hline 20 & 20 & 12 & 25 & 10 & 40 & 115 & 194 & 7,50 & 23,28 & 39,30 & 0,35 & 1,68 & 0,32 & 1,69 & 0,93 & 1,00 \\
\hline 20 & 30 & 12 & 25 & 10 & 50 & 125 & 204 & 8,00 & 24,13 & 40,26 & 0,40 & 1,63 & 0,33 & 1,67 & 0,83 & 1,03 \\
\hline 20 & 40 & 12 & 25 & 10 & 60 & 135 & 214 & 8,33 & 24,86 & 41,14 & 0,44 & 1,58 & 0,34 & 1,65 & 0,76 & 1,05 \\
\hline 20 & 50 & 12 & 25 & 10 & 70 & 145 & 224 & 8,57 & 25,49 & 41,94 & 0,48 & 1,54 & 0,34 & 1,65 & 0,70 & 1,07 \\
\hline 20 & 60 & 12 & 25 & 10 & 80 & 155 & 234 & 8,75 & 26,04 & 42,67 & 0,51 & 1,51 & 0,34 & 1,64 & 0,65 & 1,09 \\
\hline 20 & 70 & 12 & 25 & 10 & 90 & 165 & 244 & 8,89 & 26,52 & 43,34 & 0,54 & 1,47 & 0,34 & 1,63 & 0,62 & 1,11 \\
\hline 20 & 80 & 12 & 25 & 10 & 100 & 175 & 254 & 9,00 & 26,94 & 43,95 & 0,57 & 1,45 & 0,33 & 1,63 & 0,59 & 1,13 \\
\hline 20 & 90 & 12 & 25 & 10 & 110 & 185 & 264 & 9,09 & 27,32 & 44,52 & 0,59 & 1,42 & 0,33 & 1,63 & 0,56 & 1,14 \\
\hline 20 & 100 & 12 & 25 & 10 & 120 & 195 & 274 & 9,17 & 27,67 & 45,05 & 0,61 & 1,40 & 0,33 & 1,63 & 0,54 & 1,16 \\
\hline 20 & 20 & 14 & 29 & 10 & 40 & 128 & 219 & 7,50 & 25,85 & 44,41 & 0,31 & 1,71 & 0,29 & 1,72 & 0,93 & 1,00 \\
\hline 20 & 30 & 14 & 29 & 10 & 50 & 138 & 229 & 8,00 & 26,73 & 45,40 & 0,36 & 1,66 & 0,30 & 1,70 & 0,83 & 1,02 \\
\hline 20 & 40 & 14 & 29 & 10 & 60 & 148 & 239 & 8,33 & 27,49 & 46,30 & 0,41 & 1,62 & 0,30 & 1,68 & 0,75 & 1,04
\end{tabular}




\begin{tabular}{|c|c|c|c|c|c|c|c|c|c|c|c|c|c|c|c|c|}
\hline c1 & $\mathrm{c} 2$ & $\mathrm{~d}$ & $\mathrm{p}$ & $\mathrm{a}$ & uo* & $\mathrm{u}^{*}$ & $\mathrm{u}^{\prime *}$ & eo* & $\mathrm{e}^{*}$ & $e^{\prime * *}$ & uo*/u* & $\mathrm{u}^{\prime} * / \mathrm{u}^{*}$ & eo*/e* & $\mathrm{e}^{\prime} * / \mathrm{e}^{*}$ & $\eta_{\mathrm{e} 1}$ & $\eta_{\mathrm{e} 2}$ \\
\hline 20 & 50 & 14 & 29 & 10 & 70 & 158 & 249 & 8,57 & 28,16 & 47,13 & 0,44 & 1,58 & 0,30 & 1,67 & 0,69 & 1,06 \\
\hline 20 & 60 & 14 & 29 & 10 & 80 & 168 & 259 & 8,75 & 28,74 & 47,90 & 0,48 & 1,54 & 0,30 & 1,67 & 0,64 & 1,08 \\
\hline 20 & 70 & 14 & 29 & 10 & 90 & 178 & 269 & 8,89 & 29,26 & 48,61 & 0,51 & 1,51 & 0,30 & 1,66 & 0,60 & 1,10 \\
\hline 20 & 80 & 14 & 29 & 10 & 100 & 188 & 279 & 9,00 & 29,73 & 49,27 & 0,53 & 1,48 & 0,30 & 1,66 & 0,57 & 1,12 \\
\hline 20 & 90 & 14 & 29 & 10 & 110 & 198 & 289 & 9,09 & 30,14 & 49,88 & 0,56 & 1,46 & 0,30 & 1,65 & 0,54 & 1,13 \\
\hline 20 & 100 & 14 & 29 & 10 & 120 & 208 & 299 & 9,17 & 30,52 & 50,45 & 0,58 & 1,44 & 0,30 & 1,65 & 0,52 & 1,15 \\
\hline 20 & 20 & 16 & 33 & 10 & 40 & 141 & 244 & 7,50 & 28,42 & 49,52 & 0,28 & 1,74 & 0,26 & 1,74 & 0,93 & 1,00 \\
\hline 20 & 30 & 16 & 33 & 10 & 50 & 151 & 254 & 8,00 & 29,32 & 50,52 & 0,33 & 1,69 & 0,27 & 1,72 & 0,82 & 1,02 \\
\hline 20 & 40 & 16 & 33 & 10 & 60 & 161 & 264 & 8,33 & 30,11 & 51,45 & 0,37 & 1,65 & 0,28 & 1,71 & 0,74 & 1,04 \\
\hline 20 & 50 & 16 & 33 & 10 & 70 & 171 & 274 & 8,57 & 30,81 & 52,30 & 0,41 & 1,61 & 0,28 & 1,70 & 0,68 & 1,06 \\
\hline 20 & 60 & 16 & 33 & 10 & 80 & 181 & 284 & 8,75 & 31,43 & 53,10 & 0,44 & 1,57 & 0,28 & 1,69 & 0,63 & 1,07 \\
\hline 20 & 70 & 16 & 33 & 10 & 90 & 191 & 294 & 8,89 & 31,98 & 53,85 & 0,47 & 1,54 & 0,28 & 1,68 & 0,59 & 1,09 \\
\hline 20 & 80 & 16 & 33 & 10 & 100 & 201 & 304 & 9,00 & 32,48 & 54,54 & 0,50 & 1,52 & 0,28 & 1,68 & 0,56 & 1,11 \\
\hline 20 & 90 & 16 & 33 & 10 & 110 & 211 & 314 & 9,09 & 32,93 & 55,19 & 0,52 & 1,49 & 0,28 & 1,68 & 0,53 & 1,12 \\
\hline 20 & 100 & 16 & 33 & 10 & 120 & 221 & 324 & 9,17 & 33,34 & 55,80 & 0,54 & 1,47 & 0,27 & 1,67 & 0,51 & 1,14 \\
\hline 20 & 20 & 18 & 38 & 10 & 40 & 153 & 272 & 7,50 & 30,98 & 55,26 & 0,26 & 1,78 & 0,24 & 1,78 & 0,93 & 1,00 \\
\hline 20 & 30 & 18 & 38 & 10 & 50 & 163 & 282 & 8,00 & 31,90 & 56,28 & 0,31 & 1,73 & 0,25 & 1,76 & 0,82 & 1,02 \\
\hline 20 & 40 & 18 & 38 & 10 & 60 & 173 & 292 & 8,33 & 32,72 & 57,22 & 0,35 & 1,69 & 0,25 & 1,75 & 0,73 & 1,04 \\
\hline 20 & 50 & 18 & 38 & 10 & 70 & 183 & 302 & 8,57 & 33,44 & 58,11 & 0,38 & 1,65 & 0,26 & 1,74 & 0,67 & 1,05 \\
\hline 20 & 60 & 18 & 38 & 10 & 80 & 193 & 312 & 8,75 & 34,09 & 58,94 & 0,41 & 1,62 & 0,26 & 1,73 & 0,62 & 1,07 \\
\hline 20 & 70 & 18 & 38 & 10 & 90 & 203 & 322 & 8,89 & 34,68 & 59,71 & 0,44 & 1,59 & 0,26 & 1,72 & 0,58 & 1,08 \\
\hline 20 & 80 & 18 & 38 & 10 & 100 & 213 & 332 & 9,00 & 35,21 & 60,45 & 0,47 & 1,56 & 0,26 & 1,72 & 0,54 & 1,10 \\
\hline 20 & 90 & 18 & 38 & 10 & 110 & 223 & 342 & 9,09 & 35,69 & 61,13 & 0,49 & 1,54 & 0,25 & 1,71 & 0,52 & 1,12 \\
\hline 20 & 100 & 18 & 38 & 10 & 120 & 233 & 352 & 9,17 & 36,13 & 61,78 & 0,51 & 1,51 & 0,25 & 1,71 & 0,49 & 1,13 \\
\hline 20 & 20 & 20 & 40 & 10 & 40 & 166 & 291 & 7,50 & 33,54 & 59,09 & 0,24 & 1,76 & 0,22 & 1,76 & 0,93 & 1,00 \\
\hline 20 & 30 & 20 & 40 & 10 & 50 & 176 & 301 & 8,00 & 34,48 & 60,11 & 0,28 & 1,72 & 0,23 & 1,74 & 0,82 & 1,02 \\
\hline 20 & 40 & 20 & 40 & 10 & 60 & 186 & 311 & 8,33 & 35,31 & 61,07 & 0,32 & 1,68 & 0,24 & 1,73 & 0,73 & 1,03 \\
\hline 20 & 50 & 20 & 40 & 10 & 70 & 196 & 321 & 8,57 & 36,07 & 61,97 & 0,36 & 1,64 & 0,24 & 1,72 & 0,66 & 1,05 \\
\hline 20 & 60 & 20 & 40 & 10 & 80 & 206 & 331 & 8,75 & 36,74 & 62,82 & 0,39 & 1,61 & 0,24 & 1,71 & 0,61 & 1,06 \\
\hline 20 & 70 & 20 & 40 & 10 & 90 & 216 & 341 & 8,89 & 37,36 & 63,61 & 0,42 & 1,58 & 0,24 & 1,70 & 0,57 & 1,08 \\
\hline 20 & 80 & 20 & 40 & 10 & 100 & 226 & 351 & 9,00 & 37,92 & 64,37 & 0,44 & 1,56 & 0,24 & 1,70 & 0,54 & 1,09 \\
\hline 20 & 90 & 20 & 40 & 10 & 110 & 236 & 361 & 9,09 & 38,43 & 65,07 & 0,47 & 1,53 & 0,24 & 1,69 & 0,51 & 1,10 \\
\hline 20 & 100 & 20 & 40 & 10 & 120 & 246 & 371 & 9,17 & 38,90 & 65,75 & 0,49 & 1,51 & 0,24 & 1,69 & 0,48 & 1,12 \\
\hline 20 & 20 & 22 & 45 & 18 & 56 & 194 & 336 & 4,21 & 32,80 & 61,54 & 0,29 & 1,73 & 0,13 & 1,88 & 0,45 & 1,09 \\
\hline 20 & 30 & 22 & 45 & 18 & 66 & 204 & 346 & 5,09 & 33,84 & 62,63 & 0,32 & 1,69 & 0,15 & 1,85 & 0,47 & 1,09 \\
\hline 20 & 40 & 22 & 45 & 18 & 76 & 214 & 356 & 5,74 & 34,78 & 63,65 & 0,35 & 1,66 & 0,16 & 1,83 & 0,46 & 1,10 \\
\hline 20 & 50 & 22 & 45 & 18 & 86 & 224 & 366 & 6,23 & 35,63 & 64,62 & 0,38 & 1,63 & 0,17 & 1,81 & 0,46 & 1,11 \\
\hline 20 & 60 & 22 & 45 & 18 & 96 & 234 & 376 & 6,63 & 36,42 & 65,53 & 0,41 & 1,60 & 0,18 & 1,80 & 0,44 & 1,12 \\
\hline 20 & 70 & 22 & 45 & 18 & 106 & 244 & 386 & 6,94 & 37,14 & 66,40 & 0,43 & 1,58 & 0,19 & 1,79 & 0,43 & 1,13 \\
\hline 20 & 80 & 22 & 45 & 18 & 116 & 254 & 396 & 7,21 & 37,80 & 67,22 & 0,46 & 1,56 & 0,19 & 1,78 & 0,42 & 1,14 \\
\hline 20 & 90 & 22 & 45 & 18 & 126 & 264 & 406 & 7,43 & 38,41 & 68,01 & 0,48 & 1,54 & 0,19 & 1,77 & 0,41 & 1,15 \\
\hline 20 & 100 & 22 & 45 & 18 & 136 & 274 & 416 & 7,62 & 38,98 & 68,75 & 0,50 & 1,52 & 0,20 & 1,76 & 0,39 & 1,16 \\
\hline 25 & 40 & 12 & 25 & 13 & 65 & 140 & 219 & 10,10 & 26,43 & 42,67 & 0,46 & 1,56 & 0,38 & 1,61 & 0,83 & 1,04 \\
\hline 25 & 50 & 12 & 25 & 13 & 75 & 150 & 229 & 10,42 & 27,10 & 43,49 & 0,50 & 1,52 & 0,38 & 1,60 & 0,77 & 1,05 \\
\hline 25 & 60 & 12 & 25 & 13 & 85 & 160 & 239 & 10,66 & 27,69 & 44,25 & 0,53 & 1,49 & 0,39 & 1,60 & 0,73 & 1,07 \\
\hline 25 & 75 & 12 & 25 & 13 & 100 & 175 & 254 & 10,94 & 28,44 & 45,27 & 0,57 & 1,45 & 0,38 & 1,59 & 0,67 & 1,10 \\
\hline 25 & 80 & 12 & 25 & 13 & 105 & 180 & 259 & 11,01 & 28,66 & 45,58 & 0,58 & 1,44 & 0,38 & 1,59 & 0,66 & 1,11 \\
\hline 25 & 90 & 12 & 25 & 13 & 115 & 190 & 269 & 11,14 & 29,07 & 46,17 & 0,60 & 1,41 & 0,38 & 1,59 & 0,63 & 1,12 \\
\hline 25 & 100 & 12 & 25 & 13 & 125 & 200 & 279 & 11,25 & 29,44 & 46,72 & 0,62 & 1,39 & 0,38 & 1,59 & 0,61 & 1,14 \\
\hline 25 & 110 & 12 & 25 & 13 & 135 & 210 & 289 & 11,34 & 29,78 & 47,23 & 0,64 & 1,37 & 0,38 & 1,59 & 0,59 & 1,15 \\
\hline 25 & 125 & 12 & 25 & 13 & 150 & 225 & 304 & 11,46 & 30,23 & 47,94 & 0,67 & 1,35 & 0,38 & 1,59 & 0,57 & 1,18 \\
\hline 25 & 40 & 14 & 29 & 13 & 65 & 153 & 244 & 10,10 & 29,05 & 47,82 & 0,42 & 1,60 & 0,35 & 1,65 & 0,82 & 1,03 \\
\hline 25 & 50 & 14 & 29 & 13 & 75 & 163 & 254 & 10,42 & 29,75 & 48,68 & 0,46 & 1,56 & 0,35 & 1,64 & 0,76 & 1,05 \\
\hline 25 & 60 & 14 & 29 & 13 & 85 & 173 & 264 & 10,66 & 30,38 & 49,47 & 0,49 & 1,53 & 0,35 & 1,63 & 0,71 & 1,07 \\
\hline 25 & 75 & 14 & $|29|$ & 13 & 100 & 188 & 279 & 10,94 & 31,18 & 50,54 & 0,53 & 1,48 & 0,35 & 1,62 & 0,66 & 1,09 \\
\hline
\end{tabular}




\begin{tabular}{|c|c|c|c|c|c|c|c|c|c|c|c|c|c|c|c|c|}
\hline c1 & $\mathrm{c} 2$ & $\mathrm{~d}$ & $\mathrm{p}$ & $\mathrm{a}$ & uo* & $\mathrm{u}^{*}$ & $\mathrm{u}^{\prime *}$ & eo* & $\mathrm{e}^{*}$ & $\mathrm{e}^{\prime *}$ & uo $* / u^{*}$ & $\mathrm{u}^{\prime} * / \mathrm{u}^{*}$ & eo*/e* & $\mathrm{e}^{\prime} * / \mathrm{e}^{*}$ & $\eta_{\mathrm{e} 1}$ & $n$ \\
\hline 25 & 80 & 14 & 29 & 13 & 105 & 193 & 284 & 11,01 & 31,42 & 50,88 & 0,54 & 1,47 & 0,35 & 1,62 & 0,64 & 1,10 \\
\hline 25 & 90 & 14 & 29 & 13 & 115 & 203 & 294 & 11,14 & 31,87 & 51,51 & 0,57 & 1,45 & 0,35 & 1,62 & 0,62 & 1,12 \\
\hline 25 & 100 & 14 & 29 & 13 & 125 & 213 & 304 & 11,25 & 32,28 & 52,10 & 0,59 & 1,43 & 0,35 & 1,61 & 0,59 & 1,13 \\
\hline 25 & 110 & 14 & 29 & 13 & 135 & 223 & 314 & 11,34 & 32,65 & 52,66 & 0,61 & 1,41 & 0,35 & 1,61 & 0,57 & 1,15 \\
\hline 25 & 125 & 14 & 29 & 13 & 150 & 238 & 329 & 11,46 & 33,14 & 53,42 & 0,63 & 1,38 & 0,35 & 1,61 & 0,55 & 1,17 \\
\hline 25 & 40 & 16 & 33 & 13 & 65 & 166 & 269 & 10,10 & 31,66 & 52,97 & 0,39 & 1,63 & 0,32 & 1,67 & 0,81 & 1,03 \\
\hline 25 & 50 & 16 & 33 & 13 & 75 & 176 & 279 & 10,42 & 32,39 & 53,85 & 0,43 & 1,59 & 0,32 & 1,66 & 0,75 & 1,05 \\
\hline 25 & 60 & 16 & 33 & 13 & 85 & 186 & 289 & 10,66 & 33,05 & 54,66 & 0,46 & 1,56 & 0,32 & 1,65 & 0,70 & 1,06 \\
\hline 25 & 75 & 16 & 33 & 13 & 100 & 201 & 304 & 10,94 & 33,90 & 55,79 & 0,50 & 1,52 & 0,32 & 1,65 & 0,65 & 1,08 \\
\hline 25 & 80 & 16 & 33 & 13 & 105 & 206 & 309 & 11,01 & 34,16 & 56,14 & 0,51 & 1,50 & 0,32 & 1,64 & 0,63 & 1,09 \\
\hline 25 & 90 & 16 & 33 & 13 & 115 & 216 & 319 & 11,14 & 34,64 & 56,81 & 0,53 & 1,48 & 0,32 & 1,64 & 0,60 & 1,11 \\
\hline 25 & 100 & 16 & 33 & 13 & 125 & 226 & 329 & 11,25 & 35,08 & 57,44 & 0,55 & 1,46 & 0,32 & 1,64 & 0,58 & 1,12 \\
\hline 25 & 110 & 16 & 33 & 13 & 135 & 236 & 339 & 11,34 & 35,48 & 58,03 & 0,57 & 1,44 & 0,32 & 1,64 & 0,56 & 1,14 \\
\hline 25 & 125 & 16 & 33 & 13 & 150 & 251 & 354 & 11,46 & 36,02 & 58,85 & 0,60 & 1,41 & 0,32 & 1,63 & 0,53 & 1,16 \\
\hline 25 & 40 & 18 & 38 & 13 & 65 & 178 & 297 & 10,10 & 34,26 & 58,74 & 0,36 & 1,67 & 0,29 & 1,71 & 0,81 & 1,03 \\
\hline 25 & 50 & 18 & 38 & 13 & 75 & 188 & 307 & 10,42 & 35,02 & 59,64 & 0,40 & 1,63 & 0,30 & 1,70 & 0,75 & 1,04 \\
\hline 25 & 60 & 18 & 38 & 13 & 85 & 198 & 317 & 10,66 & 35,70 & 60,49 & 0,43 & 1,60 & 0,30 & 1,69 & 0,70 & 1,06 \\
\hline 25 & 75 & 18 & 38 & 13 & 100 & 213 & 332 & 10,94 & 36,60 & 61,66 & 0,47 & 1,56 & 0,30 & 1,68 & 0,64 & 1,08 \\
\hline 25 & 80 & 18 & 38 & 13 & 105 & 218 & 337 & 11,01 & 36,87 & 62,03 & 0,48 & 1,55 & 0,30 & 1,68 & 0,62 & 1,09 \\
\hline 25 & 90 & 18 & 38 & 13 & 115 & 228 & 347 & 11,14 & 37,38 & 62,74 & 0,50 & 1,52 & 0,30 & 1,68 & 0,59 & 1,10 \\
\hline 25 & 100 & 18 & 38 & 13 & 125 & 238 & 357 & 11,25 & 37,85 & 63,40 & 0,52 & 1,50 & 0,30 & 1,68 & 0,57 & 1,12 \\
\hline 25 & 110 & 18 & 38 & 13 & 135 & 248 & 367 & 11,34 & 38,28 & 64,03 & 0,54 & 1,48 & 0,30 & 1,67 & 0,54 & 1,13 \\
\hline 25 & 125 & 18 & 38 & 13 & 150 & 263 & 382 & 11,46 & 38,86 & 64,91 & 0,57 & 1,45 & 0,29 & 1,67 & 0,52 & 1,15 \\
\hline 25 & 40 & 20 & 40 & 13 & 65 & 191 & 316 & 10,10 & 36,86 & 62,59 & 0,34 & 1,66 & 0,27 & 1,70 & 0,80 & 1,02 \\
\hline 25 & 50 & 20 & 40 & 13 & 75 & 201 & 326 & 10,42 & 37,64 & 63,50 & 0,37 & 1,63 & 0,28 & 1,69 & 0,74 & 1,04 \\
\hline 25 & 60 & 20 & 40 & 13 & 85 & 211 & 336 & 10,66 & 38,34 & 64,37 & 0,40 & 1,60 & 0,28 & 1,68 & 0,69 & 1,05 \\
\hline 25 & 75 & 20 & 40 & 13 & 100 & 226 & 351 & 10,94 & 39,28 & 65,57 & 0,44 & 1,56 & 0,28 & 1,67 & 0,63 & 1,07 \\
\hline 25 & 80 & 20 & 40 & 13 & 105 & 231 & 356 & 11,01 & 39,57 & 65,94 & 0,46 & 1,54 & 0,28 & 1,67 & 0,61 & 1,08 \\
\hline 25 & 90 & 20 & 40 & 13 & 115 & 241 & 366 & 11,14 & 40,11 & 66,67 & 0,48 & 1,52 & 0,28 & 1,66 & 0,58 & 1,09 \\
\hline 25 & 100 & 20 & 40 & 13 & 125 & 251 & 376 & 11,25 & 40,60 & 67,36 & 0,50 & 1,50 & 0,28 & 1,66 & 0,56 & 1,11 \\
\hline 25 & 110 & 20 & 40 & 13 & 135 & 261 & 386 & 11,34 & 41,06 & 68,01 & 0,52 & 1,48 & 0,28 & 1,66 & 0,53 & 1,12 \\
\hline 25 & 125 & 20 & 40 & 13 & 150 & 276 & 401 & 11,46 & 41,68 & 68,92 & 0,54 & 1,46 & 0,27 & 1,65 & 0,51 & 1,14 \\
\hline 25 & 40 & 22 & 45 & 13 & 65 & 203 & 345 & 10,10 & 39,44 & 68,35 & 0,32 & 1,70 & 0,26 & 1,73 & 0,80 & 1,02 \\
\hline 25 & 50 & 22 & 45 & 13 & 75 & 213 & 355 & 10,42 & 40,24 & 69,28 & 0,35 & 1,66 & 0,26 & 1,72 & 0,74 & 1,04 \\
\hline 25 & 60 & 22 & 45 & 13 & 85 & 223 & 365 & 10,66 & 40,97 & 70,17 & 0,38 & 1,63 & 0,26 & 1,71 & 0,68 & 1,05 \\
\hline 25 & 75 & 22 & 45 & 13 & 100 & 238 & 380 & 10,94 & 41,95 & 71,41 & 0,42 & 1,59 & 0,26 & 1,70 & 0,62 & 1,07 \\
\hline 25 & 80 & 22 & 45 & 13 & 105 & 243 & 385 & 11,01 & 42,25 & 71,80 & 0,43 & 1,58 & 0,26 & 1,70 & 0,60 & 1,07 \\
\hline 25 & 90 & 22 & 45 & 13 & 115 & 253 & 395 & 11,14 & 42,81 & 72,55 & 0,45 & 1,56 & 0,26 & 1,69 & 0,57 & 1,09 \\
\hline 25 & 100 & 22 & 45 & 13 & 125 & 263 & 405 & 11,25 & 43,33 & 73,27 & 0,47 & 1,54 & 0,26 & 1,69 & 0,55 & 1,10 \\
\hline 25 & 110 & 22 & 45 & 13 & 135 & 273 & 415 & 11,34 & 43,81 & 73,95 & 0,49 & 1,52 & 0,26 & 1,69 & 0,52 & 1,11 \\
\hline 25 & 125 & 22 & 45 & 13 & 150 & 288 & 430 & 11,46 & 44,47 & 74,91 & 0,52 & 1,49 & 0,26 & 1,68 & 0,50 & 1,13 \\
\hline 30 & 30 & 12 & 25 & 15 & 60 & 135 & 214 & 11,25 & 27,16 & 43,27 & 0,44 & 1,58 & 0,41 & 1,59 & 0,93 & 1,01 \\
\hline 30 & 40 & 12 & 25 & 15 & 70 & 145 & 224 & 11,79 & 27,98 & 44,19 & 0,48 & 1,54 & 0,42 & 1,58 & 0,87 & 1,03 \\
\hline 30 & 50 & 12 & 25 & 15 & 80 & 155 & 234 & 12,19 & 28,69 & 45,04 & 0,51 & 1,51 & 0,42 & 1,57 & 0,83 & 1,04 \\
\hline 30 & 60 & 12 & 25 & 15 & 90 & 165 & 244 & 12,50 & 29,31 & 45,82 & 0,54 & 1,47 & 0,43 & 1,56 & 0,78 & 1,06 \\
\hline 30 & 70 & 12 & 25 & 15 & 100 & 175 & 254 & 12,75 & 29,86 & 46,53 & 0,57 & 1,45 & 0,43 & 1,56 & 0,75 & 1,08 \\
\hline 30 & 80 & 12 & 25 & 15 & 110 & 185 & 264 & 12,95 & 30,36 & 47,19 & 0,59 & 1,42 & 0,43 & 1,55 & 0,72 & 1,09 \\
\hline 30 & 90 & 12 & 25 & 15 & 120 & 195 & 274 & 13,13 & 30,80 & 47,81 & 0,61 & 1,40 & 0,43 & 1,55 & 0,69 & 1,11 \\
\hline 30 & 100 & 12 & 25 & 15 & 130 & 205 & 284 & 13,27 & 31,20 & 48,38 & 0,63 & 1,38 & 0,43 & 1,55 & 0,67 & 1,12 \\
\hline 30 & 110 & 12 & 25 & 15 & 140 & 215 & 294 & 13,39 & 31,56 & 48,91 & 0,65 & 1,36 & 0,42 & 1,55 & 0,65 & 1,14 \\
\hline 30 & 120 & 12 & 25 & 15 & 150 & 225 & 304 & 13,50 & 31,89 & 49,40 & 0,67 & 1,35 & 0,42 & 1,55 & 0,64 & 1,15 \\
\hline 30 & 130 & 12 & 25 & 15 & 160 & 235 & 314 & 13,59 & 32,19 & 49,87 & 0,68 & 1,33 & 0,42 & 1,55 & 0,62 & 1,16 \\
\hline 30 & 140 & 12 & 25 & 15 & 170 & 245 & 324 & 13,68 & 32,47 & 50,31 & 0,69 & 1,32 & 0,42 & 1,55 & 0,61 & 1,17 \\
\hline 30 & 150 & 12 & 25 & 15 & 180 & 255 & 334 & 13,75 & 32,73 & 50,72 & 0,70 & 1,31 & 0,42 & 1,55 & 0,60 & 1,19 \\
\hline 30 & 30 & 14 & $|29|$ & 15 & 60 & 148 & 239 & 11,25 & 29,75 & 48,39 & 0,41 & 1,62 & 0,38 & 1,63 & 0,93 & 1,01 \\
\hline
\end{tabular}




\begin{tabular}{|c|c|c|c|c|c|c|c|c|c|c|c|c|c|c|c|c|}
\hline $\mathrm{c} 1$ & $\mathrm{c} 2$ & $\mathrm{~d}$ & $\mathrm{p}$ & $\mathrm{a}$ & uo* & $\mathrm{u}^{*}$ & $\mathrm{u}^{\prime *}$ & eo* & $e^{*}$ & $\mathrm{e}^{\prime *}$ & uo*/u u $^{*}$ & $\mathrm{u}^{\prime} * / \mathrm{u}^{*}$ & eo*/e* & $\mathrm{e}^{\prime * / \mathrm{e}^{*}}$ & $\eta_{\mathrm{el}}$ & $\eta_{\mathrm{e} 2}$ \\
\hline 30 & 40 & 14 & 29 & 15 & 70 & 158 & 249 & 11,79 & 30,59 & 49,34 & 0,44 & 1,58 & 0,39 & 1,61 & 0,87 & 1,02 \\
\hline 30 & 50 & 14 & 29 & 15 & 80 & 168 & 259 & 12,19 & 31,33 & 50,21 & 0,48 & 1,54 & 0,39 & 1,60 & 0,82 & 1,04 \\
\hline 30 & 60 & 14 & 29 & 15 & 90 & 178 & 269 & 12,50 & 31,99 & 51,02 & 0,51 & 1,51 & 0,39 & 1,60 & 0,77 & 1,06 \\
\hline 30 & 70 & 14 & 29 & 15 & 100 & 188 & 279 & 12,75 & 32,57 & 51,78 & 0,53 & 1,48 & 0,39 & 1,59 & 0,74 & 1,07 \\
\hline 30 & 80 & 14 & 29 & 15 & 110 & 198 & 289 & 12,95 & 33,10 & 52,48 & 0,56 & 1,46 & 0,39 & 1,59 & 0,70 & 1,09 \\
\hline 30 & 90 & 14 & 29 & 15 & 120 & 208 & 299 & 13,13 & 33,58 & 53,13 & 0,58 & 1,44 & 0,39 & 1,58 & 0,68 & 1,10 \\
\hline 30 & 100 & 14 & 29 & 15 & 130 & 218 & 309 & 13,27 & 34,01 & 53,74 & 0,60 & 1,42 & 0,39 & 1,58 & 0,65 & 1,11 \\
\hline 30 & 110 & 14 & 29 & 15 & 140 & 228 & 319 & 13,39 & 34,40 & 54,31 & 0,61 & 1,40 & 0,39 & 1,58 & 0,63 & 1,13 \\
\hline 30 & 120 & 14 & 29 & 15 & 150 & 238 & 329 & 13,50 & 34,76 & 54,85 & 0,63 & 1,38 & 0,39 & 1,58 & 0,62 & 1,14 \\
\hline 30 & 130 & 14 & 29 & 15 & 160 & 248 & 339 & 13,59 & 35,10 & 55,35 & 0,65 & 1,37 & 0,39 & 1,58 & 0,60 & 1,15 \\
\hline 30 & 140 & 14 & 29 & 15 & 170 & 258 & 349 & 13,68 & 35,40 & 55,83 & 0,66 & 1,35 & 0,39 & 1,58 & 0,59 & 1,17 \\
\hline 30 & 150 & 14 & 29 & 15 & 180 & 268 & 359 & 13,75 & 35,69 & 56,28 & 0,67 & 1,34 & 0,39 & 1,58 & 0,57 & 1,18 \\
\hline 30 & 30 & 16 & 33 & 15 & 60 & 161 & 264 & 11,25 & 32,34 & 53,51 & 0,37 & 1,65 & 0,35 & 1,65 & 0,93 & 1,01 \\
\hline 30 & 40 & 16 & 33 & 15 & 70 & 171 & 274 & 11,79 & 33,20 & 54,48 & 0,41 & 1,61 & 0,36 & 1,64 & 0,86 & 1,02 \\
\hline 30 & 50 & 16 & 33 & 15 & 80 & 181 & 284 & 12,19 & 33,96 & 55,38 & 0,44 & 1,57 & 0,36 & 1,63 & 0,81 & 1,04 \\
\hline 30 & 60 & 16 & 33 & 15 & 90 & 191 & 294 & 12,50 & 34,65 & 56,21 & 0,47 & 1,54 & 0,36 & 1,62 & 0,76 & 1,05 \\
\hline 30 & 70 & 16 & 33 & 15 & 100 & 201 & 304 & 12,75 & 35,26 & 56,99 & 0,50 & 1,52 & 0,36 & 1,62 & 0,73 & 1,07 \\
\hline 30 & 80 & 16 & 33 & 15 & 110 & 211 & 314 & 12,95 & 35,82 & 57,73 & 0,52 & 1,49 & 0,36 & 1,61 & 0,69 & 1,08 \\
\hline 30 & 90 & 16 & 33 & 15 & 120 & 221 & 324 & 13,13 & 36,33 & 58,41 & 0,54 & 1,47 & 0,36 & 1,61 & 0,66 & 1,09 \\
\hline 30 & 100 & 16 & 33 & 15 & 130 & 231 & 334 & 13,27 & 36,79 & 59,06 & 0,56 & 1,45 & 0,36 & 1,61 & 0,64 & 1,11 \\
\hline 30 & 110 & 16 & 33 & 15 & 140 & 241 & 344 & 13,39 & 37,21 & 59,67 & 0,58 & 1,43 & 0,36 & 1,60 & 0,62 & 1,12 \\
\hline 30 & 120 & 16 & 33 & 15 & 150 & 251 & 354 & 13,50 & 37,60 & 60,24 & 0,60 & 1,41 & 0,36 & 1,60 & 0,60 & 1,13 \\
\hline 30 & 130 & 16 & 33 & 15 & 160 & 261 & 364 & 13,59 & 37,96 & 60,78 & 0,61 & 1,40 & 0,36 & 1,60 & 0,58 & 1,15 \\
\hline 30 & 140 & 16 & 33 & 15 & 170 & 271 & 374 & 13,68 & 38,30 & 61,30 & 0,63 & 1,38 & 0,36 & 1,60 & 0,57 & 1,16 \\
\hline 30 & 150 & 16 & 33 & 15 & 180 & 281 & 384 & 13,75 & 38,61 & 61,79 & 0,64 & 1,37 & 0,36 & 1,60 & 0,56 & 1,17 \\
\hline 30 & 30 & 18 & 38 & 15 & 60 & 173 & 292 & 11,25 & 34,91 & 59,27 & 0,35 & 1,69 & 0,32 & 1,70 & 0,93 & 1,00 \\
\hline 30 & 40 & 18 & 38 & 15 & 70 & 183 & 302 & 11,79 & 35,79 & 60,25 & 0,38 & 1,65 & 0,33 & 1,68 & 0,86 & 1,02 \\
\hline 30 & 50 & 18 & 38 & 15 & 80 & 193 & 312 & 12,19 & 36,58 & 61,17 & 0,41 & 1,62 & 0,33 & 1,67 & 0,80 & 1,03 \\
\hline 30 & 60 & 18 & 38 & 15 & 90 & 203 & 322 & 12,50 & 37,29 & 62,03 & 0,44 & 1,59 & 0,34 & 1,66 & 0,76 & 1,05 \\
\hline 30 & 70 & 18 & 38 & 15 & 100 & 213 & 332 & 12,75 & 37,93 & 62,84 & 0,47 & 1,56 & 0,34 & 1,66 & 0,72 & 1,06 \\
\hline 30 & 80 & 18 & 38 & 15 & 110 & 223 & 342 & 12,95 & 38,52 & 63,61 & 0,49 & 1,54 & 0,34 & 1,65 & 0,68 & 1,08 \\
\hline 30 & 90 & 18 & 38 & 15 & 120 & 233 & 352 & 13,13 & 39,05 & 64,33 & 0,51 & 1,51 & 0,34 & 1,65 & 0,65 & 1,09 \\
\hline 30 & 100 & 18 & 38 & 15 & 130 & 243 & 362 & 13,27 & 39,55 & 65,01 & 0,53 & 1,49 & 0,34 & 1,64 & 0,63 & 1,10 \\
\hline 30 & 110 & 18 & 38 & 15 & 140 & 253 & 372 & 13,39 & 40,00 & 65,65 & 0,55 & 1,47 & 0,33 & 1,64 & 0,61 & 1,12 \\
\hline 30 & 120 & 18 & 38 & 15 & 150 & 263 & 382 & 13,50 & 40,42 & 66,26 & 0,57 & 1,45 & 0,33 & 1,64 & 0,59 & 1,13 \\
\hline 30 & 130 & 18 & 38 & 15 & 160 & 273 & 392 & 13,59 & 40,80 & 66,84 & 0,59 & 1,44 & 0,33 & 1,64 & 0,57 & 1,14 \\
\hline 30 & 140 & 18 & 38 & 15 & 170 & 283 & 402 & 13,68 & 41,16 & 67,39 & 0,60 & 1,42 & 0,33 & 1,64 & 0,55 & 1,15 \\
\hline 30 & 150 & 18 & 38 & 15 & 180 & 293 & 412 & 13,75 & 41,50 & 67,92 & 0,61 & 1,41 & 0,33 & 1,64 & 0,54 & 1,16 \\
\hline 30 & 30 & 20 & 40 & 15 & 60 & 186 & 311 & 11,25 & 37,49 & 63,10 & 0,32 & 1,68 & 0,30 & 1,68 & 0,93 & 1,00 \\
\hline 30 & 40 & 20 & 40 & 15 & 70 & 196 & 321 & 11,79 & 38,38 & 64,09 & 0,36 & 1,64 & 0,31 & 1,67 & 0,86 & 1,02 \\
\hline 30 & 50 & 20 & 40 & 15 & 80 & 206 & 331 & 12,19 & 39,19 & 65,03 & 0,39 & 1,61 & 0,31 & 1,66 & 0,80 & 1,03 \\
\hline 30 & 60 & 20 & 40 & 15 & 90 & 216 & 341 & 12,50 & 39,92 & 65,90 & 0,42 & 1,58 & 0,31 & 1,65 & 0,75 & 1,04 \\
\hline 30 & 70 & 20 & 40 & 15 & 100 & 226 & 351 & 12,75 & 40,59 & 66,73 & 0,44 & 1,56 & 0,31 & 1,64 & 0,71 & 1,06 \\
\hline 30 & 80 & 20 & 40 & 15 & 110 & 236 & 361 & 12,95 & 41,20 & 67,51 & 0,47 & 1,53 & 0,31 & 1,64 & 0,67 & 1,07 \\
\hline 30 & 90 & 20 & 40 & 15 & 120 & 246 & 371 & 13,13 & 41,76 & 68,25 & 0,49 & 1,51 & 0,31 & 1,63 & 0,64 & 1,08 \\
\hline 30 & 100 & 20 & 40 & 15 & 130 & 256 & 381 & 13,27 & 42,28 & 68,96 & 0,51 & 1,49 & 0,31 & 1,63 & 0,62 & 1,09 \\
\hline 30 & 110 & 20 & 40 & 15 & 140 & 266 & 391 & 13,39 & 42,76 & 69,62 & 0,53 & 1,47 & 0,31 & 1,63 & 0,59 & 1,11 \\
\hline 30 & 120 & 20 & 40 & 15 & 150 & 276 & 401 & 13,50 & 43,20 & 70,25 & 0,54 & 1,46 & 0,31 & 1,63 & 0,57 & 1,12 \\
\hline 30 & 130 & 20 & 40 & 15 & 160 & 286 & 411 & 13,59 & 43,62 & 70,86 & 0,56 & 1,44 & 0,31 & 1,62 & 0,56 & 1,13 \\
\hline 30 & 140 & 20 & 40 & 15 & 170 & 296 & 421 & 13,68 & 44,00 & 71,43 & 0,57 & 1,43 & 0,31 & 1,62 & 0,54 & 1,14 \\
\hline 30 & 150 & 20 & 40 & 15 & 180 & 306 & 431 & 13,75 & 44,36 & 71,98 & 0,59 & 1,41 & 0,31 & 1,62 & 0,53 & 1,15 \\
\hline 30 & 30 & 22 & 45 & 15 & 60 & 198 & 340 & 11,25 & 40,06 & 68,85 & 0,30 & 1,71 & 0,28 & 1,72 & 0,93 & 1,00 \\
\hline 30 & 40 & 22 & 45 & 15 & 70 & 208 & 350 & 11,79 & 40,97 & 69,85 & 0,34 & 1,68 & 0,29 & 1,71 & 0,86 & 1,02 \\
\hline 30 & 50 & 22 & 45 & 15 & 80 & 218 & 360 & 12,19 & 41,79 & 70,80 & 0,37 & 1,65 & 0,29 & 1,69 & 0,80 & 1,03 \\
\hline 30 & 60 & 22 & 45 & $\mid 15$ & 90 & 228 & 370 & 12,50 & 42,55 & 71,70 & 0,39 & 1,62 & 0,29 & 1,69 & 0,75 & 1,04 \\
\hline
\end{tabular}




\begin{tabular}{|c|c|c|c|c||c|c|c||c|c|c||c|c|c|c|c|c|}
$\mathrm{c} 1$ & $\mathrm{c} 2$ & $\mathrm{~d}$ & $\mathrm{p}$ & $\mathrm{a}$ & $\mathrm{u}{ }^{*}$ & $\mathrm{u}^{*}$ & $\mathrm{u}^{\prime *}$ & $\mathrm{e}^{*}$ & $\mathrm{e}^{*}$ & $\mathrm{e}^{\prime *}$ & $\mathrm{uo}^{*} / \mathrm{u}^{*}$ & $\mathrm{u}^{\prime *} / \mathrm{u}^{*}$ & $\mathrm{e}^{*} / \mathrm{e}^{*}$ & $\mathrm{e}^{\prime *} / \mathrm{e}^{*}$ & $\eta_{\mathrm{e} 1}$ & $\eta_{\mathrm{e} 2}$ \\
\hline 30 & 70 & 22 & 45 & 15 & 100 & 238 & 380 & 12,75 & 43,24 & 72,55 & 0,42 & 1,59 & 0,29 & 1,68 & 0,70 & 1,05 \\
\hline 30 & 80 & 22 & 45 & 15 & 110 & 248 & 390 & 12,95 & 43,87 & 73,36 & 0,44 & 1,57 & 0,30 & 1,67 & 0,67 & 1,07 \\
\hline 30 & 90 & 22 & 45 & 15 & 120 & 258 & 400 & 13,13 & 44,46 & 74,13 & 0,46 & 1,55 & 0,30 & 1,67 & 0,64 & 1,08 \\
\hline 30 & 100 & 22 & 45 & 15 & 130 & 268 & 410 & 13,27 & 45,00 & 74,86 & 0,48 & 1,53 & 0,29 & 1,66 & 0,61 & 1,09 \\
\hline 30 & 110 & 22 & 45 & 15 & 140 & 278 & 420 & 13,39 & 45,50 & 75,55 & 0,50 & 1,51 & 0,29 & 1,66 & 0,58 & 1,10 \\
\hline 30 & 120 & 22 & 45 & 15 & 150 & 288 & 430 & 13,50 & 45,97 & 76,21 & 0,52 & 1,49 & 0,29 & 1,66 & 0,56 & 1,11 \\
\hline 30 & 130 & 22 & 45 & 15 & 160 & 298 & 440 & 13,59 & 46,41 & 76,84 & 0,54 & 1,47 & 0,29 & 1,66 & 0,55 & 1,12 \\
\hline 30 & 140 & 22 & 45 & 15 & 170 & 308 & 450 & 13,68 & 46,82 & 77,45 & 0,55 & 1,46 & 0,29 & 1,65 & 0,53 & 1,13 \\
\hline 30 & 150 & 22 & 45 & 15 & 180 & 318 & 460 & 13,75 & 47,20 & 78,03 & 0,57 & 1,44 & 0,29 & 1,65 & 0,52 & 1,14 \\
\hline
\end{tabular}

Tabela B.4 - Valores de $\eta_{\mathrm{e} 1}$ e de $\eta_{\mathrm{e} 2}$ para pilares de borda com $c_{1}>c_{2}$

\begin{tabular}{|c|c|c|c|c|c|c|c|c|c|c|c|c|c|c|c|c|}
\hline c1 & $\mathrm{c} 2$ & $\mathrm{~d}$ & $\mathrm{p}$ & $\mathrm{a}$ & uo* & $\mathrm{u}^{*}$ & $\mathrm{u}^{\prime *}$ & eo* & $\mathrm{e}^{*}$ & $\mathrm{e}^{\prime *}$ & uо $* / \mathrm{u}^{*}$ & $\mathrm{u}^{\prime *} / \mathrm{u}^{*}$ & eo*/e* & $\mathrm{e}^{\prime *} \mathrm{e}^{*}$ & $\eta_{\mathrm{e} 1}$ & $\eta_{\mathrm{e} 2}$ \\
\hline 30 & 20 & 12 & 25 & 15 & 50 & 125 & 204 & 10,50 & 26,22 & 42,25 & 0,40 & 1,63 & 0,40 & 1,61 & 1,00 & 0,99 \\
\hline 30 & 20 & 14 & 29 & 15 & 50 & 138 & 229 & 10,50 & 28,79 & 47,36 & 0,36 & 1,66 & 0,36 & 1,64 & 1,01 & 0,99 \\
\hline 30 & 20 & 16 & 33 & 15 & 50 & 151 & 254 & 10,50 & 31,36 & 52,47 & 0,33 & 1,69 & 0,33 & 1,67 & 1,01 & 0,99 \\
\hline 30 & 20 & 18 & 38 & 15 & 50 & 163 & 282 & 10,50 & 33,93 & 58,21 & 0,31 & 1,73 & 0,31 & 1,72 & 1,01 & 0,99 \\
\hline 30 & 20 & 20 & 40 & 15 & 50 & 176 & 301 & 10,50 & 36,49 & 62,04 & 0,28 & 1,72 & 0,29 & 1,70 & 1,01 & 0,99 \\
\hline 30 & 20 & 22 & 45 & 15 & 50 & 188 & 330 & 10,50 & 39,05 & 67,78 & 0,27 & 1,75 & 0,27 & 1,74 & 1,01 & 0,99 \\
\hline 40 & 20 & 12 & 25 & 18 & 56 & 131 & 210 & 14,21 & 29,95 & 46,00 & 0,43 & 1,60 & 0,47 & 1,54 & 1,11 & 0,96 \\
\hline 40 & 25 & 12 & 25 & 18 & 61 & 136 & 215 & 14,69 & 30,47 & 46,53 & 0,45 & 1,58 & 0,48 & 1,53 & 1,08 & 0,97 \\
\hline 40 & 30 & 12 & 25 & 18 & 66 & 141 & 220 & 15,09 & 30,95 & 47,04 & 0,47 & 1,56 & 0,49 & 1,52 & 1,04 & 0,98 \\
\hline 40 & 20 & 14 & 29 & 20 & 60 & 148 & 239 & 13,33 & 31,68 & 50,28 & 0,41 & 1,62 & 0,42 & 1,59 & 1,04 & 0,98 \\
\hline 40 & 25 & 14 & 29 & 20 & 65 & 153 & 244 & 13,85 & 32,21 & 50,82 & 0,42 & 1,60 & 0,43 & 1,58 & 1,01 & 0,99 \\
\hline 40 & 30 & 14 & 29 & 20 & 70 & 158 & 249 & 14,29 & 32,71 & 51,35 & 0,44 & 1,58 & 0,44 & 1,57 & 0,99 & 1,00 \\
\hline 40 & 20 & 16 & 33 & 20 & 60 & 161 & 264 & 13,33 & 34,25 & 55,39 & 0,37 & 1,65 & 0,39 & 1,62 & 1,04 & 0,98 \\
\hline 40 & 25 & 16 & 33 & 20 & 65 & 166 & 269 & 13,85 & 34,79 & 55,94 & 0,39 & 1,63 & 0,40 & 1,61 & 1,01 & 0,99 \\
\hline 40 & 30 & 16 & 33 & 20 & 70 & 171 & 274 & 14,29 & 35,29 & 56,47 & 0,41 & 1,61 & 0,40 & 1,60 & 0,99 & 1,00 \\
\hline 40 & 20 & 18 & 38 & 20 & 60 & 173 & 292 & 13,33 & 36,82 & 61,14 & 0,35 & 1,69 & 0,36 & 1,66 & 1,04 & 0,98 \\
\hline 40 & 25 & 18 & 38 & 20 & 65 & 178 & 297 & 13,85 & 37,36 & 61,69 & 0,36 & 1,67 & 0,37 & 1,65 & 1,02 & 0,99 \\
\hline 40 & 30 & 18 & 38 & 20 & 70 & 183 & 302 & 14,29 & 37,87 & 62,22 & 0,38 & 1,65 & 0,38 & 1,64 & 0,99 & 0,99 \\
\hline 40 & 20 & 20 & 40 & 20 & 60 & 186 & 311 & 13,33 & 39,39 & 64,97 & 0,32 & 1,68 & 0,34 & 1,65 & 1,05 & 0,98 \\
\hline 40 & 25 & 20 & 40 & 20 & 65 & 191 & 316 & 13,85 & 39,93 & 65,52 & 0,34 & 1,66 & 0,35 & 1,64 & 1,02 & 0,99 \\
\hline 40 & 30 & 20 & 40 & 20 & 70 & 196 & 321 & 14,29 & 40,44 & 66,06 & 0,36 & 1,64 & 0,35 & 1,63 & 0,99 & 0,99 \\
\hline 40 & 20 & 22 & 45 & 20 & 60 & 198 & 340 & 13,33 & 41,95 & 70,71 & 0,30 & 1,71 & 0,32 & 1,69 & 1,05 & 0,98 \\
\hline 40 & 25 & 22 & 45 & 20 & 65 & 203 & 345 & 13,85 & 42,50 & 71,27 & 0,32 & 1,70 & 0,33 & 1,68 & 1,02 & 0,99 \\
\hline 40 & 30 & 22 & 45 & 20 & 70 & 208 & 350 & 14,29 & 43,01 & 71,81 & 0,34 & 1,68 & 0,33 & 1,67 & 0,99 & 0,99 \\
\hline 50 & 20 & 12 & 25 & 18 & 56 & 131 & 210 & 19,21 & 34,95 & 51,00 & 0,43 & 1,60 & 0,55 & 1,46 & 1,29 & 0,91 \\
\hline 50 & 25 & 12 & 25 & 18 & 61 & 136 & 215 & 19,69 & 35,47 & 51,53 & 0,45 & 1,58 & 0,56 & 1,45 & 1,24 & 0,92 \\
\hline 50 & 30 & 12 & 25 & 18 & 66 & 141 & 220 & 20,09 & 35,95 & 52,04 & 0,47 & 1,56 & 0,56 & 1,45 & 1,20 & 0,93 \\
\hline 50 & 20 & 14 & 29 & 21 & 62 & 150 & 241 & 17,89 & 36,25 & 54,85 & 0,41 & 1,61 & 0,49 & 1,51 & 1,19 & 0,94 \\
\hline 50 & 25 & 14 & 29 & 21 & 67 & 155 & 246 & 18,42 & 36,79 & 55,41 & 0,43 & 1,59 & 0,50 & 1,51 & 1,16 & 0,95 \\
\hline 50 & 30 & 14 & 29 & 21 & 72 & 160 & 251 & 18,88 & 37,30 & 55,94 & 0,45 & 1,57 & 0,51 & 1,50 & 1,12 & 0,96 \\
\hline 50 & 20 & 16 & 33 & 24 & 68 & 169 & 272 & 16,53 & 37,53 & 58,70 & 0,40 & 1,62 & 0,44 & 1,56 & 1,09 & 0,97 \\
\hline 50 & 25 & 16 & 33 & 24 & 73 & 174 & 277 & 17,11 & 38,09 & 59,27 & 0,42 & 1,60 & 0,45 & 1,56 & 1,07 & 0,97 \\
\hline 50 & 30 & 16 & 33 & 24 & 78 & 179 & 282 & 17,62 & 38,62 & 59,81 & 0,44 & 1,58 & 0,46 & 1,55 & 1,04 & 0,98 \\
\hline 50 & 20 & 18 & 38 & 25 & 70 & 183 & 302 & 16,07 & 39,68 & 64,03 & 0,38 & 1,65 & 0,41 & 1,61 & 1,06 & 0,98 \\
\hline 50 & 25 & 18 & 38 & 25 & 75 & 188 & 307 & 16,67 & 40,24 & 64,60 & 0,40 & 1,63 & 0,41 & 1,61 & 1,04 & 0,98 \\
\hline 50 & 30 & 18 & 38 & 25 & 80 & 193 & 312 & 17,19 & 40,78 & 65,15 & 0,41 & 1,62 & 0,42 & 1,60 & 1,02 & 0,99 \\
\hline 50 & 20 & 20 & 40 & 25 & 70 & 196 & 321 & 16,07 & 42,25 & 67,87 & 0,36 & 1,64 & 0,38 & 1,61 & 1,06 & 0,98 \\
\hline 50 & 25 & 20 & 40 & 25 & 75 & 201 & 326 & 16,67 & 42,82 & 68,44 & 0,37 & 1,63 & 0,39 & 1,60 & 1,04 & 0,98 \\
\hline
\end{tabular}




\begin{tabular}{|c|c|c|c|c|c|c|c|c|c|c|c|c|c|c|c|c|}
\hline c1 & c2 & $\mathrm{d}$ & $\mathrm{p}$ & $\mathrm{a}$ & uo* & $\mathrm{u}^{*}$ & $\mathrm{u}^{\prime * *}$ & eo* & $e^{*}$ & $\mathrm{e}^{\prime *}$ & ио*/u* & $\mathrm{u}^{\prime *} / \mathrm{u}^{*}$ & eo*/e" & $\mathrm{e}^{\mathrm{e}^{\prime *} \mathrm{e}^{*}}$ & $\eta_{\mathrm{e} 1}$ & $\eta_{\mathrm{e} 2}$ \\
\hline 50 & 30 & 20 & 40 & 25 & 80 & 206 & 331 & 17,19 & 43,36 & 68,99 & 0,39 & 1,61 & 0,40 & 1,59 & 1,02 & 0,99 \\
\hline 50 & 20 & 22 & 45 & 25 & 70 & 208 & 350 & 16,07 & 44,82 & 73,62 & 0,34 & 1,68 & 0,36 & 1,64 & 1,07 & 0,98 \\
\hline 50 & 25 & 22 & 45 & 25 & 75 & 213 & 355 & 16,67 & 45,39 & 74,19 & 0,35 & 1,66 & 0,37 & 1,63 & 1,04 & 0,98 \\
\hline 50 & 30 & 22 & 45 & 25 & 80 & 218 & 360 & 17,19 & 45,93 & 74,74 & 0,37 & 1,65 & 0,37 & 1,63 & 1,02 & 0,99 \\
\hline 60 & 20 & 12 & 25 & 18 & 56 & 131 & 210 & 24,21 & 39,95 & 56,00 & 0,43 & 1,60 & 0,61 & 1,40 & 1,42 & 0,88 \\
\hline 60 & 25 & 12 & 25 & 18 & 61 & 136 & 215 & 24,69 & 40,47 & 56,53 & 0,45 & 1,58 & 0,61 & 1,40 & 1,36 & 0,89 \\
\hline 60 & 30 & 12 & 25 & 18 & 66 & 141 & 220 & 25,09 & 40,95 & 57,04 & 0,47 & 1,56 & 0,61 & 1,39 & 1,31 & 0,90 \\
\hline 60 & 20 & 14 & 29 & 21 & 62 & 150 & 241 & 22,89 & 41,25 & 59,85 & 0,41 & 1,61 & 0,55 & 1,45 & 1,34 & 0,90 \\
\hline 60 & 25 & 14 & 29 & 21 & 67 & 155 & 246 & 23,42 & 41,79 & 60,41 & 0,43 & 1,59 & 0,56 & 1,45 & 1,30 & 0,91 \\
\hline 60 & 30 & 14 & 29 & 21 & 72 & 160 & 251 & 23,88 & 42,30 & 60,94 & 0,45 & 1,57 & 0,56 & 1,44 & 1,25 & 0,92 \\
\hline 60 & 20 & 16 & 33 & 24 & 68 & 169 & 272 & 21,53 & 42,53 & 63,70 & 0,40 & 1,62 & 0,51 & 1,50 & 1,25 & 0,93 \\
\hline 60 & 25 & 16 & 33 & 24 & 73 & 174 & 277 & 22,11 & 43,09 & 64,27 & 0,42 & 1,60 & 0,51 & 1,49 & 1,22 & 0,93 \\
\hline 60 & 30 & 16 & 33 & 24 & 78 & 179 & 282 & 22,62 & 43,62 & 64,81 & 0,44 & 1,58 & 0,52 & 1,49 & 1,19 & 0,94 \\
\hline 60 & 20 & 18 & 38 & 27 & 74 & 187 & 306 & 20,15 & 43,81 & 68,19 & 0,40 & 1,64 & 0,46 & 1,56 & 1,16 & 0,95 \\
\hline 60 & 25 & 18 & 38 & 27 & 79 & 192 & 311 & 20,77 & 44,38 & 68,76 & 0,41 & 1,62 & 0,47 & 1,55 & 1,14 & 0,96 \\
\hline 60 & 30 & 18 & 38 & 27 & 84 & 197 & 316 & 21,32 & 44,93 & 69,32 & 0,43 & 1,61 & 0,47 & 1,54 & 1,11 & 0,96 \\
\hline 60 & 20 & 20 & 40 & 30 & 80 & 206 & 331 & 18,75 & 45,07 & 70,75 & 0,39 & 1,61 & 0,42 & 1,57 & 1,07 & 0,97 \\
\hline 60 & 25 & 20 & 40 & 30 & 85 & 211 & 336 & 19,41 & 45,66 & 71,33 & 0,40 & 1,60 & 0,43 & 1,56 & 1,05 & 0,98 \\
\hline 60 & 30 & 20 & 40 & 30 & 90 & 216 & 341 & 20,00 & 46,23 & 71,90 & 0,42 & 1,58 & 0,43 & 1,56 & 1,04 & 0,98 \\
\hline 60 & 20 & 22 & 45 & 30 & 80 & 218 & 360 & 18,75 & 47,65 & 76,50 & 0,37 & 1,65 & 0,39 & 1,61 & 1,07 & 0,97 \\
\hline 60 & 25 & 22 & 45 & 30 & 85 & 223 & 365 & 19,41 & 48,24 & 77,08 & 0,38 & 1,63 & 0,40 & 1,60 & 1,06 & 0,98 \\
\hline 60 & 30 & 22 & 45 & 30 & 90 & 228 & 370 & 20,00 & 48,81 & 77,65 & 0,39 & 1,62 & 0,41 & 1,59 & 1,04 & 0,98 \\
\hline 70 & 20 & 12 & 25 & 18 & 56 & 131 & 210 & 29,21 & 44,95 & 61,00 & 0,43 & 1,60 & 0,65 & 1,36 & 1,52 & 0,85 \\
\hline 70 & 30 & 12 & 25 & 18 & 66 & 141 & 220 & 30,09 & 45,95 & 62,04 & 0,47 & 1,56 & 0,65 & 1,35 & 1,40 & 0,87 \\
\hline 70 & 20 & 14 & 29 & 21 & 62 & 150 & 241 & 27,89 & 46,25 & 64,85 & 0,41 & 1,61 & 0,60 & 1,40 & 1,46 & 0,87 \\
\hline 70 & 30 & 14 & 29 & 21 & 72 & 160 & 251 & 28,88 & 47,30 & 65,94 & 0,45 & 1,57 & 0,61 & 1,39 & 1,36 & 0,89 \\
\hline 70 & 20 & 16 & 33 & 24 & 68 & 169 & 272 & 26,53 & 47,53 & 68,70 & 0,40 & 1,62 & 0,56 & 1,45 & 1,38 & 0,89 \\
\hline 70 & 30 & 16 & 33 & $24 \mid$ & 78 & 179 & 282 & 27,62 & 48,62 & 69,81 & 0,44 & 1,58 & 0,57 & 1,44 & 1,30 & 0,91 \\
\hline 70 & 20 & 18 & 38 & 27 & 74 & 187 & 306 & 25,15 & 48,81 & 73,19 & 0,40 & 1,64 & 0,52 & 1,50 & 1,30 & 0,92 \\
\hline 70 & 30 & 18 & 38 & $27 \mid$ & 84 & 197 & 316 & 26,32 & 49,93 & 74,32 & 0,43 & 1,61 & 0,53 & 1,49 & 1,24 & 0,93 \\
\hline 70 & 20 & 20 & 40 & 30 & 80 & 206 & 331 & 23,75 & 50,07 & 75,75 & 0,39 & 1,61 & 0,47 & 1,51 & 1,22 & 0,94 \\
\hline 70 & 30 & 20 & 40 & 30 & 90 & 216 & 341 & 25,00 & 51,23 & 76,90 & 0,42 & 1,58 & 0,49 & 1,50 & 1,17 & 0,95 \\
\hline 70 & 20 & 22 & 45 & 33 & 86 & 224 & 366 & 22,34 & 51,34 & 80,22 & 0,38 & 1,63 & 0,44 & 1,56 & 1,13 & 0,96 \\
\hline 70 & 30 & 22 & 45 & 33 & 96 & 234 & 376 & 23,66 & 52,52 & 81,39 & 0,41 & 1,60 & 0,45 & 1,55 & 1,10 & 0,97 \\
\hline 75 & 25 & 12 & 25 & 18 & 61 & 136 & 215 & 32,19 & 47,97 & 64,03 & 0,45 & 1,58 & 0,67 & 1,33 & 1,50 & 0,85 \\
\hline 75 & 25 & 14 & 29 & 21 & 67 & 155 & 246 & 30,92 & 49,29 & 67,91 & 0,43 & 1,59 & 0,63 & 1,38 & 1,45 & 0,87 \\
\hline 75 & 25 & 16 & 33 & 24 & 73 & 174 & 277 & 29,61 & 50,59 & 71,77 & 0,42 & 1,60 & 0,59 & 1,42 & 1,39 & 0,89 \\
\hline 75 & 25 & 18 & 38 & 27 & 79 & 192 & 311 & 28,27 & 51,88 & 76,26 & 0,41 & 1,62 & 0,54 & 1,47 & 1,33 & 0,91 \\
\hline 75 & 25 & 20 & 40 & 30 & 85 & 211 & 336 & 26,91 & 53,16 & 78,83 & 0,40 & 1,60 & 0,51 & 1,48 & 1,25 & 0,93 \\
\hline 75 & 25 & 22 & 45 & 33 & 91 & 229 & 371 & 25,53 & 54,44 & 83,31 & 0,40 & 1,62 & 0,47 & 1,53 & 1,18 & 0,95 \\
\hline 80 & 20 & 12 & 25 & 18 & 56 & 131 & 210 & 34,21 & 49,95 & 66,00 & 0,43 & 1,60 & 0,68 & 1,32 & 1,61 & 0,83 \\
\hline 80 & 25 & 12 & 25 & 18 & 61 & 136 & 215 & 34,69 & 50,47 & 66,53 & 0,45 & 1,58 & 0,69 & 1,32 & 1,54 & 0,84 \\
\hline 80 & 30 & 12 & 25 & 18 & 66 & 141 & 220 & 35,09 & 50,95 & 67,04 & 0,47 & 1,56 & 0,69 & 1,32 & 1,48 & 0,85 \\
\hline 80 & 20 & 14 & 29 & 21 & 62 & 150 & 241 & 32,89 & 51,25 & 69,85 & 0,41 & 1,61 & 0,64 & 1,36 & 1,55 & 0,85 \\
\hline 80 & 25 & 14 & 29 & 21 & 67 & 155 & 246 & 33,42 & 51,79 & 70,41 & 0,43 & 1,59 & 0,65 & 1,36 & 1,49 & 0,86 \\
\hline 80 & 30 & 14 & 29 & 21 & 72 & 160 & 251 & 33,88 & 52,30 & 70,94 & 0,45 & 1,57 & 0,65 & 1,36 & 1,44 & 0,86 \\
\hline 80 & 20 & 16 & 33 & 24 & 68 & 169 & 272 & 31,53 & 52,53 & 73,70 & 0,40 & 1,62 & 0,60 & 1,40 & 1,49 & 0,87 \\
\hline 80 & 25 & 16 & 33 & 24 & 73 & 174 & 277 & 32,11 & 53,09 & 74,27 & 0,42 & 1,60 & 0,60 & 1,40 & 1,44 & 0,88 \\
\hline 80 & 30 & 16 & 33 & 24 & 78 & 179 & 282 & 32,62 & 53,62 & 74,81 & 0,44 & 1,58 & 0,61 & 1,40 & 1,39 & 0,88 \\
\hline 80 & 20 & 18 & 38 & $27 \mid$ & 74 & 187 & 306 & 30,15 & 53,81 & 78,19 & 0,40 & 1,64 & 0,56 & 1,45 & 1,42 & 0,89 \\
\hline 80 & 25 & 18 & 38 & 27 & 79 & 192 & 311 & 30,77 & 54,38 & 78,76 & 0,41 & 1,62 & 0,57 & 1,45 & 1,38 & 0,89 \\
\hline 80 & 30 & 18 & 38 & 27 & 84 & 197 & 316 & 31,32 & 54,93 & 79,32 & 0,43 & 1,61 & 0,57 & 1,44 & 1,34 & 0,90 \\
\hline 80 & 20 & 20 & 40 & 30 & 80 & 206 & 331 & 28,75 & 55,07 & 80,75 & 0,39 & 1,61 & 0,52 & 1,47 & 1,34 & 0,91 \\
\hline 80 & 25 & 20 & 40 & 30 & 85 & 211 & 336 & 29,41 & 55,66 & 81,33 & 0,40 & 1,60 & 0,53 & 1,46 & 1,31 & 0,92 \\
\hline 00 & 30 & 20 & 40 & $30 \mid$ & 90 & 216 & 341 & 30,00 & 56,23 & 81,90 & 0,42 & 1,58 & 0,53 & 1,46 & 1,28 & 0,92 \\
\hline
\end{tabular}




\begin{tabular}{|c|c|c|c|c|c|c|c|c|c|c|c|c|c|c|c|c|}
\hline $\mathrm{c} 1$ & $\mathrm{c} 2$ & $\mathrm{~d}$ & $\mathrm{p}$ & $\mathrm{a}$ & uo* & $\mathrm{u}^{*}$ & $\mathrm{u}^{\prime *}$ & eo* & $e^{*}$ & $\mathrm{e}^{\prime *}$ & uo*/u* & $\mathrm{u}^{\prime *} * \mathrm{u}^{*}$ & $\mathrm{eo} * / \mathrm{e}^{*}$ & $\mathrm{e}^{\prime *} \mathrm{e}^{*}$ & $\eta_{\mathrm{el}}$ & $\eta_{e}$ \\
\hline 80 & 20 & 22 & 45 & 33 & 86 & 224 & 366 & 27,34 & 56,34 & 85,22 & 0,38 & 1,63 & 0,49 & 1,51 & 1,27 & 0,93 \\
\hline 80 & 25 & 22 & 45 & 33 & 91 & 229 & 371 & 28,03 & 56,94 & 85,81 & 0,40 & 1,62 & 0,49 & 1,51 & 1,24 & 0,93 \\
\hline 80 & 30 & 22 & 45 & 33 & 96 & 234 & 376 & 28,66 & 57,52 & 86,39 & 0,41 & 1,60 & 0,50 & 1,50 & 1,22 & 0,94 \\
\hline 90 & 20 & 12 & 25 & 18 & 56 & 131 & 210 & 39,21 & 54,95 & 71,00 & 0,43 & 1,60 & 0,71 & 1,29 & 1,67 & 0,81 \\
\hline 90 & 25 & 12 & 25 & 18 & 61 & 136 & 215 & \begin{tabular}{|l}
39,69 \\
\end{tabular} & 55,47 & 71,53 & 0,45 & 1,58 & 0,72 & 1,29 & 1,60 & 0,82 \\
\hline 90 & 30 & 12 & 25 & 18 & 66 & 141 & 220 & 40,09 & 55,95 & 72,04 & 0,47 & 1,56 & 0,72 & 1,29 & 1,54 & 0,83 \\
\hline 90 & 20 & 14 & 29 & 21 & 62 & 150 & 241 & 37,89 & 56,25 & 74,85 & 0,41 & 1,61 & 0,67 & 1,33 & 1,63 & 0,83 \\
\hline 90 & 25 & 14 & 29 & 21 & 67 & 155 & 246 & 38,42 & 56,79 & 75,41 & 0,43 & 1,59 & 0,68 & 1,33 & 1,56 & 0,84 \\
\hline 90 & 30 & 14 & 29 & 21 & 72 & 160 & 251 & 38,88 & 57,30 & 75,94 & 0,45 & 1,57 & 0,68 & 1,33 & 1,51 & 0,84 \\
\hline 90 & 20 & 16 & 33 & 24 & 68 & 169 & 272 & 36,53 & 57,53 & 78,70 & 0,40 & 1,62 & 0,63 & 1,37 & 1,57 & 0,85 \\
\hline 90 & 25 & 16 & 33 & 24 & 73 & 174 & 277 & 37,11 & 58,09 & 79,27 & 0,42 & 1,60 & 0,64 & 1,36 & 1,52 & 0,85 \\
\hline 90 & 30 & 16 & 33 & 24 & 78 & 179 & 282 & 37,62 & 58,62 & 79,81 & 0,44 & 1,58 & 0,64 & 1,36 & 1,47 & 0,86 \\
\hline 90 & 20 & 18 & 38 & 27 & 74 & 187 & 306 & 35,15 & 58,81 & 83,19 & 0,40 & 1,64 & 0,60 & 1,41 & 1,51 & 0,86 \\
\hline 90 & 25 & 18 & 38 & 27 & 79 & 192 & 311 & 35,77 & 59,38 & 83,76 & 0,41 & 1,62 & 0,60 & 1,41 & 1,46 & 0,87 \\
\hline 90 & 30 & 18 & 38 & 27 & 84 & 197 & 316 & 36,32 & 59,93 & 84,32 & 0,43 & 1,61 & 0,61 & 1,41 & 1,42 & 0,88 \\
\hline 90 & 20 & 20 & 40 & 30 & 80 & 206 & 331 & 33,75 & 60,07 & 85,75 & 0,39 & 1,61 & 0,56 & 1,43 & 1,44 & 0,89 \\
\hline 90 & 25 & 20 & 40 & 30 & 85 & 211 & 336 & 34,41 & 60,66 & 86,33 & 0,40 & 1,60 & 0,57 & 1,42 & 1,41 & 0,89 \\
\hline 90 & 30 & 20 & 40 & 30 & 90 & 216 & 341 & 35,00 & 61,23 & 86,90 & 0,42 & 1,58 & 0,57 & 1,42 & 1,37 & 0,90 \\
\hline 90 & 20 & 22 & 45 & 33 & 86 & 224 & 366 & 32,34 & 61,34 & 90,22 & 0,38 & 1,63 & 0,53 & 1,47 & 1,37 & 0,90 \\
\hline 90 & 25 & 22 & 45 & 33 & 91 & 229 & 371 & 33,03 & 61,94 & 90,81 & 0,40 & 1,62 & 0,53 & 1,47 & 1,34 & 0,91 \\
\hline 90 & 30 & 22 & 45 & 33 & 96 & 234 & 376 & 33,66 & 62,52 & 91,39 & 0,41 & 1,60 & 0,54 & 1,46 & 1,31 & 0,91 \\
\hline 100 & 20 & 12 & 25 & 18 & 56 & 131 & 210 & 44,21 & 59,95 & 76,00 & 0,43 & 1,60 & 0,74 & 1,27 & 1,73 & 0,79 \\
\hline 100 & 25 & 12 & 25 & 18 & 61 & 136 & 215 & 44,69 & 60,47 & 76,53 & 0,45 & 1,58 & 0,74 & 1,27 & 1,65 & 0,80 \\
\hline 100 & 30 & 12 & 25 & 18 & 66 & 141 & 220 & \begin{tabular}{|l}
45,09 \\
\end{tabular} & 60,95 & 77,04 & 0,47 & 1,56 & 0,74 & 1,26 & 1,59 & 0,81 \\
\hline 100 & 20 & 14 & 29 & 21 & 62 & 150 & 241 & 42,89 & 61,25 & 79,85 & 0,41 & 1,61 & 0,70 & 1,30 & 1,69 & 0,81 \\
\hline 100 & 25 & 14 & 29 & 21 & 67 & 155 & 246 & 43,42 & 61,79 & 80,41 & 0,43 & 1,59 & 0,70 & 1,30 & 1,63 & 0,82 \\
\hline 100 & 30 & 14 & 29 & 21 & 72 & 160 & 251 & 43,88 & 62,30 & 80,94 & 0,45 & 1,57 & 0,70 & 1,30 & 1,56 & 0,83 \\
\hline 100 & 20 & 16 & 33 & 24 & 68 & 169 & 272 & 41,53 & 62,53 & 83,70 & 0,40 & 1,62 & 0,66 & 1,34 & 1,65 & 0,83 \\
\hline 100 & 25 & 16 & 33 & 24 & 73 & 174 & 277 & 42,11 & 63,09 & 84,27 & 0,42 & 1,60 & 0,67 & 1,34 & 1,59 & 0,84 \\
\hline 100 & 30 & 16 & 33 & 24 & 78 & 179 & 282 & 42,62 & 63,62 & 84,81 & 0,44 & 1,58 & 0,67 & 1,33 & 1,53 & 0,84 \\
\hline 100 & 20 & 18 & 38 & 27 & 74 & 187 & 306 & 40,15 & 63,81 & 88,19 & 0,40 & 1,64 & 0,63 & 1,38 & 1,59 & 0,84 \\
\hline 100 & 25 & 18 & 38 & 27 & 79 & 192 & 311 & 40,77 & 64,38 & 88,76 & 0,41 & 1,62 & 0,63 & 1,38 & 1,54 & 0,85 \\
\hline 100 & 30 & 18 & 38 & 27 & 84 & 197 & 316 & \begin{tabular}{|l|}
41,32 \\
\end{tabular} & 64,93 & 89,32 & 0,43 & 1,61 & 0,64 & 1,38 & 1,49 & 0,86 \\
\hline 100 & 20 & 20 & 40 & 30 & 80 & 206 & 331 & 38,75 & 65,07 & 90,75 & 0,39 & 1,61 & 0,60 & 1,39 & 1,53 & 0,87 \\
\hline 100 & 25 & 20 & 40 & 30 & 85 & 211 & 336 & 39,41 & 65,66 & 91,33 & 0,40 & 1,60 & 0,60 & 1,39 & 1,49 & 0,87 \\
\hline 100 & 30 & 20 & 40 & 30 & 90 & 216 & 341 & 40,00 & 66,23 & 91,90 & 0,42 & 1,58 & 0,60 & 1,39 & 1,45 & 0,88 \\
\hline 100 & 20 & 22 & 45 & 33 & 86 & 224 & 366 & 37,34 & 66,34 & 95,22 & 0,38 & 1,63 & 0,56 & 1,44 & 1,47 & 0,88 \\
\hline 100 & 25 & 22 & 45 & 33 & 91 & 229 & 371 & 38,03 & 66,94 & 95,81 & 0,40 & 1,62 & 0,57 & 1,43 & 1,43 & 0,89 \\
\hline 100 & 30 & 22 & 45 & 33 & 96 & 234 & 376 & 38,66 & 67,52 & 96,39 & 0,41 & 1,60 & 0,57 & 1,43 & 1,40 & 0,89 \\
\hline 110 & 25 & 12 & 25 & 18 & 61 & 136 & 215 & 49,69 & 65,47 & 81,53 & 0,45 & 1,58 & 0,76 & 1,25 & 1,70 & 0,79 \\
\hline 110 & 30 & 12 & 25 & 18 & 66 & 141 & 220 & \begin{tabular}{|l}
50,09 \\
\end{tabular} & 65,95 & 82,04 & 0,47 & 1,56 & 0,76 & 1,24 & 1,63 & 0,80 \\
\hline 110 & 25 & 14 & 29 & 21 & 67 & 155 & 246 & 48,42 & 66,79 & 85,41 & 0,43 & 1,59 & 0,72 & 1,28 & 1,68 & 0,81 \\
\hline 110 & 30 & 14 & 29 & 21 & 72 & 160 & 251 & 48,88 & 67,30 & 85,94 & 0,45 & 1,57 & 0,73 & 1,28 & 1,61 & 0,81 \\
\hline 110 & 25 & 16 & 33 & 24 & 73 & 174 & 277 & 47,11 & 68,09 & 89,27 & 0,42 & 1,60 & 0,69 & 1,31 & 1,64 & 0,82 \\
\hline 110 & 30 & 16 & 33 & 24 & 78 & 179 & 282 & 47,62 & 68,62 & 89,81 & 0,44 & 1,58 & 0,69 & 1,31 & 1,59 & 0,83 \\
\hline 110 & 25 & 18 & 38 & 27 & 79 & 192 & 311 & 45,77 & 69,38 & 93,76 & 0,41 & 1,62 & 0,66 & 1,35 & 1,60 & 0,83 \\
\hline 110 & 30 & 18 & 38 & 27 & 84 & 197 & 316 & 46,32 & 69,93 & 94,32 & 0,43 & 1,61 & 0,66 & 1,35 & 1,55 & 0,84 \\
\hline 110 & 25 & 20 & 40 & 30 & 85 & 211 & 336 & 44,41 & 70,66 & 96,33 & 0,40 & 1,60 & 0,63 & 1,36 & 1,56 & 0,85 \\
\hline 110 & 30 & 20 & 40 & 30 & 90 & 216 & 341 & 45,00 & 71,23 & 96,90 & 0,42 & 1,58 & 0,63 & 1,36 & 1,51 & 0,86 \\
\hline 110 & 25 & 22 & 45 & 33 & 91 & 229 & 371 & 43,03 & 71,94 & 100,81 & 0,40 & 1,62 & 0,60 & 1,40 & 1,51 & 0,87 \\
\hline 110 & 30 & 22 & 45 & 33 & 96 & 234 & 376 & 43,66 & 72,52 & 101,39 & 0,41 & 1,60 & 0,60 & 1,40 & 1,47 & 0,87 \\
\hline 120 & 30 & 12 & 25 & 18 & 66 & 141 & 220 & 55,09 & 70,95 & 87,04 & 0,47 & 1,56 & 0,78 & 1,23 & 1,66 & 0,79 \\
\hline 120 & 30 & 14 & 29 & 21 & 72 & 160 & 251 & 53,88 & 72,30 & 90,94 & 0,45 & 1,57 & 0,75 & 1,26 & 1,66 & 0,80 \\
\hline 120 & 30 & 16 & 33 & 24 & 78 & 179 & 282 & 52,62 & 73,62 & 94,81 & 0,44 & 1,58 & 0,71 & 1,29 & 1,64 & 0,81 \\
\hline 120 & 30 & 18 & 38 & 27 & 84 & 197 & 316 & 51,32 & 74,93 & 99,32 & 0,43 & 1,61 & 0,68 & 1,33 & 1,61 & 0,83 \\
\hline
\end{tabular}




\begin{tabular}{|c|c|c|c|c|c|c|c|c|c|c|c|c|c|c|c|c|}
\hline $\mathrm{c} 1$ & c2 & $\mathrm{d}$ & $\mathrm{p}$ & $\mathrm{a}$ & uo* & $\mathrm{u}^{*}$ & $\mathrm{u}^{\prime *}$ & eo* & $e^{*}$ & $\mathrm{e}^{\prime *}$ & uo*/u* & $\mathrm{u}^{\prime *} / \mathrm{u}^{*}$ & eo*/e* & $\mathrm{e}^{\prime *} \mathrm{e}^{*}$ & $\eta_{\mathrm{e} 1}$ & $\eta_{\mathrm{e} 2}$ \\
\hline 120 & 30 & 20 & 40 & 30 & 90 & 216 & 341 & 50,00 & 76,23 & 101,90 & 0,42 & 1,58 & 0,66 & 1,34 & 1,57 & 0,84 \\
\hline 120 & 30 & 22 & 45 & 33 & 96 & 234 & 376 & 48,66 & 77,52 & 106,39 & 0,41 & 1,60 & 0,63 & 1,37 & 1,53 & 0,86 \\
\hline 125 & 25 & 12 & 25 & 28 & 81 & 156 & 235 & 52,82 & 68,69 & 84,82 & 0,52 & 1,50 & 0,77 & 1,23 & 1,48 & 0,82 \\
\hline 125 & 25 & 14 & 29 & 21 & 67 & 155 & 246 & 55,92 & 74,29 & 92,91 & 0,43 & 1,59 & 0,75 & 1,25 & 1,74 & 0,79 \\
\hline 125 & 25 & 16 & 33 & 24 & 73 & 174 & 277 & 54,61 & 75,59 & 96,77 & 0,42 & 1,60 & 0,72 & 1,28 & 1,72 & 0,80 \\
\hline 125 & 25 & 18 & 38 & 27 & 79 & 192 & 311 & 53,27 & 76,88 & 101,26 & 0,41 & 1,62 & 0,69 & 1,32 & 1,68 & 0,81 \\
\hline 125 & 25 & 20 & 40 & 30 & 85 & 211 & 336 & 51,91 & 78,16 & 103,83 & 0,40 & 1,60 & 0,66 & 1,33 & 1,65 & 0,83 \\
\hline 125 & 25 & 22 & 45 & 33 & 91 & 229 & 371 & 50,53 & 79,44 & 108,31 & 0,40 & 1,62 & 0,64 & 1,36 & 1,60 & 0,84 \\
\hline 130 & 30 & 12 & 25 & 18 & 66 & 141 & 220 & 60,09 & 75,95 & 92,04 & 0,47 & 1,56 & 0,79 & 1,21 & 1,70 & 0,78 \\
\hline 130 & 30 & 14 & 29 & 21 & 72 & 160 & 251 & 58,88 & 77,30 & 95,94 & 0,45 & 1,57 & 0,76 & 1,24 & 1,69 & 0,79 \\
\hline 130 & 30 & 16 & 33 & 24 & 78 & 179 & 282 & 57,62 & 78,62 & 99,81 & 0,44 & 1,58 & 0,73 & 1,27 & 1,68 & 0,80 \\
\hline 130 & 30 & 18 & 38 & 27 & 84 & 197 & 316 & 56,32 & 79,93 & 104,32 & 0,43 & 1,61 & 0,70 & 1,31 & 1,65 & 0,81 \\
\hline 130 & 30 & 20 & 40 & 30 & 90 & 216 & 341 & 55,00 & 81,23 & 106,90 & 0,42 & 1,58 & 0,68 & 1,32 & 1,62 & 0,83 \\
\hline 130 & 30 & 22 & 45 & 33 & 96 & 234 & 376 & 53,66 & 82,52 & 111,39 & 0,41 & 1,60 & 0,65 & 1,35 & 1,59 & 0,84 \\
\hline 140 & 30 & 12 & 25 & 18 & 66 & 141 & 220 & 65,09 & 80,95 & 97,04 & 0,47 & 1,56 & 0,80 & 1,20 & 1,72 & 0,77 \\
\hline 140 & 30 & 14 & 29 & 21 & 72 & 160 & 251 & 63,88 & 82,30 & 100,94 & 0,45 & 1,57 & 0,78 & 1,23 & 1,72 & 0,78 \\
\hline 140 & 30 & 16 & 33 & 24 & 78 & 179 & 282 & 62,62 & 83,62 & 104,81 & 0,44 & 1,58 & 0,75 & 1,25 & 1,71 & 0,79 \\
\hline 140 & 30 & 18 & 38 & 27 & 84 & 197 & 316 & 61,32 & 84,93 & 109,32 & 0,43 & 1,61 & 0,72 & 1,29 & 1,69 & 0,80 \\
\hline 140 & 30 & 20 & 40 & 30 & 90 & 216 & 341 & 60,00 & 86,23 & 111,90 & 0,42 & 1,58 & 0,70 & 1,30 & 1,67 & 0,82 \\
\hline 140 & 30 & 22 & 45 & 33 & 96 & 234 & 376 & 58,66 & 87,52 & 116,39 & 0,41 & 1,60 & 0,67 & 1,33 & 1,64 & 0,83 \\
\hline 150 & 30 & 12 & 25 & 18 & 66 & 141 & 220 & 70,09 & 85,95 & 102,04 & 0,47 & 1,56 & 0,82 & 1,19 & 1,75 & 0,76 \\
\hline 150 & 30 & 14 & 29 & 21 & 72 & 160 & 251 & 68,88 & 87,30 & 105,94 & 0,45 & 1,57 & 0,79 & 1,21 & 1,75 & 0,77 \\
\hline 150 & 30 & 16 & 33 & 24 & 78 & 179 & 282 & 67,62 & 88,62 & 109,81 & 0,44 & 1,58 & 0,76 & 1,24 & 1,75 & 0,78 \\
\hline 150 & 30 & 18 & 38 & 27 & 84 & 197 & 316 & 66,32 & 89,93 & 114,32 & 0,43 & 1,61 & 0,74 & 1,27 & 1,73 & 0,79 \\
\hline 150 & 30 & 20 & 40 & 30 & 90 & 216 & 341 & 65,00 & 91,23 & 116,90 & 0,42 & 1,58 & 0,71 & 1,28 & 1,71 & 0,81 \\
\hline 150 & 30 & 22 & 45 & 33 & 96 & 234 & 376 & 63,66 & 92,52 & 121,39 & 0,41 & 1,60 & 0,69 & 1,31 & 1,68 & 0,82 \\
\hline & & & & & & & & & & & & & & média & 1,37 & 0,89 \\
\hline & & & & & & & & & & & & & & desvio & 0,2446 & 0,0683 \\
\hline
\end{tabular}

Tabela B.5 - Valores de $\eta_{\mathrm{e} 1}$ e de $\eta_{\mathrm{e} 2}$ para pilares de canto com $\mathrm{c}_{1} \leq \mathrm{c}_{2}$

\begin{tabular}{|c|c|c|c|c|c|c|c|c|c|c|c|c|c|c|c|c|c|}
\hline c1 & c2 & $\mathrm{d}$ & $\mathrm{p}$ & $\begin{array}{ll}\text { a1 } \\
\end{array}$ & $\mathrm{a} 2$ & uo* & $\mathrm{u}^{*}$ & $\mathrm{u}^{\prime *}$ & eo* & $\mathrm{e}^{*}$ & $\mathrm{e}^{\prime *}$ & uo*/u* & $\mathrm{u}^{\prime} * / \mathrm{u}^{*}$ & eo*/e* & $\mathrm{e}^{\prime *} / \mathrm{e}^{*}$ & $\eta \mathrm{e} 1$ & $\eta \mathrm{e} 2$ \\
\hline 20 & 20 & 12 & 25 & 10 & 10 & 20 & 58 & 97 & 7,50 & 23,28 & 39,30 & 0,35 & 1,68 & 0,32 & 1,69 & 0,93 & 1,00 \\
\hline 20 & 30 & 12 & 25 & 10 & 15 & 25 & 63 & 102 & 8,00 & 24,13 & 40,26 & 0,40 & 1,63 & 0,33 & 1,67 & 0,83 & 1,03 \\
\hline 20 & 40 & 12 & 25 & 10 & 18 & 28 & 66 & 105 & 8,21 & 24,58 & 40,80 & 0,43 & 1,60 & 0,33 & 1,66 & 0,78 & 1,04 \\
\hline 20 & 50 & 12 & 25 & 10 & 18 & 28 & 66 & 105 & 8,21 & 24,58 & 40,80 & 0,43 & 1,60 & 0,33 & 1,66 & 0,78 & 1,04 \\
\hline 20 & 60 & 12 & 25 & 10 & 18 & 28 & 66 & 105 & 8,21 & 24,58 & 40,80 & 0,43 & 1,60 & 0,33 & 1,66 & 0,78 & 1,04 \\
\hline 20 & 70 & 12 & 25 & 10 & 18 & 28 & 66 & 105 & 8,21 & 24,58 & 40,80 & 0,43 & 1,60 & 0,33 & 1,66 & 0,78 & 1,04 \\
\hline 20 & 80 & 12 & 25 & 10 & 18 & 28 & 66 & 105 & 8,21 & 24,58 & 40,80 & 0,43 & 1,60 & 0,33 & 1,66 & 0,78 & 1,04 \\
\hline 20 & 90 & 12 & 25 & 10 & 18 & 28 & 66 & 105 & 8,21 & 24,58 & 40,80 & 0,43 & 1,60 & 0,33 & 1,66 & 0,78 & 1,04 \\
\hline 20 & 100 & 12 & 25 & 10 & 18 & 28 & 66 & 105 & 8,21 & 24,58 & 40,80 & 0,43 & 1,60 & 0,33 & 1,66 & 0,78 & 1,04 \\
\hline 20 & 20 & 14 & 29 & 10 & 10 & 20 & 64 & 110 & 7,50 & 25,85 & 44,41 & 0,31 & 1,71 & 0,29 & 1,72 & 0,93 & 1,00 \\
\hline 20 & 30 & 14 & 29 & 10 & 15 & 25 & 69 & 115 & 8,00 & 26,73 & 45,40 & 0,36 & 1,66 & 0,30 & 1,70 & 0,83 & 1,02 \\
\hline 20 & 40 & 14 & 29 & 10 & 20 & 30 & 74 & 120 & 8,33 & 27,49 & 46,30 & 0,41 & 1,62 & 0,30 & 1,68 & 0,75 & 1,04 \\
\hline 20 & 50 & 14 & 29 & 10 & 21 & 31 & 75 & 121 & 8,39 & 27,63 & 46,47 & 0,41 & 1,61 & 0,30 & 1,68 & 0,73 & 1,05 \\
\hline 20 & 60 & 14 & 29 & 10 & 21 & 31 & 75 & 121 & 8,39 & 27,63 & 46,47 & 0,41 & 1,61 & 0,30 & 1,68 & 0,73 & 1,05 \\
\hline 20 & 70 & 14 & 29 & 10 & 21 & 31 & 75 & 121 & 8,39 & 27,63 & 46,47 & 0,41 & 1,61 & 0,30 & 1,68 & 0,73 & 1,05 \\
\hline 20 & 80 & 14 & 29 & 10 & 21 & 31 & 75 & 121 & 8,39 & 27,63 & 46,47 & 0,41 & 1,61 & 0,30 & 1,68 & 0,73 & 1,05 \\
\hline 20 & 90 & 14 & 29 & 10 & 21 & 31 & 75 & 121 & 8,39 & 27,63 & 46,47 & 0,41 & 1,61 & 0,30 & 1,68 & 0,73 & 1,05 \\
\hline 20 & 100 & 14 & 29 & 10 & 21 & 31 & 75 & 121 & 8,39 & 27,63 & 46,47 & 0,41 & 1,61 & 0,30 & 1,68 & 0,73 & 1,05 \\
\hline 20 & 20 & 16 & 33 & 10 & 10 & 20 & 70 & 122 & 7,50 & 28,42 & 49,52 & 0,28 & 1,74 & 0,26 & 1,74 & 0,93 & 1,00 \\
\hline 20 & 30 & 16 & 33 & 10 & 15 & 25 & 75 & 127 & 8,00 & 29,32 & 50,52 & 0,33 & 1,69 & 0,27 & 1,72 & 0,82 & 1,02 \\
\hline 20 & 40 & 16 & 33 & 10 & 20 & 30 & 80 & 132 & 8,33 & 30,11 & 51,45 & 0,37 & 1,65 & 0,28 & 1,71 & 0,74 & 1,04 \\
\hline 20 & 50 & 16 & 33 & 10 & 24 & 34 & 84 & 136 & 8,53 & 30,67 & 52,14 & 0,40 & 1,62 & 0,28 & 1,70 & 0,69 & 1,05 \\
\hline
\end{tabular}




\begin{tabular}{|c|c|c|c|c|c|c|c|c|c|c|c|c|c|c|c|c|c|}
\hline $\mathrm{c} 1$ & $\mathrm{c} 2$ & $\mathrm{~d}$ & $\mathrm{p}$ & al & a2 & uo* & $\mathrm{u}^{*}$ & $\mathrm{u}^{\prime *}$ & eo* & $\mathrm{e}^{*}$ & $\mathrm{e}^{\prime *}$ & uo*/u* & $\mathrm{u}^{\prime *} / \mathrm{u}^{*}$ & eo*/e* & $\mathrm{e}^{\prime *} / \mathrm{e}^{*}$ & $\eta \mathrm{e} 1$ & $\eta \mathrm{e} 2$ \\
\hline 20 & 60 & 16 & 33 & 10 & 24 & 34 & 84 & 136 & 8,53 & 30,67 & 52,14 & 0,40 & 1,62 & 0,28 & 1,70 & 0,69 & 1,05 \\
\hline 20 & 70 & 16 & 33 & 10 & 24 & 34 & 84 & 136 & 8,53 & 30,67 & 52,14 & 0,40 & 1,62 & 0,28 & 1,70 & 0,69 & 1,05 \\
\hline 20 & 80 & 16 & 33 & 10 & 24 & 34 & 84 & 136 & 8,53 & 30,67 & 52,14 & 0,40 & 1,62 & 0,28 & 1,70 & 0,69 & 1,05 \\
\hline 20 & 90 & 16 & 33 & 10 & 24 & 34 & 84 & 136 & 8,53 & 30,67 & 52,14 & 0,40 & 1,62 & 0,28 & 1,70 & 0,69 & 1,05 \\
\hline 20 & 100 & 16 & 33 & 10 & 24 & 34 & 84 & 136 & 8,53 & 30,67 & 52,14 & 0,40 & 1,62 & 0,28 & 1,70 & 0,69 & 1,05 \\
\hline 20 & 20 & 18 & 38 & 10 & 10 & 20 & 77 & 136 & 7,50 & 30,98 & 55,26 & 0,26 & 1,78 & 0,24 & 1,78 & 0,93 & 1,00 \\
\hline 20 & 30 & 18 & 38 & 10 & 15 & 25 & 82 & 141 & 8,00 & 31,90 & 56,28 & 0,31 & 1,73 & 0,25 & 1,76 & 0,82 & 1,02 \\
\hline 20 & 40 & 18 & 38 & 10 & 20 & 30 & 87 & 146 & 8,33 & 32,72 & 57,22 & 0,35 & 1,69 & 0,25 & 1,75 & 0,73 & 1,04 \\
\hline 20 & 50 & 18 & 38 & 10 & 25 & 35 & 92 & 151 & 8,57 & 33,44 & 58,11 & 0,38 & 1,65 & 0,26 & 1,74 & 0,67 & 1,05 \\
\hline 20 & 60 & 18 & 38 & 10 & 27 & 37 & 94 & 153 & 8,65 & 33,71 & 58,45 & 0,40 & 1,64 & 0,26 & 1,73 & 0,65 & 1,06 \\
\hline 20 & 70 & 18 & 38 & 10 & 27 & 37 & 94 & 153 & 8,65 & 33,71 & 58,45 & 0,40 & 1,64 & 0,26 & 1,73 & 0,65 & 1,06 \\
\hline 20 & 80 & 18 & 38 & 10 & 27 & 37 & 94 & 153 & 8,65 & 33,71 & 58,45 & 0,40 & 1,64 & 0,26 & 1,73 & 0,65 & 1,06 \\
\hline 20 & 90 & 18 & 38 & 10 & 27 & 37 & 94 & 153 & 8,65 & 33,71 & 58,45 & 0,40 & 1,64 & 0,26 & 1,73 & 0,65 & 1,06 \\
\hline 20 & 100 & 18 & 38 & 10 & 27 & 37 & 94 & 153 & 8,65 & 33,71 & 58,45 & 0,40 & 1,64 & 0,26 & 1,73 & 0,65 & 1,06 \\
\hline 20 & 20 & 20 & 40 & 10 & 10 & 20 & 83 & 146 & 7,50 & 33,54 & 59,09 & 0,24 & 1,76 & 0,22 & 1,76 & 0,93 & 1,00 \\
\hline 20 & 30 & 20 & 40 & 10 & 15 & 25 & 88 & 151 & 8,00 & 34,48 & 60,11 & 0,28 & 1,72 & 0,23 & 1,74 & 0,82 & 1,02 \\
\hline 20 & 40 & 20 & 40 & 10 & 20 & 30 & 93 & 156 & 8,33 & 35,31 & 61,07 & 0,32 & 1,68 & 0,24 & 1,73 & 0,73 & 1,03 \\
\hline 20 & 50 & 20 & 40 & 10 & 25 & 35 & 98 & 161 & 8,57 & 36,07 & 61,97 & 0,36 & 1,64 & 0,24 & 1,72 & 0,66 & 1,05 \\
\hline 20 & 60 & 20 & 40 & 10 & 30 & 40 & 103 & 166 & 8,75 & 36,74 & 62,82 & 0,39 & 1,61 & 0,24 & 1,71 & 0,61 & 1,06 \\
\hline 20 & 70 & 20 & 40 & 10 & 30 & 40 & 103 & 166 & 8,75 & 36,74 & 62,82 & 0,39 & 1,61 & 0,24 & 1,71 & 0,61 & 1,06 \\
\hline 20 & 80 & 20 & 40 & 10 & 30 & 40 & 103 & 166 & 8,75 & 36,74 & 62,82 & 0,39 & 1,61 & 0,24 & 1,71 & 0,61 & 1,06 \\
\hline 20 & 90 & 20 & 40 & 10 & 30 & 40 & 103 & 166 & 8,75 & 36,74 & 62,82 & 0,39 & 1,61 & 0,24 & 1,71 & 0,61 & 1,06 \\
\hline 20 & 100 & 20 & 40 & 10 & 30 & 40 & 103 & 166 & 8,75 & 36,74 & 62,82 & 0,39 & 1,61 & 0,24 & 1,71 & 0,61 & 1,06 \\
\hline 20 & 20 & 22 & 45 & 18 & 10 & 28 & 97 & 168 & 4,21 & 32,80 & 61,54 & 0,29 & 1,73 & 0,13 & 1,88 & 0,45 & 1,09 \\
\hline 20 & 30 & 22 & 45 & 18 & 15 & 33 & 102 & 173 & 5,09 & 33,84 & 62,63 & 0,32 & 1,69 & 0,15 & 1,85 & 0,47 & 1,09 \\
\hline 20 & 40 & 22 & 45 & 18 & 20 & 38 & 107 & 178 & 5,74 & 34,78 & 63,65 & 0,35 & 1,66 & 0,16 & 1,83 & 0,46 & 1,10 \\
\hline 20 & 50 & 22 & 45 & 18 & 25 & 43 & 112 & 183 & 6,23 & 35,63 & 64,62 & 0,38 & 1,63 & 0,17 & 1,81 & 0,46 & 1,11 \\
\hline 20 & 60 & 22 & 45 & 18 & 30 & 48 & 117 & 188 & 6,63 & 36,42 & 65,53 & 0,41 & 1,60 & 0,18 & 1,80 & 0,44 & 1,12 \\
\hline 20 & 70 & 22 & 45 & 18 & 33 & 51 & 120 & 191 & 6,82 & 36,86 & 66,06 & 0,42 & 1,59 & 0,19 & 1,79 & 0,44 & 1,13 \\
\hline 20 & 80 & 22 & 45 & 18 & 33 & 51 & 120 & 191 & 6,82 & 36,86 & 66,06 & 0,42 & 1,59 & 0,19 & 1,79 & 0,44 & 1,13 \\
\hline 20 & 90 & \begin{tabular}{|l|} 
\\
\end{tabular} & 45 & 18 & 33 & 51 & 120 & 191 & 6,82 & 36,86 & 66,06 & 0,42 & 1,59 & 0,19 & 1,79 & 0,44 & 1,13 \\
\hline 20 & 100 & $22 \mid$ & 45 & 18 & 33 & 51 & 120 & 191 & 6,82 & 36,86 & 66,06 & 0,42 & 1,59 & 0,19 & 1,79 & 0,44 & 1,13 \\
\hline 25 & 40 & 12 & 25 & 13 & 18 & 31 & 68 & 107 & 9,94 & 26,13 & 42,32 & 0,45 & 1,58 & 0,38 & 1,62 & 0,85 & 1,03 \\
\hline 25 & 50 & 12 & 25 & 13 & 18 & 31 & 68 & 107 & 9,94 & 26,13 & 42,32 & 0,45 & 1,58 & 0,38 & 1,62 & 0,85 & 1,03 \\
\hline 25 & 60 & 12 & 25 & 13 & 18 & 31 & 68 & 107 & 9,94 & 26,13 & 42,32 & 0,45 & 1,58 & 0,38 & 1,62 & 0,85 & 1,03 \\
\hline 25 & 75 & 12 & 25 & 13 & 18 & 31 & 68 & 107 & 9,94 & 26,13 & 42,32 & 0,45 & 1,58 & 0,38 & 1,62 & 0,85 & 1,03 \\
\hline 25 & 80 & 12 & 25 & 13 & 18 & 31 & 68 & 107 & 9,94 & 26,13 & 42,32 & 0,45 & 1,58 & 0,38 & 1,62 & 0,85 & 1,03 \\
\hline 25 & 90 & 12 & 25 & 13 & 18 & 31 & 68 & 107 & 9,94 & 26,13 & 42,32 & 0,45 & 1,58 & 0,38 & 1,62 & 0,85 & 1,03 \\
\hline 25 & 100 & 12 & 25 & 13 & 18 & 31 & 68 & 107 & 9,94 & 26,13 & 42,32 & 0,45 & 1,58 & 0,38 & 1,62 & 0,85 & 1,03 \\
\hline 25 & 110 & 12 & 25 & 13 & 18 & 31 & 68 & 107 & 9,94 & 26,13 & 42,32 & 0,45 & 1,58 & 0,38 & 1,62 & 0,85 & 1,03 \\
\hline 25 & 125 & 12 & 25 & 13 & 18 & 31 & 68 & 107 & 9,94 & 26,13 & 42,32 & 0,45 & 1,58 & 0,38 & 1,62 & 0,85 & 1,03 \\
\hline 25 & 40 & 14 & 29 & 13 & 20 & 33 & 76 & 122 & 10,10 & 29,05 & 47,82 & 0,42 & 1,60 & 0,35 & 1,65 & 0,82 & 1,03 \\
\hline 25 & 50 & 14 & 29 & 13 & 21 & 34 & 77 & 123 & 10,17 & 29,20 & 48,00 & 0,43 & 1,59 & 0,35 & 1,64 & 0,81 & 1,04 \\
\hline 25 & 60 & 14 & 29 & 13 & 21 & 34 & 77 & 123 & 10,17 & 29,20 & 48,00 & 0,43 & 1,59 & 0,35 & 1,64 & 0,81 & 1,04 \\
\hline 25 & 75 & 14 & 29 & 13 & 21 & 34 & 77 & 123 & 10,17 & 29,20 & 48,00 & 0,43 & 1,59 & 0,35 & 1,64 & 0,81 & 1,04 \\
\hline 25 & 80 & 14 & 29 & 13 & 21 & 34 & 77 & 123 & 10,17 & 29,20 & 48,00 & 0,43 & 1,59 & 0,35 & 1,64 & 0,81 & 1,04 \\
\hline 25 & 90 & 14 & 29 & 13 & 21 & 34 & 77 & 123 & 10,17 & 29,20 & 48,00 & 0,43 & 1,59 & 0,35 & 1,64 & 0,81 & 1,04 \\
\hline 25 & 100 & 14 & 29 & 13 & 21 & 34 & 77 & 123 & 10,17 & 29,20 & 48,00 & 0,43 & 1,59 & 0,35 & 1,64 & 0,81 & 1,04 \\
\hline 25 & 110 & 14 & 29 & 13 & 21 & 34 & 77 & 123 & 10,17 & 29,20 & 48,00 & 0,43 & 1,59 & 0,35 & 1,64 & 0,81 & 1,04 \\
\hline 25 & 125 & 14 & 29 & 13 & 21 & 34 & 77 & 123 & 10,17 & 29,20 & 48,00 & 0,43 & 1,59 & 0,35 & 1,64 & 0,81 & 1,04 \\
\hline 25 & 40 & 16 & 33 & 13 & 20 & 33 & 83 & 135 & 10,10 & 31,66 & 52,97 & 0,39 & 1,63 & 0,32 & 1,67 & 0,81 & 1,03 \\
\hline 25 & 50 & 16 & 33 & 13 & 24 & 37 & 87 & 139 & 10,36 & 32,25 & 53,67 & 0,42 & 1,60 & 0,32 & 1,66 & 0,76 & 1,04 \\
\hline 25 & 60 & 16 & \begin{tabular}{|l|}
33 \\
\end{tabular} & 13 & 24 & 37 & 87 & 139 & 10,36 & 32,25 & 53,67 & 0,42 & 1,60 & 0,32 & 1,66 & 0,76 & 1,04 \\
\hline 25 & 75 & 16 & 33 & 13 & 24 & 37 & 87 & 139 & 10,36 & 32,25 & 53,67 & 0,42 & 1,60 & 0,32 & 1,66 & 0,76 & 1,04 \\
\hline 25 & 80 & 16 & 33 & 13 & 24 & 37 & 87 & 139 & 10,36 & 32,25 & 53,67 & 0,42 & 1,60 & 0,32 & 1,66 & 0,76 & 1,04 \\
\hline
\end{tabular}




\begin{tabular}{|c|c|c|c|c|c|c|c|c|c|c|c|c|c|c|c|c|c|}
\hline $\mathrm{c} 1$ & c2 & $\mathrm{d}$ & $\mathrm{p}$ & a1 & a2 & uo* & $\mathrm{u}^{*}$ & $\mathrm{u}^{\prime *}$ & eo* & $\mathrm{e}^{*}$ & $\mathrm{e}^{\prime *}$ & uo*/u* & $\mathrm{u}^{\prime} * / \mathrm{u}^{*}$ & eo*/e* & $\mathrm{e}^{\prime *} / \mathrm{e}^{*}$ & $\eta \mathrm{e} 1$ & $\eta \mathrm{e} 2$ \\
\hline 25 & 90 & 16 & 33 & 13 & 24 & 37 & 87 & 139 & 10,36 & 32,25 & 53,67 & 0,42 & 1,60 & 0,32 & 1,66 & 0,76 & 1,04 \\
\hline 25 & \begin{tabular}{|l|}
100 \\
\end{tabular} & 16 & 33 & 13 & 24 & 37 & 87 & 139 & 10,36 & 32,25 & 53,67 & 0,42 & 1,60 & 0,32 & 1,66 & 0,76 & 1,04 \\
\hline 25 & \begin{tabular}{|l|}
110 \\
\end{tabular} & 16 & 33 & 13 & 24 & 37 & 87 & 139 & 10,36 & 32,25 & 53,67 & 0,42 & 1,60 & 0,32 & 1,66 & 0,76 & 1,04 \\
\hline 25 & 125 & 16 & 33 & 13 & 24 & 37 & 87 & 139 & 10,36 & 32,25 & 53,67 & 0,42 & 1,60 & 0,32 & 1,66 & 0,76 & 1,04 \\
\hline 25 & 40 & 18 & 38 & 13 & 20 & 33 & 89 & 149 & 10,10 & 34,26 & 58,74 & 0,36 & 1,67 & 0,29 & 1,71 & 0,81 & 1,03 \\
\hline 25 & 50 & 18 & 38 & 13 & 25 & 38 & 94 & 154 & 10,42 & 35,02 & 59,64 & 0,40 & 1,63 & 0,30 & 1,70 & 0,75 & 1,04 \\
\hline 25 & 60 & 18 & 38 & 13 & 27 & 40 & 96 & 156 & 10,52 & 35,30 & 59,99 & 0,41 & 1,62 & 0,30 & 1,70 & 0,72 & 1,05 \\
\hline 25 & 75 & 18 & 38 & 13 & 27 & 40 & 96 & 156 & 10,52 & 35,30 & 59,99 & 0,41 & 1,62 & 0,30 & 1,70 & 0,72 & 1,05 \\
\hline 25 & 80 & 18 & 38 & 13 & 27 & 40 & 96 & 156 & 10,52 & 35,30 & 59,99 & 0,41 & 1,62 & 0,30 & 1,70 & 0,72 & 1,05 \\
\hline 25 & 90 & 18 & 38 & 13 & 27 & 40 & 96 & 156 & 10,52 & 35,30 & 59,99 & 0,41 & 1,62 & 0,30 & 1,70 & 0,72 & 1,05 \\
\hline 25 & 100 & 18 & 38 & 13 & 27 & 40 & 96 & 156 & 10,52 & 35,30 & 59,99 & 0,41 & 1,62 & 0,30 & 1,70 & 0,72 & 1,05 \\
\hline 25 & 110 & 18 & 38 & 13 & 27 & 40 & 96 & 156 & 10,52 & 35,30 & 59,99 & 0,41 & 1,62 & 0,30 & 1,70 & 0,72 & 1,05 \\
\hline 25 & 125 & 18 & 38 & 13 & 27 & 40 & 96 & 156 & 10,52 & 35,30 & 59,99 & 0,41 & 1,62 & 0,30 & 1,70 & 0,72 & 1,05 \\
\hline 25 & 40 & 20 & 40 & 13 & 20 & 33 & 95 & 158 & 10,10 & 36,86 & 62,59 & 0,34 & 1,66 & 0,27 & 1,70 & 0,80 & 1,02 \\
\hline 25 & 50 & 20 & 40 & 13 & 25 & 38 & 100 & 163 & 10,42 & 37,64 & 63,50 & 0,37 & 1,63 & 0,28 & 1,69 & 0,74 & 1,04 \\
\hline 25 & 60 & 20 & 40 & 13 & 30 & 43 & 105 & 168 & 10,66 & 38,34 & 64,37 & 0,40 & 1,60 & 0,28 & 1,68 & 0,69 & 1,05 \\
\hline 25 & 75 & 20 & 40 & 13 & 30 & 43 & 105 & 168 & 10,66 & 38,34 & 64,37 & 0,40 & 1,60 & 0,28 & 1,68 & 0,69 & 1,05 \\
\hline 25 & 80 & 20 & 40 & 13 & 30 & 43 & 105 & 168 & 10,66 & 38,34 & 64,37 & 0,40 & 1,60 & 0,28 & 1,68 & 0,69 & 1,05 \\
\hline 25 & 90 & 20 & 40 & 13 & 30 & 43 & 105 & 168 & 10,66 & 38,34 & 64,37 & 0,40 & 1,60 & 0,28 & 1,68 & 0,69 & 1,05 \\
\hline 25 & 100 & 20 & 40 & 13 & 30 & 43 & 105 & 168 & 10,66 & 38,34 & 64,37 & 0,40 & 1,60 & 0,28 & 1,68 & 0,69 & 1,05 \\
\hline 25 & 110 & 20 & 40 & 13 & 30 & 43 & 105 & 168 & 10,66 & 38,34 & 64,37 & 0,40 & 1,60 & 0,28 & 1,68 & 0,69 & 1,05 \\
\hline 25 & 125 & 20 & 40 & 13 & 30 & 43 & 105 & 168 & 10,66 & 38,34 & 64,37 & 0,40 & 1,60 & 0,28 & 1,68 & 0,69 & 1,05 \\
\hline 25 & 40 & 22 & 45 & 13 & 20 & 33 & 102 & 172 & 10,10 & 39,44 & 68,35 & 0,32 & 1,70 & 0,26 & 1,73 & 0,80 & 1,02 \\
\hline 25 & 50 & 22 & 45 & 13 & 25 & 38 & 107 & 177 & 10,42 & 40,24 & 69,28 & 0,35 & 1,66 & 0,26 & 1,72 & 0,74 & 1,04 \\
\hline 25 & 60 & 22 & 45 & 13 & 30 & 43 & 112 & 182 & 10,66 & 40,97 & 70,17 & 0,38 & 1,63 & 0,26 & 1,71 & 0,68 & 1,05 \\
\hline 25 & 75 & 22 & 45 & 13 & 33 & 46 & 115 & 185 & 10,78 & 41,38 & 70,67 & 0,40 & 1,62 & 0,26 & 1,71 & 0,66 & 1,06 \\
\hline 25 & 80 & 22 & 45 & 13 & 33 & 46 & 115 & 185 & 10,78 & 41,38 & 70,67 & 0,40 & 1,62 & 0,26 & 1,71 & 0,66 & 1,06 \\
\hline 25 & 90 & 22 & 45 & 13 & 33 & 46 & 115 & 185 & 10,78 & 41,38 & 70,67 & 0,40 & 1,62 & 0,26 & 1,71 & 0,66 & 1,06 \\
\hline 25 & 100 & 22 & 45 & 13 & 33 & 46 & 115 & 185 & 10,78 & 41,38 & 70,67 & 0,40 & 1,62 & 0,26 & 1,71 & 0,66 & 1,06 \\
\hline 25 & 110 & 22 & 45 & 13 & 33 & 46 & 115 & 185 & 10,78 & 41,38 & 70,67 & 0,40 & 1,62 & 0,26 & 1,71 & 0,66 & 1,06 \\
\hline 25 & 125 & 22 & 45 & 13 & 33 & 46 & 115 & 185 & 10,78 & 41,38 & 70,67 & 0,40 & 1,62 & 0,26 & 1,71 & 0,66 & 1,06 \\
\hline 30 & 30 & 12 & 25 & 15 & 15 & 30 & 68 & 107 & 11,25 & 27,16 & 43,27 & 0,44 & 1,58 & 0,41 & 1,59 & 0,93 & 1,01 \\
\hline 30 & 40 & 12 & 25 & 15 & 18 & 33 & 71 & 110 & 11,59 & 27,67 & 43,83 & 0,47 & 1,56 & 0,42 & 1,58 & 0,90 & 1,02 \\
\hline 30 & 50 & 12 & 25 & 15 & 18 & 33 & 71 & 110 & 11,59 & 27,67 & 43,83 & 0,47 & 1,56 & 0,42 & 1,58 & 0,90 & 1,02 \\
\hline 30 & 60 & 12 & 25 & 15 & 18 & 33 & 71 & 110 & 11,59 & 27,67 & 43,83 & 0,47 & 1,56 & 0,42 & 1,58 & 0,90 & 1,02 \\
\hline 30 & 70 & 12 & 25 & 15 & 18 & 33 & 71 & 110 & 11,59 & 27,67 & 43,83 & 0,47 & 1,56 & 0,42 & 1,58 & 0,90 & 1,02 \\
\hline 30 & 80 & 12 & 25 & 15 & 18 & 33 & 71 & 110 & 11,59 & 27,67 & 43,83 & 0,47 & 1,56 & 0,42 & 1,58 & 0,90 & 1,02 \\
\hline 30 & 90 & 12 & 25 & 15 & 18 & 33 & 71 & 110 & 11,59 & 27,67 & 43,83 & 0,47 & 1,56 & 0,42 & 1,58 & 0,90 & 1,02 \\
\hline 30 & 100 & 12 & 25 & 15 & 18 & 33 & 71 & 110 & 11,59 & 27,67 & 43,83 & 0,47 & 1,56 & 0,42 & 1,58 & 0,90 & 1,02 \\
\hline 30 & 110 & 12 & 25 & 15 & 18 & 33 & 71 & 110 & 11,59 & 27,67 & 43,83 & 0,47 & 1,56 & 0,42 & 1,58 & 0,90 & 1,02 \\
\hline 30 & 120 & 12 & 25 & 15 & 18 & 33 & 71 & 110 & 11,59 & 27,67 & 43,83 & 0,47 & 1,56 & 0,42 & 1,58 & 0,90 & 1,02 \\
\hline 30 & 130 & 12 & 25 & 15 & 18 & 33 & 71 & 110 & 11,59 & 27,67 & 43,83 & 0,47 & 1,56 & 0,42 & 1,58 & 0,90 & 1,02 \\
\hline 30 & 140 & 12 & 25 & 15 & 18 & 33 & 71 & 110 & 11,59 & 27,67 & 43,83 & 0,47 & 1,56 & 0,42 & 1,58 & 0,90 & 1,02 \\
\hline 30 & 150 & 12 & 25 & 15 & 18 & 33 & 71 & 110 & 11,59 & 27,67 & 43,83 & 0,47 & 1,56 & 0,42 & 1,58 & 0,90 & 1,02 \\
\hline 30 & 30 & 14 & 29 & 15 & 15 & 30 & 74 & 120 & 11,25 & 29,75 & 48,39 & 0,41 & 1,62 & 0,38 & 1,63 & 0,93 & 1,01 \\
\hline 30 & 40 & 14 & 29 & 15 & 20 & 35 & 79 & 125 & 11,79 & 30,59 & 49,34 & 0,44 & 1,58 & 0,39 & 1,61 & 0,87 & 1,02 \\
\hline 30 & 50 & 14 & 29 & 15 & 21 & 36 & 80 & 126 & 11,88 & 30,75 & 49,52 & 0,45 & 1,57 & 0,39 & 1,61 & 0,86 & 1,03 \\
\hline 30 & 60 & 14 & 29 & 15 & 21 & 36 & 80 & 126 & 11,88 & 30,75 & 49,52 & 0,45 & 1,57 & 0,39 & 1,61 & 0,86 & 1,03 \\
\hline 30 & 70 & 14 & 29 & 15 & 21 & 36 & 80 & 126 & 11,88 & 30,75 & 49,52 & 0,45 & 1,57 & 0,39 & 1,61 & 0,86 & 1,03 \\
\hline 30 & 80 & 14 & 29 & 15 & 21 & 36 & 80 & 126 & 11,88 & 30,75 & 49,52 & 0,45 & 1,57 & 0,39 & 1,61 & 0,86 & 1,03 \\
\hline 30 & 90 & 14 & 29 & 15 & 21 & 36 & 80 & 126 & 11,88 & 30,75 & 49,52 & 0,45 & 1,57 & 0,39 & 1,61 & 0,86 & 1,03 \\
\hline 30 & 100 & 14 & 29 & 15 & 21 & 36 & 80 & 126 & 11,88 & 30,75 & 49,52 & 0,45 & 1,57 & 0,39 & 1,61 & 0,86 & 1,03 \\
\hline 30 & 110 & 14 & 29 & 15 & 21 & 36 & 80 & 126 & 11,88 & 30,75 & 49,52 & 0,45 & 1,57 & 0,39 & 1,61 & 0,86 & 1,03 \\
\hline 30 & 120 & 14 & 29 & 15 & 21 & 36 & 80 & 126 & 11,88 & 30,75 & 49,52 & 0,45 & 1,57 & 0,39 & 1,61 & 0,86 & 1,03 \\
\hline 00 & 130 & 14 & 29 & 15 & 21 & 36 & 80 & 126 & 11,88 & 30,75 & 49,52 & 0,45 & 1,57 & 0,39 & 1,61 & 0,86 & 1,03 \\
\hline
\end{tabular}




\begin{tabular}{|c|c|c|c|c|c|c|c|c|c|c|c|c|c|c|c|c|c|}
\hline c1 & $\mathrm{c} 2$ & $\mathrm{~d}$ & $\mathrm{p}$ & a1 & a2 & uo* & $\mathrm{u}^{*}$ & $\mathrm{u}^{\prime *}$ & eo* & $\mathrm{e}^{*}$ & $\mathrm{e}^{\prime *}$ & uo*/u* & $\mathrm{u}^{\prime *} / \mathrm{u}^{*}$ & eo*/e* & $\mathrm{e}^{\prime * / \mathrm{e}^{*}}$ & $\eta \mathrm{e} 1$ & $\eta \mathrm{e} 2$ \\
\hline 30 & 140 & 14 & 29 & 15 & 21 & 36 & 80 & 126 & 11,88 & 30,75 & 49,52 & 0,45 & 1,57 & 0,39 & 1,61 & 0,86 & 1,03 \\
\hline 30 & 150 & 14 & 29 & 15 & 21 & 36 & 80 & 126 & 11,88 & 30,75 & 49,52 & 0,45 & 1,57 & 0,39 & 1,61 & 0,86 & 1,03 \\
\hline 30 & 30 & 16 & 33 & 15 & 15 & 30 & 80 & 132 & 11,25 & 32,34 & 53,51 & 0,37 & 1,65 & 0,35 & 1,65 & 0,93 & 1,01 \\
\hline 30 & 40 & 16 & 33 & 15 & 20 & 35 & 85 & 137 & 11,79 & 33,20 & 54,48 & 0,41 & 1,61 & 0,36 & 1,64 & 0,86 & 1,02 \\
\hline 30 & 50 & 16 & 33 & 15 & 24 & 39 & 89 & 141 & 12,12 & 33,81 & 55,20 & 0,44 & 1,58 & 0,36 & 1,63 & 0,82 & 1,03 \\
\hline 30 & 60 & 16 & 33 & 15 & 24 & 39 & 89 & 141 & 12,12 & 33,81 & 55,20 & 0,44 & 1,58 & 0,36 & 1,63 & 0,82 & 1,03 \\
\hline 30 & 70 & 16 & 33 & 15 & 24 & 39 & 89 & 141 & 12,12 & 33,81 & 55,20 & 0,44 & 1,58 & 0,36 & 1,63 & 0,82 & 1,03 \\
\hline 30 & 80 & 16 & 33 & 15 & 24 & 39 & 89 & 141 & 12,12 & 33,81 & 55,20 & 0,44 & 1,58 & 0,36 & 1,63 & 0,82 & 1,03 \\
\hline 30 & 90 & 16 & 33 & 15 & 24 & 39 & 89 & 141 & 12,12 & 33,81 & 55,20 & 0,44 & 1,58 & 0,36 & 1,63 & 0,82 & 1,03 \\
\hline 30 & 100 & 16 & 33 & 15 & 24 & 39 & 89 & 141 & 12,12 & 33,81 & 55,20 & 0,44 & 1,58 & 0,36 & 1,63 & 0,82 & 1,03 \\
\hline 30 & 110 & 16 & 33 & 15 & 24 & 39 & 89 & 141 & 12,12 & 33,81 & 55,20 & 0,44 & 1,58 & 0,36 & 1,63 & 0,82 & 1,03 \\
\hline 30 & 120 & 16 & 33 & 15 & 24 & 39 & 89 & 141 & 12,12 & 33,81 & 55,20 & 0,44 & 1,58 & 0,36 & 1,63 & 0,82 & 1,03 \\
\hline 30 & 130 & 16 & 33 & 15 & 24 & 39 & 89 & 141 & 12,12 & 33,81 & 55,20 & 0,44 & 1,58 & 0,36 & 1,63 & 0,82 & 1,03 \\
\hline 30 & 140 & 16 & 33 & 15 & 24 & 39 & 89 & 141 & 12,12 & 33,81 & 55,20 & 0,44 & 1,58 & 0,36 & 1,63 & 0,82 & 1,03 \\
\hline 30 & 150 & 16 & 33 & 15 & 24 & 39 & 89 & 141 & 12,12 & 33,81 & 55,20 & 0,44 & 1,58 & 0,36 & 1,63 & 0,82 & 1,03 \\
\hline 30 & 30 & 18 & 38 & 15 & 15 & 30 & 87 & 146 & 11,25 & 34,91 & 59,27 & 0,35 & 1,69 & 0,32 & 1,70 & 0,93 & 1,00 \\
\hline 30 & 40 & 18 & 38 & 15 & 20 & 35 & 92 & 151 & 11,79 & 35,79 & 60,25 & 0,38 & 1,65 & 0,33 & 1,68 & 0,86 & 1,02 \\
\hline 30 & 50 & 18 & 38 & 15 & 25 & 40 & 97 & 156 & 12,19 & 36,58 & 61,17 & 0,41 & 1,62 & 0,33 & 1,67 & 0,80 & 1,03 \\
\hline 30 & 60 & 18 & 38 & 15 & 27 & 42 & 99 & 158 & 12,32 & 36,87 & 61,52 & 0,43 & 1,61 & 0,33 & 1,67 & 0,78 & 1,04 \\
\hline 30 & 70 & 18 & 38 & 15 & 27 & 42 & 99 & 158 & 12,32 & 36,87 & 61,52 & 0,43 & 1,61 & 0,33 & 1,67 & 0,78 & 1,04 \\
\hline 30 & 80 & 18 & 38 & 15 & 27 & 42 & 99 & 158 & 12,32 & 36,87 & 61,52 & 0,43 & 1,61 & 0,33 & 1,67 & 0,78 & 1,04 \\
\hline 30 & 90 & 18 & 38 & 15 & 27 & 42 & 99 & 158 & 12,32 & 36,87 & 61,52 & 0,43 & 1,61 & 0,33 & 1,67 & 0,78 & 1,04 \\
\hline 30 & 100 & 18 & 38 & 15 & 27 & 42 & 99 & 158 & 12,32 & 36,87 & 61,52 & 0,43 & 1,61 & 0,33 & 1,67 & 0,78 & 1,04 \\
\hline 30 & 110 & 18 & 38 & 15 & 27 & 42 & 99 & 158 & 12,32 & 36,87 & 61,52 & 0,43 & 1,61 & 0,33 & 1,67 & 0,78 & 1,04 \\
\hline 30 & 120 & 18 & 38 & 15 & 27 & 42 & 99 & 158 & 12,32 & 36,87 & 61,52 & 0,43 & 1,61 & 0,33 & 1,67 & 0,78 & 1,04 \\
\hline 30 & 130 & 18 & 38 & 15 & 27 & 42 & 99 & 158 & 12,32 & 36,87 & 61,52 & 0,43 & 1,61 & 0,33 & 1,67 & 0,78 & 1,04 \\
\hline 30 & 140 & 18 & 38 & 15 & 27 & 42 & 99 & 158 & 12,32 & 36,87 & 61,52 & 0,43 & 1,61 & 0,33 & 1,67 & 0,78 & 1,04 \\
\hline 30 & 150 & 18 & 38 & 15 & 27 & 42 & 99 & 158 & 12,32 & 36,87 & 61,52 & 0,43 & 1,61 & 0,33 & 1,67 & 0,78 & 1,04 \\
\hline 30 & 30 & 20 & 40 & 15 & 15 & 30 & 93 & 156 & 11,25 & 37,49 & 63,10 & 0,32 & 1,68 & 0,30 & 1,68 & 0,93 & 1,00 \\
\hline 30 & 40 & 20 & 40 & 15 & 20 & 35 & 98 & 161 & 11,79 & 38,38 & 64,09 & 0,36 & 1,64 & 0,31 & 1,67 & 0,86 & 1,02 \\
\hline 30 & 50 & 20 & 40 & 15 & 25 & 40 & 103 & 166 & 12,19 & 39,19 & 65,03 & 0,39 & 1,61 & 0,31 & 1,66 & 0,80 & 1,03 \\
\hline 30 & 60 & 20 & 40 & 15 & 30 & 45 & 108 & 171 & 12,50 & 39,92 & 65,90 & 0,42 & 1,58 & 0,31 & 1,65 & 0,75 & 1,04 \\
\hline 30 & 70 & 20 & 40 & 15 & 30 & 45 & 108 & 171 & 12,50 & 39,92 & 65,90 & 0,42 & 1,58 & 0,31 & 1,65 & 0,75 & 1,04 \\
\hline 30 & 80 & 20 & 40 & 15 & 30 & 45 & 108 & 171 & 12,50 & 39,92 & 65,90 & 0,42 & 1,58 & 0,31 & 1,65 & 0,75 & 1,04 \\
\hline 30 & 90 & 20 & 40 & 15 & 30 & 45 & 108 & 171 & 12,50 & 39,92 & 65,90 & 0,42 & 1,58 & 0,31 & 1,65 & 0,75 & 1,04 \\
\hline 30 & 100 & 20 & 40 & 15 & 30 & 45 & 108 & 171 & 12,50 & 39,92 & 65,90 & 0,42 & 1,58 & 0,31 & 1,65 & 0,75 & 1,04 \\
\hline 30 & 110 & 20 & 40 & 15 & 30 & 45 & 108 & 171 & 12,50 & 39,92 & 65,90 & 0,42 & 1,58 & 0,31 & 1,65 & 0,75 & 1,04 \\
\hline 30 & 120 & 20 & 40 & 15 & 30 & 45 & 108 & 171 & 12,50 & 39,92 & 65,90 & 0,42 & 1,58 & 0,31 & 1,65 & 0,75 & 1,04 \\
\hline 30 & 130 & 20 & 40 & 15 & 30 & 45 & 108 & 171 & 12,50 & 39,92 & 65,90 & 0,42 & 1,58 & 0,31 & 1,65 & 0,75 & 1,04 \\
\hline 30 & 140 & 20 & 40 & 15 & 30 & 45 & 108 & 171 & 12,50 & 39,92 & 65,90 & 0,42 & 1,58 & 0,31 & 1,65 & 0,75 & 1,04 \\
\hline 30 & 150 & 20 & 40 & 15 & 30 & 45 & 108 & 171 & 12,50 & 39,92 & 65,90 & 0,42 & 1,58 & 0,31 & 1,65 & 0,75 & 1,04 \\
\hline 30 & 30 & 22 & 45 & 15 & 15 & 30 & 99 & 170 & 11,25 & 40,06 & 68,85 & 0,30 & 1,71 & 0,28 & 1,72 & 0,93 & 1,00 \\
\hline 30 & 40 & 22 & 45 & 15 & 20 & 35 & 104 & 175 & 11,79 & 40,97 & 69,85 & 0,34 & 1,68 & 0,29 & 1,71 & 0,86 & 1,02 \\
\hline 30 & 50 & 22 & 45 & 15 & 25 & 40 & 109 & 180 & 12,19 & 41,79 & 70,80 & 0,37 & 1,65 & 0,29 & 1,69 & 0,80 & 1,03 \\
\hline 30 & 60 & 22 & 45 & 15 & 30 & 45 & 114 & 185 & 12,50 & 42,55 & 71,70 & 0,39 & 1,62 & 0,29 & 1,69 & 0,75 & 1,04 \\
\hline 30 & 70 & 22 & 45 & 15 & 33 & 48 & 117 & 188 & 12,66 & 42,97 & 72,22 & 0,41 & 1,60 & 0,29 & 1,68 & 0,72 & 1,05 \\
\hline 30 & 80 & 22 & 45 & 15 & 33 & 48 & 117 & 188 & 12,66 & 42,97 & 72,22 & 0,41 & 1,60 & 0,29 & 1,68 & 0,72 & 1,05 \\
\hline 30 & 90 & 22 & 45 & 15 & 33 & 48 & 117 & 188 & 12,66 & 42,97 & 72,22 & 0,41 & 1,60 & 0,29 & 1,68 & 0,72 & 1,05 \\
\hline 30 & 100 & 22 & 45 & 15 & 33 & 48 & 117 & 188 & 12,66 & 42,97 & 72,22 & 0,41 & 1,60 & 0,29 & 1,68 & 0,72 & 1,05 \\
\hline 30 & 110 & 22 & 45 & 15 & 33 & 48 & 117 & 188 & 12,66 & 42,97 & 72,22 & 0,41 & 1,60 & 0,29 & 1,68 & 0,72 & 1,05 \\
\hline 30 & 120 & 22 & 45 & 15 & 33 & 48 & 117 & 188 & 12,66 & 42,97 & 72,22 & 0,41 & 1,60 & 0,29 & 1,68 & 0,72 & 1,05 \\
\hline 30 & 130 & 22 & 45 & 15 & 33 & 48 & 117 & 188 & 12,66 & 42,97 & 72,22 & 0,41 & 1,60 & 0,29 & 1,68 & 0,72 & 1,05 \\
\hline 30 & 140 & 22 & 45 & 15 & 33 & 48 & 117 & 188 & 12.66 & 42.97 & 72.22 & 0.41 & 1.60 & 0.29 & 1.68 & 0.72 & 1.05 \\
\hline 30 & 150 & 22 & 45 & 15 & 33 & 48 & 117 & 188 & 12.66 & 42.97 & 72.22 & 0.41 & 1.60 & 0.29 & 1.68 & 0.72 & 1.05 \\
\hline & & & & & & & & & & & & & & & média & 0,77 & 1,04 \\
\hline & & & & & & & & & & & & & & & desvio & 0,1068 & 0,0221 \\
\hline
\end{tabular}


Tabela B.6 - Valores de $\eta_{\mathbf{e} 1}$ e de $\eta_{\mathbf{e} 2}$ para pilares de canto com $c_{1}>c_{2}$

\begin{tabular}{|c|c|c|c|c|c|c|c|c|c|c|c|c|c|c|c|c|c|}
\hline $\mathrm{c} 1$ & $\mathrm{c} 2$ & $\mathrm{~d}$ & $p$ & a1 & $\mathrm{a} 2$ & uo* & $u^{*}$ & $\mathrm{u}^{\prime *}$ & eo* & $e^{*}$ & $\mathrm{e}^{\prime *}$ & uo $* / u^{*}$ & $\mathrm{u}^{\prime *} / \mathrm{u}^{*}$ & eo*/e* & $\mathrm{e}^{\prime * / \mathrm{e}^{*}}$ & $\eta \mathrm{e} 1$ & $\eta \mathrm{e} 2$ \\
\hline 30 & 20 & 12 & 25 & 15 & 10 & 25 & 63 & 102 & 10,50 & 26,22 & 42,25 & 0,40 & 1,63 & 0,40 & 1,61 & 1,00 & 0,99 \\
\hline 30 & 20 & 14 & 29 & 15 & 10 & $25 \mid$ & 69 & 115 & 10,50 & 28,79 & 47,36 & 0,36 & 1,66 & 0,36 & 1,64 & 1,01 & 0,99 \\
\hline 30 & 20 & 16 & 33 & 15 & 10 & 25 & 75 & 127 & 10,50 & 31,36 & 52,47 & 0,33 & 1,69 & 0,33 & 1,67 & 1,01 & 0,99 \\
\hline 30 & 20 & 18 & 38 & 15 & 10 & 25 & 82 & 141 & 10,50 & 33,93 & 58,21 & 0,31 & 1,73 & 0,31 & 1,72 & 1,01 & 0,99 \\
\hline 30 & 20 & 20 & 40 & 15 & 10 & 25 & 88 & 151 & 10,50 & 36,49 & 62,04 & 0,28 & 1,72 & 0,29 & 1,70 & 1,01 & 0,99 \\
\hline 30 & 20 & 22 & 45 & 15 & 10 & $25 \mid$ & 94 & 165 & 10,50 & 39,05 & 67,78 & 0,27 & 1,75 & 0,27 & 1,74 & 1,01 & 0,99 \\
\hline 40 & 20 & 12 & 25 & 18 & 10 & 28 & 66 & 105 & 14,21 & 29,95 & 46,00 & 0,43 & 1,60 & 0,47 & 1,54 & 1,11 & 0,96 \\
\hline 40 & 25 & 12 & 25 & 18 & 13 & 31 & 68 & 107 & 14,69 & 30,47 & 46,53 & 0,45 & 1,58 & 0,48 & 1,53 & 1,08 & 0,97 \\
\hline 40 & 30 & 12 & 25 & 18 & 15 & 33 & 71 & 110 & 15,09 & 30,95 & 47,04 & 0,47 & 1,56 & 0,49 & 1,52 & 1,04 & 0,98 \\
\hline 40 & 20 & 14 & 29 & 20 & 10 & 30 & 74 & 120 & 13,33 & 31,68 & 50,28 & 0,41 & 1,62 & 0,42 & 1,59 & 1,04 & 0,98 \\
\hline 40 & 25 & 14 & 29 & 20 & 13 & 33 & 76 & 122 & 13,85 & 32,21 & 50,82 & 0,42 & 1,60 & 0,43 & 1,58 & 1,01 & 0,99 \\
\hline 40 & 30 & 14 & 29 & 20 & 15 & 35 & 79 & 125 & 14,29 & 32,71 & 51,35 & 0,44 & 1,58 & 0,44 & 1,57 & 0,99 & 1,00 \\
\hline 40 & 20 & 16 & 33 & 20 & 10 & 30 & 80 & 132 & 13,33 & 34,25 & 55,39 & 0,37 & 1,65 & 0,39 & 1,62 & 1,04 & 0,98 \\
\hline 40 & 25 & 16 & 33 & 20 & 13 & 33 & 83 & 135 & 13,85 & 34,79 & 55,94 & 0,39 & 1,63 & 0,40 & 1,61 & 1,01 & 0,99 \\
\hline 40 & 30 & 16 & 33 & 20 & 15 & 35 & 85 & 137 & 14,29 & 35,29 & 56,47 & 0,41 & 1,61 & 0,40 & 1,60 & 0,99 & 1,00 \\
\hline 40 & 20 & 18 & 38 & 20 & 10 & 30 & 87 & 146 & 13,33 & 36,82 & 61,14 & 0,35 & 1,69 & 0,36 & 1,66 & 1,04 & 0,98 \\
\hline 40 & 25 & 18 & 38 & 20 & 13 & 33 & 89 & 149 & 13,85 & 37,36 & 61,69 & 0,36 & 1,67 & 0,37 & 1,65 & 1,02 & 0,99 \\
\hline 40 & 30 & 18 & 38 & 20 & 15 & 35 & 92 & 151 & 14,29 & 37,87 & 62,22 & 0,38 & 1,65 & 0,38 & 1,64 & 0,99 & 0,99 \\
\hline 40 & 20 & 20 & 40 & 20 & 10 & 30 & 93 & 156 & 13,33 & 39,39 & 64,97 & 0,32 & 1,68 & 0,34 & 1,65 & 1,05 & 0,98 \\
\hline 40 & 25 & 20 & 40 & 20 & 13 & $33 \mid$ & 95 & 158 & 13,85 & 39,93 & 65,52 & 0,34 & 1,66 & 0,35 & 1,64 & 1,02 & 0,99 \\
\hline 40 & 30 & 20 & 40 & 20 & 15 & 35 & 98 & 161 & 14,29 & 40,44 & 66,06 & 0,36 & 1,64 & 0,35 & 1,63 & 0,99 & 0,99 \\
\hline 40 & 20 & 22 & 45 & 20 & 10 & 30 & 99 & 170 & 13,33 & 41,95 & 70,71 & 0,30 & 1,71 & 0,32 & 1,69 & 1,05 & 0,98 \\
\hline 40 & 25 & 22 & 45 & 20 & 13 & 33 & 102 & 172 & 13,85 & 42,50 & 71,27 & 0,32 & 1,70 & 0,33 & 1,68 & 1,02 & 0,99 \\
\hline 40 & 30 & 22 & 45 & 20 & 15 & 35 & 104 & 175 & 14,29 & 43,01 & 71,81 & 0,34 & 1,68 & 0,33 & 1,67 & 0,99 & 0,99 \\
\hline 50 & 20 & 12 & 25 & 18 & 10 & 28 & 66 & 105 & 19,21 & 34,95 & 51,00 & 0,43 & 1,60 & 0,55 & 1,46 & 1,29 & 0,91 \\
\hline 50 & 25 & 12 & 25 & 18 & 13 & 31 & 68 & 107 & 19,69 & 35,47 & 51,53 & 0,45 & 1,58 & 0,56 & 1,45 & 1,24 & 0,92 \\
\hline 50 & 30 & 12 & 25 & 18 & 15 & 33 & 71 & 110 & 20,09 & 35,95 & 52,04 & 0,47 & 1,56 & 0,56 & 1,45 & 1,20 & 0,93 \\
\hline 50 & 20 & 14 & 29 & 21 & 10 & 31 & 75 & 121 & 17,89 & 36,25 & 54,85 & 0,41 & 1,61 & 0,49 & 1,51 & 1,19 & 0,94 \\
\hline 50 & 25 & 14 & 29 & 21 & 13 & 34 & 77 & 123 & 18,42 & 36,79 & 55,41 & 0,43 & 1,59 & 0,50 & 1,51 & 1,16 & 0,95 \\
\hline 50 & 30 & 14 & 29 & 21 & 15 & 36 & 80 & 126 & 18,88 & 37,30 & 55,94 & 0,45 & 1,57 & 0,51 & 1,50 & 1,12 & 0,96 \\
\hline 50 & 20 & 16 & 33 & 24 & 10 & 34 & 84 & 136 & 16,53 & 37,53 & 58,70 & 0,40 & 1,62 & 0,44 & 1,56 & 1,09 & 0,97 \\
\hline 50 & 25 & 16 & 33 & 24 & 13 & $37 \mid$ & 87 & 139 & 17,11 & 38,09 & 59,27 & 0,42 & 1,60 & 0,45 & 1,56 & 1,07 & 0,97 \\
\hline 50 & 30 & 16 & 33 & 24 & 15 & 39 & 89 & 141 & 17,62 & 38,62 & 59,81 & 0,44 & 1,58 & 0,46 & 1,55 & 1,04 & 0,98 \\
\hline 50 & 20 & 18 & 38 & 25 & 10 & 35 & 92 & 151 & 16,07 & 39,68 & 64,03 & 0,38 & 1,65 & 0,41 & 1,61 & 1,06 & 0,98 \\
\hline 50 & 25 & 18 & 38 & 25 & 13 & 38 & 94 & 154 & 16,67 & 40,24 & 64,60 & 0,40 & 1,63 & 0,41 & 1,61 & 1,04 & 0,98 \\
\hline 50 & 30 & 18 & 38 & 25 & 15 & 40 & 97 & 156 & 17,19 & 40,78 & 65,15 & 0,41 & 1,62 & 0,42 & 1,60 & 1,02 & 0,99 \\
\hline 50 & 20 & 20 & 40 & 25 & 10 & 35 & 98 & 161 & 16,07 & 42,25 & 67,87 & 0,36 & 1,64 & 0,38 & 1,61 & 1,06 & 0,98 \\
\hline 50 & 25 & 20 & 40 & 25 & 13 & \begin{tabular}{|l|}
38 \\
\end{tabular} & 100 & 163 & 16,67 & 42,82 & 68,44 & 0,37 & 1,63 & 0,39 & 1,60 & 1,04 & 0,98 \\
\hline 50 & 30 & 20 & 40 & 25 & 15 & 40 & 103 & 166 & 17,19 & 43,36 & 68,99 & 0,39 & 1,61 & 0,40 & 1,59 & 1,02 & 0,99 \\
\hline 50 & 20 & 22 & 45 & 25 & 10 & 35 & 104 & 175 & 16,07 & 44,82 & 73,62 & 0,34 & 1,68 & 0,36 & 1,64 & 1,07 & 0,98 \\
\hline 50 & 25 & 22 & 45 & 25 & 13 & 38 & 107 & 177 & 16,67 & 45,39 & 74,19 & 0,35 & 1,66 & 0,37 & 1,63 & 1,04 & 0,98 \\
\hline 50 & 30 & 22 & 45 & 25 & 15 & 40 & 109 & 180 & 17,19 & 45,93 & 74,74 & 0,37 & 1,65 & 0,37 & 1,63 & 1,02 & 0,99 \\
\hline 60 & 20 & 12 & 25 & 18 & 10 & 28 & 66 & 105 & 24,21 & 39,95 & 56,00 & 0,43 & 1,60 & 0,61 & 1,40 & 1,42 & 0,88 \\
\hline 60 & 25 & 12 & 25 & 18 & 13 & 31 & 68 & 107 & 24,69 & 40,47 & 56,53 & 0,45 & 1,58 & 0,61 & 1,40 & 1,36 & 0,89 \\
\hline 60 & 30 & 12 & 25 & 18 & 15 & 33 & 71 & 110 & 25,09 & 40,95 & 57,04 & 0,47 & 1,56 & 0,61 & 1,39 & 1,31 & 0,90 \\
\hline 60 & 20 & 14 & 29 & 21 & 10 & 31 & 75 & 121 & 22,89 & 41,25 & 59,85 & 0,41 & 1,61 & 0,55 & 1,45 & 1,34 & 0,90 \\
\hline 60 & 25 & 14 & 29 & 21 & 13 & 34 & 77 & 123 & 23,42 & 41,79 & 60,41 & 0,43 & 1,59 & 0,56 & 1,45 & 1,30 & 0,91 \\
\hline 60 & 30 & 14 & 29 & 21 & 15 & 36 & 80 & 126 & 23,88 & 42,30 & 60,94 & 0,45 & 1,57 & 0,56 & 1,44 & 1,25 & 0,92 \\
\hline 60 & 20 & 16 & 33 & 24 & 10 & \begin{tabular}{|l|}
34 \\
\end{tabular} & 84 & 136 & 21,53 & 42,53 & 63,70 & 0,40 & 1,62 & 0,51 & 1,50 & 1,25 & 0,93 \\
\hline 60 & 25 & 16 & 33 & 24 & 13 & 37 & 87 & 139 & 22,11 & 43,09 & 64,27 & 0,42 & 1,60 & 0,51 & 1,49 & 1,22 & 0,93 \\
\hline 60 & 30 & 16 & 33 & 24 & 15 & 39 & 89 & 141 & 22,62 & 43,62 & 64,81 & 0,44 & 1,58 & 0,52 & 1,49 & 1,19 & 0,94 \\
\hline 60 & 20 & 18 & 38 & 27 & 10 & 37 & 94 & 153 & 20,15 & 43,81 & 68,19 & 0,40 & 1,64 & 0,46 & 1,56 & 1,16 & 0,95 \\
\hline 60 & 25 & $|18|$ & 38 & $27 \mid$ & 13 & $|40|$ & 96 & 156 & 20,77 & 44,38 & 68,76 & 0,41 & 1,62 & 0,47 & 1,55 & 1,14 & 0,96 \\
\hline
\end{tabular}




\begin{tabular}{|c|c|c|c|c|c|c|c|c|c|c|c|c|c|c|c|c|c|}
\hline & c2 & $\mathrm{d}$ & $p$ & a1 & a2 & |uo*| & $\mathrm{u}^{*}$ & $\mathrm{u}^{\prime *}$ & eo* & $e^{*}$ & $e^{\prime *}$ & uo*/u* & $\mathrm{u}^{\prime *} / \mathrm{u}^{*}$ & | ео*/e & $\mathrm{e}^{\prime * / \mathrm{e}^{*}}$ & $\eta$ "1 & १e2 \\
\hline 60 & 30 & 18 & 38 & 27 & 15 & 42 & 99 & 158 & 21,32 & 44,93 & 69,32 & 0,43 & 1,61 & 0,47 & 1,54 & 1,11 & 0,96 \\
\hline 60 & 20 & 20 & 40 & 30 & 10 & 40 & 103 & 166 & 18,75 & 45,07 & 70,75 & 0,39 & 1,61 & 0,42 & 1,57 & 1,07 & 0,97 \\
\hline 60 & 25 & 20 & 40 & 30 & 13 & 43 & 105 & 168 & 9,41 & 45,66 & 71,33 & 0,40 & 1,60 & 0,43 & 1,56 & 1,05 & 0,98 \\
\hline 60 & 30 & 20 & 40 & 30 & 15 & 45 & 108 & 171 & 20,00 & 46,23 & 71,90 & 0,42 & 1,58 & 0,43 & 1,56 & 1,04 & 0,98 \\
\hline 60 & 20 & 22 & 45 & 30 & 10 & 40 & 109 & 180 & 18,75 & 47,65 & 76,50 & 0,37 & 1,65 & 0,39 & 1,61 & 1,07 & 0,97 \\
\hline 60 & 25 & 22 & 45 & 30 & 13 & 43 & 112 & 182 & 19,41 & 48,24 & 77,08 & 0,38 & 1,63 & 0,40 & 1,60 & 1,06 & 0,98 \\
\hline 60 & 30 & 22 & 45 & 30 & 15 & 45 & 114 & 185 & 20,00 & 48,81 & 77,65 & 0,39 & 1,62 & 0,41 & 1,59 & 1,04 & 0,98 \\
\hline 70 & 20 & 12 & 25 & 18 & 10 & 28 & 66 & 105 & 29,21 & 44,95 & 61,00 & 0,43 & 1,60 & 0,65 & 1,36 & 1,52 & 0,85 \\
\hline 70 & 30 & 12 & 25 & 18 & 15 & 33 & 71 & 110 & 30,09 & 45,95 & 62,04 & 0,47 & 1,56 & 0,65 & 1,35 & 1,40 & 0,87 \\
\hline 70 & 20 & 14 & 29 & 21 & 10 & 31 & 75 & 121 & 27,89 & 46,25 & 64,85 & 0,41 & 1,61 & 0,60 & 1,40 & 1,46 & 0,87 \\
\hline 70 & 30 & 14 & 29 & 21 & 15 & 36 & 80 & 126 & 28,88 & 47,30 & 65,94 & 0,45 & 1,57 & 0,61 & 1,39 & 1,36 & 0,89 \\
\hline 70 & 20 & 16 & 33 & 24 & 10 & 34 & 84 & 136 & 26,53 & 47,53 & 68,70 & 0,40 & 1,62 & 0,56 & 1,45 & 1,38 & 0,89 \\
\hline 70 & 30 & 16 & 33 & 24 & 15 & 39 & 89 & 141 & 27,62 & 48,62 & 69,81 & 0,44 & 1,58 & 0,57 & 1,44 & 1,30 & 0,91 \\
\hline 70 & 20 & 18 & 38 & $27 \mid$ & 10 & 37 & 94 & 153 & 25,15 & 48,81 & 73,19 & 0,40 & 1,64 & 0,52 & 1,50 & 1,30 & 0,92 \\
\hline 70 & 30 & 18 & 38 & 27 & 15 & 42 & 99 & 158 & 26,32 & 49,93 & 74,32 & 0,43 & 1,61 & 0,53 & 1,49 & 1,24 & 0,93 \\
\hline 70 & 20 & 20 & 40 & 30 & 10 & 40 & 103 & 166 & 23,75 & 50,07 & 75,75 & 0,39 & 1,61 & 0,47 & 1,51 & 1,22 & 0,94 \\
\hline 70 & 30 & 20 & 40 & 30 & 15 & 45 & 108 & 171 & 25,00 & 51,2 & 76,90 & 0,42 & 1,58 & 0,49 & 1,50 & 1,17 & 0,95 \\
\hline 70 & 20 & 22 & 45 & 33 & 10 & 43 & 112 & 183 & 22,34 & 51,34 & 80,22 & 0,38 & 1,63 & 0,44 & 1,56 & 1,13 & 0,96 \\
\hline 70 & 30 & 22 & 45 & 33 & 15 & 48 & 117 & 188 & 23,66 & 52,5 & 81,39 & 0,41 & 1,60 & 0,45 & 1,55 & 1,10 & 0,97 \\
\hline 75 & 25 & \begin{tabular}{|l|l|}
12 \\
\end{tabular} & \begin{tabular}{|l|} 
\\
\end{tabular} & \begin{tabular}{|l|}
18 \\
\end{tabular} & 13 & 31 & 68 & 107 & 32,19 & 47,97 & 64,03 & 0,45 & 1,58 & 0,67 & 1,33 & 1,50 & 0,85 \\
\hline 75 & 25 & 14 & 29 & 21 & 13 & 34 & 77 & 123 & 30,92 & 49,2 & 67, & & 1,59 & 0 & 1,38 & 1,45 & 0,87 \\
\hline 75 & 25 & 16 & 33 & 24 & 13 & 37 & 87 & 139 & 29,61 & 50,59 & 71,77 & 0,42 & 1,60 & 0,59 & 1,42 & 1,39 & 0,89 \\
\hline 75 & 25 & 18 & 38 & 27 & 13 & 40 & 96 & 156 & 28,2 & 51, & 76 & & 1,62 & 0,5 & 1,47 & 1,33 & 0,91 \\
\hline 75 & 25 & 20 & 40 & 30 & 13 & 43 & 105 & 168 & 26,91 & 53,1 & 78,83 & 0,40 & 1,60 & 0,5 & 1,48 & 1,25 & 0,93 \\
\hline 75 & 25 & 22 & 45 & 33 & 13 & 46 & 115 & 185 & 25,53 & 54,4 & 83,31 & & 1,62 & 0 & 1,53 & 1,18 & 0,95 \\
\hline 80 & 20 & 12 & 25 & 18 & 10 & 28 & 66 & 105 & 34,21 & 49,95 & 66,00 & 0,4 & 1,60 & 0,68 & 1,32 & 1,61 & 0,83 \\
\hline 80 & 25 & 12 & 25 & 18 & 13 & 31 & 68 & 107 & 34,65 & 50,4 & 66,53 & & 1,58 & 0,69 &, 32 & 1,54 & 0,84 \\
\hline 80 & 30 & 12 & 25 & 18 & 15 & 33 & 71 & 110 & 35,09 & 50,95 & 67,04 & 0,47 & 1,56 & 0,69 & 1,32 & 1,48 & 0,85 \\
\hline 80 & 20 & 14 & 29 & 21 & 10 & 31 & 75 & 121 & 32,89 & 51 & 69,85 & & 1,61 & 0, & 1,36 & 1,55 & 0,85 \\
\hline 80 & 25 & 14 & 29 & 21 & 13 & 34 & 77 & 123 & 33,42 & 51,79 & 70,41 & 0,43 & 1,59 & 0,65 & 1,36 & 1,49 & 0,86 \\
\hline 80 & 30 & 14 & 29 & 21 & 15 & 36 & 80 & 126 & 33,88 & 52, & 70,94 & &, 57 & 0 & 1,36 & 1,44 & 0,86 \\
\hline 80 & 20 & 16 & 33 & 24 & 10 & 34 & 84 & 136 & 31,53 & 52,53 & 73,70 & 0,40 & ,62 & 0,60 & 1,40 & 1,49 & 0,87 \\
\hline 80 & 25 & 16 & 33 & 24 & 13 & 37 & 87 & 139 & 32,11 & 53,0 & 74,27 & & ,60 & 0 & ,40 & 1,44 & 0,88 \\
\hline 80 & 30 & 16 & 33 & 24 & 15 & 39 & 89 & 141 & 32,62 & 53,62 & 74,81 & 0,44 & 1,58 & 0,61 & 1,40 & 1,39 & 0,88 \\
\hline 80 & 20 & \begin{tabular}{|l|}
18 \\
\end{tabular} & 38 & \begin{tabular}{|l|} 
\\
\end{tabular} & 10 & 37 & 94 & 153 & 30,15 & 53,8 & 78,19 & & 64 & & 1,45 & 1,42 & 0,89 \\
\hline 80 & 25 & 18 & 38 & 27 & 13 & 40 & 96 & 156 & 30,77 & 54,3 & 78,76 & 0,4 & 1,62 & 0,57 & 1,45 & 1,38 & 0,89 \\
\hline 80 & 30 & 18 & 38 & $27 \mid$ & 15 & 42 & 99 & 158 & 31,3 & 54, & 79 & & 1,61 & & ,44 & 34 & 0,90 \\
\hline 80 & 20 & 20 & 40 & 30 & 10 & 40 & 103 & 166 & 28,75 & 55,0 & 80,75 & 0,3 & 1,61 & 0,52 & 1,47 & 1,34 & 0,91 \\
\hline 80 & 25 & 20 & 40 & 30 & 13 & 43 & 105 & 168 & 29,41 & 55,66 & 81,33 & & 60 & & 1,46 & 1,31 & 0,92 \\
\hline 80 & 30 & 20 & 40 & 30 & 15 & 45 & 108 & 171 & 30,00 & 56,23 & 81,90 & 0,4 & 1,58 & 0,5 & 1,46 & 1,28 & 0,92 \\
\hline 80 & 20 & 22 & 45 & 33 & 10 & 43 & 112 & 183 & 27,34 &, 34 & 85,22 & & 63 & 49 & 1,51 & 1,27 & 0,93 \\
\hline 80 & 25 & 22 & 45 & 33 & 13 & 46 & 115 & 185 & 28,03 & 56,94 & 85,81 & 0,40 & 1,62 & 0,49 & 1,51 & 1,24 & 0,93 \\
\hline 80 & 30 & 22 & 45 & 33 & 15 & 48 & 117 & 188 & 28,66 & 57,52 & 86,39 & 0,41 & 60 & 0,50 &, 50 & 1,22 & 0,94 \\
\hline 90 & 20 & 12 & \begin{tabular}{|l|}
25 \\
\end{tabular} & 18 & 10 & \begin{tabular}{|l|}
28 \\
\end{tabular} & 66 & 105 & 39,21 & 54,9 & 71,00 & 0,4 & 1,60 & 0,71 & 1,29 & 1,67 & 0,81 \\
\hline 90 & 25 & 12 & 25 & 18 & 13 & 31 & 68 & 107 & 39,69 & 55,47 & 71,53 & 0,45 & .58 & 0,72 & 1,29 & 1,60 & 0,82 \\
\hline 90 & 30 & 12 & 25 & 18 & 15 & 33 & 71 & 110 & 40,09 & 55,95 & 72,04 & 0,47 & 1,56 & 0,72 & 1,29 & 1,54 & 0,83 \\
\hline 90 & 20 & 14 & 29 & 21 & 10 & 31 & 75 & 121 & 37,89 & 56,25 & 74,85 & 0,41 & 61 & 0,67 & ,33 & 1,63 & 0,83 \\
\hline 90 & 25 & 14 & 29 & 21 & 13 & 34 & 77 & 123 & 38,42 & 56,79 & 75,41 & 0,43 & 1,59 & 0,68 & 1,33 & 1,56 & 0,84 \\
\hline 90 & 30 & 14 & 29 & 21 & 15 & 36 & 80 & 126 & 38,8 & 57, & 75,94 & 0, & 91 & 0,0 & 33 & 1,51 & 0,84 \\
\hline 90 & 20 & 16 & 33 & 24 & 10 & 34 & 84 & 136 & 36,53 & 57,53 & 78,70 & 0,40 & 1,62 & 0,63 & 1,37 & 1,57 & 0,85 \\
\hline 90 & 25 & 16 & 33 & 24 & 13 & 37 & 87 & 139 & 37,11 & 58,0 & 79,27 & 0,42 & 50 & 0,64 &, 36 & 1,52 & 0,85 \\
\hline 90 & 30 & 16 & 33 & 24 & 15 & 39 & 89 & 141 & 37,62 & 58,62 & 79,81 & 0,44 & 1,58 & 0,64 & 1,36 & 1,47 & 0,86 \\
\hline 90 & 20 & 18 & 38 & 27 & 10 & 37 & 94 & 153 & 35,15 & 58,81 & 83,19 & 0,40 & 1,64 & 0,60 & 1,41 & 1,51 & 0,86 \\
\hline 90 & 25 & 18 & 38 & 27 & 13 & 40 & 96 & 156 & 35,77 & 59,38 & 83,76 & 0,41 & 1,62 & 0,60 & 1,41 & 1,46 & 0,87 \\
\hline & 30 & 101 & & 1271 & 115 & 42 & & 150 & 36,32 & 59,93 & 84,32 & 0,43 & 1,61 & 0,61 & 1,41 & 1,42 & $0,8 \delta$ \\
\hline
\end{tabular}




\begin{tabular}{|c|c|c|c|c|c|c|c|c|c|c|c|c|c|c|c|c|c|}
\hline c1 & $\mathrm{c} 2$ & d & $\mathrm{p}$ & a1 & a2 & uo* & $\mathrm{u}^{*}$ & $\mathrm{u}^{\prime *}$ & eo* & $e^{*}$ & $e^{\prime *}$ & uo*/u* & $\mathrm{u}^{\prime} * \mathrm{u}^{*}$ & eo*/e* & $\mathrm{e}^{\prime *} / \mathrm{e}^{*}$ & $\eta$ "1 & १e2 \\
\hline 90 & 20 & 20 & 40 & 30 & 10 & 40 & 103 & 166 & 33,75 & 60,07 & 85,75 & 0,39 & 1,61 & 0,56 & 1,43 & 1,44 & 0,89 \\
\hline 90 & 25 & 20 & 40 & 30 & 13 & 43 & 105 & 168 & 34,41 & 60,66 & 86,33 & 0,40 & 1,60 & 0,57 & 1,42 & 1,41 & 0,89 \\
\hline 90 & 30 & 20 & 40 & 30 & 15 & 45 & 108 & 171 & 35,00 & $\{1,23$ & 86,90 & 0,42 & 1,58 & 0,57 & 1,42 & 1,37 & 0,90 \\
\hline 90 & 20 & 22 & 45 & 33 & 10 & 43 & 112 & 183 & 32,34 & 61,34 & 90,22 & 0,38 & 1,63 & 0,53 & 1,47 & 1,37 & 0,90 \\
\hline 90 & 25 & 22 & 45 & 33 & 13 & 46 & 115 & 185 & 33,03 & 61,94 & 90,81 & 0,40 & 1,62 & 0,53 & 1,47 & 1,34 & 0,91 \\
\hline 90 & 30 & 22 & 45 & 33 & 15 & 48 & 117 & 188 & 33,66 & 62,52 & 91,39 & 0,41 & 1,60 & 0,54 & 1,46 & 1,31 & 0,91 \\
\hline 100 & 20 & 12 & 25 & 18 & 10 & 28 & 66 & 105 & 44,21 & 59,95 & 76,00 & 0,43 & 1,60 & 0,74 & 1,27 & 1,73 & 0,79 \\
\hline 100 & 25 & 12 & 25 & 18 & 13 & 31 & 68 & 107 & 44,69 & 60,47 & 76,53 & 0,4 & 1,58 & 0,74 & 1,27 & 1,65 & 0,80 \\
\hline 100 & 30 & 12 & 25 & 18 & 15 & 33 & 71 & 110 & 45,09 & 60,95 & 77,04 & 0,4 & 1,56 & 0,74 & 1,26 & 1,59 & 0,81 \\
\hline 100 & 20 & 14 & 29 & 21 & 10 & 31 & 75 & 121 & 42,89 & 61,25 & 79,85 & 0,41 & 1,61 & 0,70 & 1,30 & 1,69 & 0,81 \\
\hline 100 & 25 & 14 & 29 & 21 & 13 & 34 & 77 & 123 & 43,42 & 61,79 & 80,41 & 0,43 & 1,59 & 0,70 & 1,30 & 1,63 & 0,82 \\
\hline 100 & 30 & 14 & 29 & 21 & 15 & 36 & 80 & 126 & 43,88 & 62,30 & 80,94 & 0,45 & 1,57 & 0,70 & 1,30 & 1,56 & 0,83 \\
\hline 100 & 20 & 16 & 33 & 24 & 10 & 34 & 84 & 136 & 41,53 & 62,53 & 83,70 & 0,40 & 1,62 & 0,66 & 1,34 & 1,65 & 0,83 \\
\hline 100 & 25 & 16 & 33 & 24 & 13 & 37 & 87 & 139 & 42,11 & 63,09 & 84,27 & 0,42 & 1,60 & 0,67 & 1,34 & 1,59 & 0,84 \\
\hline 100 & 30 & 16 & 33 & 24 & 15 & 39 & 89 & 141 & 42,62 & 63,62 & 84,81 & 0,44 & 1,58 & 0,67 & 1,33 & 1,53 & 0,84 \\
\hline 100 & 20 & 18 & 38 & 27 & 10 & 37 & 94 & 153 & 40,15 & 63,81 & 88,19 & 0,40 & 1,64 & 0,63 & 1,38 & 1,59 & 0,84 \\
\hline 100 & 25 & 18 & 38 & 27 & 13 & 40 & 96 & 156 & 40,77 & 64,38 & 88,76 & 0,41 & 1,62 & 0,63 & 1,38 & 1,54 & 0,85 \\
\hline 100 & 30 & 18 & 38 & 27 & 15 & 42 & 99 & 158 & 41,32 & 64,93 & 89,32 & 0,43 & 1,61 & 0,64 & 1,38 & 1,49 & 0,86 \\
\hline 100 & 20 & 20 & 40 & 30 & 10 & 40 & 103 & 166 & 38,75 & 65,07 & 90,75 & 39 & 1,61 & 0,60 & 1,39 & 1,53 & 0,87 \\
\hline 100 & 25 & 20 & 40 & 30 & 13 & 43 & 105 & 168 & 39,41 & 65,66 & 91,33 & 0,40 & 1,60 & 0,60 & 1,39 & 1,49 & 0,87 \\
\hline 100 & 30 & 20 & 40 & 30 & 15 & 45 & 108 & 171 & 40,0 & 66,2 & 91,90 & & 1,58 & 0,60 & 1,39 & 1,45 & 0,88 \\
\hline 100 & 20 & 22 & 45 & 33 & 10 & 43 & 112 & 183 & 37,34 & 66,34 & 95,22 & 0,38 & 1,63 & 0,56 & 1,44 & 1,47 & 0,88 \\
\hline 100 & 25 & 22 & 45 & 33 & 13 & 46 & 115 & 185 & 38 & 66,9 & 95 , & & 1,62 & 0,57 & 43 & 1,43 & 0,89 \\
\hline 100 & 30 & 22 & 45 & 33 & 15 & 48 & 117 & 188 & 38,66 & 67,5 & 96,39 & 0,41 & 1,60 & 0,5 & 1,43 & 1,40 & 0,89 \\
\hline 110 & 25 & 12 & 25 & 18 & 13 & 31 & 68 & 107 & 49,6 & 65 & 81,5 & & 5 & 0,76 &, 25 & 1,70 & 0,79 \\
\hline 110 & 30 & 12 & 25 & 18 & 15 & 33 & 71 & 110 & 50,09 & 65,95 & 82,04 & 0,4 & 1,56 & 0,76 & 1,24 & 1,63 & 0,80 \\
\hline 110 & 25 & 14 & 29 & 21 & 13 & 34 & 77 & 123 & 48,42 & 66,7 & 85,41 & & 15 & 0,72 &, 28 & 1,68 & 0,81 \\
\hline 110 & 30 & 14 & 29 & 21 & 15 & 36 & 80 & 126 & 48,88 & 67,30 & 85,94 & 0,45 & 1,57 & 0,73 & 1,28 & 1,61 & 0,81 \\
\hline 110 & 25 & 16 & 33 & 24 & 13 & 37 & 87 & 139 & 47, & 68 & 89,27 & & 1,60 & 0 & 1,31 & 1 & 0,82 \\
\hline 110 & 30 & 16 & 33 & 24 & 15 & 39 & 89 & 141 & 47,62 & 68,62 & 89,81 & 0,44 & 1,58 & 0,69 & 1,31 & 1,59 & 0,83 \\
\hline 110 & 25 & 18 & 38 & 27 & 13 & 40 & 96 & 156 & 45,7 & 69, & 93,76 & & 62 & 0,66 &, 35 & 60 & 0,83 \\
\hline 110 & 30 & 18 & 38 & 27 & 15 & 42 & 99 & 158 & 46,32 & 69,93 & 94,32 & 0,43 & 1,61 & 0,66 & 1,35 & 1,55 & 0,84 \\
\hline 110 & 25 & 20 & 40 & 30 & 13 & 43 & 105 & 168 & 44 & 70, & 96,33 & & & 0 & 1,36 & 1 & 0,85 \\
\hline 110 & 30 & 20 & 40 & 30 & 15 & 45 & 108 & 171 & 45,00 & 71,23 & 96,90 & 0,42 & 1,58 & 0,63 & 1,36 & 1,51 & 0,86 \\
\hline 110 & 25 & 22 & 45 & 33 & 13 & 46 & 115 & 185 & 43,03 & 7 & 100,8 & & 62 & 0,60 & 1,40 & 1,51 & 0,87 \\
\hline 110 & 30 & 22 & 45 & 33 & 15 & 48 & 117 & 188 & 43,6 & 72,52 & 101,39 & 0,4 & 1,60 & 0,60 & 1,40 & 1,47 & 0,87 \\
\hline 120 & 30 & 12 & 25 & 18 & 15 & 33 & 71 & 110 & 55 & & 87,04 & & & &, 23 & 1 , & 0,79 \\
\hline 120 & 30 & 14 & 29 & 21 & 15 & 36 & 80 & 126 & 53,8 & 72,30 & 90,94 & 0,4 & 1,57 & 0,7 & 1,26 & 1,66 & 0,80 \\
\hline 120 & 30 & 16 & 33 & 24 & 15 & 39 & 89 & 141 & 52,6 & 73,62 & 94,81 & & & & ,29 & 64 & 0,81 \\
\hline 120 & 30 & 18 & 38 & 27 & 15 & 42 & 99 & 158 & 51,32 & 74,93 & 99,32 & 0,4 & 1,61 & 0,68 & 1,33 & 1,61 & 0,83 \\
\hline 120 & 30 & 20 & 40 & 30 & 15 & 45 & 108 & 171 & 50,00 & & 101,90 & & & 0 & ,34 & 1,57 & 0,84 \\
\hline 120 & 30 & 22 & 45 & 33 & 15 & 48 & 117 & 188 & 48,66 & 77,52 & 106,39 & 0,4 & 1,60 & 0,63 & 1,37 & 1,53 & 0,86 \\
\hline 125 & 25 & 12 & 25 & 28 & 13 & 41 & 78 & 117 & 52 & ,69 & 84,82 & 0,52 & 50 & 0,77 &, 23 & 1,48 & 0,82 \\
\hline 125 & 25 & 14 & 29 & 21 & 13 & 34 & 77 & 123 & 55, & 74,2 & 92,91 & 0,4 & 1,59 & 0,75 & 1,25 & 1,74 & 0,79 \\
\hline 125 & 25 & 16 & 33 & 24 & 13 & 37 & 87 & 139 & 54,61 &, 59 & 96,77 & 0,42 & 60 & 0,72 & ,28 & 1,72 & 0,80 \\
\hline 125 & 25 & 18 & 38 & 27 & 13 & 40 & 96 & 156 & 53,27 & 76,88 & 101,26 & 0,41 & 1,62 & 0,69 & 1,32 & 1,68 & 0,81 \\
\hline 125 & 25 & 20 & 40 & 30 & 13 & 43 & 105 & 168 & 51,91 & 78,16 & 103,83 & 0,40 & 60 & 0,66 &, 33 & 1,65 & 0,83 \\
\hline 125 & 25 & 22 & 45 & 33 & 13 & 46 & 115 & 185 & 50,53 & 79,44 & 108,31 & 0,40 & 1,62 & 0,64 & 1,36 & 1,60 & 0,84 \\
\hline 130 & 30 & 12 & 25 & 18 & 15 & 33 & 71 & 110 & 60,09 & 75,95 & 92,04 & 0,47 & .56 & 0,79 & 1,21 & 1,70 & 0,78 \\
\hline 130 & 30 & 14 & 29 & 21 & 15 & 36 & 80 & 126 & 58,88 & 77,30 & 95,94 & 0,45 & 1,57 & 0,76 & 1,24 & 1,69 & 0,79 \\
\hline 130 & 30 & 16 & 33 & 24 & 15 & 39 & 89 & 141 & 57,6 & 7 & 99,8 & 0,4 & & 0,73 &, 27 & 1,68 & 0,80 \\
\hline 130 & 30 & \begin{tabular}{|l|}
18 \\
\end{tabular} & 38 & 27 & 15 & 42 & 99 & 158 & 56,32 & 79,93 & 104,32 & 0,43 & 1,61 & 0,70 & 1,31 & 1,65 & 0,81 \\
\hline 130 & 30 & 20 & 40 & 30 & 15 & 45 & 108 & 171 & 55,00 & 81,23 & 106,90 & 0,42 & 1,58 & 0,68 & 1,32 & 1,62 & 0,83 \\
\hline 130 & 30 & 22 & 45 & 33 & 15 & 48 & 117 & 188 & 53,66 & 82,52 & 111,39 & 0,41 & 1,60 & 0,65 & 1,35 & 1,59 & 0,84 \\
\hline & 30 & $12 \mid$ & | $25 \mid$ & $\mid$ & 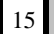 & 33 & 11 & 110 & 65,09 & 80,95 & 97,04 & 0,47 & 1,56 & 0,80 & 1,20 & 1,72 & 0,77 \\
\hline
\end{tabular}




\begin{tabular}{|c|c|c|c|c|c||c|c|c||c|c|c||c|c|c|c|c|c|}
$\mathrm{c} 1$ & $\mathrm{c} 2$ & $\mathrm{~d}$ & $\mathrm{p}$ & $\mathrm{a} 1$ & $\mathrm{a} 2$ & $\mathrm{uo}$ & $\mathrm{u}^{*}$ & $\mathrm{u}^{\prime *}$ & $\mathrm{eo}$ & $\mathrm{e}^{*}$ & $\mathrm{e}^{\prime *}$ & $\mathrm{uo} * / \mathrm{u}^{*}$ & $\mathrm{u}^{*} / \mathrm{u}^{*}$ & $\mathrm{eo} / / \mathrm{e}^{*}$ & $\mathrm{e}^{\prime * / \mathrm{e}^{*}}$ & $\eta \mathrm{e} 1$ & $\eta \mathrm{e} 2$ \\
\hline 140 & 30 & 14 & 29 & 21 & 15 & 36 & 80 & 126 & 63,88 & 82,30 & 100,94 & 0,45 & 1,57 & 0,78 & 1,23 & 1,72 & 0,78 \\
\hline 140 & 30 & 16 & 33 & 24 & 15 & 39 & 89 & 141 & 62,62 & 83,62 & 104,81 & 0,44 & 1,58 & 0,75 & 1,25 & 1,71 & 0,79 \\
\hline 140 & 30 & 18 & 38 & 27 & 15 & 42 & 99 & 158 & 61,32 & 84,93 & 109,32 & 0,43 & 1,61 & 0,72 & 1,29 & 1,69 & 0,80 \\
\hline 140 & 30 & 20 & 40 & 30 & 15 & 45 & 108 & 171 & 60,00 & 86,23 & 111,90 & 0,42 & 1,58 & 0,70 & 1,30 & 1,67 & 0,82 \\
\hline 140 & 30 & 22 & 45 & 33 & 15 & 48 & 117 & 188 & 58,66 & 87,52 & 116,39 & 0,41 & 1,60 & 0,67 & 1,33 & 1,64 & 0,83 \\
\hline 150 & 30 & 12 & 25 & 18 & 15 & 33 & 71 & 110 & 70,09 & 85,95 & 102,04 & 0,47 & 1,56 & 0,82 & 1,19 & 1,75 & 0,76 \\
\hline 150 & 30 & 14 & 29 & 21 & 15 & 36 & 80 & 126 & 68,88 & 87,30 & 105,94 & 0,45 & 1,57 & 0,79 & 1,21 & 1,75 & 0,77 \\
\hline 150 & 30 & 16 & 33 & 24 & 15 & 39 & 89 & 141 & 67,62 & 88,62 & 109,81 & 0,44 & 1,58 & 0,76 & 1,24 & 1,75 & 0,78 \\
\hline 150 & 30 & 18 & 38 & 27 & 15 & 42 & 99 & 158 & 66,32 & 89,93 & 114,32 & 0,43 & 1,61 & 0,74 & 1,27 & 1,73 & 0,79 \\
\hline 150 & 30 & 20 & 40 & 30 & 15 & 45 & 108 & 171 & 65,00 & 91,23 & 116,90 & 0,42 & 1,58 & 0,71 & 1,28 & 1,71 & 0,81 \\
\hline 150 & 30 & 22 & 45 & 33 & 15 & 48 & 117 & 188 & 63,66 & 92,52 & 121,39 & 0,41 & 1,60 & 0,69 & 1,31 & 1,68 & 0,82 \\
\hline
\end{tabular}



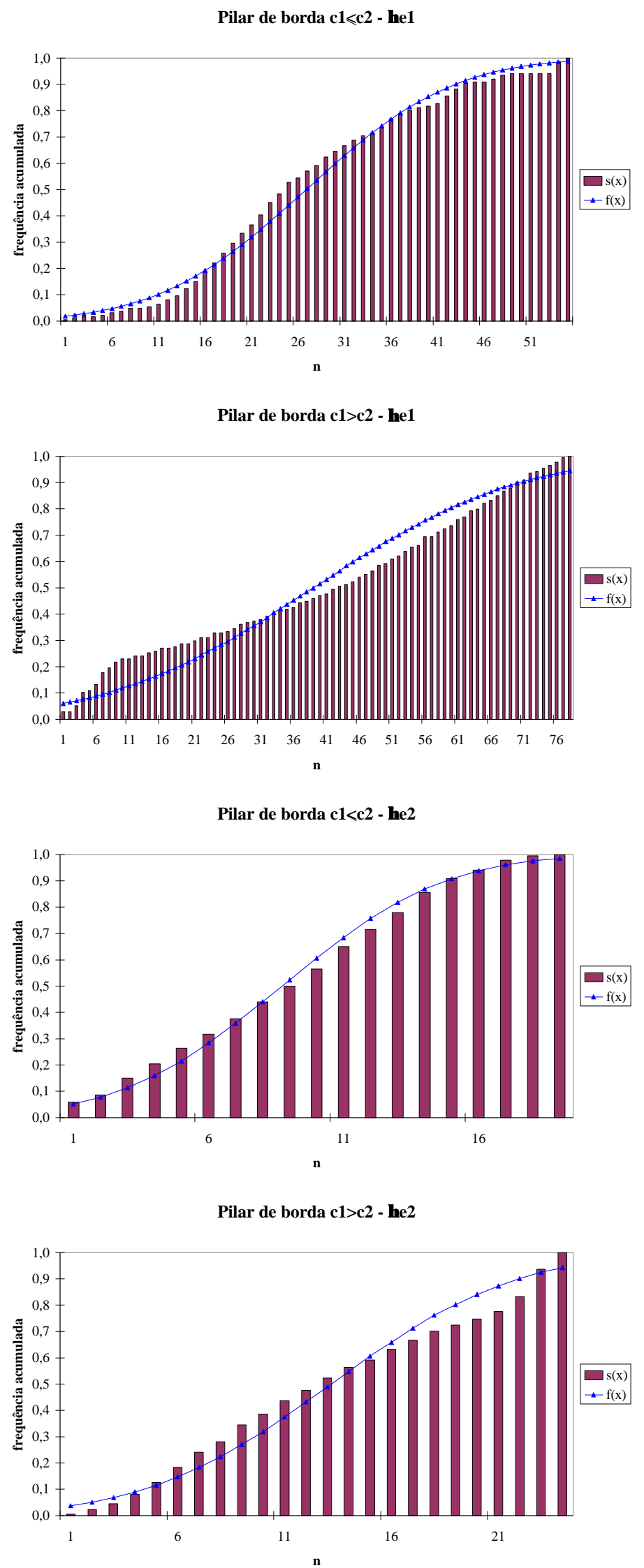

Figura B.1 - Teste de Kolmorogov-Smirnov para pilares de borda 
Pilar de canto c1 $\leqslant c 2$ - $\eta \mathrm{e} 1$

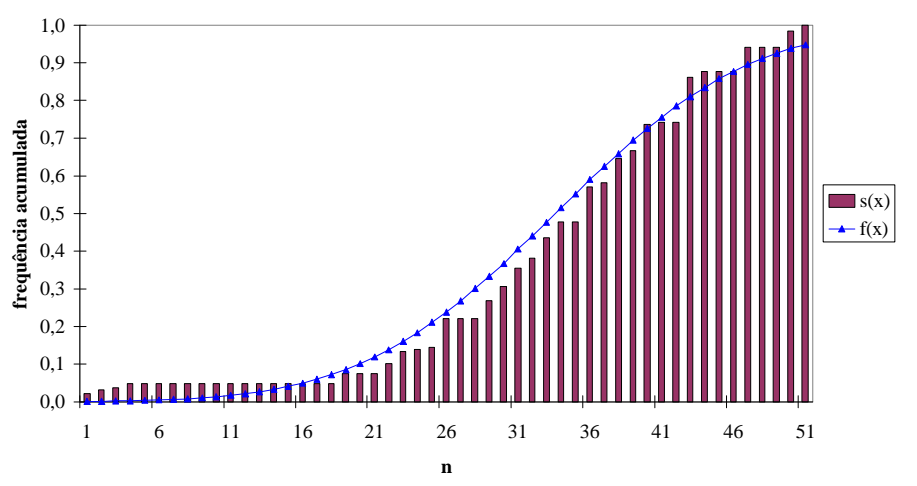

Pilar de canto c1>c2 - $\eta \mathrm{e} 1$

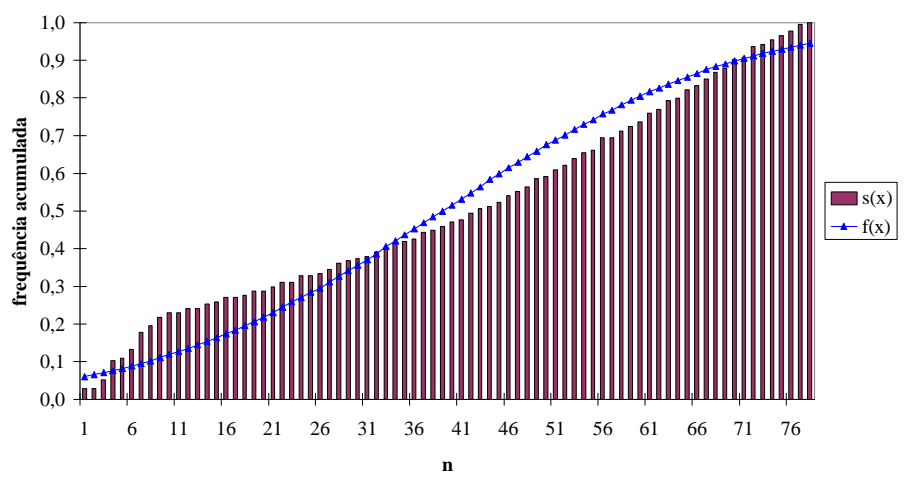

Pilar de canto $c 1 \leqslant c 2$ - $\eta \mathrm{e} 2$

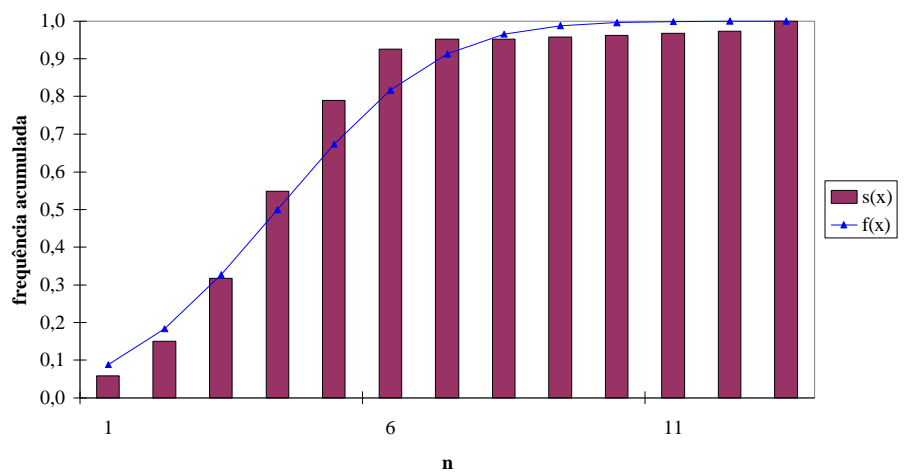

Pilar de canto c1>c2 - $\eta \mathrm{e} 2$

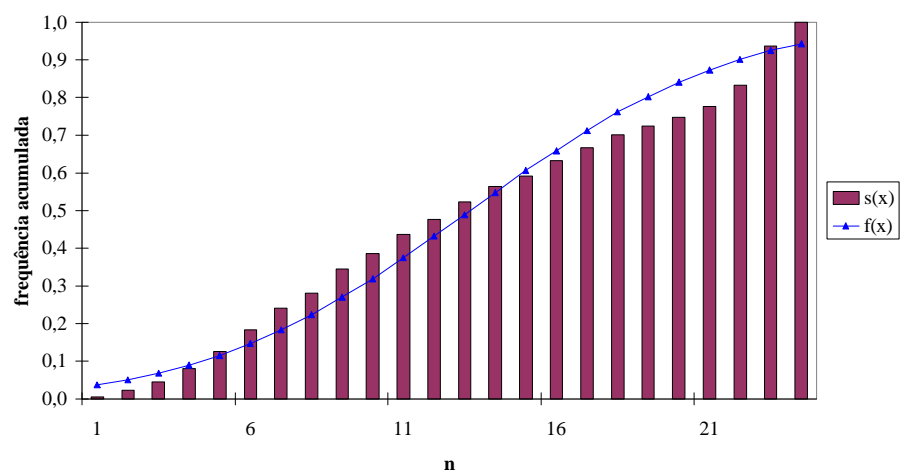

Figura B.2 - Teste de Kolmorogov-Smirnov para pilares de canto 


\section{AneXo C}

\section{DETERMINAÇÃO DOS VALORES DE $\beta$}

Para a determinação dos valores de $\beta$, foram resolvidos diversos exemplos com mesmas características mencionadas no Anexo A, a menos da maior dimensão da seção do pilar. Esta dimensão foi limitada a 3 vezes a outra, uma vez que a NBR 6118 (2000) só indica valores de $\mathrm{K}$ para $\mathrm{c}_{1} / \mathrm{c}_{2} \leq 3$. Mais uma vez, os exemplos foram agrupados de acordo com a situação de cálculo e considerando-se a direção da excentricidade em relação aos lados do pilar. Foram estudados os seguintes casos:

- pilares internos com momento atuante em uma direção e $c_{1} \leq c_{2}$ (Tabela C.4);

- pilares internos com momento atuante em uma direção e $c_{1}>c_{2}$ (Tabela C.5);

- pilares internos com momentos atuantes nas duas direções e $c_{1} \leq c_{2}$ (Tabela C.6);

- pilares internos com momentos atuantes nas duas direções e $c_{1}>c_{2}$ (Tabela C.7);

- pilares de borda sem momento no plano paralelo à borda e $c_{1} \leq \mathrm{c}_{2}$ (Tabela C.8);

- pilares de borda sem momento no plano paralelo à borda e $\mathrm{c}_{1}>\mathrm{c}_{2}$ (Tabela C.9);

- pilares de borda com momento no plano paralelo à borda e $\mathrm{c}_{1} \leq \mathrm{c}_{2}$ (Tabela C.10);

- pilares de borda com momento no plano paralelo à borda e $\mathrm{c}_{1}>\mathrm{c}_{2}$ (Tabela C.11);

- pilares de canto com $\mathrm{c}_{1} \leq \mathrm{c}_{2}$ (Tabela C.12);

- pilares de canto com $c_{1}>c_{2}$ (Tabela C.13).

Nas tabelas apresentadas, $\beta_{\mathbf{o}}, \boldsymbol{\beta}$ e $\beta$ ' correspondem aos contornos $\mathbf{C}, \mathbf{C}$ ' e $\mathbf{C}$ ', respectivamente. 
Foram calculados as médias e os desvios padrões de $\beta$ para todos os casos, e estudou-se a possibilidade de se admiti-lo como uma variável de distribuição normal. Mais uma vez, foi utilizado o Kolmogorov-Smirnov goodness-of-fit test, a partir do qual se observou a validade da aproximação para todas as situações estudadas. Assim, tomando-se o nível de significância de $10 \%$, pode-se escrever:

$$
\beta=\bar{\beta}+1,28 \cdot \delta
$$

sendo:

$\bar{\beta}$ - valor médio dos $\beta$;

$\boldsymbol{\delta}$ - desvio padrão.

Os valores obtidos dessa forma encontram-se na Tabela C.1. Agrupando-se e aproximando-se esses resultados, podem ser sugeridos os valores da Tabela C.2 e da Tabela C.3.

Tabela C.1 - Valores de $\beta$ para o nível de significância de 10\%

\begin{tabular}{|l|c|c|c|c|c|c|c|}
\hline \multicolumn{1}{|c|}{ Situação de Cálculo } & \multicolumn{3}{|c|}{$\boldsymbol{c}_{1} \leq \boldsymbol{c}_{2}$} & \multicolumn{3}{c|}{$\boldsymbol{c}_{1}>\boldsymbol{c}_{2}$} \\
\cline { 2 - 8 } & $\boldsymbol{C}$ & $\boldsymbol{C}^{\prime}$ & $\boldsymbol{C}^{\prime}$ & $\boldsymbol{C}$ & $\boldsymbol{C}^{\prime}$ & $\boldsymbol{C}^{\prime \prime}$ \\
\hline $\begin{array}{l}\text { Pilar interno, } \\
\text { com momento aplicado em uma direção }\end{array}$ & 1,13 & 1,13 & 1,08 & 1,12 & 1,12 & 1,08 \\
\hline $\begin{array}{l}\text { Pilar interno, } \\
\text { com momentos aplicados nas duas direçães }\end{array}$ & 1,16 & 1,16 & 1,10 & 1,14 & 1,14 & 1,09 \\
\hline $\begin{array}{l}\text { Pilar de borda, } \\
\text { sem momento aplicado no plano paralelo à borda livre }\end{array}$ & 1,46 & 1,15 & 1,01 & 1,64 & 1,35 & 1,00 \\
\hline $\begin{array}{l}\text { Pilar de borda, } \\
\text { com momento aplicado no plano paralelo à borda livre }\end{array}$ & 1,50 & 1,22 & 1,12 & 1,68 & 1,39 & 1,03 \\
\hline Pilar de canto & 1,62 & 1,35 & 1,10 & 1,44 & 1,16 & 1,03 \\
\hline
\end{tabular}


Tabela C.2 - Valores de $\boldsymbol{\beta}$ sugeridos para $c_{1} \leq c_{2}$ e suas probabilidades de ocorrência

\begin{tabular}{|c|c|c|c|}
\hline \multirow{2}{*}{$\begin{array}{l}\text { Situação de } \\
\text { Cálculo }\end{array}$} & \multicolumn{3}{|c|}{$c_{1} \leq c_{2}$} \\
\hline & $C$ & $C^{\prime}$ & $C^{\prime \prime}$ \\
\hline $\begin{array}{l}\text { Pilar interno, com } \\
\text { momento aplicado }\end{array}$ & $\begin{array}{c}1,2 \\
(99 \% \text { para um momento }) \\
(99 \% \text { para dois momentos })\end{array}$ & $\begin{array}{c}1,2 \\
\text { (99\% para um momento) } \\
\text { (99\% para dois momentos) }\end{array}$ & $\begin{array}{c}1,1 \\
(99 \% \text { para um momento) } \\
(90 \% \text { para dois momentos })\end{array}$ \\
\hline Pilar de borda & $\begin{array}{c}1,5 \\
(93 \% \text { para um momento }) \\
(90 \% \text { para dois momentos })\end{array}$ & $\begin{array}{c}1,3 \\
(99 \% \text { para um momento }) \\
(99 \% \text { para dois momentos })\end{array}$ & $\begin{array}{c}1,2 \\
\text { (99\% para um momento) } \\
\text { (99\% para dois momentos) }\end{array}$ \\
\hline Pilar de canto & $\begin{array}{c}1,7 \\
(94 \%)\end{array}$ & $\begin{array}{c}1,4 \\
(94 \%)\end{array}$ & $\begin{array}{c}1,1 \\
(90 \%)\end{array}$ \\
\hline
\end{tabular}

Tabela C.3 - Valores de $\boldsymbol{\beta}$ sugeridos para $c_{1}>c_{2}$ e suas probabilidades de ocorrência

\begin{tabular}{|c|c|c|c|}
\hline \multirow{2}{*}{$\begin{array}{l}\text { Situação de } \\
\text { Cálculo }\end{array}$} & \multicolumn{3}{|c|}{$c_{1}>c_{2}$} \\
\hline & $C$ & $C^{\prime}$ & $C^{\prime \prime}$ \\
\hline $\begin{array}{l}\text { Pilar interno, com } \\
\text { momento aplicado }\end{array}$ & $\begin{array}{c}1,2 \\
(99 \% \text { para um momento) } \\
\text { (99\% para dois momentos) }\end{array}$ & $\begin{array}{c}1,2 \\
\text { (99\% para um momento) } \\
\text { (99\% para dois momentos) } \\
\end{array}$ & $\begin{array}{c}1,1 \\
\text { (99\% para um momento) } \\
\text { (99\% para dois momentos) }\end{array}$ \\
\hline Pilar de borda & $\begin{array}{c}1,7 \\
\text { (93\% para um momento) } \\
(91 \% \text { para dois momentos) }\end{array}$ & $\begin{array}{c}1,4 \\
\text { (93\% para um momento) } \\
\text { (91\% para dois momentos) }\end{array}$ & $\begin{array}{c}1,1 \\
\text { (99\% para um momento) } \\
\text { (99\% para dois momentos) }\end{array}$ \\
\hline Pilar de canto & $\begin{array}{c}1,5 \\
(95 \%)\end{array}$ & $\begin{array}{c}1,2 \\
(96 \%)\end{array}$ & $\begin{array}{c}1,1 \\
(99 \%)\end{array}$ \\
\hline
\end{tabular}


Tabela C.4 - Valores de $\beta$ para pilares internos com momento atuante em uma direção e $c_{1} \leq c_{2}$

\begin{tabular}{|c|c|c|c|c|c|c|c|c|c|c|c|c|c|c|c|}
\hline $\mathrm{c} 1$ & $\mathrm{c} 2$ & d & $\mathrm{p}$ & uo & $\mathrm{u}$ & $\mathrm{u}^{\prime}$ & wp1o & wp1 & wp1' & $\mathrm{K} 1$ & Fsd & Msd & $\beta o$ & $\beta$ & $\beta^{\prime}$ \\
\hline 20 & 20 & 12,0 & 25 & 80 & 231 & 388 & 1862 & 5372 & 15243 & 0,600 & 100 & 1000 & 1,26 & 1,26 & 1,15 \\
\hline 20 & 30 & 12,0 & 25 & 100 & 251 & 408 & 2413 & 6052 & 16423 & 0,501 & 150 & 1100 & 1,15 & 1,15 & 1,09 \\
\hline 20 & 40 & 12,0 & 25 & 120 & 271 & 428 & 2983 & 6732 & 17603 & 0,450 & 200 & 1200 & 1,11 & 1,11 & 1,07 \\
\hline 20 & 50 & 12,0 & 25 & 140 & 291 & 448 & 3568 & 7412 & 18783 & 0,450 & 250 & 1300 & 1,09 & 1,09 & 1,06 \\
\hline 20 & 60 & 12,0 & 25 & 160 & 311 & 468 & 4166 & 8092 & 19963 & 0,450 & 300 & 1400 & 1,08 & 1,08 & 1,05 \\
\hline 20 & 20 & 14,0 & 29 & 80 & 256 & 438 & 2068 & 6615 & 19457 & 0,600 & 100 & 1000 & 1,23 & 1,23 & 1,14 \\
\hline 20 & 30 & 14,0 & 29 & 100 & 276 & 458 & 2673 & 7375 & 20797 & 0,501 & 150 & 1100 & 1,14 & 1,14 & 1,08 \\
\hline 20 & 40 & 14,0 & 29 & 120 & 296 & 478 & 3299 & 8135 & 22137 & 0,450 & 200 & 1200 & 1,10 & 1,10 & 1,06 \\
\hline 20 & 50 & 14,0 & 29 & 140 & 316 & 498 & 3942 & 8895 & 23477 & 0,450 & 250 & 1300 & 1,08 & 1,08 & 1,05 \\
\hline 20 & 60 & 14,0 & 29 & 160 & 336 & 518 & 4599 & 9655 & 24817 & 0,450 & 300 & 1400 & 1,07 & 1,07 & 1,04 \\
\hline 20 & 20 & 16,0 & 33 & 80 & 281 & 488 & 2273 & 7987 & 24184 & 0,600 & 100 & 1000 & 1,21 & 1,21 & 1,12 \\
\hline 20 & 30 & 16,0 & 33 & 100 & 301 & 508 & 2932 & 8827 & 25684 & 0,501 & 150 & 1100 & 1,13 & 1,13 & 1,07 \\
\hline 20 & 40 & 16,0 & 33 & 120 & 321 & 528 & 3613 & 9667 & 27184 & 0,450 & 200 & 1200 & 1,09 & 1,09 & 1,05 \\
\hline 20 & 50 & 16,0 & 33 & 140 & 341 & 548 & 4313 & 10507 & 28684 & 0,450 & 250 & 1300 & 1,08 & 1,08 & 1,04 \\
\hline 20 & 60 & 16,0 & 33 & 160 & 361 & 568 & 5028 & 11347 & 30184 & 0,450 & 300 & 1400 & 1,07 & 1,07 & 1,04 \\
\hline 20 & 20 & 18,0 & 38 & 80 & 306 & 545 & 2478 & 9486 & 30114 & 0,600 & 100 & 1000 & 1,19 & 1,19 & 1,11 \\
\hline 20 & 30 & 18,0 & 38 & 100 & 326 & 565 & 3190 & 10406 & 31794 & 0,501 & 150 & 1100 & 1,12 & 1,12 & 1,07 \\
\hline 20 & 40 & 18,0 & 38 & 120 & 346 & 585 & 3926 & 11326 & 33474 & 0,450 & 200 & 1200 & 1,08 & 1,08 & 1,05 \\
\hline 20 & 50 & 18,0 & 38 & 140 & 366 & 605 & 4682 & 12246 & 35154 & 0,450 & 250 & 1300 & 1,07 & 1,07 & 1,04 \\
\hline 20 & 60 & 18,0 & 38 & 160 & 386 & 625 & 5455 & 13166 & 36834 & 0,450 & 300 & 1400 & 1,06 & 1,06 & 1,04 \\
\hline 20 & 20 & 20,0 & 40 & 80 & 331 & 583 & 2683 & 11113 & 34427 & 0,600 & 100 & 1000 & 1,18 & 1,18 & 1,10 \\
\hline 20 & 30 & 20,0 & 40 & 100 & 351 & 603 & 3448 & 12113 & 36227 & 0,501 & 150 & 1100 & 1,11 & 1,11 & 1,06 \\
\hline 20 & 40 & 20,0 & 40 & 120 & 371 & 623 & 4238 & 13113 & 38027 & 0,450 & 200 & 1200 & 1,08 & 1,08 & 1,04 \\
\hline 20 & 50 & 20,0 & 40 & 140 & 391 & 643 & 5049 & 14113 & 39827 & 0,450 & 250 & 1300 & 1,06 & 1,06 & 1,04 \\
\hline 20 & 60 & 20,0 & 40 & 160 & 411 & 663 & 5879 & 15113 & 41627 & 0,450 & 300 & 1400 & 1,06 & 1,06 & 1,03 \\
\hline 20 & 20 & 22,0 & 45 & 80 & 356 & 639 & 2888 & 12869 & 41436 & 0,600 & 100 & 1000 & 1,17 & 1,17 & 1,09 \\
\hline 20 & 30 & 22,0 & 45 & 100 & 376 & 659 & 3705 & 13949 & 43416 & 0,501 & 150 & 1100 & 1,10 & 1,10 & 1,06 \\
\hline 20 & 40 & 22,0 & 45 & 120 & 396 & 679 & 4549 & 15029 & 45396 & 0,450 & 200 & 1200 & 1,07 & 1,07 & 1,04 \\
\hline 20 & 50 & 22,0 & 45 & 140 & 416 & 699 & 5415 & 16109 & 47376 & 0,450 & 250 & 1300 & 1,06 & 1,06 & 1,03 \\
\hline 20 & 60 & 22,0 & 45 & 160 & 436 & 719 & 6301 & 17189 & 49356 & 0,450 & 300 & 1400 & 1,05 & 1,05 & 1,03 \\
\hline 25 & \begin{tabular}{|l|}
40 \\
\end{tabular} & 12,0 & 25 & 130 & \begin{tabular}{|l|}
281 \\
\end{tabular} & 438 & 3436 & 7421 & 18685 & 0,489 & 250 & 1500 & 1,11 & 1,11 & 1,07 \\
\hline
\end{tabular}




\begin{tabular}{|c|c|c|c|c|c|c|c|c|c|c|c|c|c|c|c|}
\hline $\mathrm{c} 1$ & c2 & d & $\mathrm{p}$ & uo & $\mathrm{u}$ & $\mathrm{u}^{\prime}$ & wp1o & wp1 & wp1' & $\mathrm{K} 1$ & Fsd & Msd & $\beta o$ & $\beta$ & $\beta^{\prime}$ \\
\hline 25 & 50 & 12,0 & 25 & 150 & 301 & 458 & 4065 & 8151 & 19915 & 0,450 & 350 & 1600 & 1,08 & 1,08 & 1,05 \\
\hline 25 & 60 & 12,0 & 25 & 170 & 321 & 478 & 4707 & 8881 & 21145 & 0,450 & 450 & 1700 & 1,06 & 1,06 & 1,04 \\
\hline 25 & 75 & 12,0 & 25 & 200 & 351 & 508 & 5688 & 9976 & 22990 & 0,450 & 500 & 1800 & 1,06 & 1,06 & 1,04 \\
\hline 25 & 40 & 14,0 & 29 & 130 & 306 & 488 & 3777 & 8888 & 23345 & 0,489 & 250 & 1500 & 1,10 & 1,10 & 1,06 \\
\hline 25 & 50 & 14,0 & 29 & 150 & 326 & 508 & 4463 & 9698 & 24735 & 0,450 & 350 & 1600 & 1,07 & 1,07 & 1,04 \\
\hline 25 & 60 & 14,0 & 29 & 170 & 346 & 528 & 5164 & 10508 & 26125 & 0,450 & 450 & 1700 & 1,06 & 1,06 & 1,03 \\
\hline 25 & 75 & 14,0 & 29 & 200 & 376 & 558 & 6237 & 11723 & 28210 & 0,450 & 500 & 1800 & 1,05 & 1,05 & 1,03 \\
\hline 25 & 40 & 16,0 & 33 & 130 & 331 & 538 & 4116 & 10482 & 28518 & 0,489 & 250 & 1500 & 1,09 & 1,09 & 1,06 \\
\hline 25 & 50 & 16,0 & 33 & 150 & 351 & 558 & 4859 & 11372 & 30068 & 0,450 & 350 & 1600 & 1,06 & 1,06 & 1,04 \\
\hline 25 & 60 & 16,0 & 33 & 170 & 371 & 578 & 5618 & 12262 & 31618 & 0,450 & 450 & 1700 & 1,05 & 1,05 & 1,03 \\
\hline 25 & 75 & 16,0 & 33 & 200 & 401 & 608 & 6780 & 13597 & 33943 & 0,450 & 500 & 1800 & 1,05 & 1,05 & 1,03 \\
\hline 25 & 40 & 18,0 & 38 & 130 & 356 & 595 & 4454 & 12204 & 34948 & 0,489 & 250 & 1500 & 1,09 & 1,09 & 1,05 \\
\hline 25 & 50 & 18,0 & 38 & 150 & 376 & 615 & 5253 & 13174 & 36678 & 0,450 & 350 & 1600 & 1,06 & 1,06 & 1,03 \\
\hline 25 & 60 & 18,0 & 38 & 170 & 396 & 635 & 6069 & 14144 & 38408 & 0,450 & 450 & 1700 & 1,05 & 1,05 & 1,03 \\
\hline 25 & 75 & 18,0 & 38 & 200 & 426 & 665 & 7320 & 15599 & 41003 & 0,450 & 500 & 1800 & 1,04 & 1,04 & 1,03 \\
\hline 25 & 40 & 20,0 & 40 & 130 & 381 & 633 & 4791 & 14054 & 39596 & 0,489 & 250 & 1500 & 1,08 & 1,08 & 1,05 \\
\hline 25 & 50 & 20,0 & 40 & 150 & 401 & 653 & 5645 & 15104 & 41446 & 0,450 & 350 & 1600 & 1,05 & 1,05 & 1,03 \\
\hline 25 & 60 & 20,0 & 40 & 170 & 421 & 673 & 6518 & 16154 & 43296 & 0,450 & 450 & 1700 & 1,04 & 1,04 & 1,03 \\
\hline 25 & 75 & 20,0 & 40 & 200 & 451 & 703 & 7856 & 17729 & 46071 & 0,450 & 500 & 1800 & 1,04 & 1,04 & 1,02 \\
\hline 25 & 40 & 22,0 & 45 & 130 & 406 & 689 & 5128 & 16032 & 47107 & 0,489 & 250 & 1500 & 1,07 & 1,07 & 1,04 \\
\hline 25 & 50 & 22,0 & 45 & 150 & 426 & 709 & 6037 & 17162 & 49137 & 0,450 & 350 & 1600 & 1,05 & 1,05 & 1,03 \\
\hline 25 & 60 & 22,0 & 45 & 170 & 446 & 729 & 6965 & 18292 & 51167 & 0,450 & 450 & 1700 & 1,04 & 1,04 & 1,02 \\
\hline 25 & 75 & 22,0 & 45 & 200 & 476 & 759 & 8390 & 19987 & 54212 & 0,450 & 500 & 1800 & 1,04 & 1,04 & 1,02 \\
\hline 30 & 30 & 12,0 & 25 & 120 & 271 & 428 & 3260 & 7356 & 18512 & 0,600 & 250 & 1600 & 1,14 & 1,14 & 1,09 \\
\hline 30 & 40 & 12,0 & 25 & 140 & 291 & 448 & 3917 & 8136 & 19792 & 0,525 & 350 & 1800 & 1,10 & 1,10 & 1,06 \\
\hline 30 & 50 & 12,0 & 25 & 160 & 311 & 468 & 4590 & 8916 & 21072 & 0,480 & 450 & 2000 & 1,07 & 1,07 & 1,05 \\
\hline 30 & 60 & 12,0 & 25 & 180 & 331 & 488 & 5276 & 9696 & 22352 & 0,450 & 500 & 2200 & 1,07 & 1,07 & 1,04 \\
\hline 30 & 70 & 12,0 & 25 & 200 & 351 & 508 & 5973 & 10476 & 23632 & 0,450 & 500 & 2400 & 1,07 & 1,07 & 1,05 \\
\hline 30 & 80 & 12,0 & 25 & 220 & 371 & 528 & 6678 & 11256 & 24912 & 0,450 & 600 & 2600 & 1,06 & 1,06 & 1,04 \\
\hline 30 & 90 & 12,0 & 25 & 240 & 391 & 548 & 7392 & 12036 & 26192 & 0,450 & 650 & 2800 & 1,06 & 1,06 & 1,04 \\
\hline 30 & 30 & 14,0 & 29 & 120 & 296 & 478 & 3570 & 8805 & 23138 & 0,600 & 250 & 1600 & 1,13 & 1,13 & 1,08 \\
\hline 30 & 40 & 14,0 & 29 & 140 & 316 & 498 & 4283 & 9665 & 24578 & 0,525 & 300 & 1800 & 1,10 & 1,10 & 1,06 \\
\hline 30 & 50 & 14,0 & 29 & 160 & 336 & 518 & 5013 & 10525 & 26018 & 0,480 & 350 & 2000 & 1,09 & 1,09 & 1,05 \\
\hline
\end{tabular}




\begin{tabular}{|c|c|c|c|c|c|c|c|c|c|c|c|c|c|c|c|}
\hline $\mathrm{c} 1$ & $\mathrm{c} 2$ & d & $\mathrm{p}$ & uo & $\mathrm{u}$ & $\mathrm{u}^{\prime}$ & wp1o & wp1 & $\mathrm{wp1}^{\prime}$ & $\mathrm{K} 1$ & Fsd & Msd & o & $\beta$ & $\beta$ \\
\hline 30 & 60 & 14,0 & 29 & 180 & 356 & 538 & 5758 & 11385 & 27458 & 0,450 & 450 & 2200 & 1,07 & 1,07 & 1,04 \\
\hline 30 & 70 & 14,0 & 29 & 200 & 376 & 558 & 6514 & 12245 & 28898 & 0,450 & 500 & 2400 & 1,07 & 1,07 & 1,04 \\
\hline 30 & 80 & 14,0 & 29 & 220 & 396 & 578 & 7282 & 13105 & 30338 & 0,450 & 600 & 2600 & 1,06 & 1,06 & 1,04 \\
\hline 30 & \begin{tabular}{|l|}
90 \\
\end{tabular} & 14,0 & 29 & 240 & 416 & 598 & 8058 & 13965 & 31778 & 0,450 & 650 & 2800 & 1,06 & 1,06 & 1,04 \\
\hline 30 & 30 & 16,0 & 33 & 120 & 321 & 528 & 3880 & 10382 & 28276 & 0,600 & 250 & 1600 & 1,12 & 1,12 & 1,07 \\
\hline 30 & $\begin{array}{l}40 \\
\end{array}$ & 16,0 & 33 & 140 & 341 & 548 & 4647 & 11322 & 29876 & 0,525 & 300 & 1800 & 1,09 & 1,09 & 1,06 \\
\hline 30 & 50 & 16,0 & 33 & 160 & 361 & 568 & 5434 & 12262 & 31476 & 0,480 & 350 & 2000 & 1,08 & 1,08 & 1,05 \\
\hline 30 & 60 & 16,0 & 33 & 180 & 381 & 588 & 6236 & 13202 & 33076 & 0,450 & 450 & 2200 & 1,06 & 1,06 & 1,04 \\
\hline 30 & $\begin{array}{l}70 \\
\end{array}$ & 16,0 & 33 & 200 & 401 & 608 & 7052 & 14142 & 34676 & 0,450 & 500 & 2400 & 1,06 & 1,06 & 1,04 \\
\hline 30 & 80 & 16,0 & 33 & 220 & 421 & 628 & 7880 & 15082 & 36276 & 0,450 & 600 & 2600 & 1,05 & 1,05 & 1,03 \\
\hline 30 & \begin{tabular}{|l|}
90 \\
\end{tabular} & 16,0 & 33 & 240 & 441 & 648 & 8718 & 16022 & 37876 & 0,450 & 650 & 2800 & 1,05 & 1,05 & 1,03 \\
\hline 30 & 30 & 18,0 & 38 & 120 & 346 & 585 & 4190 & 12087 & 34668 & 0,600 & 250 & 1600 & 1,11 & 1,11 & 1,06 \\
\hline 30 & 40 & 18,0 & 38 & 140 & 366 & 605 & 5011 & 13107 & 36448 & 0,525 & 300 & 1800 & 1,09 & 1,09 & 1,05 \\
\hline 30 & 50 & 18,0 & 38 & 160 & 386 & 625 & 5853 & 14127 & 38228 & 0,480 & 350 & 2000 & 1,07 & 1,07 & 1,04 \\
\hline 30 & 60 & 18,0 & 38 & 180 & 406 & 645 & 6712 & 15147 & 40008 & 0,450 & 450 & 2200 & 1,06 & 1,06 & 1,04 \\
\hline 30 & 70 & 18,0 & 38 & 200 & 426 & 665 & 7587 & 16167 & 41788 & 0,450 & 500 & 2400 & 1,06 & 1,06 & 1,03 \\
\hline 30 & \begin{tabular}{|l|}
80 \\
\end{tabular} & 18,0 & 38 & 220 & 446 & 685 & 8474 & 17187 & 43568 & 0,450 & 600 & 2600 & 1,05 & 1,05 & 1,03 \\
\hline 30 & 90 & 18,0 & 38 & 240 & 466 & 705 & 9373 & 18207 & 45348 & 0,450 & 650 & 2800 & 1,05 & 1,05 & 1,03 \\
\hline 30 & 30 & 20,0 & 40 & 120 & 371 & 623 & 4498 & 13920 & 39290 & 0,600 & 250 & 1600 & 1,10 & 1,10 & 1,06 \\
\hline 30 & $\begin{array}{l}40 \\
\end{array}$ & 20,0 & 40 & 140 & 391 & 643 & 5373 & 15020 & 41190 & 0,525 & 300 & 1800 & 1,08 & 1,08 & 1,05 \\
\hline 30 & 50 & 20,0 & 40 & 160 & 411 & 663 & 6270 & 16120 & 43090 & 0,480 & 350 & 2000 & 1,07 & 1,07 & 1,04 \\
\hline 30 & 60 & 20,0 & 40 & 180 & 431 & 683 & 7186 & 17220 & 44990 & 0,450 & 450 & 2200 & 1,06 & 1,06 & 1,03 \\
\hline 30 & 70 & 20,0 & 40 & 200 & 451 & 703 & 8118 & 18320 & 46890 & 0,450 & 500 & 2400 & 1,05 & 1,05 & 1,03 \\
\hline 30 & 80 & 20,0 & 40 & 220 & 471 & 723 & 9065 & 19420 & 48790 & 0,450 & 600 & 2600 & 1,05 & 1,05 & 1,03 \\
\hline 30 & 90 & 20,0 & 40 & 240 & 491 & 743 & 10023 & 20520 & 50690 & 0,450 & 650 & 2800 & 1,05 & 1,05 & 1,03 \\
\hline 30 & 30 & 22,0 & 45 & 120 & 396 & 679 & 4807 & 15881 & 46762 & 0,600 & 250 & 1600 & 1,10 & 1,10 & 1,06 \\
\hline 30 & 40 & 22,0 & 45 & \begin{tabular}{|l|}
140 \\
\end{tabular} & 416 & 699 & 5735 & 17061 & 48842 & 0,525 & 300 & 1800 & 1,08 & 1,08 & 1,05 \\
\hline 30 & 50 & 22,0 & 45 & 160 & 436 & 719 & 6687 & 18241 & 50922 & 0,480 & 350 & 2000 & 1,07 & 1,07 & 1,04 \\
\hline 30 & 60 & 22,0 & 45 & 180 & 456 & 739 & 7658 & 19421 & 53002 & 0,450 & 450 & 2200 & 1,05 & 1,05 & 1,03 \\
\hline 30 & 70 & 22,0 & 45 & 200 & 476 & 759 & 8647 & 20601 & 55082 & 0,450 & 500 & 2400 & 1,05 & 1,05 & 1,03 \\
\hline 30 & 80 & 22,0 & 45 & 220 & 496 & 7779 & 9652 & 21781 & 57162 & 0,450 & 600 & 2600 & 1,04 & 1,04 & 1,03 \\
\hline 30 & 90 & 22,0 & 45 & 240 & 516 & 799 & 10670 & 22961 & 59242 & 0,450 & 650 & 2800 & 1,04 & 1,04 & 1,03 \\
\hline & & & & & & & & & & & & média & 1,08 & 1,08 & 1,05 \\
\hline & & & & & & & & & & & & desvio & 0,0411 & 0,0411 & 0,0237 \\
\hline
\end{tabular}


Tabela C.5 - Valores de $\beta$ para pilares internos com momento atuante em uma direção e $c_{1}>c_{2}$

\begin{tabular}{|c|c|c|c|c|c|c|c|c|c|c|c|c|c|c|c|}
\hline $\mathrm{c} 1$ & c2 & d & $\mathrm{p}$ & uo & $\mathrm{u}$ & $\mathrm{u}^{\prime}$ & wp1o & wp1 & wp1' & $\mathrm{K} 1$ & Fsd & Msd1 & ßo & $\beta$ & $\beta^{\prime}$ \\
\hline 30 & 20 & 12,0 & 25 & 100 & 251 & 408 & 2622 & 6576 & 17232 & 0,650 & 150 & 1100 & 1,18 & 1,18 & 1,11 \\
\hline 30 & 20 & 14,0 & \begin{tabular}{|l|}
29 \\
\end{tabular} & 100 & 276 & 458 & 2879 & 7945 & 21698 & 0,650 & 150 & 1100 & 1,17 & 1,17 & 1,10 \\
\hline 30 & 20 & 16,0 & 33 & 100 & 301 & 508 & 3136 & 9442 & 26676 & 0,650 & 150 & 1100 & 1,15 & 1,15 & 1,09 \\
\hline 30 & 20 & 18,0 & 38 & 100 & 326 & 565 & 3393 & 11067 & 32888 & 0,650 & 150 & 1100 & 1,14 & 1,14 & 1,08 \\
\hline 30 & 20 & 20,0 & 40 & 100 & 351 & 603 & 3649 & 12820 & 37390 & 0,650 & 150 & 1100 & 1,13 & 1,13 & 1,08 \\
\hline 30 & 20 & 22,0 & 45 & 100 & 376 & 659 & 3905 & 14701 & 44682 & 0,650 & 150 & 1100 & 1,12 & 1,12 & 1,07 \\
\hline 40 & 20 & 12,0 & $25 \mid$ & 120 & 271 & 428 & 3492 & 7880 & 19322 & 0,700 & 200 & 1200 & 1,14 & 1,14 & 1,09 \\
\hline 40 & 25 & 12,0 & 25 & 130 & 281 & 438 & 3852 & 8320 & 20012 & 0,660 & 250 & 1500 & 1,13 & 1,13 & 1,09 \\
\hline 40 & 30 & 12,0 & $25 \mid$ & 140 & 291 & 448 & 4217 & 8760 & 20702 & 0,633 & 350 & 1800 & 1,11 & 1,11 & 1,07 \\
\hline 40 & 20 & 14,0 & $29 \mid$ & 120 & 296 & 478 & 3801 & 9375 & 24039 & 0,700 & 200 & 1200 & 1,13 & 1,13 & 1,08 \\
\hline 40 & 25 & 14,0 & 29 & 130 & 306 & 488 & 4188 & 9855 & 24809 & 0,660 & 250 & 1500 & 1,12 & 1,12 & 1,08 \\
\hline 40 & 30 & 14,0 & $29 \mid$ & 140 & 316 & 498 & 4580 & 10335 & 25579 & 0,633 & 300 & 1800 & 1,12 & 1,12 & 1,07 \\
\hline 40 & 20 & 16,0 & 33 & 120 & 321 & 528 & 4110 & 10997 & 29268 & 0,700 & 200 & 1200 & 1,12 & 1,12 & 1,08 \\
\hline 40 & 25 & 16,0 & 33 & 130 & 331 & 538 & 4523 & 11517 & 30118 & 0,660 & 250 & 1500 & 1,11 & 1,11 & 1,07 \\
\hline 40 & 30 & 16,0 & 33 & 140 & 341 & 548 & 4941 & 12037 & 30968 & 0,633 & 300 & 1800 & 1,11 & 1,11 & 1,07 \\
\hline 40 & 20 & 18,0 & 38 . & 120 & 346 & 585 & 4419 & 12748 & 35763 & 0,700 & 200 & 1200 & 1,11 & 1,11 & 1,07 \\
\hline 40 & $25 \mid$ & 18,0 & 38 & 130 & 356 & 595 & 4857 & 13308 & 36703 & 0,660 & 250 & 1500 & 1,11 & 1,11 & 1,06 \\
\hline 40 & 30 & 18,0 & 38 | & 140 & 366 & 605 & 5302 & 13868 & 37643 & 0,633 & 300 & 1800 & 1,10 & 1,10 & 1,06 \\
\hline 40 & 20 & 20,0 & 40 & 120 & 371 & 623 & 4727 & 14627 & 40453 & 0,700 & 200 & 1200 & 1,11 & 1,11 & 1,06 \\
\hline 40 & 25 & 20,0 & 40 & 130 & 381 & 633 & 5191 & 15227 & 41453 & 0,660 & 250 & 1500 & 1,10 & 1,10 & 1,06 \\
\hline 40 & 30 & 20,0 & $40 \mid$ & 140 & 391 & 643 & 5662 & 15827 & 42453 & 0,633 & 300 & 1800 & 1,09 & 1,09 & 1,06 \\
\hline 40 & 20 & 22,0 & 45 & 120 & 396 & 679 & 5035 & 16633 & 48028 & 0,700 & 200 & 1200 & 1,10 & 1,10 & 1,06 \\
\hline 40 & 25 & 22,0 & 45 & 130 & 406 & 689 & 5525 & 17273 & 49118 & 0,660 & 250 & 1500 & 1,09 & 1,09 & 1,06 \\
\hline 40 & 30 & 22,0 & 45 & 140 & 416 & 699 & 6022 & 17913 & 50208 & 0,633 & 300 & 1800 & 1,09 & 1,09 & 1,05 \\
\hline 50 & 20 & 12,0 & $25 \mid$ & 140 & 291 & 448 & 4470 & 9284 & 21511 & 0,750 & 250 & 1300 & 1,12 & 1,12 & 1,08 \\
\hline 50 & 25 & 12,0 & 25 & 150 & 301 & 458 & 4874 & 9774 & 22251 & 0,700 & 350 & 1600 & 1,10 & 1,10 & 1,07 \\
\hline 50 & 30 & 12,0 & $25 \mid$ & 160 & 311 & 468 & 5284 & 10264 & 22991 & 0,667 & 450 & 2000 & 1,09 & 1,09 & 1,06 \\
\hline 50 & 20 & 14,0 & \begin{tabular}{|l|}
29 \\
\end{tabular} & 140 & 316 & 498 & 4832 & 10904 & 26480 & 0,750 & 250 & 1300 & 1,11 & 1,11 & 1,07 \\
\hline 50 & 25 & 14,0 & $29 \mid$ & 150 & 326 & 508 & 5262 & 11434 & 27300 & 0,700 & 350 & 1600 & 1,09 & 1,09 & 1,06 \\
\hline 50 & 30 & 14,0 & $29 \mid$ & 160 & 336 & 518 & 5698 & 11964 & 28120 & 0,667 & 350 & 2000 & 1,11 & 1,11 & 1,07 \\
\hline 50 & 20 & 16,0 & $|33|$ & 140 & 341 & 548 & 5194 & 12653 & 31960 & 0,750 & 250 & 1300 & 1,11 & 1,11 & 1,07 \\
\hline
\end{tabular}




\begin{tabular}{|c|c|c|c|c|c|c|c|c|c|c|c|c|c|c|c|}
\hline c1 & \begin{tabular}{|l|} 
c2 \\
\end{tabular} & d & $\mathrm{p}$ & uo & $\mathrm{u}$ & $\mathrm{u}^{\prime}$ & wplo & wp1 & wp1' & K1 & Fsd & Msd1 & Bo & $\beta$ & $\beta^{\prime}$ \\
\hline 50 & 25 & 16,0 & 33 & 150 & 351 & 558 & 5650 & 13223 & 32860 & 0,700 & 350 & 1600 & 1,08 & 1,08 & 1,05 \\
\hline 50 & 30 & 16,0 & 33 & 160 & 361 & 568 & 6112 & 13793 & 33760 & 0,667 & 350 & 2000 & 1,10 & 1,10 & 1,06 \\
\hline 50 & 20 & 18,0 & 38 & 140 & 366 & 605 & 5555 & 14529 & 38738 & 0,750 & 250 & 1300 & 1,10 & 1,10 & 1,06 \\
\hline 50 & 25 & 18,0 & 38 & 150 & 376 & 615 & 6036 & 15139 & 39728 & 0,700 & 350 & 1600 & 1,08 & 1,08 & 1,05 \\
\hline 50 & 30 & 18,0 & 38 & 160 & 386 & 625 & 6525 & 15749 & 40718 & 0,667 & 350 & 2000 & 1,09 & 1,09 & 1,06 \\
\hline 50 & 20 & 20,0 & 40 & 140 & 391 & 643 & 5915 & 16533 & 43616 & 0,750 & 250 & 1300 & 1,09 & 1,09 & 1,06 \\
\hline 50 & 25 & 20,0 & 40 & 150 & 401 & 653 & 6422 & 17183 & 44666 & 0,700 & 350 & 1600 & 1,07 & 1,07 & 1,05 \\
\hline 50 & 30 & 20,0 & 40 & 160 & 411 & 663 & 6937 & 17833 & 45716 & 0,667 & 350 & 2000 & 1,09 & 1,09 & 1,06 \\
\hline 50 & 20 & 22,0 & 45 & 140 & 416 & 699 & 6275 & 18666 & 51474 & 0,750 & 250 & 1300 & 1,09 & 1,09 & 1,05 \\
\hline 50 & 25 & 22,0 & 45 & 150 & 426 & 709 & 6808 & 19356 & 52614 & 0,700 & 350 & 1600 & 1,07 & 1,07 & 1,04 \\
\hline 50 & 30 & 22,0 & 45 & 160 & 436 & 719 & 7348 & 20046 & 53754 & 0,667 & 350 & 2000 & 1,08 & 1,08 & 1,05 \\
\hline 60 & 20 & 12,0 & 25 & 160 & 311 & 468 & 5554 & 10788 & 23800 & 0,800 & 300 & 1400 & 1,11 & 1,11 & 1,07 \\
\hline 60 & 25 & 12,0 & 25 & 170 & 321 & 478 & 6003 & 11328 & 24590 & 0,740 & 450 & 1700 & 1,08 & 1,08 & 1,05 \\
\hline 60 & 30 & 12,0 & 25 & 180 & 331 & 488 & 6458 & 11868 & 25380 & 0,700 & 500 & 2200 & 1,09 & 1,09 & 1,06 \\
\hline 60 & 20 & 14,0 & 29 & 160 & 336 & 518 & 5970 & 12534 & 29020 & 0,800 & 300 & 1400 & 1,10 & 1,10 & 1,07 \\
\hline 60 & 25 & 14,0 & 29 & 170 & 346 & 528 & 6445 & 13114 & 29890 & 0,740 & 450 & 1700 & 1,07 & 1,07 & 1,05 \\
\hline 60 & 30 & 14,0 & 29 & 180 & 356 & 538 & 6925 & 13694 & 30760 & 0,700 & 450 & 2200 & 1,09 & 1,09 & 1,06 \\
\hline 60 & 20 & 16,0 & 33 & 160 & 361 & 568 & 6385 & 14408 & 34752 & 0,800 & 300 & 1400 & 1,09 & 1,09 & 1,06 \\
\hline 60 & 25 & 16,0 & 33 & 170 & 371 & 578 & 6885 & 15028 & 35702 & 0,740 & 450 & 1700 & 1,07 & 1,07 & 1,05 \\
\hline 60 & 30 & 16,0 & 33 & 180 & 381 & 588 & 7391 & 15648 & 36652 & 0,700 & 450 & 2200 & 1,08 & 1,08 & 1,05 \\
\hline 60 & 20 & 18,0 & 38 & 160 & 386 & 625 & 6799 & 16410 & 41813 & 0,800 & 300 & 1400 & 1,09 & 1,09 & 1,06 \\
\hline 60 & 25 & 18,0 & 38 & 170 & 396 & 635 & 7324 & 17070 & 42853 & 0,740 & 450 & 1700 & 1,06 & 1,06 & 1,04 \\
\hline 60 & 30 & 18,0 & 38 & 180 & 406 & 645 & 7857 & 17730 & 43893 & 0,700 & 450 & 2200 & 1,08 & 1,08 & 1,05 \\
\hline 60 & 20 & 20,0 & 40 & 160 & 411 & 663 & 7212 & 18540 & 46880 & 0,800 & 300 & 1400 & 1,08 & 1,08 & 1,05 \\
\hline 60 & 25 & 20,0 & 40 & 170 & 421 & 673 & 7763 & 19240 & 47980 & 0,740 & 450 & 1700 & 1,06 & 1,06 & 1,04 \\
\hline 60 & 30 & 20,0 & 40 & 180 & 431 & 683 & 8321 & 19940 & 49080 & 0,700 & 450 & 2200 & 1,07 & 1,07 & 1,05 \\
\hline 60 & 20 & 22,0 & 45 & 160 & 436 & 719 & 7624 & 20798 & 55020 & 0,800 & 300 & 1400 & 1,08 & 1,08 & 1,05 \\
\hline 60 & 25 & 22,0 & 45 & 170 & 446 & 729 & 8201 & 21538 & 56210 & 0,740 & 450 & 1700 & 1,06 & 1,06 & 1,04 \\
\hline 60 & 30 & 22,0 & 45 & 180 & 456 & 739 & 8785 & 22278 & 57400 & 0,700 & 450 & 2200 & 1,07 & 1,07 & 1,04 \\
\hline 70 & 30 & 12,0 & 25 & 200 & 351 & 508 & 7738 & 13572 & 27870 & 0,733 & 500 & 2400 & 1,09 & 1,09 & 1,06 \\
\hline 70 & 30 & 14,0 & 29 & 200 & 376 & 558 & 8259 & 15524 & 33501 & 0,733 & 500 & 2400 & 1,09 & 1,09 & 1,06 \\
\hline 70 & 30 & 16,0 & 33 & 200 & 401 & 608 & 8778 & 17603 & 39644 & 0,733 & 500 & 2400 & 1,08 & 1,08 & 1,05 \\
\hline 70 & 30 & 18,0 & 38 & 200 & 426 & 665 & 9297 & 19811 & 47167 & 0,733 & 500 & 2400 & 1,08 & 1,08 & 1,05 \\
\hline
\end{tabular}




\begin{tabular}{|c|c|c|c||c|c|c||c|c|c||c||c|c||c|c|c|}
$\mathrm{c} 1$ & $\mathrm{c} 2$ & $\mathrm{~d}$ & $\mathrm{p}$ & $\mathrm{uo}$ & $\mathrm{u}$ & $\mathrm{u}^{\prime}$ & $\mathrm{wp} 1 \mathrm{0}$ & $\mathrm{wp} 1$ & $\mathrm{wp1}$ & $\mathrm{K} 1$ & $\mathrm{Fsd}$ & $\mathrm{Msd}$ & $\beta \mathrm{O}$ & $\beta$ & $\beta^{\prime}$ \\
\hline 70 & 30 & 20,0 & 40 & 200 & 451 & 703 & 9814 & 22146 & 52543 & 0,733 & 500 & 2400 & 1,07 & 1,07 & 1,05 \\
\hline 70 & 30 & 22,0 & 45 & 200 & 476 & 759 & 10330 & 24610 & 61146 & 0,733 & 500 & 2400 & 1,07 & 1,07 & 1,04 \\
\hline 75 & 25 & 12,0 & 25 & 200 & 351 & 508 & 7894 & 13846 & 28287 & 0,800 & 500 & 1800 & 1,07 & 1,07 & 1,05 \\
\hline 75 & 25 & 14,0 & 29 & 200 & 376 & 558 & 8417 & 15821 & 33964 & 0,800 & 500 & 1800 & 1,07 & 1,07 & 1,05 \\
\hline 75 & 25 & 16,0 & 33 & 200 & 401 & 608 & 8938 & 17923 & 40153 & 0,800 & 500 & 1800 & 1,06 & 1,06 & 1,04 \\
\hline 75 & 25 & 18,0 & 38 & 200 & 426 & 665 & 9458 & 20154 & 47727 & 0,800 & 500 & 1800 & 1,06 & 1,06 & 1,04 \\
\hline 75 & 25 & 20,0 & 40 & 200 & 451 & 703 & 9976 & 22512 & 53137 & 0,800 & 500 & 1800 & 1,06 & 1,06 & 1,04 \\
\hline 75 & 25 & 22,0 & 45 & 200 & 476 & 759 & 10494 & 24999 & 61792 & 0,800 & 500 & 1800 & 1,05 & 1,05 & 1,04 \\
\hline 80 & 30 & 12,0 & 25 & 220 & 371 & 528 & 9123 & 15376 & 30459 & 0,767 & 600 & 2600 & 1,08 & 1,08 & 1,06 \\
\hline 80 & 30 & 14,0 & 29 & 220 & 396 & 578 & 9698 & 17453 & 36342 & 0,767 & 600 & 2600 & 1,08 & 1,08 & 1,05 \\
\hline 80 & 30 & 16,0 & 33 & 220 & 421 & 628 & 10271 & 19658 & 42736 & 0,767 & 600 & 2600 & 1,07 & 1,07 & 1,05 \\
\hline 80 & 30 & 18,0 & 38 & 220 & 446 & 685 & 10843 & 21992 & 50542 & 0,767 & 600 & 2600 & 1,07 & 1,07 & 1,05 \\
\hline 80 & 30 & 20,0 & 40 & 220 & 471 & 723 & 11414 & 24453 & 56106 & 0,767 & 600 & 2600 & 1,06 & 1,06 & 1,04 \\
\hline 80 & 30 & 22,0 & 45 & 220 & 496 & 779 & 11983 & 27042 & 64992 & 0,767 & 600 & 2600 & 1,06 & 1,06 & 1,04 \\
\hline 90 & 30 & 12,0 & 25 & 240 & 391 & 548 & 10612 & 17280 & 33148 & 0,800 & 650 & 2800 & 1,08 & 1,08 & 1,06 \\
\hline 90 & 30 & 14,0 & 29 & 240 & 416 & 598 & 11242 & 19483 & 39282 & 0,800 & 650 & 2800 & 1,07 & 1,07 & 1,05 \\
\hline 90 & 30 & 16,0 & 33 & 240 & 441 & 648 & 11870 & 21814 & 45928 & 0,800 & 650 & 2800 & 1,07 & 1,07 & 1,05 \\
\hline 90 & 30 & 18,0 & 38 & 240 & 466 & 705 & 12496 & 24273 & 54017 & 0,800 & 650 & 2800 & 1,07 & 1,07 & 1,04 \\
\hline 90 & 30 & 20,0 & 40 & 240 & 491 & 743 & 13120 & 26860 & 59770 & 0,800 & 650 & 2800 & 1,06 & 1,06 & 1,04 \\
\hline 90 & 30 & 22,0 & 45 & 240 & 516 & 799 & 13743 & 29575 & 68938 & 0,800 & 650 & 2800 & 1,06 & 1,06 & 1,04 \\
\hline
\end{tabular}


Tabela C.6 - Valores de $\beta$ para pilares internos com momentos atuantes nas duas direções e $c_{1} \leq c_{2}$

\begin{tabular}{|c|c|c|c|c|c|c|c|c|c|c|c|c|c|c|c|c|c|c|c|c|c|c|}
\hline \multicolumn{11}{|c|}{ direção 1} & \multicolumn{9}{|c|}{ direção 2} & \multirow[b]{2}{*}{$\beta o$} & \multirow[b]{2}{*}{$\beta$} & \multirow[b]{2}{*}{$\beta^{\prime}$} \\
\hline $\mathrm{c} 1$ & $\mathrm{c} 2$ & $\mathrm{~d}$ & $\mathrm{p}$ & uo & $\mathrm{u}$ & $\mathrm{u}^{\prime}$ & wp1o & wp1 & wp1' & $\mathrm{K} 1$ & $\mathrm{c} 1$ & c2 & wp2o & wp2 & wp2' & $\mathrm{K} 2$ & Fsd & Msd1 & Msd2 & & & \\
\hline 20 & 20 & 12,0 & 25 & 80 & 231 & 388 & 1862 & 5372 & 15243 & 0,600 & 20 & 20 & 1862 & 5372 & 15243 & 0,600 & 100 & 500 & 500 & 1,26 & 1,26 & 1,15 \\
\hline 20 & 30 & 12,0 & 25 & 100 & 251 & 408 & 2413 & 6052 & 16423 & 0,501 & 30 & 20 & 2622 & 6576 & 17232 & 0,650 & 150 & 550 & 750 & 1,20 & 1,20 & 1,12 \\
\hline 20 & 40 & 12,0 & 25 & 120 & 271 & 428 & 2983 & 6732 & 17603 & 0,450 & 40 & 20 & 3492 & 7880 & 19322 & 0,700 & 200 & 600 & 1000 & 1,17 & 1,17 & 1,11 \\
\hline 20 & 50 & 12,0 & 25 & 140 & 291 & 448 & 3568 & 7412 & 18783 & 0,450 & 50 & 20 & 4470 & 9284 & 21511 & 0,750 & 250 & 650 & 1250 & 1,16 & 1,16 & 1,11 \\
\hline 20 & 60 & 12,0 & 25 & 160 & 311 & 468 & 4166 & 8092 & 19963 & 0,450 & 60 & 20 & 5554 & 10788 & 23800 & 0,800 & 300 & 700 & 1500 & 1,16 & 1,16 & 1,10 \\
\hline 20 & 20 & 14,0 & 29 & 80 & 256 & 438 & 2068 & 6615 & 19457 & 0,600 & 20 & 20 & 2068 & 6615 & 19457 & 0,600 & 100 & 500 & 500 & 1,23 & 1,23 & 1,14 \\
\hline 20 & 30 & 14,0 & 29 & 100 & 276 & 458 & 2673 & 7375 & 20797 & 0,501 & 30 & 20 & 2879 & 7945 & 21698 & 0,650 & 150 & 550 & 750 & 1,18 & 1,18 & 1,11 \\
\hline 20 & 40 & 14,0 & 29 & 120 & 296 & 478 & 3299 & 8135 & 22137 & 0,450 & 40 & 20 & 3801 & 9375 & 24039 & 0,700 & 200 & 600 & 1000 & 1,16 & 1,16 & 1,10 \\
\hline 20 & 50 & 14,0 & 29 & 140 & 316 & 498 & 3942 & 8895 & 23477 & 0,450 & 50 & 20 & 4832 & 10904 & 26480 & 0,750 & 250 & 650 & 1250 & 1,15 & 1,15 & 1,10 \\
\hline 20 & 60 & 14,0 & 29 & 160 & 336 & 518 & 4599 & 9655 & 24817 & 0,450 & 60 & 20 & 5970 & 12534 & 29020 & 0,800 & 300 & 700 & 1500 & 1,14 & 1,14 & 1,09 \\
\hline 20 & 20 & 16,0 & 33 & 80 & 281 & 488 & 2273 & 7987 & 24184 & 0,600 & 20 & 20 & 2273 & 7987 & 24184 & 0,600 & 100 & 500 & 500 & 1,21 & 1,21 & 1,12 \\
\hline 20 & 30 & 16,0 & 33 & 100 & 301 & 508 & 2932 & 8827 & 25684 & 0,501 & 30 & 20 & 3136 & 9442 & 26676 & 0,650 & 150 & 550 & 750 & 1,17 & 1,17 & 1,10 \\
\hline 20 & 40 & 16,0 & 33 & 120 & 321 & 528 & 3613 & 9667 & 27184 & 0,450 & 40 & 20 & 4110 & 10997 & 29268 & 0,700 & 200 & 600 & 1000 & 1,15 & 1,15 & 1,09 \\
\hline 20 & 50 & 16,0 & 33 & 140 & 341 & 548 & 4313 & 10507 & 28684 & 0,450 & 50 & 20 & 5194 & 12653 & 31960 & 0,750 & 250 & 650 & 1250 & 1,14 & 1,14 & 1,09 \\
\hline 20 & 60 & 16,0 & 33 & 160 & 361 & 568 & 5028 & 11347 & 30184 & 0,450 & 60 & 20 & 6385 & 14408 & 34752 & 0,800 & 300 & 700 & 1500 & 1,13 & 1,13 & 1,09 \\
\hline 20 & 20 & 18,0 & 38 & 80 & 306 & 545 & 2478 & 9486 & 30114 & 0,600 & 20 & 20 & 2478 & 9486 & 30114 & 0,600 & 100 & 500 & 500 & 1,19 & 1,19 & 1,11 \\
\hline 20 & 30 & 18,0 & 38 & 100 & 326 & 565 & 3190 & 10406 & 31794 & 0,501 & 30 & 20 & 3393 & 11067 & 32888 & 0,650 & 150 & 550 & 750 & 1,15 & 1,15 & 1,09 \\
\hline 20 & 40 & 18,0 & 38 & 120 & 346 & 585 & 3926 & 11326 & 33474 & 0,450 & 40 & 20 & 4419 & 12748 & 35763 & 0,700 & 200 & 600 & 1000 & 1,14 & 1,14 & 1,08 \\
\hline 20 & 50 & 18,0 & 38 & 140 & 366 & 605 & 4682 & 12246 & 35154 & 0,450 & 50 & 20 & 5555 & 14529 & 38738 & 0,750 & 250 & 650 & 1250 & 1,13 & 1,13 & 1,08 \\
\hline 20 & 60 & 18,0 & 38 & 160 & 386 & 625 & 5455 & 13166 & 36834 & 0,450 & 60 & 20 & 6799 & 16410 & 41813 & 0,800 & 300 & 700 & 1500 & 1,12 & 1,12 & 1,08 \\
\hline 20 & 20 & 20,0 & 40 & 80 & 331 & 583 & 2683 & 11113 & 34427 & 0,600 & 20 & 20 & 2683 & 11113 & 34427 & 0,600 & 100 & 500 & 500 & 1,18 & 1,18 & 1,10 \\
\hline 20 & 30 & \begin{tabular}{|l|l}
20,0 \\
\end{tabular} & 40 & 100 & 351 & \begin{tabular}{|l}
603 \\
\end{tabular} & 3448 & 12113 & 36227 & 0,501 & 30 & 20 & 3649 & 12820 & 37390 & 0,650 & 150 & 550 & 750 & 1,14 & 1,14 & 1,08 \\
\hline 20 & 40 & \begin{tabular}{|l}
20,0 \\
\end{tabular} & 40 & 120 & 371 & 623 & 4238 & 13113 & 38027 & 0,450 & 40 & 20 & 4727 & 14627 & 40453 & 0,700 & 200 & 600 & 1000 & 1,13 & 1,13 & 1,08 \\
\hline 20 & 50 & 20,0 & 40 & 140 & 391 & 643 & 5049 & 14113 & 39827 & 0,450 & 50 & 20 & 5915 & 16533 & 43616 & 0,750 & 250 & 650 & 1250 & 1,12 & 1,12 & 1,07 \\
\hline 20 & 60 & 20,0 & 40 & 160 & 411 & 663 & 5879 & 15113 & 41627 & 0,450 & 60 & 20 & 7212 & 18540 & 46880 & 0,800 & 300 & 700 & 1500 & 1,12 & 1,12 & 1,07 \\
\hline 20 & 20 & 22,0 & 45 & 80 & 356 & 639 & 2888 & 12869 & 41436 & 0,600 & 20 & 20 & 2888 & 12869 & 41436 & 0,600 & 100 & 500 & 500 & 1,17 & 1,17 & 1,09 \\
\hline 20 & 30 & 22,0 & 45 & 100 & 376 & \begin{tabular}{|l}
659 \\
\end{tabular} & 3705 & 13949 & 43416 & 0,501 & 30 & 20 & 3905 & 14701 & 44682 & 0,650 & 150 & 550 & 750 & 1,13 & 1,13 & 1,08 \\
\hline 20 & 40 & 22,0 & 45 & 120 & 396 & 679 & 4549 & 15029 & 45396 & 0,450 & 40 & 20 & 5035 & 16633 & 48028 & 0,700 & 200 & 600 & 1000 & 1,12 & 1,12 & 1,07 \\
\hline 20 & 50 & 22,0 & 45 & 140 & 416 & 699 & 5415 & 16109 & 47376 & 0,450 & 50 & 20 & 6275 & 18666 & 51474 & 0,750 & 250 & 650 & 1250 & 1,11 & 1,11 & 1,07 \\
\hline 20 & 60 & 22,0 & 45 & 160 & 436 & 719 & 6301 & 17189 & 49356 & 0,450 & 60 & 20 & 7624 & 20798 & 55020 & 0,800 & 300 & 700 & 1500 & 1,11 & 1,11 & 1,07 \\
\hline 25 & 40 & 12,0 & 25 & 130 & $\mid 281$ & 438 & 3436 & 7421 & 18685 & 0,489 & 40 & 25 & 3852 & 8320 & 20012 & 0,660 & 250 & 750 & 1250 & 1,17 & 1,17 & 1,11 \\
\hline
\end{tabular}




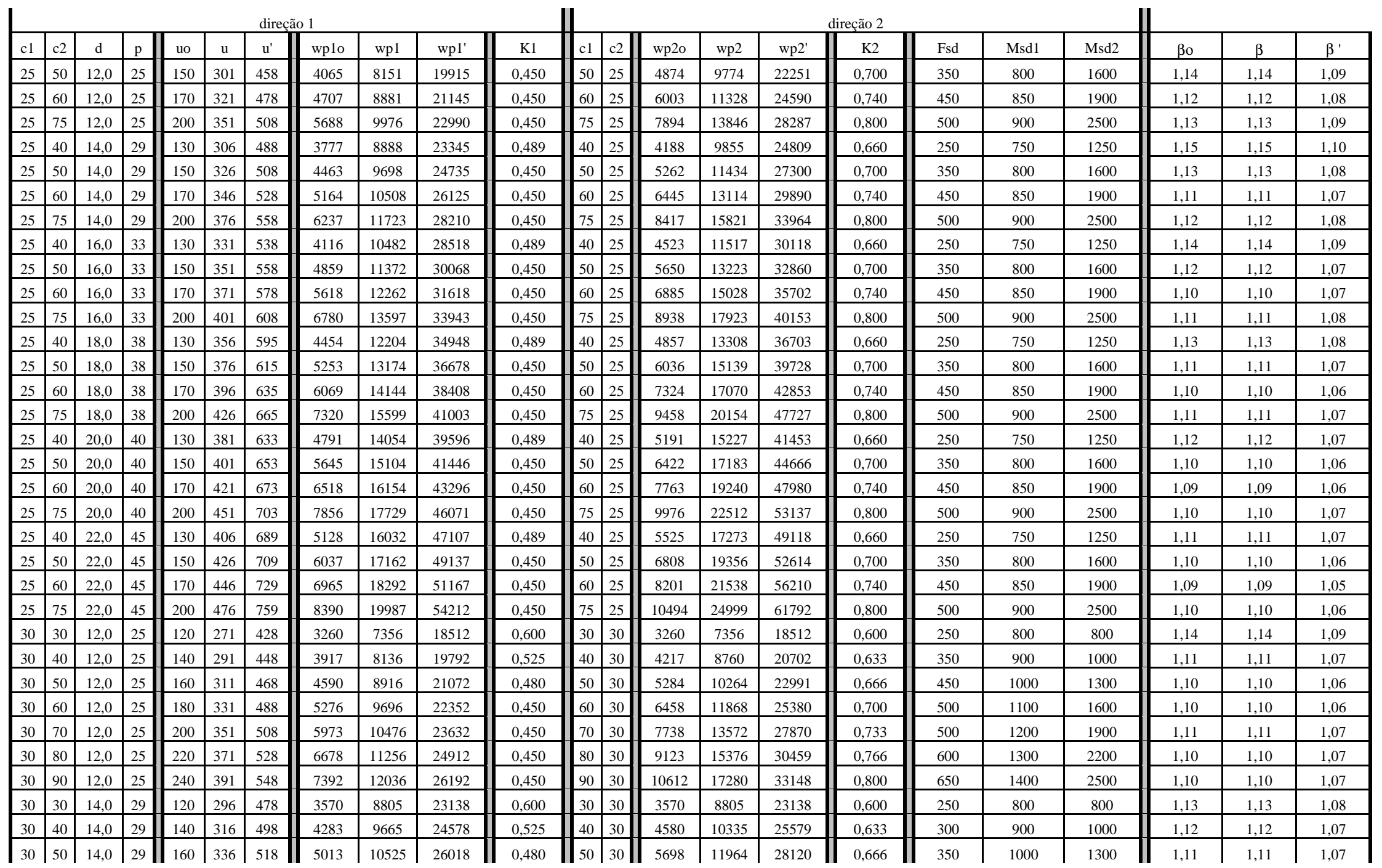




\begin{tabular}{|c|c|c|c|c|c|c|c|c|c|c|c|c|c|c|c|c|c|c|c|c|c|c|}
\hline \multicolumn{11}{|c|}{ direção 1} & \multicolumn{9}{|c|}{ direção 2} & \\
\hline c1 & c2 2 & $\mathrm{~d}$ & $\mathrm{p}$ & uo & $\mathrm{u}$ & $\mathrm{u}^{\prime}$ & wp1o & wp1 & wp1' & K1 & c1 & c2 & wp2o & wp2 & wp2' & K2 & Fsd & Msd1 & Msd2 & $\beta o$ & $\beta$ & $\beta^{\prime}$ \\
\hline 30 & 60 & 14,0 & 29 & 180 & 356 & 538 & 5758 & 11385 & 27458 & 0,450 & 60 & 30 & 6925 & 13694 & 30760 & 0,700 & 450 & 1100 & 1600 & 1,10 & 1,10 & 1,07 \\
\hline 30 & 70 & 14,0 & 29 & 200 & 376 & 558 & 6514 & 12245 & 28898 & 0,450 & 70 & 30 & 8259 & 15524 & 33501 & 0,733 & 500 & 1200 & 1900 & 1,10 & 1,10 & 1,07 \\
\hline 30 & 80 & 14,0 & 29 & 220 & 396 & 578 & 7282 & 13105 & 30338 & 0,450 & 80 & 30 & 9698 & 17453 & 36342 & 0,766 & 600 & 1300 & 2200 & 1,09 & 1,09 & 1,06 \\
\hline 30 & 90 & 14,0 & 29 & 240 & 416 & 598 & 8058 & 13965 & 31778 & 0,450 & 90 & 30 & 11242 & 19483 & 39282 & 0,800 & 650 & 1400 & 2500 & 1,09 & 1,09 & 1,07 \\
\hline 30 & 30 & 16,0 & 33 & 120 & 321 & 528 & 3880 & 10382 & 28276 & 0,600 & 30 & 30 & 3880 & 10382 & 28276 & 0,600 & 250 & 800 & 800 & 1,12 & 1,12 & 1,07 \\
\hline 30 & 40 & 16,0 & 33 & 140 & 341 & 548 & 4647 & 11322 & 29876 & 0,525 & \begin{tabular}{|l|l|}
40 \\
\end{tabular} & 30 & 4941 & 12037 & 30968 & 0,633 & 300 & 900 & 1000 & 1,11 & 1,11 & 1,07 \\
\hline 30 & 50 & 16,0 & 33 & 160 & 361 & 568 & 5434 & 12262 & 31476 & 0,480 & 50 & 30 & 6112 & 13793 & 33760 & 0,666 & 350 & 1000 & 1300 & 1,11 & 1,11 & 1,07 \\
\hline 30 & 60 & 16,0 & 33 & 180 & 381 & 588 & 6236 & 13202 & 33076 & 0,450 & 60 & 30 & 7391 & 15648 & 36652 & 0,700 & 450 & 1100 & 1600 & 1,09 & 1,09 & 1,06 \\
\hline 30 & 70 & 16,0 & 33 & 200 & 401 & 608 & 7052 & 14142 & 34676 & 0,450 & 70 & 30 & 8778 & 17603 & 39644 & 0,733 & 500 & 1200 & 1900 & 1,09 & 1,09 & 1,06 \\
\hline 30 & 80 & 16,0 & 33 & 220 & 421 & 628 & 7880 & 15082 & 36276 & 0,450 & 80 & 30 & 10271 & 19658 & 42736 & 0,766 & 600 & 1300 & 2200 & 1,09 & 1,09 & 1,06 \\
\hline 30 & 90 & 16,0 & 33 & 240 & 441 & 648 & 8718 & 16022 & 37876 & 0,450 & 90 & 30 & 11870 & 21814 & 45928 & 0,800 & 650 & 1400 & 2500 & 1,09 & 1,09 & 1,06 \\
\hline 30 & 30 & 18,0 & 38 & 120 & 346 & 585 & 4190 & 12087 & 34668 & 0,600 & 30 & 30 & 4190 & 12087 & 34668 & 0,600 & 250 & 800 & 800 & 1,11 & 1,11 & 1,06 \\
\hline 30 & 40 & 18,0 & 38 & 140 & 366 & 605 & 5011 & 13107 & 36448 & 0,525 & 40 & 30 & 5302 & 13868 & 37643 & 0,633 & 300 & 900 & 1000 & 1,10 & 1,10 & 1,06 \\
\hline 30 & 50 & 18,0 & 38 & 160 & 386 & 625 & 5853 & 14127 & 38228 & 0,480 & 50 & 30 & 6525 & 15749 & 40718 & 0,666 & 350 & 1000 & 1300 & 1,10 & 1,10 & 1,06 \\
\hline 30 & 60 & 18,0 & 38 & 180 & 406 & 645 & 6712 & 15147 & 40008 & 0,450 & 60 & 30 & 7857 & 17730 & 43893 & 0,700 & 450 & 1100 & 1600 & 1,09 & 1,09 & 1,05 \\
\hline 30 & \begin{tabular}{l|l}
70 \\
\end{tabular} & 18,0 & \begin{tabular}{|l|}
38 \\
\end{tabular} & 200 & \begin{tabular}{l|l}
426 \\
\end{tabular} & 665 & 7587 & 16167 & 41788 & 0,450 & \begin{tabular}{|l|}
70 \\
\end{tabular} & \begin{tabular}{|l|}
30 \\
\end{tabular} & 9297 & 19811 & 47167 & 0,733 & 500 & 1200 & 1900 & 1,09 & 1,09 & 1,06 \\
\hline 30 & 80 & 18,0 & 38 & 220 & 446 & 685 & 8474 & 17187 & 43568 & 0,450 & 80 & 30 & 10843 & 21992 & 50542 & 0,766 & 600 & 1300 & 2200 & 1,08 & 1,08 & 1,05 \\
\hline 30 & 90 & 18,0 & 38 & 240 & 466 & 705 & 9373 & 18207 & 45348 & 0,450 & \begin{tabular}{|l|}
90 \\
\end{tabular} & 30 & 12496 & 24273 & 54017 & 0,800 & 650 & 1400 & 2500 & 1,08 & 1,08 & 1,06 \\
\hline 30 & 30 & 20,0 & 40 & 120 & 371 & 623 & 4498 & 13920 & 39290 & 0,600 & \begin{tabular}{|l|}
30 \\
\end{tabular} & 30 & 4498 & 13920 & 39290 & 0,600 & 250 & 800 & 800 & 1,10 & 1,10 & 1,06 \\
\hline 30 & 40 & 20,0 & 40 & 140 & 391 & 643 & 5373 & 15020 & 41190 & 0,525 & 40 & 30 & 5662 & 15827 & 42453 & 0,633 & 300 & 900 & 1000 & 1,09 & 1,09 & 1,06 \\
\hline 30 & 50 & 20,0 & 40 & 160 & 411 & 663 & 6270 & 16120 & 43090 & 0,480 & 50 & 30 & 6937 & 17833 & 45716 & 0,666 & 350 & 1000 & 1300 & 1,09 & 1,09 & 1,06 \\
\hline 30 & \begin{tabular}{l|l}
60 \\
\end{tabular} & 20,0 & \begin{tabular}{|l|}
40 \\
\end{tabular} & 180 & 431 & 683 & 7186 & 17220 & 44990 & 0,450 & \begin{tabular}{|l|}
60 \\
\end{tabular} & \begin{tabular}{|l|}
30 \\
\end{tabular} & 8321 & 19940 & 49080 & 0,700 & 450 & 1100 & 1600 & 1,08 & 1,08 & 1,05 \\
\hline 30 & 70 & 20,0 & 40 & 200 & 451 & 703 & 8118 & 18320 & 46890 & 0,450 & 70 & 30 & 9814 & 22146 & 52543 & 0,733 & 500 & 1200 & 1900 & 1,08 & 1,08 & 1,05 \\
\hline 30 & 80 & 20,0 & 40 & 220 & 471 & 723 & 9065 & 19420 & 48790 & 0,450 & 80 & 30 & 11414 & 24453 & 56106 & 0,766 & 600 & 1300 & 2200 & 1,08 & 1,08 & 1,05 \\
\hline 30 & 90 & 20,0 & 40 & 240 & 491 & 743 & 10023 & 20520 & 50690 & 0,450 & 90 & 30 & 13120 & 26860 & 59770 & 0,800 & 650 & 1400 & 2500 & 1,08 & 1,08 & 1,05 \\
\hline 30 & 30 & 22,0 & 45 & 120 & 396 & 679 & 4807 & 15881 & 46762 & 0,600 & 30 & 30 & 4807 & 15881 & 46762 & 0,600 & 250 & 800 & 800 & 1,10 & 1,10 & 1,06 \\
\hline 30 & 40 & 22,0 & 45 & 140 & 416 & 699 & 5735 & 17061 & 48842 & 0,525 & 40 & 30 & 6022 & 17913 & 50208 & 0,633 & 300 & 900 & 1000 & 1,09 & 1,09 & 1,05 \\
\hline 30 & \begin{tabular}{l|l}
50 \\
\end{tabular} & 22,0 & 45 & 160 & 436 & 719 & 6687 & 18241 & 50922 & 0,480 & 50 & \begin{tabular}{|l|}
30 \\
\end{tabular} & 7348 & 20046 & 53754 & 0,666 & 350 & 1000 & 1300 & 1,09 & 1,09 & 1,05 \\
\hline 30 & \begin{tabular}{l|l}
60 \\
\end{tabular} & 22,0 & \begin{tabular}{|l|}
45 \\
\end{tabular} & 180 & $\begin{array}{ll}456 \\
\end{array}$ & 739 & 7658 & 19421 & 53002 & 0,450 & \begin{tabular}{|l|}
60 \\
\end{tabular} & \begin{tabular}{|l|}
30 \\
\end{tabular} & 8785 & 22278 & 57400 & 0,700 & 450 & 1100 & 1600 & 1,08 & 1,08 & 1,05 \\
\hline 30 & 70 & 22,0 & 45 & 200 & 476 & 759 & 8647 & 20601 & 55082 & 0,450 & 70 & 30 & 10330 & 24610 & 61146 & 0,733 & 500 & 1200 & 1900 & 1,08 & 1,08 & 1,05 \\
\hline 30 & 80 & 22,0 & 45 & 220 & 496 & 779 & 9652 & 21781 & 57162 & 0,450 & 80 & 30 & 11983 & 27042 & 64992 & 0,766 & 600 & 1300 & 2200 & 1,07 & 1,07 & 1,05 \\
\hline 30 & 90 & 22,0 & 45 & 240 & 516 & 799 & 10670 & 22961 & 59242 & 0,450 & 90 & 30 & 13743 & 29575 & 68938 & 0,800 & 650 & 1400 & 2500 & 1,08 & 1,08 & 1,05 \\
\hline & & & & & & & & & & & & & & & & & & & média & 1,12 & 1,12 & 1,07 \\
\hline & & & & & & & & & & & & & & & & & & & desvio & 0,0353 & 0,0353 & 0,0202 \\
\hline
\end{tabular}


Tabela C.7 - Valores de $\beta$ para pilares internos com momentos atuantes nas duas direções e $c_{1}>c_{2}$

\begin{tabular}{|c|c|c|c|c|c|c|c|c|c|c|c|c|c|c|c|c|c|c|c|c|c|c|}
\hline \multicolumn{11}{|c|}{ direção 1} & \multicolumn{9}{|c|}{ direção 2} & \multirow[b]{2}{*}{$\beta 0$} & \multirow[b]{2}{*}{$\beta$} & \multirow[b]{2}{*}{$\beta^{\prime}$} \\
\hline $\mathrm{c} 1$ & $\begin{array}{ll}\mathrm{c} 2 \\
\end{array}$ & $\mathrm{~d}$ & $p$ & uo & $\mathrm{u}$ & $\mathrm{u}^{\prime}$ & wplo & wp1 & wp1' & K1 & $\mathrm{c} 1$ & c2 & wp2o & wp2 & wp2' & K2 & Fsd & Msd1 & $\operatorname{Msd} 2$ & & & \\
\hline 30 & 20 & 12,0 & 25 & 100 & 251 & \begin{tabular}{|l}
408 \\
\end{tabular} & 2622 & 6576 & 17232 & 0,650 & 20 & 30 & 2413 & 6052 & 16423 & 0,498 & 150 & 550 & 750 & 1,19 & 1,19 & 1,12 \\
\hline 30 & 20 & 14,0 & 29 & 100 & 276 & 458 & 2879 & 7945 & 21698 & 0,650 & 20 & 30 & 2673 & 7375 & 20797 & 0,498 & 150 & 550 & 750 & 1,18 & 1,18 & 1,11 \\
\hline 30 & 20 & 16,0 & 33 & 100 & 301 & \begin{tabular}{|l|}
508 \\
\end{tabular} & 3136 & 9442 & 26676 & 0,650 & 20 & 30 & 2932 & 8827 & 25684 & 0,498 & 150 & 550 & 750 & 1,16 & 1,16 & 1,09 \\
\hline 30 & 20 & 18,0 & 38 & 100 & 326 & 565 & 3393 & 11067 & 32888 & 0,650 & 20 & 30 & 3190 & 10406 & 31794 & 0,498 & 150 & 550 & 750 & 1,15 & 1,15 & 1,09 \\
\hline 30 & 20 & 20,0 & 40 & 100 & 351 & \begin{tabular}{|l|}
603 \\
\end{tabular} & 3649 & 12820 & 37390 & 0,650 & 20 & 30 & 3448 & 12113 & 36227 & 0,498 & 150 & 550 & 750 & 1,14 & 1,14 & 1,08 \\
\hline 30 & 20 & 22,0 & 45 & 100 & 376 & 659 & 3905 & 14701 & 44682 & 0,650 & 20 & 30 & 3705 & 13949 & 43416 & 0,498 & 150 & 550 & 750 & 1,13 & 1,13 & 1,07 \\
\hline 40 & 20 & 12,0 & 25 & 120 & 271 & 428 & 3492 & 7880 & 19322 & 0,700 & 20 & 40 & 2983 & 6732 & 17603 & 0,450 & 200 & 600 & 1000 & 1,16 & 1,16 & 1,10 \\
\hline 40 & 25 & 12,0 & 25 & 130 & 281 & 438 & 3852 & 8320 & 20012 & 0,660 & 25 & 40 & 3436 & 7421 & 18685 & 0,486 & 250 & 750 & 1250 & 1,16 & 1,16 & 1,10 \\
\hline 40 & 30 & 12,0 & 25 & 140 & 291 & \begin{tabular}{|l}
448 \\
\end{tabular} & 4217 & 8760 & 20702 & 0,633 & 30 & 40 & 3917 & 8136 & 19792 & 0,525 & 350 & 900 & 1000 & 1,11 & 1,11 & 1,07 \\
\hline 40 & \begin{tabular}{|l|}
20 \\
\end{tabular} & \begin{tabular}{|l}
14,0 \\
\end{tabular} & 29 & 120 & 296 & \begin{tabular}{|l|}
478 \\
\end{tabular} & 3801 & 9375 & 24039 & 0,700 & 20 & 40 & 3299 & 8135 & 22137 & 0,450 & 200 & 600 & 1000 & 1,15 & 1,15 & 1,09 \\
\hline 40 & \begin{tabular}{|l|}
25 \\
\end{tabular} & 14,0 & 29 & 130 & 306 & \begin{tabular}{|l|l|}
488 \\
\end{tabular} & 4188 & 9855 & 24809 & 0,660 & 25 & 40 & 3777 & 8888 & 23345 & 0,486 & 250 & 750 & 1250 & 1,15 & 1,15 & 1,09 \\
\hline 40 & 30 & 14,0 & 29 & 140 & 316 & \begin{tabular}{|l|}
498 \\
\end{tabular} & 4580 & 10335 & 25579 & 0,633 & 30 & 40 & 4283 & 9665 & 24578 & 0,525 & 300 & 900 & 1000 & 1,12 & 1,12 & 1,07 \\
\hline 40 & \begin{tabular}{|l|l|} 
& \\
\end{tabular} & 16,0 & 33 & 120 & 321 & 528 & 4110 & 10997 & 29268 & 0,700 & 20 & \begin{tabular}{|l|}
40 \\
\end{tabular} & 3613 & 9667 & 27184 & 0,450 & 200 & 600 & 1000 & 1,14 & 1,14 & 1,08 \\
\hline 40 & 25 & 16,0 & 33 & 130 & 331 & \begin{tabular}{|l|}
538 \\
\end{tabular} & 4523 & 11517 & 30118 & 0,660 & 25 & 40 & 4116 & 10482 & 28518 & 0,486 & 250 & 750 & 1250 & 1,13 & 1,13 & 1,08 \\
\hline 40 & 30 & 16,0 & 33 & 140 & 341 & 548 & 4941 & 12037 & 30968 & 0,633 & 30 & 40 & 4647 & 11322 & 29876 & 0,525 & 300 & 900 & 1000 & 1,11 & 1,11 & 1,07 \\
\hline 40 & 20 & 18,0 & 38 & 120 & 346 & 585 & 4419 & 12748 & 35763 & 0,700 & 20 & 40 & 3926 & 11326 & 33474 & 0,450 & 200 & 600 & 1000 & 1,13 & 1,13 & 1,07 \\
\hline 40 & 25 & 18,0 & 38 & 130 & 356 & \begin{tabular}{|l|}
595 \\
\end{tabular} & 4857 & 13308 & 36703 & 0,660 & 25 & 40 & 4454 & 12204 & 34948 & 0,486 & 250 & 750 & 1250 & 1,12 & 1,12 & 1,07 \\
\hline 40 & 30 & \begin{tabular}{|l}
18,0 \\
\end{tabular} & 38 & 140 & 366 & \begin{tabular}{|l|l|}
605 \\
\end{tabular} & 5302 & 13868 & 37643 & 0,633 & 30 & 40 & 5011 & 13107 & 36448 & 0,525 & 300 & 900 & 1000 & 1,10 & 1,10 & 1,06 \\
\hline 40 & 20 & 20,0 & 40 & 120 & 371 & 623 & 4727 & 14627 & 40453 & 0,700 & 20 & 40 & 4238 & 13113 & 38027 & 0,450 & 200 & 600 & 1000 & 1,12 & 1,12 & 1,07 \\
\hline 40 & 25 & 20,0 & 40 & 130 & 381 & \begin{tabular}{|l}
633 \\
\end{tabular} & 5191 & 15227 & 41453 & 0,660 & 25 & 40 & 4791 & 14054 & 39596 & 0,486 & 250 & 750 & 1250 & 1,12 & 1,12 & 1,07 \\
\hline 40 & 30 & 20,0 & 40 & 140 & 391 & 643 & 5662 & 15827 & 42453 & 0,633 & 30 & \begin{tabular}{|l|}
40 \\
\end{tabular} & 5373 & 15020 & 41190 & 0,525 & 300 & 900 & 1000 & 1,09 & 1,09 & 1,06 \\
\hline 40 & 20 & 22,0 & 45 & 120 & 396 & \begin{tabular}{|l}
679 \\
\end{tabular} & 5035 & 16633 & 48028 & 0,700 & 20 & 40 & 4549 & 15029 & 45396 & 0,450 & 200 & 600 & 1000 & 1,11 & 1,11 & 1,06 \\
\hline 40 & 25 & 22,0 & 45 & 130 & 406 & \begin{tabular}{|l}
689 \\
\end{tabular} & 5525 & 17273 & 49118 & 0,660 & 25 & 40 & 5128 & 16032 & 47107 & 0,486 & 250 & 750 & 1250 & 1,11 & 1,11 & 1,06 \\
\hline 40 & 30 & 22,0 & 45 & 140 & 416 & \begin{tabular}{|l|}
699 \\
\end{tabular} & 6022 & 17913 & 50208 & 0,633 & 30 & 40 & 5735 & 17061 & 48842 & 0,525 & 300 & 900 & 1000 & 1,09 & 1,09 & 1,05 \\
\hline 50 & 20 & 12,0 & 25 & 140 & 291 & \begin{tabular}{|l|l}
448 \\
\end{tabular} & 4470 & 9284 & 21511 & 0,750 & 20 & 50 & 3568 & 7412 & 18783 & 0,450 & 250 & 650 & 1250 & 1,15 & 1,15 & 1,09 \\
\hline 50 & 25 & 12,0 & 25 & 150 & 301 & 458 & 4874 & 9774 & 22251 & 0,700 & 25 & 50 & 4065 & 8151 & 19915 & 0,450 & 350 & 800 & 1600 & 1,13 & 1,13 & 1,08 \\
\hline 50 & 30 & 12,0 & 25 & 160 & 311 & 468 & 5284 & 10264 & 22991 & 0,667 & 30 & 50 & 4590 & 8916 & 21072 & 0,480 & 450 & 1000 & 1300 & 1,09 & 1,09 & 1,06 \\
\hline 50 & 20 & 14,0 & 29 & 140 & 316 & \begin{tabular}{|l}
498 \\
\end{tabular} & 4832 & 10904 & 26480 & 0,750 & 20 & 50 & 3942 & 8895 & 23477 & 0,450 & 250 & 650 & 1250 & 1,14 & 1,14 & 1,08 \\
\hline 50 & 25 & \begin{tabular}{|l}
14,0 \\
\end{tabular} & 29 & 150 & 326 & \begin{tabular}{|l|}
508 \\
\end{tabular} & 5262 & 11434 & 27300 & 0,700 & 25 & 50 & 4463 & 9698 & 24735 & 0,450 & 350 & 800 & 1600 & 1,11 & 1,11 & 1,07 \\
\hline 50 & 30 & 14,0 & 29 & 160 & 336 & 518 & 5698 & 11964 & 28120 & 0,667 & 30 & 50 & 5013 & 10525 & 26018 & 0,480 & 350 & 1000 & 1300 & 1,11 & 1,11 & 1,07 \\
\hline 50 & 20 & 16,0 & 33 & 140 & 341 & \begin{tabular}{|l|l|} 
& 548
\end{tabular} & 5194 & 12653 & 31960 & 0,750 & 20 & 50 & 4313 & 10507 & 28684 & 0,450 & 250 & 650 & 1250 & 1,13 & 1,13 & 1,08 \\
\hline
\end{tabular}




\begin{tabular}{|c|c|c|c|c|c|c|c|c|c|c|c|c|c|c|c|c|c|c|c|c|c|c|}
\hline \multicolumn{11}{|c|}{ direção 1} & \multicolumn{9}{|c|}{ direção 2} & \\
\hline c1 & c2 2 & $\mathrm{~d}$ & $\mathrm{p}$ & uo & $\mathrm{u}$ & $\mathrm{u}^{\prime}$ & wp1o & wp1 & wp1' & K1 & c1 & $\mathrm{c} 2$ & wp2o & wp2 & wp2' & K2 & Fsd & Msd1 & Msd2 & $\beta_{0}$ & $\beta$ & $\beta^{\prime}$ \\
\hline 50 & 25 & 16,0 & 33 & 150 & 351 & 558 & 5650 & 13223 & 32860 & 0,700 & 25 & 50 & 4859 & 11372 & 30068 & 0,450 & 350 & 800 & 1600 & 1,11 & 1,11 & 1,07 \\
\hline 50 & 30 & 16,0 & 33 & 160 & 361 & 568 & 6112 & 13793 & 33760 & 0,667 & 30 & 50 & 5434 & 12262 & 31476 & 0,480 & 350 & 1000 & 1300 & 1,10 & 1,10 & 1,06 \\
\hline 50 & 20 & 18,0 & 38 & 140 & 366 & 605 & 5555 & 14529 & 38738 & 0,750 & 20 & 50 & 4682 & 12246 & 35154 & 0,450 & 250 & 650 & 1250 & 1,12 & 1,12 & 1,07 \\
\hline 50 & 25 & 18,0 & 38 & 150 & 376 & 615 & 6036 & 15139 & 39728 & 0,700 & 25 & 50 & 5253 & 13174 & 36678 & 0,450 & 350 & 800 & 1600 & 1,10 & 1,10 & 1,06 \\
\hline 50 & 30 & 18,0 & 38 & 160 & 386 & 625 & 6525 & 15749 & 40718 & 0,667 & 30 & 50 & 5853 & 14127 & 38228 & 0,480 & 350 & 1000 & 1300 & 1,10 & 1,10 & 1,06 \\
\hline 50 & 20 & 20,0 & 40 & 140 & 391 & 643 & 5915 & 16533 & 43616 & 0,750 & 20 & 50 & 5049 & 14113 & 39827 & 0,450 & 250 & 650 & 1250 & 1,11 & 1,11 & 1,07 \\
\hline 50 & 25 & 20,0 & 40 & 150 & 401 & 653 & 6422 & 17183 & 44666 & 0,700 & 25 & 50 & 5645 & 15104 & 41446 & 0,450 & 350 & 800 & 1600 & 1,09 & 1,09 & 1,06 \\
\hline 50 & 30 & 20,0 & 40 & 160 & 411 & 663 & 6937 & 17833 & 45716 & 0,667 & 30 & 50 & 6270 & 16120 & 43090 & 0,480 & 350 & 1000 & 1300 & 1,09 & 1,09 & 1,06 \\
\hline 50 & 20 & 22,0 & 45 & 140 & 416 & 699 & 6275 & 18666 & 51474 & 0,750 & 20 & 50 & 5415 & 16109 & 47376 & 0,450 & 250 & 650 & 1250 & 1,10 & 1,10 & 1,06 \\
\hline 50 & 25 & 22,0 & 45 & 150 & 426 & 709 & 6808 & 19356 & 52614 & 0,700 & 25 & 50 & 6037 & 17162 & 49137 & 0,450 & 350 & 800 & 1600 & 1,09 & 1,09 & 1,05 \\
\hline 50 & 30 & 22,0 & 45 & 160 & 436 & 719 & 7348 & 20046 & 53754 & 0,667 & 30 & 50 & 6687 & 18241 & 50922 & 0,480 & 350 & 1000 & 1300 & 1,08 & 1,08 & 1,05 \\
\hline 60 & 20 & 12,0 & 25 & 160 & 311 & 468 & 5554 & 10788 & 23800 & 0,800 & 20 & 60 & 4166 & 8092 & 19963 & 0,450 & 300 & 700 & 1500 & 1,14 & 1,14 & 1,09 \\
\hline 60 & 25 & 12,0 & 25 & 170 & 321 & 478 & 6003 & 11328 & 24590 & 0,740 & 25 & 60 & 4707 & 8881 & 21145 & 0,450 & 450 & 850 & 1900 & 1,11 & 1,11 & 1,07 \\
\hline 60 & 30 & 12,0 & 25 & 180 & 331 & 488 & 6458 & 11868 & 25380 & 0,700 & 30 & 60 & 5276 & 9696 & 22352 & 0,450 & 500 & 1100 & 1600 & 1,09 & 1,09 & 1,06 \\
\hline 60 & 20 & 14,0 & 29 & 160 & 336 & 518 & 5970 & 12534 & 29020 & 0,800 & 20 & 60 & 4599 & 9655 & 24817 & 0,450 & 300 & 700 & 1500 & 1,13 & 1,13 & 1,08 \\
\hline 60 & 25 & 14,0 & 29 & 170 & 346 & 528 & 6445 & 13114 & 29890 & 0,740 & 25 & 60 & 5164 & 10508 & 26125 & 0,450 & 450 & 850 & 1900 & 1,10 & 1,10 & 1,06 \\
\hline 60 & 30 & 14,0 & 29 & 180 & 356 & 538 & 6925 & 13694 & 30760 & 0,700 & 30 & 60 & 5758 & 11385 & 27458 & 0,450 & 450 & 1100 & 1600 & 1,09 & 1,09 & 1,06 \\
\hline 60 & 20 & 16,0 & 33 & 160 & 361 & 568 & 6385 & 14408 & 34752 & 0,800 & 20 & 60 & 5028 & 11347 & 30184 & 0,450 & 300 & 700 & 1500 & 1,12 & 1,12 & 1,07 \\
\hline 60 & 25 & 16,0 & 33 & 170 & 371 & 578 & 6885 & 15028 & 35702 & 0,740 & 25 & 60 & 5618 & 12262 & 31618 & 0,450 & 450 & 850 & 1900 & 1,09 & 1,09 & 1,06 \\
\hline 60 & 30 & 16,0 & 33 & 180 & 381 & 588 & 7391 & 15648 & 36652 & 0,700 & 30 & 60 & 6236 & 13202 & 33076 & 0,450 & 450 & 1100 & 1600 & 1,09 & 1,09 & 1,06 \\
\hline 60 & 20 & 18,0 & 38 & 160 & 386 & 625 & 6799 & 16410 & 41813 & 0,800 & 20 & 60 & 5455 & 13166 & 36834 & 0,450 & 300 & 700 & 1500 & 1,11 & 1,11 & 1,07 \\
\hline 60 & 25 & 18,0 & 38 & 170 & 396 & 635 & 7324 & 17070 & 42853 & 0,740 & 25 & 60 & 6069 & 14144 & 38408 & 0,450 & 450 & 850 & 1900 & 1,09 & 1,09 & 1,05 \\
\hline 60 & 30 & 18,0 & 38 & 180 & 406 & 645 & 7857 & 17730 & 43893 & 0,700 & 30 & 60 & 6712 & 15147 & 40008 & 0,450 & 450 & 1100 & 1600 & 1,08 & 1,08 & 1,05 \\
\hline 60 & 20 & 20,0 & 40 & 160 & 411 & 663 & 7212 & 18540 & 46880 & 0,800 & 20 & 60 & 5879 & 15113 & 41627 & 0,450 & 300 & 700 & 1500 & 1,10 & 1,10 & 1,06 \\
\hline 60 & 25 & 20,0 & 40 & 170 & 421 & 673 & 7763 & 19240 & 47980 & 0,740 & 25 & 60 & 6518 & 16154 & 43296 & 0,450 & 450 & 850 & 1900 & 1,08 & 1,08 & 1,05 \\
\hline 60 & 30 & 20,0 & 40 & 180 & 431 & 683 & 8321 & 19940 & 49080 & 0,700 & 30 & 60 & 7186 & 17220 & 44990 & 0,450 & 450 & 1100 & 1600 & 1,08 & 1,08 & 1,05 \\
\hline 60 & 20 & 22,0 & 45 & 160 & 436 & 719 & 7624 & 20798 & 55020 & 0,800 & 20 & 60 & 6301 & 17189 & 49356 & 0,450 & 300 & 700 & 1500 & 1,10 & 1,10 & 1,06 \\
\hline 60 & 25 & 22,0 & 45 & 170 & 446 & 729 & 8201 & 21538 & 56210 & 0,740 & 25 & 60 & 6965 & 18292 & 51167 & 0,450 & 450 & 850 & 1900 & 1,08 & 1,08 & 1,05 \\
\hline 60 & 30 & 22,0 & 45 & 180 & 456 & 739 & 8785 & 22278 & 57400 & 0,700 & 30 & 60 & 7658 & 19421 & 53002 & 0,450 & 450 & 1100 & 1600 & 1,07 & 1,07 & 1,04 \\
\hline 70 & 30 & 12,0 & 25 & 200 & 351 & 508 & 7738 & 13572 & 27870 & 0,733 & 30 & 70 & 5973 & 10476 & 23632 & 0,450 & 500 & 1200 & 1900 & 1,10 & 1,10 & 1,07 \\
\hline 70 & 30 & 14,0 & 29 & 200 & 376 & 558 & 8259 & 15524 & 33501 & 0,733 & 30 & 70 & 6514 & 12245 & 28898 & 0,450 & 500 & 1200 & 1900 & 1,10 & 1,10 & 1,06 \\
\hline 70 & 30 & 16,0 & 33 & 200 & 401 & 608 & 8778 & 17603 & 39644 & 0,733 & 30 & 70 & 7052 & 14142 & 34676 & 0,450 & 500 & 1200 & 1900 & 1,09 & 1,09 & 1,06 \\
\hline 70 & 30 & 18,0 & 38 & 200 & 426 & 665 & 9297 & 19811 & 47167 & 0,733 & 30 & 70 & 7587 & 16167 & 41788 & 0,450 & 500 & 1200 & 1900 & 1,08 & 1,08 & 1,05 \\
\hline
\end{tabular}




\begin{tabular}{|c|c|c|c|c|c|c|c|c|c|c|c|c|c|c|c|c|c|c|c|c|c|c|}
\hline \multicolumn{11}{|c|}{ direção 1} & \multicolumn{9}{|c|}{ direção 2} & \\
\hline $\mathrm{c} 1$ & $\mathrm{c} 2$ & $\mathrm{~d}$ & $\mathrm{p}$ & uo & $\mathrm{u}$ & $\mathrm{u}^{\prime}$ & wp1o & wp1 & wp1' & K1 & $\mathrm{c} 1$ & $\mathrm{c} 2$ & wp2o & wp2 & wp2' & $\mathrm{K} 2$ & Fsd & Msd1 & Msd2 & $\beta_{0}$ & $\beta$ & $\beta^{\prime}$ \\
\hline 70 & 30 & 20,0 & 40 & 200 & 451 & 703 & 9814 & 22146 & 52543 & 0,733 & 30 & 70 & 8118 & 18320 & 46890 & 0,450 & 500 & 1200 & 1900 & 1,08 & 1,08 & 1,05 \\
\hline 70 & 30 & 22,0 & 45 & 200 & 476 & 759 & 10330 & 24610 & 61146 & 0,733 & 30 & 70 & 8647 & 20601 & 55082 & 0,450 & 500 & 1200 & 1900 & 1,07 & 1,07 & 1,05 \\
\hline 75 & 25 & 12,0 & 25 & 200 & 351 & 508 & 7894 & 13846 & 28287 & 0,800 & 25 & 75 & 5688 & 9976 & 22990 & 0,450 & 500 & 900 & 2500 & 1,12 & 1,12 & 1,08 \\
\hline 75 & 25 & \begin{tabular}{|l|}
14,0 \\
\end{tabular} & 29 & 200 & 376 & 558 & 8417 & 15821 & 33964 & 0,800 & 25 & 75 & 6237 & 11723 & 28210 & 0,450 & 500 & 900 & 2500 & 1,11 & 1,11 & 1,07 \\
\hline 75 & 25 & 16,0 & 33 & 200 & 401 & 608 & 8938 & 17923 & 40153 & 0,800 & 25 & 75 & 6780 & 13597 & 33943 & 0,450 & 500 & 900 & 2500 & 1,10 & 1,10 & 1,06 \\
\hline 75 & 25 & 18,0 & 38 & 200 & 426 & 665 & 9458 & 20154 & 47727 & 0,800 & 25 & 75 & 7320 & 15599 & 41003 & 0,450 & 500 & 900 & 2500 & 1,09 & 1,09 & 1,06 \\
\hline 75 & 25 & 20,0 & 40 & 200 & 451 & 703 & 9976 & 22512 & 53137 & 0,800 & 25 & 75 & 7856 & 17729 & 46071 & 0,450 & 500 & 900 & 2500 & 1,09 & 1,09 & 1,05 \\
\hline 75 & 25 & 22,0 & 45 & 200 & 476 & 759 & 10494 & 24999 & 61792 & 0,800 & 25 & 75 & 8390 & 19987 & 54212 & 0,450 & 500 & 900 & 2500 & 1,08 & 1,08 & 1,05 \\
\hline 80 & 30 & 12,0 & 25 & 220 & 371 & 528 & 9123 & 15376 & 30459 & 0,767 & 30 & 80 & 6678 & 11256 & 24912 & 0,450 & 600 & 1300 & 2200 & 1,09 & 1,09 & 1,06 \\
\hline 80 & 30 & 14,0 & 29 & 220 & 396 & 578 & 9698 & 17453 & 36342 & 0,767 & 30 & 80 & 7282 & 13105 & 30338 & 0,450 & 600 & 1300 & 2200 & 1,09 & 1,09 & 1,06 \\
\hline 80 & 30 & 16,0 & 33 & 220 & 421 & 628 & 10271 & 19658 & 42736 & 0,767 & 30 & 80 & 7880 & 15082 & 36276 & 0,450 & 600 & 1300 & 2200 & 1,08 & 1,08 & 1,05 \\
\hline 80 & 30 & 18,0 & 38 & 220 & 446 & 685 & 10843 & 21992 & 50542 & 0,767 & 30 & 80 & 8474 & 17187 & 43568 & 0,450 & 600 & 1300 & 2200 & 1,08 & 1,08 & 1,05 \\
\hline 80 & 30 & 20,0 & 40 & 220 & 471 & 723 & 11414 & 24453 & 56106 & 0,767 & 30 & 80 & 9065 & 19420 & 48790 & 0,450 & 600 & 1300 & 2200 & 1,07 & 1,07 & 1,05 \\
\hline 80 & 30 & 22,0 & 45 & 220 & 496 & 779 & 11983 & 27042 & 64992 & 0,767 & 30 & 80 & 9652 & 21781 & 57162 & 0,450 & 600 & 1300 & 2200 & 1,07 & 1,07 & 1,04 \\
\hline 90 & 30 & 12,0 & 25 & 240 & 391 & 548 & 10612 & 17280 & 33148 & 0,800 & 30 & 90 & 7392 & 12036 & 26192 & 0,450 & 650 & 1400 & 2500 & 1,10 & 1,10 & 1,06 \\
\hline 90 & 30 & 14,0 & 29 & 240 & 416 & 598 & 11242 & 19483 & 39282 & 0,800 & 30 & 90 & 8058 & 13965 & 31778 & 0,450 & 650 & 1400 & 2500 & 1,09 & 1,09 & 1,06 \\
\hline 90 & 30 & 16,0 & 33 & 240 & 441 & 648 & 11870 & 21814 & 45928 & 0,800 & 30 & 90 & 8718 & 16022 & 37876 & 0,450 & 650 & 1400 & 2500 & 1,08 & 1,08 & 1,05 \\
\hline 90 & 30 & 18,0 & 38 & 240 & 466 & 705 & 12496 & 24273 & 54017 & 0,800 & 30 & 90 & 9373 & 18207 & 45348 & 0,450 & 650 & 1400 & 2500 & 1,08 & 1,08 & 1,05 \\
\hline 90 & 30 & 20,0 & 40 & 240 & 491 & 743 & 13120 & 26860 & 59770 & 0,800 & $30 \mid$ & 90 & 10023 & 20520 & 50690 & 0,450 & 650 & 1400 & 2500 & 1,07 & 1,07 & 1,05 \\
\hline 90 & 30 & 22,0 & 45 & 240 & 516 & 799 & 13743 & 29575 & 68938 & 0,800 & 30 & 90 & 10670 & 22961 & 59242 & 0,450 & 650 & 1400 & 2500 & 1,07 & 1,07 & 1,04 \\
\hline & & & & & & & & & & & & & & & & & & & média & 1,11 & 1,11 & 1,06 \\
\hline & & & & & & & & & & & & & & & & & & & desvio & 0,0263 & 0,0263 & 0,0156 \\
\hline
\end{tabular}


Tabela C.8 - Valores de $\beta$ para pilares de borda sem momento no plano paralelo à borda e $\mathrm{c}_{1} \leq \mathrm{c}_{2}$

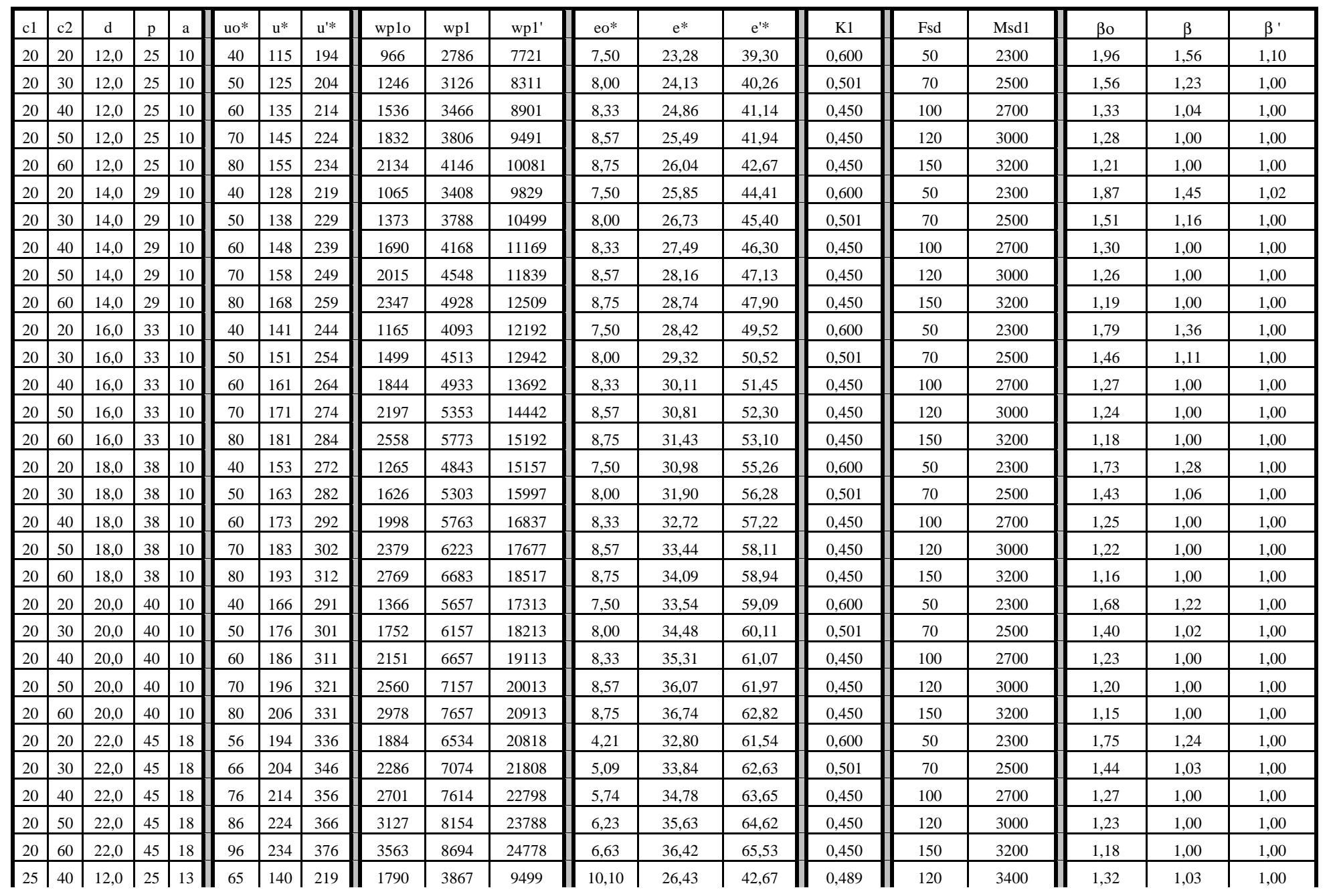




\begin{tabular}{|c|c|c|c|c|c|c|c|c|c|c|c|c|c|c|c|c|c|c|c|}
\hline $\mathrm{c} 1$ & c2 & $\mathrm{d}$ & $\mathrm{p}$ & $\mathrm{a}$ & uo* & $\mathrm{u}^{*}$ & $\mathrm{u}^{\prime *}$ & wp1o & wp1 & wp1' & eo* & $e^{*}$ & $\mathrm{e}^{\prime *}$ & $\mathrm{~K} 1$ & Fsd & Msd1 & $\beta o$ & $\beta$ & $\beta^{\prime}$ \\
\hline 25 & 50 & 12,0 & 25 & 13 & 75 & 150 & 229 & 2110 & 4232 & 10114 & 10,42 & 27,10 & 43,49 & 0,450 & 170 & 3600 & 1,17 & 1,00 & 1,00 \\
\hline 25 & 60 & 12,0 & 25 & 13 & 85 & 160 & 239 & 2436 & 4597 & 10729 & 10,66 & 27,69 & 44,25 & 0,450 & 220 & 3900 & 1,11 & 1,00 & 1,00 \\
\hline 25 & 75 & 12,0 & 25 & 13 & 100 & 175 & 254 & 2933 & 5144 & 11651 & 10,94 & 28,44 & 45,27 & 0,450 & 250 & 4100 & 1,08 & 1,00 & 1,00 \\
\hline 25 & 50 & 14,0 & 29 & 13 & 75 & 163 & 254 & 2303 & 5005 & 12524 & 10,42 & 29,75 & 48,68 & 0,450 & 170 & 3600 & 1,16 & 1,00 & 1,00 \\
\hline 25 & 60 & 14,0 & 29 & 13 & 85 & 173 & 264 & 2659 & 5410 & 13219 & 10,66 & 30,38 & 49,47 & 0,450 & 220 & 3900 & 1,10 & 1,00 & 1,00 \\
\hline 25 & 75 & 14,0 & 29 & 13 & 100 & 188 & 279 & 3201 & 6018 & 14261 & 10,94 & 31,18 & 50,54 & 0,450 & 250 & 4100 & 1,08 & 1,00 & 1,00 \\
\hline 25 & 60 & 16,0 & 33 & 13 & 85 & 186 & 289 & 2880 & 6287 & 15965 & 10,66 & 33,05 & 54,66 & 0,450 & 220 & 3900 & 1,09 & 1,00 & 1,00 \\
\hline 25 & 75 & 16,0 & 33 & 13 & 100 & 201 & 304 & 3468 & 6955 & 17128 & 10,94 & 33,90 & 55,79 & 0,450 & 250 & 4100 & 1,07 & 1,00 & 1,00 \\
\hline 25 & 40 & 18,0 & 38 & 13 & 65 & 178 & 297 & 2284 & 6258 & 17630 & 10,10 & 34,26 & 58,74 & 0,489 & 120 & 3400 & 1,25 & 1,00 & 1,00 \\
\hline 25 & 50 & 18,0 & 38 & 13 & 75 & 188 & 307 & 2689 & 6743 & 18495 & 10,42 & 35,02 & 59,64 & 0,450 & 170 & 3600 & 1,14 & 1,00 & 1,00 \\
\hline 25 & 60 & 18,0 & 38 & 13 & 85 & 198 & 317 & 3101 & 7228 & 19360 & 10,66 & 35,70 & 60,49 & 0,450 & 220 & 3900 & 1,09 & 1,00 & 1,00 \\
\hline 25 & 75 & 18,0 & 38 & 13 & 100 & 213 & 332 & 3733 & 7956 & 20658 & 10,94 & 36,60 & 61,66 & 0,450 & 250 & 4100 & 1,07 & 1,00 & 1,00 \\
\hline 25 & 75 & 20,0 & 40 & 13 & 100 & 226 & 351 & 3997 & 9021 & 23192 & 10,94 & 39,28 & 65,57 & 0,450 & 250 & 4100 & 1,06 & 1,00 & 1,00 \\
\hline 25 & 40 & 22,0 & 45 & 13 & 65 & 203 & 345 & 2614 & 8172 & 23710 & 10,10 & 39,44 & 68,35 & 0,489 & 120 & 3400 & 1,22 & 1,00 & 1,00 \\
\hline 25 & 50 & 22,0 & 45 & 13 & 75 & 213 & 355 & 3073 & 8737 & 24725 & 10,42 & 40,24 & 69,28 & 0,450 & 170 & 3600 & 1,12 & 1,00 & 1,00 \\
\hline 25 & 60 & 22,0 & 45 & 13 & 85 & 223 & 365 & 3542 & 9302 & 25740 & 10,66 & 40,97 & 70,17 & 0,450 & 220 & 3900 & 1,08 & 1,00 & 1,00 \\
\hline 25 & 75 & 22,0 & 45 & 13 & 100 & 238 & 380 & 4261 & 10150 & 27262 & 10,94 & 41,95 & 71,41 & 0,450 & 250 & 4100 & 1,06 & 1,00 & 1,00 \\
\hline 30 & 30 & 12,0 & 25 & 15 & 60 & 135 & 214 & 1730 & 3903 & 9481 & 11,25 & 27,16 & 43,27 & 0,600 & 120 & 3600 & 1,39 & 1,06 & 1,00 \\
\hline 30 & 40 & 12,0 & 25 & 15 & 70 & 145 & 224 & 2067 & 4293 & 10121 & 11,79 & 27,98 & 44,19 & 0,525 & 150 & 4100 & 1,28 & 1,00 & 1,00 \\
\hline 30 & 50 & 12,0 & 25 & 15 & 80 & 155 & 234 & 2411 & 4683 & 10761 & 12,19 & 28,69 & 45,04 & 0,480 & 170 & 4500 & 1,23 & 1,00 & 1,00 \\
\hline 30 & 60 & 12,0 & 25 & 15 & 90 & 165 & 244 & 2760 & 5073 & 11401 & 12,50 & 29,31 & 45,82 & 0,450 & 220 & 5000 & 1,15 & 1,00 & 1,00 \\
\hline 30 & 70 & 12,0 & 25 & 15 & 100 & 175 & 254 & 3115 & 5463 & 12041 & 12,75 & 29,86 & 46,53 & 0,450 & 250 & 5400 & 1,13 & 1,00 & 1,00 \\
\hline 30 & 80 & 12,0 & 25 & 15 & 110 & 185 & 264 & 3473 & 5853 & 12681 & 12,95 & 30,36 & 47,19 & 0,450 & 300 & 5900 & 1,10 & 1,00 & 1,00 \\
\hline 30 & 90 & 12,0 & 25 & 15 & 120 & 195 & 274 & 3834 & 6243 & 13321 & 13,13 & 30,80 & 47,81 & 0,450 & 320 & 6300 & 1,09 & 1,00 & 1,00 \\
\hline
\end{tabular}




\begin{tabular}{|c|c|c|c|c|c|c|c|c|c|c|c|c|c|c|c|c|c|c|c|}
\hline $\mathrm{c} 1$ & c2 & $\mathrm{d}$ & $\mathrm{p}$ & $\mathrm{a}$ & uo* & $\mathrm{u}^{*}$ & $\mathrm{u}^{\prime *}$ & wp1o & wp1 & wp1' & eo* & $\mathrm{e}^{*}$ & $\mathrm{e}^{\prime * *}$ & K1 & Fsd & Msd1 & Bo & $\beta$ & $\beta^{\prime}$ \\
\hline 30 & 60 & 14,0 & 29 & 15 & 90 & 178 & 269 & 2993 & 5917 & 13954 & 12,50 & 31,99 & 51,02 & 0,450 & 220 & 5000 & 1,14 & 1,00 & 1,00 \\
\hline 30 & 70 & 14,0 & 29 & 15 & 100 & 188 & 279 & 3377 & 6347 & 14674 & 12,75 & 32,57 & 51,78 & 0,450 & 250 & 5400 & 1,12 & 1,00 & 1,00 \\
\hline 30 & 80 & 14,0 & 29 & 15 & 110 & 198 & 289 & 3766 & 6777 & 15394 & 12,95 & 33,10 & 52,48 & 0,450 & 300 & 5900 & 1,09 & 1,00 & 1,00 \\
\hline 30 & 30 & 16,0 & 33 & 15 & 60 & 161 & 264 & 2024 & 5416 & 14363 & 11,25 & 32,34 & 53,51 & 0,600 & 120 & 3600 & 1,33 & 1,00 & 1,00 \\
\hline 30 & 40 & 16,0 & 33 & 15 & 70 & 171 & 274 & 2416 & 5886 & 15163 & 11,79 & 33,20 & 54,48 & 0,525 & 150 & 4100 & 1,24 & 1,00 & 1,00 \\
\hline 30 & 50 & 16,0 & 33 & 15 & 80 & 181 & 284 & 2817 & 6356 & 15963 & 12,19 & 33,96 & 55,38 & 0,480 & 170 & 4500 & 1,19 & 1,00 & 1,00 \\
\hline 30 & 80 & 16,0 & 33 & 15 & 110 & 211 & 314 & 4058 & 7766 & 18363 & 12,95 & 35,82 & 57,73 & 0,450 & 300 & 5900 & 1,08 & 1,00 & 1,00 \\
\hline 30 & 90 & 16,0 & 33 & 15 & 120 & 221 & 324 & 4482 & 8236 & 19163 & 13,13 & 36,33 & 58,41 & 0,450 & 320 & 6300 & 1,08 & 1,00 & 1,00 \\
\hline 30 & 30 & 18,0 & 38 & 15 & 60 & 173 & 292 & 2173 & 6268 & 17559 & 11,25 & 34,91 & 59,27 & 0,600 & 120 & 3600 & 1,31 & 1,00 & 1,00 \\
\hline 30 & 40 & 18,0 & 38 & 15 & 70 & 183 & 302 & 2591 & 6778 & 18449 & 11,79 & 35,79 & 60,25 & 0,525 & 150 & 4100 & 1,22 & 1,00 & 1,00 \\
\hline 30 & 50 & 18,0 & 38 & 15 & 80 & 193 & 312 & 3020 & 7288 & 19339 & 12,19 & 36,58 & 61,17 & 0,480 & 170 & 4500 & 1,18 & 1,00 & 1,00 \\
\hline 30 & 60 & 18,0 & 38 & 15 & 90 & 203 & 322 & 3456 & 7798 & 20229 & 12,50 & 37,29 & 62,03 & 0,450 & 220 & 5000 & 1,12 & 1,00 & 1,00 \\
\hline 30 & 40 & 20,0 & 40 & 15 & 70 & 196 & 321 & 2767 & 7735 & 20820 & 11,79 & 38,38 & 64,09 & 0,525 & 150 & 4100 & 1,21 & 1,00 & 1,00 \\
\hline 30 & 50 & 20,0 & 40 & 15 & 80 & 206 & 331 & 3223 & 8285 & 21770 & 12,19 & 39,19 & 65,03 & 0,480 & 170 & 4500 & 1,17 & 1,00 & 1,00 \\
\hline 30 & 60 & 20,0 & 40 & 15 & 90 & 216 & 341 & 3687 & 8835 & 22720 & 12,50 & 39,92 & 65,90 & 0,450 & 220 & 5000 & 1,11 & 1,00 & 1,00 \\
\hline 30 & 70 & 20,0 & 40 & 15 & 100 & 226 & 351 & 4159 & 9385 & 23670 & 12,75 & 40,59 & 66,73 & 0,450 & 250 & 5400 & 1,10 & 1,00 & 1,00 \\
\hline 30 & 80 & 20,0 & 40 & 15 & 110 & 236 & 361 & 4637 & 9935 & 24620 & 12,95 & 41,20 & 67,51 & 0,450 & 300 & 5900 & 1,07 & 1,00 & 1,00 \\
\hline 30 & 90 & 20,0 & 40 & 15 & 120 & 246 & 371 & 5122 & 10485 & 25570 & 13,13 & 41,76 & 68,25 & 0,450 & 320 & 6300 & 1,07 & 1,00 & 1,00 \\
\hline 30 & 30 & 22,0 & 45 & 15 & 60 & 198 & 340 & 2472 & 8165 & 23606 & 11,25 & 40,06 & 68,85 & 0,600 & 120 & 3600 & 1,27 & 1,00 & 1,00 \\
\hline 30 & 40 & 22,0 & 45 & 15 & 70 & 208 & 350 & 2943 & 8755 & 24646 & 11,79 & 40,97 & 69,85 & 0,525 & 150 & 4100 & 1,19 & 1,00 & 1,00 \\
\hline 30 & 50 & 22,0 & 45 & 15 & 80 & 218 & 360 & 3426 & 9345 & 25686 & 12,19 & 41,79 & 70,80 & 0,480 & 170 & 4500 & 1,16 & 1,00 & 1,00 \\
\hline 30 & 60 & 22,0 & 45 & 15 & 90 & 228 & 370 & 3918 & 9935 & 26726 & 12,50 & 42,55 & 71,70 & 0,450 & 220 & 5000 & 1,11 & 1,00 & 1,00 \\
\hline 30 & 70 & 22,0 & 45 & 15 & 100 & 238 & 380 & 4418 & 10525 & 27766 & 12,75 & 43,24 & 72,55 & 0,450 & 250 & 5400 & 1,09 & 1,00 & 1,00 \\
\hline 30 & 80 & 22,0 & 45 & 15 & 110 & 248 & 390 & 4926 & 11115 & 28806 & 12,95 & 43,87 & 73,36 & 0,450 & 300 & 5900 & 1,07 & 1,00 & 1,00 \\
\hline
\end{tabular}


Tabela C.9 - Valores de $\beta$ para pilares de borda sem momento no plano paralelo à borda e $c_{1}>c_{2}$

\begin{tabular}{|c|c|c|c|c|c|c|c|c|c|c|c|c|c|c|c|c|c|c|c|}
\hline $\mathrm{c} 1$ & $\mathrm{c} 2$ & $\mathrm{~d}$ & $\mathrm{p}$ & $\mathrm{a}$ & uo* & $\mathrm{u}^{*}$ & $\mathrm{u}^{\prime} *$ & wp1o & wp1 & wp1' & eo* & $\mathrm{e}^{*}$ & $\mathrm{e}^{\prime *}$ & $\mathrm{~K} 1$ & Fsd & Msd1 & $\beta o$ & $\beta$ & $\beta^{\prime}$ \\
\hline 30 & 20 & 12,0 & 25 & 15 & 50 & 125 & 204 & 1401 & 3513 & 8841 & 10,50 & 26,22 & 42,25 & 0,650 & 70 & 2800 & 1,93 & 1,93 & 1,00 \\
\hline 30 & 20 & 14,0 & 29 & 15 & 50 & 138 & 229 & 1521 & 4197 & 11074 & 10,50 & 28,79 & 47,36 & 0,650 & 70 & 2800 & 1,85 & 1,85 & 1,00 \\
\hline 30 & 20 & 16,0 & 33 & 15 & 50 & 151 & 254 & 1643 & 4946 & 13563 & 10,50 & 31,36 & 52,47 & 0,650 & 70 & 2800 & 1,79 & 1,79 & 1,00 \\
\hline 30 & 20 & 20,0 & 40 & 15 & 50 & 176 & 301 & 1889 & 6635 & 18920 & 10,50 & 36,49 & 62,04 & 0,650 & 70 & 2800 & 1,69 & 1,69 & 1,00 \\
\hline 30 & 20 & 22,0 & 45 & 15 & 50 & 188 & 330 & 2012 & 7575 & 22566 & 10,50 & 39,05 & 67,78 & 0,650 & 70 & 2800 & 1,65 & 1,65 & 1,00 \\
\hline 40 & 20 & 12,0 & 25 & 18 & 56 & 131 & 210 & 1850 & 4340 & 10061 & 14,21 & 29,95 & 46,00 & 0,700 & 100 & 3000 & 1,64 & 1,64 & 1,00 \\
\hline 40 & 20 & 14,0 & 29 & 18 & 56 & 144 & 235 & 1979 & 5087 & 12419 & 14,21 & 32,53 & 51,11 & 0,700 & 100 & 3000 & 1,59 & 1,00 & 1,00 \\
\hline 40 & 25 & 14,0 & $29 \mid$ & 20 & 65 & 153 & 244 & 2264 & 5327 & 12804 & 13,85 & 32,21 & 50,82 & 0,660 & 120 & 3800 & 1,60 & 1,00 & 1,00 \\
\hline 40 & 30 & 14,0 & \begin{tabular}{|l|}
29 \\
\end{tabular} & 20 & 70 & 158 & 249 & 2467 & 5567 & 13189 & 14,29 & 32,71 & 51,35 & 0,633 & 150 & 4500 & 1,54 & 1,00 & 1,00 \\
\hline 40 & 20 & 16,0 & 33 & 18 & 56 & 157 & 260 & 2110 & 5899 & 15034 & 14,21 & 35,10 & 56,23 & 0,700 & 100 & 3000 & 1,56 & 1,00 & 1,00 \\
\hline 40 & 25 & 16,0 & 33 & 20 & 65 & 166 & 269 & 2418 & 6159 & 15459 & 13,85 & 34,79 & 55,94 & 0,660 & 120 & 3800 & 1,56 & 1,00 & 1,00 \\
\hline 40 & 20 & 20,0 & $40 \mid$ & 20 & 60 & 186 & 311 & 2493 & 7713 & 20627 & 13,33 & 39,39 & 64,97 & 0,700 & 100 & 3000 & 1,51 & 1,00 & 1,00 \\
\hline 40 & 25 & 20,0 & 40 & 20 & 65 & 191 & 316 & 2732 & 8013 & 21127 & 13,85 & 39,93 & 65,52 & 0,660 & 120 & 3800 & 1,50 & 1,00 & 1,00 \\
\hline 40 & 30 & 20,0 & 40 & 20 & 70 & 196 & 321 & 2974 & 8313 & 21627 & 14,29 & 40,44 & 66,06 & 0,633 & 150 & 4500 & 1,45 & 1,00 & 1,00 \\
\hline 40 & 20 & 22,0 & 45 & 20 & 60 & 198 & 340 & 2638 & 8717 & 24414 & 13,33 & 41,95 & 70,71 & 0,700 & 100 & 3000 & 1,48 & 1,00 & 1,00 \\
\hline 40 & $25 \mid$ & 22,0 & 45 & 20 & 65 & 203 & 345 & 2890 & 9037 & 24959 & 13,85 & 42,50 & 71,27 & 0,660 & 120 & 3800 & 1,47 & 1,00 & 1,00 \\
\hline 40 & 30 & 22,0 & \begin{tabular}{|l|} 
\\
\end{tabular} & 20 & 70 & 208 & 350 & 3145 & 9357 & 25504 & 14,29 & 43,01 & 71,81 & 0,633 & 150 & 4500 & 1,42 & 1,00 & 1,00 \\
\hline 50 & 20 & 12,0 & $25 \mid$ & 18 & 56 & 131 & 210 & 2245 & 5267 & 11380 & 19,21 & 34,95 & 51,00 & 0,750 & 120 & 3300 & 1,51 & 1,00 & 1,00 \\
\hline 50 & 25 & 12,0 & 25 & 24 & 73 & 148 & 227 & 2711 & 5512 & 11750 & 17,11 & 32,92 & 49,02 & 0,700 & 170 & 4000 & 1,44 & 1,00 & 1,00 \\
\hline 50 & 30 & 12,0 & $25 \mid$ & 25 & 80 & 155 & 234 & 2964 & 5757 & 12120 & 17,19 & 33,02 & 49,14 & 0,667 & 170 & 5000 & 1,53 & 1,00 & 1,00 \\
\hline 50 & $20 \mid$ & 14,0 & \begin{tabular}{|l|}
29 \\
\end{tabular} & 18 & 56 & 144 & 235 & 2364 & 6077 & 13865 & 19,21 & 37,53 & 56,11 & 0,750 & 120 & 3300 & 1,49 & 1,00 & 1,00 \\
\hline 50 & $25 \mid$ & 14,0 & $29 \mid$ & 24 & 73 & 161 & 252 & 2876 & 6342 & 14275 & 17,11 & 35,51 & 54,15 & 0,700 & 170 & 4000 & 1,42 & 1,00 & 1,00 \\
\hline 50 & 30 & 14,0 & \begin{tabular}{|l|} 
\\
\end{tabular} & 25 & 80 & 168 & 259 & 3147 & 6607 & 14685 & 17,19 & 35,62 & 54,27 & 0,667 & 170 & 5000 & 1,50 & 1,00 & 1,00 \\
\hline
\end{tabular}




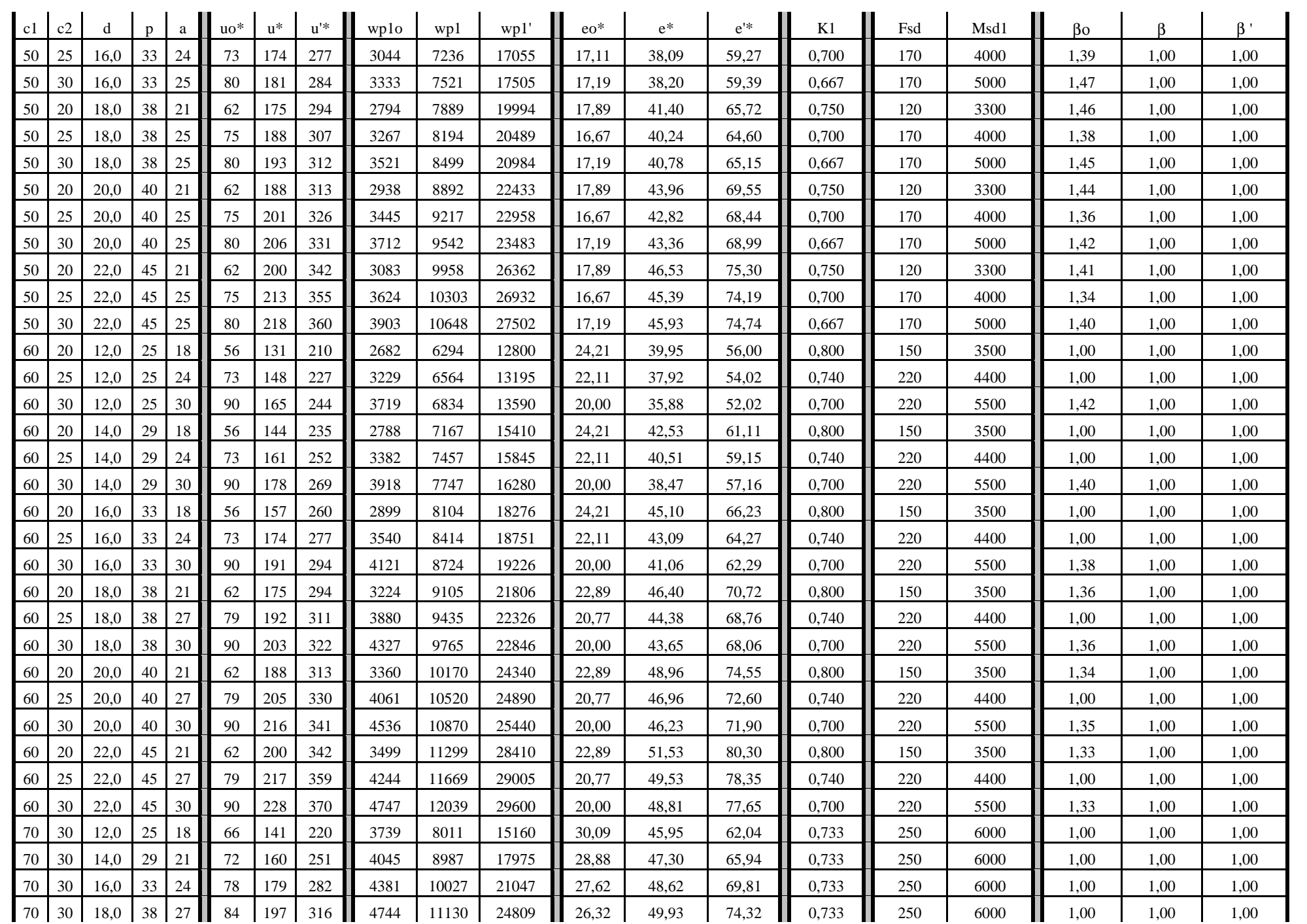




\begin{tabular}{|c|c|c|c|c|c|c|c|c|c|c|c|c|c|c|c|c|c|c|c|}
\hline $\mathrm{c} 1$ & $\mathrm{c} 2$ & $\mathrm{~d}$ & $\mathrm{p}$ & $\mathrm{a}$ & uo* & \begin{tabular}{|l|}
$*$ \\
\end{tabular} & $\mathrm{u}^{\prime *}$ & wp1o & wp1 & wp1' & eo* & $\mathrm{e}^{*}$ & $\mathrm{e}^{\prime *}$ & K1 & Fsd & Msd1 & ßo & $\beta$ & $\beta^{\prime}$ \\
\hline 70 & 30 & 20,0 & 40 & 30 & 90 & 216 & 341 & 5132 & 12298 & 27496 & 25,00 & 51,23 & 76,90 & 0,733 & 250 & 6000 & 1,00 & 1,00 & 1,00 \\
\hline 70 & 30 & 22,0 & 45 & 33 & 96 & 234 & 376 & 5545 & 13530 & 31798 & 23,66 & 52,52 & 81,39 & 0,733 & 250 & 6000 & 1,30 & 1,00 & 1,00 \\
\hline 75 & 25 & 12,0 & 25 & 18 & 61 & 136 & 215 & 3725 & 8329 & 15550 & 32,19 & 47,97 & 64,03 & 0,800 & 250 & 4500 & 1,00 & 1,00 & 1,00 \\
\hline 75 & 25 & 16,0 & 33 & 24 & 73 & 174 & 277 & 4362 & 10368 & 21483 & 29,61 & 50,59 & 71,77 & 0,800 & 250 & 4500 & 1,00 & 1,00 & 1,00 \\
\hline 75 & 25 & 18,0 & 38 & 27 & 79 & 192 & 311 & 4722 & 11483 & 25270 & 28,27 & 51,88 & 76,26 & 0,800 & 250 & 4500 & 1,00 & 1,00 & 1,00 \\
\hline 75 & 25 & 20,0 & 40 & 30 & 85 & 211 & 336 & 5109 & 12662 & 27975 & 26,91 & 53,16 & 78,83 & 0,800 & 250 & 4500 & 1,00 & 1,00 & 1,00 \\
\hline 80 & 30 & 14,0 & 29 & 21 & 72 & 160 & 251 & 4648 & 10327 & 19771 & 33,88 & 52,30 & 70,94 & 0,767 & 300 & 6500 & 1,00 & 1,00 & 1,00 \\
\hline 80 & 30 & 16,0 & 33 & 24 & 78 & 179 & 282 & 4993 & 11429 & 22968 & 32,62 & 53,62 & 74,81 & 0,767 & 300 & 6500 & 1,00 & 1,00 & 1,00 \\
\hline 80 & 30 & 18,0 & 38 & 27 & 84 & 197 & 316 & 5368 & 12596 & 26871 & 31,32 & 54,93 & 79,32 & 0,767 & 300 & 6500 & 1,00 & 1,00 & 1,00 \\
\hline 80 & 30 & 20,0 & 40 & 30 & 90 & 216 & 341 & 5770 & 13827 & 29653 & 30,00 & 56,23 & 81,90 & 0,767 & 300 & 6500 & 1,00 & 1,00 & 1,00 \\
\hline 80 & 30 & 22,0 & 45 & 33 & 96 & 234 & 376 & 6197 & 15121 & 34096 & 28,66 & 57,52 & 86,39 & 0,767 & 300 & 6500 & 1,00 & 1,00 & 1,00 \\
\hline 90 & 30 & 20,0 & 40 & 30 & 90 & 216 & 341 & 6450 & 15455 & 31910 & 35,00 & 61,23 & 86,90 & 0,800 & 320 & 7000 & 1,00 & 1,00 & 1,00 \\
\hline 90 & 30 & 22,0 & 45 & 33 & 96 & 234 & 376 & 6891 & 16812 & 36494 & 33,66 & 62,52 & 91,39 & 0,800 & 320 & 7000 & 1,00 & 1,00 & 1,00 \\
\hline & & & & & & & & & & & & & & & & média & 1,31 & 1,07 & 1,00 \\
\hline & & & & & & & & & & & & & & & & desvio & 0,2632 & 0,2209 & 0,0000 \\
\hline
\end{tabular}


Tabela C.10 - Valores de $\beta$ para pilares de borda com momento no plano paralelo à borda e $\mathrm{c}_{1} \leq \mathrm{c}_{2}$

\begin{tabular}{|c|c|c|c|c|c|c|c|c|c|c|c|c|c|c|c|c|c|c|c|c|c|c|c|c|}
\hline c1 & c2 2 & $d$ & p & $a$ & uo* & $u^{*}$ & $\mathrm{u}^{\prime *}$ & wp1o & wp1 & wp1' & eo* & $\mathrm{e}^{*}$ & $\mathrm{e}^{\prime *}$ & K1 & wp2o & wp2 & $\mathrm{wp} 2{ }^{\prime}$ & K2 & Fsd & Msd1 1 & \begin{tabular}{|l|} 
Msd2 \\
\end{tabular} & $\beta_{0}$ & $\beta$ & $\beta^{\prime}$ \\
\hline 20 & 20 & 2,0 & $25 \mid$ & 10 & 40 & 115 & 194 & 966 & 786 & 7721 & 7,50 & 23,28 & 39,30 & $0,0,600$ & 1167 & 366 & 8801 & 0,500 & 50 & 2000 & 300 & 1,91 & 1,52 & 1,08 \\
\hline 20 & 30 & 12,0 & 25 & 10 & 50 & 125 & 204 & 1246 & 3126 & 8311 & 8,00 & 24,13 & 40,26 & 0,501 & 1622 & 4068 & 9896 & 0,750 & 70 & 2200 & 450 & 1,62 & 1,30 & 1,10 \\
\hline 20 & 40 & 12,0 & $25 \mid$ & 10 & 60 & 35 & 214 & 1536 & 3466 & 8901 & 8,33 & 24,86 & 41,14 & \begin{tabular}{|l} 
\\
\end{tabular} & 2136 & 4820 & 11041 & 1,000 & 100 & 2400 & 600 & 1,44 & 1,17 & 1,12 \\
\hline 20 & 50 & 2,0 & 25 & 10 & 70 & 145 & 224 & 1832 & 06 & 9491 & 8,5 & 49 & 41,94 & 0,450 & 2707 & 622 & 12235 & 1,250 & 120 & 2600 & 750 & 1.43 & 1.20 & 1.14 \\
\hline 20 & 60 & 12,0 & 25 & 10 & 80 & 155 & 234 & 2134 & 4146 & 10081 & 8,75 & 26,04 & 42,67 & 0,450 & 3333 & 6474 & 13480 & 1,500 & 150 & 2800 & 900 & 1,38 & 1,22 & 1,16 \\
\hline 20 & 20 & 14,0 & $29 \mid$ & 10 & 40 & 128 & 219 & 1065 & 3408 & 9829 & 7,50 & 25,85 & 44,41 & 0,600 & 1271 & 4068 & 11069 & 0,500 & 50 & 2000 & 300 & 1,83 & 1,41 & 1,06 \\
\hline 20 & 30 & 14,0 & 29 & 10 & 50 & 138 & 229 & 1373 & 3788 & 10499 & 8,00 & 26,73 & 45,40 & 0,501 & 1751 & 4832 & 12289 & 0,750 & 70 & 2200 & 450 & 1,57 & 1,22 & 1,09 \\
\hline 20 & 40 & 14,0 & \begin{tabular}{|l|}
29 \\
\end{tabular} & 10 & 60 & 48 & 239 & 1690 & 4168 & 11169 & 8,33 & 27,49 & 46,30 & 0 & 2290 & 5647 & 13559 & 1,000 & 100 & 2400 & 600 & 1,41 & 1,1 & 1,11 \\
\hline 20 & \begin{tabular}{|l|}
50 \\
\end{tabular} & 14,0 & \begin{tabular}{|l|}
29 \\
\end{tabular} & 10 & 70 & 158 & 249 & 2015 & 4548 & 11839 & 8,57 & 28,16 & 47,13 & $0,0,450$ & 2886 & 6512 & 14880 & \begin{tabular}{|l|}
1,250 \\
\end{tabular} & 120 & 2600 & 750 & 1,39 & 1,19 & 1,13 \\
\hline 20 & 60 & 14,0 & 29 & 10 & 80 & 68 & 259 & 2347 & 4928 & 12509 & 8,75 & 28,74 & 47,90 & 0,450 & 3537 & 742 & 16250 & 1,500 & 150 & 2800 & 900 & 1,36 & 1,2 & 1,14 \\
\hline 20 & 20 & 16,0 & 33 & 10 & 40 & 141 & 244 & 1165 & 4093 & 12192 & 7,50 & 28,42 & 49,52 & 0,600 & 1376 & 4833 & 13592 & 0,500 & 50 & 2000 & 300 & 1,76 & 1,33 & 1,05 \\
\hline 20 & \begin{tabular}{|l|}
30 \\
\end{tabular} & 16,0 & 33 & \begin{tabular}{|l|}
10 \\
\end{tabular} & 50 & 151 & 254 & 1499 & 4513 & 12942 & 8,00 & 29,32 & 50,52 & \begin{tabular}{|l|l}
0,501 \\
\end{tabular} & 1880 & 5661 & 14938 & 0,750 & 70 & \begin{tabular}{|l|l|}
2200 \\
\end{tabular} & 450 & 1,52 & 1,16 & 1,08 \\
\hline 20 & 40 & 16,0 & 33 & 10 & 60 & 161 & 264 & 1844 & 4933 & 13692 & 8,33 & 30,11 & 51,45 & 0,450 & 2444 & 6539 & 16334 & 1,000 & 100 & 2400 & 600 & 1,38 & 1,1 & 1,10 \\
\hline 20 & \begin{tabular}{|l|}
50 \\
\end{tabular} & 16,0 & 33 & 10 & 70 & 171 & 274 & 2197 & 5353 & 14442 & 8,57 & 30,81 & 52,30 & 0,450 & 3065 & 7466 & 17780 & 1,250 & 120 & 2600 & 750 & 1,37 & 1,18 & 1,12 \\
\hline 20 & \begin{tabular}{|l|}
60 \\
\end{tabular} & 16,0 & \begin{tabular}{|l|}
33 \\
\end{tabular} & \begin{tabular}{|l|}
10 \\
\end{tabular} & 80 & 181 & 284 & 2558 & 5773 & 15192 & 8,75 & 31,43 & 53,10 & \begin{tabular}{|l|l}
0,450 \\
\end{tabular} & 3742 & 8444 & 19276 & \begin{tabular}{|l|}
1,500 \\
\end{tabular} & 150 & \begin{tabular}{|l|l|}
2800 \\
\end{tabular} & 900 & 1,33 & 1,19 & 1,13 \\
\hline 20 & 20 & 18,0 & 38 & 10 & 40 & 153 & 272 & 1265 & 4843 & 15157 & 7,50 & 30,98 & 55,26 & 0,600 & 1480 & 5663 & 16737 & 0,500 & 50 & 2000 & 300 & 1,70 & 1,2 & 1,05 \\
\hline 20 & 30 & 18,0 & 38 & 10 & 50 & 163 & 282 & 1626 & 5303 & 15997 & 8,00 & 31,90 & 56,28 & 0,501 & 2009 & 6553 & 18224 & 0,750 & 70 & 2200 & 450 & 1,48 & 1,1 & 1,07 \\
\hline 20 & \begin{tabular}{|l|}
40 \\
\end{tabular} & 18,0 & \begin{tabular}{|l|}
38 \\
\end{tabular} & \begin{tabular}{|l|}
10 \\
\end{tabular} & 60 & 173 & 292 & 1998 & 5763 & 16837 & 8,33 & 32,72 & 57,22 & \begin{tabular}{|l|}
0,450 \\
\end{tabular} & 2598 & 7494 & 19762 & \begin{tabular}{|l}
1,000 \\
\end{tabular} & 100 & 2400 & 600 & 1,35 & 1,14 & 1,09 \\
\hline 20 & 50 & 18,0 & 38 & 10 & 70 & 183 & 302 & 2379 & 6223 & 17677 & 8,57 & 33,44 & 58,11 & 0 & 3244 & 8484 & 21349 & 1,250 & 120 & 2600 & 750 & 1,34 & 1,17 & 1,11 \\
\hline 20 & 60 & 18,0 & 38 & 10 & 80 & 33 & 312 & 2769 & 6683 & 18517 & 8,75 & 34,09 & 58,94 & 0,450 & 3946 & 9525 & 22986 & 1,500 & 150 & 2800 & 900 & 1,31 & 1,18 & 1,12 \\
\hline 20 & \begin{tabular}{|l|}
20 \\
\end{tabular} & 20,0 & \begin{tabular}{|l|}
40 \\
\end{tabular} & \begin{tabular}{|l|}
10 \\
\end{tabular} & 40 & 166 & 291 & 1366 & 5657 & 17313 & 7,50 & 33,54 & 59,09 & \begin{tabular}{|l|}
0,600 \\
\end{tabular} & 1583 & 6557 & 19013 & \begin{tabular}{|l}
0,500 \\
\end{tabular} & 50 & 2000 & 300 & 1,65 & 1,19 & 1,05 \\
\hline 20 & \begin{tabular}{|l|}
30 \\
\end{tabular} & 20,0 & \begin{tabular}{|l|}
40 \\
\end{tabular} & \begin{tabular}{|l|}
10 \\
\end{tabular} & 50 & 176 & 301 & 1752 & 6157 & 18213 & 8,00 & 34,48 & 60,11 & \begin{tabular}{|l|}
0,501 \\
\end{tabular} & 2138 & 7510 & 20595 & 0,750 & 70 & \begin{tabular}{|l|l|}
2200 \\
\end{tabular} & 450 & 1,45 & 1,11 & 1,07 \\
\hline 20 & 40 & 20,0 & 40 & 10 & 60 & 186 & 311 & 2151 & 6657 & 19113 & 8,33 & 35,31 & 61,07 & 0,450 & 2751 & 8513 & 22227 & 1,000 & 100 & 2400 & 600 & 1,33 & 1,13 & 1,08 \\
\hline 20 & \begin{tabular}{|l|}
50 \\
\end{tabular} & 20,0 & \begin{tabular}{|l|}
40 \\
\end{tabular} & \begin{tabular}{|l|}
10 \\
\end{tabular} & 70 & 196 & 321 & 2560 & 7157 & 20013 & 8,57 & 36,07 & 61,97 & \begin{tabular}{|l|l}
0,450 \\
\end{tabular} & 3423 & 9567 & 23908 & 1,250 & 120 & 2600 & 750 & 1,32 & 1,16 & 1,11 \\
\hline 20 & \begin{tabular}{|l|}
60 \\
\end{tabular} & 20,0 & \begin{tabular}{|l|}
40 \\
\end{tabular} & \begin{tabular}{|l|}
10 \\
\end{tabular} & 80 & 206 & 331 & 2978 & 7657 & 20913 & 8,75 & 36,74 & 62,82 & \begin{tabular}{|l|}
0,450 \\
\end{tabular} & 4150 & 10670 & 25640 & \begin{tabular}{|l}
1,500 \\
\end{tabular} & 150 & 2800 & 900 & 1,29 & 1,17 & 1,12 \\
\hline 20 & 20 & 22,0 & \begin{tabular}{|l|} 
\\
\end{tabular} & 18 & 56 & 194 & 336 & 1884 & 6534 & 20818 & 4,21 & 32,80 & 61,54 & 0,000 & 2167 & 7514 & 22698 & \begin{tabular}{|l|}
0,500 \\
\end{tabular} & 50 & 2000 & 300 & 1,72 & 1,21 & 1,04 \\
\hline 20 & 30 & 22,0 & 45 & 18 & 66 & 204 & 346 & 2286 & 7074 & 21808 & 5,09 & 33,84 & 62,63 & 0,501 & 2757 & 8530 & 24421 & 0,750 & 70 & 2200 & 450 & 1,50 & 1,12 & 1,07 \\
\hline 20 & \begin{tabular}{|l|}
40 \\
\end{tabular} & 22,0 & \begin{tabular}{|l|}
45 \\
\end{tabular} & \begin{tabular}{|l|}
18 \\
\end{tabular} & 76 & 214 & 356 & 2701 & 7614 & 22798 & 5,74 & 34,78 & 63,65 & \begin{tabular}{|l|}
0,450 \\
\end{tabular} & 3404 & 9597 & 26194 & $\begin{array}{l}1,000 \\
\end{array}$ & 100 & 2400 & 600 & 1,37 & 13 & 1,08 \\
\hline 20 & 50 & 22,0 & \begin{tabular}{|l|} 
\\
\end{tabular} & 18 & 86 & 224 & 366 & 3127 & 8154 & 23788 & 6,23 & 35,63 & 64,62 & 0 & 4109 & 10713 & 28017 & 1,250 & 120 & 2600 & 750 & 1,35 & 1,16 & 1,10 \\
\hline 20 & 60 & 22,0 & 45 & 18 & 96 & 234 & 376 & 3563 & 8694 & 24778 & 6,63 & 36,42 & 65,53 & 0,450 & 4869 & 11879 & 29890 & 1,50 & 150 & 2800 & 900 & 1,32 & 1,18 & 11 \\
\hline & & 2,0 & 2 & & 5 & 40 & 19 & 1790 & 3867 & 3499 & 10,10 & 26,4 & 2,07 & & 2435 & 5260 & $11 / 31$ & & 120 & 3000 & 150 & 1,40 & 1,13 & 1,0 \\
\hline
\end{tabular}




\begin{tabular}{|c|c|c|c|c|c|c|c|c|c|c|c|c|c|c|c|c|c|c|c|c|c|c|c|c|}
\hline $\mathrm{c} 1$ & c2 & d & $\mathrm{p}$ & $\mathrm{a}$ & uo* & $\mathrm{u}^{*}$ & $\mathrm{u}^{\mathrm{u} *}$ & wp1o & wp1 & wp1' & eo* & $e^{*}$ & $\mathrm{e}^{\prime *}$ & K1 & wp2o & wp2 & wp2' & $\mathrm{K} 2$ & Fsd & Msd1 & Msd2 & $\beta o$ & $\beta$ & $\beta^{\prime}$ \\
\hline 25 & 50 & 12,0 & 25 & 13 & 75 & 150 & 229 & 2110 & 4232 & 10114 & 10,42 & 7,10 & 43,49 & 0,450 & 3048 & 6112 & 12975 & 1,000 & 170 & 3200 & 950 & 1,27 & 1,14 & 1,10 \\
\hline 25 & 60 & 12,0 & 25 & 13 & 85 & 160 & 239 & 2436 & 4597 & 10729 & 10,66 & 27,69 & 44,25 & 0,450 & 3717 & 7014 & 14270 & 1,200 & 220 & 3400 & 1100 & 1,21 & 1,14 & 1,10 \\
\hline 25 & 75 & 12,0 & 25 & 13 & 100 & 175 & 254 & 2933 & 5144 & 11651 & 10,94 & 28,44 & 45,27 & 0,450 & 4824 & 8461 & 16306 & 1,500 & 250 & 3600 & 1500 & 1,24 & 1,19 & 1,14 \\
\hline 25 & 40 & 14,0 & 29 & 13 & 65 & 153 & 244 & 1955 & 4600 & 11829 & 10,10 & 29,05 & 47,82 & 0,489 & 2604 & 6127 & 14329 & 0,800 & 120 & 3000 & 750 & 1,37 & 1,12 & 1,09 \\
\hline 25 & 50 & 14,0 & 29 & 13 & 75 & 163 & 254 & 2303 & 5005 & 12524 & 10,42 & 29,75 & 48,68 & 0,450 & 3241 & 7042 & 15700 & 1,000 & 170 & 3200 & 950 & 1,25 & 1,13 & 1,09 \\
\hline 25 & 60 & 14,0 & 29 & 13 & 85 & 173 & 264 & 2659 & 5410 & 13219 & 10,66 & 30,38 & 49,47 & 0,450 & 3935 & 8007 & 17120 & 1,200 & 220 & 3400 & 1100 & 1,20 & 1,13 & 1,09 \\
\hline 25 & 75 & 14,0 & 29 & 13 & 100 & 188 & 279 & 3201 & 6018 & 14261 & 10,94 & 31,18 & 50,54 & 0,450 & 5080 & 9548 & 19344 & 1,500 & 250 & 3600 & 1500 & 1,23 & 1,18 & 1,13 \\
\hline 25 & 40 & 16,0 & 33 & 13 & 65 & 166 & 269 & 2119 & 5397 & 14415 & 10,10 & 31,66 & 52,97 & 0,489 & 2772 & 7059 & 17184 & 0,800 & 120 & 3000 & 750 & 1,34 & 1,12 & 1,08 \\
\hline 25 & 50 & 16,0 & 33 & 13 & 75 & 176 & 279 & 2496 & 5842 & 15190 & 10,42 & 32,39 & 53,85 & 0,450 & 3434 & 8036 & 18680 & 1,000 & 170 & 3200 & 950 & 1,24 & 1,12 & 1,08 \\
\hline 25 & 60 & 16,0 & 33 & 13 & 85 & 186 & 289 & 2880 & 6287 & 15965 & 10,66 & 33,05 & 54,66 & 0,450 & 4153 & 9064 & 20226 & 1,200 & 220 & 3400 & 1100 & 1,19 & 1,12 & 1,09 \\
\hline 25 & 75 & 16,0 & 33 & 13 & 100 & 201 & 304 & 3468 & 6955 & 17128 & 10,94 & 33,90 & 55,79 & 0,450 & 5335 & 10699 & 22639 & 1,500 & 250 & 3600 & 1500 & 1,21 & 1,17 & 1,12 \\
\hline 25 & 40 & 18,0 & 38 & 13 & 65 & 178 & 297 & 2284 & 6258 & 17630 & 10,10 & 34,26 & 58,74 & 0,489 & 2939 & 8054 & 20702 & 0,800 & 120 & 3000 & 750 & 1,32 & 1,11 & 1,07 \\
\hline 25 & 50 & 18,0 & 38 & 13 & 75 & 188 & 307 & 2689 & 6743 & 18495 & 10,42 & 35,02 & 59,64 & 0,450 & 3626 & 9094 & 22339 & 1,000 & 170 & 3200 & 950 & 1,22 & 1,12 & 1,08 \\
\hline 25 & \begin{tabular}{|l|}
60 \\
\end{tabular} & 18,0 & 38 & 13 & 85 & 198 & 317 & 3101 & 7228 & 19360 & 10,66 & 35,70 & 60,49 & 0,450 & 4370 & 10185 & 24026 & 1,200 & 220 & 3400 & 1100 & 1,18 & 1,12 & 1,08 \\
\hline 25 & 75 & 18,0 & 38 & 13 & 100 & 213 & 332 & 3733 & 7956 & 20658 & 10,94 & 36,60 & 61,66 & 0,450 & 5591 & 11914 & 26651 & 1,500 & 250 & 3600 & 1500 & 1,20 & 1,16 & 1,11 \\
\hline 25 & 40 & 20,0 & 40 & 13 & 65 & 191 & 316 & 2449 & 7183 & 19954 & 10,10 & 36,86 & 62,59 & 0,489 & 3107 & 9113 & 23227 & 0,800 & 120 & 3000 & 750 & 1,30 & 1,10 & 1,07 \\
\hline 25 & 50 & 20,0 & 40 & 13 & 75 & 201 & 326 & 2881 & 7708 & 20879 & 10,42 & 37,64 & 63,50 & 0,450 & 3819 & 10217 & 24958 & 1,000 & 170 & 3200 & 950 & 1,21 & 1,11 & 1,07 \\
\hline 25 & 60 & 20,0 & 40 & 13 & 85 & 211 & 336 & 3322 & 8233 & 21804 & 10,66 & 38,34 & 64,37 & 0,450 & 4588 & 11370 & 26740 & 1,200 & 220 & 3400 & 1100 & 1,17 & 1,11 & 1,08 \\
\hline 25 & 75 & 20,0 & 40 & 13 & 100 & 226 & 351 & 3997 & 9021 & 23192 & 10,94 & 39,28 & 65,57 & 0,450 & 5847 & 13194 & 29506 & 1,500 & 250 & 3600 & 1500 & 1,19 & 1,15 & 1,11 \\
\hline 25 & 40 & 22,0 & 45 & 13 & 65 & 203 & 345 & 2614 & 8172 & 23710 & 10,10 & 39,44 & 68,35 & 0,489 & 3274 & 10237 & 27284 & \begin{tabular}{|l|l} 
\\
\end{tabular}, 880 & 120 & 3000 & 750 & 1,28 & 1,10 & 1,06 \\
\hline 25 & 50 & 22,0 & 45 & 13 & 75 & 213 & 355 & 3073 & 8737 & 24725 & 10,42 & 40,24 & 69,28 & 0,450 & 4011 & 11403 & 29157 & 1,000 & 170 & 3200 & 950 & 1,20 & 1,10 & 1,07 \\
\hline 25 & 60 & 22,0 & 45 & 13 & 85 & 223 & 365 & 3542 & 9302 & 25740 & 10,66 & 40,97 & 70,17 & 0,450 & 4805 & 12619 & 31080 & 1,200 & 220 & 3400 & 1100 & 1,16 & 1,11 & 1,07 \\
\hline 25 & 75 & 22,0 & 45 & 13 & 100 & 238 & 380 & 4261 & 10150 & 27262 & 10,94 & 41,95 & 71,41 & 0,450 & 6102 & 14537 & 34058 & 1,500 & 250 & 3600 & 1500 & 1,18 & 1,15 & 1,10 \\
\hline 30 & 30 & 12,0 & 25 & 15 & 60 & 135 & 214 & 1730 & 3903 & 9481 & 11,25 & 27,16 & 43,27 & 0,600 & 2148 & 4848 & 11176 & 0,500 & 120 & 3200 & 500 & 1,38 & 1,06 & 1,04 \\
\hline 30 & 40 & 12,0 & 25 & 15 & 70 & 145 & 224 & 2067 & 4293 & 10121 & 11,79 & 27,98 & 44,19 & 0,525 & 2744 & 5700 & 12421 & 0,667 & 150 & 3600 & 600 & 1,29 & 1,07 & 1,05 \\
\hline 30 & 50 & 12,0 & 25 & 15 & 80 & 155 & 234 & 2411 & 4683 & 10761 & 12,19 & 28,69 & 45,04 & 0,480 & 3399 & 6602 & 13715 & 0,833 & 170 & 4000 & 800 & 1,27 & 1,09 & 1,07 \\
\hline 30 & 60 & 12,0 & 25 & 15 & 90 & 165 & 244 & 2760 & 5073 & 11401 & 12,50 & 29,31 & 45,82 & 0,450 & 4110 & 7554 & 15060 & 1,000 & 220 & 4400 & 950 & 1,20 & 1,09 & 1,07 \\
\hline 30 & 70 & 12,0 & 25 & 15 & 100 & 175 & 254 & 3115 & 5463 & 12041 & 12,75 & 29,86 & 46,53 & 0,450 & 4878 & 8556 & 16455 & 1,167 & 250 & 4800 & 1100 & 1,20 & 1,11 & 1,08 \\
\hline 30 & 80 & 12,0 & 25 & 15 & 110 & 185 & 264 & 3473 & 5853 & 12681 & 12,95 & 30,36 & 47,19 & 0,450 & 5701 & 9608 & 17900 & 1,333 & 300 & 5200 & 1300 & 1,17 & 1,11 & 1,09 \\
\hline 30 & 90 & 12,0 & 25 & 15 & 120 & 195 & 274 & 3834 & 6243 & 13321 & 13,13 & 30,80 & 47,81 & 0,450 & 6577 & 10710 & 19394 & 1,500 & 320 & 5600 & 1500 & 1,19 & 1,13 & 1,10 \\
\hline 30 & 30 & 14,0 & 29 & 15 & 60 & 148 & 239 & 1876 & 4627 & 11794 & 11,25 & 29,75 & 48,39 & 0,600 & 2308 & 5692 & 13729 & 0,500 & 120 & 3200 & 500 & 1,35 & 1,05 & 1,04 \\
\hline 30 & 40 & 14,0 & 29 & 15 & 70 & 158 & 249 & 2241 & 5057 & 12514 & 11,79 & 30,59 & 49,34 & 0,525 & 2928 & 6607 & 15099 & \begin{tabular}{|l}
0,667 \\
\end{tabular} & 150 & 3600 & 600 & 1,26 & 1,06 & 1,04 \\
\hline 30 & $|50|$ & 14,0 & 29 & 15 & 80 & 168 & 259 & 2614 & 5487 & 13234 & 12,19 & 31,33 & 50,21 &, 480 & 3607 & 7572 & 16520 & 0,8 & 170 & 4000 & 800 & 1,25 & 1,09 & 1,06 \\
\hline
\end{tabular}




\begin{tabular}{|c|c|c|c|c|c|c|c|c|c|c|c|c|c|c|c|c|c|c|c|c|c|c|c|c|}
\hline $\mathrm{c} 1$ & c2 & $\mathrm{d}$ & $\mathrm{p}$ & $\mathrm{a}$ & uo* & $\mathrm{u}^{*}$ & $\mathrm{u}^{\prime *}$ & wp1o & wp1 & wp1' & eo* & $\mathrm{e}^{*}$ & $e^{\prime *}$ & K1 & wp2o & $\mathrm{wp} 2$ & wp2' & K2 & Fsd & Msd1 & Msd2 & ßo & $\beta$ & $\beta^{\prime}$ \\
\hline 30 & 60 & 14,0 & 29 & 15 & 90 & 178 & 269 & 2993 & 5917 & 13954 & 12,50 & 31,99 & 51,02 & 0,450 & 4343 & 8587 & 17990 & 1,000 & 220 & 4400 & 950 & 1,19 & 1,09 & 1,06 \\
\hline 30 & 70 & 14,0 & 29 & 15 & 100 & 188 & 279 & 3377 & 6347 & 14674 & 12,75 & 32,57 & 51,78 & 0,450 & 5135 & 9652 & 19510 & 1,167 & 250 & 4800 & 1100 & 1,19 & 1,10 & 1,07 \\
\hline 30 & 80 & 14,0 & 29 & 15 & 110 & 198 & 289 & 3766 & 6777 & 15394 & 12,95 & 33,10 & 52,48 & 0,450 & 5983 & 10767 & 21081 & 1,333 & 300 & 5200 & 1300 & 1,16 & 1,11 & 1,08 \\
\hline 30 & 90 & 14,0 & 29 & 15 & 120 & 208 & 299 & 4159 & 7207 & 16114 & 13,13 & 33,58 & 53,13 & 0,450 & 6885 & 11931 & 22701 & 1,500 & 320 & 5600 & 1500 & 1,18 & 1,12 & 1,09 \\
\hline 30 & 30 & 16,0 & 33 & 15 & 60 & 161 & 264 & 2024 & 5416 & 14363 & 11,25 & 32,34 & 53,51 & 0,600 & 2467 & 6601 & 16538 & 0,500 & 120 & 3200 & 500 & 1,32 & 1,05 & 1,03 \\
\hline 30 & 40 & 16,0 & 33 & 15 & 70 & 171 & 274 & 2416 & 5886 & 15163 & 11,79 & 33,20 & 54,48 & 0,525 & 3111 & 7579 & 18034 & \begin{tabular}{|l|}
0,667 \\
\end{tabular} & 150 & 3600 & 600 & 1,25 & 1,06 & 1,04 \\
\hline 30 & 50 & 16,0 & 33 & 15 & 80 & 181 & 284 & 2817 & 6356 & 15963 & 12,19 & 33,96 & 55,38 & 0,480 & 3814 & 8606 & 19580 & 0,833 & 170 & 4000 & 800 & 1,24 & 1,08 & 1,06 \\
\hline 30 & 60 & 16,0 & 33 & 15 & 90 & 191 & 294 & 3224 & 6826 & 16763 & 12,50 & 34,65 & 56,21 & 0,450 & 4574 & 9684 & 21176 & 1,000 & 220 & 4400 & 950 & 1,18 & 1,08 & 1,06 \\
\hline 30 & 70 & 16,0 & 33 & 15 & 100 & 201 & 304 & 3638 & 7296 & 17563 & 12,75 & 35,26 & 56,99 & 0,450 & 5391 & 10812 & 22822 & 1,167 & 250 & 4800 & 1100 & 1,17 & 1,10 & 1,07 \\
\hline 30 & 80 & 16,0 & 33 & 15 & 110 & 211 & 314 & 4058 & 7766 & 18363 & 12,95 & 35,82 & 57,73 & 0,450 & 6264 & 11989 & 24518 & \begin{tabular}{|l}
, 333 \\
\end{tabular} & 300 & 5200 & 1300 & 1,15 & 1,10 & 1,07 \\
\hline 30 & 90 & 16,0 & 33 & 15 & 120 & 221 & 324 & 4482 & 8236 & 19163 & 13,13 & 36,33 & 58,41 & 0,450 & 7192 & 13217 & 26264 & 1,500 & 320 & 5600 & 1500 & 1,17 & 1,12 & 1,09 \\
\hline 30 & 30 & 18,0 & 38 & 15 & 60 & 173 & 292 & 2173 & 6268 & 17559 & 11,25 & 34,91 & 59,27 & 0,600 & 2625 & 7573 & 20004 & 0,500 & 120 & 3200 & 500 & 1,30 & 1,05 & 1,03 \\
\hline 30 & 40 & 18,0 & 38 & 15 & 70 & 183 & 302 & 2591 & 6778 & 18449 & 11,79 & 35,79 & 60,25 & 0,525 & 3293 & 8614 & 21642 & 0,667 & 150 & 3600 & 600 & 1,23 & 1,06 & 1,04 \\
\hline 30 & 50 & 18,0 & 38 & 15 & 80 & 193 & 312 & 3020 & 7288 & 19339 & 12,19 & 36,58 & 61,17 & 0,480 & 4021 & 9704 & 23329 & 0,833 & 170 & 4000 & 800 & 1,22 & 1,08 & 1,05 \\
\hline 30 & 60 & 18,0 & 38 & 15 & 90 & 203 & 322 & 3456 & 7798 & 20229 & 12,50 & 37,29 & 62,03 & 0,450 & 4806 & 10845 & 25066 & 1,000 & 220 & 4400 & 950 & 1,17 & 1,08 & 1,06 \\
\hline 30 & 70 & 18,0 & 38 & 15 & 100 & 213 & 332 & 3899 & 8308 & 21119 & 12,75 & 37,93 & 62,84 & 0,450 & 5648 & 12035 & 26854 & 1,167 & 250 & 4800 & 1100 & 1,17 & 1,09 & 1,06 \\
\hline 30 & 80 & 18,0 & 38 & 15 & 110 & 223 & 342 & 4348 & 8818 & 22009 & 12,95 & 38,52 & 63,61 & 0,450 & 6546 & 13276 & 28691 & 1,333 & 300 & 5200 & 1300 & 1,15 & 1,10 & 1,07 \\
\hline 30 & 90 & 18,0 & 38 & 15 & 120 & 233 & 352 & 4802 & 9328 & 22899 & 13,13 & 39,05 & 64,33 & 0,450 & 7499 & 14566 & 30579 & 1,500 & 320 & 5600 & 1500 & 1,16 & 1,11 & 1,08 \\
\hline 30 & 30 & 20,0 & 40 & 15 & 60 & 186 & 311 & 2322 & 7185 & 19870 & 11,25 & 37,49 & 63,10 & 0,600 & 2782 & 8610 & 22495 & 0,500 & 120 & 3200 & 500 & 1,28 & 1,04 & 1,03 \\
\hline 30 & 40 & 20,0 & 40 & 15 & 70 & 196 & 321 & 2767 & 7735 & 20820 & 11,79 & 38,38 & 64,09 & 0,525 & 3475 & 9713 & 24227 & 0,667 & 150 & 3600 & 600 & 1,22 & 1,05 & 1,04 \\
\hline 30 & 50 & 20,0 & 40 & 15 & 80 & 206 & 331 & 3223 & 8285 & 21770 & 12,19 & 39,19 & 65,03 & 0,480 & 4227 & 10867 & 26008 & \begin{tabular}{|l|}
0,833 \\
\end{tabular} & 170 & 4000 & 800 & 1,21 & 1,07 & 1,05 \\
\hline 30 & 60 & 20,0 & 40 & 15 & 90 & 216 & 341 & 3687 & 8835 & 22720 & 12,50 & 39,92 & 65,90 & 0,450 & 5037 & 12070 & 27840 & 1,000 & 220 & 4400 & 950 & 1,16 & 1,08 & 1,05 \\
\hline 30 & 70 & 20,0 & 40 & 15 & 100 & 226 & 351 & 4159 & 9385 & 23670 & 12,75 & 40,59 & 66,73 & 0,450 & 5904 & 13323 & 29721 & 1,167 & 250 & 4800 & 1100 & 1,16 & 1,09 & 1,06 \\
\hline 30 & 80 & 20,0 & 40 & 15 & 110 & 236 & 361 & 4637 & 9935 & 24620 & 12,95 & 41,20 & 67,51 & 0,450 & 6827 & 14627 & 31653 & 1,333 & 300 & 5200 & 1300 & 1,14 & 1,09 & 1,07 \\
\hline 30 & 90 & 20,0 & 40 & 15 & 120 & 246 & 371 & 5122 & 10485 & 25570 & 13,13 & 41,76 & 68,25 & 0,450 & 7806 & 15980 & 33635 & 1,500 & 320 & 5600 & 1500 & 1,15 & 1,11 & 1,08 \\
\hline 30 & 30 & 22,0 & 45 & 15 & 60 & 198 & 340 & 2472 & 8165 & 23606 & 11,25 & 40,06 & 68,85 & 0,600 & 2939 & 9710 & 26501 & 0,500 & 120 & 3200 & 500 & 1,27 & 1,04 & 1,03 \\
\hline 30 & 40 & 22,0 & 45 & 15 & 70 & 208 & 350 & 2943 & 8755 & 24646 & 11,79 & 40,97 & 69,85 & 0,525 & 3656 & 10877 & 28374 & 0,667 & 150 & 3600 & 600 & 1,20 & 1,05 & 1,03 \\
\hline 30 & 50 & 22,0 & 45 & 15 & 80 & 218 & 360 & 3426 & 9345 & 25686 & 12,19 & 41,79 & 70,80 & 0,480 & 4433 & 12093 & 30297 & 0,833 & 170 & 4000 & 800 & 1,20 & 1,07 & 1,05 \\
\hline 30 & 60 & 22,0 & 45 & 15 & 90 & 228 & 370 & 3918 & 9935 & 26726 & 12,50 & 42,55 & 71,70 & 0,450 & 5268 & 13359 & 32270 & 1,000 & 220 & 4400 & 950 & 1,15 & 1,07 & 1,05 \\
\hline 30 & 70 & 22,0 & 45 & 15 & 100 & 238 & 380 & 4418 & 10525 & 27766 & 12,75 & 43,24 & 72,55 & 0,450 & 6160 & 14675 & 34293 & 1,167 & 250 & 4800 & 1100 & 1,15 & 1,08 & 1,06 \\
\hline 30 & 80 & 22,0 & 45 & 15 & 110 & 248 & 390 & 4926 & 11115 & 28806 & 12,95 & 43,87 & 73,36 & 0,450 & 7108 & 16041 & 36366 & 1,333 & 300 & 5200 & 1300 & 1,13 & 1,09 & 1,06 \\
\hline 30 & 90 & 22,0 & 45 & 15 & 120 & 258 & 400 & 5440 & 11705 & 29846 & 13,13 & 44,46 & 74,13 & 0,450 & 8112 & 17457 & 38489 & 1,500 & 320 & 5600 & 1500 & 1,15 & 1,10 & 1,07 \\
\hline & & & & & & & & & & & & & & & & & & & & & média & 1,30 & 1,13 & 1,08 \\
\hline & & & & & & & & & & & & & & & & & & & & & desvio & 0,1590 & 0,0725 & 0,0289 \\
\hline
\end{tabular}


Tabela C.11 - Valores de $\beta$ para pilares de borda com momento no plano paralelo à borda e $\mathrm{c}_{1}>\mathrm{c}_{2}$

\begin{tabular}{|c|c|c|c|c|c|c|c|c|c|c|}
\hline & c2 & d & & & 10* & $\mathrm{u}^{*}$ & $\mathrm{u}^{\prime \prime *}$ & plo & vpl & wp1 \\
\hline 30 & 20 & 12,0 & 25 & 15 & 50 & 125 & 204 & 1401 & 3513 & 8841 \\
\hline & 20 & 14,0 & & 15 & 50 & 138 & 229 & 52 & 4197 & 11074 \\
\hline 30 & 20 & 16,0 & 33 & 15 & 50 & 151 & 254 & 64 & 94 & 1356 \\
\hline 30 & 20 & 18,0 & 38 & 15 & 50 & 163 & 282 & 176 & 5758 & 6669 \\
\hline 30 & 20 & 20,0 & \begin{tabular}{|l|}
40 \\
\end{tabular} & 15 & 50 & 176 & 301 & 1886 & 663 & 1892 \\
\hline 30 & 20 & 2,0 & 45 & 15 & 50 & 188 & 330 & & 157. & 256 \\
\hline 40 & 20 & 12,0 & 25 & 18 & 56 & 131 & 210 & 185 & 4340 & 1006 \\
\hline 40 & \begin{tabular}{|l|} 
\\
\end{tabular} & 2,0 & \begin{tabular}{|l|}
25 \\
\end{tabular} & 20 & 65 & \begin{tabular}{|l|l|}
140 \\
\end{tabular} & 219 & 211 & 4560 & 10406 \\
\hline 40 & 30 & 12,0 & 25 & 20 & 70 & 145 & 22 & 23 & & 1075 \\
\hline 40 & 20 & 4,0 & 29 & 18 & 56 & 144 & 23 & 197 & 5087 & 241 \\
\hline 40 & 25 & 14,0 & \begin{tabular}{|l|}
29 \\
\end{tabular} & 20 & 65 & \begin{tabular}{|l|l}
153 \\
\end{tabular} & 244 & 226 & 5327 & 12804 \\
\hline 40 & 30 & 4,0 & 29 & 20 & 70 & 158 & 249 & 246 & 556 & 318 \\
\hline 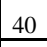 & 20 & 16,0 & \begin{tabular}{|l|}
33 \\
\end{tabular} & 18 & 56 & 157 & 260 & 2116 & 589 & 5034 \\
\hline 40 & 25 & 16,0 & \begin{tabular}{|l|}
33 \\
\end{tabular} & 20 & 65 & \begin{tabular}{|l|l|}
166 \\
\end{tabular} & 269 & 241 & 6159 & 15459 \\
\hline 40 & 30 & 16,0 & 33 & 20 & $\begin{array}{l}70 \\
\end{array}$ & $\mid 171$ & 274 & 263 & $641 \mathrm{c}$ & 15884 \\
\hline 40 & 20 & & 38 & 20 & 60 & \begin{tabular}{|l|l}
173 \\
\end{tabular} & 292 & 234 & 67 & 18282 \\
\hline 40 & 25 & \begin{tabular}{|l|l}
18,0 \\
\end{tabular} & \begin{tabular}{|l|}
38 \\
\end{tabular} & 20 & 65 & 178 & 297 & 257 & 7054 & 18752 \\
\hline 40 & 30 & 18,0 & 38 | & 20 & 70 & 183 & 302 & 280 & 7334 & 19222 \\
\hline 4 & 20 & 20,0 & \begin{tabular}{|l|}
40 \\
\end{tabular} & 20 & 60 & \begin{tabular}{|l|l}
186 \\
\end{tabular} & 311 & 249 & 713 & 20627 \\
\hline 40 & 25 & 20,0 & \begin{tabular}{|l|}
40 \\
\end{tabular} & 20 & 65 & \begin{tabular}{|l|l|}
191 \\
\end{tabular} & 316 & 273 & 3 & 21127 \\
\hline 40 & 30 & 20,0 & \begin{tabular}{|l|l|}
40 \\
\end{tabular} & 20 & 70 & \begin{tabular}{|l|l|}
196 \\
\end{tabular} & 321 & 297 & 8313 & 21627 \\
\hline 40 & 20 & \begin{tabular}{|l}
22,0 \\
\end{tabular} & \begin{tabular}{|l|}
45 \\
\end{tabular} & 20 & \begin{tabular}{|l|} 
\\
\end{tabular} & $\mid 198$ & 340 & 2638 & 7717 & 24414 \\
\hline 40 & 25 & 22,0 & \begin{tabular}{|l|}
45 \\
\end{tabular} & 20 & 65 & 203 & 345 & 280 & 037 & 24959 \\
\hline 40 & 30 & 22,0 & \begin{tabular}{|l|}
45 \\
\end{tabular} & 20 & 70 & \begin{tabular}{|l|l}
208 \\
\end{tabular} & 350 & 3145 & 3357 & 25504 \\
\hline 50 & 20 & 12,0 & 25 & 18 & 56 & \begin{tabular}{|l}
131 \\
\end{tabular} & 210 & 224 & 5267 & 11380 \\
\hline 50 & 25 & 12,0 & \begin{tabular}{|l|}
25 \\
\end{tabular} & 24 & 73 & \begin{tabular}{|l|l|}
148 \\
\end{tabular} & 227 & 2711 & & 11750 \\
\hline 50 & 30 & 12,0 & \begin{tabular}{|l|}
25 \\
\end{tabular} & 25 & \begin{tabular}{|l|}
80 \\
\end{tabular} & \begin{tabular}{|l|l}
155 \\
\end{tabular} & 234 & 2966 & 757 & 2120 \\
\hline 50 & 20 & 14,0 & 29 & 18 & 56 & 144 & 235 & 2364 & 077 & 13865 \\
\hline 5 & 25 & 14,0 & \begin{tabular}{|l|}
29 \\
\end{tabular} & 24 & 73 & 161 & 252 & 287 & 634 & 4275 \\
\hline 50 & 30 & 14,0 & 29 & 25 & 80 & 168 & 259 & 31 & 6607 & 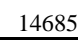 \\
\hline & 20 & \begin{tabular}{|l|l}
16,0 \\
\end{tabular} & 33 & & 56 & 157 & & & 695 & 660 \\
\hline
\end{tabular}

\begin{tabular}{|c|c|c|c|c|c|c|c|c|c|c|c|c|c|}
\hline $\mathrm{o}^{*}$ & $\mathrm{e}^{*}$ & $\mathrm{e}^{\prime * *}$ & 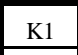 & 20 & p2 & vp2' & K2 & Fsd & Msd1 & \begin{tabular}{l|l} 
Msd2 \\
\end{tabular} & ㅇ & $\beta$ & $\beta^{\prime}$ \\
\hline 10,50 & 26,22 & 42,25 & 0,650 & 1613 & 4046 & 9981 & 0,333 & 70 & 2800 & 450 & 1,99 & 1,99 & 1,04 \\
\hline 50 & 28,79 & 47,36 & 0,650 & 1750 & 4828 & 12409 & 0,333 & 70 & 2800 & 450 & 1,92 & 1,92 & 1,04 \\
\hline 0,50 & 31,36 & 47 & 0.65 & 1884 & 5673 & 15092 & 0,333 & 70 & 800 & 450 & 1.85 & 185 & 1.04 \\
\hline 10,50 & 33,93 & 58,21 & 0,650 & 2018 & 6583 & 18417 & 0,333 & 70 & 2800 & 450 & 1,79 & 1,7 & 1,03 \\
\hline 10,50 & 36,49 & 62,04 & $\begin{array}{l}0,650 \\
\end{array}$ & 2151 & 7557 & 20813 & \begin{tabular}{|l}
0,333 \\
\end{tabular} & 70 & 2800 & 450 & 1,74 & 1,74 & 1,03 \\
\hline 10,50 & 39.05 & 67,78 & 0,650 & 228 & 94 & 24678 & 0,333 & 70 & 2800 & 450 & 6 & & 03 \\
\hline 14,21 & 29,95 & 46,00 & 0,700 & 2014 & 4726 & 11161 & 0,250 & 100 & 3000 & 600 & 1,68 & 1,6 & 1,03 \\
\hline 13,85 & 29,63 & 45,70 & 0,660 & 2394 & 5171 & 11802 & 0,313 & 120 & 3800 & 750 & 1,70 & 1,7 & 1,04 \\
\hline 14,29 & 30,12 & 46,22 & 0,633 & 2710 & 5628 & 12456 & 0,375 & 150 & 4500 & 600 & 1,6 & & 1,03 \\
\hline 14,21 & 32,5 & 51,11 & 0,700 & 2174 & 5588 & 13749 & 0,250 & 100 & 3000 & 600 & 1,63 & 1,04 & 1,03 \\
\hline 13,85 & 32,21 & 50,82 & 0,660 & 2577 & 6064 & 14453 & 0,313 & 120 & 3800 & 750 & 1,65 & 1,0 & 1,03 \\
\hline 14,29 & 32,71 & 51,35 & 0,633 & 2904 & 6552 & 15169 & 0,375 & 150 & 4500 & 600 & 1,57 & 1,04 & 1,02 \\
\hline 14,21 & 35,1 & 56,23 & 0,700 & 2330 & 6513 & 16592 & 0,250 & 100 & 3000 & 600 & 1,59 & 1,04 & 1,02 \\
\hline 13,85 & 34,79 & 55,94 & 0,660 & 2757 & 7021 & 17359 & 0,313 & 120 & 3800 & 750 & 1,61 & 1,0 & 1,03 \\
\hline 14,29 & 35,29 & 56,47 & 0,633 & 3095 & 7541 & 18138 & 0,375 & 150 & 4500 & 600 & 1,54 & 1,03 & 1,02 \\
\hline 13,33 & 36,8 & 61,14 & 0,700 & 2601 & 7503 & 20097 & 0,250 & 100 & 3000 & 600 & 1,57 & 1,03 & 1,02 \\
\hline 13,85 & 37,36 & 61,69 & 0,660 & 2935 & 8042 & 20934 & 0,313 & 120 & 3800 & 750 & 1,57 & 1,0 & 1,03 \\
\hline 14,29 & 37,87 & 62,22 & $\mid 0,633$ & 3285 & 8593 & 21784 & 0,375 & 150 & 4500 & 600 & 1,51 & 1,0 & 1,02 \\
\hline 13,33 & $\begin{array}{r}39,39 \\
\end{array}$ & 64,97 & 0,700 & 2765 & 8557 & 22613 & 0,250 & 100 & 3000 & 600 & 1,54 & 1,0 & 1,02 \\
\hline 13,85 & 39,93 & 65,52 & 0,660 & 3112 & 9127 & 23498 & 0,313 & 120 & 3800 & 750 & 1,54 & 1,04 & 1,03 \\
\hline 14,29 & 40,44 & 66,06 & \begin{tabular}{|l}
0,633 \\
\end{tabular} & 3474 & 9710 & 24395 & 0,375 & 150 & 4500 & 600 & 1,48 & 1,03 & 1,02 \\
\hline 13,33 & 41,95 & 70,71 & 0,700 & 2928 & 9674 & 26658 & 0,250 & 100 & 3000 & 600 & 1,51 & 1,0 & 1,02 \\
\hline 13,85 & 42,50 & 71,27 & 0,660 & 3287 & 10276 & 27613 & 0,313 & 120 & 3800 & 750 & 1,51 & 1,0 & 1,02 \\
\hline 14,29 & 43,01 & 71,81 & \begin{tabular}{|l}
0,633 \\
\end{tabular} & 3661 & 10890 & 28581 & 0,375 & 150 & 4500 & 600 & 1,45 & 1,03 & 1,02 \\
\hline 19,21 & 34,95 & 51,00 & 0,750 & 2304 & 5406 & 12344 & 0,200 & 120 & 3300 & 750 & 1,54 & 1,03 & 1,02 \\
\hline 17,11 & 32,92 & 49,02 & 0,700 & 2903 & 5901 & 13032 & 0,250 & 170 & 4000 & 950 & 1,48 & 1,04 & 1,02 \\
\hline 17,19 & 33,02 & 49,14 & 0,667 & 3299 & 6408 & 13736 & 0,300 & 170 & 5000 & 800 & 1,56 & 1,03 & 1,02 \\
\hline 19,21 & 37,53 & 56,11 & 0,750 & 2469 & 6348 & 15089 & 0,200 & 120 & 3300 & 750 & 1,52 & 1,03 & 1,02 \\
\hline 17,1 & 35,51 & 54,15 & 0,700 & 3117 & 6874 & 15843 & 0,250 & 170 & 4000 & 950 & 1,45 & 1,03 & 1,02 \\
\hline 17,19 & 35,62 & 54,27 & 0,667 & 3530 & 7412 & 16609 & \begin{tabular}{|l}
0,300 \\
\end{tabular} & 170 & 5000 & 800 & 1,53 & 1,03 & 1,02 \\
\hline 1921 & 40,10 & 61, & & 2631 & 7353 & 1809 & 0.2 & 120 & 3300 & 750 & 1,49 & 1,03 & 1,02 \\
\hline
\end{tabular}




\begin{tabular}{|c|c|c|c|c|c|c|c|c|c|c|c|c|c|c|c|c|c|c|c|c|c|c|c|c|}
\hline $\mathrm{c} 1$ & c2 & $\mathrm{d}$ & $\mathrm{p}$ & $\mathrm{a}$ & uo* & $\mathrm{u}^{*}$ & $\mathrm{u}^{\prime *}$ & wp1o & wp1 & wp1' & eо* & $e^{e^{*}}$ & $\frac{\mathrm{e}^{\prime *}}{}$ & K1 & wp2o & wp2 & wp2' & $\mathrm{K} 2$ & Fsd & Msd1 & Msd2 & ßo & $\beta$ & $\beta^{\prime}$ \\
\hline 50 & 25 & 16,0 & 33 & 24 & 73 & 174 & 277 & 3044 & 7236 & 17055 & 17,11 & 8,09 & 59,27 & 0,700 & 3328 & 7911 & 18909 & 0,250 & 170 & 4000 & 950 & 1,43 & 1,03 & 1,02 \\
\hline 50 & 30 & 16,0 & 33 & 25 & 80 & 181 & 284 & 3333 & 7521 & 17505 & 17,19 & 38,20 & 59,39 & 0,667 & 3758 & 8481 & 19738 & 0,300 & 170 & 5000 & 800 & 1,50 & 1,03 & 1,02 \\
\hline 50 & 20 & 18,0 & 38 & 21 & 62 & 175 & 294 & 2794 & 7889 & 19994 & 17,89 & 41,40 & 65,72 & 0,750 & 2982 & 8423 & 21777 & 0,200 & 120 & 3300 & 750 & 1,48 & 1,03 & 1,02 \\
\hline 50 & 25 & 18,0 & 38 & 25 & 75 & 188 & 307 & 3267 & 8194 & 20489 & 16,67 & 40,24 & 64,60 & 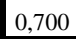 & 3593 & 9012 & 22664 & 0,250 & 170 & 4000 & 950 & 1,41 & 1,03 & 1,02 \\
\hline 50 & 30 & 18,0 & 38 & 25 & 80 & 193 & 312 & 3521 & 8499 & 20984 & 17,19 & 40,78 & 65,15 & 0,667 & 3983 & 9613 & 23564 & 0,300 & 170 & 5000 & 800 & 1,47 & 1,03 & 1,02 \\
\hline 50 & 20 & 20,0 & 40 & 21 & 62 & 188 & 313 & 2938 & 8892 & 22433 & 17,89 & 43,96 & 69,55 & 0,750 & 3157 & 9557 & 24413 & 0,200 & 120 & 3300 & 750 & 1,46 & 1,02 & 1,02 \\
\hline 50 & 25 & 20,0 & 40 & 25 & 75 & 201 & 326 & 3445 & 9217 & 22958 & 16,67 & 42,82 & 68,44 & 0,700 & 3804 & 10177 & 25348 & 0,250 & 170 & 4000 & 950 & 1,39 & 1,03 & 1,02 \\
\hline 50 & 30 & 20,0 & 40 & 25 & 80 & 206 & 331 & 3712 & 9542 & 23483 & 17,19 & 43,36 & 68,99 & 0,667 & 4205 & 10810 & 26295 & 0,300 & 170 & 5000 & 800 & 1,45 & 1,03 & 1,02 \\
\hline 50 & 20 & 22,0 & 45 & 21 & 62 & 200 & 342 & 3083 & 9958 & 26362 & 17,89 & 46,53 & 75,30 & 0,750 & 3330 & 10754 & 28638 & 0,200 & 120 & 3300 & 750 & 1,44 & 1,02 & 1,01 \\
\hline 50 & 25 & 22,0 & 45 & 25 & 75 & 213 & 355 & 3624 & 10303 & 26932 & 16,67 & 45,39 & 74,19 & 0,700 & 4012 & 11406 & 29643 & 0,250 & 170 & 4000 & 950 & 1,37 & 1,03 & 1,02 \\
\hline 50 & 30 & 22,0 & 45 & 25 & 80 & 218 & 360 & 3903 & 10648 & 27502 & 17,19 & 45,93 & 74,74 & 0,667 & 4425 & 12070 & 30661 & 0,300 & 170 & 5000 & 800 & 1,43 & 1,03 & 1,02 \\
\hline 60 & 20 & 12,0 & 25 & 18 & 56 & 131 & 210 & 2682 & 6294 & 12800 & 24,21 & 39,95 & 56,00 & 0,800 & 2594 & 6086 & 13521 & 0,167 & 150 & 3500 & 900 & 1,02 & 1,02 & 1,02 \\
\hline 60 & 25 & 12,0 & 25 & 24 & 73 & 148 & 227 & 3229 & 6564 & 13195 & 22,11 & 37,92 & 54,02 & 0,740 & 3262 & 6631 & 14262 & 0,208 & 220 & \begin{tabular}{|l|l} 
\\
\end{tabular} & 1100 & 1,02 & 1,02 & 1,02 \\
\hline 60 & 30 & 12,0 & 25 & 30 & 90 & 165 & 244 & 3719 & 6834 & 13590 & 20,00 & 35,88 & 52,02 & 0,700 & 3911 & 7188 & 15016 & 0,250 & 220 & 5500 & 950 & 1,45 & 1,02 & 1,02 \\
\hline 60 & 20 & 14,0 & 29 & 18 & 56 & 144 & 235 & 2788 & 7167 & 15410 & 24,21 & 42,53 & 61,11 & 0,800 & 2765 & 7108 & 16429 & 0,167 & 150 & 3500 & 900 & 1,02 & 1,02 & 1,01 \\
\hline 60 & 25 & 14,0 & 29 & 24 & 73 & 161 & 252 & 3382 & 7457 & 15845 & 22,11 & 40,51 & 59,15 & 0,740 & 3485 & 7684 & 17233 & 0,208 & 220 & 4400 & 1100 & 1,02 & 1,02 & 1,02 \\
\hline 60 & 30 & 14,0 & 29 & 30 & 90 & 178 & 269 & 3918 & 7747 & 16280 & 20,00 & 38,47 & 57,16 & 0,700 & 4184 & 8272 & 18049 & 0,250 & 220 & 5500 & 950 & 1,43 & 1,02 & 1,02 \\
\hline 60 & 20 & 16,0 & 33 & 18 & 56 & 157 & 260 & 2899 & 8104 & 18276 & 24,21 & 45,10 & 66,23 & 0,800 & 2931 & 8193 & 19592 & 0,167 & 150 & 3500 & 900 & 1,02 & 1,02 & 1,01 \\
\hline 60 & 25 & 16,0 & 33 & 24 & 73 & 174 & 277 & 3540 & 8414 & 18751 & 22,11 & 43,09 & 64,27 & 0,740 & 3702 & 8801 & 20459 & 0,208 & 220 & 4400 & 1100 & 1,02 & 1,02 & 1,01 \\
\hline 60 & 30 & 16,0 & 33 & 30 & 90 & 191 & 294 & 4121 & 8724 & 19226 & 20,00 & 41,06 & 62,29 & 0,700 & 4450 & 9421 & 21338 & 0,250 & 220 & 5500 & 950 & 1,40 & 1,02 & 1,01 \\
\hline 60 & 20 & 18,0 & 38 & 21 & 62 & 175 & 294 & 3224 & 9105 & 21806 & 22,89 & 46,40 & 70,72 & 0,800 & 3308 & 9343 & 23457 & 0,167 & 150 & 3500 & 900 & 1,38 & 1,02 & 1,01 \\
\hline 60 & 25 & 18,0 & 38 & 27 & 79 & 192 & 311 & 3880 & 9435 & 22326 & 20,77 & 44,38 & 68,76 & 0,740 & 4105 & 9982 & 24394 & 0,208 & 220 & 4400 & 1100 & 1,02 & 1,02 & 1,01 \\
\hline 60 & 30 & 18,0 & 38 & 30 & 90 & 203 & 322 & 4327 & 9765 & 22846 & 20,00 & 43,65 & 68,06 & 0,700 & 4712 & 10633 & 25344 & 0,250 & 220 & 5500 & 950 & 1,38 & 1,02 & 1,01 \\
\hline 60 & 20 & 20,0 & 40 & 21 & 62 & 188 & 313 & 3360 & 10170 & 24340 & 22,89 & 48,96 & 74,55 & 0,800 & 3488 & 10557 & 26213 & 0,167 & 150 & 3500 & 900 & 1,36 & 1,02 & 1,01 \\
\hline 60 & 25 & 20,0 & 40 & 27 & 79 & 205 & 330 & 4061 & 10520 & 24890 & 20,77 & 46,96 & 72,60 & 0,740 & 4334 & 11227 & 27198 & 0,208 & 220 & 4400 & 1100 & 1,02 & 1,02 & 1,01 \\
\hline 60 & 30 & 20,0 & 40 & 30 & 90 & 216 & 341 & 4536 & 10870 & 25440 & 20,00 & 46,23 & 71,90 & 0,700 & 4970 & 11910 & 28195 & 0,250 & 220 & 5500 & 950 & 1,37 & 1,02 & 1,01 \\
\hline 60 & 20 & 22,0 & 45 & 21 & 62 & 200 & 342 & 3499 & 11299 & 28410 & 22,89 & 51,53 & 80,30 & 0,800 & 3664 & 11834 & 30618 & 0,167 & 150 & 3500 & 900 & 1,35 & 1,02 & 1,01 \\
\hline 60 & 25 & 22,0 & 45 & 27 & 79 & 217 & 359 & 4244 & 11669 & 29005 & 20,77 & 49,53 & 78,35 & 0,740 & 4559 & 12536 & 31673 & 0,208 & 220 & 4400 & 1100 & 1,02 & 1,02 & 1,01 \\
\hline 60 & 30 & 22,0 & 45 & 30 & 90 & 228 & 370 & 4747 & 12039 & 29600 & 20,00 & 48,81 & 77,65 & 0,700 & 5225 & 13250 & 32741 & 0,250 & 220 & 5500 & 950 & 1,35 & 1,02 & 1,01 \\
\hline 70 & 30 & 12,0 & 25 & 18 & 66 & 141 & 220 & 3739 & 8011 & 15160 & 30,09 & 45,95 & 62,04 & 0,733 & 3719 & 7968 & 16296 & 0,214 & 250 & 6000 & 1100 & 1,02 & 1,02 & 1,01 \\
\hline 70 & 30 & 14,0 & 29 & 21 & 72 & 160 & 251 & 4045 & 8987 & 17975 & 28,88 & 47,30 & 65,94 & 0,733 & 4111 & 9132 & 19489 & 0,214 & 250 & 6000 & 1100 & 1,02 & 1,02 & 1,01 \\
\hline 70 & 30 & 16,0 & 33 & 24 & 78 & 179 & 282 & 4381 & 10027 & 21047 & 27,62 & 48,62 & 69,81 & 0,733 & 4527 & 10361 & 22938 & 0,214 & 250 & 6000 & 1100 & 1,02 & 1,02 & 1,01 \\
\hline 70 & 30 & 18,0 & $\mid 38$ & 27 & 84 & 197 & 316 & 4744 & 11130 & 24809 & 26,32 & 49,93 & 74,32 & 0,73 & 4967 & 11653 & 2712 & 0.214 & 50 & 6000 & 10 & 1,02 & 1,02 & 01 \\
\hline
\end{tabular}




\begin{tabular}{|c|c|c|c|c|c|c|c|c|c|c|c|c|c|c|c|c|c|c|c|c|c|c|c|c|}
\hline c1 & c2 & $\mathrm{d}$ & $\mathrm{p}$ & $\mathrm{a}$ & uo* & $\mathrm{u}^{*}$ & $\mathrm{u}^{\prime *}$ & wp1o & wp1 & wp1' & eo* & $e^{*}$ & $\mathrm{e}^{\prime *}$ & $\mathrm{~K} 1$ & wp2o & wp2 & wp2' & $\mathrm{K} 2$ & Fsd & Msd1 & Msd2 & $\beta o$ & $\beta$ & $\beta^{\prime}$ \\
\hline 70 & 30 & 20,0 & 40 & 30 & 90 & 216 & 341 & 5132 & 12298 & 27496 & 25,00 & 51,23 & 76,90 & 0,733 & 5429 & 13010 & 30095 & 0,214 & 250 & 6000 & 1100 & 1,02 & 1,02 & 1,01 \\
\hline 70 & 30 & 22,0 & 45 & 33 & 96 & 234 & 376 & 5545 & 13530 & 31798 & 23,66 & 52,52 & 81,39 & 0,733 & 5914 & 14430 & 34821 & 0,214 & 250 & 6000 & 1100 & 1,32 & 1,02 & 1,01 \\
\hline 75 & 25 & 12,0 & 25 & 18 & 61 & 136 & 215 & 3725 & 8329 & 15550 & 32,19 & 47,97 & 64,03 & 0,800 & 3455 & 7726 & 16107 & 0,167 & 250 & 4500 & 1500 & 1,02 & 1,02 & 1,01 \\
\hline 75 & 25 & 14,0 & 29 & 21 & 67 & 155 & 246 & 4028 & 9317 & 18388 & 30,92 & 49,29 & 67,91 & 0,800 & 3847 & 8899 & 19318 & \begin{tabular}{|l|}
0,167 \\
\end{tabular} & 250 & 4500 & 1500 & 1,02 & 1,02 & 1,01 \\
\hline 75 & 25 & 16,0 & 33 & 24 & 73 & 174 & 277 & 4362 & 10368 & 21483 & 29,61 & 50,59 & 71,77 & 0,800 & 4264 & 10136 & 22784 & \begin{tabular}{|l|}
0,167 \\
\end{tabular} & 250 & 4500 & 1500 & 1,02 & 1,02 & 1,01 \\
\hline 75 & 25 & 18,0 & 38 & 27 & 79 & 192 & 311 & 4722 & 11483 & 25270 & 28,27 & 51,88 & 76,26 & 0,800 & 4703 & 11437 & 26989 & 0,167 & 250 & 4500 & 1500 & 1,02 & 1,02 & 1,01 \\
\hline 75 & 25 & 20,0 & 40 & 30 & 85 & 211 & 336 & 5109 & 12662 & 27975 & 26,91 & 53,16 & 78,83 & 0,800 & 5165 & 12802 & 29973 & 0,167 & 250 & 4500 & 1500 & 1,02 & 1,02 & 1,01 \\
\hline 75 & 25 & 22,0 & 45 & 33 & 91 & 229 & 371 & 5520 & 13906 & 32302 & 25,53 & 54,44 & 83,31 & 0,800 & 5649 & 14231 & 34718 & \begin{tabular}{|l|}
0,167 \\
\end{tabular} & 250 & 4500 & 1500 & 1,02 & 1,02 & 1,01 \\
\hline 80 & 30 & 12,0 & 25 & 18 & 66 & 141 & 220 & 4335 & 9288 & 16830 & 35,09 & 50,95 & 67,04 & 0,767 & 4083 & 8748 & 17576 & 0,188 & 300 & 6500 & 1300 & 1,01 & 1,01 & 1,01 \\
\hline 80 & 30 & 14,0 & 29 & 21 & 72 & 160 & 251 & 4648 & 10327 & 19771 & 33,88 & 52,30 & 70,94 & 0,767 & 4498 & 9992 & 20929 & 0,188 & 300 & 6500 & 1300 & 1,01 & 1,01 & 1,01 \\
\hline 80 & 30 & 16,0 & 33 & 24 & 78 & 179 & 282 & 4993 & 11429 & 22968 & 32,62 & 53,62 & 74,81 & 0,767 & 4937 & 11301 & 24538 & 0,188 & 300 & 6500 & 1300 & 1,01 & 1,01 & 1,01 \\
\hline 80 & 30 & 18,0 & 38 & 27 & 84 & 197 & 316 & 5368 & 12596 & 26871 & 31,32 & 54,93 & 79,32 & 0,767 & 5401 & 12673 & 28904 & 0,188 & 300 & 6500 & 1300 & 1,01 & 1,01 & 1,01 \\
\hline 80 & 30 & 20,0 & 40 & 30 & 90 & 216 & 341 & 5770 & 13827 & 29653 & 30,00 & 56,23 & 81,90 & 0,767 & 5888 & 14110 & 31995 & 0,188 & 300 & 6500 & 1300 & 1,01 & 1,01 & 1,01 \\
\hline 80 & 30 & 22,0 & 45 & 33 & 96 & 234 & 376 & 6197 & 15121 & 34096 & 28,66 & 57,52 & 86,39 & 0,767 & 6398 & 15610 & 36901 & \begin{tabular}{|l|}
0,188 \\
\end{tabular} & 300 & \begin{tabular}{|l|l|}
6500 \\
\end{tabular} & 1300 & 1,01 & 1,01 & 1,01 \\
\hline 90 & 30 & 12,0 & 25 & 18 & 66 & 141 & 220 & 4978 & 10665 & 18599 & 40,09 & 55,95 & 72,04 & 0,800 & 4447 & 9528 & 18856 & \begin{tabular}{|l}
0,167 \\
\end{tabular} & 320 & \begin{tabular}{|l|l|}
7000 \\
\end{tabular} & 1500 & 1,01 & 1,01 & 1,01 \\
\hline 90 & 30 & 14,0 & 29 & 21 & 72 & 160 & 251 & 5296 & 11766 & 21666 & 38,88 & 57,30 & 75,94 & 0,800 & 4885 & 10852 & 22369 & \begin{tabular}{|l|l|}
0,167 \\
\end{tabular} & 320 & 7000 & 1500 & 1,01 & 1,01 & 1,01 \\
\hline 90 & 30 & 16,0 & 33 & 24 & 78 & 179 & 282 & 5650 & 12932 & 24989 & 37,62 & 58,62 & 79,81 & 0,800 & 5348 & 12241 & 26138 & 0,167 & 320 & \begin{tabular}{|l}
7000 \\
\end{tabular} & 1500 & 1,01 & 1,01 & 1,01 \\
\hline 90 & 30 & 18,0 & 38 & 27 & 84 & 197 & 316 & 6035 & 14161 & 29034 & 36,32 & 59,93 & 84,32 & 0,800 & 5836 & 13693 & 30684 & 0,167 & 320 & 7000 & 1500 & 1,01 & 1,01 & 1,01 \\
\hline 90 & 30 & 20,0 & 40 & 30 & 90 & 216 & 341 & 6450 & 15455 & 31910 & 35,00 & 61,23 & 86,90 & 0,800 & 6347 & 15210 & 33895 & 0,167 & 320 & 7000 & 1500 & 1,01 & 1,01 & 1,01 \\
\hline 90 & 30 & 22,0 & 45 & 33 & 96 & 234 & 376 & 6891 & 16812 & 36494 & 33,66 & 62,52 & 91,39 & 0,800 & 6882 & 16790 & 38981 & 0,167 & 320 & \begin{tabular}{|l|l}
7000 \\
\end{tabular} & 1500 & 1,01 & 1,01 & 1,01 \\
\hline & & & & & & & & & & & & & & & & & & & & & média & 1,33 & 1,10 & 1,02 \\
\hline & & & & & & & & & & & & & & & & & & & & & \begin{tabular}{|l} 
desvio \\
\end{tabular} & 0,2745 & 0,2301 & 0,0080 \\
\hline
\end{tabular}


Tabela C.12 - Valores de $\beta$ para pilares de canto com $\mathrm{c}_{1} \leq \mathrm{c}_{2}$

\begin{tabular}{|c|c|c|c|c|c|c|c|c|c|c|c|c|c|c|c|c|c|c|c|c|c|c|c|c|c|c|c|}
\hline & $\frac{d}{d}$ & $\mathrm{p}$ & \begin{tabular}{|l|l|}
$\mathrm{a} 1$ & $\mathrm{a} 2$ \\
\end{tabular} & uo* & $u^{*}$ & $\mathrm{u}^{\prime \prime *}$ & p1o & wp1 & $\mathrm{Np} 1$ & é* & $*$ & $1 *$ & & \begin{tabular}{|l|}
$\mathrm{c} 2$ \\
\end{tabular} & 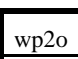 & vp2 & Np2' & eo* & $e^{*}$ & 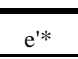 & K2 & Fsd & Msd1 & Msd2 & Bo & R & \\
\hline 20 & \begin{tabular}{|l|l|}
12,0 \\
\end{tabular} & .0 & \begin{tabular}{|l|l|}
10 & 10 \\
\end{tabular} & 20 & 58 & 97 & 601 & 333 & 1451 & 7,50 & 3,28 & 39,30 & \begin{tabular}{|l|}
0,600 \\
\end{tabular} & \begin{tabular}{ll|l|l|}
20 & 20
\end{tabular} & 601 & 1733 & 4451 & 7,50 & 23,28 & 39,30 & 1,000 & 20 & 500 & 300 & $2,3:$ &, 03 & ,47 \\
\hline 20 & \begin{tabular}{l|l|l}
0 & 12,0 \\
\end{tabular} &, 0 & \begin{tabular}{|l|l}
10 & 15 \\
\end{tabular} & & 63 & 102 & 827 & 2073 & 041 & 8,00 & 4,13 & 40,26 & 501 & \begin{tabular}{|l|l|}
30 & 20 \\
\end{tabular} & 856 & 2146 & 061 & 0,50 & 26,22 & 2,25 & 500 & 30 & 00 & 450 & 1,69 & 44 & 13 \\
\hline 20 & \begin{tabular}{l|l}
40 & 12,0
\end{tabular} &, 0 & \begin{tabular}{|l|l|}
10 & 18 \\
\end{tabular} & 28 & \begin{tabular}{|l|}
66 \\
\end{tabular} & 105 & 028 & & 631 & 8,2 & & .80 & 50 & \begin{tabular}{|l|l|}
40 & 20 \\
\end{tabular} & 12 & 10 & 720 & 14,21 &, 95 & .00 & 100 & 50 & 800 & 600 & 1.34 & 14 & .00 \\
\hline 20 & $\begin{array}{lll}50 & 12,0 \\
\end{array}$ & $\begin{array}{l}0 \\
0\end{array}$ & \begin{tabular}{|l|l|}
10 & 18 \\
\end{tabular} & 28 & \begin{tabular}{|l|}
66 \\
\end{tabular} & 105 & 1173 & 2753 & 6221 & 8,2 & 24,58 & 40,80 & 0,45 & \begin{tabular}{|l|l|}
50 & 20 \\
\end{tabular} & 1331 & 3123 & 6430 & 19,2 & 34,95 & 1,00 & 2,50 & 60 & 000 & 750 & 1.27 & 1,09 & 1,00 \\
\hline 20 & \begin{tabular}{l|l}
60 & 12,0 \\
\end{tabular} & \begin{tabular}{l|l|l|}
0 & 25 \\
\end{tabular} & \begin{tabular}{|l|l}
10 & 18 \\
\end{tabular} & 28 & 66 & 105 & 1318 & 3093 & 6811 & 8,2 & 24,58 & 40,80 & 0,450 & \begin{tabular}{|l|l|l|}
60 & 20 \\
\end{tabular} & 1571 & 3687 & 7190 & 24,2 & 39,95 & 56,00 & 3,000 & 70 & 100 & 900 & 1,21 & 1,05 & ,00 \\
\hline 20 & \begin{tabular}{l|l}
20 & 14,0 \\
\end{tabular} & .0 & \begin{tabular}{|l|l|}
10 & 10 \\
\end{tabular} & 20 & 64 & 110 & 651 & 2084 & 84 & 7,5 & 25,85 & $\begin{array}{r}44,41 \\
\end{array}$ & {$[0,600 \mid$} & \begin{tabular}{|l|l|}
20 & 20 \\
\end{tabular} & 651 & 2084 & 5584 & 7,50 & 5,85 & 44,41 & 500 & 20 & 500 & 300 & 2,2 & 91 & 36 \\
\hline 20 & \begin{tabular}{l|l}
30 & 14,0 \\
\end{tabular} & \begin{tabular}{l|l|l}
0 & 29 \\
\end{tabular} & \begin{tabular}{|l|l|}
10 & 15 \\
\end{tabular} & 25 & $69 \mid$ & 115 & 893 & 64 & 54 & 8,00 & 26,73 & 40 & 0,501 & \begin{tabular}{|l|l|}
30 & 20 \\
\end{tabular} & 916 & 2529 & 257 & 10,50 & 88,79 &, 36 & 1,56 & 30 & 000 & 450 & 1.64 & 37 & 07 \\
\hline 20 & \begin{tabular}{l|l|l}
40 & 14,0 \\
\end{tabular} & $\underline{0}$ & \begin{tabular}{|l|l|}
10 & 20 \\
\end{tabular} & 30 & 74 & 120 & 1153 & 2844 & 24 & 8,3 & 27,49 & 46,30 & 0,450 & 20 & 1226 & 3024 & 6980 & 13,33 & 1,68 & 50,28 & 2,000 & 50 & 800 & 600 & 1,32 & 1,10 & 1,00 \\
\hline 20 & \begin{tabular}{l|l}
50 & 14,0 \\
\end{tabular} & \begin{tabular}{l|l|}
0 & 29 \\
\end{tabular} & \begin{tabular}{|l|l|}
10 & 21 \\
\end{tabular} & 31 & \begin{tabular}{|l|l|}
75 \\
\end{tabular} & 121 & 1333 & 3224 & 7594 & 8,34 & 27,63 & 46,47 & 0,450 & \begin{tabular}{|l|l|}
50 & 20 \\
\end{tabular} & 1475 & 3569 & 7752 & 17,89 &,, 2. & 44,85 & 2,500 & 60 & 2000 & 750 & 1,2 & 06 & ,00 \\
\hline 20 & \begin{tabular}{l|l}
60 & 14,0 \\
0
\end{tabular} & \begin{tabular}{l|l|}
0 & 29 \\
\end{tabular} & $\begin{array}{ll}10 & 21 \\
\end{array}$ & \begin{tabular}{|l|}
31 \\
\end{tabular} & 75 & 121 & 1490 & 3604 & 264 & 8,3 & .63 &, 47 & \begin{tabular}{|l|l|}
0,450 \\
\end{tabular} & \begin{tabular}{|l|l|}
60 & 20 \\
\end{tabular} & 1721 & 4163 & 8575 & 22, & 41,25 & 59,85 & 00 & 70 & 2100 & 900 & 1,2 & & 00 \\
\hline 20 & 5,0 & 0 & \begin{tabular}{l|l|l}
10 & 10 \\
\end{tabular} & 20 & 70 & 122 & 702 & 2467 & 846 & 7,5 & 28,42 & 49,52 & \begin{tabular}{|l|l|}
0,600 \\
\end{tabular} & \begin{tabular}{|l|l|}
0 & 20
\end{tabular} & 702 & 2467 & 6846 & 7,50 & 28,42 & 49,52 & 1,000 & 20 & 1500 & 300 & 2,15 & 1,80 & 1,27 \\
\hline 20 & \begin{tabular}{l|l}
30 & 16,0
\end{tabular} & \begin{tabular}{l|l|}
0 & 33 \\
\end{tabular} & \begin{tabular}{|l|l|}
10 & 15 \\
\end{tabular} & 25 & 75 & 127 & 959 & 2887 & 7596 & 8,00 & 29,32 & 50,52 & $0,501 \mid$ & $|30| 20 \mid$ & 978 & 2943 & 7582 & 10,50 & 31,36 & 52,47 & 1,500 & 30 & 1600 & 450 & 1,5 & 31 & ,02 \\
\hline 20 & \begin{tabular}{l|l}
40 & 16,0
\end{tabular} & \begin{tabular}{l|l|l|}
0 & 33 \\
\end{tabular} & \begin{tabular}{|l|l|}
10 & 20 \\
\end{tabular} & 30 & \begin{tabular}{|l|}
80 \\
\end{tabular} & 132 & 1236 & 3307 & 8346 & 8,33 & 0,11 & 51,45 & \begin{tabular}{|l|l|}
0,450 \\
\end{tabular} & \begin{tabular}{|l|l|}
40 & 20 \\
\end{tabular} & 1297 & 169 & 8367 & 13,33 &, 25 & 55,39 & 2,000 & 50 & 00 & 600 & 1,30 & 06 & 00 \\
\hline 20 &, 0 & \begin{tabular}{l|l|l|}
0 & 33 \\
\end{tabular} & \begin{tabular}{|l|l|}
10 & 24 \\
\end{tabular} & 34 & 84 & 136 & 1504 & 3727 & 9096 & \begin{tabular}{|l|l|}
8,53 \\
\end{tabular} & 30,67 & 52,14 & 0,450 & \begin{tabular}{|l|l|}
50 & 20 \\
\end{tabular} & 1632 & \begin{tabular}{|l|l|} 
\\
\end{tabular} & 9203 & 16,53 & 7,53 & 58,70 & 2,500 & 60 & 000 & 750 & 1,25 & 03 & 1,00 \\
\hline 20 & \begin{tabular}{l|l}
60 & 16,0 \\
\end{tabular} & \begin{tabular}{|l|l|}
0 & 33 \\
\end{tabular} & \begin{tabular}{|l|l|}
10 & 24 \\
\end{tabular} & 34 & \begin{tabular}{|l|}
84 \\
\end{tabular} & 136 & 1673 & 4147 & 9846 & \begin{tabular}{|l|l}
8,53 \\
\end{tabular} & 30,67 & 52,14 & 0,450 & \begin{tabular}{|l|l|}
60 & 20 \\
\end{tabular} & 1885 & \begin{tabular}{|l|l|}
4672 \\
\end{tabular} & 10088 & 21,53 & 2,53 & 63,70 & 3,000 & 70 & 100 & 900 & 1,20 & 1,00 & ,00 \\
\hline 20 & \begin{tabular}{l|l}
20 & 18,0
\end{tabular} & \begin{tabular}{l|l|}
0 & 38 \\
\end{tabular} & \begin{tabular}{|l|l|}
10 & 10 \\
\end{tabular} & 20 & \begin{tabular}{|l|}
77 \\
\end{tabular} & 136 & 753 & 28 & 8418 & 7,50 & 30,98 & 55,26 & \begin{tabular}{|l|l|}
0,600 \\
\end{tabular} & \begin{tabular}{|l|l|}
20 & 20 \\
\end{tabular} & 753 & 81 & 8418 & 7,50 & 30,98 & 55,26 & 1,000 & 20 & 00 & 300 & 2,08 & 70 & ,19 \\
\hline 20 & \begin{tabular}{l|l}
30 & 18,0 \\
\end{tabular} & \begin{tabular}{l|l|l|}
0 & 38 \\
\end{tabular} & \begin{tabular}{|l|l|l|}
10 & 15 \\
\end{tabular} & 25 & 82 & 141 & 1024 & 3341 & 9258 & 8,00 & 31,90 & 56,28 & 0,501 & \begin{tabular}{|l|l|}
30 \\
\end{tabular} & 1039 & 3389 & 9225 & 10,50 & 33,93 & 58,21 & 1,500 & 30 & 600 & 450 & 1,55 & 26 & ,00 \\
\hline 20 & \begin{tabular}{l|l}
40 & 18,0 \\
\end{tabular} & \begin{tabular}{|l|l|}
0 & 38 \\
\end{tabular} & \begin{tabular}{|l|l|}
10 & 20 \\
\end{tabular} & 30 & \begin{tabular}{|l|}
87 \\
\end{tabular} & 146 & 1318 & 3801 & 10098 & \begin{tabular}{|l|l|}
8,33 \\
\end{tabular} & 32,72 & 57,22 & \begin{tabular}{|l|l|}
0,450 \\
\end{tabular} & \begin{tabular}{|l|l|l|} 
\\
\end{tabular} & 1368 & \begin{tabular}{|l|l|}
3947 \\
\end{tabular} & 10081 & 13,33 & 36,82 & 61,14 & 2,000 & 50 & \begin{tabular}{|l|l|}
1800 \\
\end{tabular} & 600 & 1,2 & .03 & 1,00 \\
\hline 20 & \begin{tabular}{l|l}
50 & 18,0
\end{tabular} & \begin{tabular}{l|l|}
0 & 38 \\
\end{tabular} & \begin{tabular}{|l|l|}
10 & 25 \\
\end{tabular} & 35 & 92 & 151 & 1629 & 4261 & 10938 & \begin{tabular}{|l|}
8,57 \\
\end{tabular} & 33,44 & 58,11 & \begin{tabular}{|l|}
0,450 \\
\end{tabular} & \begin{tabular}{|l|l|l|}
50 & 20 \\
\end{tabular} & 1741 & \begin{tabular}{|l|l|}
4555 \\
\end{tabular} & 10987 & 16,07 & 39,68 & 64,03 & 2,500 & 60 & 000 & 750 & 1,24 & 0 & 00 \\
\hline 20 & \begin{tabular}{|l|l}
60 & 18,0 \\
\end{tabular} & \begin{tabular}{|l|l|}
0 & 38 \\
\end{tabular} & \begin{tabular}{|l|l|l|}
10 & 27 \\
\end{tabular} & \begin{tabular}{|l|}
37 \\
\end{tabular} & \begin{tabular}{|l|l|}
94 \\
\end{tabular} & 153 & \begin{tabular}{|l|}
1867 \\
\end{tabular} & 4721 & 1778 & \begin{tabular}{|l|}
8,65 \\
\end{tabular} & 33,71 & 58,45 & \begin{tabular}{|l|}
0,450 \\
\end{tabular} & \begin{tabular}{|l|l|}
60 & 20 \\
\end{tabular} & \begin{tabular}{|l|}
2062 \\
\end{tabular} & $\{12$ & 11943 & 20,15 & 43,81 & 68,19 & 3,000 & 70 & 100 & 900 & & 00 & 00 \\
\hline 20 & \begin{tabular}{l|l}
20 & 20,0
\end{tabular} & \begin{tabular}{l|l|}
0 & 40 \\
\end{tabular} & \begin{tabular}{|l|l|}
10 & 10 \\
\end{tabular} & 20 & \begin{tabular}{|l|}
83 \\
\end{tabular} & 146 & 804 & 3328 & 9557 & \begin{tabular}{|l|}
7,50 \\
\end{tabular} & 33,5 & 59,09 & \begin{tabular}{|l|l|}
0,600 \\
\end{tabular} & \begin{tabular}{|l|l|}
20 & 20
\end{tabular} & 804 & 3328 & 9557 & 7,50 & 3,5 & 59,09 & 1,000 & 20 & 500 & 300 & 2,01 & 162 & , 15 \\
\hline 20 & \begin{tabular}{|l|l|l}
30 & 20,0 \\
\end{tabular} & \begin{tabular}{|l|l|}
0 & 40 \\
\end{tabular} & \begin{tabular}{|l|l|}
10 & 15 \\
\end{tabular} & 25 & 88 & 151 & \begin{tabular}{|l|l|}
1090 \\
\end{tabular} & 3828 & 10457 & \begin{tabular}{|l|}
8,00 \\
\end{tabular} & 48 & 60,11 & \begin{tabular}{|l|}
0,501 \\
\end{tabular} & \begin{tabular}{|l|l|l|}
30 & 20 \\
\end{tabular} & \begin{tabular}{|l|l|}
1101 \\
\end{tabular} & \begin{tabular}{|l|l|}
3867 \\
\end{tabular} & 10410 & 10,50 & 6,49 & 62,04 & \begin{tabular}{|l|l|}
1,500 \\
\end{tabular} & 30 & 600 & 450 & 1,52 & 1,22 & 00 \\
\hline 20 & \begin{tabular}{l|l}
40 & 20,0
\end{tabular} & \begin{tabular}{|l|l|}
0 & 40 \\
\end{tabular} & \begin{tabular}{|l|l|}
10 & 20 \\
\end{tabular} & 30 & $93 \mid$ & 156 & 1399 & 4328 & 1357 & 8,33 & 35,3 & 61,07 & $0,450 \mid$ & \begin{tabular}{|l|l|}
40 & 20 \\
\end{tabular} & 1440 & \begin{tabular}{|l|l|}
4457 \\
\end{tabular} & 11313 & 13,33 & 39,39 & 64,97 & 2,000 & 50 & 300 & 600 & 1,27 & 01 &, 00 \\
\hline 20 & \begin{tabular}{l|l}
50 & 20,0
\end{tabular} & \begin{tabular}{|l|l|}
0 & 40 \\
\end{tabular} & \begin{tabular}{|l|l|}
10 & 25 \\
\end{tabular} & 35 & 98 & 161 & 1727 & 4828 & 2257 & \begin{tabular}{|l|}
8,57 \\
\end{tabular} & 36,0 & 61, & 0,450 & & 1823 & 96 & 12267 & 16,07 & 42.25 & 67,87 & 2,500 & 60 & 000 & 50 & 1.23 & 100 & 1,00 \\
\hline \begin{tabular}{|l|l}
20 & 6 \\
\end{tabular} & \begin{tabular}{l|l}
60 & 20,0 \\
\end{tabular} & \begin{tabular}{|l|l|l|}
0 & 40 & 1 \\
\end{tabular} & \begin{tabular}{|l|l|}
10 & 30 \\
\end{tabular} & 40 & 103 & 166 & \begin{tabular}{|l|l|}
2073 \\
\end{tabular} & 5328 & 3157 & \begin{tabular}{|l|}
8,75 \\
\end{tabular} & 36,74 & 2,82 & \begin{tabular}{|l|}
0,450 \\
\end{tabular} & \begin{tabular}{|l|l|}
60 & 20 \\
\end{tabular} & 2250 & \begin{tabular}{|l|l|}
5785 \\
\end{tabular} & 3270 & 18,75 & 5,07 & 70,75 & ,000 & 70 & 100 & 900 & 1,18 & 00 & 00 \\
\hline 20 & \begin{tabular}{l|l}
20 & 22,0
\end{tabular} & \begin{tabular}{l|l|l}
0 & 45 & 1
\end{tabular} & \begin{tabular}{|l|l|l|}
18 & 10 \\
\end{tabular} & 28 & \begin{tabular}{|l|l|}
97 \\
\end{tabular} & 168 & 1098 & 3807 & 11399 & 4,21 & 32,80 & 61,54 & 0,600 & \begin{tabular}{|l|l|}
20 & 20
\end{tabular} & 1098 & 3807 & 11399 & 8,21 & 37,58 & 66,45 & 1,000 & 20 & 500 & 300 & 2,08 & 65 & 12 \\
\hline 20 & \begin{tabular}{l|l}
30 & 22,0
\end{tabular} & \begin{tabular}{l|l|l}
0 & 45 & 1 \\
\end{tabular} & \begin{tabular}{|l|l}
18 & 15 \\
\end{tabular} & 33 & 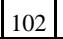 & 173 & 1405 & 4347 & 10280 & 5,09 & 33,84 & 62,6 & $D_{-1}$ & & 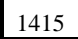 & & 12323 & -5 & 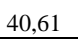 & 604 & & 20 & 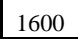 & $5=0$ & & & \\
\hline 20 & \begin{tabular}{l|l}
40 & 22,0 \\
\end{tabular} & \begin{tabular}{|l|l}
0 & 45 \\
\end{tabular} & \begin{tabular}{|l|l|}
18 & 20 \\
\end{tabular} & 38 & 07 & 178 & 1734 & 4887 & 3379 & \begin{tabular}{|l|}
5,74 \\
\end{tabular} & 34,78 & 63,65 & 0,450 & \begin{tabular}{|l|l|}
40 & 20 \\
\end{tabular} & 1773 & \begin{tabular}{|l|l|}
4998 \\
\end{tabular} & 3297 & 14,74 & 13,60 & 72,43 & .000 & 50 & 1800 & 600 & 1,30 &, 01 &, 00 \\
\hline 20 & \begin{tabular}{|l|l|}
50 & 22,0 \\
\end{tabular} & \begin{tabular}{|l|l|l|}
0 & 45 & 1 \\
\end{tabular} & \begin{tabular}{|l|l|}
18 & 25 \\
\end{tabular} & 43 & \begin{tabular}{|l|l|}
112 \\
\end{tabular} & 183 & 2081 & 5427 & 14369 & 6,23 & 35,6 & 64,62 & \begin{tabular}{|l|}
0,450 \\
\end{tabular} & \begin{tabular}{|l|l|}
50 & 20 \\
\end{tabular} & 2174 & \begin{tabular}{|l|l|}
5669 \\
\end{tabular} & 14321 & 17,73 & 46,54 & 75,39 & 2,500 & 60 & 000 & 750 & 1,2 & 00 & 00 \\
\hline 20 & 2 & \begin{tabular}{l|l|l}
0 & 45 & 1 \\
\end{tabular} & \begin{tabular}{|l|l|}
18 & 30 \\
\end{tabular} & 48 & 117 & 188 & 2446 & 5967 & 59 & 6,6 & 36,42 & 65,5 & 0,4 & & 2619 & 6389 & 15395 & 20,6 & 49,45 & 78,3 & & 70 & 2100 & 900 & 1,2 & 1,00 & \\
\hline$T_{4}$ & \begin{tabular}{l|l}
40 & 12,0
\end{tabular} & 0 & & & & & 191 & 2663 & 6979 & 1.94 & 26,13 & & 0.489 & & 1266 & 2830 & 5065 & 14,6 & & & & & 2300 & & & 15 & \\
\hline
\end{tabular}




\begin{tabular}{|c|c|c|c|c|c|c|c|c|c|c|c|c|c|c|c|c|c|c|c|c|c|c|c|c|c|c|c|c|c|c|}
\hline & c2 & $\mathrm{d}$ & $\mathrm{p}$ & a1 & $\mathrm{a} 2$ & * & $\mathrm{u}^{*}$ & $\mathrm{u}^{\prime *}$ & wp1o & p1 & wp1' & eo* & $\mathrm{e}^{*}$ & ** & $\mathrm{K} 1$ & c1 & $\mathrm{c} 2$ & wp2o & $\mathrm{Np} 2$ & wp2' & $\mathrm{o}^{*}$ & $\mathrm{e}^{*}$ & $e^{\prime *}$ & $\mathrm{~K} 2$ & Fsd & Isd1 & Msd2 & ßo & $\beta$ & \\
\hline 25 & 50 & 12,0 & \begin{tabular}{|l|}
25 \\
\end{tabular} & 13 & 18 & 31 & 68 & 107 & 1354 & 028 & 6594 & 9,94 & 5,13 & 32 & 450 & 50 & 25 & 1506 & 368 & 6800 & 19,69 & 35,47 & 51,53 & 000 & 80 & 400 & 950 & 20 & 1,04 & 00 \\
\hline 25 & 60 & 12,0 & 25 & 13 & 18 & 31 & 68 & 107 & 1518 & 3393 & 7209 & 9,94 & 6,13 & 2,32 &, 450 & 60 & 25 & 1770 & 3957 & 7585 & 24,69 & 40,47 & 56,53 & 2,400 & 110 & 2600 & 1100 &, 12 &, 00 & 1,00 \\
\hline 25 & 75 & 12,0 & 25 & 1 & 18 & 31 & 68 & 107 & 1762 & 3941 & 8132 & 9,94 & 26,13 & 2,32 &, 450 & 75 & 25 & 2206 & 4933 & 8856 & 32,19 & 47,97 & 64,03 & ,000 & 120 & 2700 & 1500 & , 10 & 1,00 & 1,00 \\
\hline 25 & 40 & 14,0 & 29 & 13 & 20 & 33 & 76 & 122 & 1322 & 3110 & 7304 & 10,10 & 29,05 & 82 & ,489 & 40 & 25 & 1387 & 3264 & 7365 & 13,85 & 32,21 & 0,82 & ,600 & 50 & 300 & 750 & 34 & 1,11 & 1,00 \\
\hline 25 & 50 & 14,0 & 29 & 13 & 21 & 34 & 77 & 123 & 1520 & 3515 & 7999 & 10,17 & 29,20 & 8,00 & 0,450 & 50 & 25 & 1657 & 3834 & 8162 & 18,42 & 36,79 & 55,41 & 2,000 & 80 & 2400 & 950 & 1,20 & 1,01 & 1,00 \\
\hline 25 & 60 & 14,0 & 29 & 13 & 21 & 34 & 77 & 123 & 1695 & 3920 & 8694 & 10,17 & 29,20 & 8,00 & 0,450 & 60 & 25 & 1925 & 4453 & 9010 & 23,42 & 41,79 & 60,41 & 2,400 & 110 & 2600 & 1100 & 1,12 & ,00 & 1,00 \\
\hline 25 & 75 & 14,0 & 29 & 13 & 21 & 34 & 77 & 123 & 1958 & 4528 & 9737 & 10,17 & 29,20 & 8,00 & 0,450 & 75 & 25 & 2368 & 5477 & 10375 & 30,92 & 49,29 & 67,91 & 3,000 & 120 & 2700 & 1500 & 1,09 & 1,00 & 1,00 \\
\hline 25 & 40 & 16,0 & 33 & 13 & 20 & 33 & 83 & 135 & 1409 & 3589 & 8758 & 10,10 & 31,66 & 2,97 & 0,489 & 40 & 25 & 1464 & 3729 & 8792 & 13,85 & 34,79 & 55,94 & 1,600 & 60 & 2300 & 750 & 1,32 & 1,08 & 1,00 \\
\hline 25 & 50 & 16,0 & 33 & 13 & 24 & 37 & 87 & 139 & 1697 & 4034 & 9533 & 10,36 & 32,25 & 53,67 & 0,450 & 50 & 25 & 1822 & 4331 & 9653 & 17,11 & 38,09 & 59,27 & 2,000 & 80 & 2400 & 950 & 1,19 & 1,00 & 1,00 \\
\hline 25 & 60 & 16,0 & $33 \mid$ & 13 & $24 \mid$ & 37 & 87 & 139 & 1884 & 4479 & 10308 & 10,36 & 32,25 & 53,67 & 0,450 & 60 & 25 & 2096 & 4982 & 10563 & 22,11 & 43,09 & 64,27 & 2,400 & 110 & 2600 & 1100 & 1,12 & 1,00 & 1,00 \\
\hline 25 & 75 & 16,0 & 33 & 13 & 24 & 37 & 87 & 139 & 2165 & 5146 & 1470 & 10,36 & 32,25 & 3,67 & 0,450 & 75 & 25 & 2546 & 6053 & 2023 & 29,61 & 50,59 & 71,77 & 3,000 & 120 & 700 & 1500 & ,09 & ,00 & 1,00 \\
\hline 25 & 40 & 18,0 & 38 & 13 & 20 & 33 & 89 & 149 & 1496 & 4099 & 0545 & 10,10 & 34,26 & 58,74 & 0,489 & 40 & 25 & 1543 & 4227 & 10551 & 13,85 & 37,36 & 61,69 & 1,600 & 60 & 2300 & 750 & 1,30 & ,04 & 1,00 \\
\hline 25 & 50 & 18,0 & 38 & 13 & 25 & 38 & 94 & 154 & 1828 & 4584 & 11410 & 10,42 & 35,02 & 59,64 & 0,450 & 50 & 25 & 1938 & 4860 & 11482 & 16,67 & 40,24 & 64,60 & 2,000 & 80 & 2400 & 950 & 1,18 & 1,00 & 1,00 \\
\hline 25 & 60 & 18,0 & 38 & 13 & 27 & 40 & 96 & 156 & 2085 & 5069 & 12275 & 10,52 & 35,30 & 9,99 & 0,450 & 60 & 25 & 2279 & 5542 & 12463 & 20,77 & 44,38 & 68,76 & 2,400 & 110 & 2600 & 1100 & 11 & 00 & 1,00 \\
\hline 25 & 75 & 18,0 & 38 & 13 & 27 & 40 & 96 & 156 & 2384 & 5797 & 13573 & 10,52 & 35,30 & 59,99 & 0,450 & 75 & 25 & 2739 & 6660 & 14029 & 28,27 & 51,88 & 76,26 & 3,000 & 120 & 2700 & 1500 & 1,09 & 00 & 1,00 \\
\hline 25 & 40 & 20,0 & 40 & 13 & 20 & 33 & 95 & 158 & 1582 & 4642 & 11827 & 10,10 & 36,86 & 62,59 & 0,489 & 40 & 25 & 1622 & 4757 & 11813 & 13,85 & 39,93 & 65,52 & 1,600 & 60 & 2300 & 750 & 1,28 & 01 & 1,00 \\
\hline 25 & 50 & 20,0 & 40 & 13 & 25 & 38 & 100 & 163 & 1931 & 5167 & 2752 & 10,42 & 37,64 & 3,50 & 0,450 & 50 & 25 & 2026 & 5421 & 12792 & 16,67 & 42,82 & 68,44 & 2,000 & 80 & 400 & 950 & 1,17 & 00 & 1,00 \\
\hline 25 & 60 & 20,0 & 40 & 13 & 30 & 43 & 105 & 168 & 2297 & 5692 & 13677 & 10,66 & 38,34 & 64,37 & 0,450 & 60 & 25 & 2475 & 6135 & 13820 & 19,41 & 45,66 & 71,33 & 2,400 & 110 & 2600 & 1100 & 1,11 & ,00 & 1,00 \\
\hline 25 & 75 & 20,0 & 40 & 13 & $30 \mid$ & 43 & 105 & 168 & 2614 & 6479 & 15065 & 10,66 & 38,34 & 64,37 & 0,450 & 75 & 25 & 2945 & 7300 & 15456 & 26,91 & 53,16 & 78,83 & 3,000 & 120 & 2700 & 1500 & 1,09 & 00 & 1,00 \\
\hline 25 & 40 & 22,0 & 45 & 13 & 20 & 33 & 102 & 172 & 1668 & 5216 & 13885 & 10,10 & 39,44 & 68,35 & 0,489 & 40 & 25 & 1701 & 5318 & 13842 & 13,85 & 42,50 & 71,27 & 1,600 & 60 & 2300 & 750 & 1,27 & , 00 & 1,00 \\
\hline 25 & 50 & 22,0 & 45 & 13 & 25 & 38 & 107 & 177 & 2033 & 5781 & 14900 & 10,42 & 40,24 & 69,28 & 0,450 & 50 & 25 & 2115 & 6014 & 14891 & 16,67 & 45,39 & 74,19 & 2,000 & 80 & 2400 & 950 & 1,16 & 00 & 1,00 \\
\hline 25 & $60 \mid$ & 22,0 & 45 & 13 & $30 \mid$ & 43 & 112 & 182 & 2416 & 6346 & 15915 & 10,66 & 40,97 & 70,17 & 0,450 & 60 & 25 & 2574 & 6759 & 15990 & 19,41 & 48,24 & 77,08 & 2,400 & 110 & 2600 & 1100 & 1,10 & 00 & 1,00 \\
\hline 25 & 75 & 22,0 & 45 & 13 & 33 & 46 & 115 & 185 & 2856 & 7194 & 17437 & 10,78 & 41,38 & 70,67 & 0,450 & 75 & 25 & 3165 & 7972 & 17732 & 25,53 & 54,44 & 83,31 & 3,000 & 120 & 2700 & 1500 & 1,08 & 1,00 & 1,00 \\
\hline 30 & 30 & 12,0 & 25 & 15 & 15 & 30 & 68 & 107 & 1124 & 2536 & 5701 & 11,25 & 27,16 & 43,27 & 0,600 & 30 & 30 & 1124 & 2536 & 5701 & 11,25 & 27,16 & 43,27 & 1,000 & 60 & 2400 & 500 & 1,46 & 1,21 & 1,00 \\
\hline 30 & 40 & 12,0 & 25 & 15 & 18 & 33 & 71 & 110 & 1366 & 2926 & 6341 & 11,59 & 27,67 & 43,83 & 0,525 & 40 & 30 & 1424 & 3050 & 6410 & 15,09 & 30,95 & 47,04 & 1,333 & 70 & 2700 & 600 & 1,34 & 1,14 & 1,00 \\
\hline 30 & 50 & 12,0 & 25 & 15 & 18 & 33 & 71 & 110 & 1548 & 3316 & 6981 & 11,59 & 27,67 & 43,83 & 0,480 & 50 & 30 & 1687 & 3613 & 7170 & 20,09 & 35,95 & 52,04 & 1,667 & 80 & 3000 & 800 & 1,27 & 1,10 & 1,00 \\
\hline 30 & 60 & 12,0 & 25 & 15 & 18 & 33 & 71 & 110 & 1730 & 3706 & 7621 & 11,59 & 27,67 & 43,83 & 0,450 & 60 & 30 & 1973 & 4227 & 7980 & 25,09 & 40,95 & 57,04 & 2,000 & 110 & 3300 & 950 & 1,16 & 1,02 & 1,00 \\
\hline 30 & 70 & 12,0 & 25 & 15 & 18 & 33 & 71 & 110 & 1912 & 4096 & 8261 & 11,59 & 27,67 & 43,83 & 0,450 & 70 & 30 & 2283 & 4890 & 8840 & 30,09 & 45,95 & 62,04 & 2,333 & 120 & 3600 & 1100 & 1,14 & 22 & 1,00 \\
\hline 30 & 80 & 12,0 & 25 & 15 & 18 & 33 & 71 & 110 & 2094 & 4486 & 8901 & 11,59 & 27,67 & 43,83 & 0,450 & 80 & 30 & 2616 & 5604 & 9750 & 35,09 & 50,95 & 67,04 & 2,667 & 150 & 3900 & 1300 & 1,10 & 1,00 & 1,00 \\
\hline 30 & 90 & 12,0 & 25 & 15 & 18 & 33 & 71 & 110 & 2276 & 4876 & 9541 & 11,59 & 27,67 & 43,83 & 0,450 & 90 & 30 & 2972 & 6367 & 10710 & 40,09 & 55,95 & 72,04 & 3,000 & 160 & 4200 & 1500 & 1,10 & 1,00 & 1,00 \\
\hline 30 & 30 & 14,0 & 29 & 15 & 15 & 30 & 74 & 120 & 1200 & 2959 & 6977 & 11,25 & 29,75 & 48,39 & 0,600 & 30 & 30 & 1200 & 2959 & 6977 & 11,25 & 29,75 & 48,39 & 1,000 & 60 & 2400 & 500 &, 43 & 15 & 1,00 \\
\hline 30 & 40 & 14,0 & 29 & 15 & 20 & 35 & 79 & 125 & 1502 & 3389 & 7697 & 11,79 & 30,59 & 49,34 & 0,525 & 40 & 30 & 1553 & 3504 & 7750 & 14,29 & 32,71 & 51,35 & 1,333 & 70 & 2700 & 600 & 1,33 & 1,10 & 1,00 \\
\hline & $|50|$ & $|14,0|$ & 29 & 15 & 21 & 36 & 80 & 126 & 1719 & 3819 & 8417 & 11,88 & 30,75 & 49,52 & , ,480 & $|50|$ & & 1845 & 4099 & 572 & 8,88 & 37,30 & 50 & & 80 & 3000 & 800 & 1,26 & 1,07 & 1,00 \\
\hline
\end{tabular}




\begin{tabular}{|c|c|c|c|c|c|c|c|c|c|c|c|c|c|c|c|c|c|c|c|c|c|c|c|c|c|c|c|c|c|}
\hline $\mathrm{c} 1$ & c2 & $\mathrm{d}$ & $\mathrm{p}$ & \begin{tabular}{l|l}
$\mathrm{a} 1$ & $\mathrm{a}$ \\
\end{tabular} & 22 & uo* & $\mathrm{u}^{*}$ & $\mathrm{u}^{\prime *}$ & wp1o & wp1 & wp1' & eo* & $\mathrm{e}^{*}$ & $\mathrm{e}^{\prime *}$ & $\mathrm{~K} 1$ & 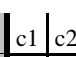 & wp2o & \begin{tabular}{|l} 
wp2 \\
\end{tabular} & wp2' & eo* & $\mathrm{e}^{*}$ & $\mathrm{e}^{\prime *}$ & $\mathrm{~K} 2$ & Fsd & Msd1 & Msd2 & $\beta o$ & $\beta$ & $\beta^{\prime}$ \\
\hline 30 & 60 & 14,0 & 29 & 15 & 21 & 36 & 80 & 126 & 1912 & 4249 & \begin{tabular}{|l}
9137 \\
\end{tabular} & 11,88 & 30,75 & 49,52 & 0,450 & \begin{tabular}{|l|l|l|}
60 & 30 \\
\end{tabular} & 2135 & \begin{tabular}{|l}
4743 \\
\end{tabular} & 9445 & 23,88 & 42,30 & 60,94 & 2,000 & 110 & 3300 & 950 & 1,15 & 1,00 & 1,00 \\
\hline 30 & 70 & 14,0 & 29 & \begin{tabular}{l|l}
15 & 2 \\
\end{tabular} & 21 & 36 & 80 & \begin{tabular}{|l|}
126 \\
\end{tabular} & 2106 & $\mid 4679$ & 9857 & 11,88 & 30,75 & 49,52 & 0,450 & \begin{tabular}{|l|l}
70 & 30 \\
\end{tabular} & 2448 & 5438 & 10368 & 28,88 & 47,30 & 65,94 & 2,333 & 120 & 3600 & 1100 & 1,14 & 1,00 & 1,00 \\
\hline 30 & 80 & 14,0 & 29 & \begin{tabular}{l|l}
15 & 2 \\
\end{tabular} & & 36 & 80 & 126 & 2299 & 5109 & 10577 & 11,88 & 30,75 & 49,52 & 0,450 & \begin{tabular}{|l|l|l|}
80 & 30 \\
\end{tabular} & 2783 & 6183 & 11340 & 33,88 & 52,30 & 70,94 & 2,667 & 150 & 3900 & 1300 & 1,10 & 1,00 & 1,00 \\
\hline 30 & 90 & 14,0 & 29 & \begin{tabular}{l|l}
15 & 2 \\
\end{tabular} & 21 & 36 & 80 & \begin{tabular}{|l|}
126 \\
\end{tabular} & 2493 & 5539 & \begin{tabular}{|l}
11297 \\
\end{tabular} & 11,88 & 30,75 & 49,52 & 0,450 & \begin{tabular}{|l|l}
90 & 30 \\
\end{tabular} & 3141 & \begin{tabular}{|l}
6978 \\
\end{tabular} & \begin{tabular}{|l}
12363 \\
\end{tabular} & 38,88 & 57,30 & 75,94 & 3,000 & 160 & 4200 & 1500 & 1,09 & 1,00 & 1,00 \\
\hline 30 & 30 & 16,0 & 33 & \begin{tabular}{l|l|}
15 & 1 \\
\end{tabular} & 15 & 30 & 80 & 132 & 1276 & 3413 & 8382 & 11,25 & 32,34 & 53,51 & 0,600 & \begin{tabular}{|l|l|}
30 & 30 \\
\end{tabular} & 1276 & 3413 & 8382 & 11,25 & 32,34 & 53,51 & 1,000 & 60 & 2400 & 500 & 1,41 & 1,11 & 1,00 \\
\hline 30 & 40 & 16,0 & 33 & \begin{tabular}{l|l}
15 & 2 \\
\end{tabular} & 20 & 35 & 85 & 137 & 1594 & 3883 & 9182 & 11,79 & 33,20 & 54,48 & \begin{tabular}{|l}
0,525 \\
\end{tabular} & \begin{tabular}{|l|l}
40 & 30 \\
\end{tabular} & 1638 & 3989 & 9217 & 14,29 & 35,29 & 56,47 & 1,333 & 70 & 2700 & 600 & 1,31 & 1,06 & 1,00 \\
\hline 30 & 50 & 16,0 & 33 & \begin{tabular}{l|l}
15 & 2 \\
\end{tabular} & 24 & 39 & 89 & \begin{tabular}{|l|l|}
141 \\
\end{tabular} & 1902 & 4353 & \begin{tabular}{|l}
9982 \\
\end{tabular} & 12,12 & 33,81 & 55,20 & 0,480 & \begin{tabular}{|l|l}
50 & 30 \\
\end{tabular} & 2017 & 4616 & 10103 & 17,62 & 38,62 & 59,81 & \begin{tabular}{|l}
1,667 \\
\end{tabular} & 80 & 3000 & 800 & 1,25 & 1,04 & 1,00 \\
\hline 30 & 60 & 16,0 & 33 & \begin{tabular}{l|l}
15 & 2 \\
\end{tabular} & 24 & 39 & 89 & 141 & 2107 & 4823 & 10782 & 12,12 & 33,81 & 55,20 & \begin{tabular}{|l}
0,450 \\
\end{tabular} & \begin{tabular}{|l|l|l|l|}
60 & 30 \\
\end{tabular} & 2312 & 5292 & 11038 & 22,62 & 43,62 & 64,81 & 2,000 & 110 & 3300 & 950 & 1,15 & 1,00 & 1,00 \\
\hline 30 & 70 & 16,0 & 33 & \begin{tabular}{l|l}
15 & 2 \\
\end{tabular} & & 39 & 89 & \begin{tabular}{|l|}
141 \\
\end{tabular} & 2312 & 5293 & 11582 & 12,12 & 33,81 & 55,20 & \begin{tabular}{|l}
0,450 \\
\end{tabular} & \begin{tabular}{|l|l|l|}
70 & 30 \\
\end{tabular} & 2629 & \begin{tabular}{|l}
6018 \\
\end{tabular} & 12024 & 27,62 & 48,62 & 69,81 & 2,333 & 120 & 3600 & 1100 & 1,14 & 1,00 & 1,00 \\
\hline 30 & 80 & 16,0 & 33 & \begin{tabular}{l|l}
15 & 2
\end{tabular} & & 39 & 89 & \begin{tabular}{|l|}
141 \\
\end{tabular} & 2518 & 5763 & 12382 & 12,12 & 33,81 & 55,20 & 0,450 & \begin{tabular}{|l|l}
80 & 30 \\
\end{tabular} & 2969 & \begin{tabular}{|l|l}
6795 \\
\end{tabular} & 13059 & 32,62 & 53,62 & 74,81 & 2,667 & 150 & 3900 & $\begin{array}{l}1300 \\
\end{array}$ & 1,10 & 1,00 & 1,00 \\
\hline 30 & 90 & 16,0 & 33 & \begin{tabular}{l|l}
15 & 2 \\
\end{tabular} & 24 & 39 & 89 & 141 & 2723 & 6233 & 13182 & 12,12 & 33,81 & 55,20 & \begin{tabular}{|l}
0,450 \\
\end{tabular} & \begin{tabular}{|l|l|l|}
90 & 30 \\
\end{tabular} & 3330 & 7621 & 14145 & 37,62 & 58,62 & 79,81 & 3,000 & 160 & 4200 & 1500 & 1,09 & 1,00 & 1,00 \\
\hline 30 & 30 & 18,0 & \begin{tabular}{|l|}
38 \\
\end{tabular} & \begin{tabular}{l|l}
15 & 1 \\
\end{tabular} & 15 & 30 & 87 & \begin{tabular}{|l|}
146 \\
\end{tabular} & 1352 & 3899 & 10115 & 11,25 & 34,91 & 59,27 & 0,600 & \begin{tabular}{|l|l}
30 & 30 \\
\end{tabular} & 1352 & 3899 & 10115 & 11,25 & 34,91 & 59,27 & 1,000 & 60 & 2400 & 500 & 1,38 & 1,07 & 1,00 \\
\hline 30 & 40 & 18,0 & 38 & \begin{tabular}{l|l}
15 & 2 \\
\end{tabular} & 20 & 35 & 92 & 151 & 1686 & 4409 & 11005 & 11,79 & 35,79 & 60,25 & 0,525 & \begin{tabular}{|l|l|}
40 & 30 \\
\end{tabular} & 1723 & 4507 & 11021 & 14,29 & 37,87 & 62,22 & 1,333 & 70 & 2700 & 600 & 1,29 & 1,03 & 1,00 \\
\hline 30 & 50 & 18,0 & 38 & \begin{tabular}{l|l}
15 & 2 \\
\end{tabular} & 25 & 40 & 97 & 156 & 2038 & 4919 & 11895 & 12,19 & 36,58 & 61,17 & 0,480 & \begin{tabular}{|l|l|l|}
50 & 30 \\
\end{tabular} & 2140 & 5165 & 11977 & 17,19 & 40,78 & 65,15 & 1,667 & 80 & 3000 & 800 & 1,24 & 1,01 & 1,00 \\
\hline 30 & 60 & 18,0 & \begin{tabular}{|l|}
38 \\
\end{tabular} & \begin{tabular}{l|l}
15 & 2
\end{tabular} & 27 & 42 & 99 & 158 & 2314 & 5429 & 12785 & 12,32 & 36,87 & 61,52 & 0,450 & \begin{tabular}{|l|l}
60 & 30 \\
\end{tabular} & 2503 & 5872 & 12983 & 21,32 & 44,93 & 69,32 & 2,000 & 110 & \begin{tabular}{|l}
3300 \\
\end{tabular} & 950 & 1,14 & 1,00 & 1,00 \\
\hline 30 & 70 & 18,0 & \begin{tabular}{|l|}
38 \\
\end{tabular} & \begin{tabular}{l|l}
15 & 2 \\
\end{tabular} & 27 & 42 & 99 & 158 & 2531 & 5939 & 13675 & 12,32 & 36,87 & 61,52 & \begin{tabular}{|l}
0,450 \\
\end{tabular} & \begin{tabular}{|l|l|}
70 & 30 \\
\end{tabular} & 2826 & \begin{tabular}{|l}
6630 \\
\end{tabular} & 14039 & \begin{tabular}{|l|}
26,32 \\
\end{tabular} & 49,93 & 74,32 & 2,333 & 120 & 3600 & 1100 & 1,13 & 1,00 & 1,00 \\
\hline 30 & 80 & 18,0 & \begin{tabular}{|l|}
38 \\
\end{tabular} & \begin{tabular}{l|l}
15 & 2 \\
\end{tabular} & 27 & 42 & 99 & 158 & \begin{tabular}{|l|}
2749 \\
\end{tabular} & 6449 & 14565 & 12,32 & 36,87 & 61,52 & \begin{tabular}{|l}
0,450 \\
\end{tabular} & \begin{tabular}{|l|l|}
80 & 30 \\
\end{tabular} & 3170 & 7438 & 15146 & 31,32 & 54,93 & 79,32 & 2,667 & 150 & 3900 & 1300 & 1,09 & 1,00 & 1,00 \\
\hline 30 & 90 & 18,0 & 38 & \begin{tabular}{l|l}
15 & 2 \\
\end{tabular} & 27 & 42 & 99 & 158 & 2966 & 6959 & 15455 & 12,32 & 36,87 & 61,52 & 0,450 & \begin{tabular}{|l|l|}
90 & 30 \\
\end{tabular} & 3535 & 8296 & 16302 & 36,32 & 59,93 & 84,32 & 3,000 & 160 & 4200 & 1500 & 1,09 & 1,00 & 1,00 \\
\hline 30 & 30 & 20,0 & 40 & \begin{tabular}{l|l}
15 & 1 \\
\end{tabular} & 15 & 30 & 93 & 156 & 1428 & 4417 & 11360 & 11,25 & 37,49 & 63,10 & \begin{tabular}{|l}
0,600 \\
\end{tabular} & \begin{tabular}{|l|l|l|}
30 & 30 \\
\end{tabular} & 1428 & \begin{tabular}{|l}
4417 \\
\end{tabular} & 11360 & 11,25 & 37,49 & 63,10 & 1,000 & 60 & 2400 & 500 & 1,36 & 1,03 & 1,00 \\
\hline 30 & 40 & 20,0 & 40 & \begin{tabular}{l|l}
15 & 2 \\
\end{tabular} & 20 & 35 & 98 & \begin{tabular}{|l|}
161 \\
\end{tabular} & 1777 & 4967 & \begin{tabular}{|l}
12310 \\
\end{tabular} & 11,79 & 38,38 & 64,09 & 0,525 & \begin{tabular}{|l|l}
40 & 30 \\
\end{tabular} & 1809 & \begin{tabular}{|l}
5057 \\
\end{tabular} & 12313 & 14,29 & 40,44 & 66,06 & 1,333 & 70 & \begin{tabular}{|l}
2700 \\
\end{tabular} & 600 & 1,28 & 1,00 & 1,00 \\
\hline 30 & \begin{tabular}{l|l}
50 \\
\end{tabular} & 20,0 & 40 & \begin{tabular}{l|l}
15 & 2 \\
\end{tabular} & 25 & 40 & 103 & \begin{tabular}{|l|}
166 \\
\end{tabular} & 2146 & 5517 & 13260 & 12,19 & 39,19 & 65,03 & 0,480 & \begin{tabular}{|l|l}
50 & 30 \\
\end{tabular} & 2235 & 5746 & 13317 & 17,19 & 43,36 & 68,99 & 1,667 & 80 & 3000 & 800 & 1,23 & 1,00 & 1,00 \\
\hline 30 & 60 & 20,0 & 40 & \begin{tabular}{l|l}
15 & 3 \\
\end{tabular} & 30 & 45 & 108 & 171 & 2532 & 6067 & 14210 & 12,50 & 39,92 & 65,90 & 0,450 & \begin{tabular}{|l|l|l|l|}
60 & 30 \\
\end{tabular} & 2706 & \begin{tabular}{|l}
6485 \\
\end{tabular} & 14370 & 20,00 & 46,23 & 71,90 & 2,000 & 110 & 3300 & 950 & 1,14 & 1,00 & 1,00 \\
\hline 30 & 70 & 20,0 & 40 & \begin{tabular}{l|l}
15 & 3 \\
\end{tabular} & 30 & 45 & 108 & \begin{tabular}{|l|}
171 \\
\end{tabular} & 2762 & 6617 & \begin{tabular}{|l|l}
15160 \\
\end{tabular} & 12,50 & 39,92 & 65,90 & 0,450 & \begin{tabular}{|l|l}
70 & 30 \\
\end{tabular} & 3036 & \begin{tabular}{|l}
7274 \\
\end{tabular} & 15473 & 25,00 & 51,23 & 76,90 & 2,333 & 120 & 3600 & 1100 & 1,13 & 1,00 & 1,00 \\
\hline 30 & 80 & 20,0 & 40 & \begin{tabular}{l|l}
15 & 3 \\
\end{tabular} & 30 & 45 & 108 & \begin{tabular}{|l|}
171 \\
\end{tabular} & 2991 & 7167 & \begin{tabular}{|l}
16110 \\
\end{tabular} & 12,50 & 39,92 & 65,90 & 0,450 & \begin{tabular}{|l|l|l|}
80 & 30 \\
\end{tabular} & 3386 & \begin{tabular}{|l|l|l} 
\\
\end{tabular} & \begin{tabular}{|l|l}
16627 \\
\end{tabular} & 30,00 & 56,23 & 81,90 & 2,667 & 150 & \begin{tabular}{|l}
3900 \\
\end{tabular} & 1300 & 1,09 & 1,00 & 1,00 \\
\hline 30 & 90 & 20,0 & 40 & \begin{tabular}{l|l}
15 & 3 \\
\end{tabular} & 30 & 45 & 108 & \begin{tabular}{|l|}
171 \\
\end{tabular} & 3221 & 7717 & \begin{tabular}{|l}
17060 \\
\end{tabular} & 12,50 & 39,92 & 65,90 & \begin{tabular}{|l}
0,450 \\
\end{tabular} & \begin{tabular}{|l|l|}
90 & 30 \\
\end{tabular} & 3757 & \begin{tabular}{|l}
9002 \\
\end{tabular} & \begin{tabular}{|l}
17830 \\
\end{tabular} & 35,00 & 61,23 & 86,90 & 3,000 & 160 & 4200 & 1500 & 1,09 & 1,00 & 1,00 \\
\hline 30 & 30 & 22,0 & 45 & \begin{tabular}{l|l}
15 & 1 \\
\end{tabular} & 15 & 30 & 99 & \begin{tabular}{|l|}
170 \\
\end{tabular} & 1504 & 4968 & 13363 & 11,25 & 40,06 & 68,85 & 0,600 & \begin{tabular}{|l|l}
30 & 30 \\
\end{tabular} & 1504 & \begin{tabular}{|l|l}
4968 \\
\end{tabular} & 13363 & 11,25 & 40,06 & 68,85 & 1,000 & 60 & 2400 & 500 & 1,34 & 1,00 & 1,00 \\
\hline 30 & 40 & 22,0 & 45 & \begin{tabular}{l|l}
15 & 2 \\
\end{tabular} & 20 & 35 & 104 & 175 & 1868 & 5558 & 14403 & 11,79 & 40,97 & 69,85 & \begin{tabular}{|l}
0,525 \\
\end{tabular} & \begin{tabular}{|l|l|l|}
40 & 30 \\
\end{tabular} & 1895 & 5638 & 14387 & 14,29 & 43,01 & 71,81 & 1,333 & 70 & 2700 & 600 & 1,26 & 1,00 & 1,00 \\
\hline 30 & 50 & 22,0 & 45 & \begin{tabular}{l|l}
15 & 2 \\
\end{tabular} & 25 & 40 & 109 & 180 & 2254 & 6148 & 15443 & 12,19 & 41,79 & 70,80 & 0,480 & \begin{tabular}{|l|l|l|}
50 & 30 \\
\end{tabular} & 2331 & \begin{tabular}{|l}
6359 \\
\end{tabular} & \begin{tabular}{|l}
15461 \\
\end{tabular} & 17,19 & 45,93 & 74,74 & 1,667 & 80 & 3000 & 800 & 1,22 & 1,00 & 1,00 \\
\hline 30 & 60 & 22,0 & \begin{tabular}{|l|}
45 \\
\end{tabular} & \begin{tabular}{l|l}
15 & 3 \\
\end{tabular} & 30 & 45 & 114 & 185 & 2657 & 6738 & 16483 & 12,50 & 42,55 & 71,70 & 0,450 & \begin{tabular}{|l|l}
60 & 30 \\
\end{tabular} & 2811 & 7129 & 16585 & 20,00 & 48,81 & 77,65 & 2,000 & 110 & 3300 & 950 & 1,13 & 1,00 & 1,00 \\
\hline 30 & 70 & 22,0 & 45 & \begin{tabular}{l|l}
15 & 3 \\
\end{tabular} & 33 & 48 & 117 & 188 & 3003 & 7328 & 17523 & 12,66 & 42,97 & 72,22 & \begin{tabular}{|l}
0,450 \\
\end{tabular} & \begin{tabular}{|l|l|l|}
70 & 30 \\
\end{tabular} & 3258 & 7950 & \begin{tabular}{|l}
17759 \\
\end{tabular} & 23,66 & 52,52 & 81,39 & 2,333 & 120 & 3600 & 1100 & 1,12 & 1,00 & 1,00 \\
\hline 30 & 80 & 22,0 & \begin{tabular}{|l|}
45 \\
\end{tabular} & \begin{tabular}{l|l}
15 & 3 \\
\end{tabular} & 33 & 48 & 117 & \begin{tabular}{|l|}
188 \\
\end{tabular} & 3245 & 7918 & 18563 & 12,66 & 42,97 & 72,22 & 0,450 & \begin{tabular}{|l|l}
80 & 30 \\
\end{tabular} & 3615 & \begin{tabular}{|l}
8821 \\
\end{tabular} & 18983 & 28,66 & 57,52 & 86,39 & 2,667 & 150 & \begin{tabular}{|l}
3900 \\
\end{tabular} & 1300 & 1,09 & 1,00 & 1,00 \\
\hline 30 & 90 & 22,0 & \begin{tabular}{|l|}
45 \\
\end{tabular} & \begin{tabular}{l|l|}
15 & 3
\end{tabular} & 33 & 48 & 117 & \begin{tabular}{|l|}
188 \\
\end{tabular} & 3487 & 8508 & 19603 & 12,66 & 42,97 & 72,22 & 0,450 & \begin{tabular}{|l|l|}
90 & 30 \\
\end{tabular} & 3992 & 9741 & 20257 & 33,66 & 62,52 & 91,39 & 3,000 & 160 & 4200 & \begin{tabular}{|l|}
1500 \\
\end{tabular} & 1,08 & 1,00 & 1,00 \\
\hline & & & & & & & & & & & & & & & & & & & & & & & & & & média & 1,29 & 1,09 & 1,02 \\
\hline & & & & & & & & & & & & & & & & & & & & & & & & & & desvi & 0,2618 & 0,2013 & 0,071 \\
\hline
\end{tabular}


Tabela C.13 - Valores de $\boldsymbol{\beta}$ para pilares de canto com $c_{1}>c_{2}$

\begin{tabular}{|c|c|c|c|c|c|c|c|c|c|c|c|c|c|c|c|c|c|c|c|c|c|c|c|c|c|c|c|}
\hline & $\mathrm{d}$ & $p$ & \begin{tabular}{|l|l|}
$\mathrm{a} 1$ & $\mathrm{a} 2$ \\
\end{tabular} & uo* & $u^{*}$ & 1:* & plo & wp1 & vp1' & o* & $*$ & $1 *$ & & \begin{tabular}{|l|}
$\mathrm{c} 2$ \\
\end{tabular} & 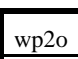 & vp2 & Np2' & eo* & $e^{*}$ & (i, & 22 & Fsd & Msd1 & Msd2 & $\beta o$ & R & \\
\hline 30 & 12,0 & 25 & 10 & 25 & \begin{tabular}{|l|}
63 \\
\end{tabular} & 102 & 56 & 146 & 61 & 10,50 & 26,22 & 42,25 & 0,650 & \begin{tabular}{lll|}
20 & 30
\end{tabular} & 827 & 2073 & 5041 & 8,00 & 4,13 & 40,26 & \begin{tabular}{|l}
0,667 \\
\end{tabular} & 30 & 1600 & 450 & 1,8 & 1,51 &, 15 \\
\hline 30 & 4,0 & 9 & 10 & 25 & 69 & 115 & 916 & 2529 & 257 & 0,56 & 8,79 & 47,36 & 50 & 30 & 893 & 64 & 6254 & 8,00 & 6,73 & 40 & $0,0,66$ & 30 & 00 & 450 &, 76 & 44 & 07 \\
\hline 30 & 5,0 & 33 & 10 & 25 & \begin{tabular}{|l|}
75 \\
\end{tabular} & 27 & 78 & & 82 & 50 & 36 & 52,47 & & 30 & 959 & 87 & 596 & 8,0 & &, 52 & 0,667 & 30 & 500 & 450 & 71 & & 01 \\
\hline 30 & $\begin{array}{lll}20 & 18,0 \\
\end{array}$ & 38 & \begin{tabular}{l|l}
5 & 10 \\
\end{tabular} & 25 & 82 & 141 & 1039 & 3389 & 9225 & 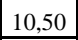 & 33,93 & 58,21 & 0,65 & \begin{tabular}{|l|l|}
20 & 30 \\
\end{tabular} & 1024 & 3341 & 58 & 8,0 & 31,90 &, 28 & \begin{tabular}{|l}
0,667 \\
\end{tabular} & 30 & 500 & 450 & 1,67 & 1,30 & 1,00 \\
\hline 30 & 20,0 & 40 & \begin{tabular}{l|l}
5 & 10 \\
\end{tabular} & 25 & \begin{tabular}{|l|}
88 \\
\end{tabular} & 151 & 1101 & 367 & 410 & 10,5 & 36,49 & 62,04 & 0,650 & \begin{tabular}{|l|l|}
20 & 30 \\
\end{tabular} & 1090 & 3828 & 10457 & 8,6 & 4,48 & 60,11 & \begin{tabular}{|l}
0,667 \\
\end{tabular} & 30 & 1600 & 450 & 1,6 & 1,25 & ,00 \\
\hline 30 & \begin{tabular}{l|l}
20 & 22,0 \\
\end{tabular} & 45 & \begin{tabular}{|l|l|}
5 & 18 \\
\end{tabular} & 33 & \begin{tabular}{|l|}
102 \\
\end{tabular} & 173 & 1415 & 4378 & 323 & 11,59 & 40,61 & 69,46 & \begin{tabular}{|l}
0,650 \\
\end{tabular} & \begin{tabular}{|l|l|}
20 & 30 \\
\end{tabular} & 1405 & 347 & 12389 & 5,0 &, 84 & 62,63 & \begin{tabular}{|l|l} 
\\
\end{tabular} & 30 & 000 & 450 & 1,63 & 19 & , 00 \\
\hline 40 & $\begin{array}{ll}20 & 12,0 \\
\end{array}$ & 25 & \begin{tabular}{l|l}
18 & 10 \\
\end{tabular} & 28 & $66 \mid$ & 105 & 1112 & 2610 & 20 & 14,21 & 95 & 46,00 & 0,700 & \begin{tabular}{|l|l|}
20 & 40 \\
\end{tabular} & 1028 & 113 & 5631 & 8,2 & 24.58 & 0,80 & 0,56 & 50 & 1800 & 600 & 1.38 & 11 & .00 \\
\hline 40 & \begin{tabular}{l|l}
5 & 12,0 \\
\end{tabular} & 4 & \begin{tabular}{|l|l|}
18 & 13 \\
\end{tabular} & 31 & 68 & 107 & 1266 & 2830 & 5065 & \begin{tabular}{|l|}
14,6 \\
\end{tabular} & 30,4 & 46,53 & 0,660 & 40 & 1191 & \begin{tabular}{|l|l|}
2663 \\
\end{tabular} & 5979 & 9,9 & 26,13 & 42,32 & 0,625 & 60 & 2300 & 750 & 1,38 & 1,13 & 1,00 \\
\hline 40 & \begin{tabular}{l|l}
30 & 12,0 \\
\end{tabular} & 25 & \begin{tabular}{|l|l|}
18 & 15 \\
\end{tabular} & 33 & 71 & 110 & 1424 & 3050 & 6410 & 15,09 & 30,95 & 47,04 & 0,633 & $|30| 40 \mid$ & 1366 & 2926 & 6341 & 11,59 & 27,67 & 43,83 & 0,750 & 70 & 2700 & 600 & 1,3 & ,11 & ,00 \\
\hline 40 & \begin{tabular}{l|l}
20 & 14,0
\end{tabular} & 29 & \begin{tabular}{|l|l|l}
20 & 10 \\
\end{tabular} & \begin{tabular}{|l|}
30 \\
\end{tabular} & \begin{tabular}{|l|l|}
74 \\
\end{tabular} & 120 & 1226 & 3024 & 80 & 13,33 & 68 & 0,28 & 0,700 & \begin{tabular}{|l|l|}
20 & 40 \\
\end{tabular} & 1153 & 2844 & 6924 & 8, & ,49 & 30 & 0,500 & 50 & 80 & 600 & 1,3 & & 00 \\
\hline 40 & 4,0 & 29 & \begin{tabular}{|l|l|l|}
20 & 13 \\
\end{tabular} & 33 & 76 & 22 & 1387 & 64 & 65 & 13,8 & 32,2 & 50,82 & 0,66 & 40 & 1322 & 3110 & 7304 & 10,10 & 29,05 & 47,82 & 0,625 & 60 & 2300 & 750 & 1,38 & 1,09 & 1,00 \\
\hline 40 & \begin{tabular}{l|l}
30 & 14,0
\end{tabular} & 29 & \begin{tabular}{|l|l|}
20 & 15 \\
\end{tabular} & 35 & 79 & 125 & 1553 & 3504 & 7750 & 14,29 & 32,71 & 51,35 & 0,633 & \begin{tabular}{|l|l|}
30 & 40 \\
\end{tabular} & 1502 & \begin{tabular}{|l|l}
3389 \\
\end{tabular} & 7697 & 11,79 & 30,59 & 49,34 & 0,750 & 70 & 2700 & 600 & 1,3 & ,08 & 1,00 \\
\hline 40 & $\begin{array}{ll}20 & 16,0 \\
\end{array}$ & 33 & \begin{tabular}{|l|l}
20 & 10 \\
\end{tabular} & 30 & 80 & 132 & 1297 & 3469 & 367 & 13,33 & 1,25 & 55,39 & 0,700 & \begin{tabular}{|l|l|}
20 & 40 \\
\end{tabular} & 1236 & 3307 & 8346 & 8,33 & 30,11 & 51,45 & $\begin{array}{l}0,500 \\
\end{array}$ & 50 & 1800 & 600 & 1,37 & 1,03 & 1,00 \\
\hline 40 &, 0 & 33 & \begin{tabular}{|l|l|l|}
20 & 13 \\
\end{tabular} & 33 & 83 & 135 & 1464 & 3729 & 8792 & 13,85 & 34,79 & 5,94 & 0,660 & \begin{tabular}{|l|l|}
25 & 40 \\
\end{tabular} & 1409 & 3589 & 8758 & 10,10 & 1,66 & 52,97 & 0,625 & 60 & 2300 & 750 & 1,36 &, 05 & 1,00 \\
\hline 40 & \begin{tabular}{c|c|c|}
30 & 16,0 \\
\end{tabular} & 33 & \begin{tabular}{|l|l}
20 & 15 \\
\end{tabular} & 35 & \begin{tabular}{|l|}
85 \\
\end{tabular} & 137 & 1638 & 989 & 9217 & 14,29 & 35,29 & 56,47 & 0,633 & \begin{tabular}{|l|l|}
30 & 40 \\
\end{tabular} & 1594 & \begin{tabular}{|l|l|}
3883 \\
\end{tabular} & 9182 & 11,79 & 3,20 & 54,48 & 0,750 & 70 & 700 & 600 & 1,33 & 1,04 & ,00 \\
\hline 40 & \begin{tabular}{l|l}
20 & 18,0 \\
\end{tabular} & 38 & \begin{tabular}{|l|l|}
20 & 10 \\
\end{tabular} & 30 & \begin{tabular}{|l|}
87 \\
\end{tabular} & 146 & 1368 & 3947 & 10081 & 13,33 & 36,82 & 61,14 & 0,700 & \begin{tabular}{|l|l|}
20 & 40 \\
\end{tabular} & 1318 & 01 & 10098 & 8,33 & 32,72 & 57,22 & 0,500 & 50 & 00 & 600 & 1,35 & $\pi$ & .00 \\
\hline 40 & \begin{tabular}{|l|l|}
25 & 18,0 \\
\end{tabular} & 38 & \begin{tabular}{|l|l|}
20 & 13 \\
\end{tabular} & \begin{tabular}{|l|}
33 \\
\end{tabular} & \begin{tabular}{|l|}
89 \\
\end{tabular} & 149 & 1543 & 4227 & 551 & 13,85 & 37,36 & 61,69 & 0,660 & \begin{tabular}{|l|l|}
25 & 40 \\
\end{tabular} & \begin{tabular}{|l|}
1496 \\
\end{tabular} & \begin{tabular}{|l|l|}
4099 \\
\end{tabular} & 10545 & 10,10 & 4,26 & 58,74 & \begin{tabular}{|l|l|}
0,625 \\
\end{tabular} & 60 & 300 & 750 & 1,34 & 01 &, 00 \\
\hline 40 & \begin{tabular}{l|l}
30 & 18,0 \\
\end{tabular} & 38 & \begin{tabular}{|c|c|}
20 & 15 \\
\end{tabular} & 35 & \begin{tabular}{|l|}
92 \\
\end{tabular} & 151 & 1723 & 4507 & 11021 & \begin{tabular}{|l|}
14,29 \\
\end{tabular} & 37,87 & 62,22 & 0,633 & \begin{tabular}{|l|l|}
30 & 40 \\
\end{tabular} & \begin{tabular}{|l|l|}
1686 \\
\end{tabular} & \begin{tabular}{|l|l|}
4409 \\
\end{tabular} & 11005 & 11,79 & 35,79 & 60,25 & 0,750 & 70 & 2700 & 600 & 1,3 & 01 & 1,00 \\
\hline 40 & \begin{tabular}{l|l}
20 & 20,0
\end{tabular} & 40 & \begin{tabular}{|l|l|l}
20 & 10 \\
\end{tabular} & 30 & \begin{tabular}{|l|}
93 \\
\end{tabular} & 156 & 1440 & 4457 & 1313 & 13,33 & 39,3 & 64,97 & 0,700 & \begin{tabular}{|l|l|}
20 & 40 \\
\end{tabular} & 1399 & 28 & 11357 & 8,3 & 35,31 & 61,07 & 0,500 & 50 & 300 & 600 & 1,33 & 0 & 00 \\
\hline 40 & $\begin{array}{ll}25 & 20,0 \\
\end{array}$ & 40 & \begin{tabular}{|l|l|}
20 & 13 \\
\end{tabular} & 33 & \begin{tabular}{|l|l|}
95 \\
\end{tabular} & 158 & 1622 & 4757 & 1813 & 13,85 & 39,93 & 65,52 & 0,660 & \begin{tabular}{|l|l|}
25 & 40 \\
\end{tabular} & 1582 & \begin{tabular}{|l|l|}
4642 \\
\end{tabular} & 11827 & 10,1 & 36,8 & 62,59 & 0,625 & 60 & 300 & 750 & 1,32 & 00 & 00 \\
\hline 40 & \begin{tabular}{l|l|l}
30 & 20,0 \\
\end{tabular} & 40 & \begin{tabular}{|l|l}
20 & 15 \\
\end{tabular} & 35 & \begin{tabular}{|l|}
98 \\
\end{tabular} & 161 & 1809 & 5057 & 12313 & 14,29 & 40,44 & 66,06 & 0,633 & \begin{tabular}{|l|l|}
30 & 40
\end{tabular} & 1777 & 4967 & 12310 & 11,79 & 38.38 & 64,09 & 0,750 & 70 & 700 & 600 & 1,30 & 1,00 & ,00 \\
\hline 40 & \begin{tabular}{l|l}
20 & 22,0 \\
\end{tabular} & 45 & \begin{tabular}{|l|l|}
20 & 18 \\
\end{tabular} & 38 & 107 & 178 & \begin{tabular}{|l|l}
1773 \\
\end{tabular} & 4998 & 13297 & 144,74 & 43,60 & 72,43 & 0,700 & \begin{tabular}{|l|l|}
20 & 40 \\
\end{tabular} & \begin{tabular}{|l|}
1734 \\
\end{tabular} & \begin{tabular}{|l|l|}
4887 \\
\end{tabular} & 13379 & 5,74 & 4,78 & 63,65 & \begin{tabular}{|l|}
0,500 \\
\end{tabular} & 50 & 800 & 600 & 1,32 & 00 & .00 \\
\hline 40 & \begin{tabular}{l|l}
25 & 22,0
\end{tabular} & 45 & \begin{tabular}{|l|l|}
20 & 13 \\
\end{tabular} & 33 & \begin{tabular}{|l|}
102 \\
\end{tabular} & 172 & 1701 & 5318 & 13842 & 13,85 & 42,50 & 71,27 & 0,660 & \begin{tabular}{|l|l|}
25 & 40 \\
\end{tabular} & 1668 & \begin{tabular}{|l|l|}
5216 \\
\end{tabular} & 13885 & 10,10 & 39,44 & 68,35 & 0,625 & 60 & 300 & 750 & 1,31 & 00 & ,00 \\
\hline 40 & \begin{tabular}{l|l}
30 & 22,0
\end{tabular} & $|43|$ & 15 & 35 & \begin{tabular}{|l|}
104 \\
\end{tabular} & 175 & 1895 & 56 & 87 & 29 & 43,01 & 71,8 & 0,63 & \begin{tabular}{|l|l|}
30 & 40
\end{tabular} & 1868 & 58 & 14403 & 11,79 & 40,97 & 69,85 & 0,750 & 70 & 00 & 00 & 128 & 100 & 1,00 \\
\hline 50 & \begin{tabular}{l|l}
20 & 12,0 \\
\end{tabular} & 25 & \begin{tabular}{|l|l}
18 & 10 \\
\end{tabular} & \begin{tabular}{|l|}
28 \\
\end{tabular} & \begin{tabular}{|l|}
66 \\
\end{tabular} & 105 & 1331 & 3123 & 6430 & \begin{tabular}{|l|}
19,21 \\
\end{tabular} & 34,95 & 51,00 & 0,750 & \begin{tabular}{|l|l|}
20 & 50 \\
\end{tabular} & \begin{tabular}{|l|l|}
1173 \\
\end{tabular} & \begin{tabular}{|l|l|}
2753 \\
\end{tabular} & 221 & 8,21 & 1,58 & 40,80 & 400 & 60 & 2000 & 750 & 1,22 & .00 &, 00 \\
\hline 50 & \begin{tabular}{l|l}
25 & 12,0 \\
\end{tabular} & 25 & \begin{tabular}{|l|l|l}
18 & 13 \\
\end{tabular} & I & \begin{tabular}{|l|} 
\\
\end{tabular} & 107 & 1506 & 3368 & 6800 & 19,69 & 35,47 & 51,53 & 0,700 & \begin{tabular}{l|l}
25 & 50
\end{tabular} & 1354 & 3028 & 6594 & 9,94 & 26,13 & 42,32 & 0,500 & 80 & 400 & 950 & 1,15 & 00 & ,00 \\
\hline 50 & \begin{tabular}{l|l}
0 & 12,0 \\
\end{tabular} & 25 & \begin{tabular}{|l|l|l}
18 & 15 \\
\end{tabular} & 33 & 71 & 110 & 1687 & 3613 & 7170 & ת ח00 & 350 & 52,04 & 06 & & 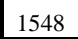 & 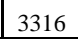 & 6081 & 11,59 & & & & 0 & 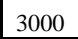 & 000 & & & \\
\hline 30 & \begin{tabular}{l|l}
20 & 14,0 \\
\end{tabular} & 29 & 2 & 31 & 75 & 21 & 1475 & 3569 & 7752 & 117,89 &, 2.5 & 54,85 & 0,750 & 50 & 1333 & 3224 & 7594 & \begin{tabular}{|l|}
8,39 \\
\end{tabular} & 27,63 & 46,47 & 400 & 60 & 2000 & 750 & 1,24 &, 00 &, 00 \\
\hline 50 & \begin{tabular}{l|l}
25 & 14,0 \\
\end{tabular} & 29 & \begin{tabular}{|l|l|}
21 & 13 \\
\end{tabular} & 34 & \begin{tabular}{|l|l|} 
\\
\end{tabular} & 123 & 1657 & 3834 & 8162 & 18,42 & 36,7 & 55,41 & 0,700 & \begin{tabular}{|l|l|}
25 & 50 \\
\end{tabular} & 1520 & 3515 & 7999 & 10,17 & 29,20 & 48,00 & 0,500 & 80 & 400 & 950 & 1,16 & 00 &, 00 \\
\hline 50 & 14,0 & 29 & 21 & 36 & 80 & 126 & 1845 & 4099 & 8572 & &, 30 & 55,94 & & & 17 & 381 & 8417 & 11 & 30,7 & 49,52 & 0,600 & 80 & & 800 & 1,24 & 00 & 00 \\
\hline 0 & \begin{tabular}{l|l}
20 & 16,0
\end{tabular} & $|33|$ & & & 84 & & 1632 & 4046 & 9203 & 6,5 & 37,5 & 58,70 & 0,75 & $20 \mid 30$ & 1504 & 727 & 9096 & 8,53 & 30,67 & & & & 2000 & & & 1,00 & \\
\hline
\end{tabular}




\begin{tabular}{|c|c|c|c|c|c|c|c|c|c|c|c|c|c|c|c|c|c|c|c|c|c|c|c|c|c|c|c|c|c|c|}
\hline & c2 & $\mathrm{d}$ & $\mathrm{p}$ & a1 & $\mathrm{a} 2$ & ** & $\mathrm{u}^{*}$ & $\mathrm{u}^{\prime *}$ & wp1o & p1 & vp1' & eo* & $\mathrm{e}^{*}$ & $e^{* x}$ & K1 & c1 & $\mathrm{c} 2$ & wp2o & vp2 & wp2' & $\mathrm{o}^{*}$ & $\mathrm{e}^{*}$ & & $\mathrm{~K} 2$ & isd & Msd1 & Msd2 & ßo & $\beta$ & \\
\hline 50 & 25 & 16,0 & \begin{tabular}{|l|}
33 \\
\end{tabular} & 24 & 13 & 37 & 87 & 139 & 1822 & 331 & 653 & 7,11 & 3,09 & 27 & 0,700 & 25 & 50 & 1697 & 034 & 533 & 10,36 & 32,25 & 53,67 & 0,500 & 80 & 2400 & 950 & 18 & 1,00 & 00 \\
\hline 50 & 30 & 16,0 & 33 & 24 & 15 & 39 & 89 & 141 & 2017 & 4616 & 0103 & 7,62 & 8,62 & 9,81 & 0,667 & 30 & 50 & 1902 & 4353 & 9982 & 12,12 & 33,81 & 55,20 & 0,600 & 80 & 3000 & 800 & 26 &, 00 & 1,00 \\
\hline 50 & 20 & 18,0 & 38 & 25 & 10 & 35 & 2 & 151 & 1741 & 555 & 9987 & 16,07 & 9,68 & 4,03 & 0,750 & 20 & 50 & 1629 & 4261 & 10938 & 8,57 & 33,44 & 58,11 & 0,400 & 60 & 2000 & 750 & ,26 & ,00 & 1,00 \\
\hline 50 & 25 & 18,0 & 38 & 25 & 13 & 38 & 94 & 154 & 1938 & 4860 & 1482 & 16,67 & 40,24 & 4,60 & 0,700 & 25 & 50 & 1828 & 4584 & 11410 & 10,42 & 35,02 & 59,64 & 1,500 & 80 & 2400 & 950 & , 18 &, 00 & 1,00 \\
\hline 50 & 30 & 18,0 & 38 & 25 & 15 & 40 & 97 & 156 & 2140 & 5165 & 1977 & 17,19 & 40,78 & 5,15 & 0,667 & 30 & 50 & 2038 & 4919 & 11895 & 12,19 & 36,58 & 61,17 & 0,600 & 80 & 3000 & 800 &, 25 & 1,00 & 1,00 \\
\hline 50 & 20 & 20,0 & 40 & 25 & 10 & 35 & 88 & 161 & 1823 & 5096 & 2267 & 16,07 & 42,25 & 7,87 & 0,750 & 20 & 50 & 1727 & 4828 & 12257 & 8,57 & 36,07 & 61,97 & 0,400 & 60 & 2000 & 750 &, 25 & 1,00 & 1,00 \\
\hline 50 & 25 & 20,0 & 40 & 25 & 13 & 38 & 100 & 163 & 2026 & 5421 & 2792 & 16,67 & 42,82 & 8,44 & 0,700 & 25 & 50 & 1931 & 5167 & 12752 & 10,42 & 37,64 & 63,50 & 0,500 & 80 & 2400 & 950 & 17 & 1,00 & 1,00 \\
\hline 50 & 30 & 20,0 & 40 & 25 & 15 & 40 & 103 & 166 & 2235 & 5746 & 3317 & 17,19 & 43,36 & 8,99 & 0,667 & 30 & 50 & 2146 & 5517 & 13260 & 12,19 & 39,19 & 65,03 & 0,600 & 80 & 3000 & 800 & ,24 & 1,00 & 1,00 \\
\hline 50 & 20 & 22,0 & 45 & 25 & 18 & 43 & 112 & 183 & 2174 & 5669 & 4321 & 17,73 & 46,54 & 75,39 & 0,750 & 20 & 50 & 2081 & 5427 & 14369 & 6,23 & 35,63 & 64,62 & 0,400 & 60 & 2000 & 750 & 1,23 & 1,00 & 1,00 \\
\hline 50 & 25 & 22,0 & 45 & 25 & 13 & 38 & 107 & 177 & 2115 & 6014 & 14891 & 16,67 & 45,39 & 74,19 & 0,700 & 25 & 50 & 2033 & 5781 & 14900 & 10,42 & 40,24 & 69,28 & 0,500 & 80 & 2400 & 950 & 1,17 & 1,00 & 1,00 \\
\hline 50 & 30 & 22,0 & 45 & 25 & 15 & 40 & 109 & 180 & 2331 & 6359 & 461 & 17,19 & 45,93 & 4,74 & 0,667 & 30 & 50 & 2254 & 6148 & 15443 & 12,19 & 41,79 & 70,80 & 0,600 & 30 & 000 & 800 &, 23 & 00 & 1,00 \\
\hline 60 & 20 & 12,0 & 25 & 18 & 10 & 28 & 66 & 105 & 1571 & 3687 & 7190 & 24,21 & 39,95 & 56,00 & 0,800 & 20 & 60 & 1318 & 3093 & 6811 & 8,21 & 24,58 & 40,80 & 0,333 & 70 & 2100 & 900 & 1,08 & ,00 & 1,00 \\
\hline 60 & 25 & 12,0 & 25 & 18 & 13 & 31 & 68 & 107 & 1770 & 3957 & 7585 & 24,69 & 40,47 & 56,53 & 0,740 & 25 & 60 & 1518 & 3393 & 7209 & 9,94 & 26,13 & 42,32 & 0,417 & 110 & 2600 & 1100 & 1,00 & 1,00 & 1,00 \\
\hline 60 & 30 & 12,0 & 25 & 18 & 15 & 33 & 71 & 110 & 1973 & 4227 & 7980 & 25,09 & 40,95 & 57,04 & 0,700 & 30 & 60 & 1730 & 3706 & 7621 & 11,59 & 27,67 & 43,83 & 0,500 & 10 & 3300 & 950 & ,06 & 1,00 & 1,00 \\
\hline 60 & 20 & 14,0 & 29 & 21 & 10 & 31 & 75 & 121 & 1721 & 4163 & 8575 & 22,89 & 41,25 & 59,85 & 0,800 & 20 & 60 & 1490 & 3604 & 8264 & 8,39 & 27,63 & 46,47 & 0,333 & 70 & 2100 & 900 & 1,10 & 1,00 & 1,00 \\
\hline 60 & 25 & 14,0 & 29 & 21 & 13 & 34 & 77 & 123 & 1925 & 4453 & 9010 & 23,42 & 41,79 & 60,41 & 0,740 & 25 & 60 & 1695 & 3920 & 8694 & 10,17 & 29,20 & 48,00 & 0,417 & 110 & 2600 & 1100 & 1,00 & 1,00 & 1,00 \\
\hline 60 & 30 & 14,0 & 29 & 21 & 15 & 36 & 80 & 126 & 2135 & 4743 & 9445 & 23,88 & 42,30 & 0,94 & 0,700 & 30 & 60 & 1912 & 424 & 9137 & 11,88 & 30,75 & 49,52 & 0,500 & 110 & 3300 & 950 & 07 & 00 & 1,00 \\
\hline 60 & 20 & 16,0 & 33 & 24 & 10 & 34 & 84 & 136 & 1885 & 4672 & 10088 & 21,53 & 42,53 & 63,70 & 0,800 & 20 & 60 & 1673 & 4147 & 9846 & 8,53 & 30,67 & 52,14 & 0,333 & 70 & 2100 & 900 & 1,12 & 1,00 & 1,00 \\
\hline 60 & 25 & 16,0 & 33 & 24 & 13 & 37 & 87 & 139 & 2096 & 4982 & 10563 & 22,11 & 43,09 & 64,27 & 0,740 & 25 & 60 & 1884 & 4479 & 10308 & 10,36 & 32,25 & 53,67 & 0,417 & 110 & 2600 & 1100 & 1,02 & 00 & 1,00 \\
\hline 60 & 30 & 16,0 & $33 \mid$ & 24 & 15 & 39 & 89 & 141 & 2312 & 5292 & 038 & 22,62 & 43,62 & 64,81 & 0,700 & $30 \mid$ & 60 & 2107 & 4823 & 10782 & 12,12 & 33,81 & 55,20 & 0,500 & 110 & 3300 & 950 & 1,09 & , 00 & 1,00 \\
\hline 60 & 20 & 18,0 & 38 & 27 & 10 & 37 & 94 & 153 & 2062 & 5212 & 11943 & 20,15 & 43,81 & 68,19 & 0,800 & 20 & 60 & 1867 & 4721 & 11778 & 8,65 & 33,71 & 58,45 & 0,333 & 70 & 2100 & 900 & 1,14 & 1,00 & 1,00 \\
\hline 60 & $25 \mid$ & 18,0 & 38 & 27 & 13 & 40 & 96 & 156 & 2279 & 5542 & 12463 & 20,77 & 44,38 & 68,76 & 0,740 & $25 \mid$ & 60 & 2085 & 5069 & 12275 & 10,52 & 35,30 & 59,99 & 0,417 & 110 & 2600 & 1100 & 1,04 & 1,00 & 1,00 \\
\hline 60 & 30 & 18,0 & 38 & 27 & 15 & 42 & 99 & 158 & 2503 & 5872 & 12983 & 21,32 & 44,93 & 69,32 & 0,700 & 30 & 60 & 2314 & 5429 & 12785 & 12,32 & 36,87 & 61,52 & 0,500 & 110 & 3300 & 950 & 1,10 & 1,00 & 1,00 \\
\hline 60 & 20 & 20,0 & 40 & 30 & 10 & 40 & 103 & 166 & 2250 & 5785 & 13270 & 18,75 & 45,07 & 70,75 & 0,800 & 20 & 60 & 2073 & 5328 & 13157 & 8,75 & 36,74 & 62,82 & 0,333 & 70 & 2100 & 900 & 1,16 & 1,00 & 1,00 \\
\hline 60 & 25 & 20,0 & 40 & 30 & 13 & 43 & 105 & 168 & 2475 & 6135 & 3820 & 19,41 & 45,66 & 71,33 & 0,740 & 25 & 60 & 2297 & 5692 & 13677 & 10,66 & 38,34 & 64,37 & 0,417 & 110 & 2600 & 1100 & 1,05 &, 00 & 1,00 \\
\hline 60 & 30 & 20,0 & 40 & 30 & 15 & 45 & 108 & 171 & 2706 & 6485 & 14370 & 20,00 & 46,23 & 71,90 & 0,700 & 30 & 60 & 2532 & 6067 & 14210 & 12,50 & 39,92 & 65,90 & 0,500 & 110 & 3300 & 950 & 1,12 & 1,00 & 1,00 \\
\hline 60 & 20 & 22,0 & 45 & 30 & 18 & 48 & 117 & 188 & 2619 & 6389 & 15395 & 20,63 & 49,45 & 78,31 & 0,800 & 20 & 60 & 2446 & 5967 & 15359 & 6,63 & 36,42 & 65,53 & 0,333 & 70 & 2100 & 900 & 1,14 & 1,00 & 1,00 \\
\hline 60 & $25 \mid$ & 22,0 & 45 & 30 & 13 & 43 & 112 & 182 & 2574 & 6759 & 15990 & 19,41 & 48,24 & 77,08 & 0,740 & 25 & 60 & 2416 & 6346 & 15915 & 10,66 & 40,97 & 70,17 & 0,417 & 110 & 2600 & 1100 & 1,05 & 00 & 1,00 \\
\hline 60 & 30 & 22,0 & 45 & 30 & 15 & 45 & 114 & 185 & 2811 & 7129 & 16585 & 20,00 & 48,81 & 77,65 & 0,700 & 30 & 60 & 2657 & 6738 & 16483 & 12,50 & 42,55 & 71,70 & 0,500 & 110 & 3300 & 950 & 1,11 & 1,00 & 1,00 \\
\hline 70 & 30 & 12,0 & 25 & 18 & 15 & 33 & 71 & 110 & 2283 & 4890 & 8840 & 30,09 & 45,95 & 62,04 & 0,733 & 30 & 70 & 1912 & 4096 & 8261 & 11,59 & 27,67 & 43,83 & 0,429 & 120 & 3600 & 1100 & 1,00 & 1,00 & 1,00 \\
\hline 70 & 30 & 14,0 & 29 & 21 & 15 & 36 & 80 & 126 & 2448 & 5438 & 10368 & 28,88 & 7,30 & 65,94 & 0,733 & 30 & 70 & 2106 & 4679 & 9857 & 11,88 & 30,75 & 49,52 & 0,429 & 120 & 3600 & 1100 & 1,01 & 00 & 1,00 \\
\hline 70 & 30 & 16,0 & 33 & 24 & 15 & 39 & 89 & 141 & 2629 & 6018 & 12024 & 27,62 & 48,62 & 69,81 & 0,733 & 30 & 70 & 2312 & 5293 & 11582 & 12,12 & 33,81 & 55,20 & 0,429 & 120 & 3600 & 1100 & 1,03 & 1,00 & 1,00 \\
\hline & 30 & $|18,0|$ & 38 & 27 & 15 & 42 & 99 & 158 & 2826 & 6630 & 4039 & 6,32 & 49,93 & 4,32 & 733 & $|30|$ & 7 & 2531 & 5939 & 13675 & 2,32 & 36,87 & 51.52 & 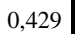 & 120 & 3600 & 100 & ,04 & 1,00 & 1,00 \\
\hline
\end{tabular}




\begin{tabular}{|c|c|c|c|c|c|c|c|c|c|c|c|c|c|c|c|c|c|c|c|c|c|c|c|c|c|c|c|c|c|}
\hline & $\mathrm{c} 2$ & d & $\mathrm{p}$ & \begin{tabular}{|l|l}
$\mathrm{a} 1$ & $\mathrm{a}$
\end{tabular} & a2 & uo* & $\mathrm{u}^{*}$ & $\mathrm{u}^{\prime *}$ & wplo & wp1 & vp1' & eo* & $e^{*}$ & $e^{\prime *}$ & K1 & \begin{tabular}{|l|l}
$\mathrm{c} 1$ & $\mathrm{c} 2$
\end{tabular} & || wp2o & wp2 & wp2' & eo* & $e^{*}$ & $e^{\prime *}$ & K2 & Fsd & Msd1 & Msd2 & ßo & $\beta$ & $B^{\prime}$ \\
\hline 70 & 30 & \begin{tabular}{|l|}
20,0 \\
\end{tabular} & \begin{tabular}{|l|}
40 \\
\end{tabular} & \begin{tabular}{|l|l}
30 & 1 \\
\end{tabular} & 15 & 45 & 108 & 171 & 3036 & 7274 & 5473 & 5,00 & 51,23 & 76,90 & 0,733 & \begin{tabular}{|l|l|}
30 & 70 \\
\end{tabular} & 2762 & 6617 & 5160 & 12,50 & 39,92 & 65,90 & 0,429 & 120 & 3600 & 1100 & 1,05 & 1,00 & 1,00 \\
\hline 70 & 30 & 22,0 & 45 & \begin{tabular}{l|l}
33 & 1 \\
\end{tabular} & 15 & 48 & 117 & 188 & 3258 & 7950 & 17759 & 23,66 & 52,52 & 81,39 & 0,733 & \begin{tabular}{|l|l|}
30 & 70 \\
\end{tabular} & 3003 & 7328 & 17523 & 12,66 & 42,97 & 72,22 & 0,429 & 120 & 3600 & 1100 & 1,07 & 1,00 & 1,00 \\
\hline 75 & 25 & 12,0 & 25 & \begin{tabular}{|l|l}
18 & 1 \\
\end{tabular} & 13 & 31 & 68 & 107 & 2206 & 4933 & 8856 & 32,19 & 47,97 & 64,03 & 0,800 & \begin{tabular}{|l|l|}
25 & 75 \\
\end{tabular} & 1762 & 3941 & 8132 & 9,94 & 26,13 & 42,32 & \begin{tabular}{|l|}
0,333 \\
\end{tabular} & 120 & 2700 & 1500 & 1,01 & 1,00 & 1,00 \\
\hline 75 & 25 & 14,0 & \begin{tabular}{|l|}
29 \\
\end{tabular} & \begin{tabular}{|l|l|}
21 & 1 \\
\end{tabular} & 13 & 34 & 77 & 123 & 2368 & 5477 & 10375 & 30,92 & 49,29 & 67,91 & 0,800 & \begin{tabular}{|l|l}
25 & 75 \\
\end{tabular} & 1958 & 4528 & 9737 & 10,17 & 29,20 & 48,00 & 0,333 & 120 & 2700 & 1500 & 1,01 & 1,00 & 1,00 \\
\hline 75 & 25 & 16,0 & 33 & \begin{tabular}{|l|l}
24 & 1 \\
\end{tabular} & 13 & 37 & 87 & 139 & 2546 & 6053 & 12023 & 29,61 & 50,59 & 71,77 & 0,800 & \begin{tabular}{|l|l|}
25 & 75 \\
\end{tabular} & 2165 & 5146 & 11470 & 10,36 & 32,25 & 53,67 & 0,333 & 120 & 2700 & 1500 & 1,01 & 1,00 & 1,00 \\
\hline 75 & 25 & 18,0 & 38 & \begin{tabular}{|l|l}
27 & 1 \\
\end{tabular} & 13 & 40 & 96 & 156 & 2739 & 6660 & 14029 & 28,27 & 51,88 & 76,26 & 0,800 & \begin{tabular}{|l|l|}
25 & 75 \\
\end{tabular} & 2384 & 5797 & 13573 & 10,52 & 35,30 & 59,99 & \begin{tabular}{|l|}
0,333 \\
\end{tabular} & 120 & 2700 & 1500 & 1,01 & 1,00 & 1,00 \\
\hline 75 & 25 & \begin{tabular}{|l|}
20,0 \\
\end{tabular} & \begin{tabular}{|l|}
40 \\
\end{tabular} & \begin{tabular}{|l|l}
30 & 1 \\
\end{tabular} & 13 & 43 & 105 & 168 & 2945 & 7300 & 15456 & 26,91 & 53,16 & 78,83 & 0,800 & \begin{tabular}{|l|l|}
25 & 75 \\
\end{tabular} & 2614 & 6479 & 15065 & 10,66 & 38,34 & 64,37 & 0,333 & 120 & 2700 & 1500 & 1,01 & 1,00 & 1,00 \\
\hline 75 & 25 & 22,0 & 45 & \begin{tabular}{|l|l}
33 & 1 \\
\end{tabular} & 13 & 46 & 115 & 185 & 3165 & 7972 & 17732 & 25,53 & 54,44 & 83,31 & 0,800 & \begin{tabular}{|l|l|}
25 & 75 \\
\end{tabular} & 2856 & 7194 & 17437 & 10,78 & 41,38 & 70,67 & \begin{tabular}{|l|}
0,333 \\
\end{tabular} & 120 & 2700 & \begin{tabular}{|l|l}
1500 \\
\end{tabular} & 1,01 & 1,00 & 1,00 \\
\hline 80 & 30 & 12,0 & 25 & \begin{tabular}{|l|l}
18 & 1 \\
\end{tabular} & 15 & 33 & 71 & 110 & 2616 & 5604 & 9750 & 35,09 & 50,95 & 67,04 & 0,767 & \begin{tabular}{|l|l|}
30 & 80 \\
\end{tabular} & 2094 & 4486 & 8901 & 11,59 & 27,67 & 43,83 & \begin{tabular}{|l|}
0,375 \\
\end{tabular} & 150 & 3900 & 1300 & 1,00 & 1,00 & 1,00 \\
\hline 80 & 30 & 14,0 & \begin{tabular}{|l|}
29 \\
\end{tabular} & \begin{tabular}{|l|l|}
21 & 1 \\
\end{tabular} & 15 & 36 & 80 & 126 & 2783 & 6183 & 11340 & 33,88 & 52,30 & 70,94 & 0,767 & \begin{tabular}{|l|l|}
30 & 80 \\
\end{tabular} & 2299 & 5109 & 10577 & 11,88 & 30,75 & 49,52 & 0,375 & 150 & 3900 & 1300 & 1,00 & 1,00 & 1,00 \\
\hline 80 & 30 & 16,0 & 33 & \begin{tabular}{|l|l|}
24 & 1 \\
\end{tabular} & 15 & 39 & \begin{tabular}{|l|}
89 \\
\end{tabular} & 141 & 2969 & 6795 & 13059 & 32,62 & 53,62 & 74,81 & 0,767 & \begin{tabular}{|l|l|}
30 & 80 \\
\end{tabular} & 2518 & 5763 & 12382 & 12,12 & 33,81 & 55,20 & \begin{tabular}{|l|}
0,375 \\
\end{tabular} & 150 & 3900 & 1300 & 1,00 & 1,00 & 1,00 \\
\hline 80 & 30 & 18,0 & 38 & \begin{tabular}{|l|l}
27 & 1 \\
\end{tabular} & 15 & 42 & 99 & 158 & 3170 & 7438 & 15146 & 31,32 & 54,93 & 79,32 & 0,767 & \begin{tabular}{|l|l|}
30 & 80 \\
\end{tabular} & 2749 & 6449 & 14565 & 12,32 & 36,87 & 61,52 & \begin{tabular}{|l|}
0,375 \\
\end{tabular} & 150 & 3900 & 1300 & 1,00 & 1,00 & 1,00 \\
\hline 80 & 30 & 20,0 & 40 & \begin{tabular}{l|l}
30 & 1 \\
\end{tabular} & 15 & 45 & 108 & 171 & 3386 & 8113 & 16627 & 30,00 & 56,23 & 81,90 & 0,767 & \begin{tabular}{|l|l|}
30 & 80 \\
\end{tabular} & 2991 & 7167 & 16110 & 12,50 & 39,92 & 65,90 & 0,375 & 150 & 3900 & 1300 & 1,00 & 1,00 & 1,00 \\
\hline 80 & 30 & 22,0 & 45 & \begin{tabular}{l|l}
33 & 1 \\
\end{tabular} & 15 & 48 & 117 & 188 & 3615 & 8821 & 18983 & 28,66 & 57,52 & 86,39 & 0,767 & \begin{tabular}{|l|l|}
30 & 80 \\
\end{tabular} & 3245 & 7918 & 18563 & 12,66 & 42,97 & 72,22 & 0,375 & 150 & 3900 & 1300 & 1,00 & 1,00 & 1,00 \\
\hline 90 & 30 & 12,0 & 25 & \begin{tabular}{|l|l}
18 & 1 \\
\end{tabular} & 15 & 33 & 71 & 110 & 2972 & 6367 & 10710 & 40,09 & 55,95 & 72,04 & 0,800 & \begin{tabular}{|l|l|}
30 & 90 \\
\end{tabular} & 2276 & 4876 & 9541 & 11,59 & 27,67 & 43,83 & \begin{tabular}{|l|}
0,333 \\
\end{tabular} & 160 & 4200 & 1500 & 1,00 & 1,00 & 1,00 \\
\hline 90 & 30 & \begin{tabular}{|l|}
14,0 \\
\end{tabular} & \begin{tabular}{|l|l|}
29 \\
\end{tabular} & \begin{tabular}{|l|l}
21 & 1 \\
\end{tabular} & 15 & 36 & 80 & 126 & 3141 & 6978 & 12363 & 38,88 & 57,30 & 75,94 & 0,800 & \begin{tabular}{|l|l|}
30 & 90 \\
\end{tabular} & 2493 & 5539 & 11297 & 11,88 & 30,75 & 49,52 & \begin{tabular}{|l|}
0,333 \\
\end{tabular} & 160 & 4200 & 1500 & 1,00 & 1,00 & 1,00 \\
\hline 90 & 30 & 16,0 & 33 & \begin{tabular}{|l|l}
24 & 1 \\
\end{tabular} & 15 & 39 & 89 & 141 & 3330 & 7621 & 14145 & 37,62 & 58,62 & 79,81 & 0,800 & \begin{tabular}{|l|l|}
30 & 90 \\
\end{tabular} & 2723 & 6233 & 13182 & 12,12 & 33,81 & 55,20 & \begin{tabular}{|l|}
0,333 \\
\end{tabular} & 160 & 4200 & 1500 & 1,00 & 1,00 & 1,00 \\
\hline 90 & 30 & 18,0 & 38 & \begin{tabular}{|l|l}
27 & 1 \\
\end{tabular} & 15 & 42 & 99 & 158 & 3535 & 8296 & 16302 & 36,32 & 59,93 & 84,32 & 0,800 & \begin{tabular}{|l|l|}
30 & 90 \\
\end{tabular} & 2966 & 6959 & 15455 & 12,32 & 36,87 & 61,52 & \begin{tabular}{|l|}
0,333 \\
\end{tabular} & 160 & 4200 & 1500 & 1,00 & 1,00 & 1,00 \\
\hline 90 & 30 & 20,0 & 40 & \begin{tabular}{|l|l}
30 & 1 \\
\end{tabular} & 15 & 45 & 108 & 171 & 3757 & 9002 & 17830 & 35,00 & 61,23 & 86,90 & 0,800 & \begin{tabular}{|l|l|}
30 & 90 \\
\end{tabular} & 3221 & 7717 & 17060 & 12,50 & 39,92 & 65,90 & 0,333 & 160 & 4200 & 1500 & 1,00 & 1,00 & 1,00 \\
\hline 90 & 30 & 22,0 & \begin{tabular}{|l|l}
45 \\
\end{tabular} & \begin{tabular}{|l|l}
33 & 1 \\
\end{tabular} & 15 & 48 & 117 & 188 & 3992 & 9741 & 20257 & 33,66 & 62,52 & 91,39 & 0,800 & \begin{tabular}{|l|l|}
30 & 90 \\
\end{tabular} & 3487 & 8508 & 19603 & 12,66 & 42,97 & 72,22 & \begin{tabular}{|l|}
0,333 \\
\end{tabular} & 160 & 4200 & 1500 & 1,00 & 1,00 & 1,00 \\
\hline & & & & & & & & & & & & & & & & & & & & & & & & & & média & 1,19 & 1,03 & 1,01 \\
\hline & & & & & & & & & & & & & & & & & & & & & & & & & & desvio & 0,1932 & 0,0951 & 0,0176 \\
\hline
\end{tabular}




\section{ANEXO D}

\section{AVALIAÇÃO DO $\gamma_{\mathrm{Z}}$ COMO MAJORADOR}

\section{D.1. EDIFÍCIOS ESTUDADOS}

Para se estudar o coeficiente $\gamma_{\mathrm{z}}$ como majorador dos esforços de primeira ordem, utilizou-se cinco edifícios de concreto armado também analisados por LIMA \& GUARDA (1999b) e projetados pela SISTEMA CONSULTORIA E PROJETOS LTDA. Suas principais características encontram-se na Tabela D.1.

Tabela D.1 - Características dos edifícios estudados

\begin{tabular}{|c|c|c|c|c|c|c|c|c|c|}
\hline \multirow[t]{2}{*}{ Edifício } & \multirow{2}{*}{$\begin{array}{c}\text { Carga na } \\
\text { Fundação }(k N)\end{array}$} & \multirow{2}{*}{$\begin{array}{c}f_{c k} \\
(M P a)\end{array}$} & \multicolumn{7}{|c|}{ Níveis } \\
\hline & & & Itens & Gar. & P.G. & $1^{o}$ & Tipo & Cob. & Total \\
\hline \multirow{2}{*}{$\begin{array}{l}\text { Orlando } \\
\text { Maia II } \\
\end{array}$} & \multirow[t]{2}{*}{50420} & \multirow[t]{2}{*}{20} & Quant. & - & 1 & 1 & 11 & 1 & 14 \\
\hline & & & $\mathrm{h}(\mathrm{m})$ & - & 3,00 & 2,85 & 2,85 & 2,85 & 40,20 \\
\hline \multirow[t]{2}{*}{ Roma } & \multirow[t]{2}{*}{76500} & \multirow[t]{2}{*}{25} & Quant. & 1 & 1 & 1 & 13 & 1 & 17 \\
\hline & & & $\mathrm{h}(\mathrm{m})$ & 2,95 & 2,95 & 3,96 & 2,95 & 2,95 & 51,16 \\
\hline \multirow[t]{2}{*}{ Vela Branca I } & \multirow[t]{2}{*}{77000} & \multirow[t]{2}{*}{25} & Quant. & 3 & 1 & 1 & 14 & 1 & 20 \\
\hline & & & $\mathrm{h}(\mathrm{m})$ & 2,90 & 2,90 & 2,90 & 2,90 & 2,90 & 58,00 \\
\hline \multirow{2}{*}{$\begin{array}{l}\text { Fontana } \\
\text { di Trevi }\end{array}$} & \multirow[t]{2}{*}{65700} & \multirow[t]{2}{*}{25} & Quant. & 1 & 1 & 1 & 19 & 1 & 23 \\
\hline & & & $\mathrm{h}(\mathrm{m})$ & 2.90 & 3,20 & 4,80 & 2,90 & 2,90 & 69,20 \\
\hline \multirow[t]{2}{*}{ Multiplus } & \multirow[t]{2}{*}{123000} & \multirow[t]{2}{*}{24} & Quant. & 4 & 1 & 1 & 18 & 1 & 25 \\
\hline & & & $\mathrm{h}(\mathrm{m})$ & 3,00 & 3,17 & 3,34 & 3,00 & 3,00 & 75,71 \\
\hline \multicolumn{3}{|c|}{ Observações: } & $\begin{array}{l}{ }^{o}=\text { prime } \\
\text { Tipo }=\text { pa }\end{array}$ & $\begin{array}{l}\text { pavi } \\
\text { iento }\end{array}$ & & \multicolumn{4}{|c|}{ Cob $=$ cobertur $a$} \\
\hline
\end{tabular}

Os edifícios foram modelados como pórticos tridimensionais no programa SAP 90, observando-se as particularidades das formas de todos os níveis e considerando-se as lajes como diafragmas rígidos. As ações horizontais atuantes foram as do vento, tomadas de 
acordo com as recomendações da NBR 6123 (1988). A Não-Linearidade Física foi considerada de forma simplificada, como comentado no item 3.9.6, utilizando-se 0,5 EI para as vigas e $0,8 \mathbf{E I}$ para os pilares.

\section{D.2. VALOR DO MAJORADOR}

Calculou-se o coeficiente $\gamma_{\mathrm{z}}$ para todos os casos, obtendo-se os valores indicados na Tabela D.2.

Tabela D.2 - Valores do coeficiente $\gamma_{\mathbf{z}}$

\begin{tabular}{|c|c|c|}
\hline Edifício & Direção & $\gamma_{z}$ \\
\hline \multirow{2}{*}{$\begin{array}{c}\text { Orlando } \\
\text { Maia II }\end{array}$} & $\mathrm{X}$ & 1,141 \\
\cline { 2 - 3 } Roma & $\mathrm{Y}$ & 1,087 \\
\cline { 2 - 3 } & $\mathrm{X}$ & 1,060 \\
\hline \multirow{2}{*}{ Vela Branca I } & $\mathrm{Y}$ & 1,163 \\
\cline { 2 - 3 } & $\mathrm{Y}$ & 1,096 \\
\hline \multirow{2}{*}{$\begin{array}{c}\text { Fontana } \\
\text { di Trevi }\end{array}$} & $\mathrm{X}$ & 1,121 \\
\hline \multirow{2}{*}{ Multiplus } & $\mathrm{Y}$ & 1,111 \\
\cline { 2 - 3 } & $\mathrm{X}$ & 1,055 \\
\hline
\end{tabular}

Em seguida, realizou-se a análise pelo processo P- $\Delta$. Foram comparados os resultados referentes à última iteração com os resultados da análise de primeira ordem, determinando-se os acréscimos percentuais (efeitos de segunda ordem) das forças normais e momentos fletores nos pilares e momentos fletores e forças cortantes nas vigas (Tabela D.5 a Tabela D.14). Um resumo dos resultados médios de cada um dos esforços e a média entre eles, para cada edifício, encontram-se na Tabela D.3.

Essas médias foram, então, escritas como coeficientes majoradores e calculou-se $0,95 \gamma_{\mathrm{z}}$, como recomenda a NBR 6118 (2000). Os valores obtidos encontram-se na Tabela D.4.

Observa-se que a majoração com $0,95 \gamma_{\mathbf{z}}$ se distancia mais da média do $\mathbf{P}-\Delta$, enquanto que o uso do $\gamma_{\mathrm{z}}$, com seu valor integral mostra-se bastante eficiente, praticamente coincidindo com a média do processo rigoroso em alguns casos. 
Tabela D.3 - Acréscimos percentuais dos esforços de primeira ordem indicados pelo processo $\mathbf{P}-\Delta$

\begin{tabular}{|c|c|r|r|r|r|}
\hline \multirow{2}{*}{ Edificio } & \multirow{2}{*}{\begin{tabular}{c} 
Direção \\
\cline { 3 - 5 }
\end{tabular}} & $\begin{array}{c}\text { Força } \\
\text { Normal }\end{array}$ & $\begin{array}{c}\text { Momentos } \\
\text { Fletores }\end{array}$ & $\begin{array}{c}\text { Momentos } \\
\text { /Cortantes }\end{array}$ & \multirow{2}{*}{ Média } \\
\hline \multirow{2}{*}{$\begin{array}{c}\text { Orlando } \\
\text { Maia II }\end{array}$} & $\mathrm{X}$ & 13,3 & 12,9 & 13,4 & 13,5 \\
\hline \multirow{2}{*}{ Roma } & $\mathrm{Y}$ & 8,7 & 9,7 & 8,7 & 9,0 \\
\cline { 2 - 5 } & $\mathrm{Y}$ & 5,8 & 5,7 & 6,0 & 5,9 \\
\hline \multirow{2}{*}{ Vela Branca 1 } & $\mathrm{X}$ & 9,2 & 10,7 & 9,3 & 9,8 \\
\cline { 2 - 6 } & $\mathrm{Y}$ & 11,5 & 13,5 & 11,8 & 12,3 \\
\hline \multirow{2}{*}{ Fontana } & $\mathrm{X}$ & 8,7 & 9,2 & 7,9 & 8,7 \\
\cline { 2 - 5 } di Trevi & $\mathrm{Y}$ & 8,9 & 10,2 & 9,5 & 9,9 \\
\hline \multirow{2}{*}{ Multiplus } & $\mathrm{X}$ & 4,7 & 4,3 & 5,6 & 5,0 \\
\cline { 2 - 5 } & $\mathrm{Y}$ & 6,4 & 6,5 & 7,1 & 6,8 \\
\hline
\end{tabular}

Tabela D.4 - Comparação entre os majoradores

\begin{tabular}{|c|c|c|c|c|}
\hline Edifício & Direção & $0,95 \gamma_{z}$ & $\gamma_{z}$ & $P-\Delta$ \\
\hline \multirow{2}{*}{$\begin{array}{l}\text { Orlando } \\
\text { Maia II }\end{array}$} & $X$ & 1,084 & 1,141 & 1,132 \\
\hline & $\mathrm{Y}$ & 1,033 & 1,087 & 1,091 \\
\hline \multirow[t]{2}{*}{ Roma } & $X$ & 1,007 & 1,060 & 1,058 \\
\hline & $\mathrm{Y}$ & 1,105 & 1,163 & 1,137 \\
\hline \multirow[t]{2}{*}{ Vela Branca I } & $X$ & 1,041 & 1,096 & 1,098 \\
\hline & $\mathrm{Y}$ & 1,065 & 1,121 & 1,124 \\
\hline \multirow{2}{*}{$\begin{array}{l}\text { Fontana } \\
\text { di Trevi }\end{array}$} & $X$ & 1,033 & 1,092 & 1,086 \\
\hline & $\mathrm{Y}$ & 1,044 & 1,111 & 1,097 \\
\hline \multirow[t]{2}{*}{ Multiplus } & $X$ & 1,00 & 1,055 & 1,049 \\
\hline & $\mathrm{Y}$ & 1,015 & 1,075 & 1,067 \\
\hline
\end{tabular}

Fazendo a análise agora não mais em termos de acréscimos médios, e sim, considerando-se a variação que cada um dos efeitos de segunda ordem sofre com a altura do edifício, foram montados os gráficos das Figuras D.1 a D.15.

Inicialmente, pode-se observar que os incrementos das forças normais dos pilares (Figura D.1 a Figura D.5) tendem a sofrer pequenos decréscimos à medida que se aproximam do topo. Os valores máximos estão próximos à base, e mantêm-se compatíveis aos de $\gamma_{\mathrm{z}}$ 
Para os momentos fletores na base e no topo dos pilares (Figura D.6 a Figura D.10), nota-se que seus incrementos têm variações bastante semelhantes ao longo da altura, apesar de seus valores absolutos serem diferentes. Há um aumento até o primeiro pavimento, que varia do segundo ao sexto nível, e a partir daí, há um decréscimo até aproximadamente $75 \%$ da altura, seguido de um leve aumento até o topo. Nos pavimentos inferiores, $0,95 \gamma_{\mathbf{z}}$ subestima bastante os acréscimos, enquanto $\gamma_{\mathbf{z}}$ os superestima um pouco na parte superior. $\mathrm{O}$ Edifício Multiplus se distancia um pouco dessas características, possivelmente devido à existência de travamentos laterais até o sexto nível (nos demais casos, esses travamentos limitavam-se aos dois primeiros níveis).

Para os momentos fletores e forças cortantes nas vigas (Figura D.11 a Figura D.15), a tendência é basicamente a mesma dos momentos fletores dos pilares.

De qualquer forma, o que se pretende mostrar é que a majoração utilizando o $\gamma_{\mathrm{z}}$ já é satisfatória, e mostra-se mais eficiente que aquela feita com $0,95 \gamma_{\mathrm{z}}$. Uma subestimativa maior, por exemplo, nos momentos fletores nos pilares, pode trazer consequiências danosas ao projeto.

\section{D.3. LIMITE PARA O USO DO $\gamma_{\mathrm{Z}}$ COMO MAJORADOR}

Para se analisar o limite para a utilização do $\gamma_{\mathbf{z}}$ como majorador, foram estudadas as relações entre os valores desse coeficiente e os acréscimos sugeridos pelo processo $\mathbf{P}-\Delta$, sendo considerados tanto aqueles correspondentes a cada um dos esforços de segunda ordem em separado, quanto aqueles relacionados à média geral. Para isso, foram elaborados diagramas de dispersão com os dados já calculados de todos os edifícios, que são apresentados na Figura D.16.

Observa-se que esses dados podem ser aproximados por linhas retas, e, para ajustálas, foi utilizado o Método dos Mínimos Quadrados. As retas resultantes são apresentadas da Figura D.17 à Figura D.20.

À medida que os valores dos acréscimos aumentam, percebe-se que tanto as retas das médias quanto as dos acréscimos individuais vão se afastando da reta que corresponde a valores de acréscimos iguais para $\gamma_{\mathrm{z}}$ e $\mathbf{P}-\Delta$, aqui chamada de ideal. De uma maneira geral, observa-se uma boa aproximação até $20 \%$. Neste ponto, as diferenças em relação aos valores da reta ideal já são de $8 \%$ para a média, $14 \%$ para a força normal e 13\% para os esforços nas vigas. Confirmando-se essa tendência, $\gamma_{\mathrm{z}}$ realmente só poderia ser considerado um bom majorador para valores inferiores a $\mathbf{1 , 2}$. 
Tabela D.5 - Acréscimos percentuais dos esforços pelo processo $\mathbf{P}-\Delta$, na direção X (Ed. Orlando Maia II)

\begin{tabular}{|c|c|c|c|c|c|}
\hline \multirow{2}{*}{ Nivel } & \multicolumn{3}{|c|}{ Pilares } & \multicolumn{2}{c|}{ Vigas } \\
\cline { 2 - 6 } & Normal & Mom. Base & Mom. Topo & Cortante & Momento \\
\hline $\mathbf{1 4}$ & 12,1 & 12,2 & 12,0 & 12,6 & 12,5 \\
\hline $\mathbf{1 3}$ & 12,3 & 9,8 & 9,6 & 10,5 & 10,6 \\
\hline $\mathbf{1 2}$ & 12,4 & 10,2 & 10,0 & 10,0 & 10,0 \\
\hline $\mathbf{1 1}$ & 12,6 & 11,2 & 10,9 & 10,8 & 10,8 \\
\hline $\mathbf{1 0}$ & 12,6 & 12,1 & 12,2 & 11,3 & 11,4 \\
\hline $\mathbf{9}$ & 12,7 & 12,8 & 13,0 & 12,3 & 12,3 \\
\hline $\mathbf{8}$ & 12,7 & 12,8 & 13,2 & 12,9 & 12,9 \\
\hline $\mathbf{7}$ & 13,1 & 13,3 & 13,9 & 14,0 & 14,0 \\
\hline $\mathbf{6}$ & 13,5 & 14,1 & 14,5 & 15,0 & 15,0 \\
\hline $\mathbf{5}$ & 14,0 & 14,9 & 15,1 & 15,8 & 15,8 \\
\hline $\mathbf{4}$ & 14,5 & 15,2 & 15,3 & 16,1 & 16,1 \\
\hline $\mathbf{3}$ & 14,6 & 15,3 & 15,3 & 16,3 & 16,3 \\
\hline $\mathbf{2}$ & 14,6 & 13,8 & 13,6 & 16,0 & 16,0 \\
\hline $\mathbf{1}$ & 14,5 & 11,7 & 11,3 & 13,9 & 13,9 \\
\hline Média & $\mathbf{1 3 , 3}$ & $\mathbf{1 2 , 8}$ & $\mathbf{1 2 , 9}$ & $\mathbf{1 3 , 4}$ & $\mathbf{1 3 , 4}$ \\
\hline \multicolumn{7}{|c|}{ Média final: $\mathbf{1 3 , 2}$} \\
\hline
\end{tabular}


Tabela D.6 - Acréscimos percentuais dos esforços pelo processo $\mathbf{P}-\Delta$, na direção Y (Ed. Orlando Maia II)

\begin{tabular}{|c|c|c|c|c|c|}
\hline \multirow{2}{*}{ Nivel } & \multicolumn{3}{|c|}{ Pilares } & \multicolumn{2}{c|}{ Vigas } \\
\cline { 2 - 6 } & Normal & Mom. Base & Mom. Topo & Cortante & Momento \\
\hline $\mathbf{1 4}$ & 8,6 & 8,6 & 8,5 & 9,2 & 9,2 \\
\hline $\mathbf{1 3}$ & 8,4 & 8,0 & 7,8 & 8,0 & 8,0 \\
\hline $\mathbf{1 2}$ & 8,4 & 7,8 & 7,6 & 7,7 & 7,7 \\
\hline $\mathbf{1 1}$ & 8,5 & 7,6 & 7,7 & 6,6 & 6,6 \\
\hline $\mathbf{1 0}$ & 8,5 & 8,3 & 8,5 & 7,4 & 7,4 \\
\hline $\mathbf{9}$ & 8,5 & 8,8 & 9,2 & 8,4 & 8,4 \\
\hline $\boldsymbol{8}$ & 8,6 & 9,7 & 10,1 & 9,0 & 9,0 \\
\hline $\mathbf{7}$ & 8,7 & 10,1 & 10,9 & 9,0 & 9,0 \\
\hline $\mathbf{6}$ & 9,0 & 10,9 & 11,2 & 9,6 & 9,6 \\
\hline $\mathbf{5}$ & 9,0 & 11,9 & 11,7 & 10,0 & 10,0 \\
\hline $\mathbf{4}$ & 9,1 & 11,9 & 11,9 & 10,0 & 10,0 \\
\hline $\mathbf{3}$ & 9,1 & 11,8 & 11,6 & 10,0 & 10,0 \\
\hline $\mathbf{2}$ & 9,1 & 10,4 & 10,0 & 9,0 & 9,0 \\
\hline $\mathbf{1}$ & 9,0 & 8,4 & 8,8 & 8,0 & 8,0 \\
\hline Média & $\mathbf{8 , 7}$ & $\mathbf{9 , 6}$ & $\mathbf{9 , 7}$ & $\mathbf{8 , 7}$ & $\mathbf{8 , 7}$ \\
\hline \multicolumn{7}{|r|}{ Média final: $9, \mathbf{1}$} \\
\hline
\end{tabular}


Tabela D.7 - Acréscimos percentuais dos esforços pelo processo P- $\Delta$, na direção X (Ed. Roma)

\begin{tabular}{|c|c|c|c|c|c|}
\hline \multirow{2}{*}{ Nivel } & \multicolumn{3}{|c|}{ Pilares } & \multicolumn{2}{c|}{ Vigas } \\
\cline { 2 - 6 } & Normal & Mom. Base & Mom. Topo & Cortante & Momento \\
\hline $\mathbf{1 7}$ & 5,3 & 4,7 & 4,6 & 4,2 & 4,2 \\
\hline $\mathbf{1 6}$ & 5,3 & 4,6 & 4,3 & 4,4 & 4,4 \\
\hline $\mathbf{1 5}$ & 5,5 & 3,8 & 4,3 & 4,4 & 4,4 \\
\hline $\mathbf{1 4}$ & 6,0 & 3,6 & 4,1 & 4,5 & 4,5 \\
\hline $\mathbf{1 3}$ & 6,1 & 3,2 & 4,4 & 4,6 & 4,6 \\
\hline $\mathbf{1 2}$ & 6,0 & 4,0 & 4,9 & 4,7 & 4,7 \\
\hline $\mathbf{1 1}$ & 6,0 & 4,3 & 5,7 & 5,1 & 5,1 \\
\hline $\mathbf{1 0}$ & 6,0 & 4,4 & 5,9 & 5,5 & 5,5 \\
\hline $\mathbf{9}$ & 5,9 & 5,2 & 6,3 & 6,3 & 6,3 \\
\hline $\mathbf{8}$ & 5,4 & 5,3 & 6,7 & 6,5 & 6,5 \\
\hline $\mathbf{7}$ & 5,5 & 6,1 & 6,8 & 6,8 & 6,8 \\
\hline $\mathbf{6}$ & 5,5 & 6,4 & 7,2 & 7,4 & 7,4 \\
\hline $\mathbf{5}$ & 5,6 & 6,4 & 7,5 & 7,6 & 7,6 \\
\hline $\mathbf{4}$ & 6,0 & 7,2 & 7,7 & 7,9 & 7,9 \\
\hline $\mathbf{3}$ & 6,3 & 8,6 & 8,3 & 8,1 & 8,1 \\
\hline $\mathbf{2}$ & 6,3 & 8,3 & 8,2 & 7,6 & 7,6 \\
\hline $\mathbf{1}$ & 6,3 & 4,8 & 4,4 & 6,5 & 6,5 \\
\hline Média & $\mathbf{5 , 8}$ & $\mathbf{5 , 3}$ & $\mathbf{6 , 0}$ & $\mathbf{6 , 0}$ & $\mathbf{6 , 0}$ \\
\hline & & \multicolumn{7}{|c|}{ Média final: $\mathbf{5 , 8}$} & & \\
\hline
\end{tabular}


Tabela D.8 - Acréscimos percentuais dos esforços pelo processo P- $\Delta$, na direção Y (Ed. Roma)

\begin{tabular}{|c|c|c|c|c|c|}
\hline \multirow{2}{*}{ Nivel } & \multicolumn{3}{|c|}{ Pilares } & \multicolumn{2}{c|}{ Vigas } \\
\cline { 2 - 6 } & Normal & Mom. Base & Mom. Topo & Cortante & Momento \\
\hline $\mathbf{1 7}$ & 10,4 & 7,4 & 7,5 & 7,6 & 7,6 \\
\hline $\mathbf{1 6}$ & 10,5 & 6,8 & 6,8 & 7,6 & 7,6 \\
\hline $\mathbf{1 5}$ & 10,7 & 7,0 & 7,3 & 7,4 & 7,4 \\
\hline $\mathbf{1 4}$ & 10,8 & 8,0 & 8,1 & 8,0 & 8,0 \\
\hline $\mathbf{1 3}$ & 11,0 & 9,2 & 9,4 & 9,0 & 9,0 \\
\hline $\mathbf{1 2}$ & 11,1 & 10,5 & 10,7 & 10,0 & 10,0 \\
\hline $\mathbf{1 1}$ & 11,2 & 11,8 & 12,0 & 11,3 & 11,3 \\
\hline $\mathbf{1 0}$ & 11,6 & 13,1 & 13,6 & 12,9 & 13,0 \\
\hline $\mathbf{9}$ & 11,9 & 15,0 & 15,0 & 14,0 & 14,0 \\
\hline $\mathbf{8}$ & 12,0 & 16,1 & 16,5 & 16,0 & 16,0 \\
\hline $\mathbf{7}$ & 12,1 & 18,0 & 18,0 & 17,0 & 17,0 \\
\hline $\mathbf{6}$ & 13,1 & 19,1 & 19,4 & 18,7 & 18,7 \\
\hline $\mathbf{5}$ & 14,3 & 20,3 & 20,9 & 20,0 & 20,0 \\
\hline $\mathbf{4}$ & 15,2 & 21,2 & 21,5 & 21,0 & 21,0 \\
\hline $\mathbf{3}$ & 15,9 & 20,9 & 21,0 & 21,1 & 21,1 \\
\hline $\mathbf{2}$ & 16,3 & 18,9 & 18,1 & 20,0 & 20,0 \\
\hline $\mathbf{1}$ & 16,4 & 13,6 & 12,6 & 17,0 & 17,0 \\
\hline Média & $\mathbf{1 2 , 6}$ & $\mathbf{1 3 , 9}$ & $\mathbf{1 4 , 0}$ & $\mathbf{1 4 , 0}$ & $\mathbf{1 4 , 0}$ \\
\hline & & & \multicolumn{3}{|c}{ Média final: $\mathbf{1 3 , 7}$} \\
\hline
\end{tabular}


Tabela D.9 - Acréscimos percentuais dos esforços pelo processo P- $\Delta$, na direção X (Ed. Vela Branca I)

\begin{tabular}{|c|c|c|c|c|c|}
\hline \multirow{2}{*}{ Nivel } & \multicolumn{3}{|c|}{ Pilares } & \multicolumn{2}{c|}{ Vigas } \\
\cline { 2 - 6 } & Normal & Mom. Base & Mom. Topo & Cortante & Momento \\
\hline $\mathbf{2 0}$ & 8,6 & 7,6 & 7,2 & 8,6 & 8,6 \\
\hline $\mathbf{1 9}$ & 8,6 & 7,4 & 6,8 & 8,6 & 8,5 \\
\hline $\mathbf{1 8}$ & 8,6 & 7,2 & 6,7 & 7,7 & 7,7 \\
\hline $\mathbf{1 7}$ & 8,7 & 6,6 & 6,4 & 7,0 & 7,0 \\
\hline $\mathbf{1 6}$ & 8,7 & 6,9 & 7,1 & 6,3 & 6,3 \\
\hline $\mathbf{1 5}$ & 8,9 & 7,4 & 8,0 & 6,7 & 6,7 \\
\hline $\mathbf{1 4}$ & 8,8 & 8,5 & 8,8 & 7,6 & 7,6 \\
\hline $\mathbf{1 3}$ & 9,0 & 9,6 & 10,2 & 7,9 & 7,9 \\
\hline $\mathbf{1 2}$ & 9,0 & 10,7 & 11,3 & 8,8 & 8,8 \\
\hline $\mathbf{1 1}$ & 9,0 & 11,7 & 12,1 & 9,0 & 9,0 \\
\hline $\mathbf{1 0}$ & 9,2 & 12,8 & 13,0 & 10,0 & 10,0 \\
\hline $\mathbf{9}$ & 9,2 & 13,8 & 14,1 & 10,2 & 10,2 \\
\hline $\boldsymbol{8}$ & 9,2 & 14,0 & 14,3 & 11,0 & 11,0 \\
\hline $\mathbf{7}$ & 9,3 & 14,2 & 14,2 & 11,2 & 11,2 \\
\hline $\mathbf{6}$ & 9,4 & 14,0 & 14,5 & 12,0 & 12,0 \\
\hline $\mathbf{5}$ & 9,6 & 14,1 & 13,9 & 12,0 & 12,0 \\
\hline $\mathbf{4}$ & 10,0 & 14,1 & 13,6 & 12,0 & 12,0 \\
\hline $\mathbf{3}$ & 10,3 & 12,6 & 12,3 & 11,1 & 11,1 \\
\hline $\mathbf{2}$ & 10,0 & 11,0 & 10,6 & 10,1 & 10,1 \\
\hline $\mathbf{1}$ & 9,7 & 7,6 & 7,9 & 7,6 & 7,6 \\
\hline Média & $\mathbf{9 , 2}$ & $\mathbf{1 0 , 6}$ & $\mathbf{1 0 , 7}$ & $\mathbf{9 , 3}$ & $\mathbf{9 , 3}$ \\
\hline & & & & & \\
\hline
\end{tabular}


Tabela D.10 - Acréscimos percentuais dos esforços pelo processo P- $\Delta$, na direção Y (Ed. Vela Branca I)

\begin{tabular}{|c|c|c|c|c|c|}
\hline \multirow{2}{*}{ Nivel } & \multicolumn{3}{|c|}{ Pilares } & \multicolumn{2}{c|}{ Vigas } \\
\cline { 2 - 6 } & Normal & Mom. Base & Mom. Topo & Cortante & Momento \\
\hline $\mathbf{2 0}$ & 9,9 & 10,6 & 10,7 & 8,8 & 8,8 \\
\hline $\mathbf{1 9}$ & 10,1 & 10,4 & 10,7 & 8,6 & 8,7 \\
\hline $\mathbf{1 8}$ & 10,2 & 10,9 & 10,7 & 9,3 & 9,3 \\
\hline $\mathbf{1 7}$ & 10,0 & 11,4 & 11,5 & 9,7 & 9,7 \\
\hline $\mathbf{1 6}$ & 10,3 & 11,9 & 12,1 & 10,3 & 10,3 \\
\hline $\mathbf{1 5}$ & 10,7 & 12,9 & 12,8 & 10,8 & 10,8 \\
\hline $\mathbf{1 4}$ & 10,9 & 13,1 & 13,6 & 11,2 & 11,2 \\
\hline $\mathbf{1 3}$ & 10,9 & 14,7 & 14,4 & 11,7 & 11,7 \\
\hline $\mathbf{1 2}$ & 11,1 & 14,8 & 15,1 & 12,9 & 12,8 \\
\hline $\mathbf{1 1}$ & 11,6 & 15,0 & 15,2 & 13,6 & 13,6 \\
\hline $\mathbf{1 0}$ & 11,8 & 15,6 & 15,3 & 14,3 & 14,3 \\
\hline $\mathbf{9}$ & 12,1 & 15,9 & 15,6 & 14,3 & 14,3 \\
\hline $\mathbf{8}$ & 12,3 & 16,0 & 15,8 & 14,3 & 14,3 \\
\hline $\mathbf{7}$ & 12,4 & 15,8 & 15,1 & 14,3 & 14,3 \\
\hline $\mathbf{6}$ & 12,4 & 15,6 & 15,2 & 14,3 & 14,3 \\
\hline $\mathbf{5}$ & 12,6 & 15,5 & 15,0 & 13,3 & 13,3 \\
\hline $\mathbf{4}$ & 12,5 & 15,3 & 14,8 & 13,0 & 13,0 \\
\hline $\mathbf{3}$ & 12,4 & 13,6 & 12,8 & 11,8 & 11,8 \\
\hline $\mathbf{2}$ & 12,5 & 12,6 & 11,9 & 10,5 & 10,5 \\
\hline $\mathbf{1}$ & 12,6 & 9,9 & 10,3 & 8,2 & 8,2 \\
\hline Média & $\mathbf{1 1 , 5}$ & $\mathbf{1 3 , 6}$ & $\mathbf{1 3 , 4}$ & $\mathbf{1 1 , 8}$ & $\mathbf{1 1 , 8}$ \\
\hline & & & & & \\
\hline & & & & & \\
\hline
\end{tabular}


Tabela D.11 - Acréscimos percentuais dos esforços pelo processo P- $\Delta$, na direção X (Ed. Fontana di Trevi)

\begin{tabular}{|c|c|c|c|c|c|}
\hline \multirow{2}{*}{ Nivel } & \multicolumn{3}{|c|}{ Pilares } & \multicolumn{2}{c|}{ Vigas } \\
\cline { 2 - 6 } & Normal & Mom. Base & Mom. Topo & Cortante & Momento \\
\hline $\mathbf{2 3}$ & 7,5 & 8,7 & 8,7 & 6,8 & 6,8 \\
\hline $\mathbf{2 2}$ & 7,5 & 8,0 & 8,0 & 6,5 & 6,5 \\
\hline $\mathbf{2 1}$ & 7,6 & 7,6 & 7,6 & 6,4 & 6,4 \\
\hline $\mathbf{2 0}$ & 7,8 & 7,3 & 7,3 & 6,1 & 6,1 \\
\hline $\mathbf{1 9}$ & 8,0 & 6,8 & 6,7 & 6,0 & 6,0 \\
\hline $\mathbf{1 8}$ & 8,2 & 6,5 & 6,5 & 6,1 & 6,1 \\
\hline $\mathbf{1 7}$ & 8,2 & 6,7 & 6,6 & 6,2 & 6,2 \\
\hline $\mathbf{1 6}$ & 8,1 & 6,9 & 6,9 & 6,4 & 6,4 \\
\hline $\mathbf{1 5}$ & 8,2 & 7,2 & 7,4 & 6,5 & 6,5 \\
\hline $\mathbf{1 4}$ & 8,3 & 7,5 & 7,5 & 7,0 & 7,0 \\
\hline $\mathbf{1 3}$ & 8,6 & 7,7 & 7,9 & 7,3 & 7,3 \\
\hline $\mathbf{1 2}$ & 8,7 & 8,4 & 8,5 & 7,6 & 7,7 \\
\hline $\mathbf{1 1}$ & 8,6 & 8,9 & 9,1 & 8,2 & 8,2 \\
\hline $\mathbf{1 0}$ & 8,7 & 9,3 & 9,6 & 8,3 & 8,3 \\
\hline $\mathbf{9}$ & 9,0 & 9,8 & 9,9 & 8,5 & 8,6 \\
\hline $\mathbf{8}$ & 9,2 & 9,9 & 10,1 & 8,9 & 8,9 \\
\hline $\mathbf{7}$ & 9,5 & 10,9 & 10,9 & 9,2 & 9,2 \\
\hline $\mathbf{6}$ & 9,5 & 11,3 & 11,2 & 9,3 & 9,3 \\
\hline $\mathbf{5}$ & 9,5 & 12,0 & 12,2 & 9,6 & 9,6 \\
\hline $\mathbf{4}$ & 9,6 & 12,8 & 12,8 & 9,8 & 9,8 \\
\hline $\mathbf{3}$ & 9,8 & 12,6 & 12,8 & 10,3 & 10,2 \\
\hline $\mathbf{2}$ & 9,9 & 12,0 & 12,0 & 10,9 & 10,9 \\
\hline $\mathbf{1}$ & 9,9 & 11,7 & 11,2 & 9,9 & 10,0 \\
\hline Média & $\mathbf{8 , 7}$ & $\mathbf{9 , 2}$ & $\mathbf{9 , 2}$ & $\mathbf{7 , 9}$ & 7,9 \\
\hline & & & & & \\
\hline & & & & & \\
\hline
\end{tabular}


Tabela D.12 - Acréscimos percentuais dos esforços pelo processo P- $\Delta$, na direção Y (Ed. Fontana di Trevi)

\begin{tabular}{|c|c|c|c|c|c|}
\hline \multirow{2}{*}{ Nivel } & \multicolumn{3}{|c|}{ Pilares } & \multicolumn{2}{c|}{ Vigas } \\
\cline { 2 - 6 } & Normal & Mom. Base & Mom. Topo & Cortante & Momento \\
\hline $\mathbf{2 3}$ & 7,7 & 8,7 & 9,1 & 9,0 & 9,1 \\
\hline $\mathbf{2 2}$ & 7,9 & 8,3 & 8,0 & 6,8 & 6,8 \\
\hline $\mathbf{2 1}$ & 7,9 & 7,9 & 7,8 & 5,8 & 5,8 \\
\hline $\mathbf{2 0}$ & 7,8 & 7,5 & 7,3 & 5,5 & 5,5 \\
\hline $\mathbf{1 9}$ & 8,0 & 7,1 & 7,1 & 5,8 & 5,8 \\
\hline $\mathbf{1 8}$ & 8,0 & 6,9 & 7,2 & 5,7 & 5,7 \\
\hline $\mathbf{1 7}$ & 8,0 & 6,9 & 7,3 & 6,2 & 6,2 \\
\hline $\mathbf{1 6}$ & 8,1 & 7,2 & 7,8 & 6,9 & 6,8 \\
\hline $\mathbf{1 5}$ & 8,2 & 7,8 & 8,3 & 7,4 & 7,4 \\
\hline $\mathbf{1 4}$ & 8,2 & 8,5 & 8,9 & 8,1 & 8,1 \\
\hline $\mathbf{1 3}$ & 8,4 & 8,9 & 9,4 & 8,7 & 8,7 \\
\hline $\mathbf{1 2}$ & 8,6 & 9,4 & 10,1 & 8,9 & 8,9 \\
\hline $\mathbf{1 1}$ & 8,6 & 10,1 & 10,6 & 9,9 & 9,9 \\
\hline $\mathbf{1 0}$ & 8,8 & 11,2 & 11,3 & 10,0 & 10,0 \\
\hline $\mathbf{9}$ & 9,2 & 11,0 & 11,6 & 11,0 & 11,0 \\
\hline $\mathbf{8}$ & 9,6 & 12,1 & 12,4 & 11,2 & 11,2 \\
\hline $\mathbf{7}$ & 9,9 & 12,5 & 12,8 & 12,0 & 12,0 \\
\hline $\mathbf{6}$ & 9,9 & 13,5 & 13,7 & 12,6 & 12,6 \\
\hline $\mathbf{5}$ & 9,9 & 14,7 & 14,8 & 13,2 & 13,2 \\
\hline $\mathbf{4}$ & 9,9 & 14,7 & 15,1 & 14,2 & 14,2 \\
\hline $\mathbf{3}$ & 10,2 & 14,6 & 14,5 & 14,7 & 14,6 \\
\hline $\mathbf{2}$ & 10,8 & 13,5 & 13,3 & 14,5 & 14,5 \\
\hline $\mathbf{1}$ & 10,9 & 9,8 & 9,4 & 11,2 & 11,3 \\
\hline Média & $\mathbf{8 , 9}$ & $\mathbf{1 0 , 1}$ & $\mathbf{1 0 , 3}$ & $\mathbf{9 , 5}$ & $\mathbf{9 , 5}$ \\
\hline & & & $M e ́ d i a$ final: 9,7 & & \\
\hline & & & & & \\
\hline
\end{tabular}


Tabela D.13 - Acréscimos percentuais dos esforços pelo processo $\mathbf{P}-\Delta$, na direção X (Ed. Multiplus)

\begin{tabular}{|c|c|c|c|c|c|}
\hline \multirow{2}{*}{ Nivel } & \multicolumn{3}{|c|}{ Pilares } & \multicolumn{2}{c|}{ Vigas } \\
\cline { 2 - 6 } & Normal & Mom. Base & Mom. Topo & Cortante & Momento \\
\hline $\mathbf{2 5}$ & 4,4 & 3,3 & 3,2 & 5,5 & 5,6 \\
\hline $\mathbf{2 4}$ & 4,3 & 3,2 & 3,1 & 5,3 & 5,3 \\
\hline $\mathbf{2 3}$ & 4,3 & 3,3 & 3,1 & 5,1 & 5,0 \\
\hline $\mathbf{2 2}$ & 4,3 & 3,5 & 3,2 & 4,8 & 4,9 \\
\hline $\mathbf{2 1}$ & 4,4 & 3,5 & 3,4 & 4,8 & 4,8 \\
\hline $\mathbf{2 0}$ & 4,4 & 3,8 & 3,6 & 4,8 & 4,8 \\
\hline $\mathbf{1 9}$ & 4,4 & 3,8 & 3,8 & 4,8 & 4,8 \\
\hline $\mathbf{1 8}$ & 4,4 & 4,0 & 4,0 & 4,8 & 4,8 \\
\hline $\mathbf{1 7}$ & 4,5 & 4,2 & 4,3 & 5,2 & 5,2 \\
\hline $\mathbf{1 6}$ & 4,5 & 4,5 & 4,6 & 5,3 & 5,5 \\
\hline $\mathbf{1 5}$ & 4,5 & 4,7 & 4,7 & 5,7 & 5,8 \\
\hline $\mathbf{1 4}$ & 4,6 & 4,7 & 4,8 & 5,8 & 5,8 \\
\hline $\mathbf{1 3}$ & 4,6 & 5,0 & 5,0 & 6,0 & 6,0 \\
\hline $\mathbf{1 2}$ & 4,5 & 5,0 & 5,1 & 6,2 & 6,2 \\
\hline $\mathbf{1 1}$ & 4,8 & 5,0 & 5,1 & 6,2 & 6,4 \\
\hline $\mathbf{1 0}$ & 4,7 & 5,0 & 5,1 & 6,3 & 6,5 \\
\hline $\mathbf{9}$ & 5,0 & 5,2 & 5,3 & 6,5 & 6,5 \\
\hline $\mathbf{8}$ & 5,0 & 5,1 & 5,1 & 6,5 & 6,5 \\
\hline $\mathbf{7}$ & 5,1 & 5,1 & 4,8 & 6,4 & 6,3 \\
\hline $\mathbf{6}$ & 5,1 & 4,9 & 4,9 & 6,2 & 6,3 \\
\hline $\mathbf{5}$ & 5,0 & 4,3 & 4,5 & 6,0 & 6,0 \\
\hline $\mathbf{4}$ & 5,0 & 4,3 & 4,5 & 5,7 & 5,7 \\
\hline $\mathbf{3}$ & 5,0 & 3,9 & 3,7 & 5,4 & 5,4 \\
\hline $\mathbf{2}$ & 5,0 & 3,9 & 3,9 & 5,0 & 5,0 \\
\hline $\mathbf{1}$ & 4,9 & 3,5 & 3,7 & 4,6 & 4,6 \\
\hline Média & $\mathbf{4 , 7}$ & $\mathbf{4 , 3}$ & $\mathbf{4 , 3}$ & $\mathbf{5 , 6}$ & $\mathbf{5 , 6}$ \\
\hline & & & Média final: 4,9 & & \\
\hline
\end{tabular}


Tabela D.14 - Acréscimos percentuais dos esforços pelo processo $\mathbf{P}-\Delta$, na direção Y (Ed. Multiplus)

\begin{tabular}{|c|c|c|c|c|c|}
\hline \multirow{2}{*}{ Nivel } & \multicolumn{3}{|c|}{ Pilares } & \multicolumn{2}{c|}{ Vigas } \\
\cline { 2 - 6 } & Normal & Mom. Base & Mom. Topo & Cortante & Momento \\
\hline $\mathbf{2 5}$ & 5,4 & 4,4 & 4,3 & 5,8 & 5,8 \\
\hline $\mathbf{2 4}$ & 5,3 & 4,3 & 4,1 & 5,5 & 5,5 \\
\hline $\mathbf{2 3}$ & 5,2 & 4,8 & 4,7 & 5,8 & 5,9 \\
\hline $\mathbf{2 2}$ & 5,3 & 5,2 & 5,0 & 6,1 & 6,1 \\
\hline $\mathbf{2 1}$ & 5,4 & 5,6 & 5,5 & 6,1 & 6,1 \\
\hline $\mathbf{2 0}$ & 5,8 & 6,0 & 5,8 & 6,2 & 6,4 \\
\hline $\mathbf{1 9}$ & 5,9 & 6,5 & 6,2 & 6,8 & 6,8 \\
\hline $\mathbf{1 8}$ & 6,0 & 6,9 & 6,7 & 6,8 & 6,8 \\
\hline $\mathbf{1 7}$ & 6,1 & 7,1 & 6,9 & 7,0 & 7,0 \\
\hline $\mathbf{1 6}$ & 6,3 & 7,4 & 7,3 & 7,0 & 7,0 \\
\hline $\mathbf{1 5}$ & 6,6 & 7,8 & 7,8 & 7,3 & 7,2 \\
\hline $\mathbf{1 4}$ & 6,5 & 8,2 & 8,1 & 7,9 & 7,9 \\
\hline $\mathbf{1 3}$ & 6,9 & 8,1 & 8,3 & 8,0 & 8,1 \\
\hline $\mathbf{1 2}$ & 7,1 & 8,2 & 8,3 & 8,1 & 8,5 \\
\hline $\mathbf{1 1}$ & 7,1 & 8,4 & 8,5 & 8,7 & 8,5 \\
\hline $\mathbf{1 0}$ & 7,0 & 8,5 & 8,4 & 8,6 & 8,6 \\
\hline $\mathbf{9}$ & 7,0 & 8,2 & 8,2 & 8,8 & 8,6 \\
\hline $\mathbf{8}$ & 7,0 & 8,0 & 8,1 & 8,8 & 8,8 \\
\hline $\mathbf{7}$ & 7,0 & 7,9 & 8,0 & 8,5 & 8,4 \\
\hline $\mathbf{6}$ & 7,1 & 7,3 & 7,6 & 7,9 & 7,8 \\
\hline $\mathbf{5}$ & 7,1 & 6,6 & 6,5 & 7,1 & 7,2 \\
\hline $\mathbf{4}$ & 6,8 & 5,6 & 5,9 & 6,7 & 6,8 \\
\hline $\mathbf{3}$ & 6,8 & 5,0 & 5,0 & 6,3 & 6,2 \\
\hline $\mathbf{2}$ & 6,8 & 4,3 & 4,2 & 5,7 & 5,7 \\
\hline $\mathbf{1}$ & 6,7 & 3,4 & 3,6 & 5,4 & 5,1 \\
\hline Média & $\mathbf{6 , 4}$ & $\mathbf{6 , 5}$ & $\mathbf{6 , 5}$ & 7,1 & $7, \mathbf{1}$ \\
\hline & & & Média final: 6,7 & & \\
\hline
\end{tabular}


Direção X

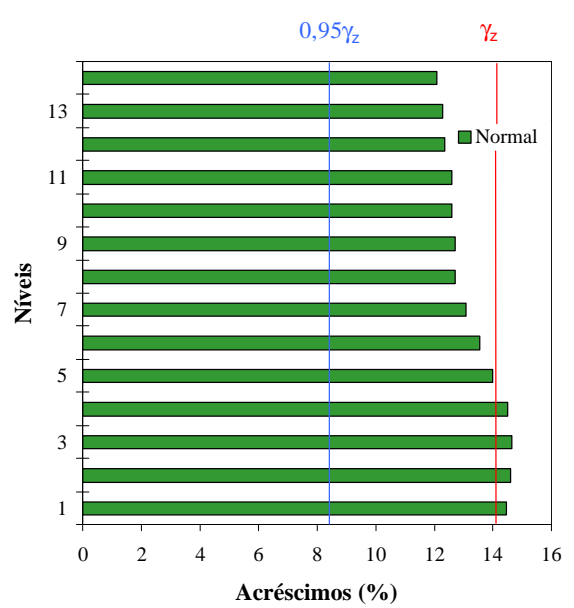

Direção Y

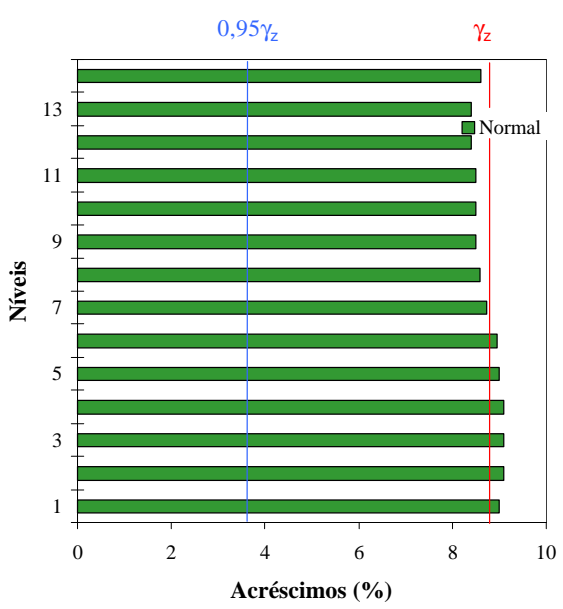

Figura D.1 - Variação dos acréscimos de força normal dos pilares, nas direções $\mathbf{X}$ e $\mathbf{Y}$

(Ed. Orlando Maia II)

Direção X

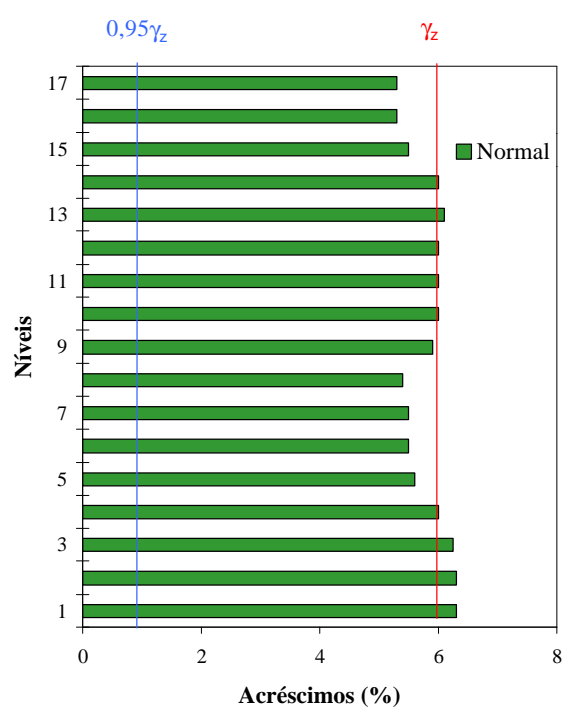

Direção $\mathbf{Y}$

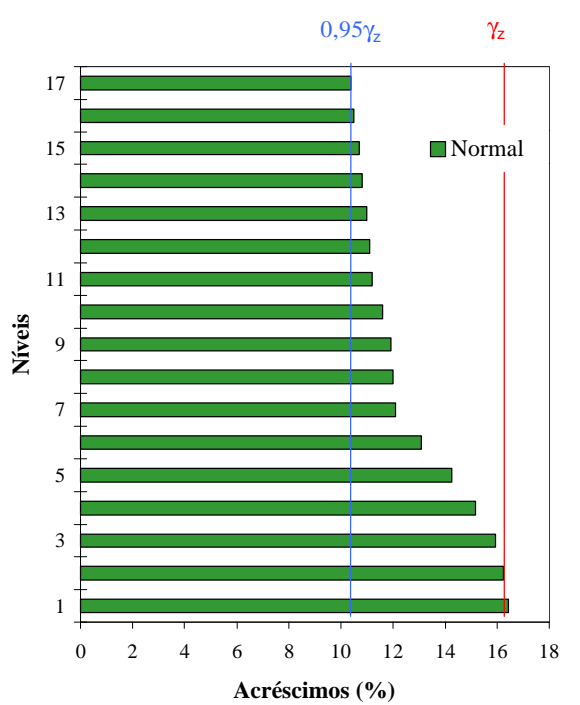

Figura D.2 - Variação dos acréscimos de força normal dos pilares, nas direções $\mathbf{X}$ e $\mathbf{Y}$

(Ed. Roma) 
Direção X

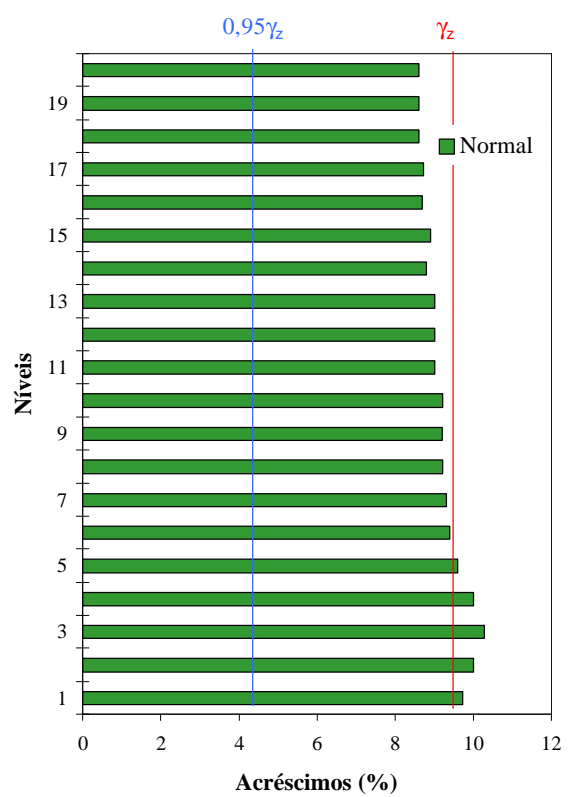

Direção Y

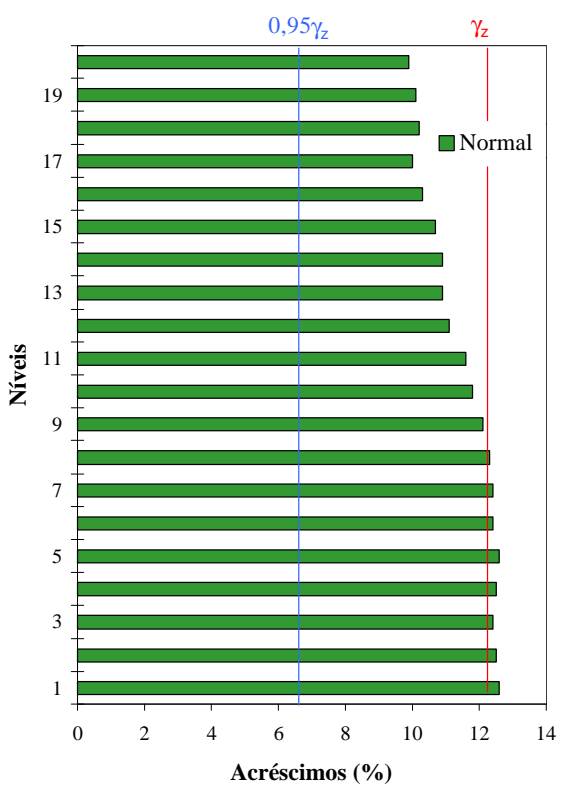

Figura D.3 - Variação dos acréscimos de força normal dos pilares, nas direções $\mathbf{X}$ e $\mathbf{Y}$ (Ed. Vela I)

Direção X

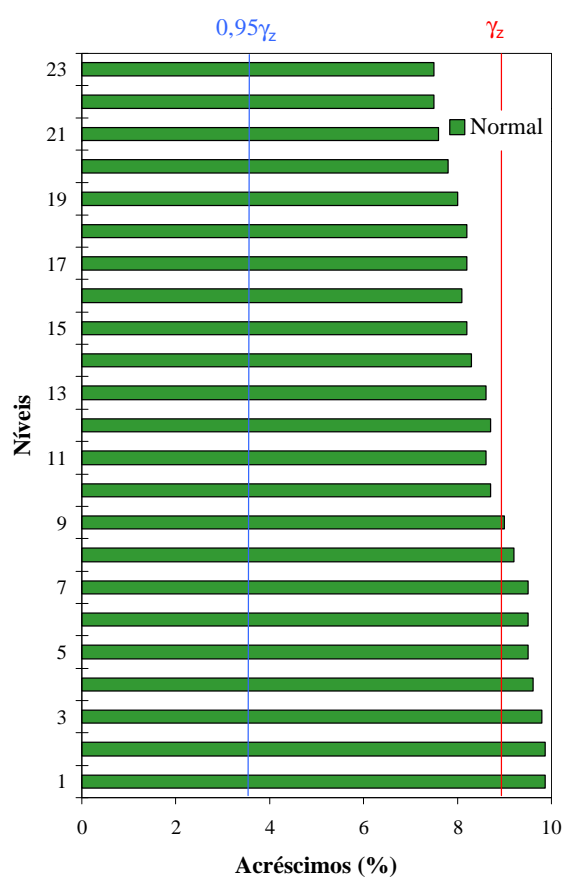

Direção $\mathbf{Y}$

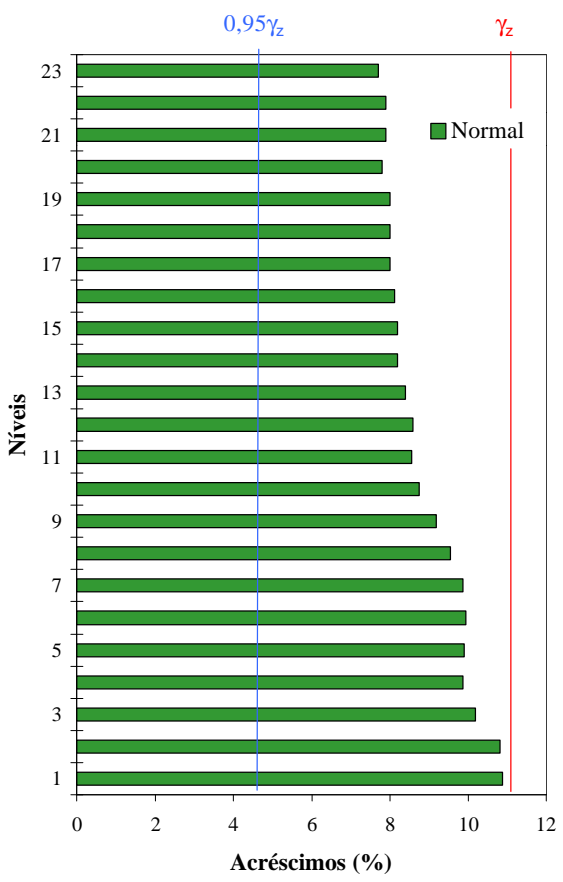

Figura D.4 - Variação dos acréscimos de força normal dos pilares, nas direções $\mathbf{X}$ e $\mathbf{Y}$

(Ed. Fontana di Trevi) 
Direção X

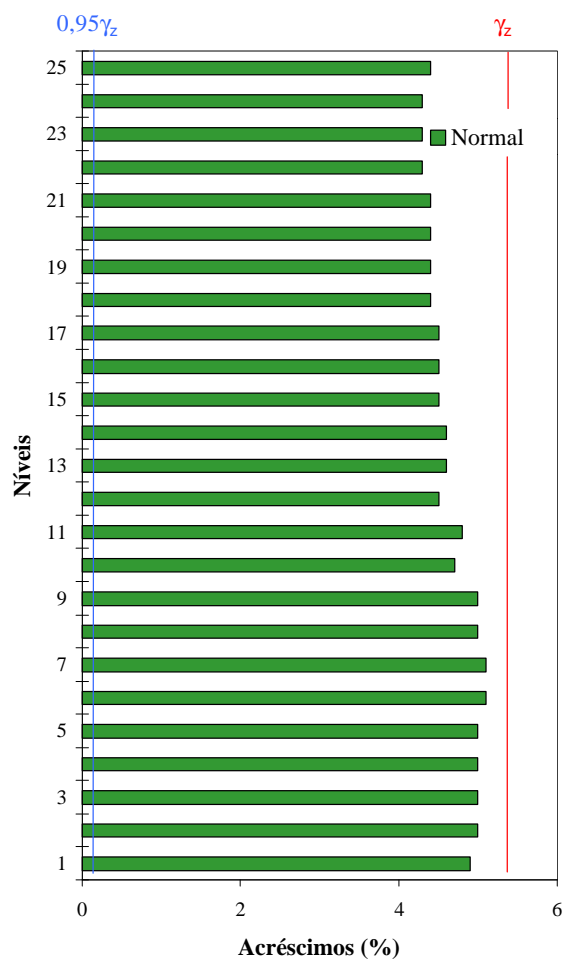

Direção $\mathbf{Y}$

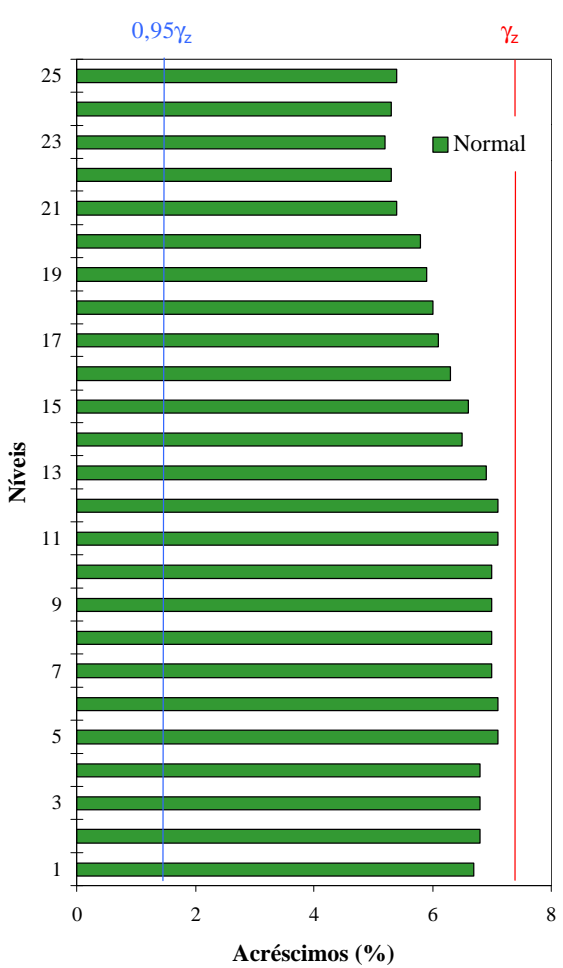

Figura D.5 - Variação dos acréscimos de força normal dos pilares, nas direções $\mathbf{X}$ e $\mathbf{Y}$

(Ed. Multiplus)

\section{Direção X}

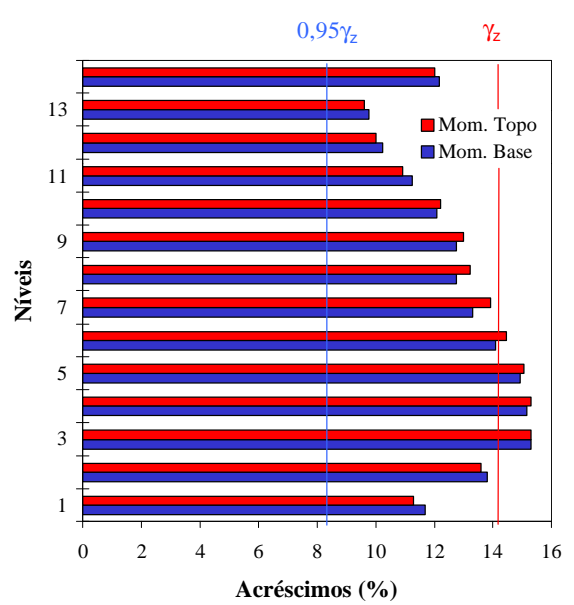

Direção Y

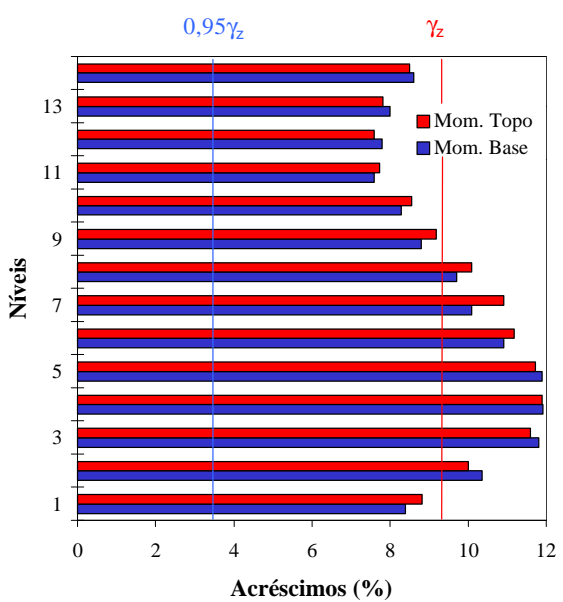

Figura D.6 - Variação dos acréscimos de momentos fletores dos pilares, nas direções $\mathbf{X}$ e $\mathbf{Y}$ (Ed. Orlando Maia II) 
Direção X

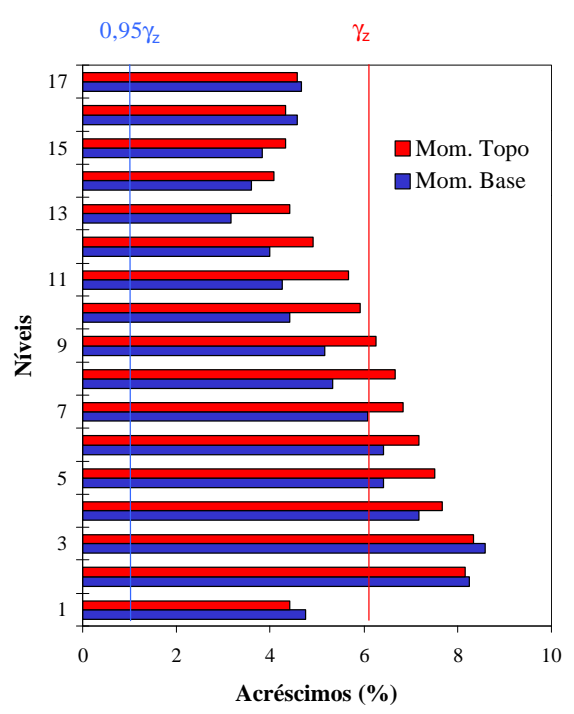

Direção $\mathbf{Y}$

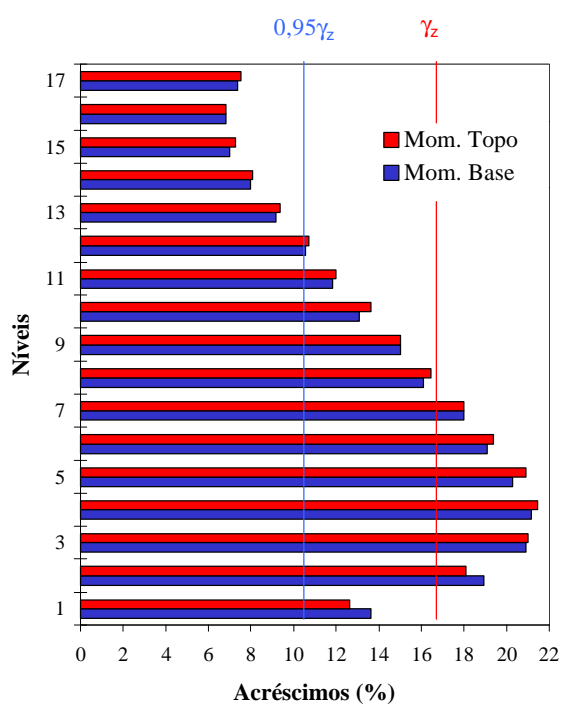

Figura D.7 - Variação dos acréscimos de momentos fletores dos pilares, nas direções $\mathbf{X}$ e $\mathbf{Y}$

(Ed. Roma)

Direção X

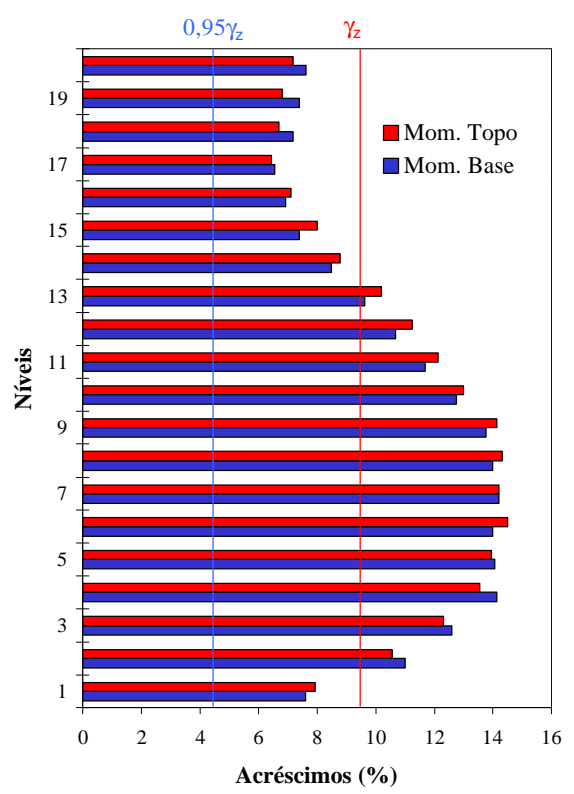

Direção $\mathbf{Y}$

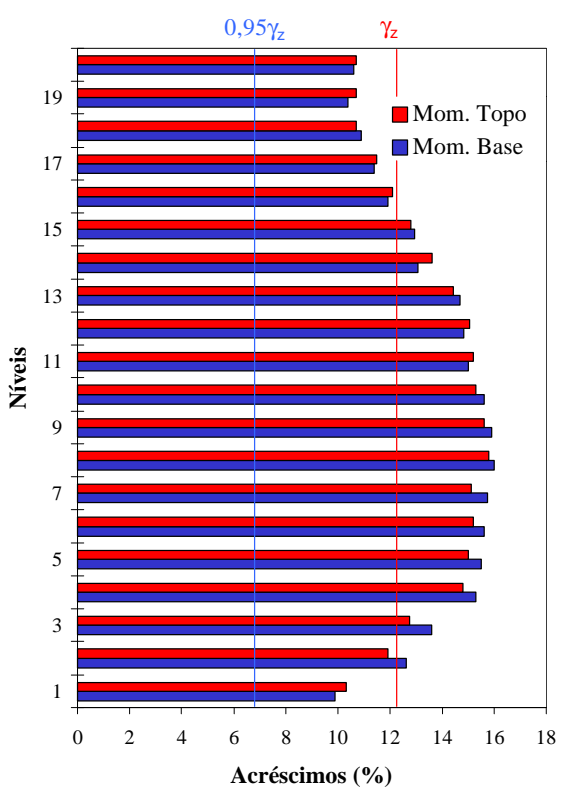

Figura D.8 - Variação dos acréscimos de momentos fletores dos pilares, nas direções $\mathbf{X}$ e $\mathbf{Y}$ (Ed. Vela I) 
Direção X

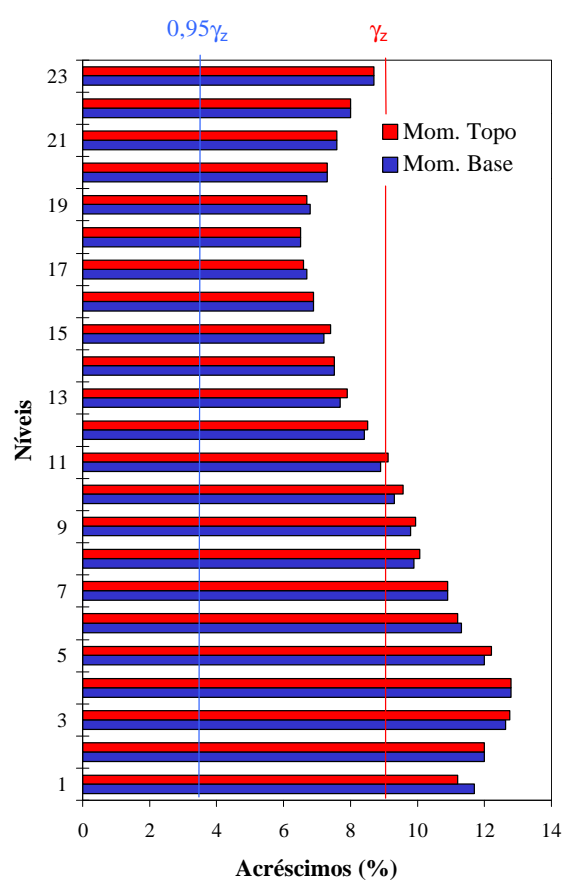

Direção Y

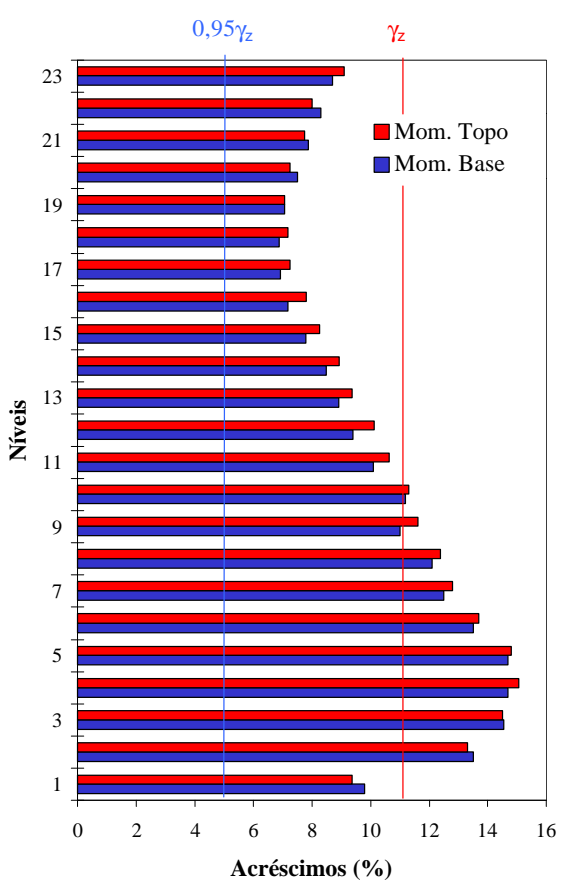

Figura D.9 - Variação dos acréscimos de momentos fletores dos pilares, nas direções $\mathbf{X}$ e $\mathbf{Y}$ (Ed. Fontana di Trevi)

Direção X

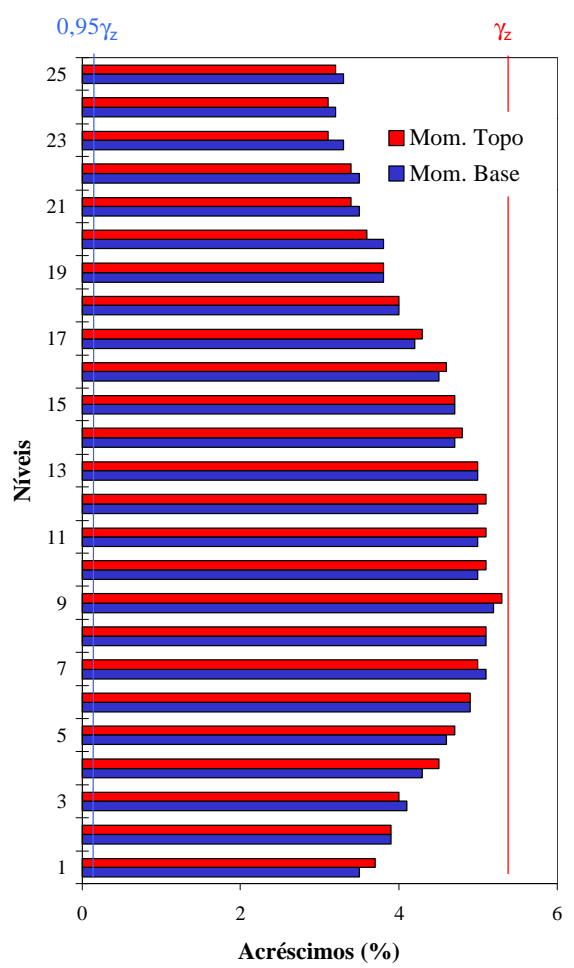

Direção Y

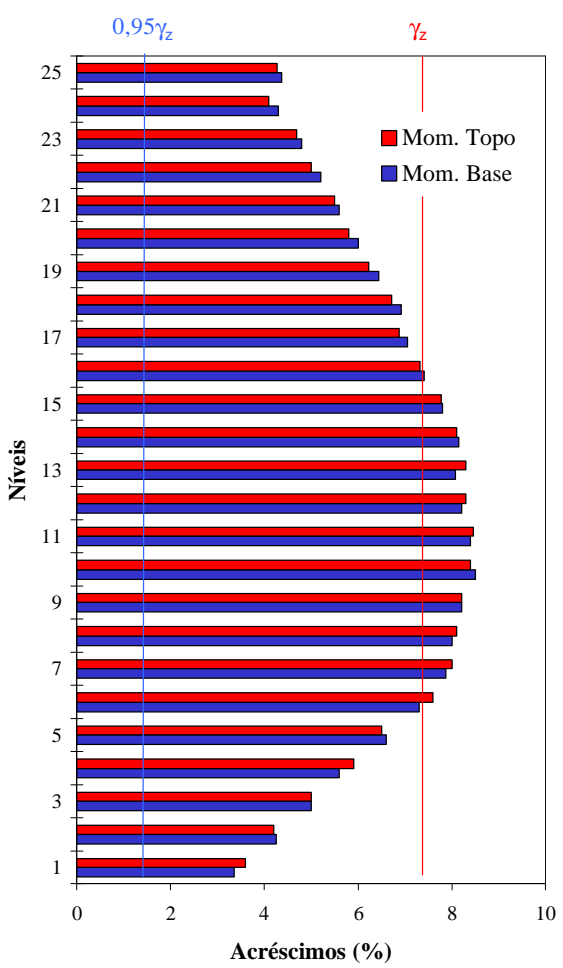

Figura D.10 - Variação dos acréscimos de momentos fletores dos pilares, nas direções $\mathbf{X}$ e $\mathbf{Y}$ (Ed. Multiplus) 

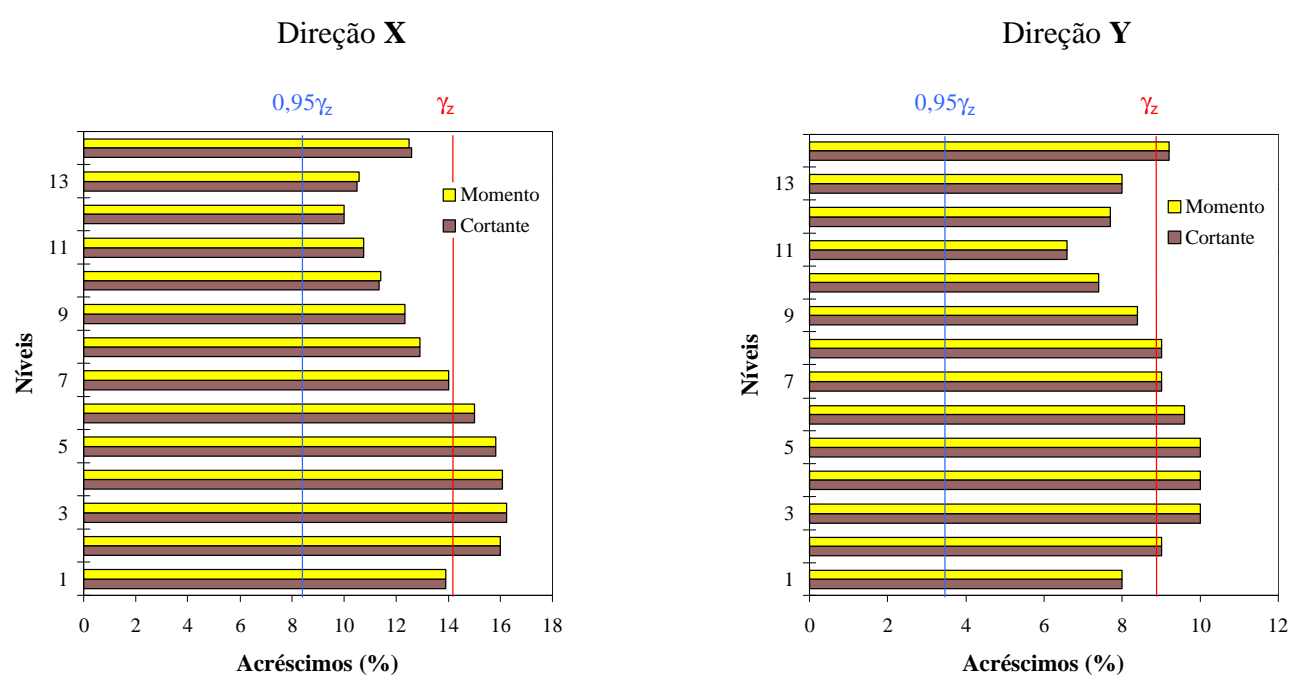

Figura D.11 - Variação dos acréscimos de esforços das vigas, nas direções $\mathbf{X}$ e $\mathbf{Y}$

(Ed. Orlando Maia II)
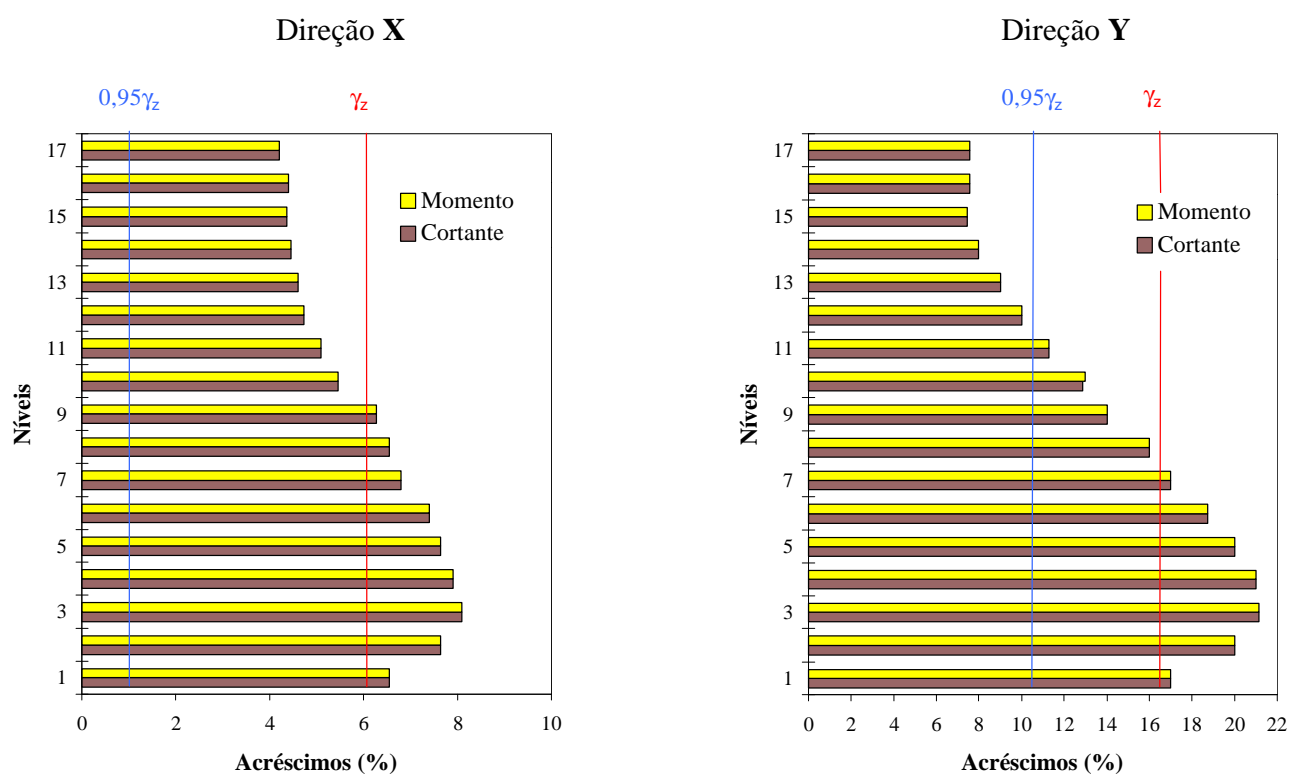

Figura D.12 - Variação dos acréscimos de esforços das vigas, nas direções $\mathbf{X}$ e $\mathbf{Y}$ (Ed. Roma) 
Direção X

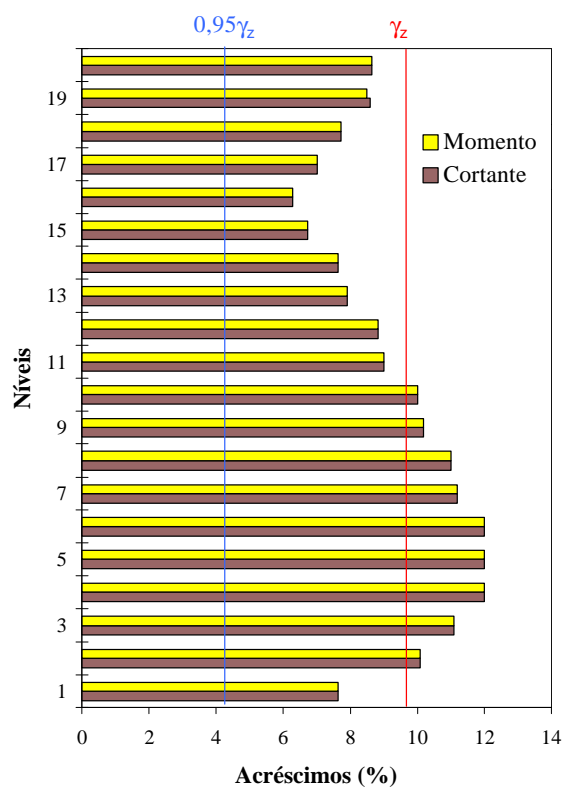

Direção $\mathbf{Y}$

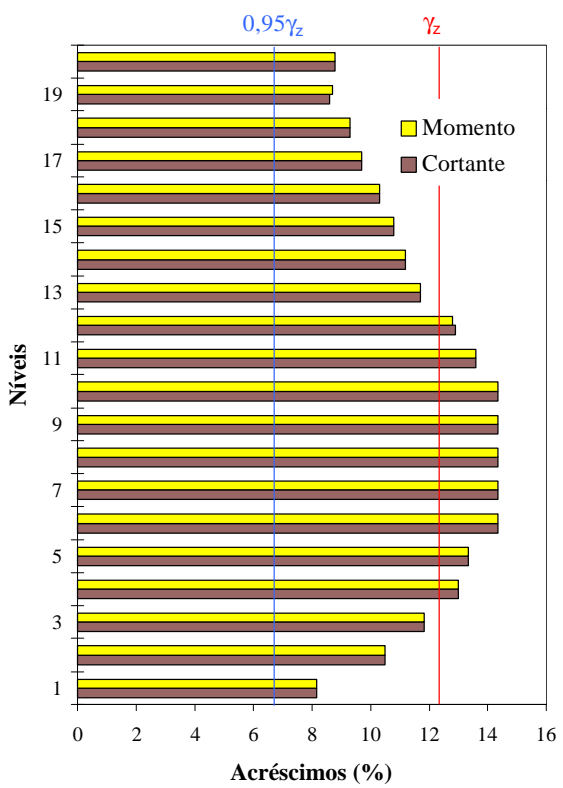

Figura D.13 - Variação dos acréscimos de esforços das vigas, nas direções $\mathbf{X}$ e $\mathbf{Y}$ (Ed. Vela I)

Direção X

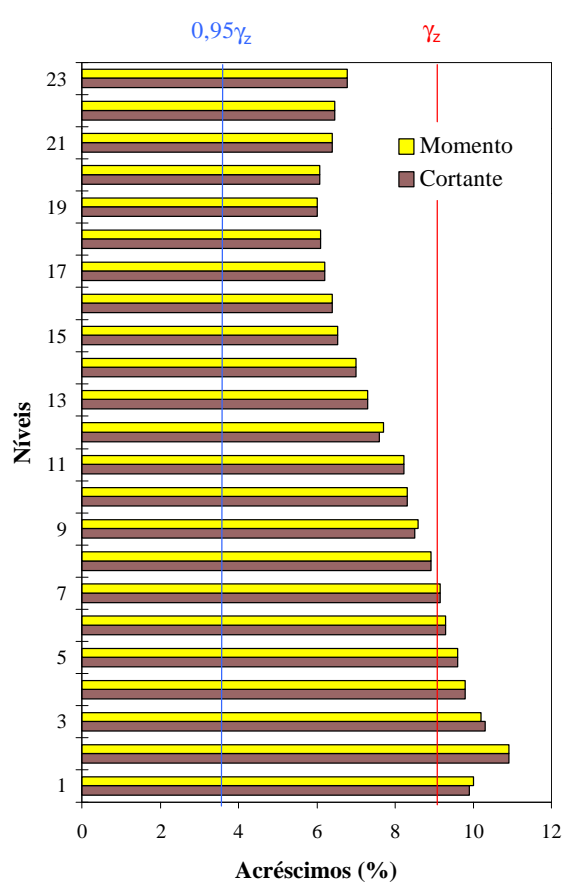

Direção Y

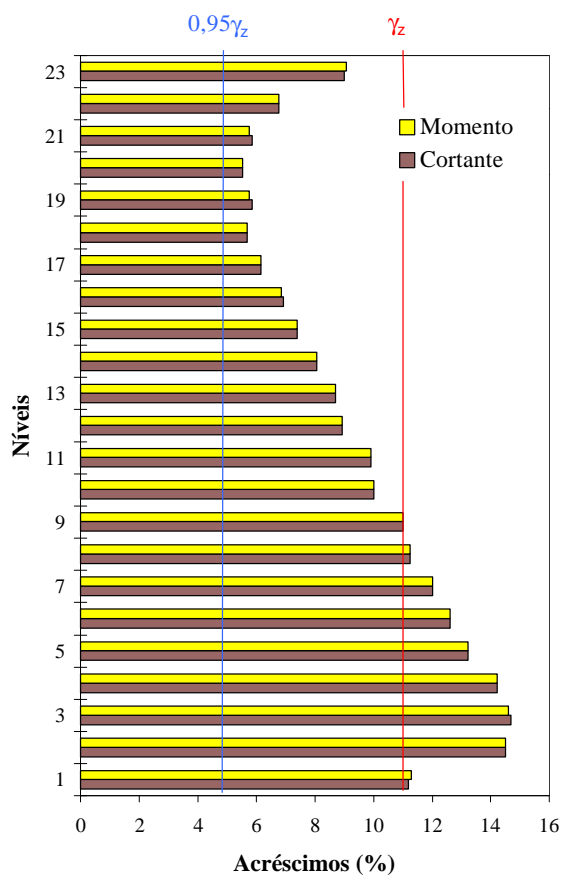

Figura D.14 - Variação dos acréscimos de esforços das vigas, nas direções $\mathbf{X}$ e $\mathbf{Y}$ (Ed. Fontana di Trevi) 
Direção X

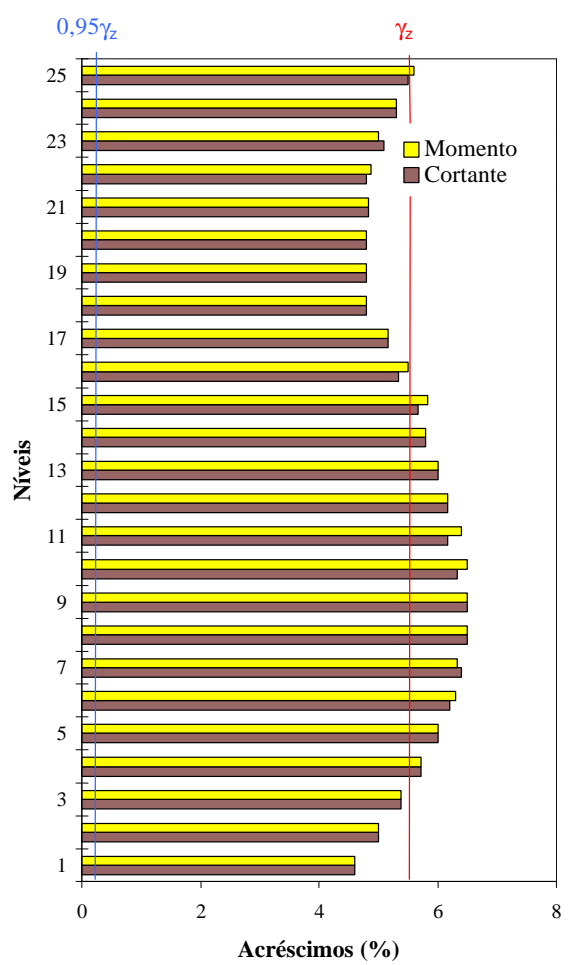

Direção Y

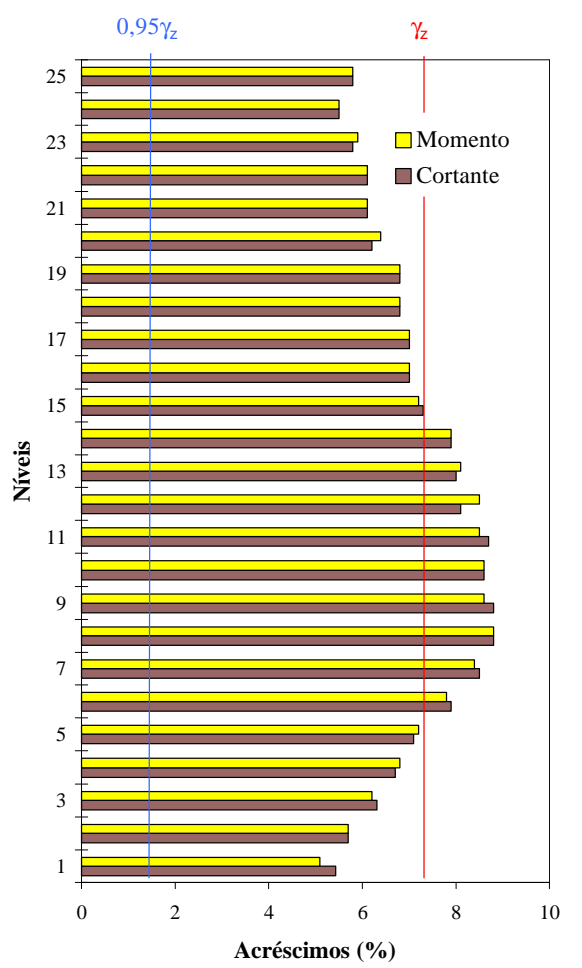

Figura D.15 - Variação dos acréscimos de esforços das vigas, nas direções $\mathbf{X}$ e $\mathbf{Y}$ (Ed. Multiplus) 

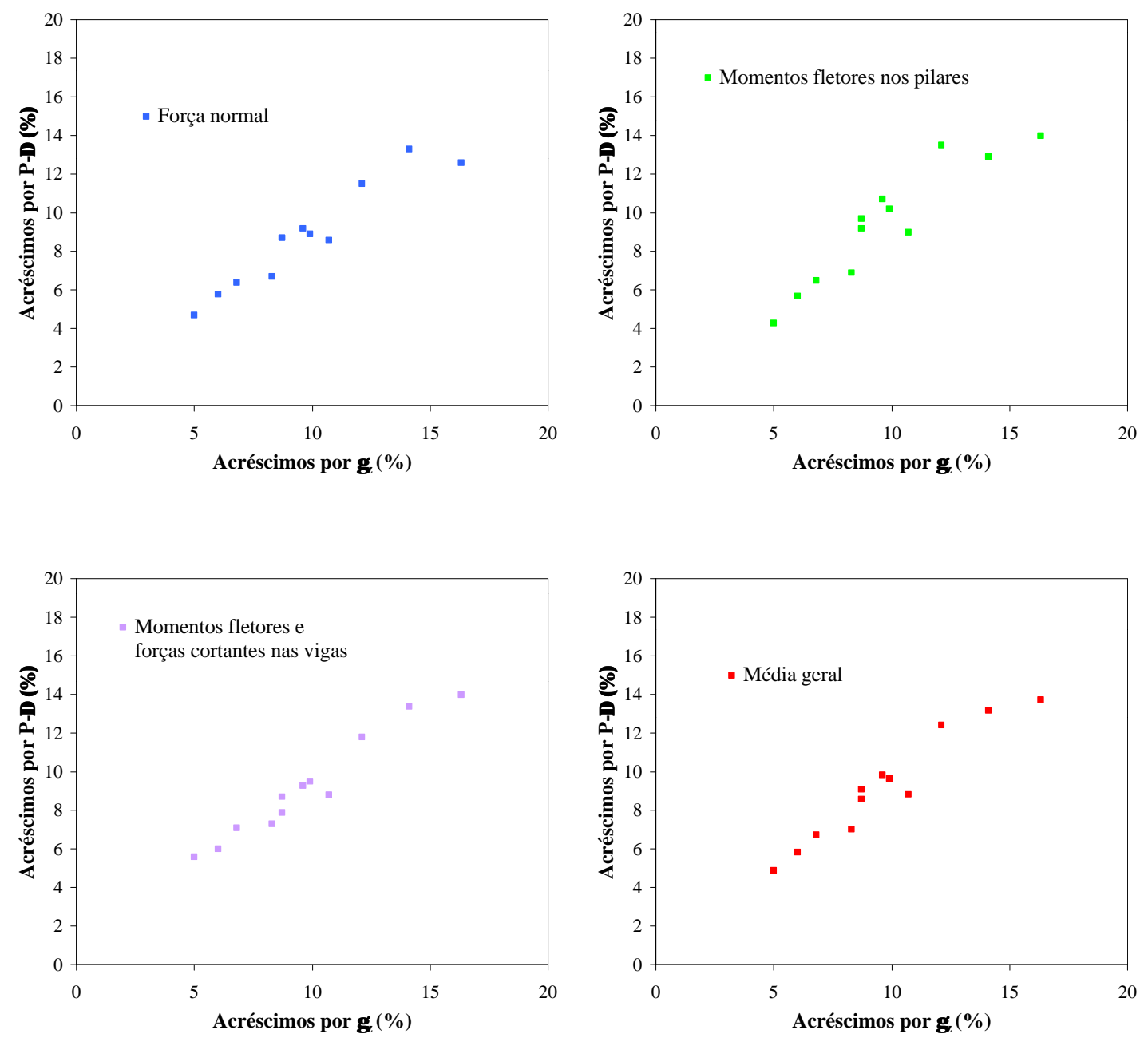

Figura D.16 - Diagramas de dispersão 


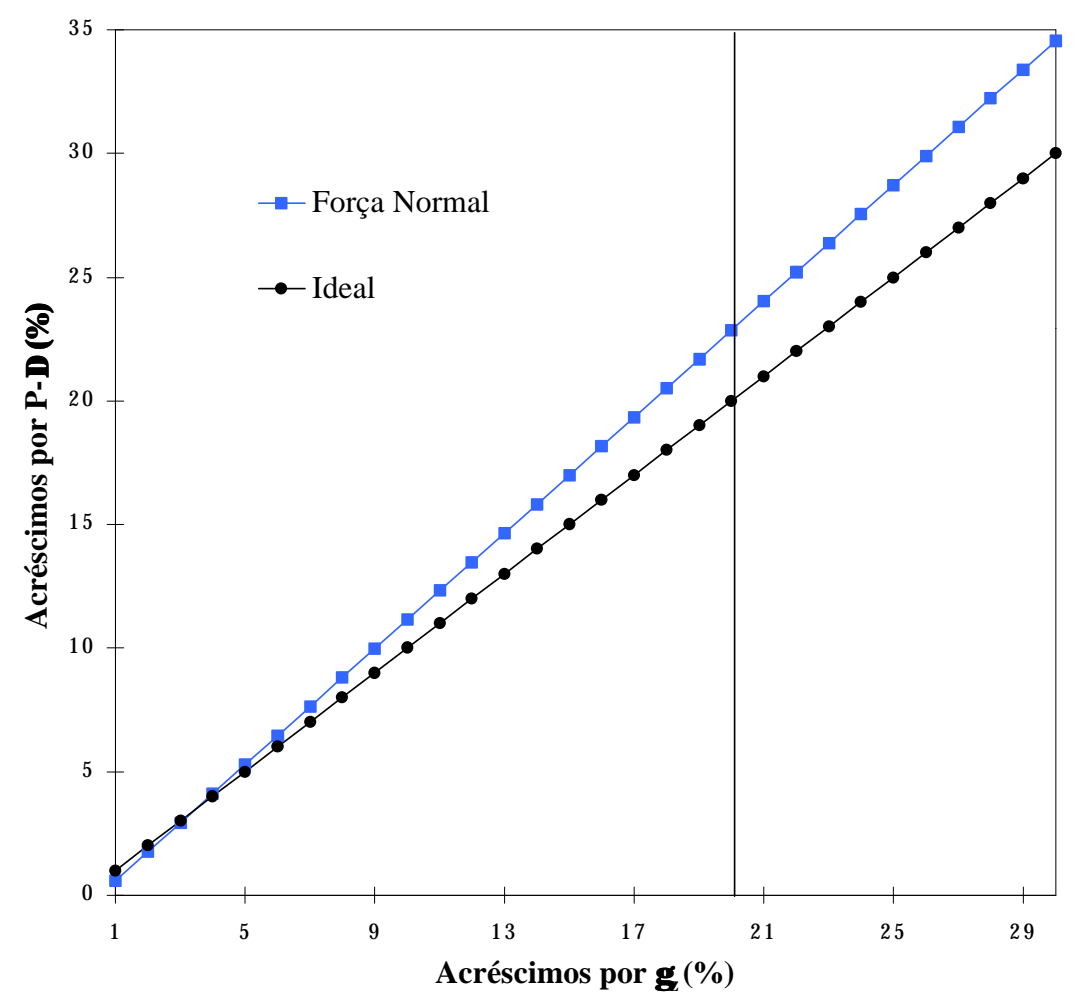

Figura D.17 - Relação entre os acréscimos sugeridos por P- $\Delta$ e $\gamma_{\mathbf{z}}$ - Força normal

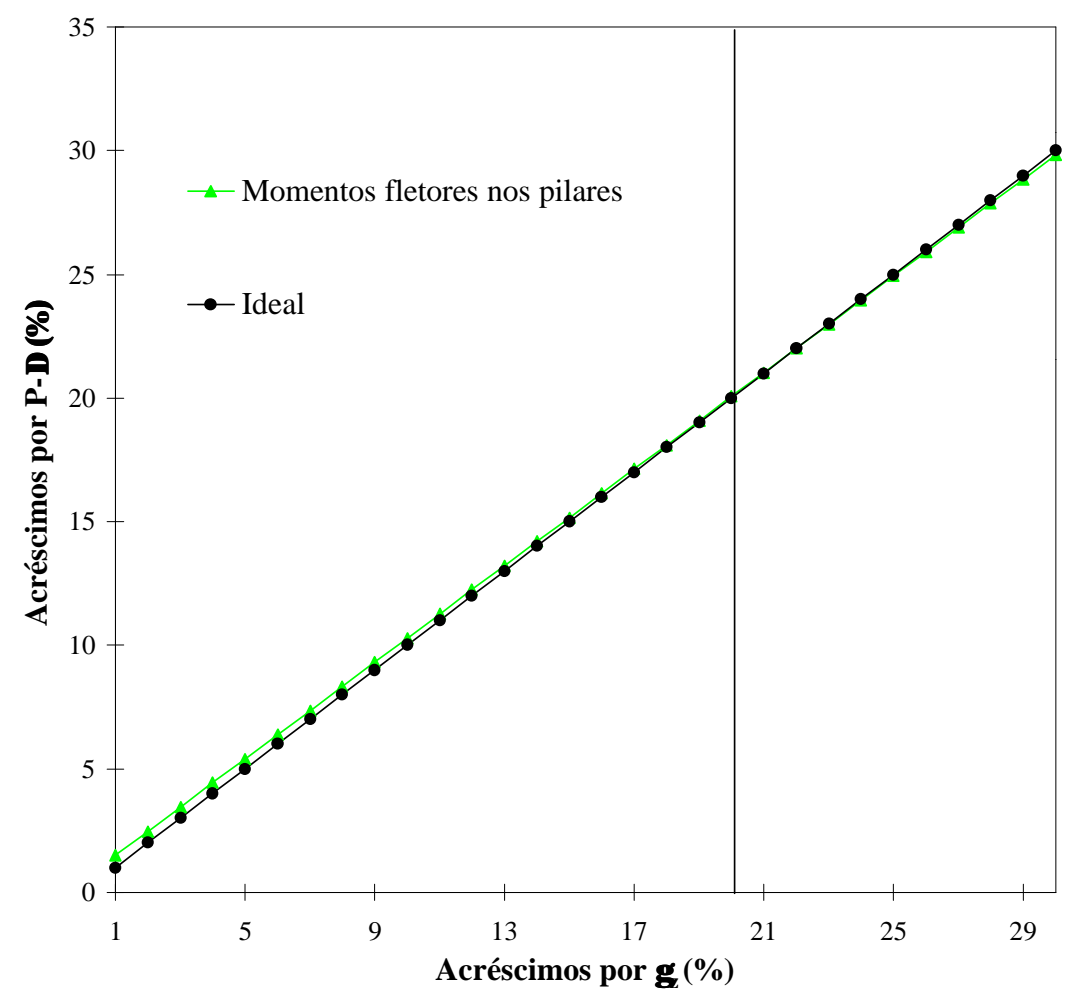

Figura D.18 - Relação entre os acréscimos sugeridos por P- $\Delta$ e $\gamma_{\mathbf{z}}$ - Momentos nos pilares 


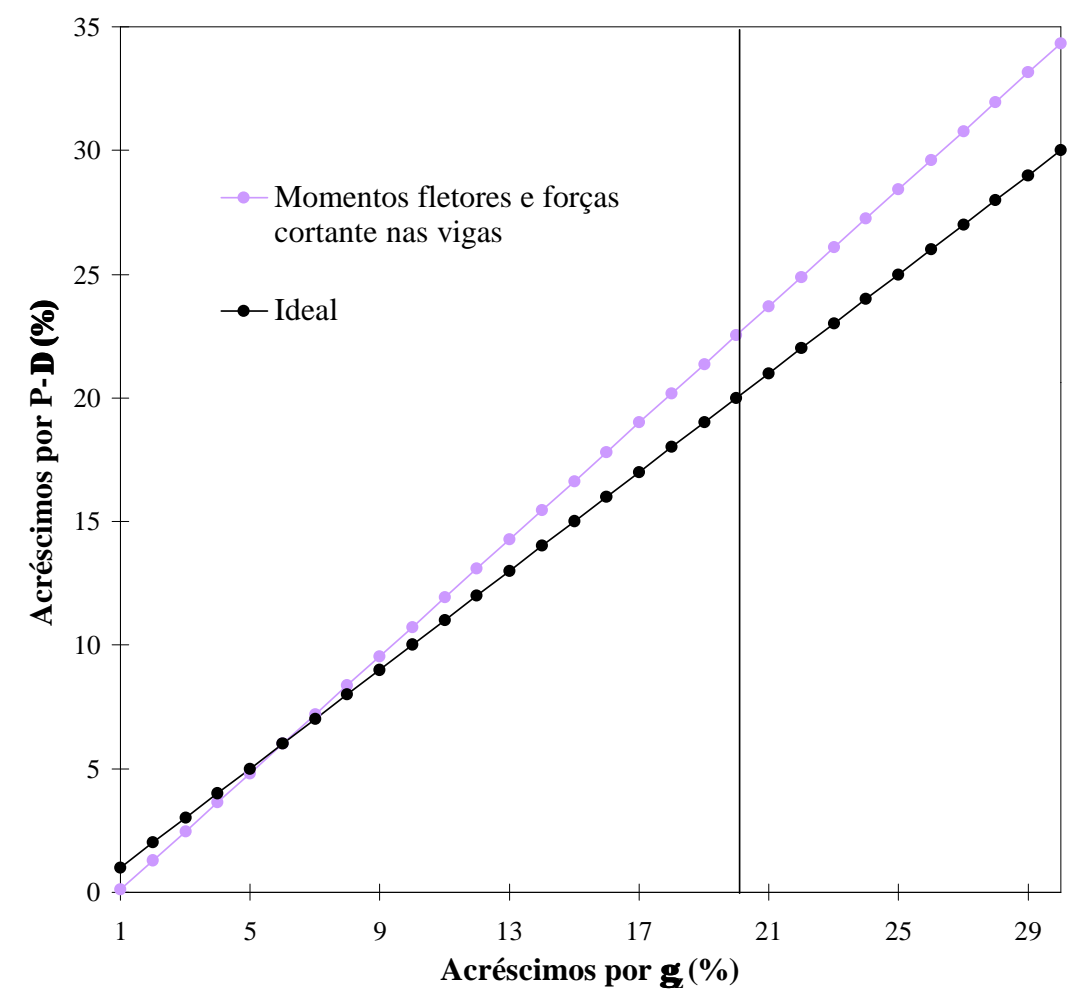

Figura D.19 - Relação entre os acréscimos sugeridos por P- $\Delta$ e $\gamma_{\mathbf{z}}$ - Esforços nas vigas

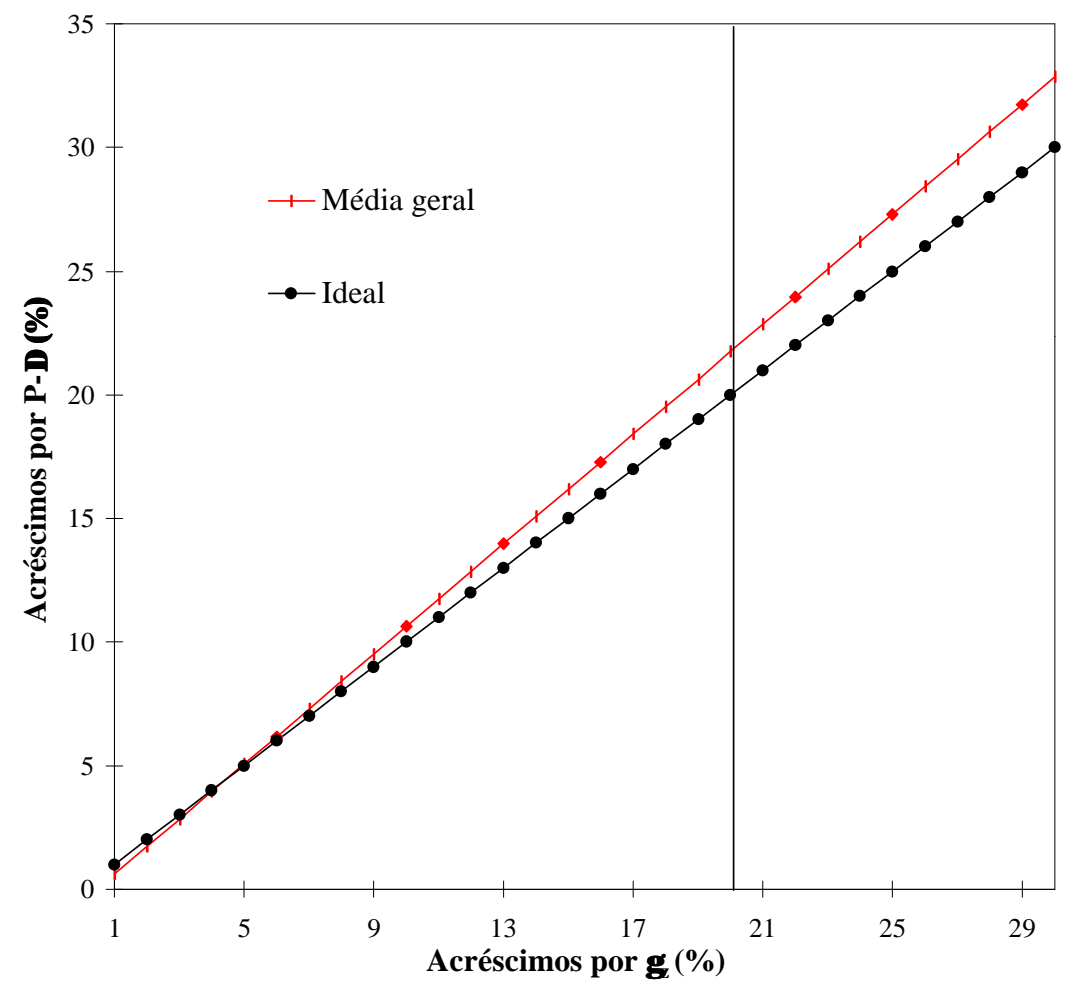

Figura D.20 - Relação entre os acréscimos sugeridos por P- $\Delta$ e $\gamma_{\mathbf{z}}$ - Média geral 